

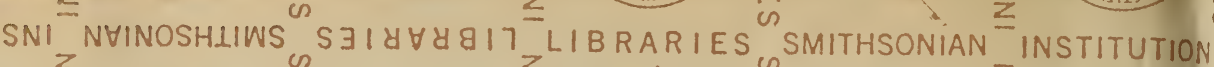
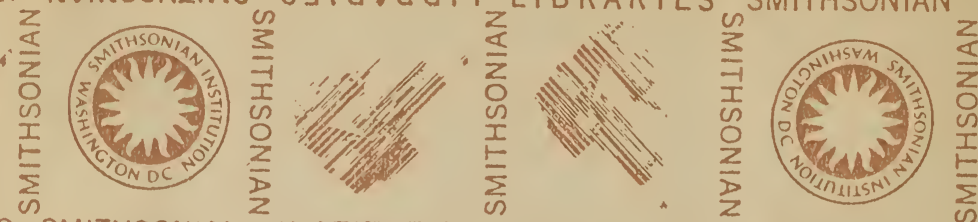

ES SMITHSONIAN

INSTITUTION NOIINIILSNI
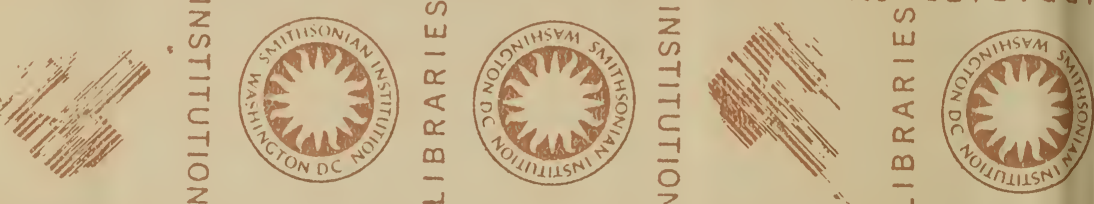

NHINOSHIIWS
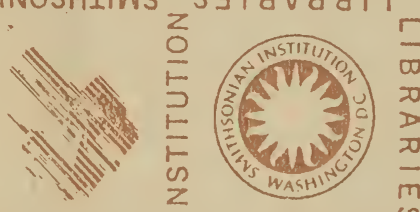

LIBRARIES

SMITHSONIAN
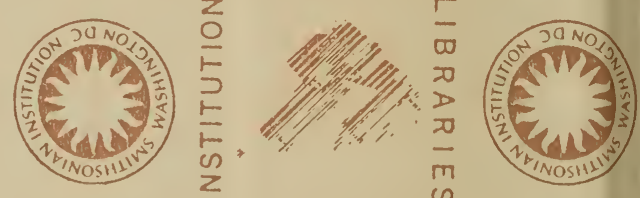

ES SMITHSONIAN INSTITUTION NOIIRIIISNI
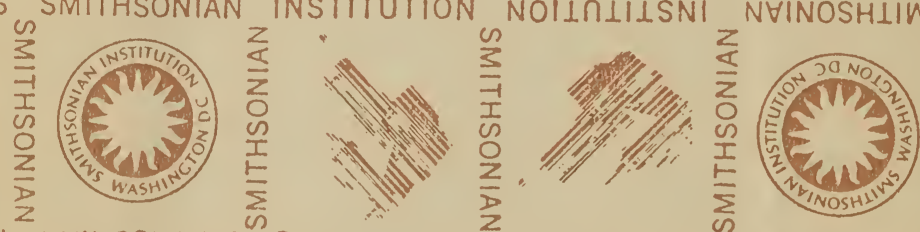

U

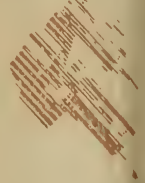

SNI_NHINOSHIIWS
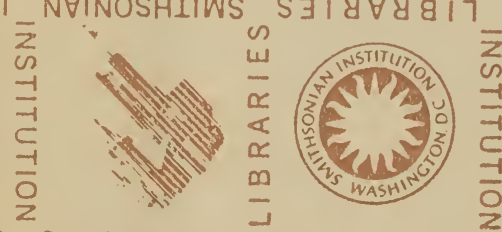

LIBRARIES

SMITHSONIAN
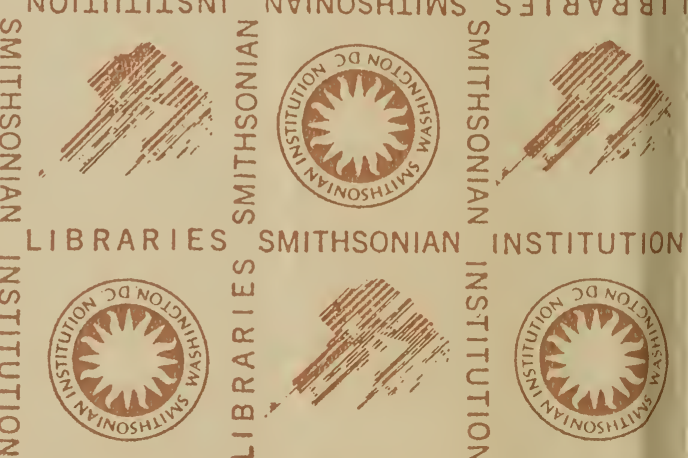

S SMITHSONIAN INSTITUTION NOIIRHIISNI NHINOSHHIWS
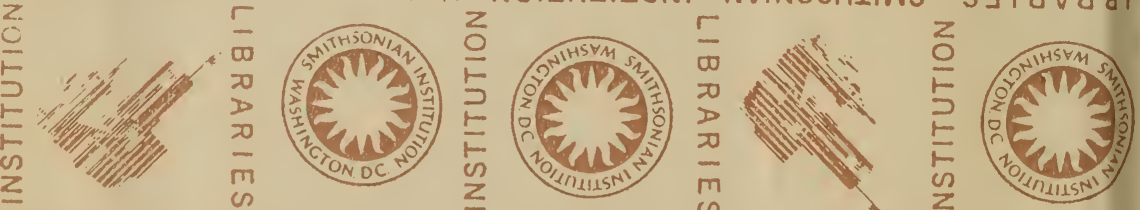

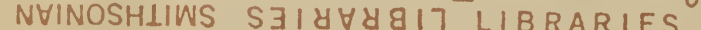
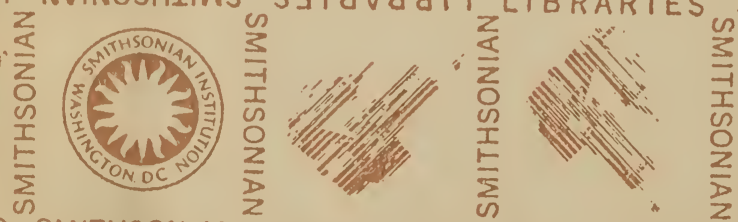

SMITHSONIAN
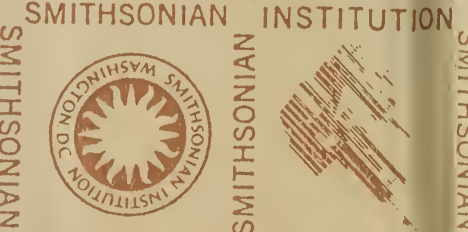

ES SMITHSONIAN INSTITUTION NOIINHIISNI NHINOSHIIWS

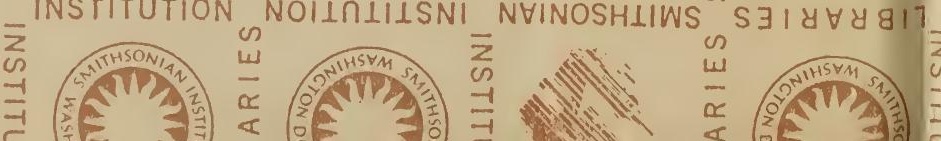


SMITHE

NVINOS

SMITHS

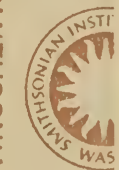

NVINOS

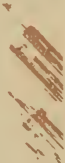

SMITHS

NVINOS

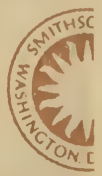

SMITHS

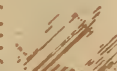






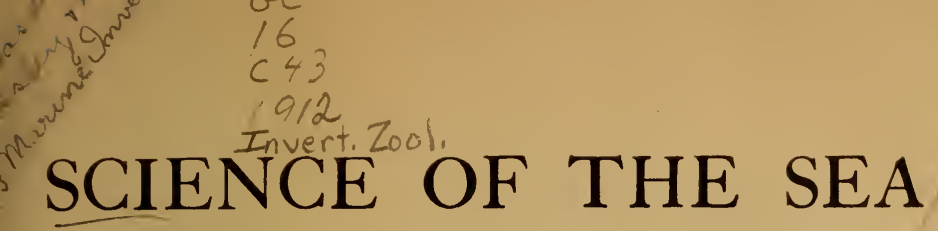

AN ELEMENTARY HANDBOOK OF PRACTICAL OCEANOGRAPHY FOR TRAVELLERS, SAILORS, AND YACHTSMEN

\author{
PREPARED BY
}

\title{
THE CHALLENGER SOCIETY
}

FOR THE PROMOTION OF THE STUDY OF OCEANOGRAPHY

\section{EDited BY G. HERBERT FOWLER, B.A., Ph.D., F.L.S., Etc. SOMETIME ASSISTANT PROFESSOR OF ZOOLOGY UNIVERSITY COLLEGE, LONDON}

\section{WITH ILLUSTRATIONS AND CHARTS}

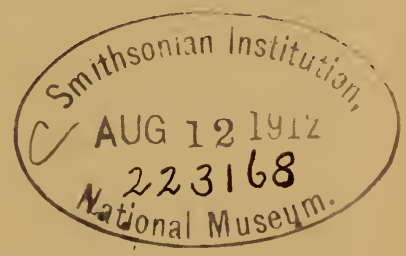

\section{LONDON}

JOHN MURRAY, ALBEMARLE STREET, W. 


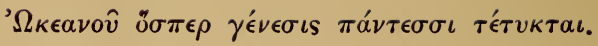

IL. xiv. 246. 


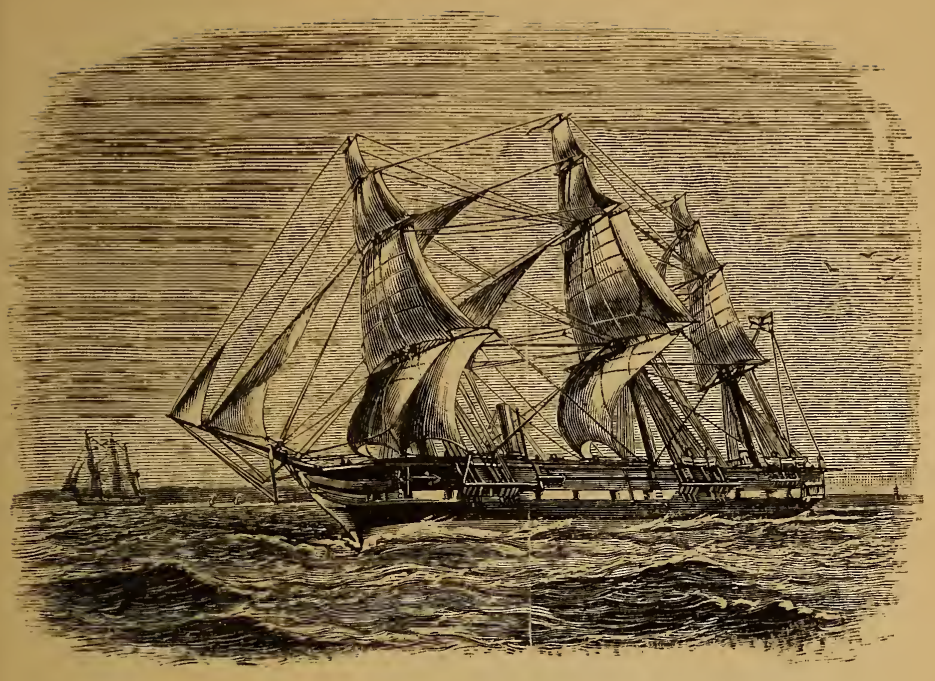

Iilg. I.-H.M.S. Challenger, I 873-I 876.

\section{PREFACE}

Not seldom those who are engaged in oceanographic work are asked by someone about to start on a long voyage: "How can I do some work for science? I don't know anything about it; where can I ' read it up '?" Such seekers after knowledge might often do most valuable work, even in waters which they would expect to be quite well known. In this study yachtsmen, and officers of the Royal Navy, who are apt to find time heavy on their hands in port or on a foreign station, could enjoy an ever-fresh interest in the sea. its workings, and its inhabitants; even officers of the Merchant Service could find time to help, especially in meteorological and surface-water work. To all such 
this handbook is primarily addressed: to those who are willing to take observations, but fear that a lack of scientific training will render their work or their collections worthless. Anyone who follows the lines here laid down may feel certain that his work will have real value, that he is building a sound brick into the pyramid of human knowledge. In order still further to promote the work, the Challenger Society has named an advisory committee of specialists in various branches of oceanography, to whom may be referred through the Honorary Secretary inquiries upon points which are beyond the elementary scope of the handbook. But all who propose to take observations, in whatever branch, are strongly advised to spend a few days at one of the marine stations (pp. 423-429), in order thoroughly to understand the practical work.

However valuable the information in this handbook may prove to be, it must remain elementary. It is no "royal road"; in no sense will it do away with the serious study which all those must undergo who, not content merely to record observations, wish also to grasp the usefulness and meaning of what they are doing. But the book may fairly claim to have brought between two covers instructions, of which many are not in print, and the rest are scattered and hard to find.

The indiscriminate use by the writers of Fahrenheit and Centigrade, metres and fathoms, will prepare the reader for what he will find in the literature of the subject; an oceanographer must be able to think in either scale.

The selected list of manufacturers and tradesmen (p. 438) should prove of value to the beginner.

The object of the volume is severely practical-what to do, and how to do it-written in language which, 
as far as possible, takes no previous scientific training for granted. The headings of the various chapters sufficiently explain the general plan. With a single exception, they have been written by Fellows of the Society; to the exception-Mrs. Dr.A. Weber van Bosse, the wife of an Honorary Fellow, and herself distinguished for researches on Algæ- the Society desires to express its special indebtedness. To those who have allowed the use of existing illustrations (notably to Sir John Murray, who placed the blocks of the Reports of H.M.S. Challenger at our disposal ; and to Mr. S. Henshaw, Curator of the Museum of Comparative Zoology at Cambridge, Mass., who allowed the use of blocks from "Three Cruises of the Blake"), as also to numerous manufacturers who have freely supplied valuable information, the Society also renders its thanks.

The first edition of such a work as this is necessarily of a tentative nature, and the Editor will gratefully receive corrections and suggestions of all kinds for a future issue.

G. HERBERT FOWLER.

Aspley Guise,

BEDFORDSHIRE,

April, I9I2. 



\section{INTRODUCTION}

BY THE EDITOR

AlTHOUGH the general arrangement of land and water at the surface of the earth, as shown in ordinary maps, is familiar to every schoolboy, yet nowadays, when the use of the globe as an instrument for teaching is somewhat out of fashion, not only the importance, but even the very shape of the water is apt to be overlooked-a neglect fostered by atlases which, as a rule, are concerned merely with the land. Yet the surface of the earth shows about two and a half times as much water as land. Again, the ordinary atlas fails to show that the land is massed towards the North Pole, the water towards the South. It is possible to draw a " great circle," the hemisphere north of which (Fig. 3) shows land and water in about equal proportions $(47: 52)$, but in its southern hemisphere (Fig. 2) nine-tenths of the surface is under water. Still less do ordinary maps display the connection between the great oceans; their South passes into a blank Unknown. It is not easy to get a proper grasp of this connection except from a globe ; but several of the star projections (Fig. 4) show fairly well that the three great oceans-Pacific, Atlantic, and Indian-can be regarded as bays of that single Southern Ocean which forms a not very wide belt round the Antarctic Continent, narrowed to about 540 sea miles between the latter and the Horn.

These three great bays have certain features in common : in the Pacific, owing to the scattered islands, 


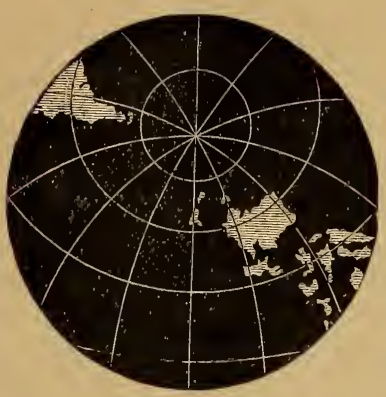

FIG. 2 .

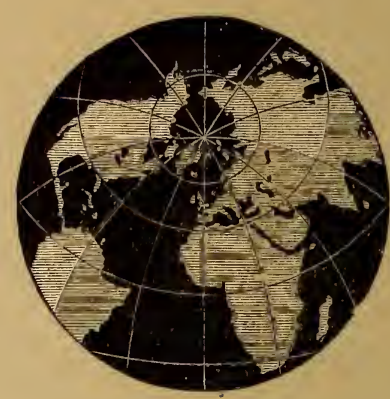

FIG. 3 .

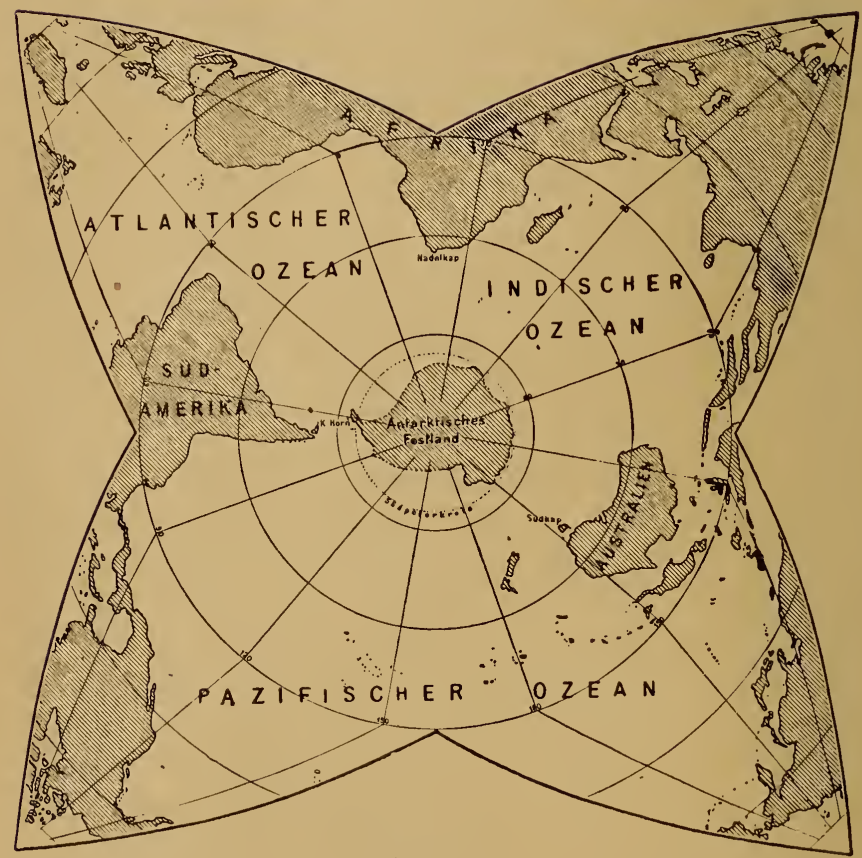

FIG. 4 .

Fig. 2.-OCEANic OR Water Hemisphere.

Fig. 3.-Continental OR Land Hemisphere.

Fig. 4.-The South Pole on the "Star Projection" of Steinhaus.

(Figs. 2 and 3 from Huxley's "Physiography" ; Fig. 4 from Krümmel's " Handbuch der Ozeanographie," by permission of Messrs. Macmillan, and J. Engelhorn's Verlag in Stuttgart respectively.) 


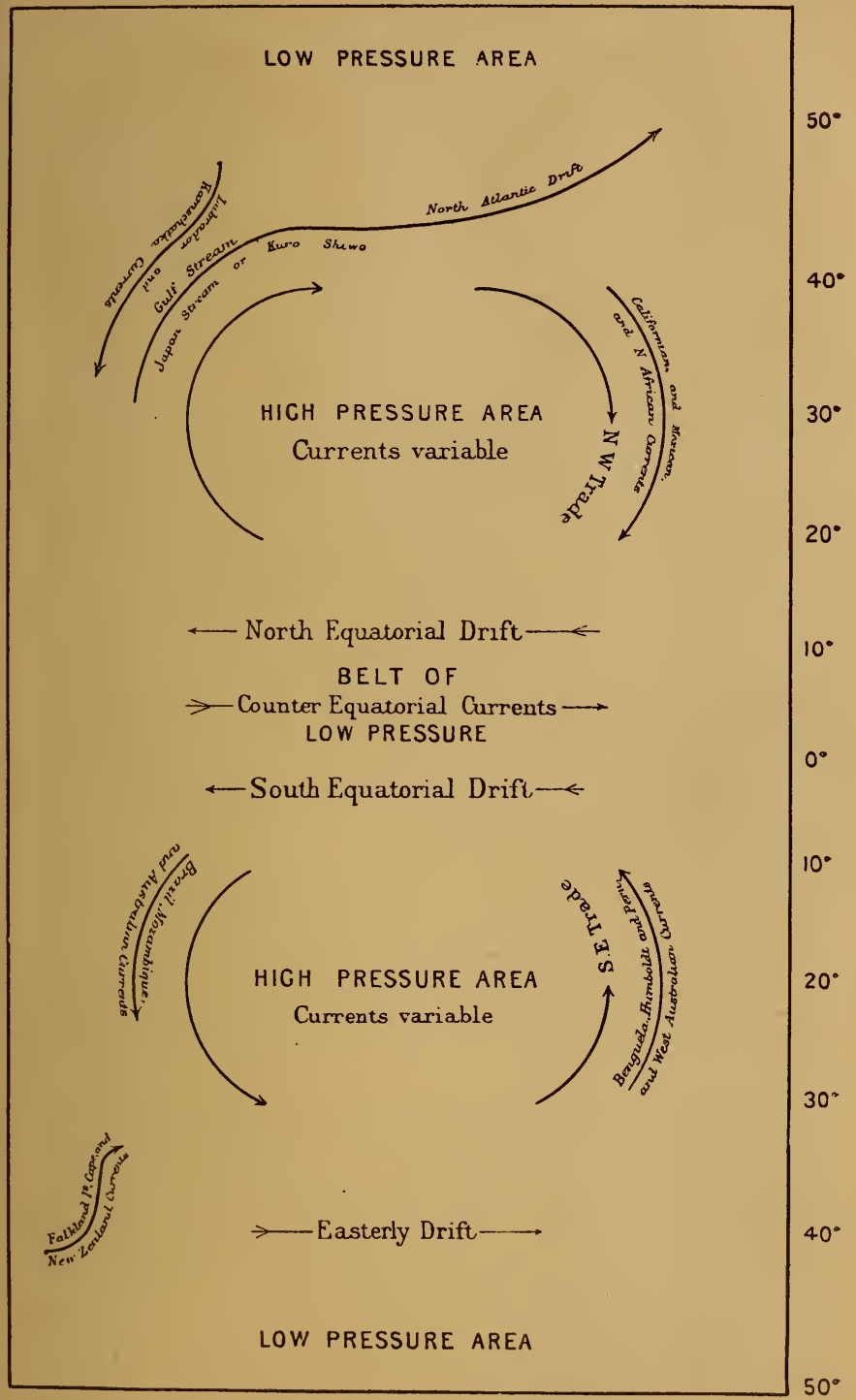

FIG. 5 . 
some of them are less well marked than in the almost islandless Atlantic; the Indian, representing, as it were, the southern half of the other two, shows them more clearly during the south-west monsoon than during that from the north-east; but they are recognisable in all. The diagram in Fig. 5 gives a rough idea of these resemblances between the three great oceanic areas, in air pressures, in winds, and in currents ; the latitudes of corresponding regions, however, vary somewhat in the different areas.

In these phenomena of pressure, wind, and current, the sun is the source of energy. It may be said, in the most general terms, that the distribution of marine animals and plants depends mainly on water temperatures, the water temperatures almost entirely on oceanic currents, the currents chiefly on prevailing winds, the winds on barometric pressures, and the pressures on the effects of the sun's rays upon Earth, Air, and Water. It is easy to make a general statement of this kind : it is not so easy to prove every link in the chain ; and, until we have accumulated far more knowledge than at present we possess, some parts of it must be of the nature of Articles of Faith ; and, like most such Articles, they have their sceptics. Still less do we know of the details of the inner working of those stupendous phenomena which affect five-sevenths of the Earth's surface.

At the other end of the scale-so far as mere size is concerned-we do not at present really understand the life of a single rock-pool, the delicate adjustment which exists between the myriads of organisms, its inhabitants. We recognize dimly the outlines of the main processes-the unending cycle in which food material passes from plant to animal, and back to plant again; the struggle for existence-as keen amongst 
the microscopic tenants of a rock-pool as among the larger animals of a more obvious world; and so forth. But we are unable to isolate mentally a single species, and to describe how it reacts to the incessant changes of its physical and organic environment.

Between these extremes of scale-between the gigantic and world-embracing movements of Air and Water, and the brief life of the minutest organismlie, intricately interwoven, the problems with which the student of oceanography must wrestle. But while his proper work is the orderly marshalling of facts into groups, as a basis for explanations-or at least for hypotheses-the facts themselves can be gathered in quantity by any traveller who chooses to take the trouble of doing so. 



\section{CONTENTS}

CHAPTER

Preface AND Introduction -

PAGES

By the EDITor.

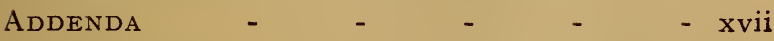

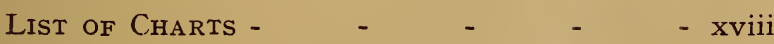

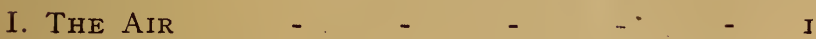

By H. R. MiLl, D.Sc., LL.D., Director of the British

Rainfall Association; and D. WILSON BARKER,

R.N.R., F.R.S.E., Captain Superintendent of the

Nautical Training College, H.M.S. Worcester.

II. THE WATER -

By H. N. Dickson, M.A., D.Sc., Professor of Geography in University College, Reading ; and D. J. MATTHEws, Hydrographer to the Marine Biological Association and to the Board of Agriculture for Ireland (Fisheries Branch); with an OUtLINE of Oceanic Circulation by the Editor.

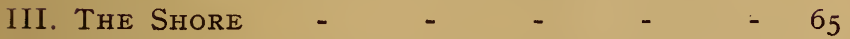

A. TROPICAL SHORE COLLECTING - - 65

B. CORAL REEFS AND ISLANDS - - 82

C. HINTS FOR TROPICAL OUTFIT - - ${ }^{0} 5$

By J.Stanley Gardiner, M.A., F.R.S., Professor of Zoology in the University of Cambridge.

IV. The Plants - $\quad$ - $\quad$ - $\quad$ -

A. FLOATING PLANTS - -

By V. H. Blackman, M.A., Professor of Plant Physiology and Pathology, Imperial College of Science and Technology.

B. FIXED PLANTS - - - - - I26

By Mrs. A. Weber - van Bosse, Ph.D. 
CHAPTER

V. The Floating Animals - - - $\quad$ - 162

By the Editor and Edward T. Browne, M.A., University College, London.

VI. The Sea Floor

By Sir John Murray, K.C.B., LL.D., F.R.S.,

Naturalist on the Expedition of H.M.S. Challenger, I873-I 876 .

VII. Animals of the Sea Floor -

$-231$

By W. T. Calman, D.Sc., F.L.S., F.Z.S., British Museum (Natural History); and G. P. FARRAN, B.A., Department of Agriculture and Technical Instruction for Ireland (Fisheries Branch).

VIII. YaChT EQUipMENT

By the Editor and Stanley W. Kemp, M.A., Indian Museum, Calcutta.

IX. Dredging and Trawling 289

By E. J. Allen, D.Sc., Director of the Plymouth

Laboratory, Honorary Secretary of the Marine Biological Association ; and Stanley W. Kemp.

X. Fishes and Fishing $-306$

By L. W. Byrne, M.A., Barrister-at-Law.

XI. Preservation of Marine Organisms

By E. J. Allen, D.Sc., and E. T. Browne, M.A.

XII. Whales, Seals, and Sea-Serpents -

By D'Arcy Wentworth Thompson, C.B., M.A.,

Professor of Zoology in University College, Dundee.

XIII. Logs, Notes, and Labels, Etc.

By the EDIToR.

List of MARine Stations

$-423$

Classifications

- 430

LITERATURE

- 434

Classified List of Recommended Firms - 438

INDEX 


\section{ADDENDA}

CHART I.-An isotherm of $90^{\circ} \mathrm{F}$. has been omitted over the North-Western part of Australia.

PAGE 29.

Dissolved Substances in $\mathrm{I}, 000$ Parts by Weight of Sea Water of "Chlorine" Content 20 Pro Mille (Calculated from the Mean of Seventy-Seven Analyses by Dittmar).

\begin{tabular}{|c|c|c|c|c|}
\hline Chlorine & & - & I9.93\} & 20.00 \\
\hline Bromine & .. & . & & \\
\hline $\mathrm{CO}_{3} \quad \ldots$ & . & . & .. & 0.075 \\
\hline $\mathrm{SO}_{4}{ }_{\text {Calcium }}$.. & $\cdots$ & $\cdots$ & $\cdots$ & $2 \cdot 777$ \\
\hline Magnesium & $\cdots$ & $\cdots$ & $\cdots$ & $\begin{array}{l}0.432 \\
\cdot 352\end{array}$ \\
\hline Potassium & $\ldots$ & $\ddot{0}$ & $\because$ & $\begin{array}{l}1353 \\
0.399\end{array}$ \\
\hline Sodium & $\ldots$ & $\ldots$ & . & II.055 \\
\hline
\end{tabular}

According to Knudsen's tables, such a sea water would have a salinity of $36 \cdot 13$ pro mille. The slight difference between them is due chiefly to improvements in analytical methods.

\section{PAGE 47.}

Messrs. Negretti and Zambra have recently made to Mr. Matthews' instructions two reversing thermometers with their original form of constriction; apart from the gradations, which are somewhat coarse, these appear on a laboratory test to be thoroughly satisfactory. An auxiliary thermometer is provided, and the glass "Jenaer $16^{\text {III " }}$ " and Vol. ${ }^{\circ}$ are marked on the stem. 


\section{LIST OF CHARTS}

I. Air Isotherms for JAnuary between pages 4-5

II. ISOBARS FOR JANUARY - - , , , , 6-7

III. Surface Water Isohalines - , , " 30-3I

IV. SURface Water Isotherms - , , , 34-35

V. OCEAN CURrents - - _ , , " 60-6I

VI. Depths - $\quad$ - $\quad$ - $\quad$ - , , , 206-207

VII. Bottom Deposits _ - _ , , , 220-22I

ViII. Areas of Distribution - - , , , 250-25I 


\section{SCIENCE OF THE SEA}

\section{CHAPTER I}

\section{THE AIR}

BY HUGH ROBERT MILL AND D. WILSON BARKER.

WHILE the waters of the ocean cover more than twothirds of the solid surface of the Earth, the atmosphere surrounds the whole of the globe ; it is the only homogeneous, unlimited expanse subject to the laws of gravitation and to the influence of radiation, found in the triple structure of lithosphere, hydrosphere, and atmosphere, which constitutes our planet. Over the surface of the land the atmosphere is irregularly distributed; a great mass of air presses heavily on the low ground, but on the higher plateaux and mountains only a fraction of the atmosphere remains above us, and bears but lightly on the ground. This is due to the fact that air is in the highest degree compressible and elastic, and it is compressed by its cwn weight to such an extent that half the mass of the atmosphere lies within 18,500 feet of sea-level. As the elevation above the level of the sea increases, the air becomes more and more rare, until, at the height of a few miles, it is in such a state of tenuity that life is impossible. Air-or at least some of the gases of which air is composed-can be traced by observations of the reflection and refraction of light and the flight of meteors to a 
height of some 300 miles ; but, so far as meteorology is concerned, 20 miles may be taken as the limit.

The passage of air across a continent is a complex of horizontal and vertical movements, in a medium of continually varying density; but over the far wider stretches of ocean the density is nearly uniform, varying by but a small fraction of its maximum amount in a horizontal direction, and falling off uniformly upwards. The oceans are, in fact, the only parts of the Earth's surface where it is possible to study the atmosphere in fairly normal conditions. The practical uniformity of level eliminates differences of pressure due to gravity; the uniform composition of the water surface eliminates the irregular heating and cooling of the air. These last are due to the different specific heat, conductivity, transparency, and power of radiation and absorption, which characterize the rocks, sand, soil, lake surfaces, and stretches of vegetation, which diversify the land, causing them to react differently and in various degree to the radiation which is received from the sun, or is emitted from the Earth. The homogeneity of the substance and form of the ocean surface favours the normal development of atmospheric equilibrium and adjustment, and gives to marine meteorology a large simplicity, more favourable to the elucidation of the great laws of atmospheric circulation and disturbance, than is to be found in the more varied meteorology of the land. Indeed, it is the effort to constitute by computation some approach to the simple conditions of the oceans which leads the meteorologist to reduce to their equivalent values at sea-level, the pressures and temperatures which have been observed on the land, before the data are considered to be in a state fit for charting in the ordinary maps of isobars and isotherms. Being free from a multitude of dis- 
turbing causes which are inseparable from the land, the observer at sea is among the most favourable conditions for investigating normal distributions as well as seasonal and diurnal changes.

There are, however, special difficulties in meteorological work at sea, caused by the impossibility of remaining in one place (for the sea is a highway, while the land is a home ; and the seafarer is always changing his latitude or his longitude, or both), and by the restricted accommodation available for instruments, which make impossible many of the arrangements considered necessary on land. On balancing the facilities and the difficulties of the study of meteorology at sea, it becomes plain that the advantages resulting from the greater simplicity of the problem to be attacked are more than counterbalanced by the greater difficulty of attacking it.

Marine meteorology may be said to date from the time of Admiral Matthew Fontaine Maury, U.S.N., whose "Physical Geography of the Sea," though out of date as to facts, and somewhat fantastic as to theories, remains a model book of popular science, written by a man who was possessed of all the knowledge of his time, and afire with the enthusiasm of research. At his instance an International Conference was held at Brussels in I853, when a plan was agreed upon for a sort of federated national agency, each country undertaking to encourage maritime meteorology, in accordance with general rules drawn up by common agreement. As a result, the British Meteorological Office was formed, with world-wide marine meteorology as its.main field of work. The instructions issued by the Meteorological Office and the instruments supplied through it should be known to all who undertake any meteorological work at sea, 
although in some points the methods, necessarily restricted to the convenient use of a mercantile marine officer without interfering with his more urgent duties, are capable of considerable expansion in the hands of a scientific student.

In the United States the Weather Bureau carries on similar researches, and the German Naval Observatory (Deutsche Seewarte) in Hamburg is equally active in the work. Both the British Meteorological Office and the United States Weather Bureau issue in advance Monthly Pilot Charts of the great oceans, on which the average meteorological conditions for the month are laid down.

The introduction by Maury of sailing directions, based on a knowledge of prevailing winds and currents, was of great profit to shipowners by shortening voyages, and stimulated the interest of shipmasters, by whom most of our a vailable information of maritime meteorology was collected in the old sailing-ships. The comparative unimportance of weather conditions in the voyages of modern steamships has led to the partial neglect of weather observations by sailors, though the officers of many vessels keep and transmit to the proper authorities excellent meteorological logs.

\section{Brief Sketch of Atmospheric Circulation and Temperature.}

The sun shining on the atmosphere, particularly where the ground below is a good absorbent and radiator of heat, warms it, and causes the air to expand, making it lighter, and so reducing its pressure on the surface. The colder and heavier air of neighbouring regions on which the sun is not shining (either because it is night or because of clouds obscuring its rays) is 


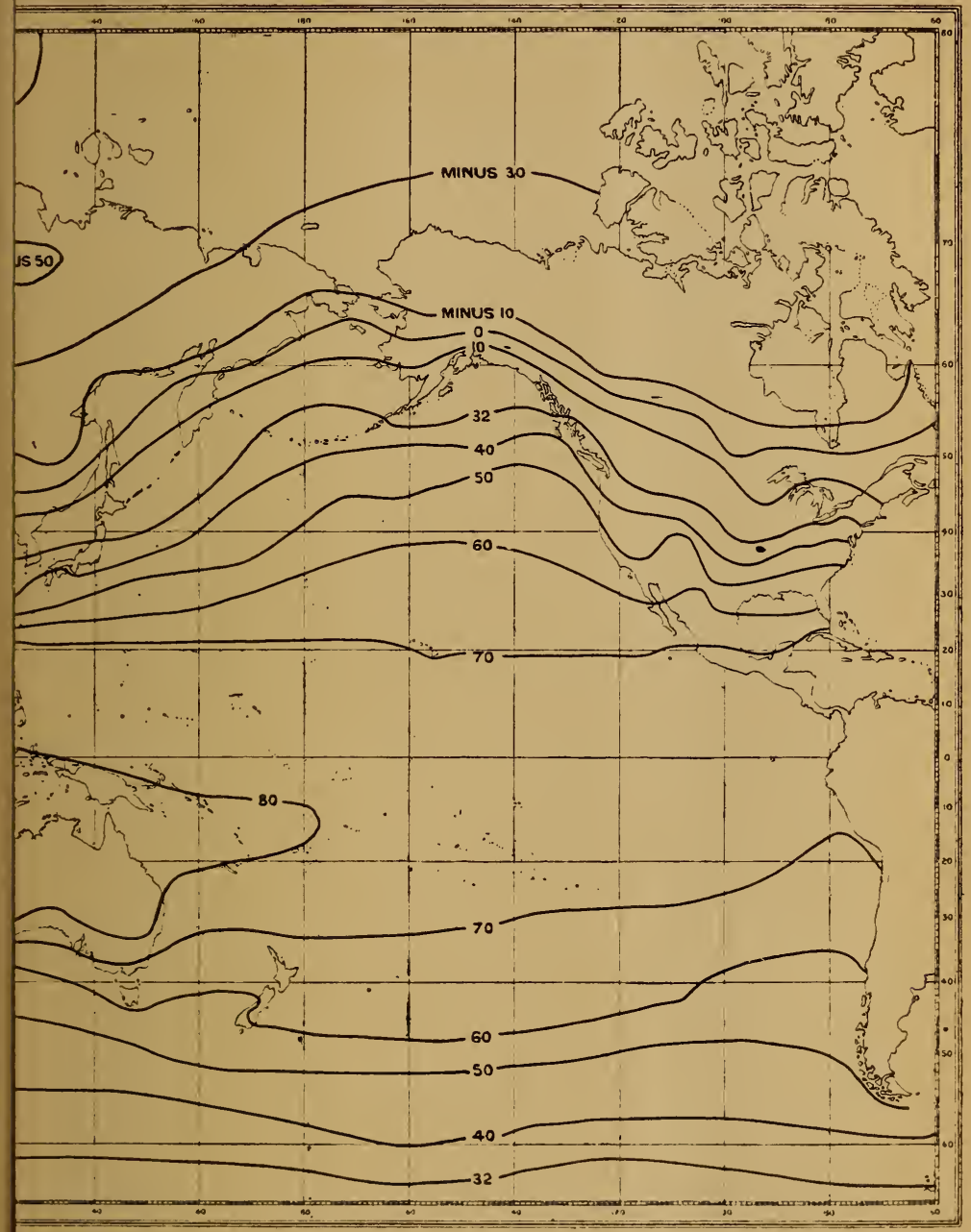

R FOR JANUARY.

grees Fahrenheit. (After Dr. H. R. Mill.)

[Between pp. 4, 5 . 



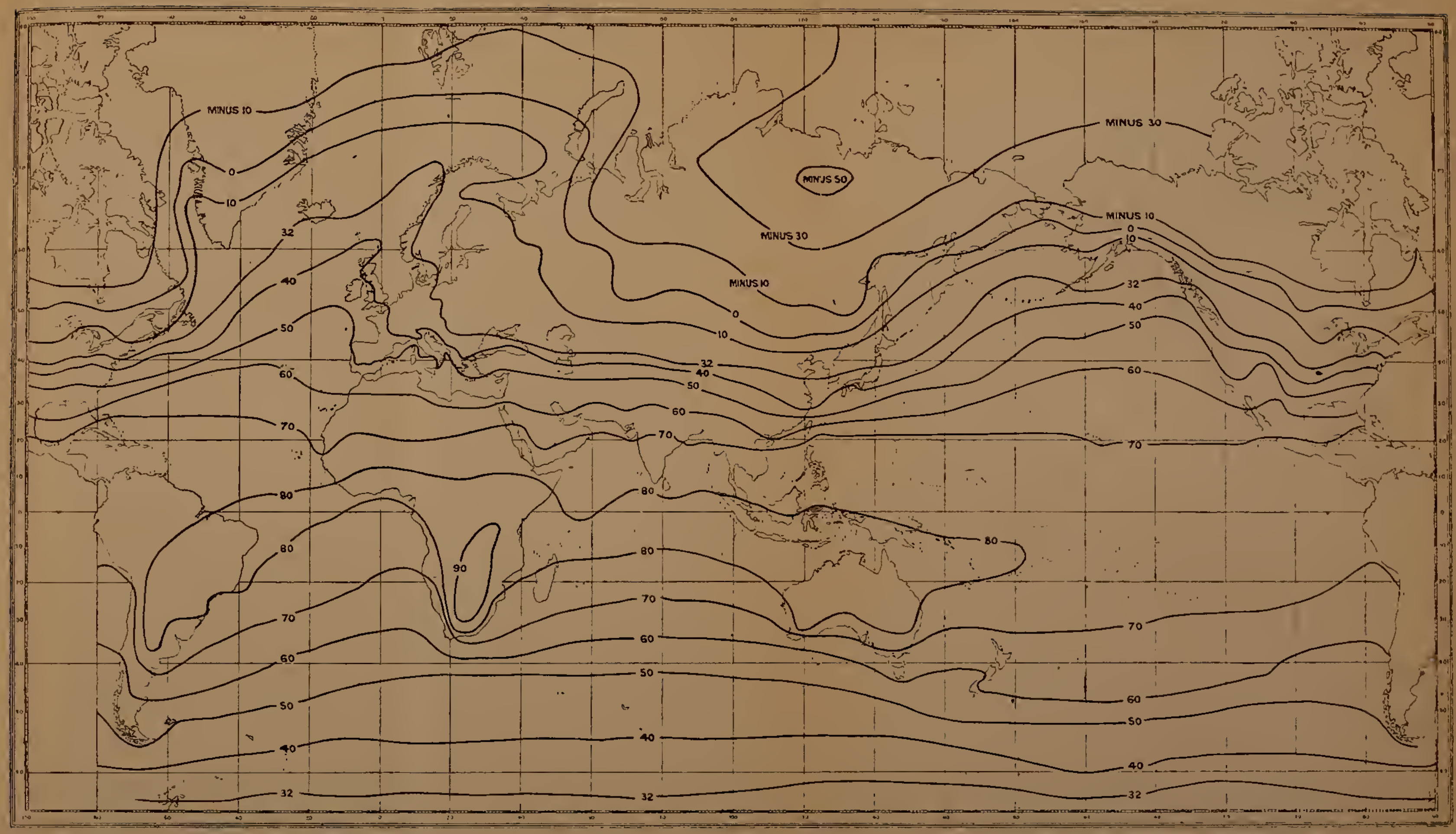

CHART I.-ISOTHERMS OF THE AIR FOR JANUARY,

These are lines drawn through points of like temperature in degrees Fahrenheit. (After Dr. H. R. Mill.)

(Between pp. 4, 5. 

denser, and thus exercises a greater pressure on the surface, and tends to spread into the areas of lower pressure. The air thus set in motion is wind, and the wind is part of a great and never-ceasing system of circulation of the atmosphere of the globe.

Broadly speaking, the heating of air between the tropics and the cooling of air within the polar circles are responsible for the whole system of atmospheric circulation, including the movement of surface air from the tropics towards the poles and the return currents of air in the upper atmosphere. The fact that these movements are taking place, not on a motionless plane, but on the surface of a rotating sphere, accounts for the deviation of the winds from a north and south direction. It is convenient to remember that any moving body (whether air, water, or projectile) on the surface of the Earth is caused by the Earth's rotation to deviate towards the right as it moves, no matter in what direction, in the northern hemisphere, and towards the left as it moves, no matter in what direction, in the southern hemisphere, the observer in all cases looking in the direction towards which the body is moving. A pole-seeking wind thus acquires a trend from the west as well as from the Equator, and an Equator-seeking wind acquires a trend from the east as well as from the pole.

There is an intimate connection between the distribution of atmospheric pressure on the surface and the direction of prevailing winds, the general relationship being that wind blows obliquely from areas of high pressure towards areas of low pressure. The distribution of pressure is expressed in isobaric charts, on the same principle as the representation of heights or depths by contour-lines on orographical maps, or on the ordinary sea charts ; and, in order to deduce from 
an isobaric map the direction and force of the wind at any point, it is sufficient to remember that the wind blows from the higher pressure to the lower pressure, with a force proportional to the gradient (that is, to the closeness with which the isobars are drawn), and in a direction tending to the right of a line drawn perpendicular to the isobars in the northern hemisphere, and to the left in the southern hemisphere. It must be remembered that an isobaric or wind chart for the year or for a month represents the average condition for the year or for that month, and may not accurately depict the condition at any particular moment of time.

If the surface of the Earth were entirely covered by the sea, so that there was no land to disturb the normal circulation of the atmosphere, the conditions of weather which actually prevail only in mid-ocean would probably hold good for the whole world, which would be girdled by concentric belts of climate as follows :

I. An Equatorial belt of permanently low pressure right round the Earth, lying approximately along the Equator, forming a region of calms with ascending air, in which occasional sharp squalls, accompanied by lightning, thunder, and heavy rain, often occur. This belt is the trough of minimum pressure, to which the winds of the whole tropical region blow, and on which all the other pressure belts depend. It would move with the season, following the sun northward in the northern summer, southward in the southern summer, and displacing the parallel belts on each side in the same directions. The belt, as it actually exists on the oceans, occupies a mean position between $5^{\circ}$ and $10^{\circ} \mathrm{N}$., on account of the indirect influence of land, and as it swings northward and southward across any given parallel, the rainy season of that parallel occurs. The belt is known to sailors as the "Doldrums." 


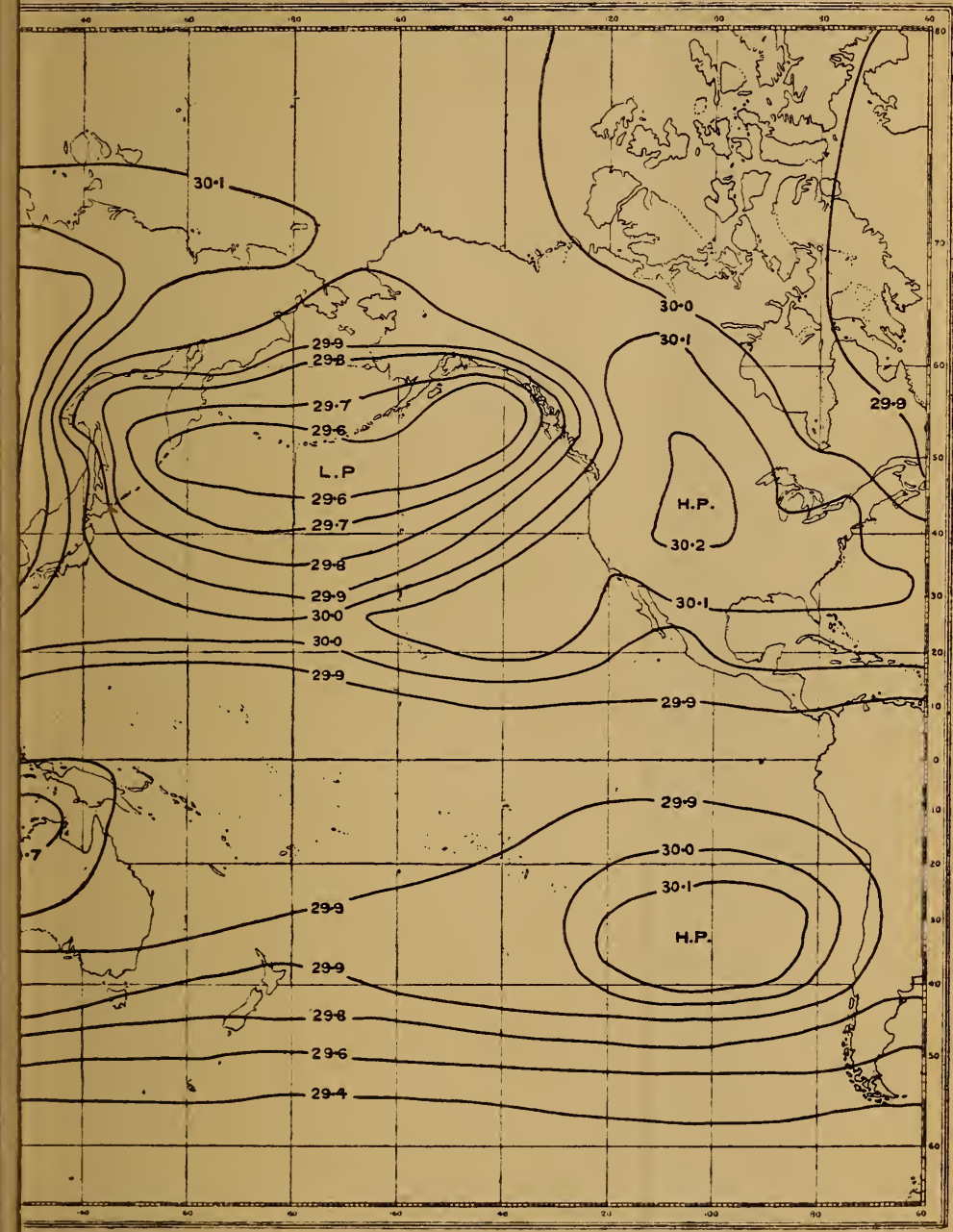

\section{JANUARY.}

c pressure. (After Dr. H. R. Mill.) 


2. Transitional belts of increasing pressure north and south of the belt of low pressure, with a steep gradient, giving rise to the trade winds, which blow strongly into the Equatorial trough from the north-east on its northern side, from the south-east on the southern. This is a region of high temperature and great evaporation.

3. Belts of permanently high pressure on the poleward side of the tropics, respectively north and south of the trade-wind regions, from which the trade winds blow. In these calms generally prevail, and they are called by sailors the " Horse Latitudes."

4. Transitional belts of diminishing pressure, respectively north and south of the belts of high pressure in the temperate zones, with south-easterly winds in the northern hemisphere, and north-westerly winds in the southern hemisphere, the winds blowing outwards from the poleward sides of the high-pressure areas.

5. Two polar belts of low pressure, towards which the westerly winds blow, are not so clearly defined, nor are they so fully investigated as to enable one to speak definitely regarding them. The theoretical circulation of air requires them, but it may be that yet another area of high pressure exists at or near the poles themselves.

The surface movements of air thus described require for the completion of the circulation a series of wind currents in the upper atmosphere practically opposite in direction, and observations on clouds and by means of balloons show that such currents exist, though our knowledge of the subject is still imperfect.

The simple conditions we have outlined do not actually exist, though over the great oceans there is a very near approach to them. The influence of land, with its diurnal and seasonal heating and cooling. 
extends far over the sea, and introduces many complications of normal climate due to geographical position. The general effect of the continents is to break up the belts of high and low pressure round the world, the high-pressure belts being most nearly continuous in the winter months, the low-pressure belts most nearly continuous in the summer months, of the respective hemispheres.

The alternate heating and cooling of continents in summer and winter gives rise to monsoons, or seasonal winds, blowing from the sea towards the lowered pressure over the heated land in summer, and from the high pressure over the chilled continents towards the warmer sea in winter. Monsoon winds occur on all continental coasts, but the monsoons attain their greatest development in the Indian Ocean, where Asia, Africa, and Australia combine in modifying the theoretical wind-directions. Over Asia the monsoonproducing conditions exist in great intensity. The result is that the south-east trade in the northern summer is drawn northward across the obliterated belt of equatorial calms and converted into a southwesterly wind, called the "South-west Monsoon," which, in many places, blows with the force of a gale.

In the northern winter the north-east trade-wind is greatly strengthened, and is called the "North-east Monsoon," but it never attains the force of the southwest monsoon. At the changing of the monsoons, approximately at the time of the equinoxes, disturbed conditions, giving rise to much bad weather, are apt to occur.

Land and sea breezes, with a diurnal period of alternation, occur in similar conditions to monsoons, but on a smaller scale, as they are due to the heating of the land by day and its cooling by night. The sea- 
breeze, blowing towards the land, prevails along tropical coasts (where day and night are nearly equal) during the day, and reaches its greatest force about 2 p.m. The land-breeze, blowing towards the sea, prevails at night, and reaches its greatest force about I a.m.

When the wind attains unusual force, the resulting effects are called storms. Storms may occur in all parts of the world, but they are much more frequent and of greater force in some regions than in others. In some places they have certain marked characteristics, which are often indicated by the local names of the prevailing types. Storms may be referred to two predominant types-namely, squalls and cyclones. The squall is a very brief phenomenon of great intensity, with a sudden change of pressure ; very often a sharp rise of the barometer, followed in a few minutes by an abrupt fall, accompanies the most violent gust. Squalls have been very imperfectly studied, and no subject appeals more for investigation. The variety known as the "line-squall" occurs simultaneously along a straight or slightly curved line, more or less at right angles to the direction in which it is propagated.

Cyclonic storms fall into two classes, the chief difference being in the magnitude of the atmospheric disturbance producing them. The more intense are small whirls of air, propagated comparatively slowly over the surface, and giving rise to so powerful an up-draught as to raise a column of water from the sea or any loose material from the land. Such a storm is termed a waterspout or a tornado, and is capable of doing immense damage over a very limited area.

Certain tropical seas are subject to revolving storms of greater dimensions than waterspouts or tornadoes, but affecting no very large areas of the surface, and moving with such comparative slowness that a ship 
may be manœuvred out of the track of the centre after the approach of the storm has been signalled on board by the fall of the barometer, the shift of the wind, and the characteristic cloud formation. They are accompanied by wind of terrific force, falling to a calm in the centre of lowest pressure (" the eye of the storm," where a glimpse of blue sky breaks the pall of cloud), and rising again as the barometer leaps up, to even greater force than before, though from a different direction. Such storms in the Indian Ocean and Mozambique Channel are called cyclones, and to describe them the word was first devised; in the West Indies they are called hurricanes, and in the China Sea typhoons. The rapid fall of the barometer to an extremely low point, and its equally rapid rise, is the most striking characteristic of such storms from the meteorological point of view. A synoptic isobaric chart, showing the pressure at the same moment at a large number of points during such a storm, exhibits a series of concentric, nearly circular isobars, the lowest in the centre; and successive charts at short intervals of time show that the storm travels with more or less regularity in a curved path, which, as a rule, can be fairly accurately forecasted by observations of the wind and the movements of the barometer. These storms move from the tropics first in a polar west direction, and later in a polar east directionin other words, their track is at first towards the west, curving as they proceed towards the right in the northern hemisphere, and towards the left in the southern hemisphere.

We know little or nothing at present of the generation of these violent cyclonic storms, though from the fact that the appearance and movements of cirrus, the highest form of cloud, usually give the first signal of 
their approach, even before the barometer begins to fall, it seems not improbable that the study of the conditions of the upper atmosphere may throw some light upon the problem. Storms in general appear to be eddies in the steady flow of the great air currents which carry on the normal circulation of the atmosphere, and they are apparently fed from the permanent high-pressure areas.

The storms of high latitudes (such as the extratropical parts of the North Atlantic, the North Pacific, and the Southern Ocean) are most frequently cyclones of far less intensity than those of the tropics, but involving a very much larger area of the ocean surface and travelling with much greater velocity; but on account of the gentler pressure-gradients the winds are rarely of such intensity, though frequently of longer duration. There are some peculiarities, still imperfectly understood, in the storms of the Southern Ocean, which require elucidation. Speaking generally, the force of the wind depends only on the pressuregradient-i.e., a great fall of the barometer in a long distance may produce a much lighter wind than a small fall of the barometer in a very short distance. The use of wireless telegraphy now permits ships at sea to compare their barometers and so to measure the gradient directly; but where this is not possible gradient can be judged by the rate of fall of the barometer. Thus, a fall of a tenth of an inch in half an hour shows a far steeper gradient, and forecasts far stronger wind, than the fall of a whole inch in ten or twelve hours.

Observations show that the air temperature over the open ocean is subject to a much smaller diurnal and annual range than over the land. It is only in such enclosed waters as the Red Sea and the Persian Gulf 
that very high temperatures are the rule, even within the tropics; while low temperatures prevail only in the vicinity of the Arctic and of the Antarctic regions. The borders of an ocean, in which the prevailing wind is off-shore, in the tropics frequently show a lowered air temperature, on account of the cold upwelling water draw̄n up from the depths by the blowing away of the warm surface water. On the other hand, the borders of an ocean, in which the prevailing wind is onshore, often has a higher air temperature on account of the warm surface water driven in from lower latitudes.

What may be termed " normal conditions of temperature " are considerably deranged by local causes in different parts of the globe-as, for instance, off Cape Guardafui, on the East Coast of Africa, where the changing of the monsoons substitutes an on-shore for an off-shore wind, giving rise to upwelling of cold water and banking up of warm water alternately. Other instances are found off the Cape of Good Hope, the Banks of Newfoundland and the Falkland Islands, where ocean currents of different temperature meet, and the same area is occupied at different times by water of varying origin and temperature, which reacts on the air.

\section{Instruments.}

It may be remarked that, as a rule, there is not much choice in the placing of meteorological instruments on board ship; this follows from the structure of the vessel and the exigencies of her special service. Besides, the instruments must be placed in the handiest position for observers, who may have to consult them without quitting their posts or otherwise interrupting the duty of the moment ; hence the routine observations made on board ship, useful as they are, leave a good 
deal to be supplemented when opportunities are offered to scien tific observers.

The most important of all meteorological instruments at sea is the barometer, for all our knowledge of the cause and general prevalence of wind and the broad lines of atmospheric circulation depends upon exact and multitudinous measurements of pressure.

I. The mercurial barometer must be hung in a vertical position, and should be placed in a room with a temperature as equable as possible, free from draughts, in a good light, and at a convenient height, so that the eye can be brought easily to the level of the top of the mercury column. These conditions are just as imperative at sea as on land, though much more difficult to fulfil. At sea a vertical position can only be preserved by a barometer so freely suspended that the ship can roll without affecting it. Even with the best arrangement of gimbals this is practically impossible, except in a very smooth sea, and the mercury in the ordinary barometer surges up and down so as to make accurate measurement extremely difficult. The surging of the mercury due to the ship's motion is checked in marine barometers by a constriction of the tube at the cistern end, so that the action is slowed down. A more serious cause of disturbance arises from the action of the wind during heavy weather. The barometer is most conveniently hung in the chart-room of a modern steamer, from 20 to 60 feet above the sea-level. In this room the windward door is kept shut and the leeward door open; and as each gust of wind sweeps past, the air is sucked out through the open door, and the mercury in the barometer sinks to the diminished pressure, rising again in the lull, and continuing to swing up and down while the "pumping" action lasts. Great skill and 
dexterity are required in setting the vernier so as to allow for this pumping, and even in the best instruments, with the most alert and patient observer, it is impossible to read with anything like the degree of accuracy which may be obtained at stations on land. The rise and fall of the ship with the waves produces a smaller irregularity, and when it is remembered that, roughly speaking, the barometer falls one-thousandth of an inch for every foot of increase of height, it is plain that the vertical rise and fall of a ship in rough weather may affect the readings by several hundredths of an inch. It is necessary, therefore, in any attempt at exact work, to take the mean of the highest and lowest readings when the ship is in the trough and on the crest of successive waves. It must be remembered that a greater degree of accuracy in reading the barometer is required for meteorological purposes than when the barometer is merely used as a nautical instrument to give warning of storms. The barometer must be kept as free as possible from artificial heat and from risk of jars or knocks ; but when it is suspended in suitable gimbals it does not require any extra springs or strapping.

2. The aneroid is a useful supplementary instrument; as it is more sensitive than the mercurial barometer, it gives earlier warning of approaching weather. It is free from the surging error due to the rolling and pitching of the ship; but no barometer capable of measuring differences of pressure can escape from the disturbances due to the pumping produced by suction of wind and to the rise and fall of the waves. A barograph, or self-registering form of aneroid, is, perhaps, the most suitable on board ship. If hung with a spring hook to the roof of a cabin, it gives a continuous record, of the utmost value when 
checked by periodical readings of the mercurial barometer. Specially sensitive patterns, provided with a drum revolving more rapidly than in the ordinary form, may be used to keep a record of the height of the waves encountered.

3. Temperature is measured by thermometers, which should be of standard type, tested at Kew or at some other national testing establishment, and supplied with a certificate of accuracy. This condition is insisted on for all the instruments supplied by the Meteorological Office for use at sea. The wet and dry bulb thermometers must be exposed in a louvred screen, quite in the open, free from all artificial heat, and protected from sea-spray and from all risk of injury. The bulb of the dry thermometer must be kept as free from moisture as possible, and the bulb of the wet thermometer free from salt. The object of the wet bulb thermometer in conjunction with the dry bulb is to supply data for calculating the humidity of the air, for which purpose tables are printed in all books of instructions for the use of meteorological instruments.

The wet and dry bulb thermometers, used for measuring the temperature and humidity of the air, act as well at sea as on shore; but the water supplied to the wet bulb and the muslin covering the bulb must be more frequently changed, to prevent incrustation with salt. A weekly change of muslin and the use of distilled water would probably be found necessary, in order to obtain accurate results. A more serious difficulty which arises is the totally inadequate character of the "Board of Trade screen " usually supplied for housing the thermometers. This is too small, and its place should be taken by an ordinary Stevenson screen, as employed on shore. The great size of modern steamers gives ample room for setting up such a screen, 
which should be placed forward of the funnels and galley chimneys and on the highest accessible part of the ship, so as to keep it freely exposed to the wind, but clear of spray except in the worst weather. The middle of the forward end of the roof of the chart-room is the ideal position. Better results would probably be obtained by the use of Assmann's aspiration psychrometer. This consists of a wet and dry bulb thermometer placed side by side in metal tubes, over which air is drawn by a quick-running fan, actuated by clockwork. It can be used in full sunshine, and the observer should stand on the windward side of the upper deck, the instrument being kept in a case safely stowed away between the times of reading.

Maximum and minimum thermometers of the ordinary type could not be used on board ship hitherto, on account of the liability of the indices to be displaced by the rolling ; but on the largest vessels of the present day there seems no reason why they should not be employed with perfect safety on most days, if they are placed fore and aft in the thermometer screen. But in any vessel a maximum and minimum thermometer of Six's type can be used alongside of the wet and dry bulb thermometers, and the results of such observations would be the more useful because, as yet, they are very rare. The best form would be one of the large-pattern deep-sea thermometers, which for this purpose need not be provided with an outer protective bulb. A thermograph hung by a spring hook from the roof of a well-exposed Stevenson screen would yield most interesting results, but everything depends on the exposure being free to the wind and protected from the sun, rain, and spray, while the clock would require to be carefully attended to and set daily to ship's time.

It would probably be of little use to attempt to 
measure solar radjation at sea, though in the hands of an interested observer Wilson's radio-integrator might be tried with some prospect of success. It would require to be exposed to the sky above all awnings.

\section{Wind Observations.}

To observe the true direction of wind in a steamer running at high speed requires the skill born of experience for judging by the crests of the waves in rough weather and by the rippling of the surface when smooth. An instrument by which the true direction can be ascertained from the apparent direction and the course of the vessel, has been devised by Professor A. L. Rotch, of Harvard, and is described in the Quarterly Journal of the Royal Meteorological Society, vol. xxx., I904, p. 3I3. The force of the wind at sea is always estimated, not measured, generally by the curl of the waves; allowance must be made for the speed of the vessel and the angle of her course, as well as for the speed of the wind and its true direction (which is deduced from the curl of the sea). When there is a following wind and the smoke rises vertically, as does occur occasionally, the speed of the ship gives the velocity of the wind with the exactness of an anemometer on land. With other winds the speed of the ship must be added to or deducted from the estimated velocity, unless the estimation is made by observing the effect of the wind on the waves. The Robinson cup anemometer cannot give trustworthy results at sea, as the spindle must be kept vertical if its indications are to be of any value. Experiments might well be made with the Dines pressure-tube anemometer, or some variation of it ; but this belongs at present to the region of research rather than of observations. 


\section{Other Meteorological Phenomena.}

Clouds may be observed to perfection at sea, where nothing interferes with the wide prospect from horizon to horizon. There are three main types of clouds : cirriform, or wisp clouds ; cumuliform, or heap clouds ; stratiform, or layer clouds. Different classifiers of clouds have subdivided these main types into several varieties, and it would be a useful exercise to compare the different classes, which have for the most part been made from observations at a shore-station in temperate latitudes, with the forms seen at sea in all parts of the world.

For many purposes the broad division into three types suffices. It is noteworthy that one type of cloud prevails more than the other in certain ocean localities. In the north-east trade region great masses of stratus abound, while in the south-east trade district the cumuliform predominates. In the doldrums and the horse latitudes the cumulus type prevails, often in the most curious and remarkable forms. In the northeast trades cirriform clouds are constantly to be seen moving away to the north-east from a south-westerly direction.

Fogs are of such serious importance in navigation that they are naturally objects of much interest at sea. Certain regions are almost constantly beset by fog-off the Newfoundland Banks, for instance, where the icebergs brought down by the cold water from the north meet the warm water coming from the south. Fogs are common, also, in the corresponding districts of the North Pacific and off the Falkland Islands, where similar causes operate. Dense fogs frequently occur round the coasts of England in the early winter months, 
when the sea surface is much warmer than the air ; but sea fogs cannot always be accounted for in this way.

Rainfall.-There is no department of marine meteorology which has been so neglected as the measurement of rainfall, and we have only a few fragmentary observations to go upon in comparing the rainfall of the land with that of the sea. In this instance, again, the large steamers of to-day offer facilities for accurate observations which were formerly unknown, though fair results have been obtained even on a vessel so small as the "Discovery," of Captain Scott's first Antarctic expedition. The rain-gauge for use at sea must be swung on gimbals, and the lower part heavily loaded so as to keep it as horizontal as a compass bowl. It should be placed in the middle of the upper deck, as far as possible from masts, funnels, or stays, and from the sides of the ship. The two chief difficulties to be overcome in measuring rainfall at sea are ascending eddies of air and the breaking of spray into the gauge. The eddies may be neutralized to some extent by preventing the wind from striking directly on the gauge or the box in which it swings ; this may be done by having a wooden frame fixed to the deck, with walls equal to the height of the gauge, and of such a size as to be at least as far from the gauge as its own height at every point. The amount of sea water which finds its way into the gauge can easily be calculated by determining the salinity of the contents of the gauge by titration, for which all appliances would be found on any vessel fitted out for marine investigations. If it were found practicable to instal a rain-gauge on an ordinary steamer, it would probably be as much as could be done to record, every time the gauge was emptied, whether the contents tasted quite fresh, or were slightly or very salt. In. the first case no cor- 
rection is required ; in the last case, unless it is known that rain fell, the contents could be treated as all due to spray, and thrown away unrecorded; but if the water is slightly salt, a note must be made of the fact, and the measurement entered with a query. Much valuable information could be obtained, even without a rain-gauge, if the time when rain began and ceased were recorded in the log, with a descriptive note as to whether the fall was light, heavy, or torrential. It is surprising that so few ships' officers have thought of recording this almost unknown factor of sea climate.

\section{The Upper Atmosphere.}

Until quite recently we had no practical means of taking observations in the upper regions of the atmosphere, but of late many experiments have been made, by means of kites and balloons, which give excellent results; and the upper atmospheric regions are being gradually explored and systematically studied. Recent research on the temperature and other conditions in the free air at great heights have shown that normally the temperature falls rapidly as the height increases, until an elevation of six miles (more or less) is reached, where the temperature is from $30^{\circ}$ to $70^{\circ}$ below zero Fahrenheit, after which there is practically no further decrease of temperature, but sometimes a distinct increase. The upper region of nearly uniform temperature has been termed by physicists the " isothermal layer," or, less aptly still, the " isothermal column." It might be better named (in conformity with the nomenclature recognized by oceanographers for the depths) the homothermic region. No vessel specially equipped for oceanographical research should be without a supply of 
meteorological kites, with the necessary wire and winch and special meteorographs; for ascents can easily be made from a ship, which can be manœuvred to help the wind in raising the kite ; but no direct investigation of the upper air is practicable on a vessel which cannot deviate from her course. A good deal can be done, however, to determine the direction of the upper air currents by letting off small balloons (pilot balloons), and measuring the angle of altitude of the liberated balloon by means of a sextant at uniform intervals of time, and the azimuth at the same intervals by means of a compass provided with suitable sights. The altitude angles give the distance of the balloon from the ship on the assumption that the rate of ascent is uniform, the time intervals thus giving the height above the sea at each observation. The rate of ascent for balloons of a given size, material, and amount of hydrogen, must be determined by measurements on land, by two theodolites at the ends of a measured base. The azimuths, taken in conjunction with the ship's course and speed, show the direction of drift of the balloon as it rises-that is, the movement of the wind at the given heights.

Without the use of any instruments the character and movements of the upper clouds are an indication of the winds in the higher regions of the atmosphere; and, when travelling in places where volcanic eruptions may occur, the observer ought to take particular note of the form, angular height, and direction of drift of any column of steam or smoke which may be seen to be thrown up by a volcano. It may be recalled that the dust of the eruption of Krakatoa, in I883, which was projected to an observed height of twenty miles, was carried by the upper currents of air, not only all round, but all over the world. In all observations 
involving direction the utmost care must be taken to state clearly whether each reading is magnetic or true, and, if magnetic, the true bearing should be calculated and entered as soon as the variation is known. Much trouble has arisen through the neglect of this very obvious precaution.

\section{Special Problems in Meteorology.}

Meteorological observations at sea on a scientific expedition are of great importance with reference to oceanographical observations, such as the temperature of the surface water and of the deeper layers, the surface currents, the occurrence of plankton, and other matters. But it is also important to consider meteorological observations from the point of view of our knowledge of the science of meteorology itself, and there are some problems which are more likely to be elucidated by observations at sea than by those on land. One of these is the angle with the horizontal made by the wind when it strikes the sea and the effect of winds of different degrees of obliquity. So far as we know, nothing has been done in this direction; but it is obviously of importance, with regard both to wind-raised waves and wind-driven currents. How such observations can be made we must leave to the ingenuity of the investigator, whose attention has been called to the subject.

Another matter, concerning which more information is required, is the diurnal variation of phenomena. The hours at which the two maxima and minima of pressure and the maximum and minimum temperature occur in each diurnal period can be determined only roughly from routine observations, and it is worth while to supplement the regular readings with more frequent 
readings about the critical hours, or, still better, with the tracings of self-recording instruments.

There are innumerable opportunities at sea for the observation of other meteorological phenomena and weather conditions for which no special instruments are at present available, or, indeed, required. Such phenomena, as being of only occasional occurrence, should always be recorded, not because of their rarity or their impressiveness, but because, as the times of their appearing cannot be predicted, and few are found ready when the phenomenon is suddenly recognized, there are very few cases on record of exact measurements. Among these are squalls, waterspouts, thunderstorms, wind-borne dust, and optical and electrical phenomena.

Waterspouts should, if possible, be photographed, the course of their formation and dispersion carefully watched and described, and an endeavour made to obtain angular measurements which will give the distance and height of the columns and their rate of movement.

The optical phenomena include rainbows, rings round the sun and moon (known as "coronæ," " halos," " paraselenæ," etc.), sun pillars, and the green ray. These phenomena give the most striking effects at sea, where they are seen much better than on land. The sun shining on the drops of a passing shower produces the rainbow by double internal reflection; sometimes a double or outer bow is visible. Rainbows are often to be seen at night, when the moon is particularly bright. Coronæ are due to rays of the sun or moon shining through loose clouds of either the cumulus or the stratus variety: they give the effect of faintly outlined rings round the orb. Halos and the other forms of ring are due to sunlight shining through 
very high cirriform clouds, in which ice crystals replace globules of water. These halos present very striking and beautiful effects, but the more complicated formations of rings are rare. Careful observations should be taken of all such phenomena, not only because they are often the first indication of an approaching storm, but because of their intrinsic interest. Thus, for example, a halo when observed should have the angular diameter of the main ring measured by a sextant, and the diameters of any fragmentary circles estimated by measuring the visible arcs. The height of the sun or moon above the horizon, the hour, and the state of the sky as regards clouds, should all be noted. A sun pillar is also a rare phenomenon; this is a pillar of light which, as the sun sets, shoots directly up into the sky for a space of from Io to 15 degrees, remaining stationary for some little time. The light appears to be reflected from the under-surface of ice crystals, as a light may be reflected from a water surface. A very rare and beautiful phenomenon may sometimes be seen at sunrise or at sunset : pink rays springing up on the horizon, opposite the sun, and sometimes reaching to the zenith. The phenomenon, known as the green ray at sunset and sunrise, is the brilliant green colour which the line bounding the upper limb of the sun assumes when it is just touching the water horizon. It is curious that, although plainly visible to the naked eye, the old navigators do not appear to have noticed it. The theory of this appearance is fully understood, but it may be used as a test of the observers' vision.

Amongst the electrical phenomena we have-apart from lightning-the auroræ and St. Elmo's fires. The sometimes radiant appearance of an aurora may indicate a connection between this phenomenon and 
cirrous clouds. At other times the aurora appears as pulsating waves of white light, flashing across the sky in independent action. An aurora is generally white, but the display is often accompanied by a decidedly red appearance of the sky. St. Elmo's fire, which appears as a sort of electrical discharge, occurs in the height of storms, not always thunderstorms. These fires indicate a highly electrical state of the atmosphere, the light seeming to play round the mastheads and yards of a ship with a faintly white glow. It would be worth noticing whether the steel masts of a steel ship with wire rigging would show this effect.

Finally, in all measurements and descriptions the observer is earnestly counselled to regard only what he sees, remembering that the main value of his observations, if they turn out to be of value, lies in the testing of the truth of theories, not in finding what other people have noticed before. It is extremely desirable that anyone aspiring to make observations of value in marine meteorology should consult the instructions issued by the Meteorological Office, study the pilot charts of the parts of the ocean which are published monthly or at more frequent intervals, and consult such standard works as are cited in the List of Literature given on p. 434 . 


\section{CHAPTER II}

\section{THE WATER}

BY H. N. DICKSON AND D. J. MATTHEWS.*

OUR knowledge of the physical geography of the sea, of its depths, the composition and physical conditions of its waters, and their movements, is wholly derived from observations made from the surface. Surface conditions themselves can of course be observed directly from on board ship. Observations in the depth must be made indirectly-i.e., by means of instruments, which can be sent to the point at which it is desired to make an observation and caused to record a condition there, or to bring back a sample from which the condition may be inferred.

The work of the earlier deep-sea expeditions, such as those of the "Challenger," brought two fundamental facts to light. It became clear first that the conditions in some regions of the sea vary within certain fairly narrow limits. Some of these variations are periodic, some non-periodic, but a knowledge of their range from season to season and from year to year is of the highest scientific and economic importance. Such knowledge is gained by repeated observations from large numbers of vessels, distributed over a wide area, and observing as far as possible

* Of the joint writers of this chapter, Dr. Dickson has contributed the more theoretical part, Mr. Matthews the practical section.-ED. 
simultaneously. Work of this kind attains its highest development in such special organizations as those of the International Committee for the Study of the Sea, or the combined Antarctic expeditions; but much useful work can be done by ships cruising in areas outside the field covered by these organizations, as in the expeditions of Dr. Wolfenden's "Walwin" and "Silver Belle," or in almost any region, by ships taking regular routine observations of a more or less elaborate character, and communicating the results to a central authority, such as the Meteorological Office, for collation with the records of other observers. As examples of what may be done in this way from surface observation alone, reference may be made to the surface temperature charts published officially in this country, the United States, and elsewhere, and the surface salinity map which illustrates this chapter. All these depend on the daily observations made on board liners, tramps, whalers, yachts, and oceanfaring craft of all descriptions.

The second fundamental fact is, that in all oceans the conditions below a certain depth are very uniform over a considerable horizontal and vertical range, and changes take place with great slowness if they occur at all. Now, observations in the depth must be made from vessels of considerable size, and with somewhat elaborate and expensive equipment ; but the minimum tonnage is well below that common amongst oceangoing steam-yachts, and the cost of the necessary equipment is not of an order of magnitude greater than other outfits in such vessels. And the conditions just explained make observations of this kind valuable, wherever and whenever they are made; for the great lines of soundings laid down by the deep-sea expeditions and the cable ships are separated by vast 
areas in which charts of all sorts remain blank to this day, even as regards the depth; and we know that each point filled in by a new sounding is, beyond a certain depth at least, practically filled in once for all.

Thus there are, so far at least as physical oceanography is concerned, two distinct kinds of work waiting to be done-the work at the surface and in moderate depths, which can be undertaken more or less fully by practically every ship that puts to sea; and the work in the abysmal depths of the unfrequented parts of the great oceans, which can be done by larger vessels, more fully equipped and not restricted as to route or time.

The following may be taken as the principal observations common to both types of work. It being assumed that a vessel has arrived at a definite point in the ocean, the latitude and longitude of which are known, information is wanted on the following points:

I. Depth.

2. Temperature of water at surface, bottom, and intermediate depths.

3. Composition of water.

4. Specific gravity of water.

5. Currents.

6. Nature of bottom.

The first and last of the above headings are dealt with in another chapter, and we need only note here, with regard to the first, that the collection of material under the headings (2) and (3) can only be associated with those methods of sounding in which the measurement by vertical sounding-line is concerned; the methods depending on measurement of pressure, as in Kelvin's sounder, are inadmissible.

The object of making these observations, and of collecting samples of water, being ultimately to ascer- 
tain the geographical distribution of the various elements, and the changes which take place in them, some general considerations may be stated before proceeding to detailed description of the methods employed.

\section{Composition of Sea Water.}

From comparison of all available analyses of sea water, it may be assumed that the composition of sea water in the open oceans is the same in all parts of the world-that is to say, ocean water contains certain salts in solution, and the relative proportions of these are constant (see Addenda, p. xvii).

Their most important features are-(a) the preponderance of sodium chloride; $(b)$ the small proportion of calcium carbonate ; and (c) the "residuum " of 0.22 per cent., which contains traces of nearly all the known elements, including gold.

There is thus present in all oceans a "brine" of particularly constant composition, and the variations which are observed in the composition of sea water consist merely of variations in the extent to which this brine is diluted, just as variations in tea made from the same leaves consist in variations of strength. Hence one of the most important factors to be determined in physical oceanography is the " strength" or salinity of the water at different points and at different depths. The salinity of a sample of water serves as a label, which often makes it possible to trace its origin and physical history and hence to draw conclusions repecting currents, and, along with its temperature in place, enables us to calculate its specific gravity. The "salinity" is the total weight of salts in bulk in solution in a given weight of water; thus, "Salinity 35 per mille" means 35 pounds of salts in 
I,00o pounds of the water solution. " Specific gravity" is the weight of a unit volume of the water solution; it varies with temperature as well as with salinity, since water expands when heated and contracts when cooled.

That the determinations of salinity must be made accurately appears from the fact that the total range of variation in the open sea is at most between 33 and 37 per I,000, the average salinity running between 35 and 36 .

The chart which follows shows the general distribution of salinity in the oceans so far as it is known, but it must be understood that in many regions, where actual observations are few and far between, the "isohalines" (lines of equal saltness) are drawn with a free hand (compare Chart IV. with this).

A study of these charts shows at once the general nature of some of the problems which a knowledge of salinity helps to elucidate, and which depend for their complete solution, in part at least, on a more intimate acquaintance with the local distribution in certain seas, and the changes which occur.

It appears $(a)$, that the saltest surface water is found in the trade wind belts, where strong sunshine and steady winds favour great evaporation. From maps of specific gravity it appears that the high temperature of the water keeps it relatively light, notwithstanding its great saltness, and hence we have to inquire as to the sources whence the deficiency of water due to removal by evaporation is made good. Again $(b)$, the freshest surface water occurs in either regions of widespread excessive rainfall - such as the Western Pacific-or regions in high latitudes, where cold fresh water is set free by the melting of floe-ice and icebergs. The investigations of the last 


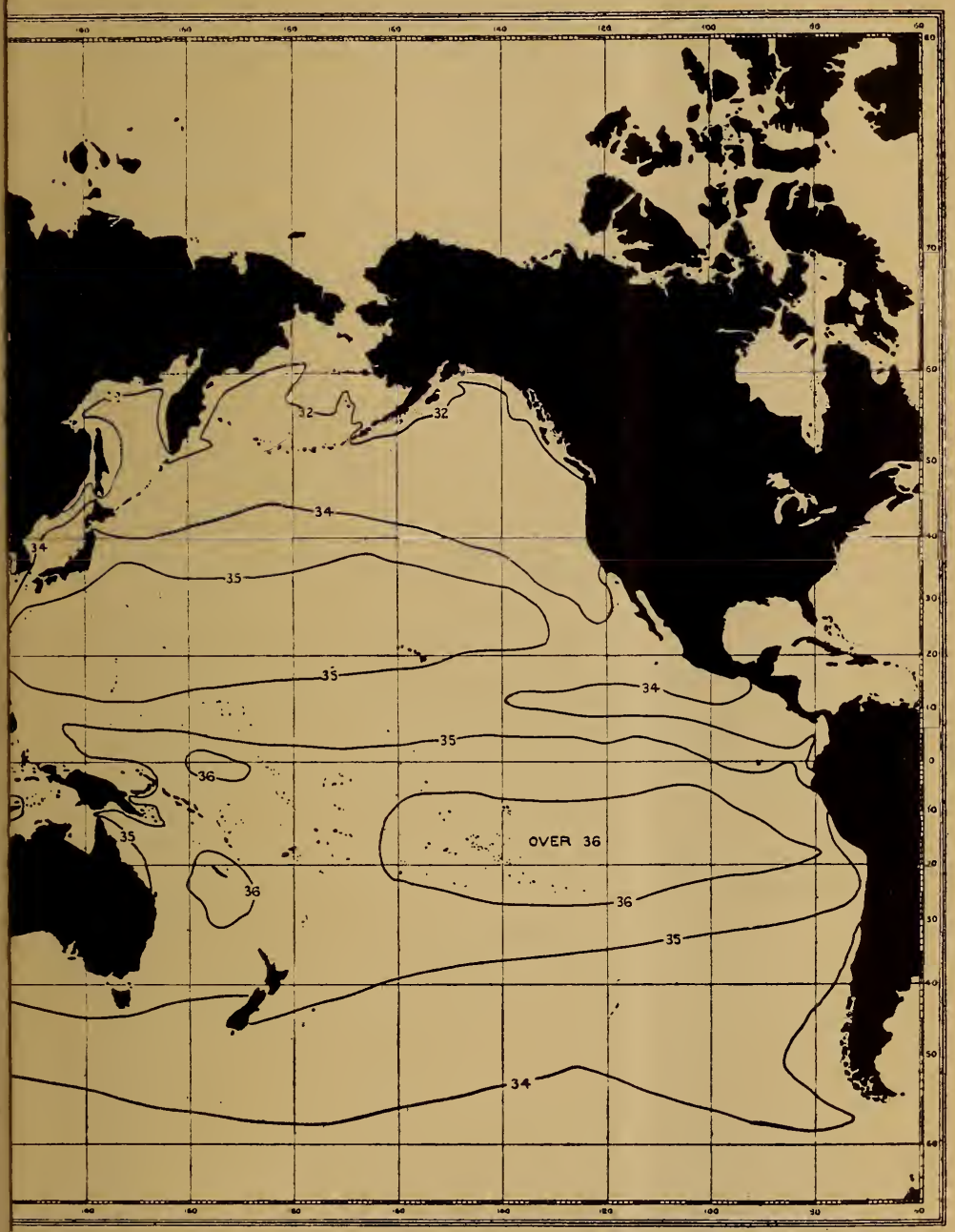

RFACE OF THE OCEANS.

lit per thousand parts of salt water. (After Dr. G. Schott.) 



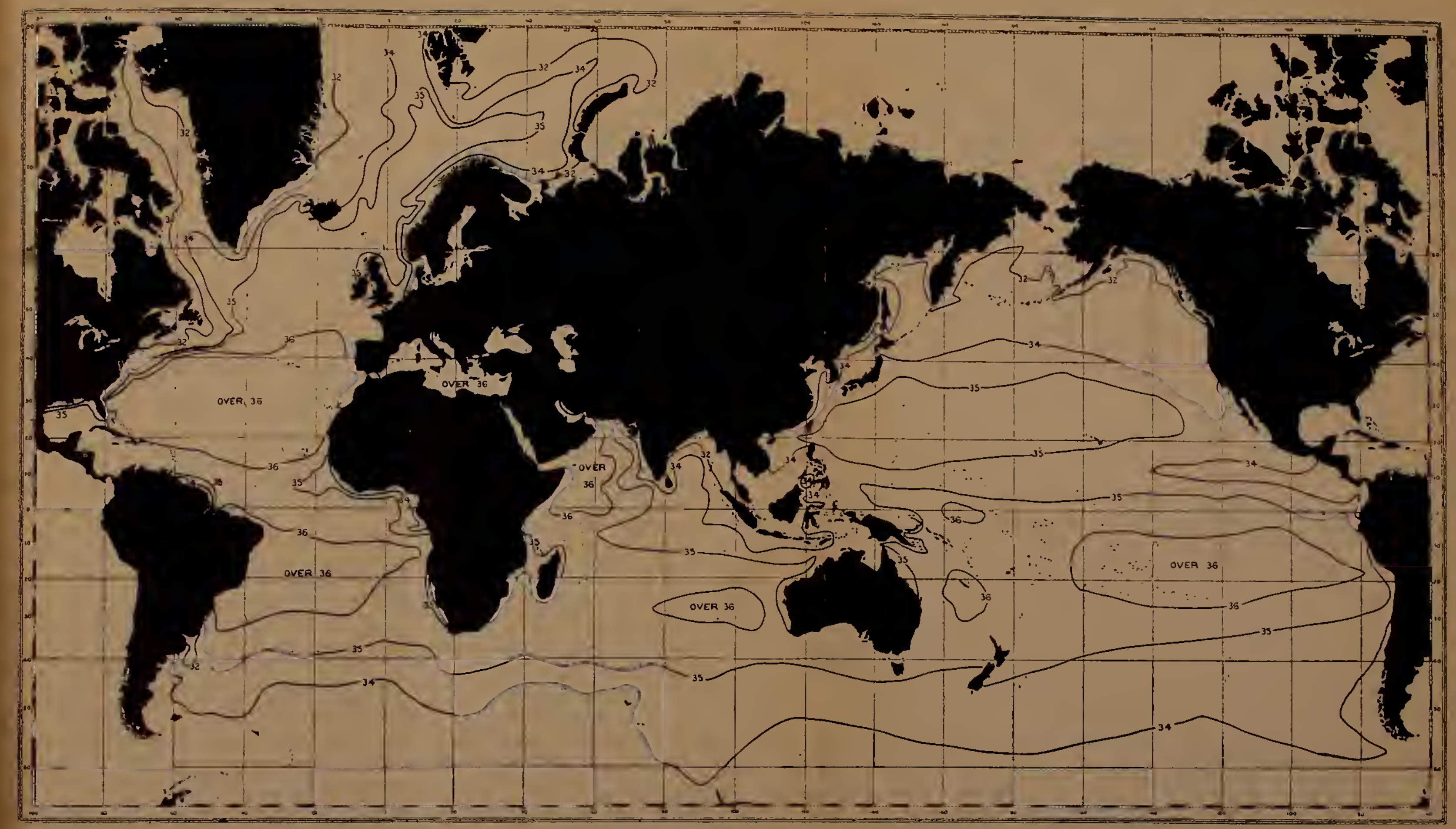

CHART III.--ISOHALINES OF THE SURFACE OF THE OCEANS.

These are lines drawn through points of like salinity ; the figures denote parts of salt per thousand parts of salt water. (After Dr. G. Schott.) 
few years have shown that the distribution of this cold water, which varies greatly from season to season, and from one year to another, has a profound effect upon climate and upon the distribution of marine life (including food-fishes), and more observations in this direction are urgently needed.

This fresh water is relatively light, notwithstanding its low temperature, but, when it moves into lower latitudes, its specific gravity tends to increase relatively to the warmer water surrounding it ; hence we have a zone of maximum specific gravity at the surface outside the latitude of the trade winds, a sort of combined effort of warm salt water on one side and cold fresh water on the other.

Lastly $(c)$, the complete mixture of waters in the oceans frequently takes place with great slowness, compared to the rate of the horizontal movements known as " currents" ; hence, fresh or salter water may often be traced for great distances merely by the difference in salinity from adjacent parts of the ocean. The opportunity which a knowledge of salinity affords in this way of tracing the course and volume of currents gives these observations their greatest value.

\section{Temperature of Sea Water.}

The distribution of temperature at the surface and in the depths is shown in Chart IV.

By this distribution several distinct questions are raised, all of which require more material for full discussion; but we may call attention to two main points :

I. Assuming the waters of the sea to be at rest, what are the main sources of gain and loss of heat which determine their temperature? The surface of 
the sea differs from that of the land in that it is not opaque, but to a certain extent transparent, at least to certain rays of light. Buchan ("Challenger" Report) found evidence that the effect of the sun's rays was appreciable to a depth of about 500 feet from the surface in deep water; more recent experiments have traced it to still farther depths. Radiation must go on to a certain depth, resulting in larger or smaller variations of temperature. Again, the surface of the sea is in contact with the air ; the latter is constantly changing its temperature, and these changes must be communicated to the sea water by conduction. The combined results of these factors are given by Buchan, who found that on the average of all the "Challenger" observations a diurnal range of the temperature in the air is three to four times that of the surface waters of the sea over which it lies.

2. The variations of temperature, taken along with those of salinity, determine variations in specific gravity in the manner already described, and they also furnish valuable additional means of tracing the major movements in the depth.

With regard to the actual methods of investigation, it may be definitely laid down that observations of the temperature and the currents must be made at sea; but determinations of the density and chemical composition, with sufficient accuracy for modern requirements, can only be carried out on shore. Analysis of the dissolved gases is a possible exception to this rule, and reference should be made to the various papers which have been published on the subject.

Samples of water must therefore be collected for 
further examination, and the kind of storage bottle is of considerable importance. If the examination is to be confined to a determination of the chlorine by chemical methods and of the specific gravity by weighing, a sample of $\mathrm{I}_{50}$ c.c. will be sufficient; larger quantities are of course more convenient, but, if many samples are to be collected, the size of the bottles is a serious consideration. One of the writers uses bottles known in the trade as " 6 -ounce milk bottles with porcelain stopper, rubber washer, and swing catch," holding about I70 c.c. These are very convenient in use and comparatively cheap. Each batch should be carefully examined when received from the makers, and any in which the washer appears to fit loosely should be rejected. For the washers nothing but the best Para rubber should be used; if there is any difficulty in obtaining them from the glass makers, they may be had from reliable dealers in chemical apparatus. All glass is slightly soluble in water on long standing; the brown variety, used for beer bottles, seems to be less affected than other kinds. With good glass this solubility diminishes with use, and bottles that have been used for sea water previously are always to be preferred. New bottles may be improved by steaming, followed by washing with hot water. For all ordinary hydrographic purposes it may be said that the solubility of the glass will not affect the determination of the chlorine by volumetric methods; but the specific gravity becomes noticeably higher with time. When the greatest accuracy is required it would be advisable to use bottles of Jena glass ; these are to be had in sizes ranging from 250 c.c. to 2,000 c.c. ; they have ground-glass stoppers, which should be replaced by india-rubber. The price, however, would be rather high. 
Suitable boxes for packing the 6-ounce milk bottles can be obtained from the glass makers. They should be divided into compartments, so that each bottle is separated from the others, and both bottom and lid should be lined with felt. No further packing is required. The boxes should have a hasp and staple for closing, and rope handles should be fitted. Hand holes give admission to rats, which eat the labels.

Care should be taken to rinse out the bottle thoroughly with part of the water, and not to fill the bottle within (say) an inch of the stopper. Frost should also be guarded against ; one of the writers has lost a number of samples from this cause.

The particulars (i.e., name of ship, date, time, latitude and longitude, depth, and temperature) should be written on stout Manilla paper labels, and tied to the bottle, the string being fastened in such a way as to obviate any possibility of the catch springing up. The number of bottles in each box will vary according to circumstances. Suitable numbers are thirty, thirtysix, and forty-two. For larger quantities of water, "imperial pints" of the same shape may be used.

Surface water is easily collected in the bottle itself or in a bucket; as the bucket will also be used for determining the temperature it is somewhat difficult to decide on the best material. It must be easily washed free from dried salt, and from this point of view a non-porous material, such as metal, is most suitable. On the other hand, a metal bucket allows the temperature to change so rapidly, that it is at times impossible to obtain a correct reading. Wood gives accurate temperatures, but requires very careful washing to free it from salt. The author prefers to use a riveted leather bucket for surface samples taken under way; but if the vessel is stopped and 


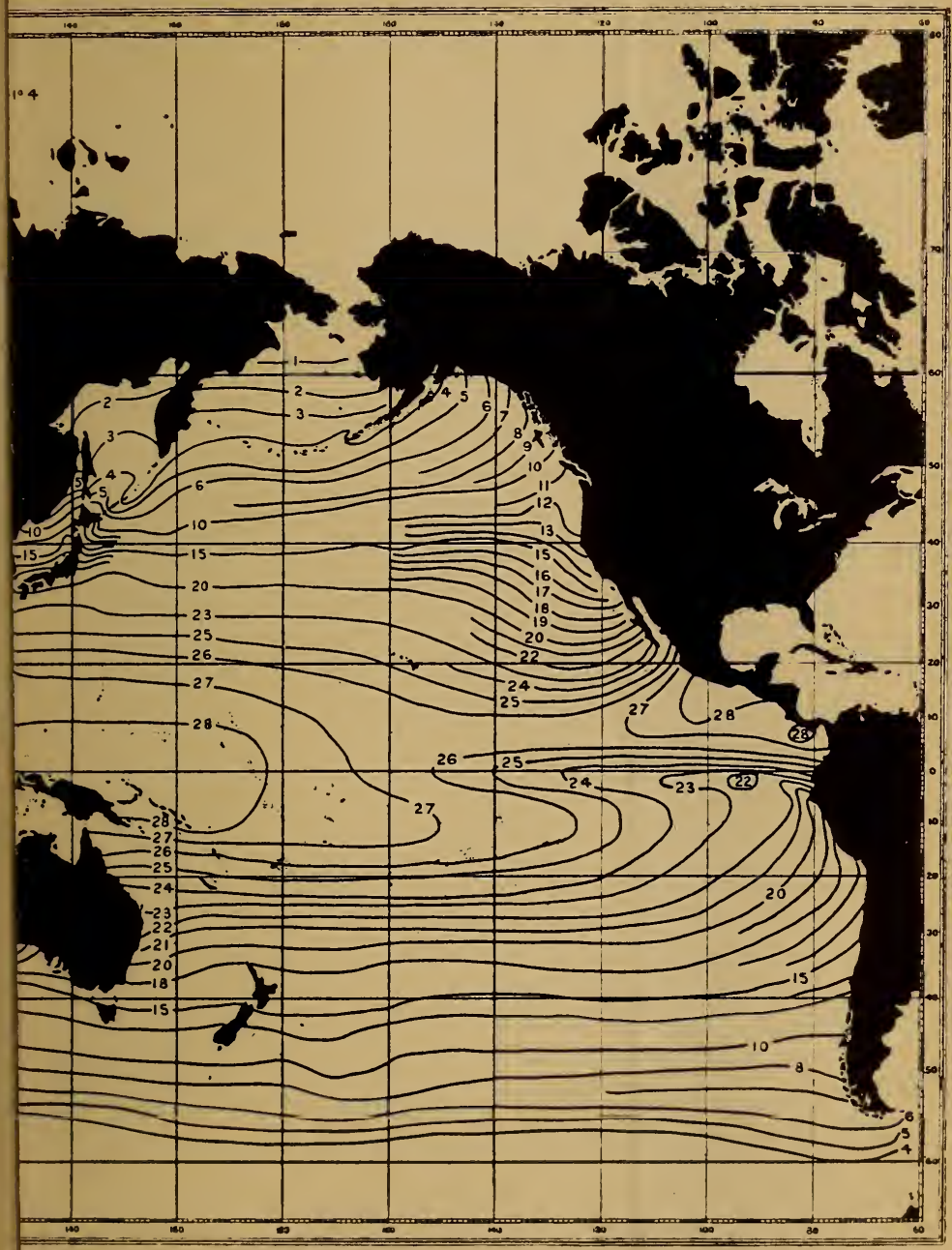

FACE OF THE SEA.

The influence of the main currents is clearly shown in the deflection pns. 


investigations are being made at various depths, it is better to use the deep-sea water-bottle for the surface also, if the weather permits of this being done.

Below the surface, water samples must be collected by means of some apparatus which can be closed at the required depth. There are many forms which are suitable, and as they are generally made to carry a thermometer the latter may be discussed here.

There is one rule which is of the greatest importance - that is, that no thermometer is to be used unless its errors are known. All the forms of thermometer used for marine investigation can be bought with a certificate of examination at some recognized institution. In England the examination is made at Kew, in Germany at the Physikalisch-Technische Reichsanstalt at Charlottenburg. It should be remembered that the error is stated in different ways. The Kew certificate gives the correction to be applied to a given reading in order to find the true temperature. Thus, if the thermometer showed $10^{\circ}$ and the correction is given as $-0 \cdot I^{\circ}$, the true reading would be the sum of the observed reading and the correction-that is, $9 \cdot 9^{\circ}$. The German certificates give the error ; $-0 \cdot I^{\circ}$ here would mean that the thermometer read $0 \cdot I^{\circ}$ too low, so that the true reading would be Io. ${ }^{\circ}$. The certificate can, of course, only show the errors at the time of examination, and these errors may be called errors of graduation.

There is, however, another error which is to be guarded against. The glass of the thermometer continues to contract slightly for years after it is made, and so causes a slow rise in the zero. In order to detect this the thermometer should be tested at intervals, either by comparison with a standard instrument of known accuracy, or better by means of 
melting ice. The thermometer is immersed in pure ice that has been crushed and washed with distilled water, so that the graduation, $0^{\circ} \mathrm{C}$. or $32^{\circ} \mathrm{F}$., is just visible. The vessel containing the ice should have an opening to permit the water formed to run away, and sufficient time should be allowed for the temperature to become steady. The best way is to make readings at intervals, tapping the thermometer lightly before each, until no further change is noticed. The comparison must be carried out in a room with a temperature above freezing-point, otherwise no melting will take place, and the greatest care must be taken to see that the ice is pure; any dissolved salts will lower the freezing-point.

The error of the zero-point, if any, will be applied equally to all temperatures in addition to the errors shown on the certificate.

The rise of the zero-point may be avoided to a certain extent by using old thermometers, and some makers graduate their instruments only many years after manufacture; or the special thermometer glasses may be used, such as the Jena glasses 59 III or I6 III. In any case, however, the instruments should be verified at intervals.

It may be taken as a general rule that it is not possible to estimate the subdivision of a small interval by eye more closely than to one-tenth, though some observers can pass this limit of accuracy with the greatest ease ; it follows, therefore, that no correction need be considered, for hydrographical purposes, which is less than one-tenth of the smallest division shown.

If the surface temperature alone is to be observed, an ordinary chemical thermometer, divided to $\frac{1}{2}^{\circ} \mathrm{C}$., is as a rule sufficient, though one more finely divided 
may be used. It is not often, however, that a surface reading can be trusted to less than $\frac{1}{10}^{\circ} \mathrm{C}$.; and the uncertainty is generally far greater. The most useful kind is that known as a "milk-glass scale" thermometer; the graduations are marked on a strip of white glass, which is protected from the water by an outer glass tube. These thermometers have no metal frame round them, and as they can easily be cleansed from salt it is allowable to use the same bucket of water for reading the temperature and bottling a sample. A very useful pattern is that used by the British Meteorological Office; the glass is protected by a metal frame, and is not easily broken, but as the bulb is surrounded by a small bucket, which may hold dried salt, a fresh lot of water should be used for the collection of a sample.

A very large number of water-bottles have been devised for the collection of samples of water below the surface, and the description will therefore be confined to that with which the authors are practically acquainted. For moderate depths, by far the best instrument is the Nansen-Pettersson insulated waterbottle, which has been made in various sizes, and can be closed either by a " messenger" or by a propeller.

\section{The Insulating Water-Bottle.}

The Nansen-Pettersson insulating water-bottle, in its latest form, is an instrument by means of which it is possible to lower an ordinary thermometer, enclosed in an outer tube to protect it against pressure, to the desired depth, and there to surround it by a number of envelopes of the water to be examined. It can then be hauled up through layers of widely different temperature without the thermometer showing any ap- 


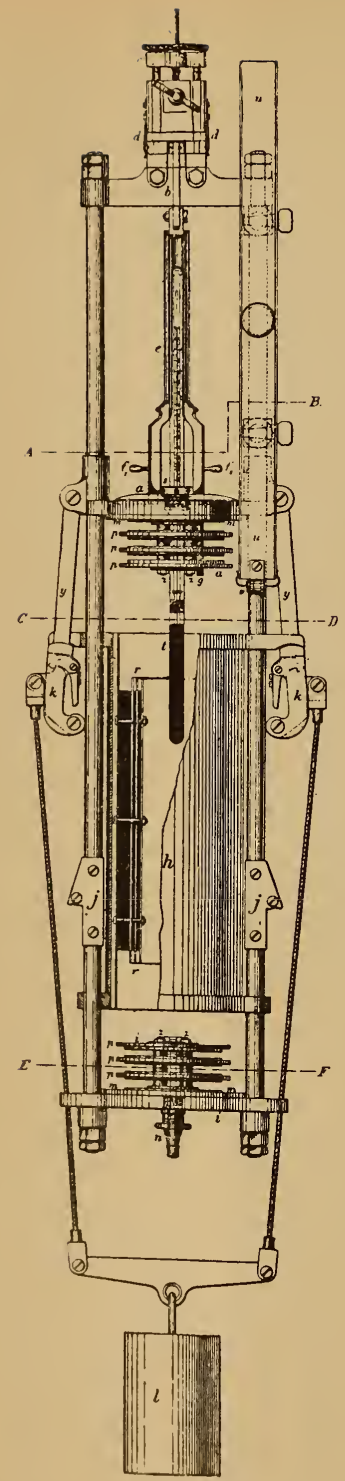

$a$, Cover or upper plate.

$b$, Hooked lever holding bottle open.

c, Striker plate.

$d$, Springs holding up striker plate.

$e$, Thermometer guard.

$f$, Catches holding thermometer guard in position; one also acts as air valve.

$g$, Air tube.

$h$, Outer cylinder.

$i$, Bottom plate.

$j$, Adjustable lugs.

$k$, (dotted lines), Locking lever which engages with the lug

$l$, Sinker.

when the bottle is closed.

$m$, Large rubber washer.

$n$, Outlet for water.

$p$, Small rubber washers.

$r$, Inner insulating cylinders.

$s$, Nut holding thermometer.

$t$, Nansen Thermometer.

$u, v$, Extra frame for reversing thermometer.

$y$, Swinging arms.

$z$, Distance pieces.

Fig. 6.-NANSEN-PetTersson

WATER-Bottle (OPEN). 
preciable change within a period of from six to eight minutes, which is amply sufficient for the moderate depths for which it is suitable. At greater depths the readings become inaccurate on account of the pressure, as will be explained below.

The construction will be understood by reference to the figure. The body of the water-bottle consists of a number of concentric cylinders, of metal and some non-conducting material alternately, and is fitted to slide freely on the two guide bars at the side. These bars are connected at the bottom by a metal plate fitted with a tap and a number of rubber washers. A similar plate is arranged to slide on the guide bars above the body of the water-bottle, and instead of a tap it is provided with a small air valve and a central hole, through which the bulb and the lower part of the stem of the thermometer pass ; they are secured by a gland and rubber washer. A thermometer guard, in the shape of a slotted tube, is fixed to the upper side of this lid and carries two hooked arms at its upper end. To set the water-bottle for use, the lid is raised and the hooks at the top of the thermometer guard are made to engage with the lower part of the spindle of the releasing gear. The striker plate is then raised and the lid is fixed. The body of the water-bottle is next raised until the lugs, which project on each side from its upper rim, engage with the two swinging arms shown pivoted to the lid, and the two small locking levers at the end of the arms are folded upwards, until they pass a spring catch which holds them in position. The lid, body, and bottom plate are now held apart from one another so that the water can pass through freely. The taps and air valves are then closed, and the water-bottle is lowered to the desired depth by means of a steel cord passing through the striker plate. 
After allowing it to remain down for two or three minutes to take up the temperature of the water, a weight or " messenger" is fixed over the wire and allowed to slide down until it hits the striker plate. This releases the catches at the top of the thermometer guard, and the lid falls on to the body and the two together fall on to the bottom plate. The two locking levers open and engage with the locking lugs on the guide bars and keep the water-bottle tightly closed. The lugs are adjustable, and their position can be altered if necessary. Before the bottle can close it is necessary that some water should escape through a relief valve fitted under one of the catches of the thermometer guard, and the time required for this can be determined by making an experiment just below the surface ; or in moderately good weather one can feel the shock of the water-bottle closing, by keeping one's hand on the wire. After allowing a sufficient interval for this purpose, the bottle is hauled up as quickly as possible, and the temperature is first read. At night an electric torch, held behind the thermometer, is of great assistance. One of the air valves in the lid is then opened, and the water drawn off from below.

The insulating water-bottle is a very efficient piece of apparatus, and can be used in any weather in which it is possible for men to work without risk of being washed overboard; it is not easily put out of order except by being allowed to strike against the ship's side. The continual blows of the messenger tend to distort the striker plate, but this is easily prevented by interposing a small piece of leather perforated for the passage of the wire. The leather should be fastened to the upper part of the frame by a few inches of string, to prevent its floating up the wire and checking the fall of the messenger. 
The interval which should be allowed for the waterbottle to take up the temperature of the water depends on the variations to which it is exposed. Six or seven minutes should be sufficient for a very wide difference, and when the water is of the same temperature at all depths, and the bottle has been kept in a place of nearly similar temperature, half a minute will suffice. In the form described the releasing gear is actuated by a messenger. Bottles can also be bought fitted with a propeller release, but the latter is uncertain in action, and the time saved by its use is negligible in the moderate depths to which the insulating waterbottle should be confined.

The advantages of the Nansen-Pettersson instrument are its accuracy and sensitiveness within its proper limits of depth, but it is somewhat heavy, and its construction renders it impossible to use a number on the same wire.

The thermometers used with it are of the ordinary form, graduated to $\frac{1}{10}^{\circ} \mathrm{C}$. on the stem, and protected against pressure by an outer glass tube. The space between the bulb and the outer tube should be partly filled with mercury to insure its taking the temperature of the water quickly.

The theory of the insulating water-bottle is too complicated for treatment here, but a very full discussion is to be found in a paper by Dr. Walfrid Ekman (Pub. de Circ., No. 23). There is, however, one serious defect, of which mention must be made here, which renders all such instruments useless for the determination of the temperatureat more than about I,00o metres, and it is unfortunately in the deeper layers that the greatest accuracy is desirable. When water is strongly compressed and then allowed to expand, it becomes colder at the same time, and water collected at great 
depths and brought to the surface under lower pressure will undergo a sensible lowering of temperature. The materials of which the water-bottle is made will similarly be cooled, and the total error may reach a large fraction of a degree. It is certainly possible to calculate this error, but the rate at which the loss of heat of the various parts affects the temperature of the central chamber and the thermometer cannot be estimated accurately. Ekman has drawn up a table in which the calculated corrections are reduced by one-half in order to allow for this latter uncertainty (p. 43). It will be seen that the error becomes larger as the temperature and the depth increase, and below $\mathrm{I}, 000$ metres the insulating water-bottle should not be used.*

\section{Reversing Water-Bottles and Thermometers.}

The reversing thermometer is made so as actually to register the temperature at any moment by the simple process of turning it upside down, and, apart from faults of construction, which unfortunately are difficult to avoid, it gives extremely good results. It differs from an ordinary thermometer in having a constriction and S-shaped dilatation immediately above the main bulb, and in having a somewhat large secondary bulb at the upper end of the stem. The graduations are reversed so that the lowest temperature is marked near the top of the capillary portion. There are two well-known models, the original form, brought out by

* For serial samples from great depths, for which the insulating water-bottle is not adapted, the handy and inexpensive "Richard" or "Monaco" bottle, worked by a messenger, should prove a useful instrument, if strengthened and provided with a place for a second thermometer. It is a modification of the large form used by Buchanan in H.M.S. "Challenger" but has been somewhat over-lightened.-ED. 


\section{EKMAN'S CORRECTION TABLE}

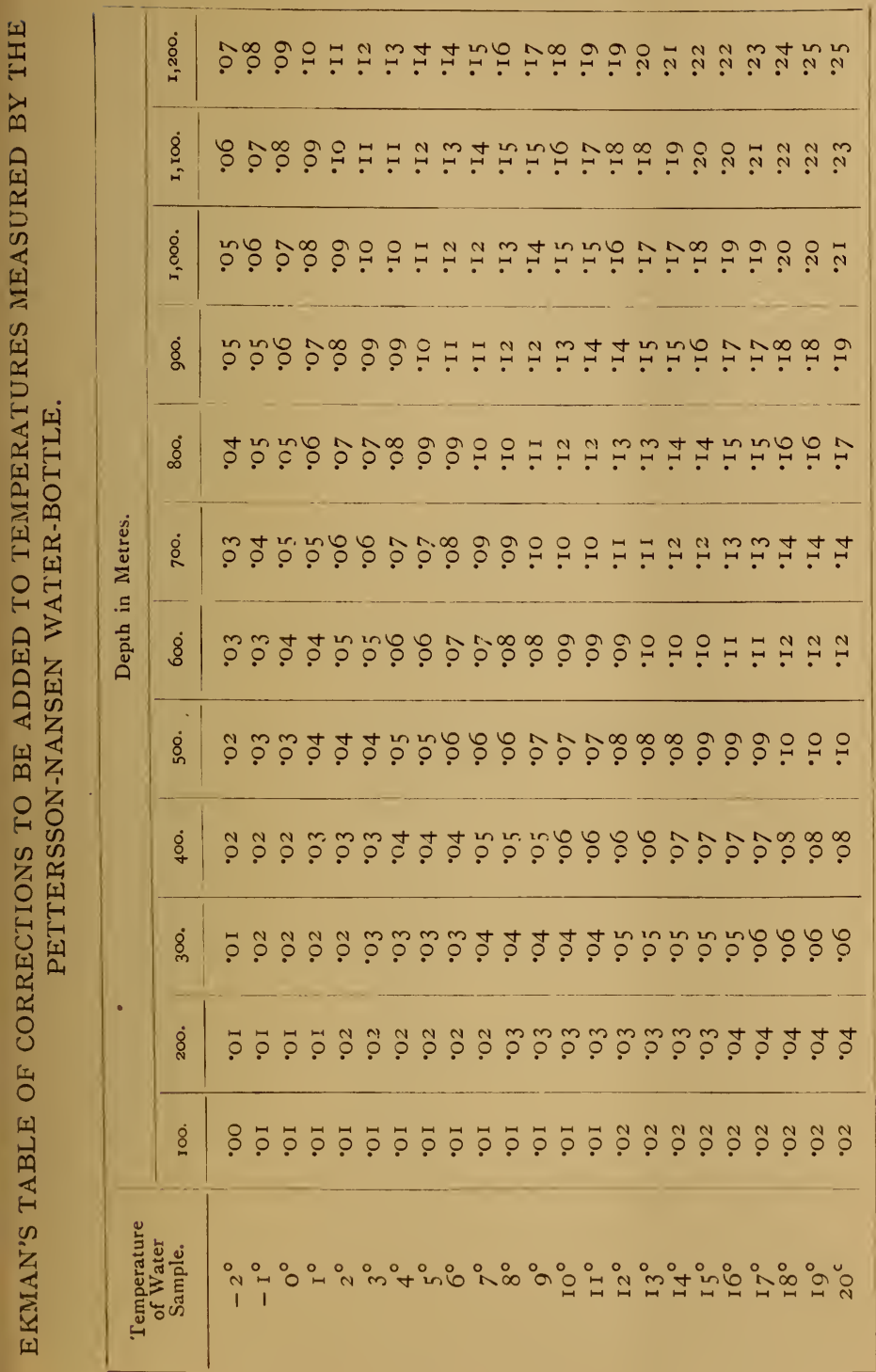


Negretti and Zambra, of London, and a modified instrument, made by Richter, of Berlin.

Fig. 8 shows the Negretti and Zambra instrument as it is sent down, and Fig. 9 the thermometer by itself reversed. The thermometer is fixed in a frame which can be turned over at will. On reversal either by a messenger (as in Fig. 8), or by a propeller, the mercury thread breaks at the constriction, and fills the small bulb at the end of the capillary and also part of the capillary itself. It is read in the reversed position, and, apart from certain corrections, to be mentioned afterwards, the graduation on the stem gives the desired temperature. The thermometer should remain at the required depth for about five minutes to take the temperature of the water.

There are three sources of error, which all arise from faults of construction. In the first place the whole of the mercury in the main bulb may pass the constriction on reversal. This is not a common fault, and thermometers subject to it should be discarded, though they may at times work well. Thermometers which show no signs of this defect on reversing in the hand, may fail when subjected to the vibration caused by hauling in from a great depth, especially in a rough sea. They should therefore be tested by reversing and tapping on a table. A second cause of inaccuracy is due to the mercury which remains in the bulb expanding past the constriction, when the thermometer is hauled up through warmer layers, or brought into a warmer atmosphere. The $\mathbf{S}$-shaped dilatation, which differs slightly in the two models, is intended to catch this mercury, but it fails to do so at times.

The third and most serious defect is that the mercury does not always part exactly at the constriction, and, 
in spite of numerous experiments, it has so far proved impossible to remove it completely. Negretti
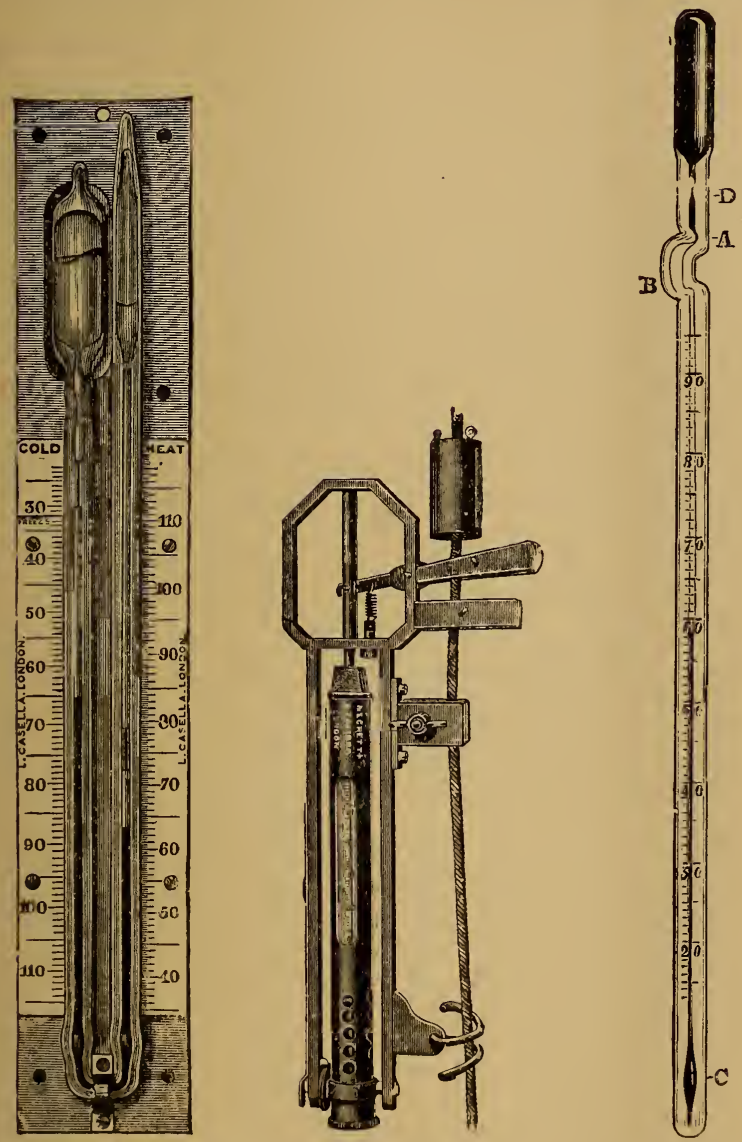

FIG. 7.-SiX MAXIMUM AND MINIMUM THERMOMETER.

Fig. 8.-FrAME OF FIG. 9.-REVERSING REVERSING THER- THERMOMETER. MOMETER.

(Figs. 8 and 9 by permission of Messrs. Negretti and Zambra.)

and Zambra trust entirely to the shape and size of the constriction, while Richter provides an additional 
short side-branch ending blindly. On reversal the mercury leaves this branch first, and then breaks at the point where it joins the main thread.

The temperature read off is not as a rule accurate, but a correction must be applied to it in addition to those shown on the certificate. If we cool a reversing thermometer-say, in water at $0^{\circ}$-reverse it, and then bring it into water at a higher temperature, it will be seen that the temperature reading continues to rise slowly for some time. This is due to the expansion of the mercury in the capillary; in fact, the capillary and the small bulb are acting like an ordinary thermometer.

To calculate the correction we require to know (a) the temperature of the thermometer at the moment of reading; $(b)$ the kind of glass of which it is made ; and $(c)$ the volume, expressed in degrees of the stem, of the secondary bulb, and the portion of the stem below the $0^{\circ}$ graduation. This information is given in the case of the thermometers made by Richter. The temperature at the moment of reading is shown by a small auxiliary thermometer sealed up in the same outer tube with the reversing thermometer. The name or number of the glass is engraved on the stem, thus: "Jenaer 59 III " or "Jenaer I6 III," and the third quantity is also marked on the stem thus: "Vol. ${ }^{\circ}=\mathrm{IOO}^{\circ}$, ," or whatever the "volume at $\mathrm{O}^{\circ}$ " happens to be. The apparent dilatation of mercury in the glass 59 III is $\frac{1}{6100}$, in I6 III $\frac{1}{6300}$. The correction to be added to the reading of the reversing thermometer is, in the case of $59 \mathrm{III}$, if vol. ${ }^{\circ}=100^{\circ}$, $\frac{(100+\mathrm{T})(\mathrm{T}-t)}{6100}$, where $\mathrm{T}$ is the temperature shown by the reverser, and $t$ that shown by the auxiliary. If the air is warmer than the water, $t$ will be greater than $\mathrm{T}$, and the correction will be negative. 
The calculation is made similarly for another glass and "Volume at $\mathrm{O}^{\circ}$."

The Negretti and Zambra instrument is not provided with an auxiliary thermometer, and the glass used is not marked on the stem. It is hardly worth while to attempt to carry the correction to an extreme degree of accuracy, as, even in the most closely divided thermometers by this firm, the graduations are somewhat coarse, and the writer prefers to determine the correction directly by reversing at a known temperature, and observing the alteration on bringing it into water of a higher or lower temperature (but see Addenda, p. xvii.).

It will be seen from what has been said above that the reversing thermometers are unreliable at the best, and they should always be used in pairs to check one another. Their behaviour is very capricious; an instrument which has worked well for years may suddenly, for no apparent reason, give readings which are incorrect by several degrees, and then, after an interval, may again act satisfactorily. When an error of registering does occur it is generally so large as to be obvious.

In the author's opinion the Richter thermometer is the better of the two models on account of its much finer and closer graduation, and the ease with which the correction is calculated. On the other hand, it is larger, heavier, and more costly than the Negretti and Zambra model.

In spite of all its defects the reversing thermometer is the only instrument available for depths greater than from 700 metres to I,000 metres.

Reversing thermometers may be mounted either in a simple reversing frame or as part of a reversing water-bottle. 
The reversing frame is actuated by a propeller or a messenger, and should be made to carry two thermometers and to fit anywhere on the wire, so that a string of instruments can be used simultaneously. The propeller is somewhat unreliable, and not infrequently fails altogether. It is fixed on a finely threaded screw, and is so arranged that on the way down it revolves till it butts against a stop. On hauling up, the direction of rotation is reversed, and the screw releases a trigger which permits the frame to fall over. The distance through which the frame must be hauled up before reversal takes place is uncertain; this is of no consequence in great depths where the temperature changes slowly, but it vitiates the results in the upper highly-heated layers. The messenger is much more reliable, and its sole defect is the time required for it to fall through great depths. In such a case the shock of its striking the frame cannot be felt, and a suitable interval must be allowed, which can be determined in shallower depths. If a string of thermometers is used, a fitting is provided by means of which each frame, as it reverses, releases a messenger hanging below it, which actuates the next frame.

Reversing water-bottles are made so as to carry thermometers and at the same time to collect a sample of water from any depth. The only form of which the writer has had practical experience* consists essentially of a brass tube, tinned inside, and mounted inside a rectangular brass frame on two pivots. A hinged lid with rubber washers is fitted to each end, and these lids are also connected to eccentrically pivoted arms. On reversal the arms cause the lids to close firmly. Made to fit anywhere on the line, it is specially adapted for serial observations and great depths.

* Ekman : Publ. de Circonstance, No. 23. 


\section{Other Forms of Deep-Sea Thermometer.}

A thermometer which has done good service in the past, and is still used by some observers, is the maximum and minimum instrument (Fig. 7). It will not be described here beyond saying that it depends on the movements of two small indexes, which are pushed along the capillary by the end of the thread of mercury. Apart from the uncertain accuracy of the readings, depending on the care with which the instrument is made, it is impossible for it to give the temperature when it does not change continually in one direction. Suppose, for instance, that the temperature from the surface to $5^{\circ}$ fathoms is $15^{\circ}$ or over; from 50 to 100 fathoms, $10^{\circ}$, and below that again it is $12^{\circ}$. In this lower layer the thermometer will fail ; the maximum index will read the temperature of the upper layer, $15^{\circ}$, and the minimum index will stand at $10^{\circ}$. Valuable work was done with this instrument when no other form was available, but the limitations pointed out make it useless for modern requirements. In the instance given the temperature of the lower layer could not be recorded unless the thermometer could pass the upper layer without being affected by it, an assumption which no observer is justified in making.*

* Quite useful work may, however, be done with these instruments at great depths in open water far from land, where, so far as we know, no "sandwiching" of hot and cold strata occurs except in the extreme south. To take serial temperatures by their means, a fine stranded wire must be used, not a rope of which the vibration jars the indexes down. For a serial of, say, over 1,000 fathoms, take observations at 100, 300, 600 first; then at 200, 400, 900 ; then at $500,700,800$ and so on. After each observation plot the temperatures on scale paper at proportionate depths; an observation which does not fall into the freehand curve drawn 
A form of insulating thermometer which may be of use in some cases is an instrument of the ordinary form, the bulb of which is surrounded by a thick mass of a badly conducting material-india-rubber, for instance. Such a thermometer will take some hours to come to the temperature of the surrounding water, and will take a similar time to lose this temperature on hauling up into the air. If the thermometer be hung just clear of the bottom from, for instance, a lightship, and be hauled up at intervals of some hours for reading, it is possible that the records will give some indication of the changes below. Under certain conditions, where there is a very small daily range, the readings may be of real value.

\section{Methods of Using Water-Bottles, ete.}

All modern instruments are made for use on wire and not on hemp rope, and in most cases only for a stranded flexible wire of a diameter of from 2 to 4 millimetres. The single wire is not now generally used, on account of its great liability to kink and break. The stranded wire is much safer, but of course offers more resistance to the water. The writer has used successfully a wire rope of about $2 \cdot 2$ millimetres diameter with a breaking strain of 400 pounds.

through the points plotted is suspect, and should be repeated. This method will also show any "critical " horizon at which the change of temperature is sudden; round this horizon more numerous observations should be taken at, say, 50 fathoms interval. At each observation mark the number of the thermometer used; this will soon show up an unreliable instrument. These thermometers are made for Admiralty use with an extra large scale, which admits of very close readings, and is to be recommended.-ED. 
Water-bottles may be used either from a davit or from a swinging boom. The latter arrangement requires at least one extra hand to work it, but it is far preferable to the davit, and makes work possible in decidedly rough weather. The depths at which observations should be made cannot be laid down beforehand. In areas which have been previously examined the records of the earlier observations give considerable help. In unknown waters one can only go on the principle that the chief object is to determine accurately the position of the dividing lines between layers of different temperature and salinity. As the latter can only be determined on shore, the number of observations should always err on the side of excess.

As a rough guide for working in unknown waters depths of $0,2,5$, IO, I5, 20, 25, 37, 50, I00, 200, 300 fathoms, etc., may be recommended. When the depth of water does not exceed 200 fathoms, the surface layers are of great importance. In the open ocean, on the other hand, fewer observations near the surface may suffice, if this should be necessary, in order to allow time for the more complete examination of the lower levels.

The distance apart at which the stations should be placed will also vary according to the locality. On the Continental plateau to the north and west of Europe they may be spaced as closely as twenty miles with advantage, but in deeper waters the programme can only be decided on after a careful consideration of the time available and the records of previous expeditions.

With regard to surface samples the case is somewhat different, as it is not necessary to stop the ship. In the English Channel and in the Bay of Biscay the writer 
has made it a rule to take a surface sample every ten miles; but, on the other hand, an Atlantic liner could do very valuable work by arranging for an observation every four hours.

\section{Chemical and Physical Examination.}

Sea water consists of a solution of various salts dissolved in pure water. The ratio these salts bear to one another is generally so constant that, for most oceanographical purposes, we may consider that it remains unchanged while the total amount present varies. It follows, therefore, that if we determine one, say the chlorine, we can calculate the total weight of all, and also the specific gravity. Tables have been drawn up from time to time to enable this to be done quickly; the most recent are Knudsen's, which werc calculated on the basis of a number of careful experiments for the International Council for the Exploration of the Sea, and as it is of the greatest importance that all modern hydrographical researches should be strictly comparable with one another, the methods and standards of the Council should be followed accurately. The work of analysis can only be carried out by, or under the supervision of, a skilled chemist. Its details are too elaborate to find a place in this elementary handbook, but the Society will be glad to advise in the matter.

A sea water can also be examined by direct determination of its density at an exactly known temperature. It should be stated here that the ordinary hydrometer of partial immersion, in which a portion of the stem appears above water, is absolutely useless for modern work, and should be discarded. The chief cause of its want of reliability is the great dis- 
turbance caused by the slightest trace of dirt either on the stem or on the surface of the water.

There are three other methods of determining the specific gravity which give accurate results. One may weigh a known volume of water in a pyknometer; or one may weigh a body of known weight and volume in the sample of water; or, finally, one may use the total immersion hydrometer. Of the first two the pyknometer method is the better, but both require an accurate balance and weights. The total immersion hydrometer is shaped like an ordinary hydrometer, with an ungraduated stem of about $\frac{1}{4}$ inch or $\frac{3}{8}$ inch long. To use it, it is loaded $w$ ith small platinum ringshaped weights, which are dropped on to the neck or on to a platinum hook fastened to it, until it floats in midwater. The system is then of the same specific gravity as the water. It is very accurate, and once the apparatus has been standardized the balance is no longer required, and the whole outfit is easily portable. The hydrometer and pyknometers should be made with the same accuracy and care, as regards the quality of the glass, as an accurate thermometer, in order to avoid uncertain changes of volume.

In all specific gravity determinations the greatest difficulty is keeping a constant and accurately known temperature throughout. The writer has found an Ostwald thermostat of great value in such work.

\section{Current Measurement.}

For the measurement of currents below the surface the Ekman meter is probably the most convenient apparatus (Fig. Io). It consists of a hollow spindle turning freely by means of ball-bearings on a wire passing through its centre, and bears on one side two 
vanes $\mathrm{A}$, inclined at a small angle to one another, and on the other a framework carrying devices for recording the velocity and direction. The velocity is measured by the revolutions of the propeller $\mathrm{B}$, which turns on centres supported in agate cups, and is connected by gear wheels with the pointers moving on the dials on the cover of the box F. These pointers move stiffly on their pivots, and can be set to zero before each observation. The velocity of the current is calculated from the number of revolutions in a given time by a formula which must be determined experimentally for each instrument.

Beneath the box $F$ is a compass, which can be quickly removed and replaced, and is kept in position by the thumb-screw shown below it. The needle is heavy, and the arms are inclined downwards, and one arm is deeply grooved on its upper surface. In the box $F$ there is a store of small shot, which are released one by one by the rotation of the propeller, and fall through a funnel on to the centre of the needle, whence they run down the grooved arm on to the compass card. The latter is divided by raised partitions, and the shot falls into the compartment below the end of the arm, and so records the direction in which the apparatus was pointing at the moment. The instrument which the writer has used has a card divided at every Io degrees, in such a way as to record the direction from which the current comes, and not that in which it goes.

The meter is started and stopped by means of messengers. When it is being lowered to the required depth, the messenger $\mathrm{C}$ is not on the wire, and the arm $\mathrm{D}$ is more nearly vertical than shown in the drawing. The other end, E, is therefore slightly raised, and the projection on the propeller blade butts 
against it, so that the apparatus is locked. To release the propeller, the first messenger $C$ is allowed to slide down the wire; it forces D outwards into the position shown in the figure; the slot in $\mathrm{E}$ is now opposite to

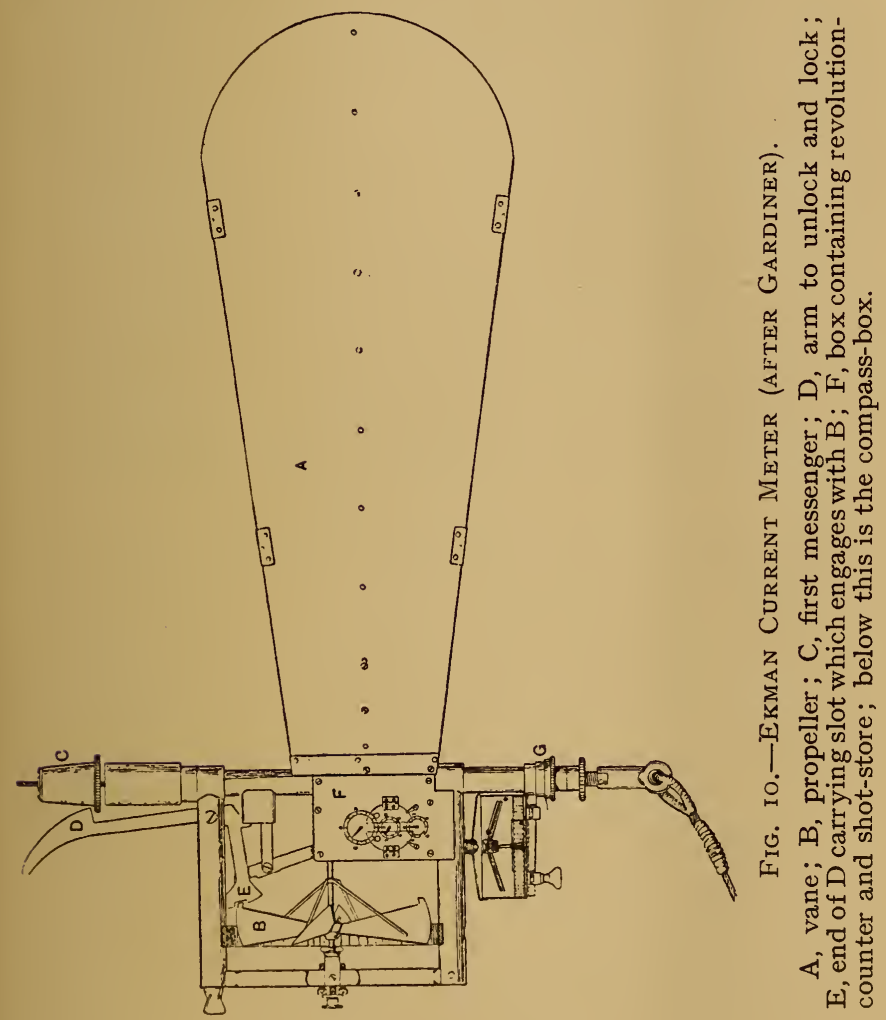

the projections, and the mechanism is freed. After a measured interval a second messenger is sent down ; this is larger than the first, and hollowed out below so as to pass over it. It forces D still farther outwards, and again locks the propeller. The direction and 
velocity of the current then can be read off from the mean position of the shots in the compass card and the number of revolutions shown on the dial.

The wire should be as fine as possible to avoid stray, and if of steel any deviation which it may cause in the compass should be determined and allowed for. The sinker may weigh from Io pounds upwards, according to the strength of the current. With currents of a knot an hour and over, in depths greater than thirty fathoms, the writer has found that it was not possible to feel and time the arrival of the messengers on account of the vibration of the wire. In such a case one must determine the time of fall of each messenger for various depths and plot the result on a curve. It will be seen that they soon reach a constant velocity, so that the time may be calculated from the depth.

The Ekman meter, of course, demands some fixed point, such as an anchored boat or ship, from which to work it, and in rough weather the velocities are not recorded accurately; under suitable conditions, however, it is very easy to use, and the results agree well among themselves. When tested at the surface from a boat, especially if the current is slow, it is seen to wave from side to side continually, but this appears to be due to eddies; below the surface in currents of over a quarter of a knot per hour it points constantly in one direction.

The interval during which the propeller should be allowed to rotate depends on the strength of the current; when this is not known approximately, four or five minutes may be tried in the first instance.

Additional apparatus has also been made by means of which it is possible to work in rough weather from a ship that is not anchored, but the writer has not had 
any experience in its use. An anchor or heavy weight is made fast to the end of the wire; above this at the requisite distance the meter is fixed, and above this again, but below the surface, is a buoy, the floating power of which is not great enough to lift the anchor from the bottom, though it keeps the line taut. The buoy contains clockwork which drops the two messengers down the line to start and stop the mechanism. The wire above the buoy is slack, and the ship steams up to it.

\section{An Outline of Oceanic Circulation.}

BY THE EDITOR.

No account of oceanic water can be deemed complete without a brief sketch of its circulation. It must be premised that while the movements of surface water are comparatively simple and fairly well understood, the circulation of deeper waters is still obscure. Even as regards the surface waters, not all oceanographers are agreed as to the exact extent to which all the various forces concerned are responsible for the driving power. But such controversies are beyond our scope here, and we may content ourselves with the crude statement that the main factors in setting the pace and direction of most ocean currents are the prevalent winds, as determined by the pressure belts (pp. 6, 7), and as modified by the influence of land masses, it being at the same time admitted that such other factors as the rotation of the earth, differences in temperature and salinity, and so forth, also play a part.

At the outset we must distinguish between stream and drift currents. Of these the stream is due in its simplest form to a head of water running down over water, as a mill-stream runs down over land; the drift current is caused chiefly by the action of prevalent 
winds which drive the surface water along. These terms, however, are not always accurately used.

There is yet a third type of current, which either upwells from below or sinks from above, its movement being determined by the relations which its temperature and salinity bear to those of the adjacent water.

\section{Surface Currents.}

If we begin with the surface movements of the ATLANTIC OCEAN - as being better known than the others, and simpler in so far as it is not studded with islands like the Pacific, nor subject to monsoonal disturbance like the Indian-the most prominent is the Gulf Stream. The North Equatorial Drift and the northwesterly arm of the South Equatorial Drift (Chart V., p. 6o), hurried along in the first instance by their respective trade winds, strike ultimately on the Windward Islands ; while a part of their water skirts the outside of the West Indian chain, in a north-westerly direction, much passes into the Caribbean Sea, and thence, in a highly heated condition, through the Straits of Yucatan into the Gulf of Mexico at anything from I5 to 70 knots a day. The water thus driven into the gulf, supplemented by the great volume of the Mississippi, forms a "hydrostatic" reservoir, the level of which is something like 40 inches above mean sea-level at Sandy Hook. Having practically only one outlet, the Straits of Florida, it rushes through them with a mean annual temperature of over $80^{\circ} \mathrm{F}$., and at a rate of 20 to Ioo knots a day, passes over the Blake plateau which it sweeps clean, and debouches into the main ocean about $30^{\circ} \mathrm{N}$., where it is joined by that branch which skirted the outside of the West Indian Islands. Here it is diverted, chiefly by preva- 
lent winds, to a north-easterly direction. This diversion may be helped by the pressure of the continuation of the cold Labrador Current, a much weaker current, composed of water of very low temperature and salinity, derived from the melted ice and snow of the Arctic regions as far north as Baffin Bay. About $50^{\circ} \mathrm{N}$. much of this current turns from south-east to an easterly, and eventually north-easterly, direction; but a part swings round Labrador to south-west, and skirts the north coasts of the eastern United States, greatly lowering their temperature. To some extent, however, the cold water in this region is attributable to upwelling caused by the pull of the Gulf Stream. The boundary between the hot and cold waters of the Gulf Stream and Labrador Current swings north and south, according to the predominant winds; it is said to be so sharp sometimes that a ship's bow may be in green cold water of arctic origin, while her stern is in warm blue water from the Gulf.

The Gulf Stream gradually assumes a more easterly trend. It has been calculated that at about $40^{\circ} \mathrm{W}$. it has lost the velocity and temperature which its water acquired in the Gulf. This water still continues, however, to travel east, but the driving power now is not the original head of water, but the prevailing south-west winds of this region. It is therefore no longer a "stream," but is better termed the North Atlantic Drift. Between $40^{\circ} \mathrm{W}$. and $20^{\circ} \mathrm{W}$., the pull of those winds round the high-pressure area, which culminate in the trade winds, draw off much surface water past the Azores in a south-easterly and southerly direction. But the main axis of the drift, being outside their influence, passes north-east, striking the Faeroe and Shetland Islands. Its influence is well shown on both isotherms and isohalines (Charts III. and IV.), as 
far as the triangle between Norway, Spitsbergen and Nova Zembla. In this region the weight of this water, due to its high salinity causes it to sink in spite of its temperature, and all traces of it are gradually lost. The water shed off from the main drift in a southeasterly direction about the Azores is mainly driven again by the trade winds into the North Equatorial Drift, which runs from east to west about $10^{\circ} \mathrm{N}$. and so the cycle of the North Atlantic begins anew. A branch, however, skirts the Guinea coast, and is known as the North Africa Current. It probably finds its way into the South Equatorial current.

In the South Atlantic the south-east trades drive water along a South Equatorial Drift from east to west between $0^{\circ}$ and $10^{\circ} \mathrm{S}$. Impinging on Brazil, a part of this turns north-west to join the North Equatorial, as we have seen ; the rest turns south-west as the Brazil Current, sending off water south and south-east into the rotatory circulation round the high-pressure area. But the currents are here complicated by the arrival of antarctic waters. In the Southern Ocean, between $40^{\circ} \mathrm{S}$. and $60^{\circ} \mathrm{S}$., there is a great Easterly Antarctic Drift of cold water round the Pole, due largely to the prevalent winds ("Roaring Forties"). The deep southward projection of South America seems to dam this to some extent, and as soon as the drift is clear of the straits between the Horn and the Antarctic continent (compare Fig. 4), a branch spreads up northwards as the Falkland Islands Currents, corresponding to the Labrador Current in the northern half of the Atlantic. This cold water meeting the warm Brazil Current off Rio de la Plato produces a most extraordinary effect on the isotherms (Chart IV.). The resultant waters get an easterly trend across the ocean. Before reaching the longitude of the 



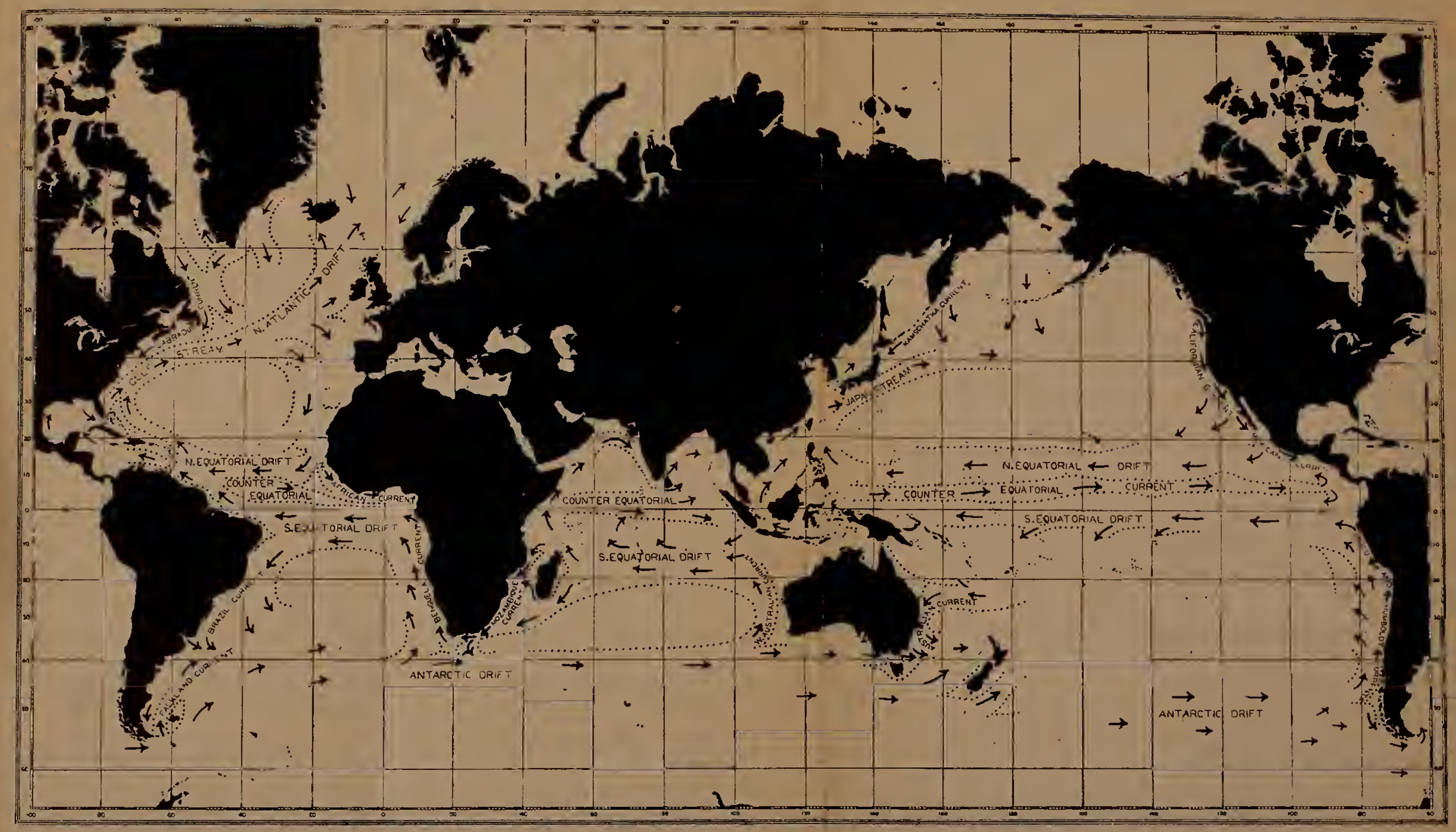

CHART V.-OCEAN CURRENTS

Based on Admiralty Chart 3,528. The arrows indicate the direction, the dotted lines the approximate boundaries, of the main surface currents. 

Cape of Good Hope, they send a branch north, which is probably attributable partly to the pull of the trade winds, partly to a resistent current in the opposite direction coming from the Indian Ocean. This branch contributes to the cold Benguela Current along the West African coast, of which a large part seems due to an upwelling of cold water from below, owing to water being drawn off the surface by the trade winds. This brings us back to our starting-point in the South Equatorial Current. Between the North and South Equatorial Currents is an ill-defined backwater, the Counter-Equatorial Current, with a slow. easterly trend.

We may now turn to the PACIFIC OCEAN. In this the simple currents of the diagram (Fig. 5) are confused, and their strength frittered away, by the numerous islands of the middle and western regions of this ocean. But we can recognize as clearly marked the North Equatorial Drift, northing and easting to form the Japan Stream (Kuro Shiwo) and North Pacific Drift; the Kamschatka Current, corresponding to the Labrador Current of the Atlantic; and the return of water from the eastern side of the high-pressure area by the pull of the north-eastern trades into the North Equatorial, in the shape of the Californian and Mexican Currents. In the south half of this ocean that branch of the South Equatorial Drift, which corresponds to the Brazil Current, forms the Australian Current, pressed eastward by a branch of the Easterly Antaretic Drift between Tasmania and New Zealand. Before the Horn is reached, a northerly branch of this contributes to the Humboldt and Peru Currents, supplemented by an upwelling as in the case of the Benguela Current. A well-marked Counter-Equatorial Current characterizes this ocean. 
In the INDIAN OCEAN, or half - ocean as it may be termed, the same general circulation is only clearly marked north of the Equator during the south-west monsoon (May to September). Off the Cape of Good Hope the Mozambique Current, which corresponds to the Brazil Current of the Atlantic, is barred by the Easterly Antarctic Drift to an extent which produces a remarkable recurving of the former from a southwesterly to an easterly direction. To the constant conflict between these hot and cold bodies of water off Cape Agulhas are attributable the well-known fogs of this area.

\section{Movements of Deeper Water.}

The rain, hail, and snow precipitated in vast quantity on the Antarctic Continent, melting to some extent in the summer, give rise to a water of very low salinity, but also of so low a temperature that it sinks below the warmer salter water of more northern origin, Chiefly from this source appears to be supplied the very cold bottom water, which lies on the bed of all deep oceans. There is some reason to believe that a lesser quantity is derived from Arctic melting. Consequently it is nearly always true that the deeper one goes in the great oceans, the colder is the water. Thus, for example, the mean temperature of all oceans at 2,200 fathoms was calculated by Dr. Buchan as $35 \cdot 2^{\circ} \mathrm{F}$. $\left(\mathrm{I} \cdot 6^{\circ} \mathrm{C}\right.$.). Hence, whenever there is an upwelling of water to the surface, due to water being drawn away from the surface by the pull of windsa phenomena which is particularly observable on the west coasts of all continents-the water thus upwelling is comparatively cold for its latitude, and of low salinity (compare the isohalines on the west of 
British Columbia, Chili, Australia, and the Cape). In addition to these upwellings alongshore, it has been suggested that they also occur at certain points in the open ocean. There is also some evidence for the existence of horizontal mid-water currents, in a direction the reverse of that of the currents immediately above them. Observations on this question are sorely needed.

Before leaving the subject, a word must be said on closed seas. The classic instance of these is the Mediterranean ; this includes two deep basins of more than $\mathrm{I}, 000$ fathoms, but its entrance at the Straits of Gibraltar is barred by a ridge of 60 to I30 fathoms in depth. Consequently, the cold bottom water of polar origin never penetrates into it, and the difference in temperature between the surface and the bottom is comparatively slight. Mediterranean water is throughout warm and of high salinity. A surface current from Atlantic to Mediterranean through the Straits is compensated by an undercurrent in the reverse direction; the water which thus escapes into the open Atlantic spreads, and sinks by reason of its high salinity, carrying its high temperature to quite unusual depths. An instance of a cold closed sea is furnished by the Faeroe Channel, shut off from the main Atlantic by the Wyville Thomson Ridge.

While exact observations on currents, and especially on mid-water currents, are much needed, the usual methods for their determination (by buoys, log-ships, etc.) are so rough and inexact that they cannot usefully be employed by any but skilled hands. Of more elaborate machines the Ekman current meter (p. 55) has proved very useful in shallow waters, and a more heavily built pattern could no doubt be made to do deeper work. But for accurate measure- 
ment, the ship must be anchored bow and stern, as even her yawing round a single cable will seriously affect the record. The Pillsbury meter, as improved by the British Hydrographic Office, is a beautiful machine, but costly, and rather cumbrous to work. It could probably be somewhat simplified and lightened. A most interesting and practically untouched field lies open to any yachtsman of ingenuity, who will attack the problem of mid-water currents, which the ordinary ship, whether naval or mercantile, has no time even to consider.

As to the daily movements of ocean water, the subject of the theory of tides is rather for the astronomer and mathematician than for the oceanographer. It will be enough to say here that if a stay of any length be made in an out-of-the-way port or harbour, daily accurate measurements of tidal movement would be found useful to the naval authorities, and of real value.

A tide-pole, well guyed, marked in feet and decimals, will do all that is necessary. A board carrying a light scale-rod, floating freely in a square tube of four planks knocked together, with holes in the bottom to admit the water, will be found easier to read, as avoiding the wash of the waves. Both these require frequent reading, if the observations are to be of real value; but regular tide-gauges can be purchased, which record the rise and fall automatically by curves on squared paper. 


\section{CHAPTER II I}

\section{THE SHORE}

BY J. STANLEY GARDINER

\section{A.-Tropical Shore Collecting.*}

THE naturalist who visits the tropics, even for the first time, can scarcely make an observation which will not be of value to some specialist or another on his return to Europe-that is, provided the observation is recorded at once, together with all its attendant circumstances. Too much care cannot be expended on this latter point, because, in the bewildering mass of new facts which pass before the eyes, memory cannot be trusted (for instance) as to the habits of some particular species of animal, while the short note on the weather and the time of day often gives a clue to what otherwise might seem an anomaly. Surface and freely moving animals often seem to be absent at noon on a sunny day from sea and shore, while, if the weather be cloudy, they are abundant. Rain also has a considerable effect, for surface animals sink into the depths below its influence, and the shores scarce show a worm, an anemone, or a sea-slug (Holothurian) on their sandy reaches; Crustacea of all sorts are hidden

* Shore-collection in the tropics has been selected as the subject of this section, as offering in some ways greater difficulty than in temperate regions. But the general methods of collection and observation are the same in all seas. and are applicable to any coast.-ED. 
in the sand or under rocks, and fish have departed for deeper waters. Thunder and lightning, and even changes of barometric pressure, make themselves felt, animals seeming scarce before an approaching cyclone. There is also a regular periodicity between night and day; many animals visit the shallow waters during the night alone, and some of the sedentary organisms only unfold their heads for feeding purposes in darkness. Again, tides should be observed, for it is common to see masses of apparently lifeless rock become covered with flowers formed by anemones, worms, etc., as soon as the first flow of the flood reaches them; sand-living animals, too, renew their activity and commence to pile up afresh their mounds of sand. These results may be due to the cooler waters of the open ocean, but observations on these matters are urgently needed. A watch, a thermometer, and a notebook should be the naturalist's invariable companions on every stroll, while a good barometer should hang in his ship or tent.

When any land is approached, its contours should be carefully noted, particularly its valleys and slopes, since the sea-bottom is bound, for some considerable distance outwards, to be formed of the rock of which the land is composed, perhaps masked by a superficial deposit of sand or mud. Specimens of rock should always be taken and carefully labelled, even before being dropped into the satchel. Its formation must, to a limited degree, be considered-whether it is volcanic, or has been formed by other agencies; how it has been cut up into its present, perhaps fantastic, shapes; what results in its contours are due to rain, to wind, to heat, and to cold, and, lastly, to the influence of plants, and, in some few cases, of animals. This will be found to be a delightful study, as it gives a new charm to the scenery, and it is only by its means that the topography 
of the island or coast, particularly in connection with its submarine slopes, can be understood. Certain effects recur on many lands, and the voyager soon begins to recognize the nature of their rocks long before he actually reaches their shores. Observations on change of level are of importance, but difficult to make.

The earth has by no means a rigid or unbreakable crust, and the present distribution of land and water is generally considered to be due to the alterations which have constantly been taking place in its surface in past geological periods. The world must not be considered as if these movements have now stopped. Indeed, their cessation is directly negatived by the existence of volcanic eruptions and earthquakes. Some movements, especially those associated with volcanoes, are very local, but others affect wide areas, such as the one which appears at the present time to be slowly elevating the North of Scandinavia; this finds its balance in a general depression of the South of England, there being thus a regular tilting over some thousands of miles. This movement, fortunately, is a slow one (as all large alterations of level probably were), and has little effect on contemporary history; but many local upheavals and subsidences must have taken place with great rapidity. There are many lines and points of weakness in the earth's crust beneath the sea, and to the subterranean forces under these we owe the existence of most of our oceanic islands. The examination of the earth's crust beneath the sea is impossible, so that special attention must be paid to all signs of change of level round coasts on oceanic islands. Elevation - that is, the emergence of formerly submerged land-is shown by marine deposits on the hill-slopes, which in the tropics are generally largely calcareous in nature. Any appearances of 
horizontal terraces above the shore should be at once investigated. When examined, they are found either to be shelves, cut out of the rock below by wave action, often strewn with pebbles and marine remains; or to be artificial formations of limestone, implanted on the rocky slope below for a foundation. If, as on many islands, there are series of these terraces, specimens of the rocks of each should be carefully collected at different elevations; their heights above sea-level should be ascertained (a good pocket aneroid with scale of heights is useful) ; and their surface, appearance, and extent should be noted down, especially the existence or non-existence of caves. Often the slopes of the land are so steep and the rainfall is so abundant that only traces of elevated rocks are found at the sides of the valleys, and sometimes even these are lost. Yet evidence of elevation may be found in the existence of isolated caves and overhanging rocks, or even scattered marine shells.

All the above land formations, wherever found, should be compared with the present action of the sea on the same coasts. This latter has its own importance as well, and should be studied all round the land-to windward and to leeward, where the current directly strikes on the land to pass out in an undercurrent which curls round its points, where it merely sweeps the capes as it passes by, and where it curls round them forming eddies. The action of the sea on the rocks of the shore is important, and the rocks themselves should be examined, to see how far they are protected by corals, Lithothamnia (massive red and white encrusting calcareous plants), seaweeds, barnacles, and other organisms. Masses of rock, small islets near the main mass of land, require examination in order to see to what causes they owe their present isolation. The 
sand of sandy beaches or points should be sampled, so as to ascertain how far it is formed by the breaking down of the rock, and how far it consists of the remains of organisms piled up by the waves. From the inhabitants we often obtain valuable information, positive measures of the loss or gain; we frequently require to learn from them whether we are examining beaches which are permanent, or which shift according to the variation of seasons or perchance the monsoons. In the course of such work we may get indications that land, formerly dry, has sunk below the sea; but this is more difficult to prove. The sea often cuts a flat at the low-tide level into the land if the latter be stationary, and the breadth of the flat may give us an indication of the period of time for which it has so remained; such a terrace, however, may be completely obliterated by the tropical rainfall. The absence of a terrace and of loose masses of rock off a steep glacis or slope may well arouse in us suspicions of the existence of subsidence, and we shall be tempted at low tide to row round, to observe whether signs of aerial weathering are visible on the submerged parts of the rocks, and perchance to carry out a few soundings. Pillars, etc., of any permanency, such as exist in the Bay of Naples, are unlikely to have been erected by the shore on any land we visit, and it is only by exact survey and careful study of the topography of the slope that we can arrive at any conclusions on the matter. A rugged coast, deep bays or fiords, a fairly constant slope without steeps to a few hundred fathoms or so, might indicate subsidence; but such observations belong rather to the Hydrographical Offices of the Admiralties-they are scarcely within the compass or time of the visiting naturalist. A close line of soundings out from the shore (made, if neces- 
sary, with a weighted and measured codline, and based on the angles obtained by the sextant between three posts fixed Ioo or 200 yards apart on the shore) is often a most useful supplement to existing charts, and gives information of great value. It would at least show the existence of submerged terraces, if present, and they are the best proof of subsidence in any region.

Whatever of marine life the naturalist collects in the tropics is almost sure to be of interest and value. If he has little time at his disposal, he will probably be able to get or to give to others a good idea of the marine life of the locality by simply walking along the shore, or visiting some outgrowing spit of sand, and dropping into a canvas bag everything which seems to him to be of organic formation, not forgetting to include also a sample of the sand itself. He may search also for the numerous animals found between the tide-marks, employing a native or two with buckets, in which the larger beasts are placed, while he himself carries a satchel with two or three dozen tubes of different sizes, into which he puts the smaller beasts, corking them up in sea water ; they can then be transferred to the proper killing and preserving fluids on his return to his ship or tent. Let him carry with him as a walking-stick a small crow-bar, to turn over masses of rock, while one of his "boys" has a hand-net of fine mesh ; coarse forceps should be looped on his belt. A little of such collecting is valuable, to give him an idea of the shore-beasts as a whole and of their work in protecting or destroying the land. But much of the action of the sea and its organisms goes on below tide-level. This can only be satisfactorily ascertained by dredging or trawling from a ship or boat. If this is impossible, let the naturalist get some old rope-ends, 
and, by unravelling the strands of the hemp, make swabs such as are used for drying up the deck. These swung over the stern of his vessel on to the bottom, with two or three fathoms of rope to spare, if taken up and cleaned every twelve hours or so, will often bring up a great variety of living organisms, pieces of rock with a couple of dozen different kinds of sedentary animals attached to them, numerous Crustacea, starfishes, worms, and other forms. A couple of planktonnets floating out from the ship at the same time, in one-third and two-thirds the depth of the anchorage, will indicate to him the floating fauna, on which the animals of the bottom so largely feed. When the anchor is raised, mud or sand is often found clinging to it, and a good sample should certainly be secured and dried, after putting any living organisms that may be found into some preserving fluid. A washing in fresh water and treatment with a little weak spirit, which otherwise would have been cast away, will prevent any objectionable smell from the sand when in process of drying.

By such methods as the above the naturalist will obtain a general view of the life of the coast which he is visiting. He may even attain an idea of the interrelations of that life with its environment-i.e., the topographical and physical conditions of the region. He may proceed farther, and see how the animals and plants interact with one another; how the freely moving forms take refuge within the branches of the sedentary organisms; how the struggle continually goes on between the sedentary animals and plants; and, lastly, how both animals and plants in their vegetative phases of growth adapt themselves to their environments. Such a study, particularly of the latter points, is of the greatest value to the worker on syste- 
matic zoology at home, and has a peculiar interest of its own. It has seldom been systematically attempted on a proper basis. A small area-a single pool, perchance-should be intensively studied in its every aspect. It should be sounded and measured; its temperature should be taken under different conditions ; the effect of the ebb and flow of the tide should be noted; a plan should be drawn of the position of each single animal and plant; and all notes should be written with the pool at one's feet. Whether the individual animals and plants are known to one or not does not matter, because a sample of each has to be taken. In the case of sedentary animals, the upper and lower surfaces, as well as those against and remote from any tidal or other currents which enter the pool, should be carefully marked. Nothing is too small to be recorded, and the more thoroughly the work is carried out, the greater will be its value.

Such collections from a single pool are, however, of little direct use to the systematist at home. They are too scrappy by far for his purposes, and he cannot from them venture to attempt any of those broader deductions on the distribution of plant and animal life which make much of his work of interest. Some naturalists, also, are more disposed to collect and accumulate specimens of different forms of life, liking to wander over wide areas. To them we say, let them collect by all means, but confine their attention to one or a few classes of animals, or to plants alone, unless they have at their disposal at least three or four months at each place, and can set up permanent laboratories on shore, conveniently arranged. In giving suggestions as to what groups to select or what groups would be of most value to the marine biologist, 
we may premise our remarks by the statements (I) that any exhaustive collection of any group from any locality is of great value, and (2) that only groups which suit the environment (particularly the nature of the bottom, whether sand, mud, rock, or weed) can be collected exhaustively enough in a few months.

In selecting the groups to be collected, we have to consider the life-histories of the animals or plants which form these groups, particularly the point whether they do or do not possess larvæ which are capable of living as larvæ for long periods of time in the surface waters of the sea, and are therefore capable of being transported by ocean currents from their original homes, often for many thousands of miles. Such larval forms are not numerous among the seaweeds, though other means of dispersal by floating pumice and timber are peculiarly adapted to them. The same genera of plants are found over wide areas, but we give plants first place, since they form the most important source of food for animals, and may kill out or prevent the growth of other sedentary organisms. They may inhabit any area, some (such as Cymodocea and Halophila, dicotyledonous forms) loving shallow flats over which the sea rushes; the former are quite grasslike in appearance. The home of plants, however, is essentially on rocks over which they form, perchance, a calcareous crust (Squamariaciæ), rounded or branched living growths (Lithothamnia), interlaced " mosses," and low "herbs." Algæ, such as those on our temperate shores, are scarce ; but there is a great variety of these other forms. The methods of selecting and observing marine plants are discussed in Chapter IV. (p. I52), and we would only further emphasize the importance of securing large series of specimens, particularly of 
the massive calcareous forms, as they vary so greatly with environment.

Of groups of free-living animals on tropic shores, the fishes, Crustacea, starfishes (except the Crinoids), and Mollusca, do not vary greatly in genera and species over each of the two great geographical ocean areas, the Atlantic and the Indo-Pacific. They are also fairly well known, having always presented great attractions to the collector, from their number and beauty, and from the ease with which they can be preserved by being simply dropped into 90 per cent. spirit; they dilute this down to about 60 per cent. by the time the tank or bottle is full. Crustacea and starfishes should always be wrapped in cloth if they are to be placed with many other animals in a large receptacle, and a preliminary soaking in dirty spirit of about 40 per cent. prevents Crustacea from getting brittle and soft sea-urchins from getting distorted. The sea-slugs, or Holothurians, should be injected by mouth and by anus with 90 per cent. spirit, using a syringe. Numbers of these groups of animals may be found in pools, in the branches of corals which require to be broken up to liberate them, in weeds, and under stones; they may be caught with the hands or by the net. Large forceps are advisable for spiny seaurchins, and digging in sand will yield a few bivalves (Lamellibranchs) and Holothurians (trepangs). A few pence-or pieces of tobacco (sticks, twenty-six to the pound, price tenpence to a shilling)-judiciously expended among the natives, will bring in many of the larger forms more difficult to catch. Heaps of stone and corals, baited with coconut scraped up and mixed with the ink of the cuttle-fish (or with poundedup land-crabs), piled on sandy flats, covered with 2 or 3 feet of water at low tide, were responsible for 
upwards of eighty different species of fish from Rotuma,* as well as for a large variety of Crustacea and other free-living animals. The animals, after a few days, find out such heaps, and make them their homes, going out with the flood in search of food, but returning with the ebb. They are then easily caught in a large basket of palm-leaves, which is kept open by a few masses of branching coral, and is placed, mouth open, in the opposite end of the heap to that which the collector is turning back. Some of the brilliantly coloured fish resist such a device, and the author knows no way of catching them save by a bare fish-hook of small size, smeared with cuttle-fish ink, which has already been mixed with patchouli or other strong-smelling scent. He has found this efficacious in the crevices of coral reefs, the line being swept in and out by the tide. As to the advisability of the inexperienced collector, who does not himself know the orders and divisions of these groups, and is not especially interested in them, gathering them up, the author of this article expresses no further opinion. The Nudibranchs and Isopleura, the smallest Crustaceans, and the minute shells from the sand, will be most profitable; while such Crinoids as may be found should certainly be kept. As a matter of actual experience, two-thirds of the time even of a trained collector, desirous of securing all forms of life on the shore, will be occupied in catching and preserving the larger members of these orders. The breaking up by the hand of masses of the more mossy seaweeds into a bottle, the larger fragments being picked out, often yields an abundance of small Crustacea and worms. The result is a dirty-

* Of 108 species of fish collected by the author from this island's shores all were known, and only about 2 per cent. of the species from other island groups were new. 
looking mess, with much sedimerit, in which are the animals ; it may be preserved by adding one-twentieth of its volume of ordinary commercial formic aldehyde (a 40 per cent. solution, see p. 347), leaving the sorting out of the different animals to be done in the laboratory of a colder climate.

While individual genera of the last groups of animals are adapted to almost every environment, most other groups of free-living forms are adapted to some particular environment. Thus Amphioxus of different genera all live in sand, though they pass their larval existence as pelagic animals. Such sand must be clean (sharp, as it is termed), and preferably in such a position that it is slightly stirred by the rise and fall of every tide. Even if present, Amphioxus is generally local, but where it occurs it is enormously abundant; large numbers may be readily obtained by sifting the sand through one or a series of sieves of different mesh fitted into one another, which are held while being shaken just submerged in the sea water. Equally sand-loving are Balanoglossus and its allies, but they prefer either rather dirty sand-flats, into which they burrow (throwing up great mole-heap-like mounds of the sand which has passed through their bodies for food), or else the rather shallow accumulations of sand under or in the crevices of stones, where they get out of the reach of the other forms of life which might prey on them. A slight smell like cyanide or "prussic acid " in the sand is a sure sign of their presence, while a smell of sulphuretted hydrogen (rotten eggs) may, practically speaking, be taken to indicate the absence of most forms of animal life. The author's receipt for the sand-living forms is to find a flat of sand overlying a bed of rock a foot or two below. The collector will see at once if there are any mounds, and, if so, he will 
probably dig with success, using any spade or shovel, but if the sand is deep he may follow the animal's burrow down into the sand till he himself is completely submerged, and meet with no success however long he tries. Both of these groups of animals are of great interest for their anatomy, and plenty of specimens should be obtained if they are present. The Balanoglossids should be kept in the shade in basins of sea water, changed every three or four hours during the daytime for twelve to twenty-four hours, until they shed the sand of which their bodies are full. The members of both groups may be killed and hardened in corrosive sublimate or other preserving agent, as described elsewhere ; or, failing these, may be dropped into 30 per cent. spirit for one hour, 50 per cent. for the same time, and then kept permanently in 70 per cent. spirit. The latter for Balanoglossids should be changed at least twice, as they possess in their bodies some substance which in the tropical heat acts on the spirit, tending to decompose it, their own bodies disintegrating at the same time.

Worms (spiny Chætopoda and Sipunculoids) are found in almost the same localities as the last groups, and many should be secured while searching for Balanoglossids, the mounds of some of them, particularly the Sipunculoids, being difficult to distinguish from those of Balanoglossids. In addition we have many Chætopods which form tubes on rocks, and members of both Chætopods and Sipunculoids are among the most important of boring organisms. There is no royal road to success in collecting, save only hard work. It is well to half fill one's boat, or send one's buckets ashore, full of masses of rotten calcareous rock, of dead and living corals, and of Lithothamnia. Then when the rise of the tide makes further work in the sea 
impossible, we sit down with hammer and chisels breaking up these masses into fragments, and carefully chipping out each animal we see, to secure it intact. We will have all around us basins, for our catch will be a varied one. There will be Crustacea, Mollusca of all kinds, flat worms (Turbellaria), and an odd Nemertean perchance in the crannies of the rock masses; we shall also find growing there a great variety of sedentary animals, some of which we shall probably feel stimulated to preserve. Then in the rock or coral itself will be more Crustaceans, some such as Hapalocarcinus and Cryptochirus, which have been grown over by the coral, and others like the barnacle, Pollicipes, a true borer, many worms of all sorts, Mollusca such as Lithodomus the " date stone," and a few Gastropods, masses of brown boring sponge, and many other animals of odd groups, such as Octopods or cuttle-fish which have annexed the holes made by others. All may be preserved in strong alcohol, preferably being first killed in weak spirit. Another method of peculiar value, especially when one is pressed for time, or night is approaching, is to place the rock masses in a tub or basin of sea water, and to leave them for some hours or the night. The animals soon get starved for oxygen, and many come out of their holes, being easily picked off with forceps.

Of other free-living forms there are the sea-spiders or Pycnogonids, which should be placed in small tubes of strong spirit, not more than two or three together. They crawl on the fine branches and stems of weeds, hydroids, and especially Polyzoa. Then there is the great group of flatworms, or Turbellaria, which dwell mainly on the under surface of stones, crawling between the sedentary sea-squirts or Tunicates, and taking refuge in any hollows of the rock. Most are small, and 
can be induced into tubes held under water against the surface of the stone. They can then be killed with a few drops of formalin dropped into the sea water in the tube, and at once corked up in the same fluid. Foraminifera, minute unicellular organisms with complicated shells (Figs. II to 20), can be seen creeping up the glass sides of any tumbler or glass into which some clean sand from below tide-level has been placed. We know little of their life-histories even in temperate seas, and tropical forms are mainly of interest to us for comparison of their shells with those in various elevated rocks. We get their shells, by simply drying the sand-i.e., in the various sand samples we have already collected for more general purposes. Of insects we may mention Halobates (Fig. I39), seen on rock-pools, though a wanderer over all tropical oceans. Its eggs and larvæ are often found on floating cuttle-bones and pumice, frequently being confused with young barnacles. Needless to say any insects in salt water are of value, and should be carefully preserved in 70 per cent. alcohol. There is a spider also (Desis) the distribution of which is interesting. Lastly, we have snakes (Hydrus), dangerous pit-vipers, but yet timid beasts, incapable of harm so long as the body is covered, and the thin parts of the hands are kept well above the surface of the water.

Of sedentary animals we might make a catalogue of Hydroids, soft corals (Alcyonaria), anemones, corals, sea-squirts (Tunicata), sponges, and Polyzoa, and say that pieces of any and all placed in 70 per cent. alcohol are likely to be of value to specialists, particularly when smaller slips for anatomical purposes are put in 90 per cent. alcohol. We are, however, at the present day beset with difficulties at every turn in respect to the determination of the species of these forms. They have 


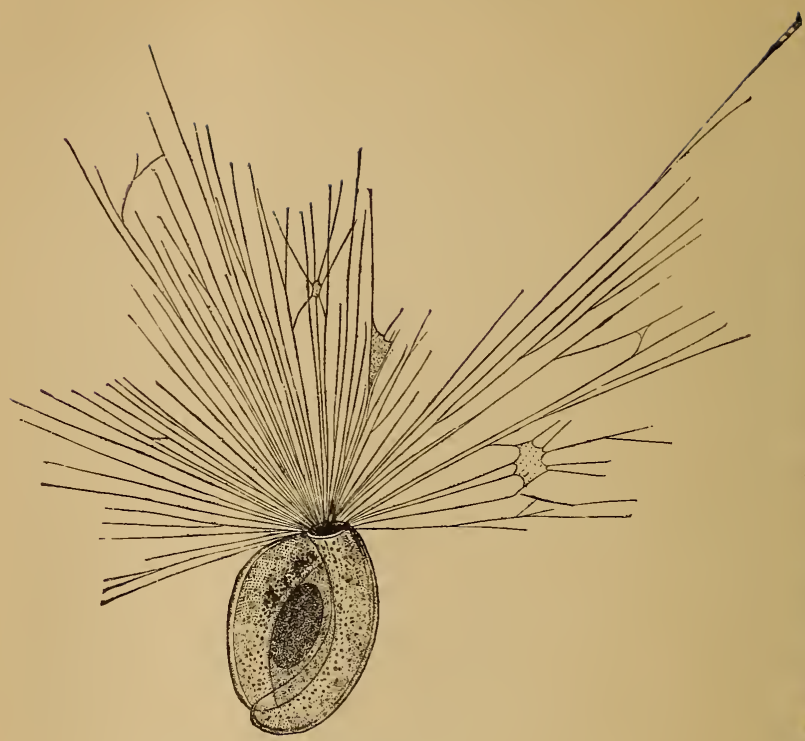

Fig. II. -MiLIOLINA.

Fig. 12.

NODSOARIA.

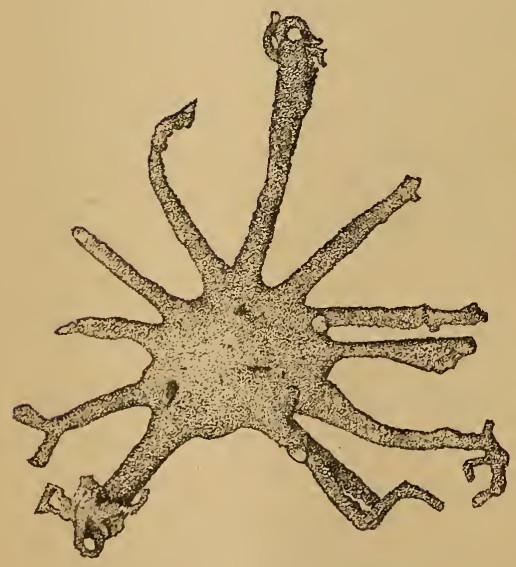

Fig. I 3.-AstrorhIZA.

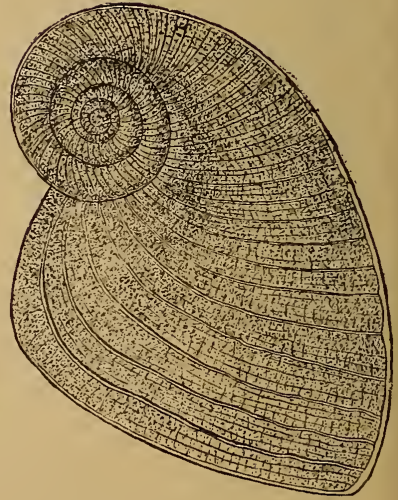

FIG. I4.-PENEROPLIS.

TYPES OF FORAMINIFERA (BLAKE). 


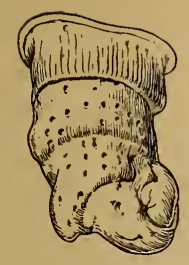

Fig. I 5.-VERTEBRALINA.

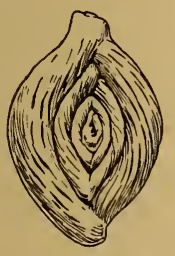

Fig. 17.-SPIRoloculina.

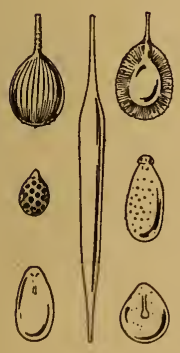

Fig. 19.-Lagenide (Various). Fig. 20.-Polystomella

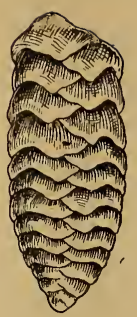

Fig. i6.-TeXtularia.

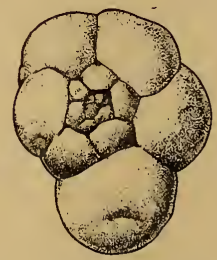

Fig. I8.-Trochammina.

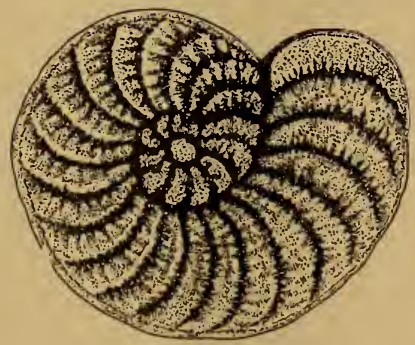

TYPES OF FORAMINIFERA.

(Drawn by Messrs. Heron-Allen and Earland.) 
for the most part floating larvæ, which can be carried by ocean currents over wide stretches of sea, and accordingly present relatively little variation of species over each of our two great tropical oceans. Let the naturalist collect a few groups only, but let him study the growth of those few carefully on the spot in relation to their environment. It does not matter whether he knows the names of their groups, families, genera, and species, or not. As we have already said, he cannot go wrong, for such intensive studies of tropical beasts have never been made. $\mathrm{He}$ will have the satisfaction of knowing that he is at least adding something of high permanent value to biological science, and he will be undertaking a study the interest in which grows as the work continues.

\section{B.-Coral Reefs and Islands.}

In the previous section we have already sufficiently emphasized the paramount importance of ascertaining the nature of the geological formation of any island which may be visited. Islands divide themselves into three classes, continental, volcanic, and coralligenous, in accordance with the composition of their rocks, though it is not always easy to separate them. A continental island is one which, from the nature of its rocks, or more generally from the considerable variety of the animals and plants which live upon it, must be supposed to have been at one time connected with some continental mass of land, upon the surface of which, according to our present views, a large variety of animals and plants may be supposed to have been evolved. Thus, for example, all the greater islands of the East and West Indies must have been connected at one time with their neighbouring continents. 
There is little room for doubting (see Fig. 2I) that Madagascar was at one time joined to Africa, and New Zealand to Asia and Australia through New Guinea; New Zealand may have had also a polar connection with South America. The Seychelles Islands are formed of granite, a type of rock essentially associated with the immense early solidifications of eruptions which formed great continents. They doubtless were a part of the Indo-African Continent, which is believed

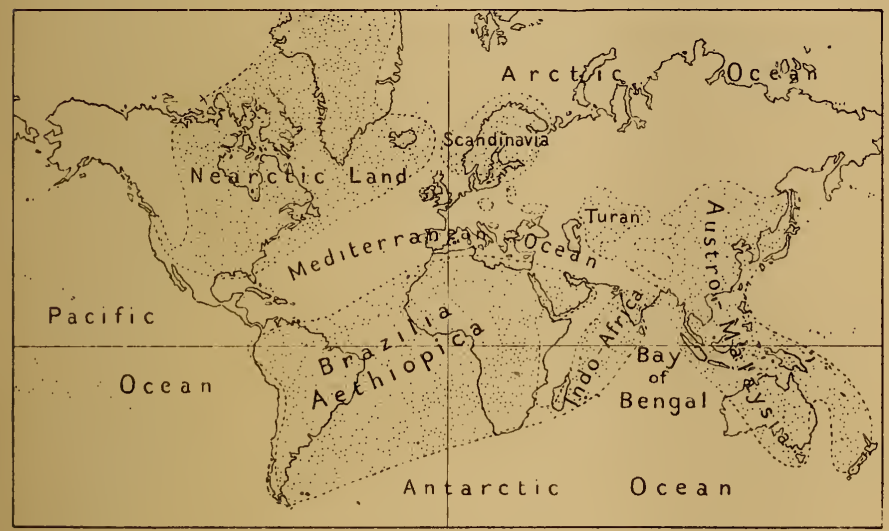

Fíi, 2I.-Chart of the WORLD, Showing the SUPposed Distribution of Land (Dotted) in the Cretaceous Period. (After Neumayr.)

by many to have once extended between Africa and India_- "Gondwanaland," as it is often termed.

The Fiji Archipelago is a more doubtful case; its rocks are of recent volcanic types, overlaid by " soapstone," composed of submarine deposits formed largely by Foraminifera, and by raised coral rocks. Its fauna and flora, however, are, comparatively speaking, rich and varied, but it must always be remembered that the numbers of species and genera of animals and 
plants on any land vary proportionately to its size, temperature, varieties of soil, and rainfall ; the exact influences of each of these cannot, of course, be exactly stated. In the case of islands formed by submarine eruptions, their proximity to other lands, and the presence or absence of currents and winds, suitable for the transport of the seeds and germs of plants and animals, are of primary importance. Hawaii, Samoa, and Tahiti were probably all formed by eruptions, and to some degree they illustrate the influence of distance and size already mentioned. Mauritius, Réunion, and Rodriguez are probably further examples; but the former may have been connected to the Seychelles, and so to Africa ; and Rodriguez was partially formed by an upheaval of the sea-floor. The Atlantic Islandsthe Canaries, Cape Verdes, and Azores-are probably all of similar origin, though some of them have been supposed to represent the remains of a continent connecting Africa to South America.

It will be now clear that the importance of the study of islands to a large degree depends on the light which they throw on the existence of former continents-on the distribution of land and sea in past geological periods. An island may exist where we are practically certain that there was formerly continental land, but it by no means follows that it was ever part of that continent, since it may have been formed subsequently to the submersion of the continent. Yet it is in islands that we might expect to find our best evidence of the existence of former connecting land masses.

The interest of our third class of islands-coral islands -is again different, and lies in the question, how far do they indicate the sites of former land masses which have disappeared by subsidence or from other causes ? Some of these islands have been elevated to great 
heights, I,000 feet or more, and are surrounded by reefs of a later formation. Such islands may be isolated, rising out of depths of $\mathrm{I}, 000$ or 2,000 fathoms. Examples of these are Christmas Island in the Indian Ocean, Metia and some of the Pelews in the Pacific, and Bermuda in the Atlantic. In Fiji high elevated coral islands are abundant, associated with volcanic islands and with landless coral reefs; every such island seems to have been formed by a separate and apparently rapid upheaval, not by a movement of elevation which affected the whole group. Many other islands, such as are ordinarily called " coral islands," are quite low, rising only a few feet above the sea-level. They rest upon the surface of broad reefs, coral plateaux at the surface of the sea; and the method of formation of these coral reefs is the important question. To avoid misconception we would at once point out that there is no adequate proof that any single coral reef owes its existence to the gradual sinking of the foundations upon which it has been built, while there is plenty of evidence that coral reefs can arise by other means, and grow into the regular ring-shape atolls so characteristic of the Indo-Pacific Ocean.

Coral reefs are found between lat. $30^{\circ} \mathrm{N}$. and lat. $30^{\circ} \mathrm{S}$., where the surface temperature of the sea does not fall below a minimum of about $70^{\circ} \mathrm{F}$. Within these limits they exist off nearly every land in the Indo-Pacific Ocean, and form a vast number of small isolated rings, most of which are crowned with land, and garlanded with coconut palms. In the Atlantic they are found in the West Indies, off Florida, and in places off the coast of Brazil, but they do not form isolated peaks in the ocean bed or exist around its other islands, except Bermuda. Further, on the eastern shores of all oceans typical coral reefs do not 
exist, while on their western shores, as, for instance, to the east of Africa and Australia, they attain great dimensions. Their shape and appearance wherever they exist is quite characteristic, a flat, almost level with the surface of the sea at low tide, on which the ocean pounds down, even in the calmest weather, with great breakers upon at least one face. The water at low tide flows over the flat for some distance, only to rush

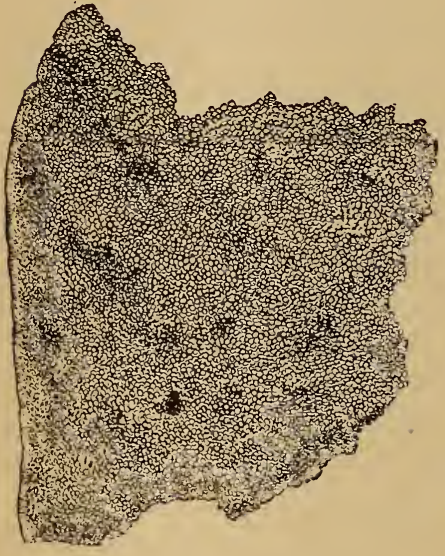

Fig. 22.-Coral Oolite.

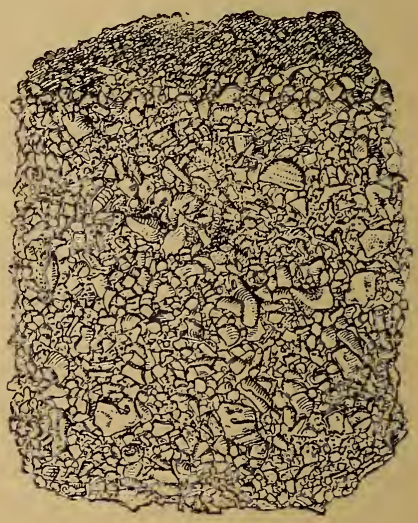

Fig. 23.-Coral Breccia.

These are formed by the grinding down of coral boulders, the fragments being cemented together by the deposition of lime at different grades of fineness. Both found abundantly on the shores and in the islands of atolls ("Blake").

back by countless fissure-like channels in the edge of the reef. This area, the reef flat, as it is termed, is marked off on its inner side by a band of boulders, generally small masses of reef rock or coral colonies, which have been hurled up from inside or outside of the reef ; hence is derived its name of the boulder zone. Instead of these boulders we may have a land, perchance formed by them, perchance of elevated coral 
rock or of volcanic material, the shore of which, in most cases, is boulder-strewn. The reef will thus form a narrow shelf around the land, being then termed a fringing reef (Fig. 24). Sometimes the land behind is separated from the boulder zone by a channel ; this may be only a few feet in depth, when it is termed a boat channel, or it may be some fathoms deep, sufficient for a ship's anchorage, when it is commonly called a lagoon. To a considerable degree the depth of this lagoon depends on the distance of the land from the surface reef outside, but it never exceeds 50 fathoms. Inside of most reefs, within the boulder zone, there is almost invariably (if no island arises within the limits

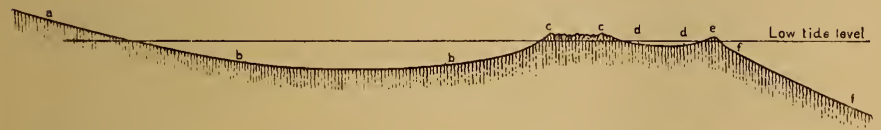

Fig. 24.-Section of Fringing Reef, Rotuma Islands, PACIFIC OCEAN.

$a$, Land ; $b, b$, boat channel or lagoon flat ; $c, c$, boulder zone ; $d$, $d$, reefflat; $e$, crest or edge of reef ; $f, f$, seaward slope.

of this zone) a broad flat, with I or 2 feet of water at low tide, more or less covered with sand, part bare, part rich in coral growth. This may be termed the lagoon flat, and may be the flat beneath our boat channel, or may be a flat before the water deepens to form the lagoon. Such a reef, with a deep lagoon within it around the land, is termed a barrier reef, but there is no sharp transition between it and the fringing reef.

Lastly, the reef may exist as an isolated structure by itself, with its reef flat, boulder zone, and lagoon flat. It may be-(I) a small mass completely swept by the breakers; or (2) a larger reef with a mere pile of boulders in its centre; or (3) with the smallest puddle of water 
in a ring of boulders; or (4) with a great shallow lagoon flat a mile or more across; or, lastly, (5) with a lagoon flat and a deep lake, like the lagoon above. In the latter case it is termed an atoll (Fig. 25). Then it is essentially a ring of reef, bent as you will, surrounding

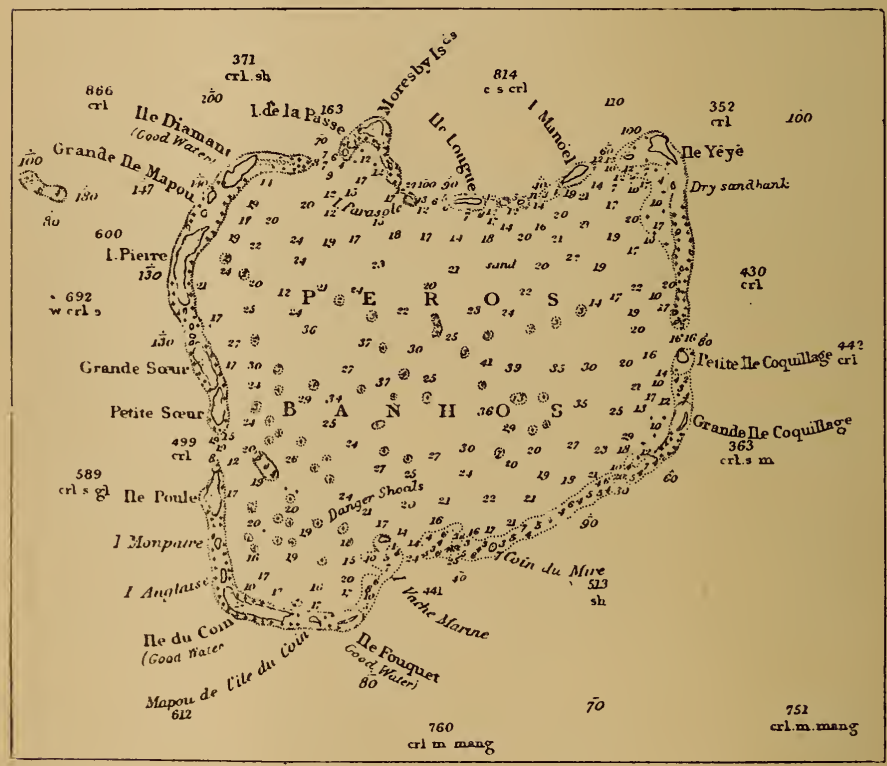

Fig. 25.-A typical Atoll; Peros Banhos, Chagos Grotip. SCALE, 4 MILLIMETRES = I MILE. (From THE ADMIRALTY CHART.)

a lake, the lagoon, which may be a mere pool or a great enclosed sea (thirty or forty miles across), which, however, never attains a greater depth than 50 fathoms.*

* This is true for the lagoons of both atoll and barrier reefs, with one exception-namely, that of Vanua Balavu (Exploring Group), Fiji. Here a bight of deep water, 6o to Ion fathoms, extends into the lagoon, superficially reminding one of a sunk valley. 
A barrier reef may extend along a thousand or more miles of a continent's shore, as the Great Barrier Reef off Queensland, or, again, it may surround an island or a mere speck of land. Were the latter removed we would have an atoll, and the obviousness of this fact was, pending the detailed examination of the reefs themselves, the cause of the prevalence for several decades of the view that the atoll ring-reefs were formed on the subsidence of the land which they once surrounded, first as fringing and later as barrier reefs.

We may now refer to the chief theories put forward to account for the formation and origin of coral reefs, much information bearing on which may be obtained by any traveller of average ability. These theories centre on the atoll, since it is easy to see that any theory must be capable of explaining the formation of both barrier and atoll reefs. A caution may be at once issued to the effect that it is unlikely that any one theory will explain the formation and origin of all coral reefs; doubtless as great a diversity exists in the composition of the earth's structure beneath the ocean's bed as in the land. As to the formation of fringing reefs and isolated reef masses in shallow waters there is no dispute, but to explain their building we require briefly to consider the bionomics of the coral animals.

The structure we know by the name of "coral" is the skeleton of animals common round the coasts of temperate lands, closely allied to the well-known seaflowers or anemones. It is formed of carbonate of lime, which is deposited by the animal in some way beneath itself, producing a firm but rough seat, from which the animal is itself incapable of stirring. Some of these anemones are solitary beasts, but most form 


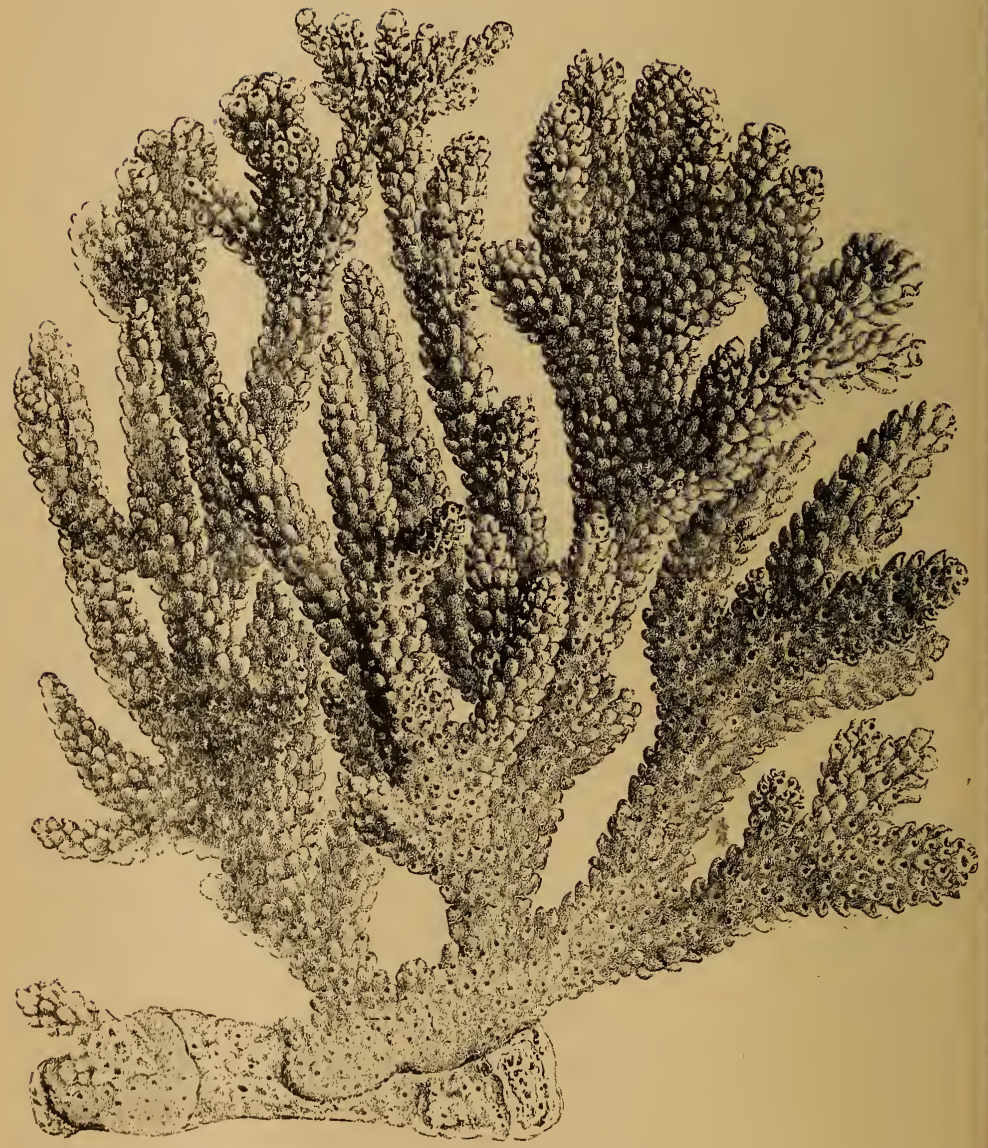

Fig. 26.-Madrepora prolifera : A True Coral ("Blake"). An abundant corai of the Lagoon Flat. 


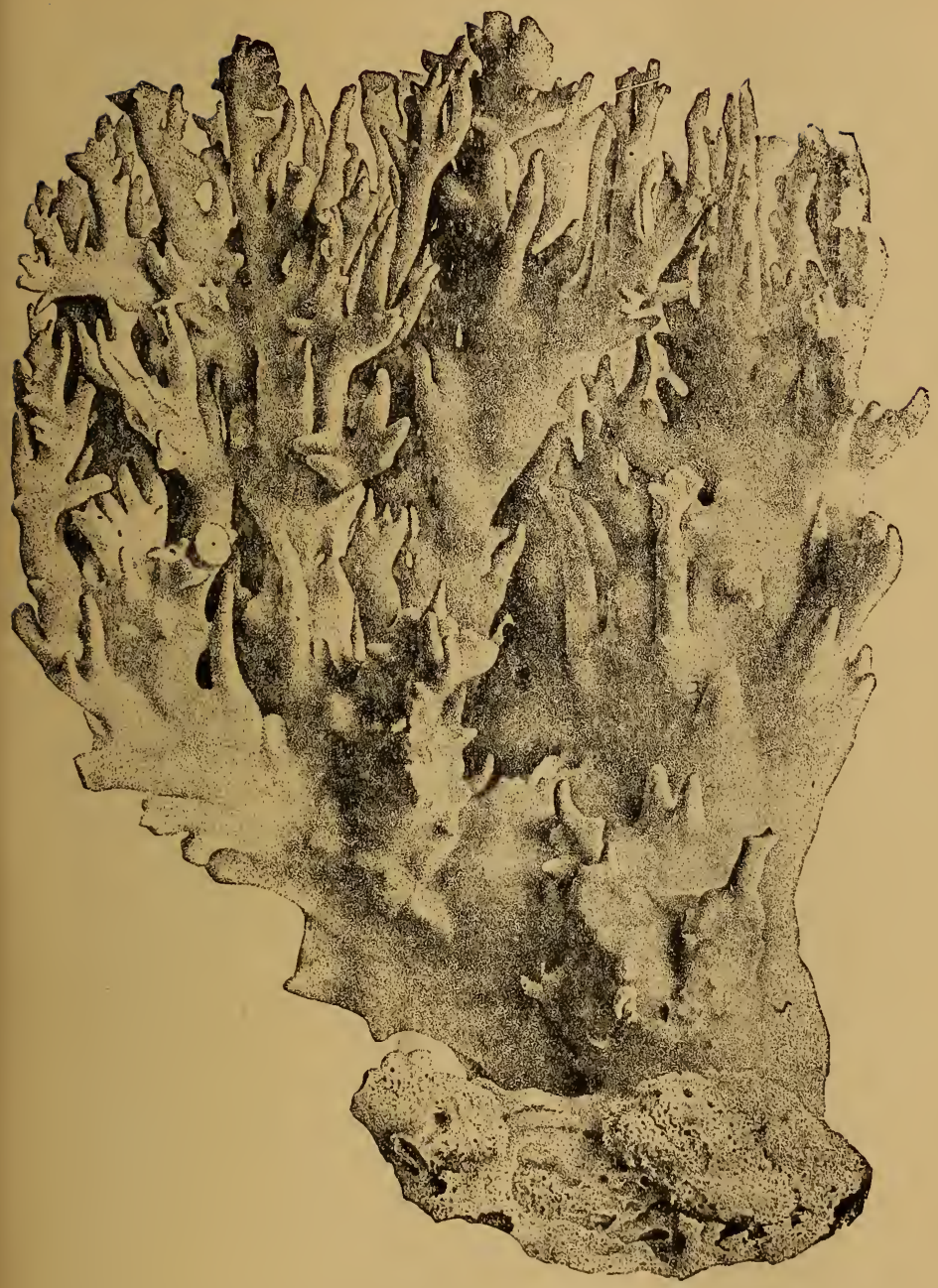

Fig. 27.-Millepora alcicornis: A Reef Builder belonging TO THE HYdRomeduse, BUT NOt A TRUe CORAL ("Blake").

Found everywhere on reefs; noticeable for its forms of growth, massive to lamellar to fine branches; they are adaptations to depths and strengths of currents. 
colonies by budding, the buds not separating, so that the whole may be regarded as a single animal with the mouth, tentacles, and all its other parts many times repeated.

Underneath the animal coral is being built; of its rate of formation we require further definite information, but a single anemone of I millimetre diameter has been known to bud out and form 693 grammes of coral in thirty-six months. Corals grow luxuriantly in tropical waters, but of their food and of the conditions which affect them we have not as yet adequate knowledge. They have slitlike mouths within their circles of tentacles, and, being fixed, are of course incapable of searching for food in any way. When cut open food is seldom found in their digestive cavities, but they are supposed to seize the small organisms which float in the surface waters of the sea as the latter flow over them. Investigations on this matter are urgently needed, for which purpose crabs or any molluscs might be cut or pounded up into small fragments, and the anemones fed with them. Reefforming corals have in addition, living in their cavities, vast numbers of minute unicellular green plants, or algæ, which especially congregate in their tentacles and towards their surfaces, generally giving the living colonies a green colour. In many species of coral they practically obliterate the digestive cavities of the animals, in one form the latter being absolutely closed off. so that it has no opening or mouth to the exterior. For their life and increase these algæ must be mainly dependent on the carbonic acid gas in solution in the water, and they are probably largely eaten up by the coral anemones as they require food. One observer states that reef corals give off a certain amount of oxygen, but his successful experiments were few in 
number. They were made by fixing funnels and inverted bottles over the surfaces of corals living in a suitably protected pool to collect the gases given off. The latter were then exploded with hydrogen, made by the action of acid on zinc, to determine the oxygen present. If correct they show an extraordinary

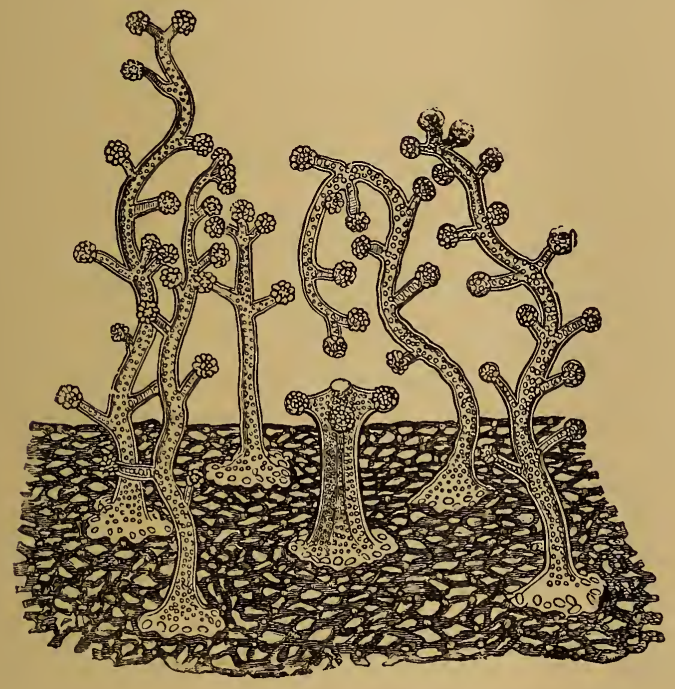

Fig. 28.-A Group of the Polyps of Millepora Expanded ("Challenger").

From the system of tubes common to the colony rise five mouthless individuals, which serve as tentacles to the central individual, which takes from them the food and digests it. Further observations on living material are much needed.

activity in coral growth, but they are open to some doubt, and should be repeated. At the same time experiments might conveniently be made on the effect of sediment, of various sized particles and kinds, on the surfaces of the corals, to see how far the anemones possess any power of cleaning mud and sand off their 
soft tissues. For this purpose fixed colonies should be selected, such as by growing together might form a solid platform. Massive forms with large anemones will be found most useful for the purpose, being easier to observe, and giving the roughest surfaces for the lodgment of sediment. At the same time observations on the expansion and contraction of the tentacles of the coral anemones, and so of the whole animals, might be added, especially in connection with the ebb and flow of the tide, with the amount of sediment in suspension in the water, and with darkness and light.

Whatever be the cause, it seems certain that the ordinary reef corals do not grow in any luxuriance at a greater depth than 30 fathoms, though isolated colonies have been dredged as deep as 50 fathoms. Down to 30 fathoms the larvæ of coral anemones affix themselves in vast numbers on any tropical coast or suitable bank, if there exist rocks or stones for their attachment. Each rapidly becomes a full-grown anemone, and buds off fresh anemones, quickly forming a colony supported on a massive skeleton of carbonate of lime. As some of the anemones die or are killed, fresh surfaces of rock are left for the fixation of further coral larvæ, and finally a rough platform is built up to the surface of the sea, beyond which growth is, of course, impossible. In this way a fringing reef may be formed round any island with a depth of 30 to 40 fathoms off its outer face, or a reef may be built up on any shallow bank to the surface. Corals are the most important organisms in its structure, but the remains of molluscs, starfishes, soft corals (Alcyonidæ), Polyzoa, and a host of other animals assist as well. Algæ also are important, both calcareous leaved forms, such as Halimeda (Figs. 50, 5I) and the more massive skeletons of Lithothamnia (Fig. 75) as firm and strong as those 
of the corals. Sand, partially the remains of the above organisms, but largely composed of the shells of pelagic unicellular organisms (Foraminifera), collects between the corals and helps to solidify the whole structure, while creeping and spreading Lithothamnia form a surface firm enough to resist the mightiest breakers. The relative share of each organism varies in each locality, and is always a matter of interest.

Let us now trace further the probable fate of our reef tefore proceeding to controversial theories. Its breadth will depend on the area of the shoal on which it was founded, or on the area within the 30-fathom line round the land. It will be a flat on the surface. with the corals dead on the top or represented only by small colonies of poor growth. The sea will be surging up around, bringing abundant " food " to its face, and here corals will be found growing vigorously as deep as the eye can see, 15 fathoms or more. The rollers will be constantly pounding down on its edges and breaking off colonies, a few of which may be cast upon the surface of the reef to form a boulder zone, but most of which will be washed outwards to bring fresh areas within suitable depths for the reef builders. As this process continues, the reef will be spreading farther and farther seawards, broadening its surface, and making life less and less possible on its inner zone as the animals become more distant from their chief source of food-supply, the open waters of the ocean. This process might continue indefinitely, the rate of outward growth depending on the steepness of the outer slope of the ocean floor. The outgrowth must be assumed to result finally in the (almost universal) gradual slope for about 200 yards to about 40 fathoms, followed by the steep slope, often with an angle of over 40 degrees to about 140 fathoms. At this depth 
the regular contour of the ocean floor is reached, * though it must be slightly altered by the deposition of coral mud and rubble from the reef above. The cause of the existence of the first slope to 40 fathoms is not known, though it has been supposed to be connected with the depth to which the effects of wind-produced waves are felt.

Further observations on the currents, bottom conditions, and fauna of the outer slope, are urgently needed. The steep is clearly a "talus" formation, resulting from the outwash of loose masses of coral from the reef above, its angle of slope being the angle of rest of such masses in comparatively calm water.

The theory of the formation of atoll and barrier reefs propounded by Charles Darwin in his "Coral Reefs," a book of genius in its line as great as his "Origin of Species," depends on the assumption that the land, round which a fringing reef has formed, is subsiding at such a rate that the coral and other organisms upon the reef can, by their growth, keep it at the surface of the sea (Fig. 29). Such organisms will grow more vigorously at the ocean edge of the reef, where they will have more food. Thus it will be easily understood that, as subsidence proceeds, a channel (at first a boat channel, and then a lagoon) might be formed between the reef and the land. This lagoon will attain its breadth by the gradual submergence of more and more of the land, which finally might be completely submerged, the formerly fringing reef becoming successively a barrier reef and an atoll reef, the contours of these roughly representing the former extension of the land mass. It is a theory delightful in its simplicity, but it depends on the assumption that the land continues to subside slowly for periods of time even geologically

* Compare this with the slopes off continents, p. 208. 
large. There are many objections to this premiss, and there is no evidence that such a general subsidence is going on as would be required by the theory-i.e., from Africa across the East Indies to Hawaii and the Paumotuas. Indeed, it seems probable that the method of formation by subsidence, if it occurs at all, is very local, but the theory is of such interest that in every place visited evidence of subsidence should be sought. The charts should be examined for sunken valleys, etc., and any additional soundings made outside the reefs will be of interest. A difficult point in this theory is the explanation of the causes which prevent the lagoons of atolls and barrier reefs from ever exceeding 50 fathoms in depth. The question -how far, if at all, material is swept over the reef to fill in the lagoon - is worthy of investigation, and in this connection the examination of the mode of formation of the lagoon flat should be interesting.

The subsidence view of the successive formation of barrier reefs and atolls is strongly opposed by all those who have in the last thirty or forty years devoted themselves to the examination of extensive series of reefs, mention in particular being made of the late Prof. A. Agassiz, Sir John Murray, and Prof. Semper, who, in addition to having made explorations themselves, have had the benefit of the experience of numerous other expeditions. It has in the first place been shown that fringing reefs might owe much of their breadth to the abrasion of the land round which they form a belt. Tall cliffs and masses of rock overhanging at their base are often found bounding the shoreward edges of the reefs. The land in such a position is evidently being rapidly removed between tide-marks, and as it recedes it leaves at low-tide level a flat platform, 
indistinguishable from the shoreward part of a reef. If organisms commence to grow on the outer edge of such a platform, its surface appearance is in

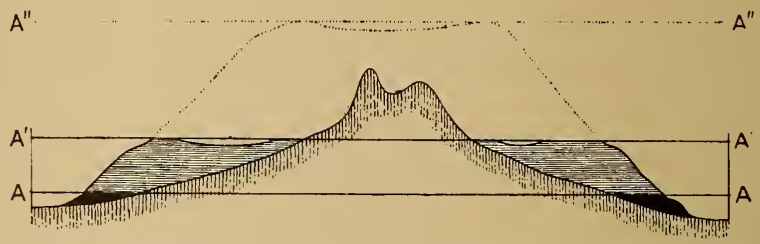

F1g. 29.-Sectional Diagram to illustrate Formation of Atoll and Barrier ReEFs by Subsidence. (AdAPted From Darwin's "CoRAL ReEFs.")

$A, A$, Sea-level of island, with fringing reef in black; $A^{\prime}, A^{\prime}$, the same after some subsidence--island, with barrier reef shaded; $\mathrm{A}^{\prime \prime}, \mathrm{A}^{\prime \prime}$, the same after the island has been submerged-atoll reef dotted. The vertical scale, as in the next figures, is many times the horizontal scale.

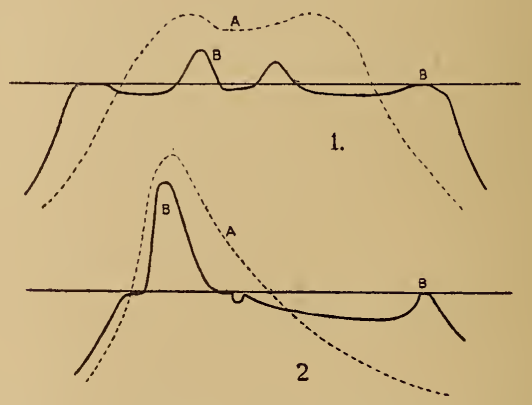

Fig. 30.-Sections to show Formation of Reefs by Abrasion OF LAND.

I, Ongea Levu, Fiji, an elevated coral island ; 2, Wakaya, Fiji, a volcanic island; $A$, supposed former sections of land; $B$, present sections of land and reef.

every respect that of a true reef. This is especially the mode of formation where the land is composed of elevated coralline limestone, as is frequent 
in island groups where fringing and barrier reefs are abundant. Again, as a fringing reef broadens, neither the reef flat nor the boulder zone increase greatly

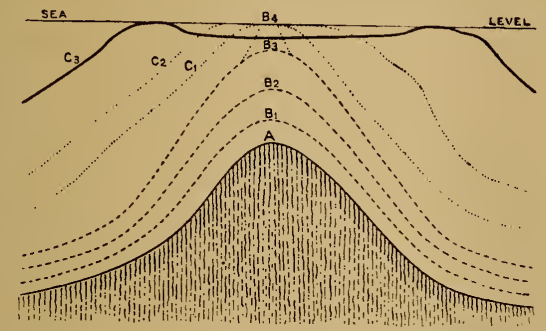

Fig. 31.-Sectional Diagram to illustrate Formation of an Atoll on a Mound of the Sea-Floor.

$\mathrm{A}$, original mound ; $\mathrm{B}^{1}-\mathrm{B}^{4}$, building up of same by remains of deepsea animals, by pelagic deposits, and, lastly, by reef organisms to the sea-level ; $\mathrm{C}^{1}-\mathrm{C}^{3}$, outward extension by accumulation of talus and other materials on the slopes and further growth of reef organisms; hollowing out of the surface by solution and removal of mud in suspension.

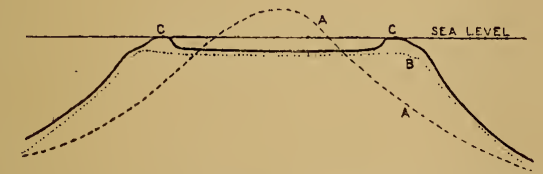

Fig. 32.- Sectional Diagram to illustrate Formation of an Atoll on the Site of an Island of Loose Material which HAS BEEN PARTLY WASHED AWAY: SUCH AN ISLAND AS IS FORMED BY A SUBMARINE ERUPTION.

$A$, Original island; B, bank after the top of the island has been washed away to 20-50 fathoms; C, atoll formed by the direct. and greater upgrowth of reef organisms on the edge of the bank.

in breadth, the inner part (lagoon or shore flat) broadening and taking up the extra breadth. - The shore or lagoon flat is obviously formed where once was boulder zone, and it should therefore be strewn with boulders. On a broad fringing reef such 
loose masses are not found on the lagoon flat,* it being generally a bare or slightly hollowed-out area, which is alternately covered and uncovered by the tides. The latter must be the ultimate agents which effect the removal of the boulders, and this they are supposed to do by removing the coral, which is composed of almost pure carbonate of lime, either in solution or as fine mud in suspension in the water, or by both means. The solvent action of sea water on coralline material is well determined, and organisms are likewise known to break up coral rock into fragments-gravel, fine sand, and, lastly, mud. The removal of material in suspension is evidently of as great importance as solution, or even greater, hundreds of thousands of square miles of oceanfloor near coral reefs being charted as covered with coral mud. How the latter is produced requires further investigation. Probably there is some animal matter left in the coral limestone. In search for this the masses of rock are riddled in the first instance with the fine borings of algæ (Achyla) and sponges, their borings invisible to the naked eye. These are followed by worms, Sipunculids, and hosts of other organisms, which cause the rotting to pieces of large masses. They are further broken down by the waves into gravel and sand, as such being ingested by other worms, seaurchins, Holothurians, Sipunculids, and Balanoglossids, which in their intestines further grind them up into the finest mud; the latter readily passes into suspension

* Boulders formed of the skeletons of the blue coral, Heliopora, often persist for long periods of time, resisting most of the ordinary agencies which in such positions cause decay. The same is also true to some degree of Millepora, the stinging "coral," which is a form of peculiar anatomical interest, as having medusæ bearing the generative products (Figs. 27 and 28 ). 
in the water, much of it being removed by the ebbing of the tidal waters.

By such methods as the above the inner boulders of the boulder zone might be removed, while the zone itself continues to extend outwards on to the reef flat as the reef grows seawards. It is easy to imagine the processes going farther, and hollowing out the inner part of the reef to form a boat channel and finally a lagoon. Should the reef start as a small mass in midocean it would pass through similar stages-a flat in the centre, then a shallow pool, and finally a lagoon. As a barrier the reef should in some degree conform to the contour of the land, but as an isolated reef it should be more or less round in its early stages. Later, both the barrier and the atoll would show the effect of currents in carrying and depositing mud and other material, so as to make the extension of the reef in certain directions easier, destroying any regularity of contour. From the first formation of any inner pool, channels would form through the boulder zone to allow the escape of the tidal water. The latter would especially rush out over the lowest parts of the encircling reef. Being charged with much sediment in suspension, it would kill any corals and other sedentary organisms in its path, and further would prevent any fresh corals from commencing to grow in its channel. Where dead rock occurs boring organisms enter, but where the surface is covered with living tissues they cannot penetrate. This is the reason why the seaward face of the reef, which is almost covered with growing organisms, is scarcely affected by solution and abrasion as compared with the lagoon. The rock under a channel, being bare, will be bored and rotted like the rocks in the lagoon, with the result that its depth may increase more or less equally with that of the lagoon 
to which it gives entrance.* The latter depth is apparently fixed by the first seaward slope, a gradual one to 40 fathoms or thereabouts, this approximately being about the depth to which lagoons generally attain. Observations on these matters are urgently needed; they should be accompanied by precise information as to the conditions in different parts of the lagoon of coral growth, sand deposition (exemplified by samples), rate of currents, etc. Estimations of the amount of solid material carried into and removed from the lagoon by the tides are wanted, and may be made by suspending plankton nets of fine mesh-we suggest two kinds, 60 and I8o meshes to the inch-in passages leading into the lagoon for one, two, or more hours at ebb and flood tides both in calm and stormy weather, and at different depths. A good current meter (Ekman) might be suspended from the same anchor chain between two of the nets.

The above theory of the formation of lagoons by solution and erosion offers no explanation to account for the submarine foundations on which atoll reefs are built up. It is conceivable that islands, which were originally surrounded by fringing reefs, may have been completely removed by abrasion and solution, the reef becoming successively of barrier and atoll type. This mode of formation is seen in the windward group of Fiji (Fig. 30), where the islands are mostly formed of raised coral rock; but atoll formation by this means is probably not of wide occurrence. Secondly, an island may be cut down by the action of wind, waves, and

* Sometimes rounded growths of Lithothamnia are common in such a position. Often the sides of such channels are rich dredging-grounds for sedentary organisms, especially Gorgonians, Polytrema, and Hydrocorallines. Where the lagoon is large and there are several channels, this question of depth becomes complicated. It should be re-investigated in each atoll. 
ocean currents to form a submarine bank, no fringing reef forming while the process is taking place, owing to sediment produced by abrasion. On such a bank an atoll would be built up owing to the more rapid growth of corals on its rim, where they would be better nourished. Submarine eruptions may occur anywhere, and the contact of the molten lava with the water produces a mound of cinders and ash, which may form an island or never appear above the surface of the sea (Fig. 32). Such a mound would rapidly be cut down to the limits of wind-wave action, perhaps even to 40 fathoms or more, on which an atoll would directly arise, in the way above suggested. Such a mound was Falcon Island, Tonga, erupted in 1883 to a height of about 250 feet, but now a submarine plateau covered by a few fathoms of water.

Thirdly, mounds might be built up beneath the sea to suitable depths for the reef builders by the remains of various organisms. On any slight elevation on the ocean floor sedentary and other animals congregate to an extraordinary degree. Chief among these are the deep-sea corals, enormous banks of which have been discovered on the floor of the Atlantic by dredging and sounding expeditions. Their remains, assisted by the remains of pelagic organisms, build up the surface of the mound to an extent out of all proportion to the upgrowth of the surrounding area of the ocean floor, so that the mound ultimately approaches the surface (Fig. 3I). The reef builders obtain sway, and a reef soon reaches the surface, later to spread out on its own talus and to be hollowed out in its centre, forming a typical atoll.

In many coral-reef regions boats are often difficult to procure, and the traveller is driven to study the low-lying islands which .are so characteristic of coral 
reefs. A few wells probably exist, which give admirable sections of the land, and, labour being cheap, others may be dug so that its structure is made thoroughly clear. We ask a few questions of the traveller. Are the islands growing or washing away, either on their seaward or lagoon sides, or on both? Are they extending farther along the line of the reef ? Whatever is happening to them, are they all following some definite law, or is each apparently adapting itself to its own immediate environment? On the flat reef itself large bare masses of coral rock are often seen standing up as high as, or even above, the high-tide level. Are they pinnacles, and therefore part of the reef on which they are standing? or are they masses which have been hurled up on to the surface of the reef by the waves in storms? In all cases they are valuable for the study of the formation of the coral rock from the heterogeneous series of organisms which build a reef. Ordinarily they are washing away, and present jagged points of coral worn out. If they are part of the reef below, this coral should be in the position of growth, a fact which can be easily ascertained by comparison with the corals growing in the vicinity. Any evidence of stratification anywhere will be of value. Pools of salt or brackish water in the islands are always of interest in connection with the formation of the islands themselves. In the land fauna and flora there is perhaps little interest, but the visitor or trader who calls at all islands of a group or a large series of islands would render service by recording the flotsam and jetsam which reaches them, in reference to the possible peopling of islands recently formed or otherwise bare. The residents will point out peculiar trees, and the examination of growing-out spits, etc., will reveal many. seeds. 
In briefly stating above the chief theories of the formation of atoll and barrier reefs, we have endeavoured to make clear the fact that all observations made by the traveller will be of value. Let him, if his time is limited, take up one point-the structure of the reef beneath his feet, the interrelations of the organisms on its surface, the reactions of corals to their environment, the feeding of corals, the relative importance of corals and algæ, the currents in the passages, the formation of sand and mud, the action of solution and erosion, the topography (especially sections) of the outer and lagoon slopes, the plankton within and without the barrier or atoll reef, etc. He will do most service and interest himself more by making himself a thorough master of one point, instead of day after day superficially examining different parts of the reef, and speculating without any precise or new data on the method of its formation. In particular, for fringing and barrier reefs observations are required as to the causes of the formation of their channels. In many places they are connected with the outflow of streams off the land, but in as many others no such connection is observed, and all notes on their formation will be interesting. The residents' statements require to be listened to with respect, but the greatest caution must be observed in accepting them in lieu of scientific evidence.

\section{C.-Hints for Tropical Outfit.}

Dress.-For ordinary tropical dress, suits of white duck or twill are recommended, with the ordinary canvas tennis-shirt and tie, white canvas shoes, and a broad pith solar topee. The traveller should have thin drawers or suspenders and a few broad body belts in case of digestive troubles. 
For work on land, on the shores, or in the sea, khaki clothing (cotton) is recommended; Norfolk jackets, with plenty of pockets; breeches fairly tight at the knee; puttees and boots, either ordinary navvies at 6 s. to Ios., or especially made and studded with small screws at about $25 \mathrm{~s}$. ; topee coming well down behind ; and strong leather belt.

The regular tropical clothes can be bought more economically in the tropics, and the cost is about as follows : White duck or twill suits, jacket and trousers I4s. ; Indian tennis shirts, 2s. ; white canvas shoes, about 6s. ; best topee, I5s. to 20s. ; khaki suits, Norfolk jacket and breeches, I5s.; puttees, 2s. ; second topee, 7s. 6d. The cheapest cloth, etc., is not found to be most economical. If travelling eastwards and not disembarking at Colombo, Singapore, or Batavia, clothing can be obtained on the voyage, the traveller being advised to pay a little more and go to such good firms as Simon Arzt, at Port Said ; or Cowasjee, Denshaw, and Company, at Aden.

The traveller is strongly recommended to observe that Englishmen dress in the tropics as carefully as they do in England, and that he will prejudice himself in the eyes of whites, and even more in those of natives, by inattention to the cleanliness and neatness of his person and dress when not actually engaged in his work.

The naturalist is advised when at work in the water, even if diving for corals, etc., to wear the above dress, only, perhaps, dispensing with his coat and topee when being constantly submerged by the waves. Abrasions of the skin and the subsequent entry of poisonous substances will thereby be averted. Sun blisters of arms and back will also be avoided. One or two pairs of stout woollen socks will assist the fitting of boots. 
The salt water will do him good, and any dryness of the skin can be corrected by rubbing on coconut oil, which will also be found quite efficacious in keeping mosquitoes off the face, hands, and neck. A regular mosquito sleeping-net is essential if there is to be any shore living : buy a piece of calico 6 feet by 30 inches and 6 yards of best mosquito netting 72 inches wide ; sew the netting all round the calico, to the corners of which suspending cords may be attached. A waterproof sheet, such as is made by Andersons of St. Paul's Churchyard, is also useful. It is perhaps unnecessary to add that all clothes, particularly boots, should be washed in fresh water after being wetted by sea water, and that needles and plenty of thread will frequently save much expense.

Medicines, ete.-For 20s. to 30s. a quite sufficient stock for an ordinarily healthy man can be procured, perhaps a small tin case from some well-known firm of makers, Io by 6 by 6 inches. Its actual contents will vary with the peculiarities of each individual. Health in the tropics is treated of in many pamphlets and books, giving the use of simple drugs and methods of bandaging, etc. The author, who, having had considerable experience, is able to adapt common materials for his purposes, takes with him a double knife lancet, two clinical thermometers, four bandages of different breadths, a card of safety-pins, cotton-wool, a small packet of cyanide gauze, a packet of lint, 4 ounces of zinc ointment made stiff, dark glasses, a wooden phial of tabellæ of cocaine in case of eye-soreness, and 2-ounce bottles of each of the following drugs: sulphate of quinine, 5-grain tabloids; salicylate of quinine, 5-grain tabloids; sodium salicylate (the natural salt), loose; Dover's powder, loose; ipecacuanha, loose; bismuth subnitrate, tabloids, 5 grains; 
boracic acid, loose; chlorodyne in liquid; cascara extract in liquid ; rhubarb and calomel pills ; Warburg's tincture of quinine, in liquid. Also smaller tubes of the following: arsenic and strychnine; calomel, $\frac{1}{10}$ grain ; chrysophanic acid, powder ; clove oil ; strong myrrh and borax; corrosive sublimate. The novice will require small scales.

The above is intended to be no full list, but it may be useful as serving for a basis for discussion between the intending traveller and his medical man. He may also require some sedative drug, for which ammonium bromide is suggested; this will be found of great value in nervous sea-sickness. The chrysophanic acid is essential for ringworm. The bowels must be kept properly open. If residence among " wild " natives is intended, a few cheap strong purgatives and plenty of quinine should be kept; dentistry also is always a great pleasure to natives, and, if practised, will make many friends.

Photographic Apparatus.-The value of photography on tropical reefs and shores is well illustrated by the monographs of Professor Alexander Agassiz. Photographs often give an idea of a reef or shore, of which no mere word descriptions are capable. They also give incontrovertible proofs of many facts. The writer himself uses a stand camera, brass-bound, with Russian leather bellows, the whole of the most expensive make. It has been three times immersed in the sea, and is still almost as good as ever after nearly four years' rough service in the tropics. He uses plates, ordinary Wratten or Ilford, which he always gets sealed up by the makers, and which he has found good after eighteen months of tropical heat. A watchlike exposure meter is essential, as the photographer from temperate zones cannot judge the actinic properties of the tropical 
light. One word only as to the use of photography, and that a warning-beauty in the view, while always to be sought for, is only of secondary importance, and mere views taken without any particular reason are seldom of use. The half-plate is best, as it is a convenient size for reproduction afterwards, and in the end saves much enlarging. The colours of coral reefs are most attractive, and the author greatly desires to see good photographs of them, with the different colours represented with their true actinic values. The expert photographer might try Wratten's Allochrome plates, which will last for six months. In case of frilling formic aldehyde will be found valuable, and washing in sea water is always possible, afterwards rinsing in fresh.

It is perhaps unnecessary to say that good binoculars (prisms) are exceedingly useful. A water telescope can always be made by bedding a spoilt negative in the cut-out base of a tin.

Collecting and Preserving Gear, etc.-Hammer with chisel end, as made for geologists (5s.) ; two strong chisels (3s.) ; crowbar, 3 feet, with chisel and claw, best steel, about 2 inches circumference, to be used as a walking-stick on the reef (6s.); coarse forceps, a common bent piece of steel with roughened ends, about 12 inches long (Is. 6d.) The above can be made by an ironmonger who employs good blacksmiths; ready-made goods are not recommended.

All nets, etc., can be obtained from the Marine Biological Association, Plymouth. For merely reef or shore work they can be dispensed with. The naturalist will have the benefit of the experience of the Association to guide him. He should have all trawls made rather heavier than is usual for temperate seas. It is well to bring out fishing lines, hooks, leads 
and gimp of varied sizes, to be fitted out as required in different places.

The naturalist will be guided by his own inclinations as to whether he carries with him dissecting instruments. He will certainly require two pairs of ordinary coarse forceps, one of which he will be well advised to attach to his belt. A good sheath knife in his belt (cost with sheath 2s. 6d.) is advisable. A satchel is necessary, and should have two pockets, one for full and one for empty tubes; two of the ordinary white soldiers' knapsacks will do as well, and perhaps be more convènient ; these will cost $5 \mathrm{~s}$. or less, but the naturalist will satisfy himself better in the end by making his own bag from a length of canvas to suit the idiosyncrasies which he is bound to develop. A couple of common galvanized buckets are as good as anything for the larger specimens of the catch, while an enamelled billy (a pot with a lid and swing handle over same) will serve for more delicate beasts ; glass tubes, of course, also being carried. Enamelled basins serve for sorting the catch, aided by ordinary plates, pie-dishes, and everything of a similar nature that can be found. Two basins and half a dozen plates will be sufficient, as a general rule, for a good day's catch.

The alcohol used for preservation should be pure spirit, not methylated in any way. It is bought as 96 per cent. spirit, and is obtained best from the Colonial Sugar Refining Company, Sydney, N.S.W., costing 2s. per gallon. It is also distilled in Mauritius, Java, and many places in the West Indies, but prices of $3 \mathrm{~s}$. to $4 \mathrm{~s}$. are frequently asked, and a stock is not kept. It may, perhaps, as well be purchased from some reliable English house (2s. 6d. per gallon, Io-gallon drums, Ios., returnable), who will see that it is shipped. Formic aldehyde (see p. 347) will also be required; it 
is not good for animals with calcareous skeletons or scales, turning slightly acid, especially in the tropics ; the much more expensive German patent formalin is no better. For the minute anatomy of tropical marine animals the best all-round killing agent is undoubtedly corrosive sublimate (mercuric chloride) in saturated solution in sea water. Picric acid is also valuable, but the naturalist is warned that it is dangerous to carry, being explosive ; it is forbidden on mail steamers by the Board of Trade regulations.*

Various anæsthetizing agents are used in temperate regions, with excellent results, but most of them are quite useless in the tropics, the animals it is desired to obtain expanded being frequently found to have rotted before the anæsthetic has taken effect. Pure spirit, a few drops at a time, placed on the surface of the water with a small pipette, is the only really good agent, as it keeps the water clean, while gradually anæsthetizing the beasts in it. It is very good for Balanoglossids and worms. Generally speaking, it is a rule in the tropics to get animals as quickly as possible into one of the two preserving fluids, in which they can be brought home-i.e., 70 per cent. alcohol, or 2 to 4 per cent. formic aldehyde.

To advise as to the amount of jars, bottles, and tubes to be taken to any tropical locality is quite beyond the author's powers without his knowing the precise circumstances of each expedition, and is also, perhaps, beyond his province. Very much may be done with cheap galvanized tanks with screw lids, of I, 2, or 3 gallons, the individual animals being wrapped and tied up in butter-cloth, each with its label stating where collected, etc. The spirit may be carried in

* The most recent regulations ordain that it shall only be carried in solution (I9II). 
these tanks, and when a large number of localities are to be visited, it is as well to keep a tank for each.

Lastly, we would emphasize the importance of duly labelling all tubes, bottles, and specimens, with locality where obtained and date. A duplicate of the label may be obtained with carbon paper, and is often useful. It is advisable to use numbers as well as writing, the record of these numbers being kept in a separate notebook. If due care is taken in the first instance, the bottles, etc., can be packed as filled and sent home, without being further looked after in any way. When bottles go wrong, it is generally due to their being too tightly crammed with animals, insufficiently soaked in weak spirit before being placed in 70 per cent. spirit, or to the corks or covers being carelessly replaced so that air can get in, and consequently fluid and vapour can escape ; the latter may be avoided by dipping their heads when thoroughly covered up into melted paraffin. A piece of string placed in the mouth of a bottle while the cork is being inserted allows the cork to be screwed home, air escaping by its sides; it can subsequently be pulled out. 


\section{HA PTER I V}

\section{THE PLANTS}

\section{A.-Floating Plants (Phytoplankton).}

BY V. H. BLACKMAN.

THE marine algæ, commonly called "seaweeds," found growing along the sea-coasts, are from their size the most conspicuous plants of the sea. Apart from these shore algæ, which are naturally fixed in position, there are an immense number of plants, practically all of them microscopic, which are found floating free in the sea.

These floating plants, known as phytoplankton, with very rare exceptions are the only form of vegetable life found over the deeper waters of the ocean, where the "fixed" algæ are naturally absent, for, except for accidental floating structures, there is no suitable "hold" other than the sea-bottom. The latter, however, is not available, for the absence of light at any considerable depth precludes the growth of vegetable organisms, for which some degree of illumination is absolutely necessary.

The phytoplankton is clearly of the greatest importance in the general economy of the ocean. In the sea the same rule holds as on land-all animal life is dependent, either directly or indirectly, on vegetable life. The vegetable organisms are the only ones which are able to obtain nourishment without preying 
upon the bodies of other animals or plants. They are able to manufacture their own food from the simple gases and mineral substances in the water. The external " power," by means of which their " foodfactory " is run, is in the light of the sun, which they intercept by the help of various colouring matters. The plants of the sea are thus able to increase and grow independently of the other marine organisms, and so ultimately they must be the source of the food-supply of all the animals which can only live by preying upon one another or upon plants.

The colouring matter used to trap the light is on land nearly always a green one; in coastal plants it may be green, red, or brown; in the open sea most of the members of the phytoplankton show a brown pigment. Only a few are green.

Collection.-The phytoplankton is, of course, collected in the same way as the animal plankton. For the various types of nets, etc., reference must be made to the section dealing with the Floating Animals. Owing to the small size of most of the vegetable organisms, the finest silk gauze, of I8o meshes to the linear inch, should be used. Even then the meshes of such gauze are far larger than many forms of the phytoplanktone.g., the Coccospheres and Rhabdospheres, and the smaller Diatoms-so that quite 50 per cent. of the possible catch may escape. The capture of all, or nearly all, the phytoplankton in a sample of water can only be achieved by slow and elaborate methods (filtering through special filter paper or through a porous filter of the Chamberland type), which are not suitable for use on board ship or for any considerable bulk of water. It is to be noted that nets which have been in use a few times become less permeable; this is due to the pores becoming reduced 
in size by fragments of Diatoms and other organisms, which become entangled in the meshes; the efficiency of the net as a filter is thus reduced, and the total catch becomes smaller in quantity but contains organisms of smaller size than were captured when the net was new. The decrease in permeability in such nets is progressive with use, so that finally they will hold water like a bucket. Such nets should be discarded, or washed by rubbing gently in soap and water, though after such treatment they are liable to rupture in use. For the care of silk nets, see p. 189 .

Owing to the small size of the plants, the phytoplankton suffers less damage than the other organisms when collected from the water pumped through the ship's hose. This method, however, is not to be recommended if any other is available, as the organisms always suffer some damage from the rough treatment to which they are subjected. The fact that a certain amount of grease from the ship's pumps always finds its way into the collecting net, and that the water necessarily comes from one particular depth, -that of the intake-are also further objections to the method.

For the capture and detention of the minutest plants numerous special methods have been devised, but so far as we know not even their authors are as yet wholly satisfied with them. For collection at the surface, nothing is better than to dip up a series of buckets full of water, and to empty them into a filter of closely woven undyed silk fabric (not a boltingcloth). Below the surface, but still at small depths, Lohmann has used a hose lowered to a known depth, and by a small hand-worked centrifugal pump delivering into a filter, has obtained very good results. 
From greater depths Kofoid's water-bottle brings up 20 litres of water, a quantity sufficient to yield a fair sample of the minutest forms. The instrument is, however, rather expensive (about $£ 20$ ).

Preservation of Material.-If only the larger forms are required, the catch can be treated in the same way as the other plankton (p. 367). A solution of formalin (I part in 6 to Io of water) is perhaps the best general preservative, but will dissolve the lime in Coccospheres and Rhabdospheres.

Nature of Phytoplankton.-The representatives of the marine phytoplankton fall into six main divisionsDiatoms, Peridiniales, Pyrocystales, Coccosphærales, Green Algæ, Blue-Green Algæ (Cyanophyceæ), and Bacteria. By far the larger number of forms are found in the two first groups.

The Bacteria are a very special group of plants, mostly colourless, which, owing to their excessively minute size, are not secured by the ordinary methods of capture, and so will not be dealt with here.

Diatoms.-Organisms of this class are found in all marine water, and sometimes in such enormous numbers (for example, in Scotch lochs at certain seasons) that a net, which is towed only for a short time, is found after draining to be partly filled with a pasty brown mass.

The distinguishing feature of all the diatoms is the possession of a translucent coat or shell, consisting mainly of silica. The shell is made of two halves, which, in the case of circular forms, fit into one another like the top and bottom of a pill-box, the edge of one portion overlapping that of the other. In some forms the double nature of the shell is clearly visible, while in others it is hardly distinguishable. Inside the transparent shell is the living body of the plant, of 
which the only conspicuous portion in the fresh state are a number of bodies of a brown colour. These brownish bodies, though very variable in size, shape, and number, according to the form examined, are always present. They are called "chromatophores" (colour bearers), and play a very important part in the life of the plant, for they enable it to intercept the light of the sun, and the "power" thus obtained is used in food manufacture.

The form of the plant itself is exceedingly variable. It may be circular and disc-like, or elongated; in the latter case it may be boat-shaped, or very narrow like a needle, and it may be pointed at one or both ends. Some forms exhibit large projections, often of very considerable length and very fine and hair-like. In many forms the surface of the coat is not perfectly smooth, but shows markings in the form of pits or slight projections; such markings are often arranged in most regular and beautiful patterns. The advantage obtained by the possession of these outgrowths is the increase of the surface of the organism, with the result that it sinks more slowly in sea water, which is of less specific gravity than itself. These plants, possessing no organs of movement, are at the mercy of currents and of changes in the specific gravity of the water. If they sink below a certain depth the light which reaches them is so feeble that their life-processes cannot be carried on, and they soon die. Possibly, also, the spinous projections may deter certain animals from devouring the diatoms so provided (Figs. 33-37).

We find that while the majority of forms live singly, others are united together into colonies, very commonly forming chains (as in Chætoceras), or having other less regular forms. 

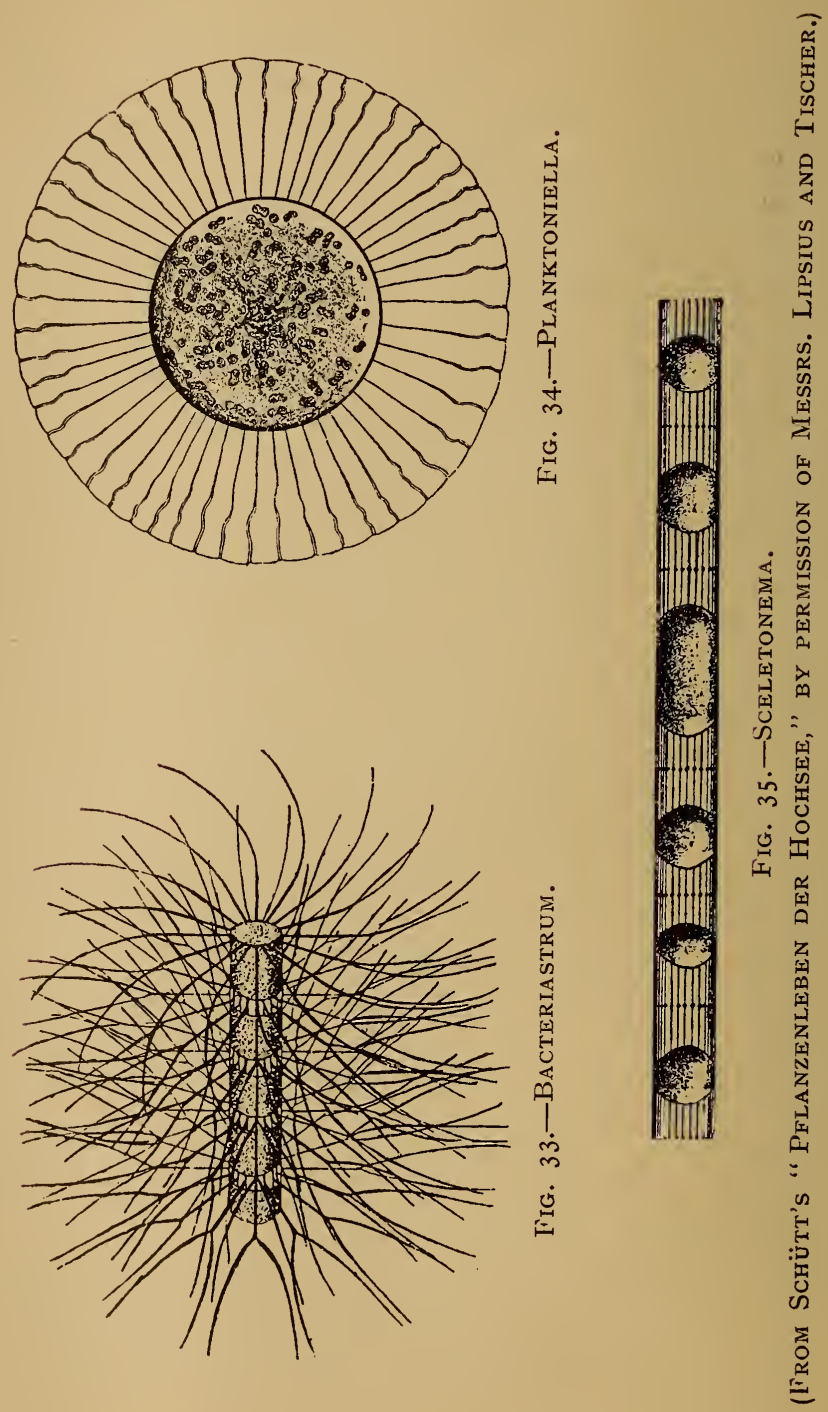


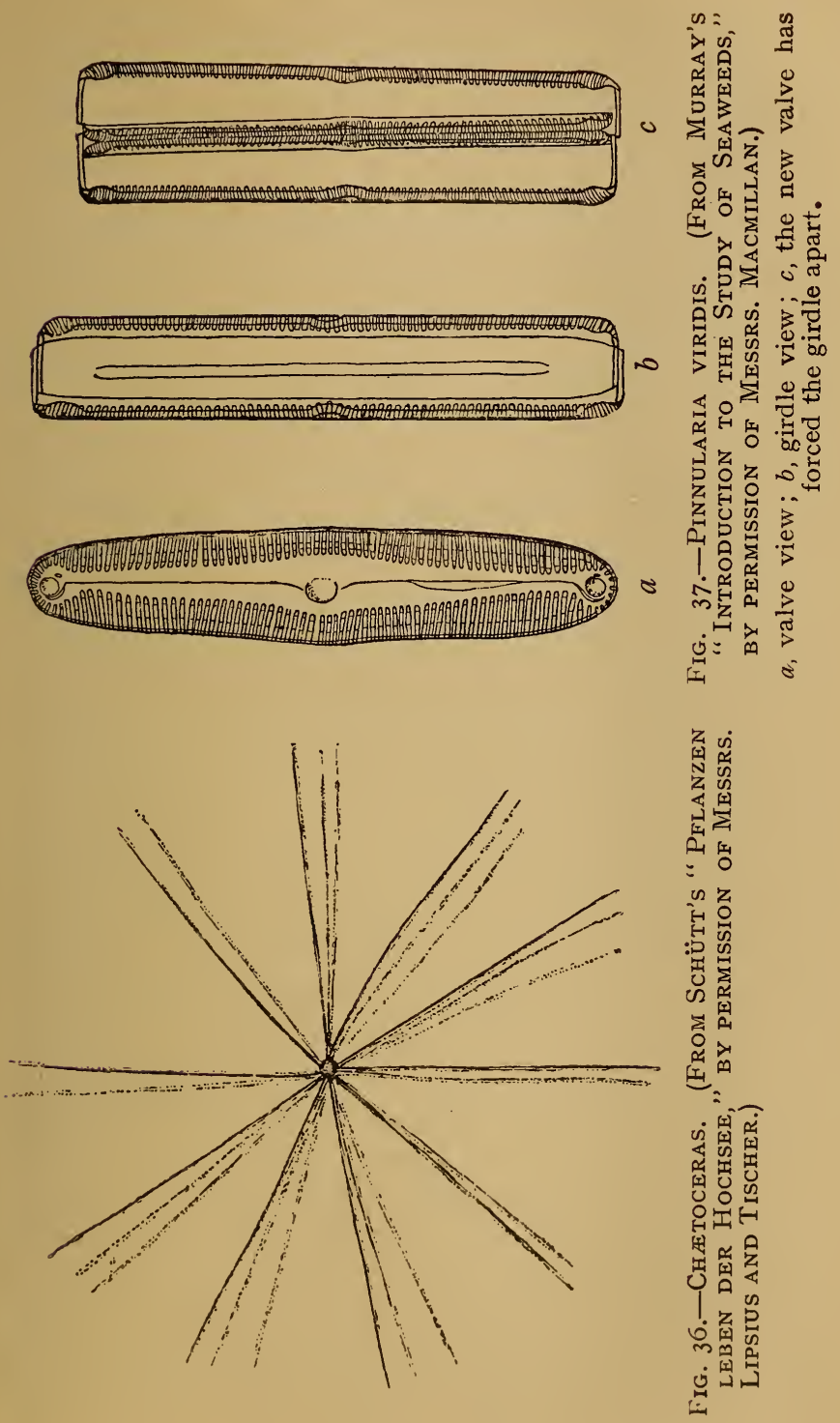


Peridiniales.-This group includes a very large proportion of the phytoplankton. The Diatoms seem to be the chief constituent of the phytoplankton in colder waters, while the Peridiniales seem the more conspicuous group in warmer seas.

The members of this group are easily distinguished from the Diatoms. Their wall is generally less transparent, so that the contents are not so clearly seen; and it is marked out, not into two portions merely, but into a number of angular plates fitting closely together. The plates may be smooth, but are usually marked with a number of pits. The walls consist not of silica, but of cellulose, the substance which is the main constituent of paper. Running round the body of the plant is found a well-marked groove, the horizontal furrow, which is connected at one point with a pore in the shell. From this aperture there grows out from the living substance of the body a long, whiplike swimming organ, the flagellum, which projects freely into the water. Arising from the same aperture is another flagellum, which lies in the horizontal groove ; these flagella can only be seen with considerable difficulty. The position of the horizontal groove varies much in different forms. In some cases, as in Ceratium (Fig. 38), it divides the body into two equal halves. In other cases the furrow is found quite at one end of the body; it may also occupy all intermediate positions. Running up from the pore there is usually a short longitudinal furrow, which is, however, far less conspicuous than the horizontal one.

The form of the body is wonderfully diverse in this group, Nature seeming to have given herself a free hand in the development of the most bizarre shapes. Some possess long, thin spines ; in others the body is enormously elongated, or rounded and swollen; others 
possess large, winglike outgrowths or frills round the horizontal furrow, etc. (Figs. 38, 39, 4I). The majority of the Peridiniales possess a yellow-brown pigment very similar to that of the Diatoms. The colouring matter is confined to small bodies, which lie in the living contents of the plant.

The Peridiniales reproduce themselves by division into two. In some cases the two new individuals do not separate from one another, but divide further, with the result that chains are produced, as in Ceratium.

Many of the Peridiniales are capable of emitting light, and the luminosity of the colder waters is mainly due to these forms.

Pyrocystales.-In this small family we find an interesting form-Pyrocystis-which owes its name to the fact that under certain conditions it is brightly luminous. The diffused luminosity of the sea in warmer regions is largely due to this organism. Pyrocystis is found in most tropical and subtropical regions where the temperature is above $68^{\circ} \mathrm{F}$. There are two chief forms-P. pseudonoctiluca and P. fusiformis. The former is spherical and about 0.6 to 0.8 millimetres diameter. It possesses an outer transparent coat of cellulose, and the internal contents are tinged brown (Fig. 45).

P. fusiformis has a similar distribution to that of the other species, but has an elongated, boat-shaped form.

Green Algæ.-There is in the open sea only one common member of the ordinary green algæ, which are so common on the land. This is a beautiful plant with a globular body, known as Halosphæra viridis, found in the warm and temperate waters of the Atlantic and Mediterranean. It has an outer transparent wall, 

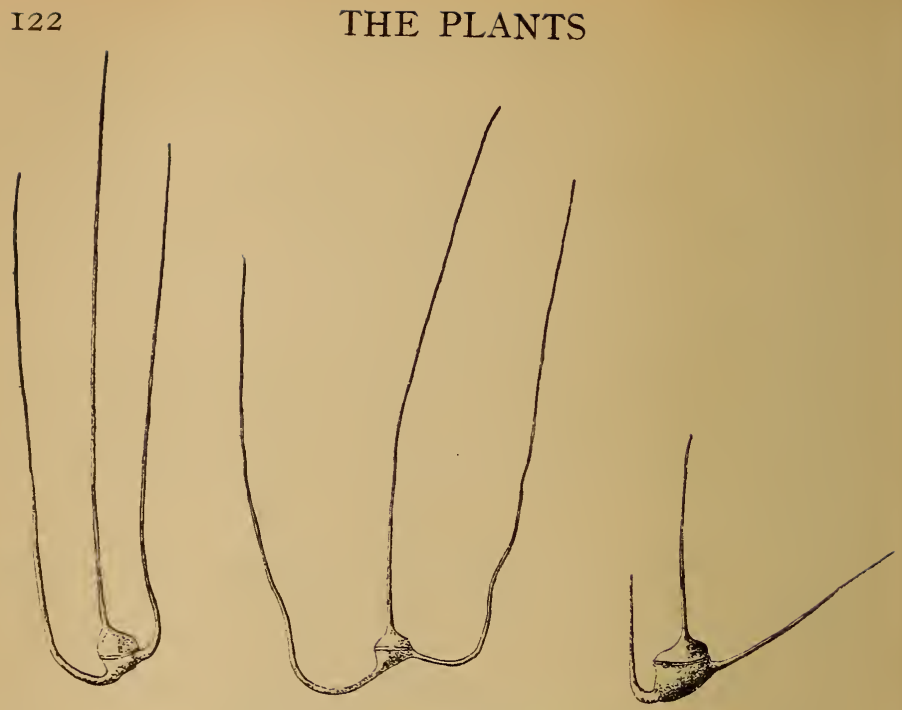

Fig. 38.-Types of Ceratium.

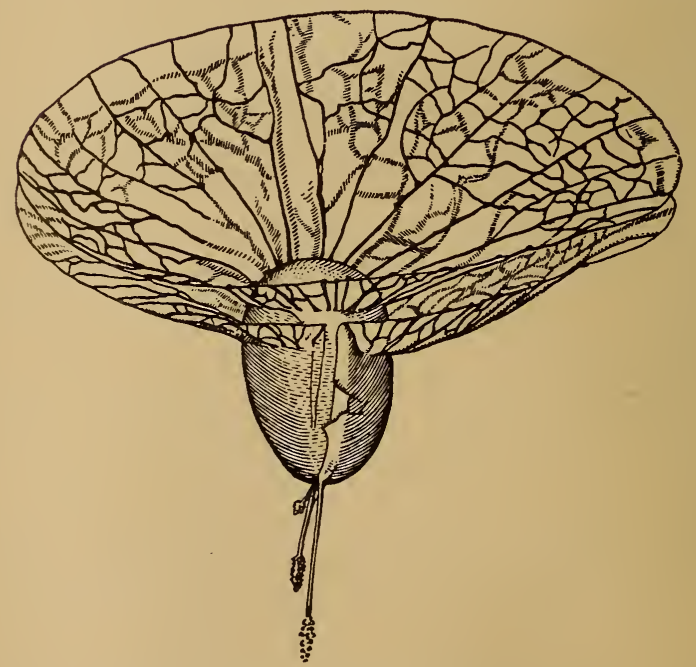

Fig. "39.- Ornithocercus. (Both Figures from Schütt's "Pflanzenleben Der Hochsee," By Permission of Messrs. LIPSIUS AND TISCHER.) 


\section{FLOATING PLANTS}

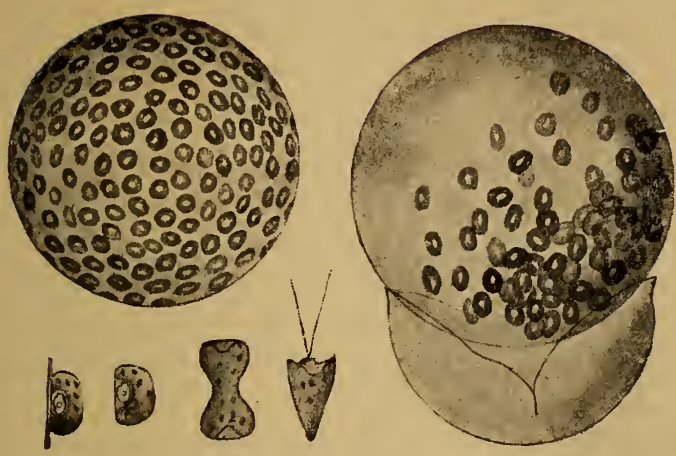

Fig. 40.-Halosphera. (From MURRay's "INTROdUction to THE Study OF Seaweeds," By PERMission OF MEssRs. Macmillan.)

In the sphere on the left the protoplasm has gathered round the nuclei lining the wall; that on the right has shed the outer membrane, and the daughter cells have separated from the wall; below are four stages in the development of the zoospores.

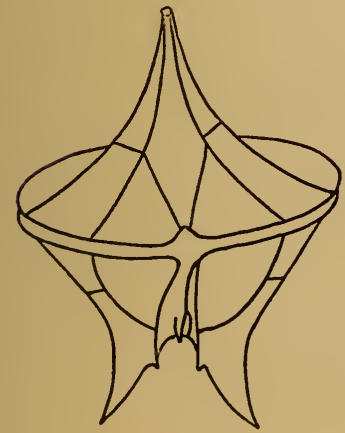

FIG. 41 .

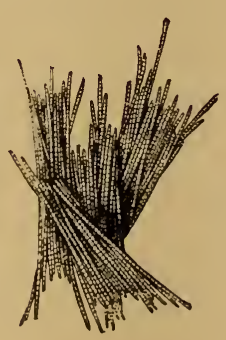

FIG. 42.

Peridinium. (After Cleve.) Trichodesmium ("Blake”). 
which encloses a living body containing a number of disc-like green structures (Fig. 40).

Blue-Green Algæ or Cyanophyceæ.-A small number of the members of this group are pelagic, though most live in fresh water. They sometimes occur in enormous numbers in tropical seas, forming large floating masses. They are usually threadlike, and arranged in groups or bundles. One form, Trichodesmium erythræum (Fig. 42), is of a reddish colour, and probably accounts for the special name of the Red Sea, for periodically it occurs in enormous quantities in those waters.

Coccolithophoridæ.-These forms, on the border line between animals and plants, are very minute, and are only met with occasionally in plankton caught in the ordinary way, since their size allows them to pass easily through the meshes of the finest silk net.

There are two chief forms, known in oceanic waters-Coccolithophora (Coccosphæra) and Rhabdosphæra. When fresh they contain one or two brown or greenish plates; frequently, however, they appear as mere skeletons, consisting of a number of closely arranged plates forming a spherical body. The plates are perforated in the centre in Coccolithophora, and have each a central projection in Rhabdosphæra (Figs. 43, 44). The plates consist of calcium carbonate (chalk), so that the organisms are lost if the material is preserved in any acid fluid.

As only the waters of the Mediterranean have been investigated for these forms by methods other than ordinary tow nets, it would be of great interest to discover their distribution in oceanic waters generally.

For the minute forms, with which a filter is used, set the filter so that it never runs quite dry, but that 
a few centimetres of water always remain at the point of the cone. Into this wash down the sides of the filter with a pipette, so as to remove any specimens which may have stuck there. This water can then be

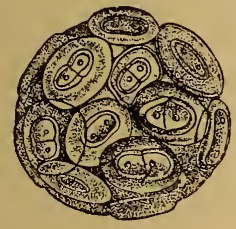

FIG. 43.-CoccosPH瓜A ("BlakE").

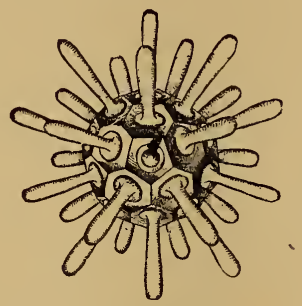

FIG. 44.-RHABDOSPHÆRA ("BlakE").

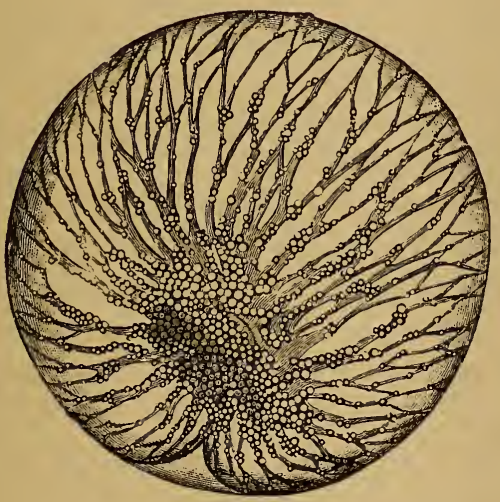

Fig. 45.-Pyrocystis Noctiluca ("Challenger").

poured off, or by perforating the tip of the cone run off into a bottle, for preservation with spirit or other chemical.

If a paper filter be used it should be of the specially " hardened " paper (Schleicher and Schull's, to be had from dealers in chemical apparatus). 


\section{B.-Fixed Plants.}

BY MRS. DR. A. WEBER-VAN BOSSE.

After a storm heaps of plants are cast ashore by the sea, especially if the coast is rocky. On closer examination, these entangled masses are found to consist of green, brown, purple, or bright red plants.

What are these? Where do they live?

These bright-coloured plants are algæ, or flowerless plants, distinguishable by their colour and various shapes from marine flowering plants; the latter have, as a rule, narrow, long, linear leaves of a dark green colour, as, for instance, the common sea grass, Zostera marina, so well known on English coasts.

This section treats only of attached or fixed marine algæ, not of the (mostly microscopical) drifting algæ belonging to the plankton. A few words will be said of algæ growing in brackish water, its interesting flora showing the influence of the changing medium; for some marine algæ migrate through brackish water into fresh water, which has, besides, a rich flora of its own.

Algæ can assume the most different shapes; their fronds may be either simple or branched filaments (Chætomorpha, Cladophora, Polysiphonia), or expanded membranes of various colours, composed of one or more layers of cells (Monostroma, Ulva, Porphyra) ; they may have the form of a smaller or larger bush with stem and branches (Splachnidium, Desmarestia, Delesseria) ; or look like a delicate bit of lace (Vanvoorstia, Claudea) ; or be composed of a long, flexible stalk, bearing long linear blades at its swollen top (Ecklonia buccinalis). Again, others form crusts, adhering closely to the substratum (Ralfsia, Hilden- 
brandtia), or have fronds entirely solidified with carbonate of lime (Lithothamnium, Corallina).

The diversity of their " thallus" (as their fronds are usually called) is enormous; some are so small that they nearly escape our notice, and others so large that stem and leaves have a length of hundreds of feet. But however great their outward diversity may be, their inner structure is comparatively simple, and built up of either thin- or thick-walled cells. Nowhere do we find a differentiation of these cells into vascular bundles, as in flowering plants. Neither have algæ any true roots that can be compared to the roots of flowering plants; their holdfasts are in many cases a few rootlets or a whorl of so-called hapteres; other algæ fix themselves with a smaller or larger disc on the substratum, and algæ growing in sandy bottom have long, hairlike, much-branched rootlets which fasten themselves to the grains of sand, and enclose so many of them that, when the plant is withdrawn from the sand, its rootlets present the appearance of a large lump.

Algæ have various colours, and in accordance with these they are divided into:

I. Blue algæ-Myxophyceæ or Cyanophyceæ.

2. Green algæ-Chlorophyceæ.

3. Brown algæ-Phæophyceæ.

4. Red algæ-Rhodophyceæ or Florideæ.

We must bear in mind, however, that, though this division is right in the main, there are many algæ that do not show the colour of the group to which they belong. Blue algæ living in deep water may become red; red algæ may turn purple, brown-red, green, or even yellow, on being more or less exposed to the glare of the sun; but with a little practice the group to 
which a certain alga belongs is easily recognised; for differences of structure and fructification correspond with the differences of colour.

Algæ are found on all coasts in both hemispheres if the outward conditions are favourable for their growth. We find them in the Arctic as well as in the tropics, forming a more or less well-defined belt along the coast. Some algæ grow so high up that only the spray of the sea as it is dashed upon the beach or against the rock can reach them; others live in deeper water, from which only a dredge can bring them up. This belt of algæ is divided into two regions : the littoral region, comprising that tract of the coast which lies dry at every ebb tide; and the sublittoral region, comprising all vegetation below low-water mark. The algæ of the littoral region are adapted to a period of exposure at every ebb, the algæ of the sublittoral region to a continually submerged existence. Both the littoral and the sublittoral regions are again divided into an upper and a lower zone, according to the different algæ found in each ; for, though many algæ have a wide distribution, yet almost every species has its own privileged locality in a vertical, as well as in a horizontal, direction.

Its internal organization and the external natural agencies determine the place it will occupy. These external agencies are light, the nature of the bottom, the salinity of the water, the strength of the currents, etc., and a few remarks may here be given about them. To understand their influence well, one has to study different localities, for agencies exercising a certain influence on the coast of Greenland will have an entirely different effect in the tropics, according to their different combination.

Light is the chief factor ; every plant wants light to reduce the carbonic acid needed for its existence. 
Some algæ may want more, others less; but without light no vegetation can exist. The depth to which rays of light penetrate the sea is the depth to which algal life is limited. But this actual limit gives us no idea of the quantity of light each alga needs to thrive well. Each alga has three limits with regard to light : an optimum, a maximum, and a minimum limit. The optimum limit is that degree of light in which a given alga thrives best; the maximum limit indicates the strongest, and the minimum limit the feeblest, degree of light in which the same plant contrives to live. The four groups of algæ just mentioned have different optima with regard to light. The blue and green algæ live in the upper part of the littoral region; the brown algælove the sunny places of the lower littoral and the upper part of the sublittoral region; and red algæ prefer deep or sheltered localities; although many of the last class live also in places exposed to the glare of the sun, they lose their bright red colours in these exposed localities. Whether it is the quality of the light (blue and violet rays penetrating deeper than red and green ones), or whether it is the quantity of light penetrating the sea that influences the colour of the algæ, is a question still open to controversy.

Depth.-The lower littoral and the upper zone of the sublittoral region are the richest in algæ; the upper littoral zone and the lower sublittoral are relatively poor in algæ. The greatest depths from which algæ have been recorded are near Capri at 66.5 to 7 I fathoms; near Minorca, 90 fathoms; near Spitzbergen, I50 fathoms ; in the Barents Sea, I75 fathoms ; in the Antarctic, 55.5 to 85.5 fathoms ; and south of the Cape, at 40 fathoms. Probably, however, the algæ found near Spitzbergen, and in the Barents Sea, will have sunk into these depths from shallower localities. 
The Bottom is another factor of great influence. A rocky and protected shore is a favourite haunt of algæ, though many species prefer the high surf of the exposed shore. A rocky coast with many tide-pools filled with fresh sea water at every flood, and lying exposed at ebb tide, is a wonderful place for algæ. Collectors should bear this in mind when studying sea charts in search for a fit place where they may expect algæ.

A sandy bottom is poor in algæ, on account of the shifting of the sand by the movement of the water, and only species with long hair-like rootlets can contrive to live in it. For the same reason, algæ avoid places covered with fine mud. If, however, a bit of stone or wood rises out of the mud, it will soon be covered by algæ.

Salinity.-Sea water contains, on the average, in the open sea from 3.5 to 4 per cent. of salts ; but on approaching the coast this percentage decreases in different degrees, according to the quantity of fresh water brought, by land drainage, into the sea. Marine algæ flourish luxuriantly in this medium, but if the percentage of salt falls considerably-for instance, when big streams pour their fresh water into inland seas (Black Sea, Baltic Sea, White Sea), and the water becomes brackish-true marine algæ grow scarce. The transition from a rich algal vegetation to a poor one is, however, gradual, and such inland seas or big estuaries are interesting spots for investigation. Marine algæ have an optimum, maximum, and minimum limit, with regard to salinity as well as with regard to light, and those limits lie for some species far asunder.

The Movement of the water influences also the growth of algæ. Some like places where the tidal waves rush along the coast; others prefer exposure to the high 
surf of the sea ; and, again, others thrive well only in quiet pools. Algæ are admirably adapted to profit by, or to withstand, the strong force of the waves. Some surf-loving algæ have long flexible stalks that follow the movement of the water, while the blades at their top swing to and fro in the waves; other algæ in the same locality can withstand the action of the waves, because their tissues are encrusted with carbonate of lime.

Temperature.-Some algæ can endure great differences of temperature without damage. Kjellman observed in Namëless Bay, Nova Zembla, Enteromorpha minima, a green alga, in fresh water of $0^{\circ} \mathrm{C}$., and in sea water of $4^{\circ}$ to $5^{\circ} \mathrm{C}$. In the tropics the algæ are exposed to the glare of the sun during ebb tide, and in the Arctic regions Kjellman found Laminarix thriving well in a temperature of $-2^{\circ} \mathrm{C}$., and on being exposed at ebb-tide, they withstood even a temperature of $-20^{\circ} \mathrm{C}$.

Algæ want, however, as a rule, a more congenial temperature, and if the coast of Norway has such a decidedly different vegetation from the coast of adjacent Polar lands, this is mainly due to the North Atlantic Drift, whose influence is felt even on the west coast of Nova Zembla. Still more striking, perhaps, is the difference on the west and east coast of South Africa. On the latter, bathed by the Mozambique current coming from the tropics, tropical and subtropical algæ flourish ; while on the west coast, with its Benguela current partly coming from the Antarctic, we find a totally different vegetation. Many more examples might be cited, all showing clearly the great influence which the temperature of the sea has on vegetation. Professor Farlow describes how Cape Cod, in North America, is a boundary between two vegetations. To 


\section{THE PLANTS}

the north of Cape Cod, under the influence of the Labrador current, Arctic and Northern European forms occur ; to the south, with its Gulf Stream, species characteristic of warmer seas. Professor Setchell was able to show that a change in the kelp flora of Western North America takes place with the increase of every $5^{\circ} \mathrm{C}$. of surface temperature.

We touch here upon the question of the geographical distribution of algæ. This is a question wanting careful investigation, for so many agencies exercise an influence on the occurrence of algæ in a given locality. The researches of Berthold in the Gulf of Naples, of Kjellman in the Arctic Sea, of Kolderup Rosenvinge on the coast of Greenland, of Börgesen at the Faeroe Islands, of Svidelius, and many others, have opened a rich field of study with regard to the conditions of algal life and the physiognomy which algæ give to the coast. When searching for algæ, we observe that large stretches of the coast are characterized by one or two-sometimes more-algæ living, in large numbers, under the same outward conditions. Other algæ may be mixed with them, but they are always in smaller numbers, or less conspicuous ; they do not put a stamp on the vegetation, as the others do. Thus, for instance, Ecklonia buccinalis is a most characteristic alga of the Cape, covering large stretches of the coast in the sublittoral region. Little red algæ live parasitically on its stem, but they are entirely hidden under the mass of brown blades floating on the sea. We may call this an Ecklonia " association," and when several associations live under the same outward conditions we speak of a "formation." Börgesen distinguishes, for instance, a formation of encrusting algæ on the coast of the Faeroe Islands, and all encrusting algæ belonging to it live under the same external conditions. 
Börgesen calls it the Hildenbrand tia formation, after the little red alga, Hildenbrandtia, which predominates in it. Such formations and associations can vary endlessly in the different seas, according to the nature of the bottom, the salinity of the water, etc. ; Svidelius has even described, for the Baltic, two detached associations of Phyllophora and Fucus at a depth of 4 to 5.5 fathoms, of which the detached specimens are absolutely sterile and far narrower than the attached plants, growing at a considerable distance, from which the loose ones have been derived. A thorough knowledge of the formations and their components on a given coast is the corner-stone of the study of the geographical distribution of algæ, so interesting in itself because it may help us to reconstruct the former aspect of the globe. By a careful study of the algæ of the Baltic and Arctic Seas, Svidelius arrived at conclusions which strengthen the already existing views of zoologists about a connection of those seas in the Glacial Period. Börgesen has given beautiful photographs of various formations occurring on the coast of the Faeroes.

How much might be done in this line if some of the many photographers of our day took to photographing algæ! The field is still new, and might tempt a spirit keen to surmount difficulties.

It is impossible to give in a few pages a systematic survey of so large a group as the algæ; their systematic arrangement can be studied in books written for that purpose. I will only name the principal divisions, and give their most striking characteristics that are of value for the collector. I will add some figures of very common or very striking algæ, and treat a little more in detail a few families. The questions touched upon will show how interesting those families are, but other 
families are equally interesting from similar or different points of view. Therefore collectors of algæ who are not botanists may feel sure that they can render good service to science if they will only collect carefully, as only well-prepared and duly labelled collections are of value.

The Myxophyceæ, or blue-green algæ, are small, and the least organized of the algal tribe; they are either uni- or multi-cellular. The latter form long filaments enclosed in a common cell-sheath, and dividing, for the sake of reproduction, into several portions called " hormogonia," which move out of the sheath. The young hormogonia secrete a new cell-sheath, and develop by division of their cells into a new filament. Myxophyceæ, after having been collected, should, as soon as possible, be spread out on the paper on which they are to dry, and not left to stand overnight. If this is neglected, the hormogonia will, in all probability, have moved out from the sheaths, and the specimen will be worthless.

Myxophyceæ live, as a rule, in the upper littoral zone, attached to stones, pebbles, or other algæ. Lyngbya majuscula-the mermaid's hair-is sometimes found floating on the sea. Some species of Calothrix (Fig. 47) form patches on the rocks; species of Rivularia have a hemispherical thallus, either solid, from as big as a pin's head to $\frac{1}{2}$ inch in diameter, or hollow and forming soft expansions. Sometimes Scytonema and Lyngbya will cover the rocks with a slippery coating, disagreeable, and even dangerous to the collector when the waves are strong. Myxophyceæ are found in all temperate and tropical seas; their genera and species have, as a rule, a very wide distribution. In the Arctic and Antarctic they seem to be rare. 
Perforating Algæ.-Several Myxophyceæ and a few Chlorophyceæ live in the shells of molluscs, in the skeleton of corals, or in calcareous algæ, where they bring about bluish, green, or violet spots. These " perforating algæ," as they are called, on account of their power to bore into calcareous tissues, are known from the temperate and tropical seas. By their incessant labour they destroy many shells, corals, and calcareous algæ, setting free carbonate of lime.

The Chlorophyceæ, or green algæ, abound in the littoral, and are also found in the sublittoral region. Their usual way of reproduction is by spores, which move by the aid of cilia. Some of these spores conjugate, others germinate without conjugation. Of Caulerpa no reproductive organs are known. Many formations of green algæ are known from the temperate and tropical seas. The filamentous Urospora, Chætomorpha (Fig. 46), Cladophora (Fig. 48), the membranelike Monostroma and Ulva (Fig. 49), the tubelike Enteromorpha, prevail in the temperate seas, while the large group of the Siphoneæ occurs chiefly in the tropics or in warmer temperate seas. The Siphoneæ attain a very high outer differentiation, but each member of this group, however complicated the structure of its frond may be, consists of only one multinucleated cell ; therefore they are called Siphoneæ from their tubular nature. Many Siphoneæ-Halimeda (Figs. 50, 5I), Neomeris, Acetabularia (Fig. 53), Udothea (Fig. 52), Bornetella (Fig. 55), Penicillus, etc. -are encrusted with carbonate of lime, and to this encrustation Halimeda owes its importance as a reefforming organism. The Caulerpæ (Figs. 54, 56) cover the coral reefs with numerous species of multifarious aspect, or live in a depth of several fathoms. Outside the tropics only a few representatives of this family 


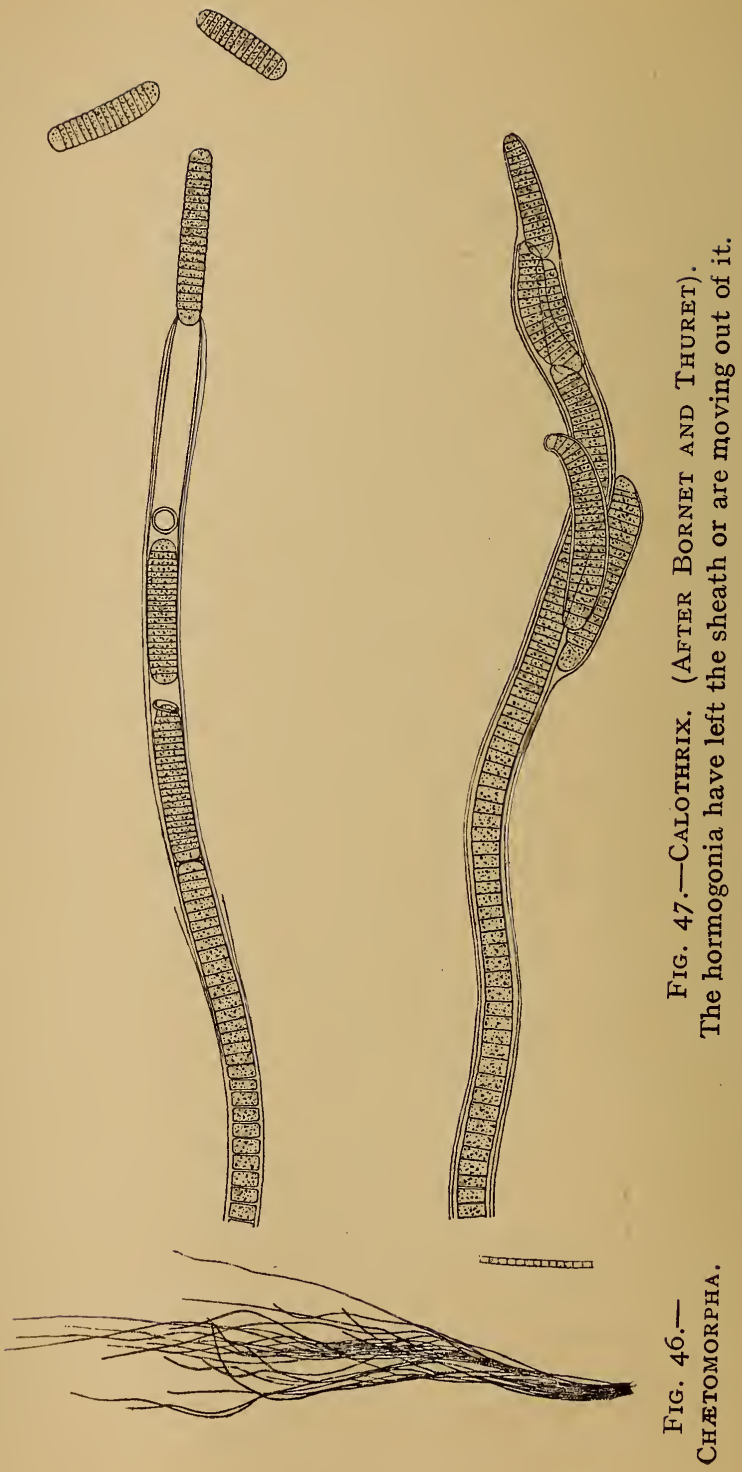


GREEN ALGÆ
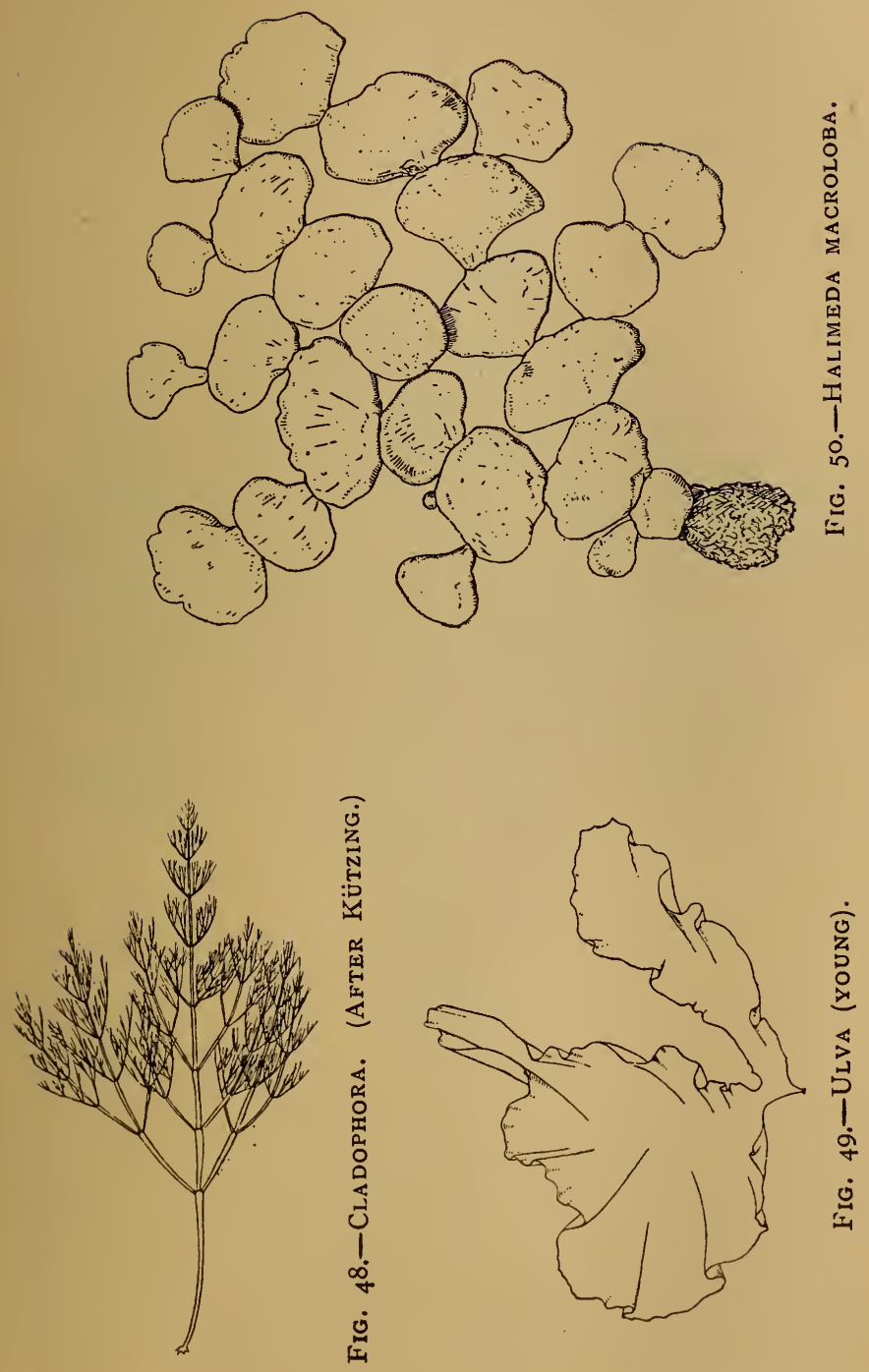
are known; Caulerpa prolifera occurs plentifully in the Mediterranean; three species on the coast of New Zealand; and five or six species along the coast of Japan, in the warm waters of the Kuro Shiwo, the "Gulf Stream" of the Pacific.

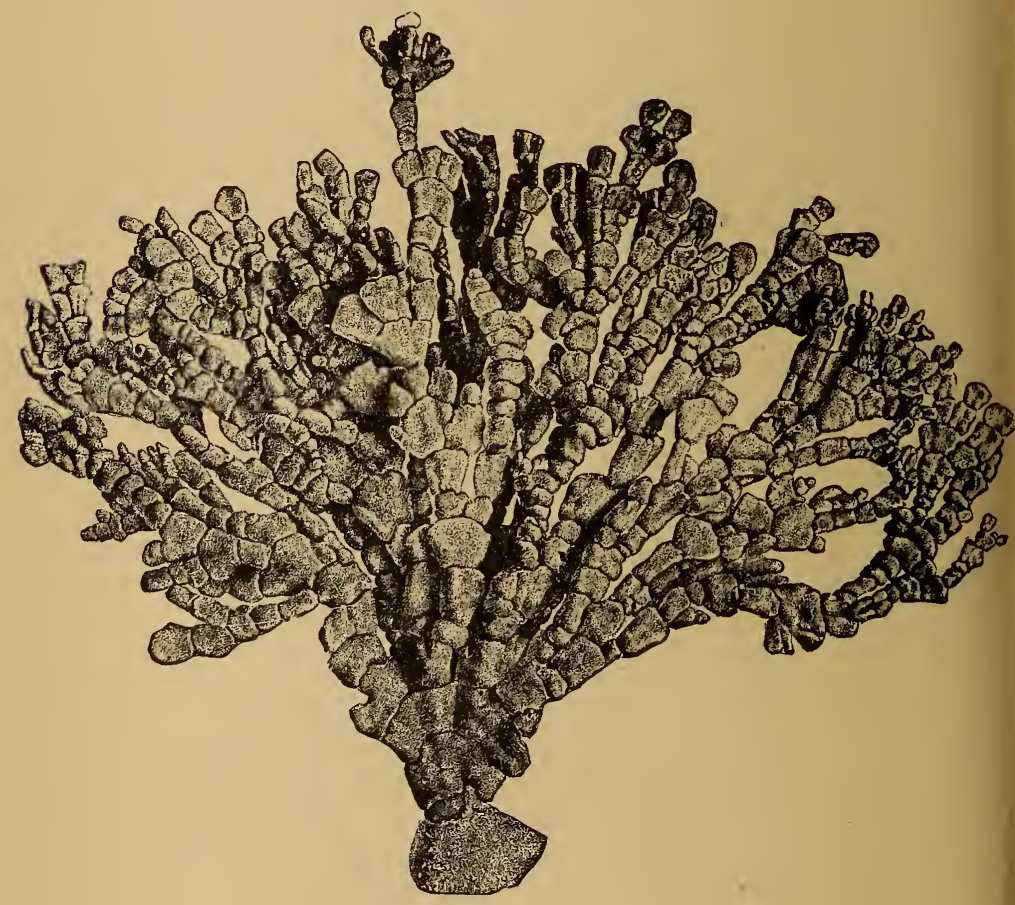

Fig. 51.-Halimeda ("Blake").

To the Phæophyceæ belong the Phæosporæ, the Dictyotaceæ, and the Fucaceæ. The Phæosporæ have conjugating and non-conjugating motile spores, all moving about by the aid of two cilia. To this group belong the greater number of brown algæ: the slender filamentous Ectocarpus family, of which many members 
lead a parasitic life on other algæ ; and the big Laminariæ, the crust-forming Ralfsiæ so easily overlooked; Asperococcus, with its saclike frond; and Cutleria, with its two alternating generations, formerly described as distinct genera under the names of Aglaozonia and Cutleria-they all, and as many more, belong to the Phæosporæ.

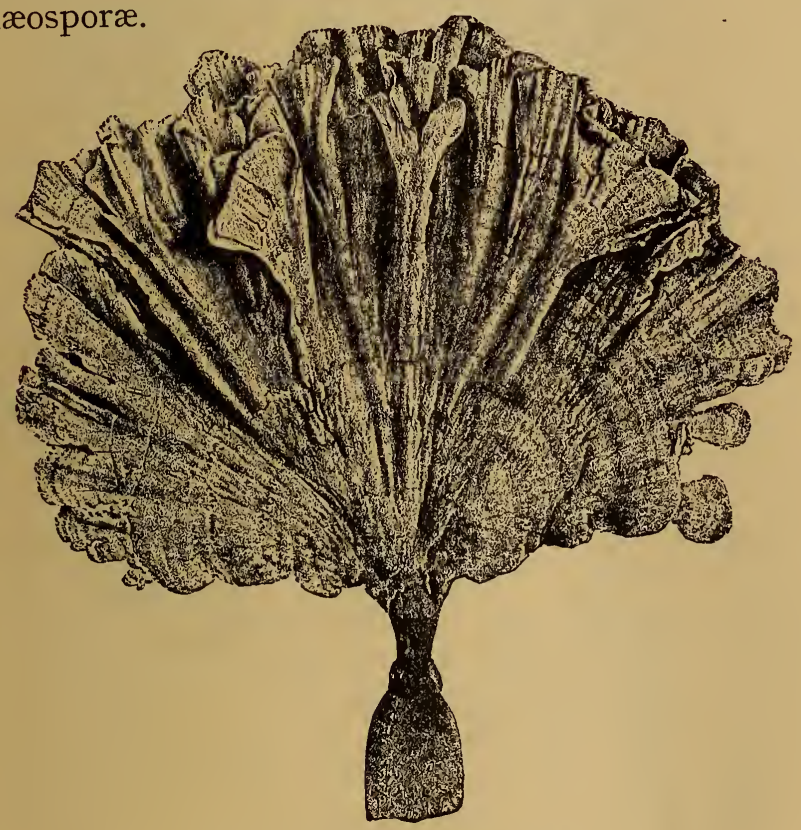

FIG. 52.-UDOTHEA ("BLAKE").

A few details may be given of the family of the Laminariaceæ, or Kelps, this family being chosen because its large members play such an important part in the physiognomy of several coasts.

When young they consist of a hold-fast, a stipe, and a linear or expanded blade, which undergoes many changes in the different genera. They live in the 


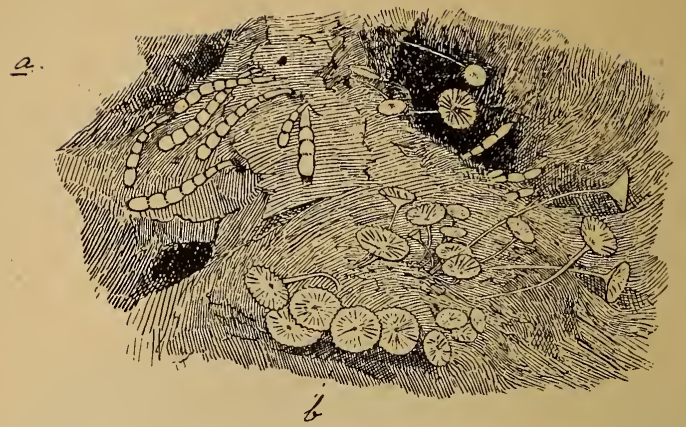

Fig. 53.-(a) Cymopolia and (b) Acetabularia.

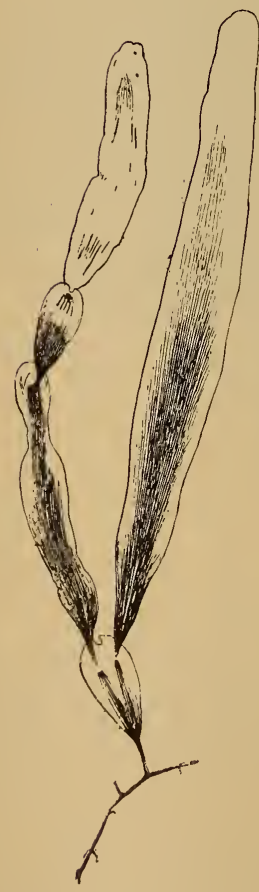

Fig. 54.-CAULERPA PROLIFERA.

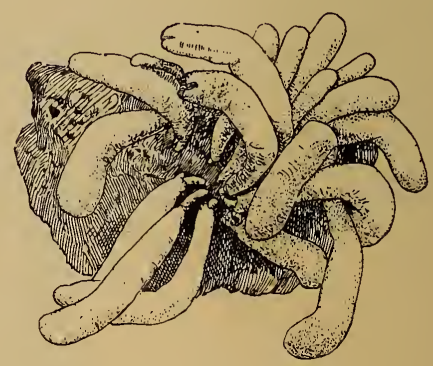

FIG. 55.-BoRnetella.

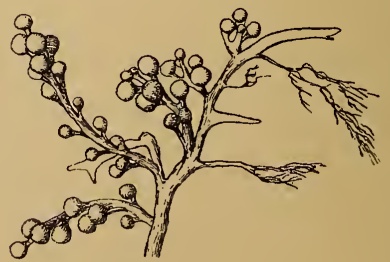

FIG. 56.-CAULERPA RACEMOSA. 


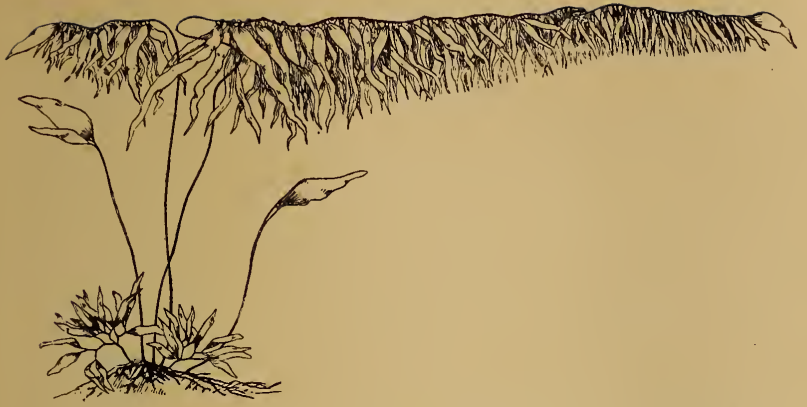

Fig. 57.-Macrocystis. (After Hooker and Harvey.)

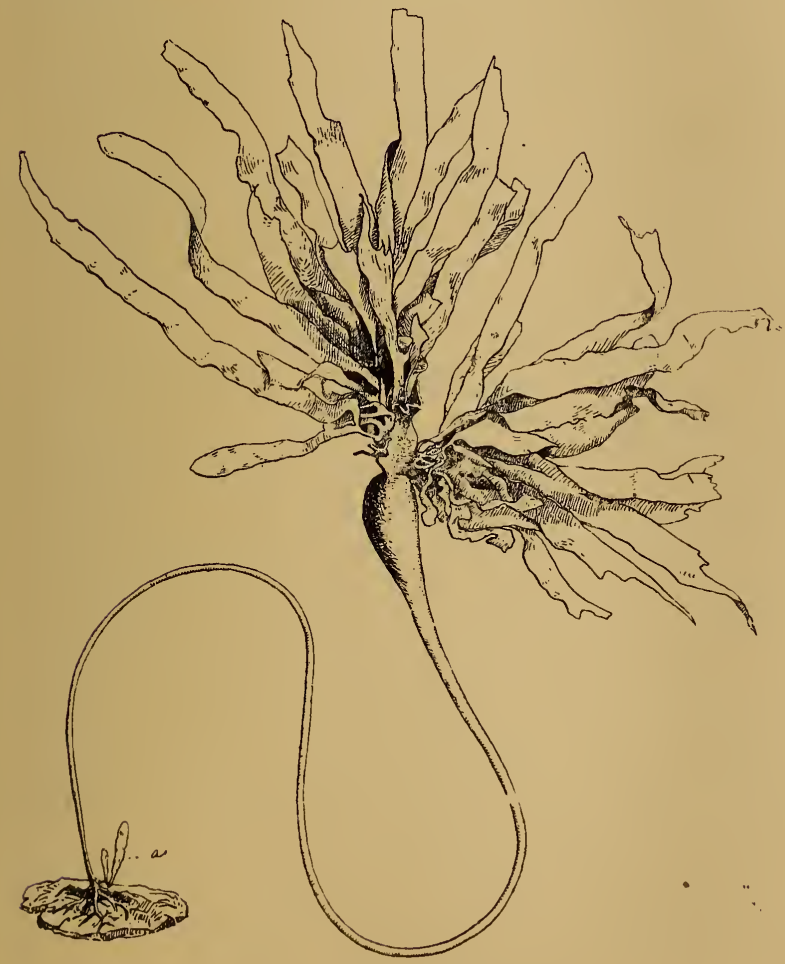

Fig. 58.-ECKLonia. 
littoral and sublittoral zone, though it is reported that Macrocystis pyrifera (Fig. 57), with a frond attaining a length of 200 metres, goes down to a great depth on the coast of Fuegia. They all love exposed places, and Darwin wrote in his "Narrative of the Beagle": "I know few things more surprising than to see the Kelp, or Macrocystis pyrifera, growing and flourishing amongst those great breakers of the western ocean, which no mass of rock, let it be ever so hard, can long resist."

Laminariaceæ avoid the tropics, but occur on almost all coasts in the temperate and Arctic seas. The latter are rich in representatives of Laminaria, Alaria, Agarum; only three Laminariæ are known from the south-west coast of Africa.

Saccorhiza bulbosa (Fig. 62), common on the coast of England and Norway, is the largest European alga, with a height of 2 to 4.60 metres, and a blade of 2 to 4 metres in length.

Lessonia (Fig. 6o) and Ecklonia (Fig. 58) are principally inhabitants of the southern hemisphere, only three Eckloniæ being known from Japan. Lessonia fuscescens assumes, on the south-west coast of America, the habitus of a tree with a height of 3 to 4 metres, and a trunk as large as a man's thigh. From California are known Dictyoneuron, Postelsia, Egregia (Fig. 59), Eisenia, and the gigantic Nereocystis (Fig. 6I).

It is interesting to know that, however different the adult stages of these various genera may be, they are all alike in their youngest stages. This points to a common origin, and collectors gathering Kelps should also look for young specimens, as there still remains much to be explained with regard to the development of these plants.

The Dictyotaceæ have light or dark brown ribbon- 
like or fan-shaped fronds, these latter often splitting up into narrow, long pieces. Their reproductive organs are motionless eggs, and mobile antherozoids contained in antheridia, which form small groups, called "sori," visible to the naked eye, and scattered over the surface of the frond. Padina pavonia has a fan-shaped frond, encrusted with carbonate of lime; it occurs on the English coast with Dictyota dichotoma (Fig. 63). Taonia and Halyseris; but Dictyotaceæ otherwise prefer warmer seas, and flourish especially well in the tropics. Lobospira is exclusively an Australian genus.

Fucaceæ.-The large family of the Fucaceæ is characterized by their non-motile eggs and mobile antherozoids being contained in special conceptacula, immersed either in the frond (Fucus, Fig. 65) or in special fruit-bearing organs (Sargassum, Fig. 66). The form of their fronds is widely different ; many of them have air bladders in the continuation of the frond (Fucus vesiculosus) or special air vesicles, allowing the plant to float on the sea, when it has been torn away from its support (Sargassum). In the Arctic and northern temperate regions Fucus, Pelvetia, Ascophyllum, Himanthalia (Fig. 68), Halidrys cover the coast with a dense vegetation. In the southern region the Laminaria-like Durvillea flourishes (Fig. 67). Australia and New Zealand are very rich in Fucaceæ; we must also mention the necklace-like Hormosira, with its parasite Notheia (Fig. 69). Scytothalia also occurs in the Antarctic. Turbinaria is strictly tropical ; Cystoseira, Cystophyllum, and Sargassum (Fig. 64) belong to the tropical and warm temperate seas. Of the latter genus we must say a few words more, as it has a right to claim the special attention of collectors.

In each complete Sargassum we can distinguish two parts - a short principal axis, with a tuft of rather 


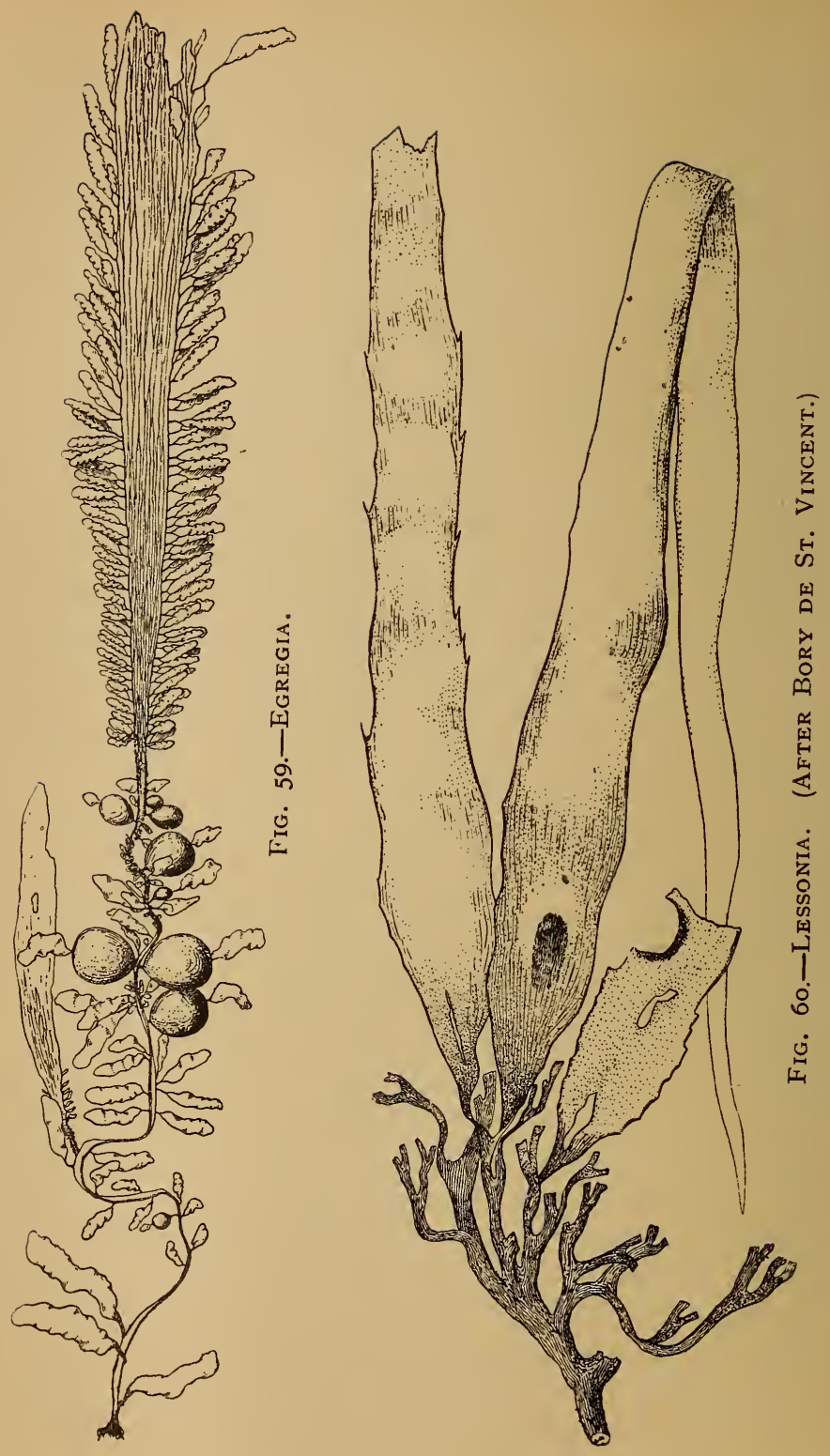




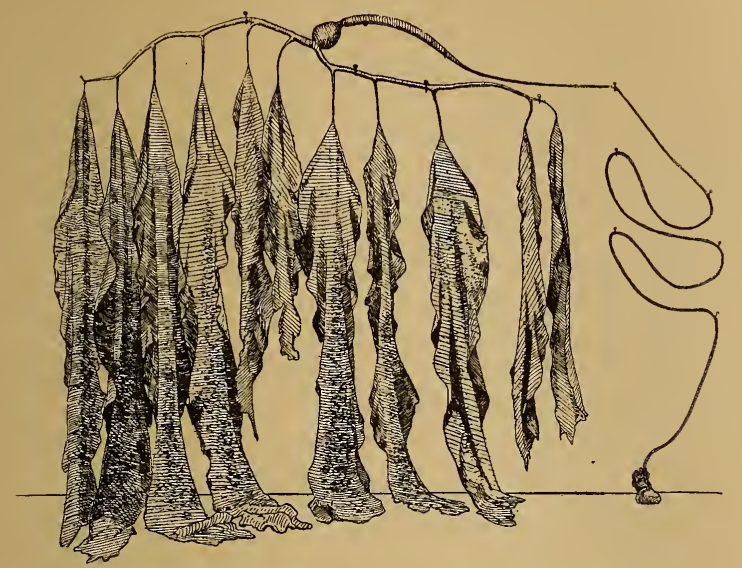

Fig. 6i.-Nereocystis. (After Setchell.)

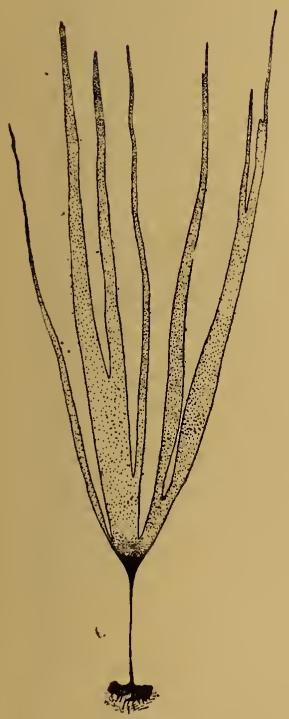

Fig. 62.--SACCORHIZA.

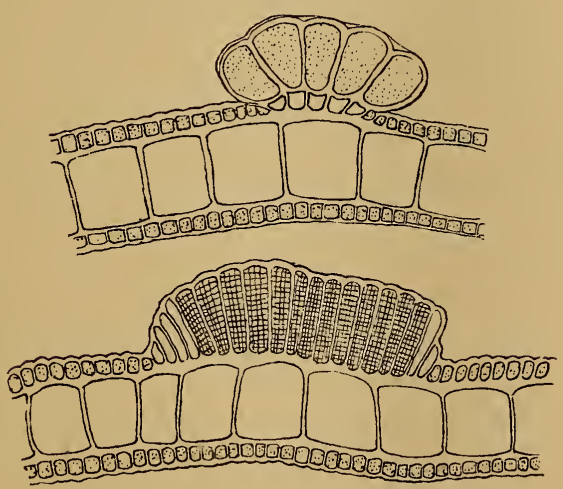

Fig. 63.-Dictyota Dichotoma. (After BORNET AND THURET.)

The sorus above with motionless eggs, below with antheridia. 
broad basal leaves, and long branching shoots of a secondary order, with, as a rule, leaves of different size, air vesicles, and special fruiting branches. When basal and upper leaves differ from each other the transition is gradual. The fruiting branches bear conceptacula which are highly differentiated in the different species. In some species the branches with male conceptacula seem to be cylindrical, and those with female conceptacula dentate, but this question must still be carefully investigated. It is important, because J. G. Agardh divided the Sargassa into various groups, according to the form of the conceptacula-bearing branches.

The genus Sargassum has approximately I50 species, and is distributed over the warmer temperate and tropical seas ; it is especially frequent on the coast of Australia. One species has for four centuries attracted the attention of men of science--Sargassum bacciferum, the alga of the famous Sargasso Sea. Discovered by Columbus, described by Humboldt, the origin of these enormous quantities of drifting seaweed is, after four centuries, still practically unknown. There are two opinions about the origin of Sargassum bacciferum. Humboldt, Forbes, Piccone, A. Agassiz, allow the possibility of the present Sargassum bacciferum being the floating form of one or more Sargassa that lived attached in a former period of the earth. If this were true, S. bacciferum should have propagated itself vegetatively for long ages, because it has been collected almost always in a barren state. Krümmel is of another opinion. In his beautiful work, "Die Reisebeschreibung der Plankton - Expedition," he gives a very interesting chart of the distribution of $\mathrm{S}$. bacciferum in the Atlantic, thereby dispelling the error of Humboldt, who believed in the existence of two fixed banks of Sargassum. Krümmel assures us 
further, on the authority of Kuntze, that S. bacciferum and $\mathrm{S}$. vulgare are identical, and he believes that $\mathrm{S}$. bacciferum is the floating form of S. vulgare, which occurs plentifully on the coast of the Bermudas. But against this opinion Sauvageau has protested most energetically; he maintains that S. bacciferum and $\mathrm{S}$. vulgare are not identical. By his kindness, for which I hereby wish to express my sincere thanks, I am allowed to make use of letters written to him by the American algologists, Farlow and Collins, who have studied the flora of the American seas, and agree that S. bacciferum and S. vulgare are different plants. Mr. Collins, in speaking of S. vulgare, says: "The plant in question grows attached in shallow water; I do not think it occurs floating, except as any other alga that is washed ashore when torn from its fastenings, but not continuing to live in a floating state." According to Professor Farlow, it might be possible that $\mathrm{S}$. bacciferum is a floating form of S. lendigerum, common in the Bermudas, but this is only a supposition ; and Collins, again, says, speaking of S. lendigerum, that its shoots soon perish after having been detached.

Farlow, Collins, and Howe agree that S. bacciferum does not occur on the coast of America growing attached.

It is clear that intelligent collectors could do much to forward our knowledge of the Sargassa. They should try, above all, to bring home entire plants, with rootlets and basal leaves as well as with the long secondary shoots, and not forget that fruit-bearing branches are of great interest.

Rhodophyceæ.-The greater part of marine algæ are Rhodophyceæ; they are usually small in size, with the exception of some species of Halymenia, Gigartina, Iridæa, etc. They are, as a rule, soft and slippery to 


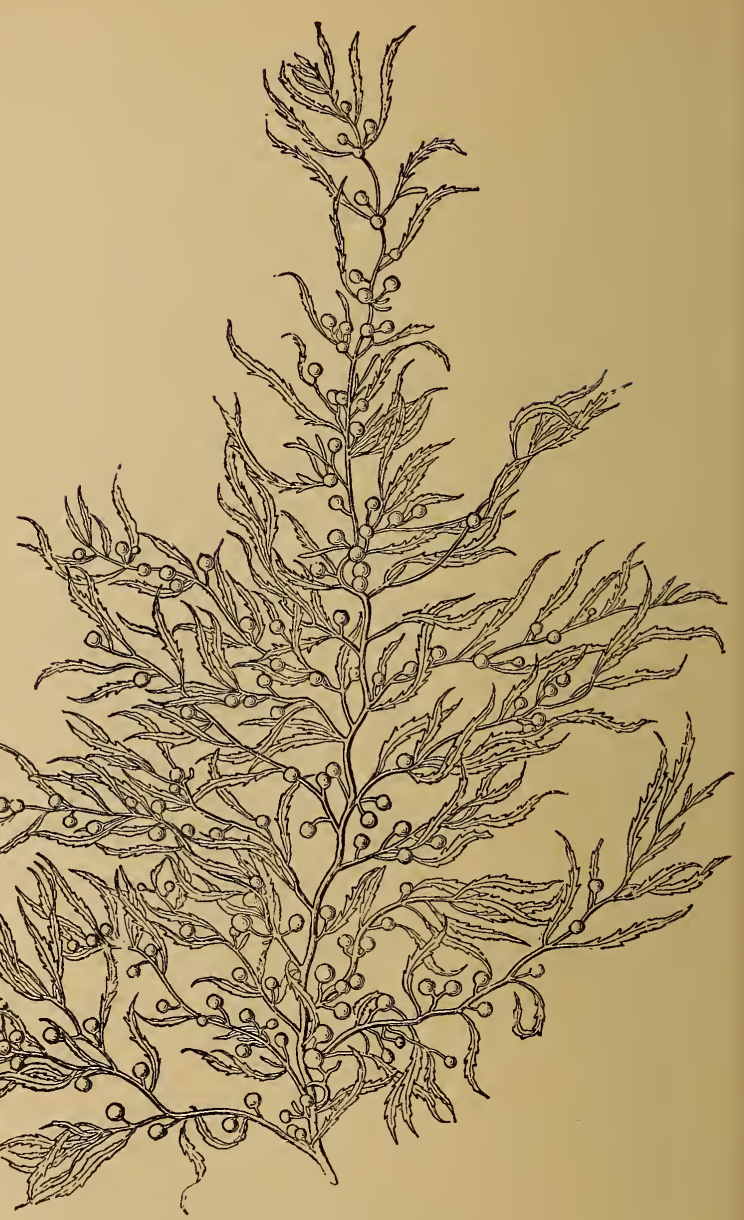

FIG. 64.-SARgASSUM ("Blake”).

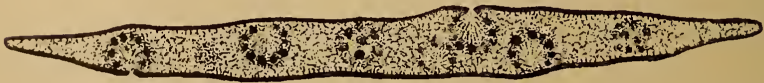

Fig. 65.-Section through Frond of'Fucus. (After BORNET AND THURET.) 


\section{BROWN AND RED ALGÆ}
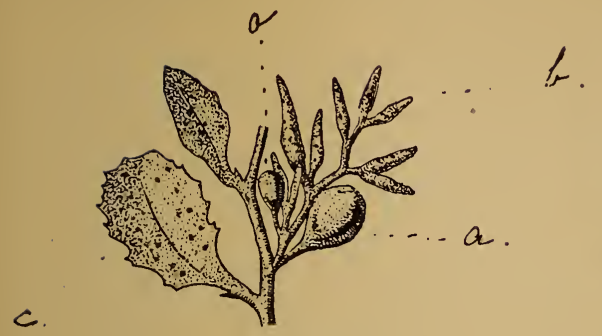

FIG. 66.-SARGASSUM.

$a$. Air vesicles; $b$, cylindrical conceptacula ; $c$, leaf.
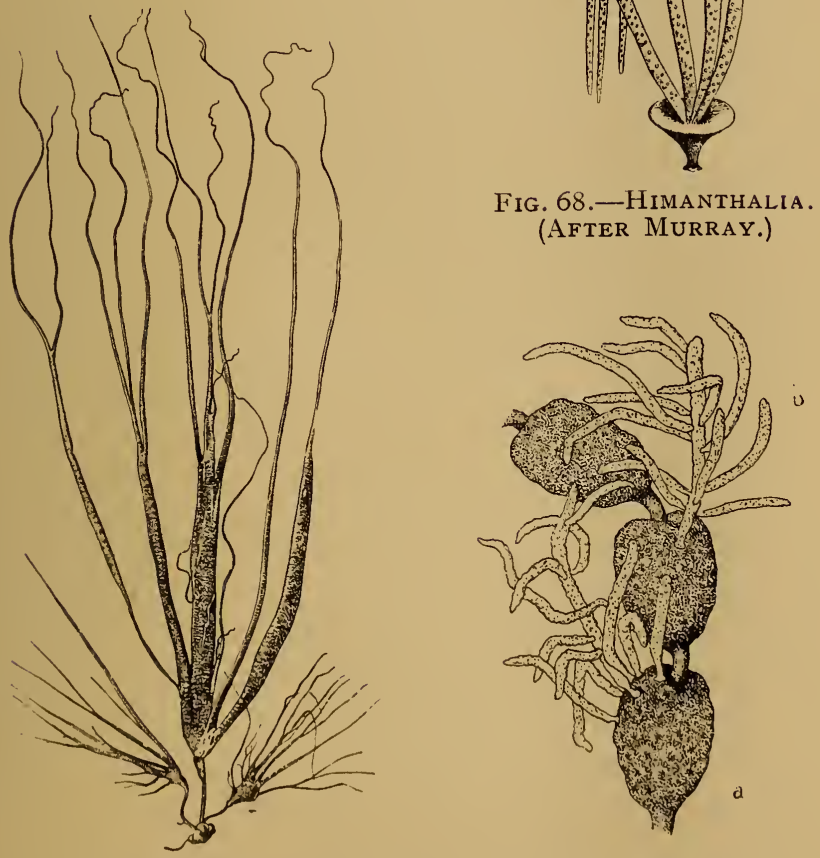

(After Murray.)

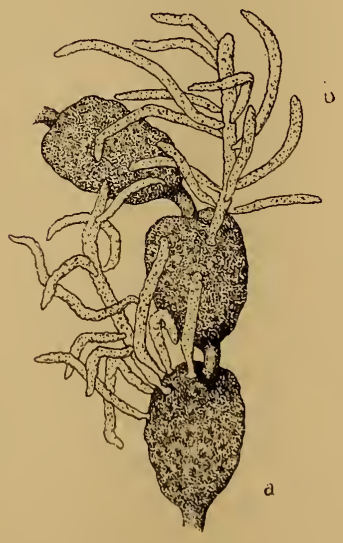

Fig. 67.-DURVILLÆA. (AFter LEMMERMANN.)

FIG. 69.- $a$, HoRMosira :

$b$, Notheia. 
the touch, and of a bright red colour, except in places exposed to the glare of the sun.

The beauty of red algæ is something exquisite, and every collector will consider his trouble well rewarded if he has been fortunate enough to collect some of these lovely algæ; for " a thing of beauty is a joy for ever."

The organs of fructification of this great group are essentially alike, and consist of asexual cruciate or tripartite motionless spores, antherozoids, and a carpogonium with a basal part containing the egg cell, and a hairlike top, called the "trichogyne." The smaller antherozoids adhere to the trichogyne, piercing its cell wall ; and their contents, entering the trichogyne, fertilize the egg cell. After this fertilization, a complicated process takes place, the result of which is the cystocarpic fruit, consisting of a globular mass of spores, either borne free (Nemalion), immersed in the tissue of the frond (Halymenia), or contained within special conceptacles. These latter are the typical cystocarpic fruits proper to the group of the Rhodomelaceæ. Polysiphonia urceolata (Fig. 70), common on the English coast, is a good example to show the cystocarpic fruit.

The Rhodophyceæ, or Florideæ, are found in all seas, but they prefer the temperate and tropical regions. Many of their genera have a limited, others a wide, distribution, but it does not follow that the species of these latter have also a wide distribution. It may be so, but more often they are limited to smaller localities.

An important group amongst the red. algæ is that of the Corallinaceæ, so called on account of the carbonate of lime which they secrete and deposit in their cell membranes, with the exception of the cells of the reproductive organs and those in the joints of the 
Corallineæ. By this process they grow as hard as stone, and have for this very reason contributed largely to the formation of the Earth's crust. They are known from very early periods in the Earth's history, for Lithothamnium jurassicum is already reported from Jurassic strata; in Cretaceous deposits they appear plentifully, and in Tertiary times they were so numerous that entire mountains were built up by them. The well-known Latomien, near Girgenti, in Sicily, are quarries in rocks consisting of Lithothamnia. In our present day they continue their work, and occur in enormous quantities, forming banks from the Poles to the tropics, where they contribute largely to the building up of coral reefs. The late Mr. Foslie, the wellknown authority on Lithothamnioneæ, kindly told me, in a letter which he allowed me to quote, that the number of known species was 276. Of these, approximately $\mathrm{I} 2$ are strictly Arctic or sub-Arctic; 82 are limited to the tropics; and 182 occur in the temperate zones. For the Lithothamnioneæ the rule holds good as for other algæ, from warm to boreal or Arctic seas the number of species decreases, but the number of individuals increases.

The Corallinaceæ are divided in many genera; best known are the slender and bushlike Corallina, Amphiroa, and Arthrocardia, and the encrusting or freebranching Melobesia, Lithophyllum (Fig. 76), and Lithothamnium (Fig. 75). The encrusting forms often act like mortar to cement loose material together; the free branching forms develop into nodules even bigger than a man's fist, and, cemented together, they can form masses of more than a metre in diameter. All Corallinaceæ are fond of strong currents ; Corallina and allied genera love places exposed to the surf of the sea; Lithophyllum and Lithothamnium prefer the 
sublittoral zone, and go down to depths even of 30 to 40 fathoms. The author has seen a bank of Lithothamnium dry at spring-tide, near the island of Timor, but this is an exceptional case. It is a curious fact that, however large a Lithothamnium bank may be, it consists chiefly of only one species. Such banks figure frequently on sea charts as " corals."

The red algæ are so numerous that it is difficult to choose which deserve special mention. I will only mention Constantinea rosa marina of Kamschatka (the name implies its likeness to a flower), Rhodymenia (Fig. 7I), Ptilota, common in northern seas, Ceramium, Polysiphonia (Fig. 70), Delesseria, Laurencia, plentiful in temperate, but also found in tropical seas where Claudea (Fig. 72) and Martensia occur by preference. These examples could be multiplied endlessly; perhaps I have mentioned already too many. The kind reader may be reminded of Harvey's Quaker, who said : "Brother, if thou knewest what I keep in, thou wouldst not grumble at what I let out."

In I899 there appeared from the hand of Professor W. A. Setchell a paper containing directions for collecting and preserving marine algæ ("Erythea," vol. vii., No. 3). Whatever the learned Professor advises the collector to do, as to the best methods of collecting and preserving algæ, is the best that can be done. I can only add a few details, and it is therefore with the kind permission of Professor Setchell that I transcribe here some passages out of his paper. For full information on the subject I refer the reader to that paper.

Collecting and Preserving Methods.-Wherever a collector goes to seek for algæ, he must first find out the time of the tides from the local authorities. The collecting-ground should be reached from one to three hours before the occurrence of extreme low water, in 
order that the collector may follow the tide as it goes down. In this way the littoral region can be explored ; the upper part of the sublittoral can only be reached by wading; its lower part lies too deep for wading, and recourse must be had to a boat. From the boat many species may be seized, and hauled into it by means of an ordinary garden rake, if the water be quiet enough ; otherwise it will be necessary to use the dredge, and that must always be used as a matter of course where the water gets deeper. If the bottom is rough, care should be taken to protect the bag of the dredge on both sides with strong sailor's canvas. If this is not done the meshes of the net will be easily caught by corals or stones; protected by canvas, the net will often glide over these impediments. The success attending the use of the dredge will depend upon local circumstances. Farlow, in his " Marine Algæ of New England," called a day spent in dredging a wasted day; but during the Dutch Siboga Expedition the dredge has brought up several times a rich harvest, and, used by the Belgian Arctic Expedition, the results were often "a fine vegetation."

The author once had in the tropics, at a depth of 6 to 7 fathoms, the help of divers, and it proved a great success. Berthold attained much by diving himself; unfortunately, diving is not a very tempting occupation.

Collectors should not forget to search the coast carefully after a stormy day, for at the time of maturity, the algæ of deeper water are more or less readily torn away from their attachments; they rise to the surface, or near to it, and are drifted ashore, especially after storms.

To the collecting apparatus belongs, first of all, a general receptacle for the transport of the collected 


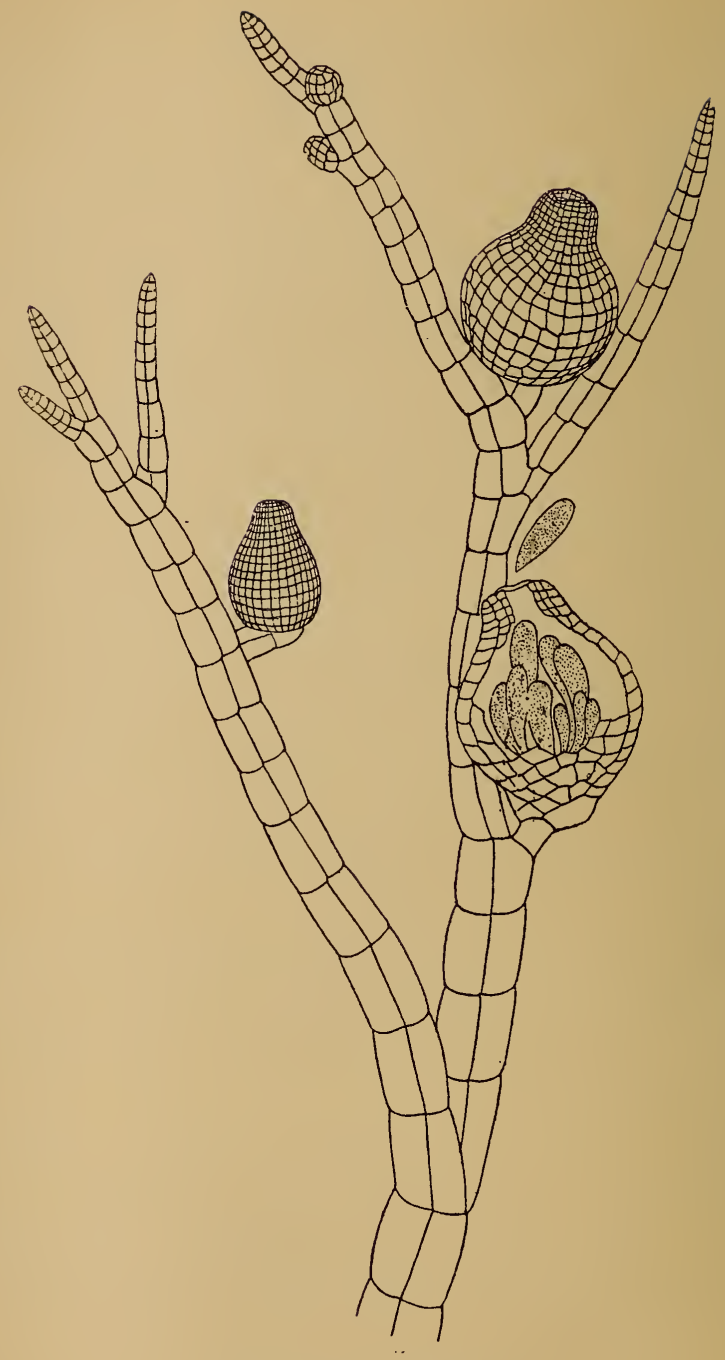

Fig. 70 -Polysiphonia. 

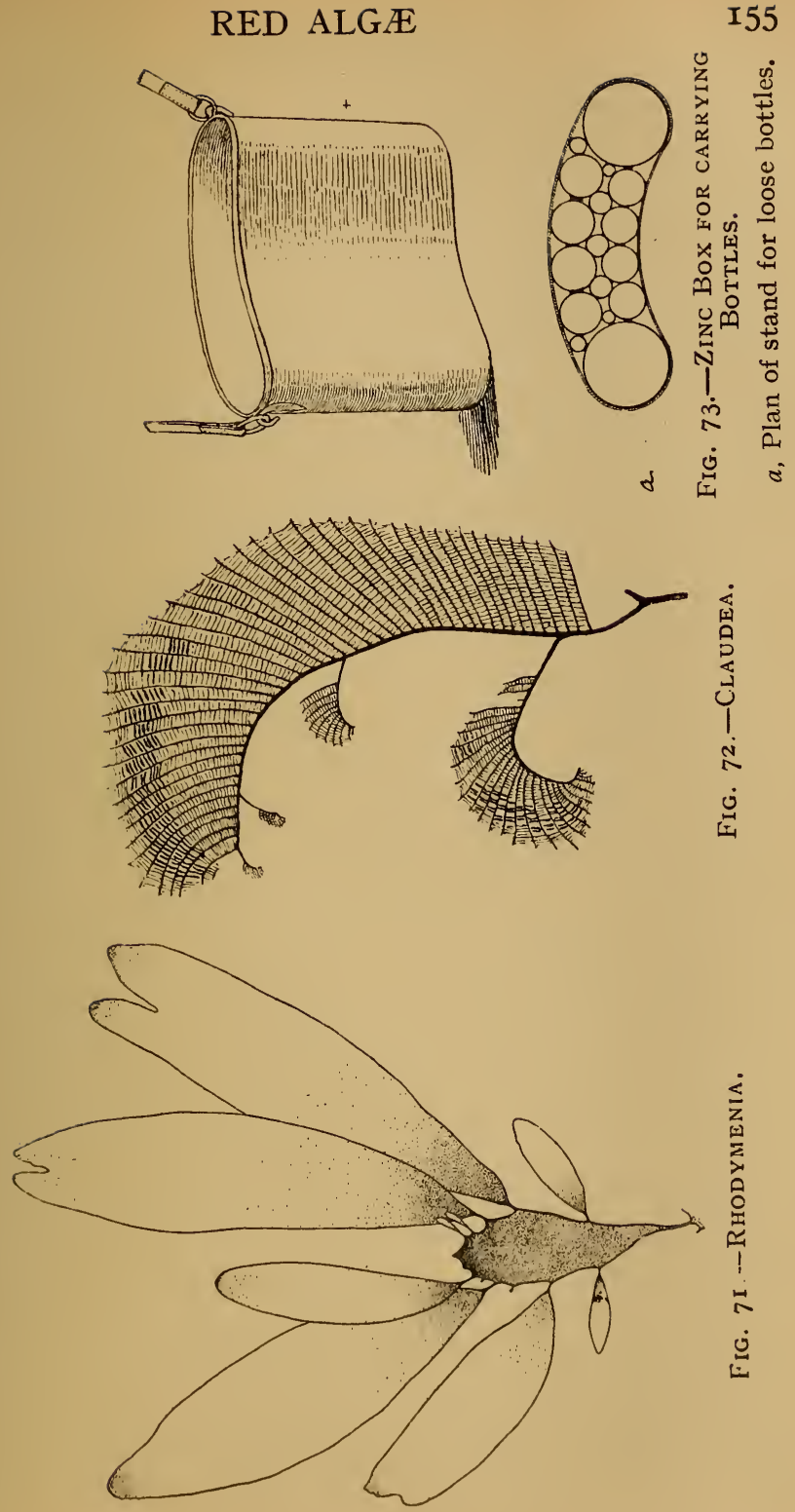
material. A good canvas or rubber bag, with a flap for closing the mouth, and a broad strap for the shoulder; a basket; a canvas pail ; or a large net with straps, are all very useful implements, out of which one may be chosen according to the collector's tastes. It is also very desirable to have some bottles with preserving fluids. To carry these we used a zinc box (Fig. 73), 35 centimetres long, 25 centimetres high, and II centimetres broad; it was a little concave on the side turned towards the body of the bearer. Inside it contained, at some distance from the bottom, a stand for loose bottles of various sizes.

Specimens for drying may be wrapped at once in newspaper, a large quantity of which should form part of a collector's outfit.

A knife, well anointed with vaseline to prevent rusting, and a fairly powerful pocket lens, are absolutely essential. A spoon or a pair of small forceps are of service in gathering from rocks small gregarious algæ, and a small geological hammer and chisel are necessary if occasion arises to collect encrusting species growing on rocks. A pair of fisherman's boots with extensible legs reaching to the hips are necessary for wading in temperate seas; ladies will do well to dress in a rather heavy skirt of pure wool, and high boots; in the tropics a bathing-costume of thin woollen material will be the thing for ladies, but care should be taken to protect the feet against the spines of sea-urchins or the rough surface of coral reefs. In some localities it will be safer for the collector to go out with a rope round the waist, held tight by friends in a safe position, on account of treacherous holes in the rocks and reefs; in others the waves may, at the turn of the tide, run in so suddenly and violently that danger of getting drowned is imminent if proper care is not taken. Col- 
lectors should study carefully each special localityabove all, on exposed rocky shores-before risking themselves too far out at ebb tide.

On the collecting-ground the best specimens available should be always selected, and, if the fruit can be detected, fertile specimens should be carried home in preference to sterile ones. Specimens covered with parasites should only be gathered for the sake of the latter. When botanizing on algologically poor and rarely visited coasts or reefs, it is best to take whatever can be found, in order that we may get an insight into the nature of the flora; but, as a rule, only specimens in a good state of preservation should be taken.

To preserve algæ there are different methods, according to their final destination, either for research in the laboratory or for the herbarium. For laboratory work they must be put in various fluids, best studied in papers enumerated at the end of the book. For each special investigation there are almost always special methods of preservation. For general investigation, algæ may be put at once in alcohol of 70 per cent., or in a solution of formalin (I to 2 c.c. formalin in 99 to 98 c.c. fresh water*). In alcohol algæ will shrink a little, and lose their colour ; in formalin they do not shrink, and keep their colour a long time if kept in the dark. But, in the long-run, a solution of formalin affects the tissues slightly. One per cent. chrome alum in distilled water, carefully filtered through sand, is, according to Guignard and Lotsy, an aqueous solution that does very well for Myxophyceæ, Chlorophyceæ and Rhodophyceæ; Phæophyceæ do better in formalin.

For the herbarium algæ can be either roughly dried,

* Sea water can also be used for making up solutions, but rusts all steel instruments used on the material afterwards in a most annoying way. 
or mounted and pressed, or salted, as desired. Large algæ, such as Kelps or species of Fucus, can be very well dried in the air, care being taken to shut out the glare of the sun, in which the algæ dry too soon, and become brittle. The method of successfully drying in the air will depend upon the moistness or dryness of each climate. In Norway Kelps dried beautifully on being exposed to the wind. To save space, one may fold or roll up big algæ, care being taken to do this before they are too dry and too brittle. They should afterwards be allowed to dry further. It is absolutely necessary to let Kelps dry before folding them up, or before putting the small ones into press; for if put into press at once they easily become mouldy. The dried specimens can afterwards be moistened again; the water absorbed in soaking them out will be very easily given up in the press.

The plants to be pressed for the herbarium ought to be carefully washed and sorted in sea water, wherein they retain their colours better than in fresh water. In a few cases it may be advisable to wash the algæ in fresh water before putting them into press. Travellers will prefer photographic dishes for this sorting and the subsequent spreading, but collectors living near the seaside will find common earthenware dishes, white within, preferable. For floating out the specimens, a method of the late Mr. Holden is recommendable, which I copy out of Professor Setchell's paper.

The utensils are very simple-a shallow dish and a rectangular piece of zinc, just a little smaller than the bottom of the dish. The corners of the zinc (or two sides) are bent over at a sharp angle, all the same way. The piece of zinc is then placed in the dish, with the bent portions downwards, so as to raise the main portion of the zinc somewhat from the bottom of the dish. Water 
is then poured in-fresh or salt, as the case may beuntil it is just the least bit above the surface of the piece of zinc. Now take a piece of white paper or card, lay it with one surface on the zinc, and turn it over, thoroughly wetting both sides. Then place the specimen to be mounted, carefully cleansed, upon the paper; with the forefinger of the left hand gently depress the paper and zinc, until the specimen is floating freely. With the right hand spread out the specimen upon the paper, using a pair of needles or a soft brush to assist in the process. When finally spread out, gradually release the pressure upon the zinc, allowing it to rise and to drain off some of the water. Then gently lift the zinc until the whole of the specimen is out of the water. When the paper is fairly dry, but before the alga has begun to show the effects, the specimen is to be placed upon a sheet of drying-paper, a thin cloth is to be put over it, another drier upon that, a specimen upon that, and so on. A flat board with some stones makes a very good press; better still is a press consisting of two iron frames, with a network of iron wire in the middle (Fig. 74), and each frame provided with four little hooks. These little hooks are fastened together by four copper chains that can be made shorter or longer, as circumstances require. The chains must be fastened loosely, or only little weight placed on the board in the beginning. The specimens may be pressed more strongly the second day. It is absolutely necessary to change the driers every day, and it is better still to change them twice a day in the beginning.

For mounting the algæ, white, unglazed, tough paper is the best; the driers must be of pretty thick drying paper, or sheets of blotting paper. The cloth must be a thin cloth or muslin, entirely free from starch. Most 
of the finer specimens will adhere sufficiently to paper, but the coarser ones must be afterwards fastened on to the mount with narrow straps of gummed paper. We have already said that blue algæ must be spread

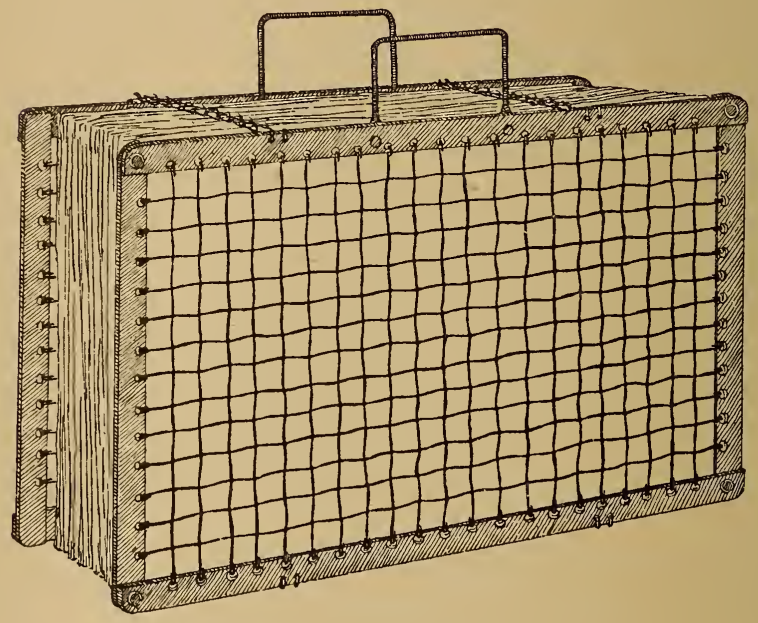

FIG. 74.-PRESS FOR DRYING ALGA.

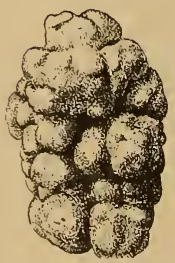

FIG. 75.-ARCH жOLITHOTHAMNIUM.

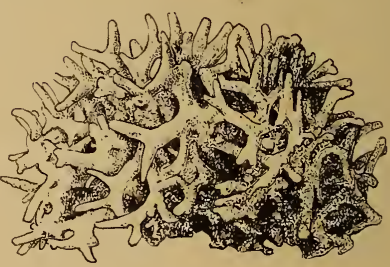

Fig. 76.-LITHOPHYLLUM.

out at once after having been collected. It is best to let them dry in the air. Each specimen should be provided with a label, on which must be mentioned the locality where it was collected, the date, the nature 
of the bottom, the depth, and a number, beginning with $I$, and so on. The numbers of the specimens must also be entered in a notebook, wherein all details are to be mentioned that strike the collector, such as the different shades of colour which some algæ have in and out of the water, and the periods of the year in which they occur; for many algæ have regular periods of growth and rest just like the higher flowering plants.

Utility of Algæ.-The commercial value of algæ is relatively small. Formerly large quantities of Kelp and Fuci were gathered, and even grown, on the coasts of islands near Ireland and Scotland for the manufacturing of carbonate of soda. This was, however, afterwards given up. Kelps are still collected for the manufacture of iodine. Many algæ are used as manure, and in Northern Norway cows are fed in winter-time on Rhodymenia palmata (Dulce), if other fodder is scarce. In the Indian Archipelago and in Japan various species of algæ are consumed by the people, and species of Eucheuma and Sphærococcus are the chief components of the famous agar-agar.

The real importance of algæ in oceanography lies in the fact that they form the basis of the ultimate food-supply of the neritic or coastal fauna.

The original drawings which illustrate this section were made under the author's direction by Mr. J. Obbes. 


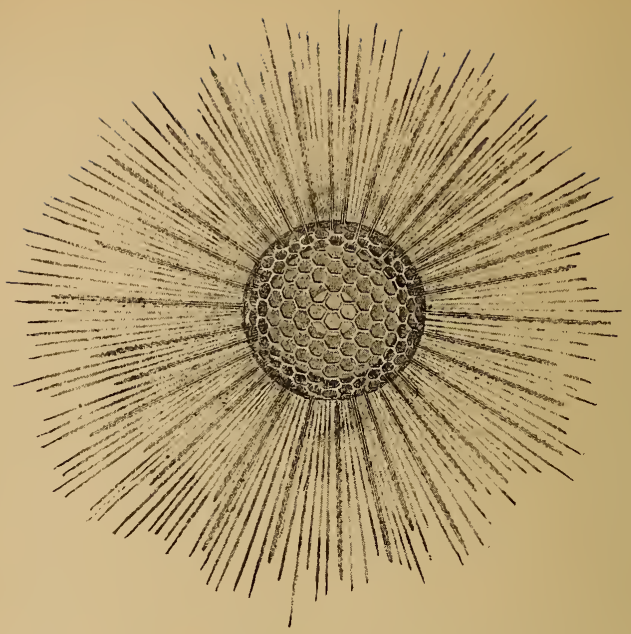

Fig. 77.-Heliosphera. (After Hertwig.)

\section{CHAPTER V}

\section{THE FLOATING ANIMALS}

BY THE EDITOR AND E. T. BROWNE

To those animals and plants which float in the sea, whether at the surface or in deep water, the term "Plankton" is applied for brevity;* they are contrasted with the creatures which crawl upon, or are fixed to, the bottom. In modern usage, Plankton is generally taken to include even powerful swimmers, such as fish and cuttle-fish, as well as helpless and minute organisms. The Animal Plankton alone forms the subject of this chapter. Both figures and text give only sufficient detail to help the beginner in finding

* Plankton, from a Greek word meaning "that which is drifted," the organisms driven about by the wind, tide, and current. 
out to what groups of animals his catch belongs. In order to find the real names of animals, or to learn something of their structure and life-history, the reader must consult the ordinary textbooks and special memoirs cited. The figures in most cases have been a good deal simplified from their originals.

None but zoologists appreciate the wealth of animal life in what appears to be clear, barren sea water. When one realizes that the Right Whale, 50 feet long, lives solely on Plankton, it is easy to see that, as the Prince of Monaco pointed out many years ago, shipwrecked sailors adrift on boat or raft need never starve, if provided with a simple muslin net. Most groups of invertebrate or backboneless animals are represented in Plankton, and the main types which are likely to be captured at or near the surface will now be sketched briefly, but, it is hoped, sufficiently to enable anyone to ascertain the group to which a specimen belongs. The exact position in the Animal Kingdom of each form named will be found in the classification (p. 430). Animals are divided into two great subkingdoms, according as they are composed of a single cell (Protozoa), or of many cells (Metazoa).

Of the single-celled animals several groups occur in Plankton, and are distinguished for great beauty and interest. Those which form a skeleton of lime (the Foraminifera) are often represented in warm and temperate seas. The shell, into which the animal can be completely withdrawn, consists of successive chambers, generally more or less spirally arranged, opening by a mouth from the largest chamber, and also perforated all over by fine holes. From the chambers radiate extraordinarily delicate spines of lime, which not only help to prevent the animals from sinking by increasing the frictional resistance to the water, but also allow 
the living matter (protoplasm), flowing out of the shellmouth and fine holes, to form a sort of bubbly lather between them, and to put out long threads for the capture of prey (Fig. 78).

Another group of unicellular animals (the Radiolaria), in which the living matter has much the same character, either form no skeleton, or form it of something else than lime. Thus, Thalassicolla is a little ball of clear jelly with a dark kernel ; and Collozoum is a colony of similar animals, looking like little dots in a common jelly; these have no skeleton. But others (Figs. 77, 79, 8I) have beautiful skeletons of flint; in yet others (Fig. 8o) the skeleton is formed of long needles of a peculiar substance, radiating from a common centre (Acanthometra). Lastly, in an oceanic group, of which at present little is known, the skeleton is very varied in shape, and often of remarkable complexity and beauty (Figs. 82 to 86 ).

The two closely allied forms, Ceratium (Fig. 38, p. I22) and Peridinium (Fig. 4I, p. I23), enclosed in a cuirass of plates, often occur in very large numbers; they are claimed by botanists as plants, but are also classed by some zoologists as animals. Another form, often very common off our own coasts, is Noctiluca (Fig. 87), an important source of the luminosity or so-called " phosphorescence," which lights up the water at night when disturbed.

Of marine unicellular animals which have no skeleton little is known, for the reason that it is rarely possible to study them alive on board, and practically impossible to preserve them properly for examination on shore; consequently, careful drawings of such forms alive and expanded are greatly needed; to those possessed of some zoological knowledge the naked Ciliata and Flagellata may be commended. 


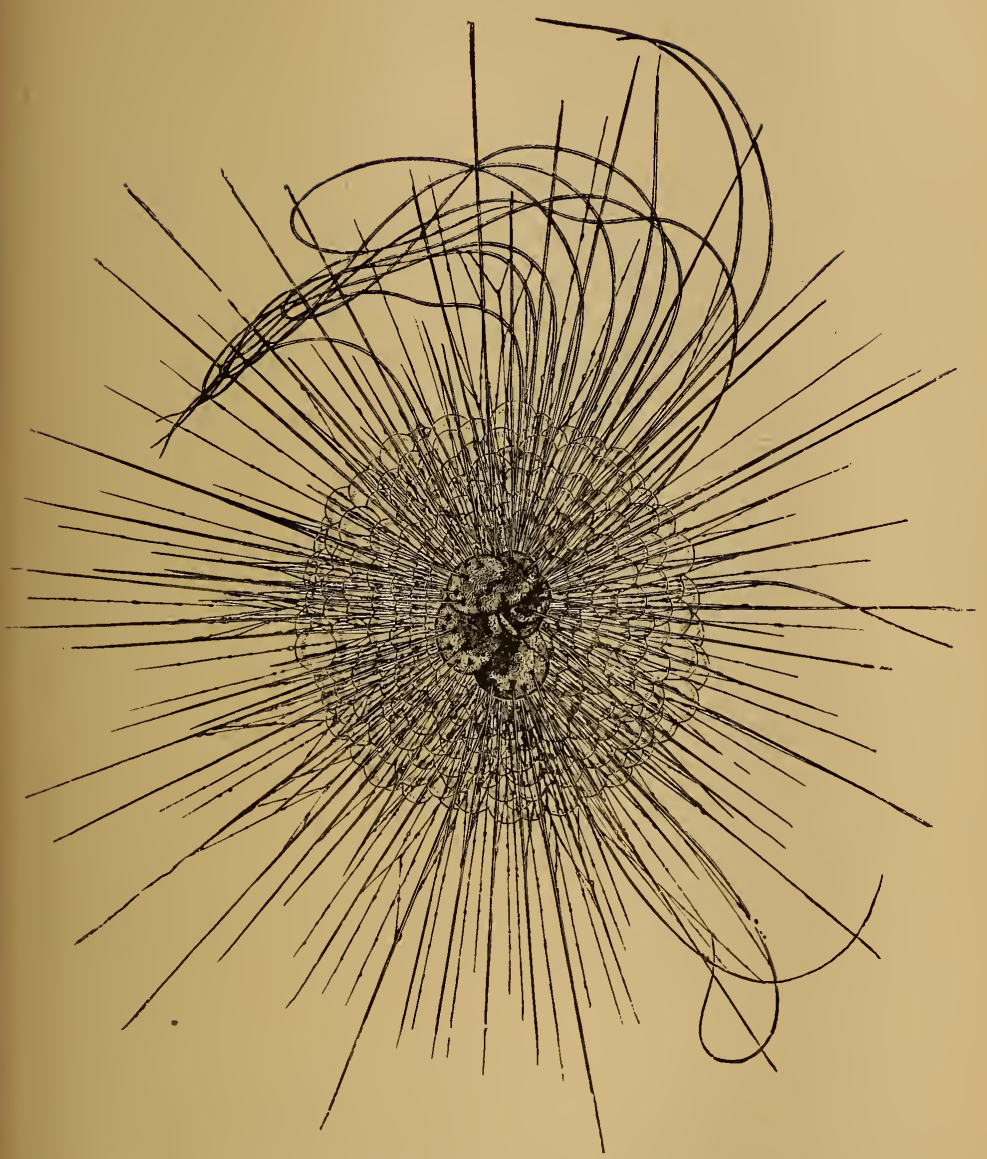

Fig. 78.-Globigerina (from a Living Specimen) ("Challenger").

The central dark mass is the shell (compare Fig. I62, p. 222), from which radiate stiff spines of lime. Round the shell is a bubbly mass of living matter, from which fine granular threads extend between the spines, generally straight, but some curved. 


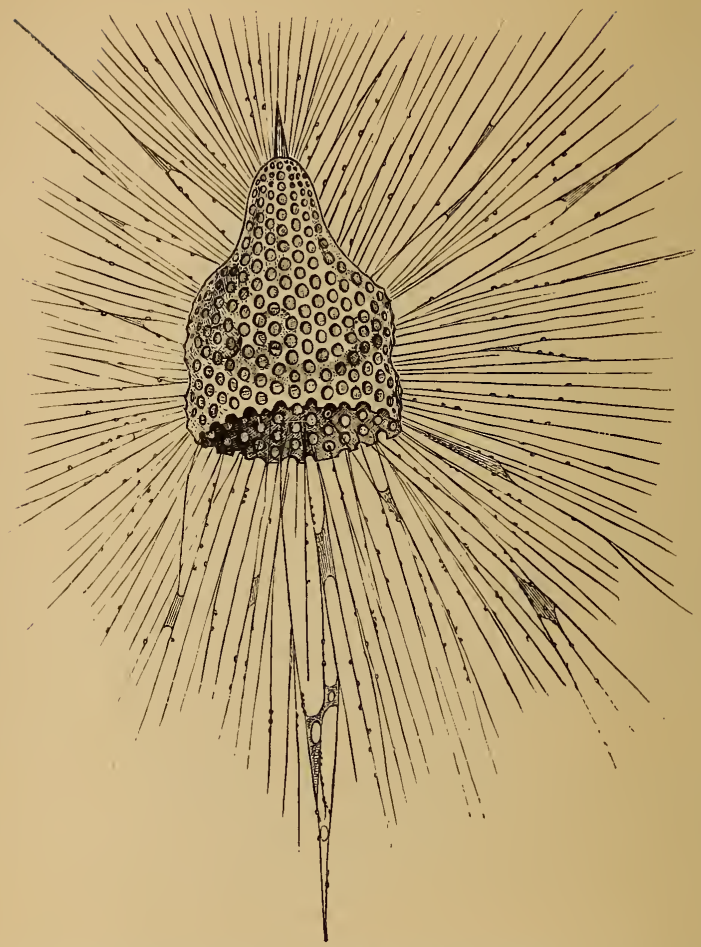

Fig. 79.-Eucyrtidium. (From Lankester's "Zoology," by PERMission of MESSRS. Black.)

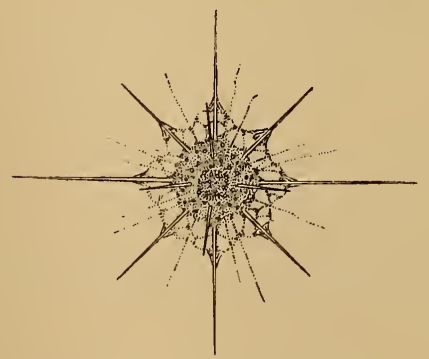

Fig. 80.-ACANTHOMETRA. (After Hertwig.)

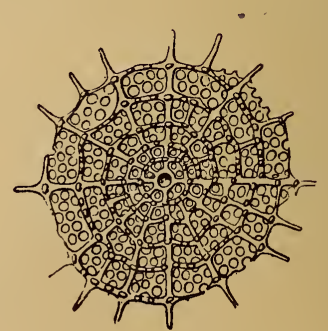

Fig. 8I.-STylospira. (AfTER Hertwig.) 

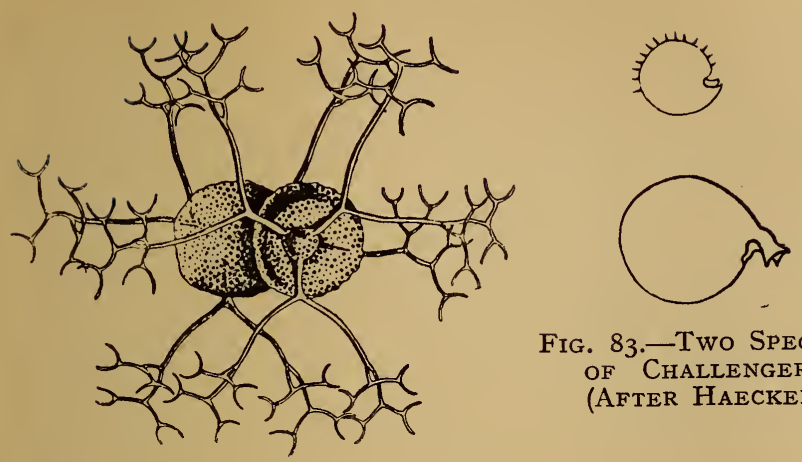

Fig. 83.-Two Species of ChallengeroN (After Haeckel.)

Fig. 82.-Colodendrum, (After BORGERT.)

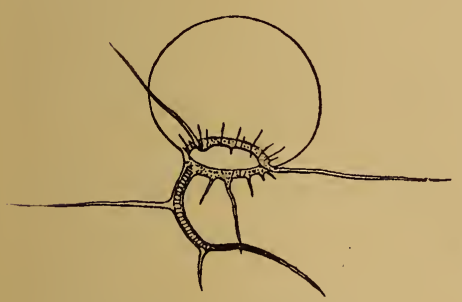

Fig. 84.-Euphysetta. (AfTer Borgert.)

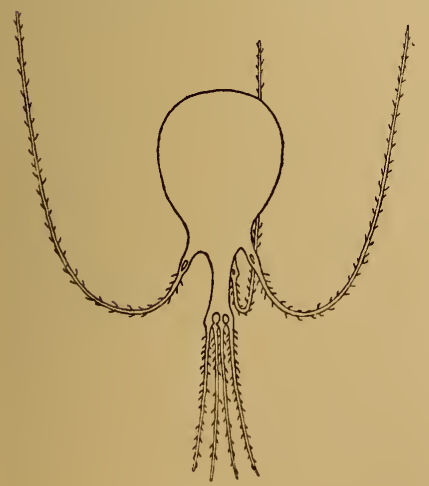

FIG. 86.--TUSCARORA.

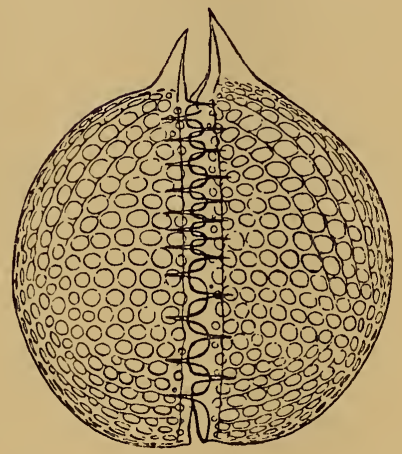

Fig. 85.-CoNCHIDIUM (AfTer Borgert.)

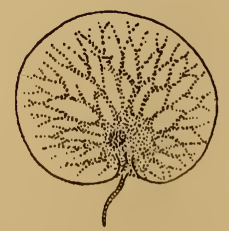

Fig. 87.-Noctiluca. 
Of the many-celled animals, the jelly-fish are among the commonest and the most attractive.

Anyone not familiar with the classification of marine animals would call any animal a " jelly-fish " which has the consistency and appearance of a jelly. But it is necessary to limit the name, even in its popular sense, so as to exclude the swimming Urochordates (pp. I84-I88), which are most likely to be mistaken by the uninitiated for true jelly-fish. The former are quite different in shape and structure, and are nearly related to the Vertebrates (cf. Figs. 88-Io0 with Figs. I49-I55).

The jelly-fishes may be separated for the sake of convenience into four groups-(I) Hydromedusæ, (2) Scyphomedusæ, (3) Siphonophores, (4) Ctenophores -each of which has well-marked characters. The jelly-fishes belonging to the first two groups are commonly called simply Medusæ.

The Hydromedusæ are small in size, seldom exceeding an inch in diameter, and are caught by means of a tow net. They may be subdivided into two groups : (I) Neritic or shore forms; (2) oceanic or blue-water forms. The neritic forms occasionally drift out into the ocean, but, as a rule, they become scarce beyond the roo-fathom line.

The neritic Medusæ (Figs. 88, 89) are budded off from small animals called " zoophytes," or " hydroids" (Figs. 90-92), which form colonies, and are permanently fixed at the bottom of the sea, or in some cases to floating objects. The hydroids, which thus bud off Medusæ, do not develop eggs, and are, therefore, asexual. The little Medusæ, after leaving their hydroids, begin an independent free-swimming career. In the course of growth and development they usually pass through a series of progressive stages, and finally become sexually adult. The eggs from the female 
Medusa do not develop into Medusæ, but into hydroids, so that there is an alternation of generations.

The geographical distribution of these littoral Medusæ depends upon the habitat and distribution of their hydroids. Some have a very wide range ; others are limited to definite localities. It is the bathymetrical limit of these hydroids, which seldom extend to a greater depth than the Ioo-fathom line, that confines this group of Medusæ to the littoral waters.

The oceanic Hydromedusæ have not a fixed hydroid stage, and the eggs develop directly into Medusæ. Their natural habitat is the ocean, but occasionally they drift into littoral waters. The species generally have a very wide geographical range, and some are found at great depths.

The large jelly-fishes, which are commonly seen from the deck of a ship slowly swimming at the surface of the sea, or found stranded on the shore by the receding tide, are representatives of the Seyphomedusæ (Figs. 93, 95). A few have the power of stinging like a nettle, but most of them may be handled with impunity. One (Fig. 95) is noted for its brilliant phosphorescence, and at night has the appearance of a globe of fire gliding through the water.

Some of the Scyphomedusæ have an alternation of generations. The eggs from an adult Medusa develop into tiny anemone-like animals, which are attached to stones, shells, etc., at the bottom of the sea. These fixed forms finally give off a number of little freeswimming rayed discs, called Ephyræ, which develop into adult Medusæ. Others omit the fixed stage in the course of development, and the eggs develop directly into Ephyræ (Fig. 94).

The Scyphomedusæ are found all over the world; some are oceanic, and others are more at home near the 


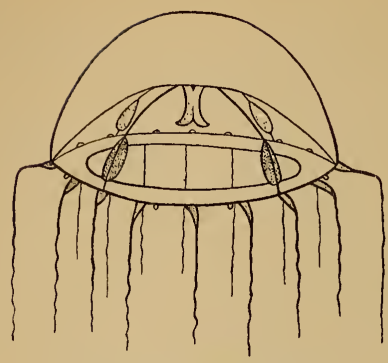

Fig. 88.-Phialidium. (AFTER BROWNE.)

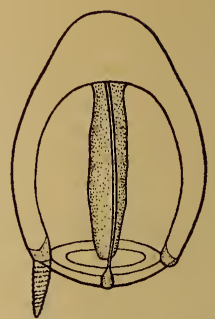

FIG. 89.-EUPHYSA.

(AFTER BROWNE.)

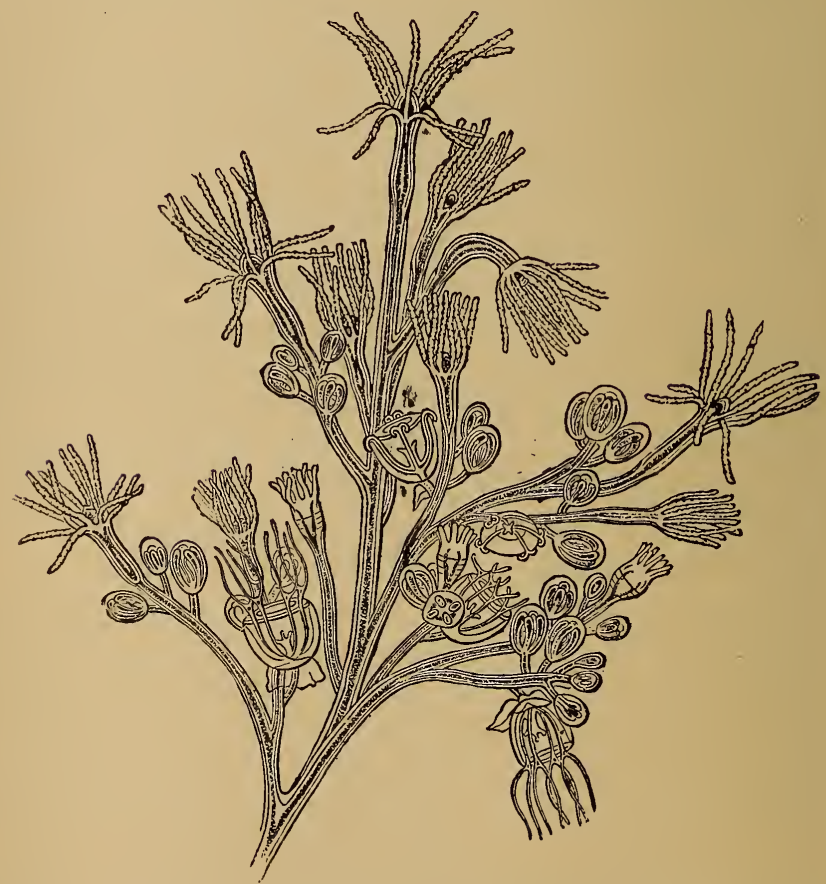

Fig. 90.-PART OF Colony of the Hydroid Bougainvillea. Showing the polyps with long tentacles, and the round or bell-shaped Medusæ (jelly-fish) which are budded off from the colony when adult. (From Lankester's "Treatise on Zoology," by permission of Messrs. Black.) 


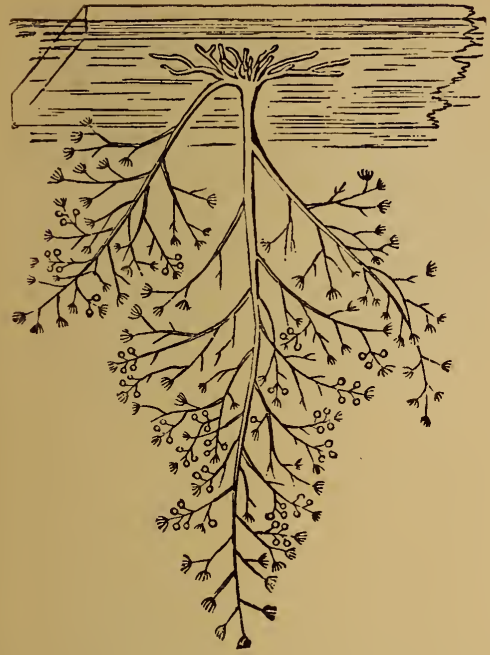

Fig. 9i.-Colony or Bougainvillea attached to a Floating Bit of WOOD.

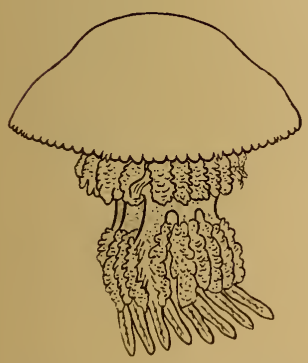

Fif. 93.-Rhizostoma. (After Milne EDWARds.)

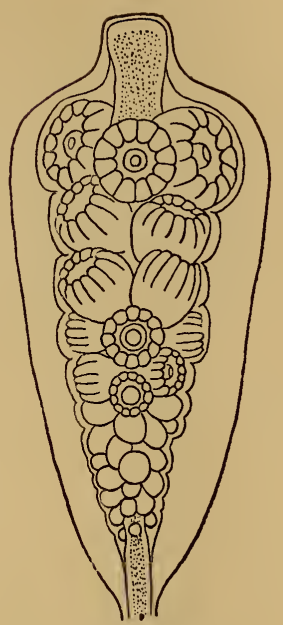

Fig. 92.-OBELIA,

Showing jelly-fish being budded at the sides of a special polyp.

(Figs. 91, 92 from Lankester's “Treatise on Zoology," by permission of Messrs. Black.) 


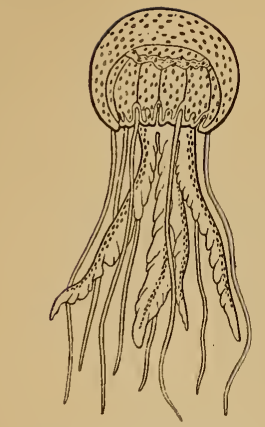

Fig. 95.-Pelagia. (AFTER ForbES.)
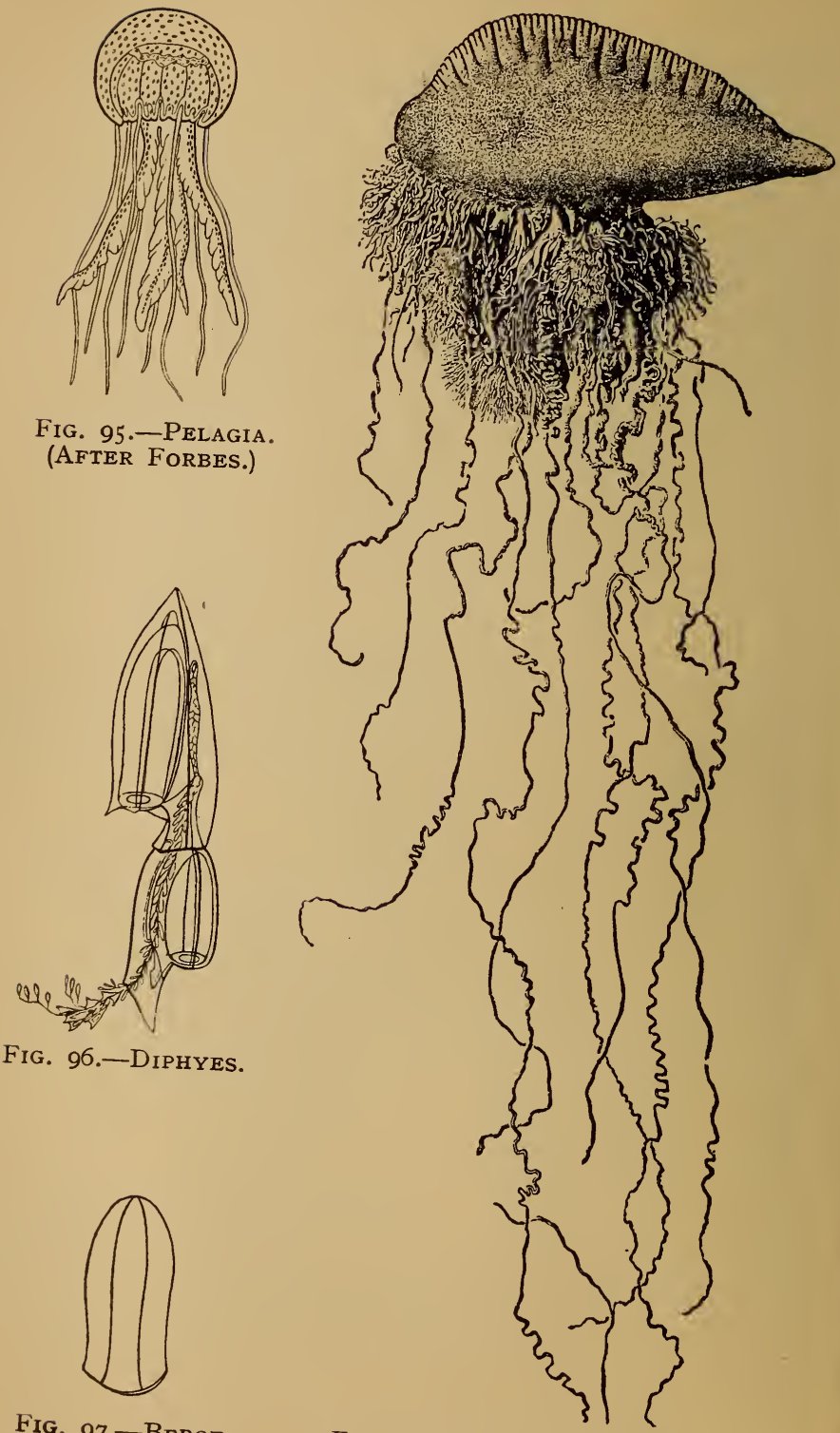

FIG. 97.-BEROE.

Fig. 98.-PhYSAlia (“BLAKE”). 


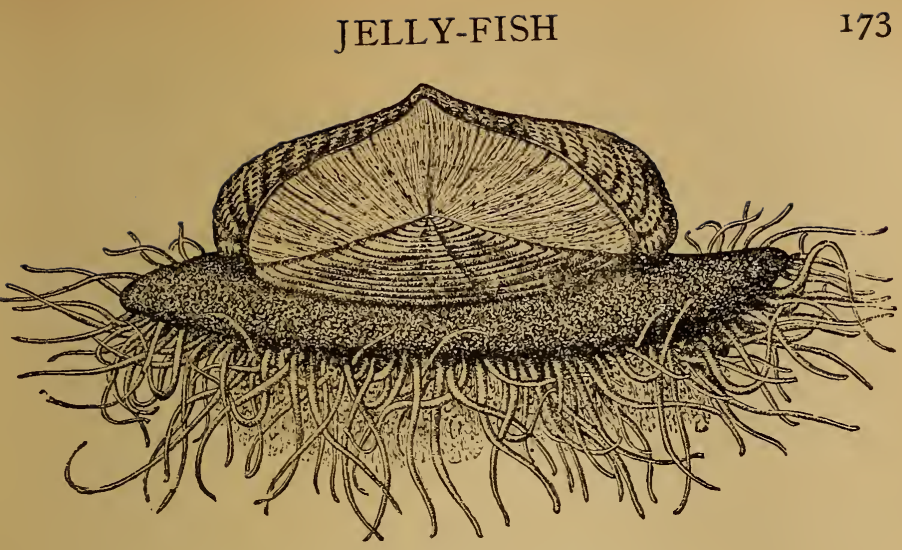

Fig. 99.-VElella ("Blake").

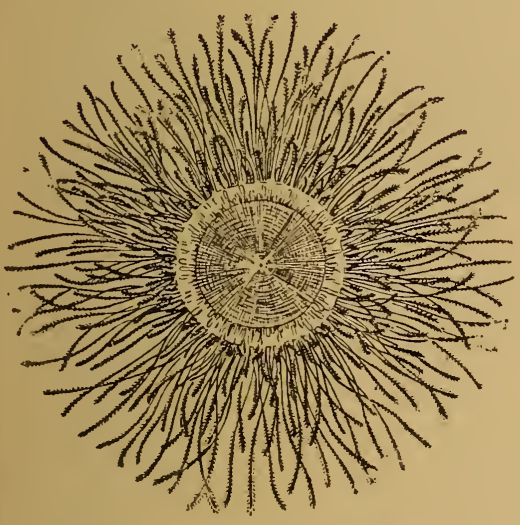

Fig. IOO.-Porpita ("Blake").

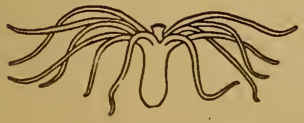

Fig. IOI.-ARachnactis.

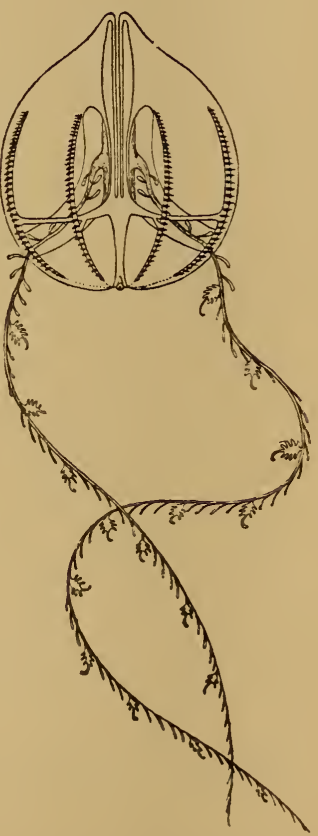

Fig. I02.-PleURobrachia. (AFTer Chun.) 
shore. A few live deep down in the very cold zones of the oceans.

The Siphonophores (Figs. 96, 98 to I0o) are closely related to the Hydromedusæ, but most of them have not the appearance of a jelly-fish. Although some are fairly simple in their construction, others are extremely complicated. They usually have the appearance of a colony of animals composed of different kinds of individuals.

This group contains some of the most beautiful, the most delicate, and the most fascinating animals that live in the sea. They are typically oceanic animals, and keep afloat by the aid of air sacs or oil globules. Nearly all swim, often at a good pace, by means of special organs called " swimming bells." As a rule, they keep below the surface of the sea, and a few have been taken at a very great depth. They are found all over the world, even under the ice off the Antarctic continent, and the species have usually a very wide geographical range.

Their life-history is very complicated, and in the course of development they pass through stages which are not at all like each other, either in structure or general appearance.

To the Siphonophores belongs the well-known Portuguese man-of-war (Physalia, Fig. 98). This is the largest Siphonophore, and it floats by the aid of an air sac at the surface of the sea. Its stinging power is tremendous, producing a maddening pain which lasts for hours. Another common form is the little blue Velella (Fig. 99), which also floats at the surface, and is not infrequently blown ashore.

Adult sea-anemones (Actiniaria) are rarely found in Plankton; but larvæ of anemones which eventually affix themselves to or burrow in the bottom, are fairly 
common near shore, and one, at least, is found on the high seas north and west of Britain (Arachnactis, Fig. IOI).

The group known as Ctenophora, from their comblike paddles, is common; Pleurobrachia (Fig. I02) may be taken off our own coasts; with its two graceful tentacles, it plays its prey exactly as an angler plays a salmon. Cestus, or Venus's girdle (Fig. I56), is an inhabitant of warmer seas. Beroe (Fig. 97), a glovefinger of pink jelly, also occurs off our coasts.

The various groups of flatworms are rarely met with in Plankton, and consequently should be carefully preserved if found. But the group of roundworms (Chætopoda), to which belong the common earthworm, and the ragworm and lugworm beloved of sea-anglers, require mention. Near shore swimming larvæ, which ultimately grow into crawling or burrowing adult worms, are frequent at some seasons ; Fig. I04 shows some of the simpler forms. Many are provided with long bristles, such as give the name to this group (" bristle-feet"). Of adult forms, perhaps the commonest is Tomopteris (Fig. I03), sometimes 2 inches long. Of the Nereids or ragworms, some are occasionally captured near shore, apparently at the breeding season. Of the curious Syllid worms (Autolytus) some reproduce asexually by forming a second or even several heads in the course of the body, and then dividing into as many worms as there are heads.

Of the wheel-animalcules (Rotifera), so common in fresh water, some seventy species are stated to be marine; little is known of them.

The little glass-arrows, or Chætognatha, are of constant occurrence, apparently in all seas; they vary in length from $\frac{1}{2}$ inch to 4 inches (Figs. 105, I06).

The group to which crabs, lobsters, and so forth 


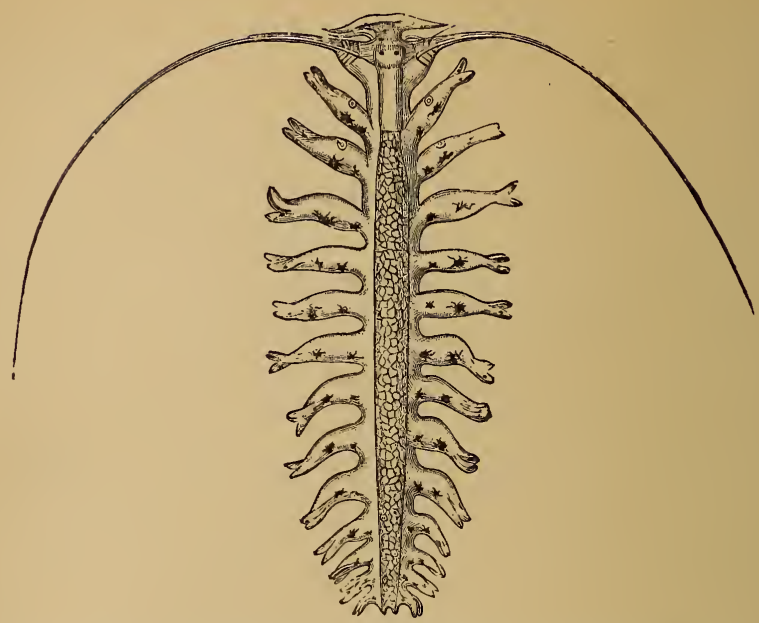

Fig. IO3.-Tomopteris. (From the "CAmbridge Natural History," BY PERMisSion of MessRs. Macmillan.)
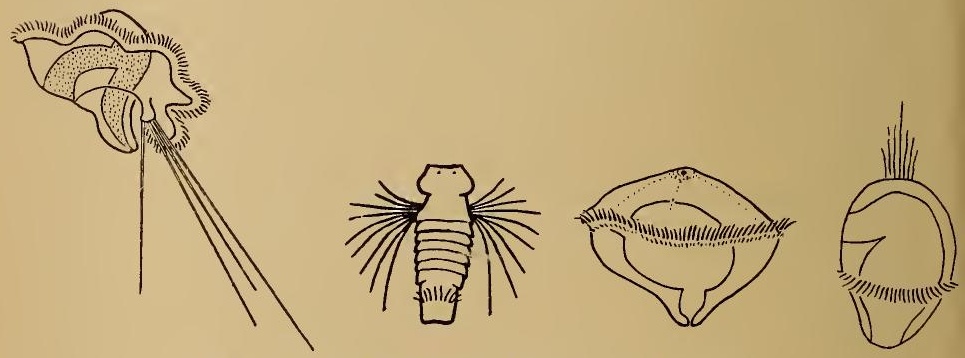

Fig. I04.-Types of Chatopod LARVæ.

From left to right : Mitraria, Nerine, Polygordius, Chætopterus.

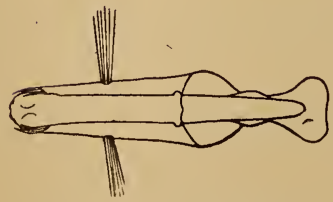

Fig. I05.-SPAdella.

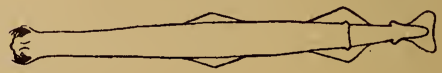

Fig. I06.-SAgitTa. 


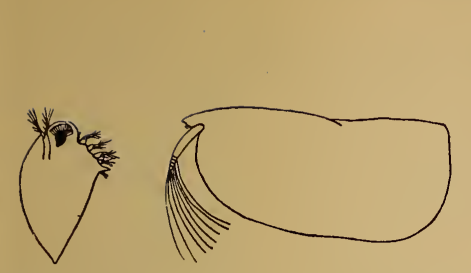

FIG. I07. FIG. IO8.-CONCHECIA EVADNe. (Left SHEll AND ANTENNA).

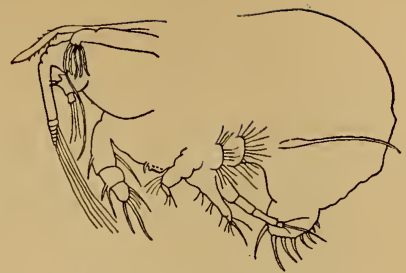

Fig. I09.-CONCHGECIA (Shell Removed).
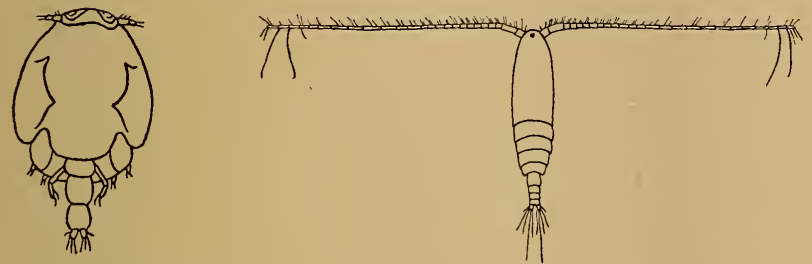

Fig. i io.-Caligus. Fig. i i i.-Calanus. (After Claus.)

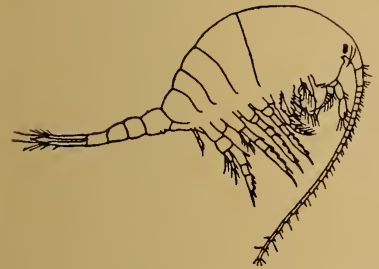

Fig. I I2.-TEMORA. (AFter Claus.)

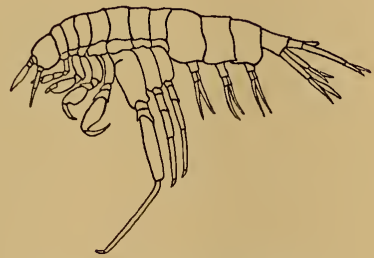

Fig. i I 3.-Euthemisto. (After Sars.)

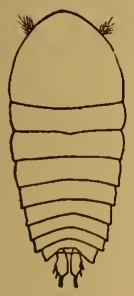

FIG. I I4. SAPPHIRINA.

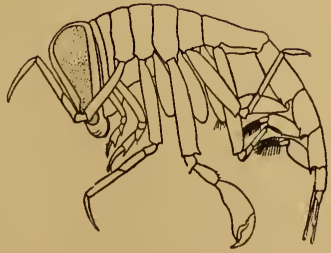

Fig. I I 5.-Phronima.

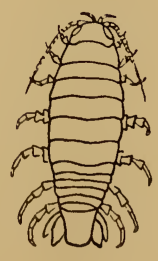

FIG. I I6.-CiroLANA. (AFTER StebBing.) 
belong-the Crustacea-are probably more plentiful than any other in Plankton. Of the "water-fleas" (Cladocera), minute animals with two shells, a large pair of rowing antennæ, and one large eye, some are not infrequently taken (Evadne, Fig. I07). Another subdivision of Crustacea, also with two shells, is termed the Ostracoda, one family of which is sometimes very abundant (Conchœcia, Figs. I08, I09).

Probably the most widely spread and prolific group of the whole Animal Kingdom, so far as Plankton is concerned, is formed by the "oar-footed " Copepoda (Figs. IIo to II2, II4), which are only very rarely, if ever, absent from a haul; generally minute, they are active swimmers ; they have been met with in such abundance as to give the sea a reddish tinge. When magnified, many show brilliant colourings, due either to iridescence (Sapphirina, Fig. II4) or to the presence of drops of coloured fat. Many of the "fish-lice" belong to this group; some are only temporary parasites, and can swim (Fig. IIO); others embed themselves in the flesh of fish and other creatures, and become so altered, in adaptation to a parasitic existence, that only a study of their development shows them to be Copepods, or, indeed, Crustaceans at all. The Barnacles, or Acorn-shells (Cirrhipedia), are not properly planktonic, but may be found attached to floating weed, driftwood, etc. These have free-swimming larval stages, enclosed in two shells, like an Ostracod.

The subdivision of Crustacea, which includes the "sand-hopper" and the so-called "fresh-water shrimp" (the Amphipoda), although far more plentiful on the bottom, has representatives (Fig. II3) in the Plankton. Some of them haunt the bells of jelly-fish, presumably for protection, while others (Phronima, Fig. II5) establish themselves in the hollow skin of 


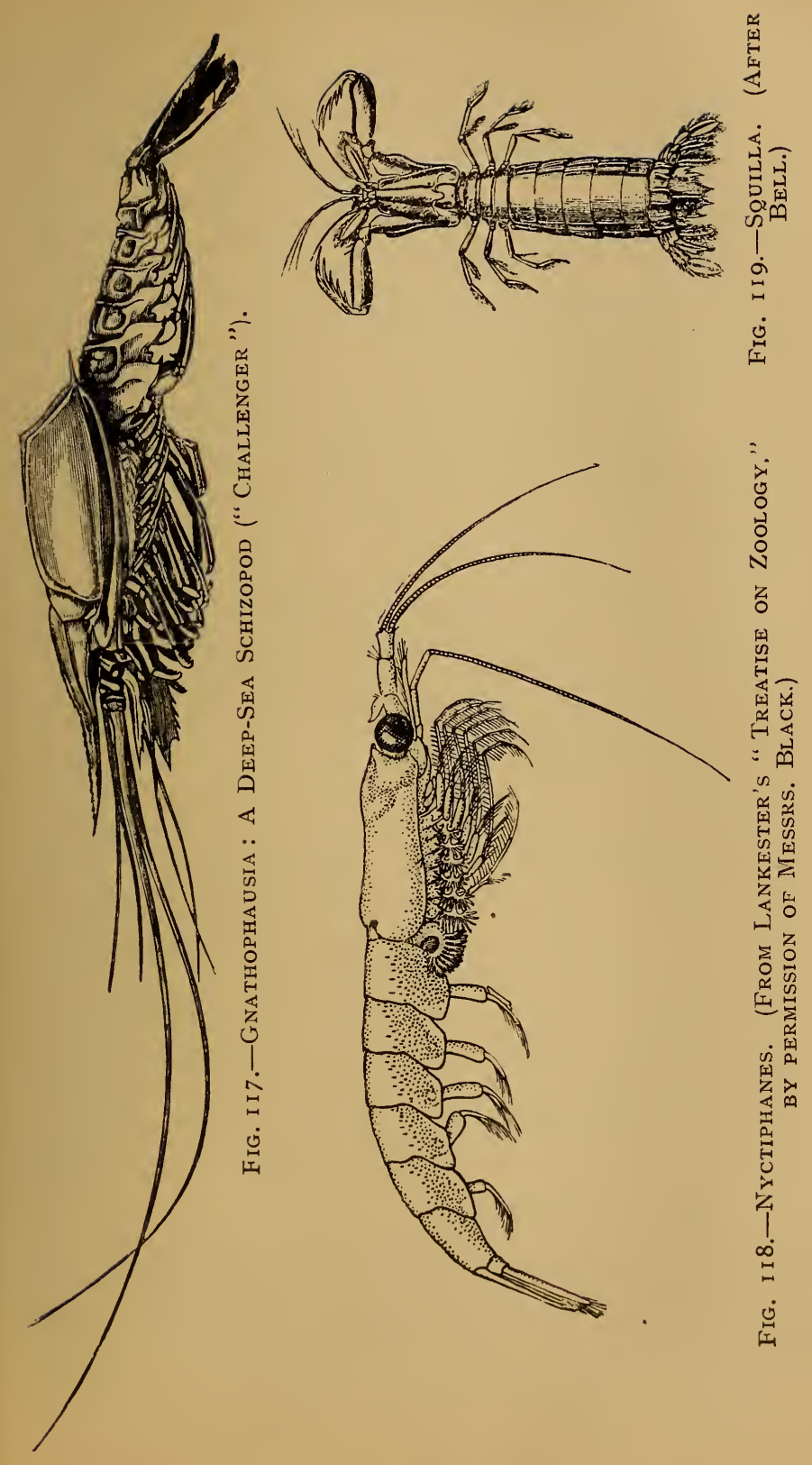


Doliolum (see p. I86). Very closely allied to these is the subdivision which includes the common wood-lice or pill-bugs; these are not insects, as is generally thought, but belong to the subdivision Isopoda; they may generally be distinguished from the previous subdivision by being flattened from above downwards, while the former are flattened from side to side. Few of them occur in Plankton on the high seas, except as parasites, either temporary or permanent (Fig. II6). Rather unexpectedly, considering their size and weight, some of the Stomatopoda may be found swimming near shore (Fig. II9) ; they should not be handled, as their big claws, shutting like a pocket-knife, can cut a finger to the bone.

The "opossum-shrimps" (Schizopoda), so called from the brood-pouch present in some species, are frequently taken. Several have special luminous organs, provided with lens and reflector, in different parts of their bodies (Fig. II8). The subdivision, which includes the lobster and shrimp, is termed Macrura-the "long-tails"; few of these are planktonic when adult, but sorne prawn-like forms are widely found. Mention must be made, however, of the curious little Sergestids (Fig. I30), not only because they are often captured, but also because of their curious larvæ (Fig. I29). Less adapted to a swimming life are the Brachyura, or "short-tails," of which the common crab is a member ; some can swim a little, and one at least has been found in quantity about 200 miles from shore over very deep water. Crabs are also found attached to gulf-weed and other floating objects.

The larvæ of Crustacea are often even more numerous than the adults. Most marine Crustacea hatch out of the egg in the form called a Nauplius, which may be known by a shield-shaped body, a single eye, and three pairs 


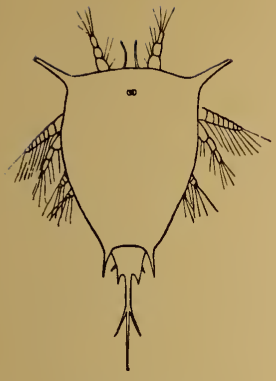

Fig. I20. - NAUPLIUS LARVA OF A BARNacle. (After Claus.)
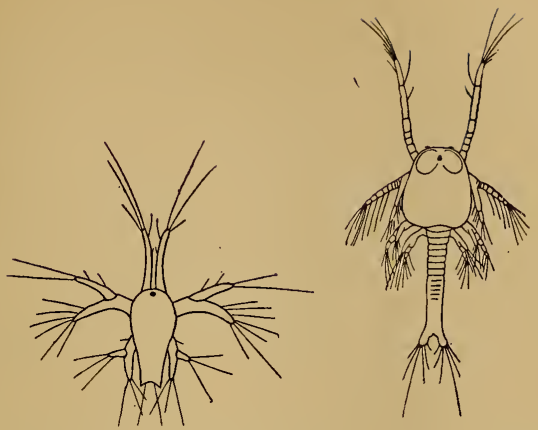

Fig. I21.-NAUPLIUS FIg. I22. - ZoËA Larva of Penaus. Larva of Penaus. (After Claus.) (After Claus.)

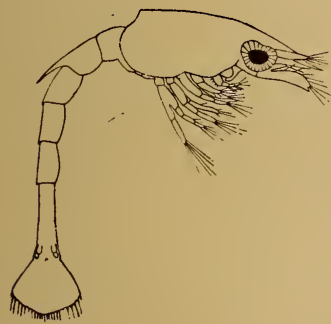

Fig. I23.-Zö̈a of Callian- Fig. I24. - Zö̈a of Thia ASSA. (After Claus.)

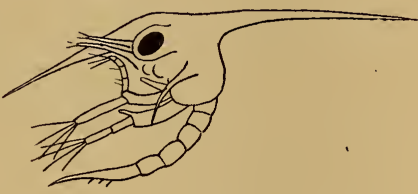

(After Claus.)

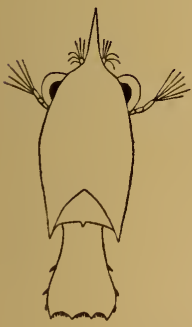

FIG. I25.- EARLY

LAR VA OF A SQUilla. (AFTER Ciaus.)

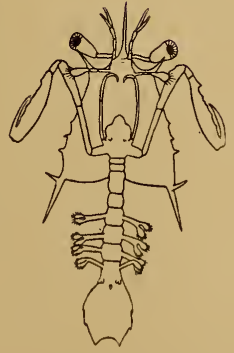

FIG. I26. - LA TE LAR VA OF A SQUilla. (AFTER BROOKS.)

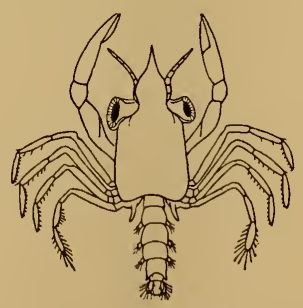

FIG. I 27.-MEGALOPA LARVA OF A CRAB. (After Claus.) 
of limbs (Figs. I20, I2I). This larval stage moults or sheds its skin repeatedly, not only growing, but also changing its shape somewhat at each moult, until it attains the parent form.

Many of the higher Crustacea, after passing through the Nauplius stage, gradually attain a Zoëa stage, which may be recognized by the limbs of the fore-part of the body having sprouted, by a pair of large eyes having appeared, and by the tail part of the body having grown out; the latter carries no limbs, except sometimes the last pair (Figs. I22-I24).

A few families have special larvæ, which are often common near shore after the breeding season. Thus the crawfish, or spiny lobster (Palinurus), passes through the remarkable stage Phyllosoma (Fig. I28); the crabs, after their zoëa stage, assume the form known as Megalopa before tucking in their tails (Fig. I27) ; and the Stomatopoda have a set of larvæ peculiar to themselves (Fig. I25, I26).

Of the group to which oysters, snails, and cuttle-fish belong, the Mollusca, some subdivisions occur in Plankton.

The oyster-forms, or Lamellibranchs, possessing two shells, are occasionally represented by larvæ (Fig. I34). The snail-forms, or Gastropoda, are frequently met. Janthina, a warm-water snail, sometimes thrown on our western shores, has a purple shell; to its foot is attached a raft, on the underside of which the eggs are embedded. Atlanta (Fig. I3I) has a spiral shell, with a narrow keel ; Carinaria, like a transparent slug, carries a shell on its hump (Fig. I32) ; very like it, but without shell or hump, are several other warm-water forms. The pteropod, or "wing-footed " forms, are found in all seas; of these the majority have shells (Figs. I33, I35). Near-shore larvæ of Gastropods are often plentiful; the most characteristic is the "Veliger" stage (Fig. I36). 


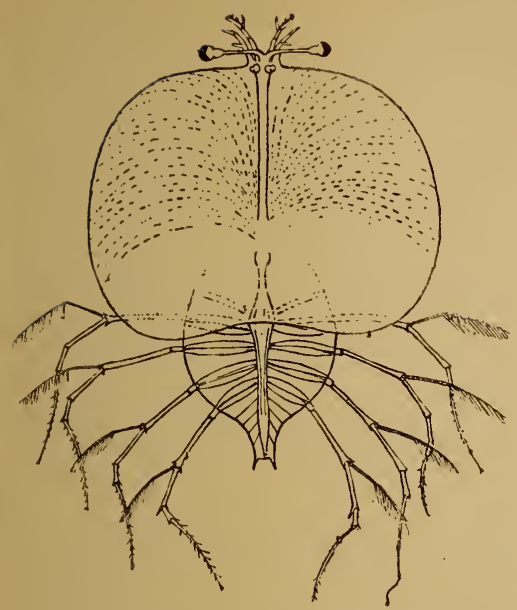

Fig. I 28.-Phyllosoma. (After GARDINER.)

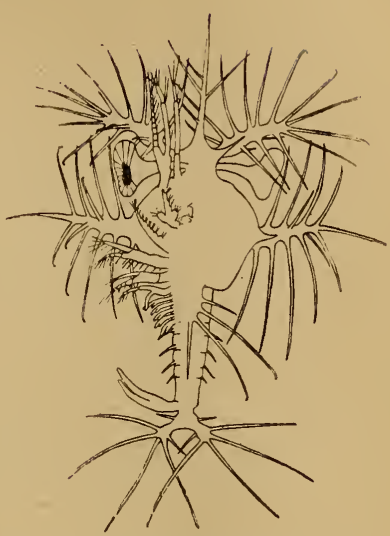

Fig. I 29.-Sergestes Larva.* (After Claus.)

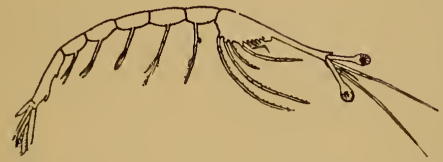

Fig. I30.-Lucifer. (After Claus.)

The cuttle-fishes, of which the octopus and squid are too well-known to require a figure, are all more or less planktonic, although many, especially in shallow water, are bottom feeders; they sometimes attain a huge size. Some have a web between the arms, which thus form a great funnel. Any forms with an external shell (except the familiar Pearly Nautilus and Argonauta) should be carefully preserved for study by experts, such as the body of the little Spirula, the dead shells of which are not uncommon in Eastern seas.

* The right side of this figure is of the dorsal or upper surface; on the left side is drawn the ventral or under surface to show the limbs. 
Of the group of Echinoderms-the starfish, brittlestars, sea-urchins, trepangs, sea-lilies-a single adult genus only has as yet been taken in Plankton, but their larvæ are frequently captured; these are even more unlike their adult form than in the Crustacea. The adult form in Crustacea was attained by a series of moults, but in the Echinoderms it rather grows out of the larvæ, which, so to speak, shrivels down on to it. Each of the five subdivisions has its own type of larvæ, four of which are here shown (Figs. I40 to I47).

Of the enormous group of Insecta, only one small family is truly planktonic (Fig. I39).

Of the Polyzoa (they have no English name) none are found in Plankton, except accidentally attached to drift wood or weed. Near shore their larvæ are common ; of these, the most likely to strike the eye has a shell like a flattened funnel (Fig. I37).

The foregoing groups are all taken from the invertebrate animals, but there remain some creatures, very common in Plankton, which only a naturalist would dream of classing anywhere near vertebrates. Yet these animals, both by structure and development, are undoubtedly akin to vertebrates ; they have (among other characteristics), either when larval or throughout life, a supporting rod in the back (the notochord), exactly like that of a sturgeon or lamprey, or the similar rod round which the vertebræ are moulded in the embryos of all vertebrates, including Man. The names of these groups refer to this notochord.

The "sea-squirts" and salps are included in the group Urochordata-i.e., with the notochord in the tail. Some of them retain it throughout life; for instance, Appendicularia (Fig. I48), which can often be captured in this country in an estuary on a flowing tide ; some species form temporary " houses" of jelly- 

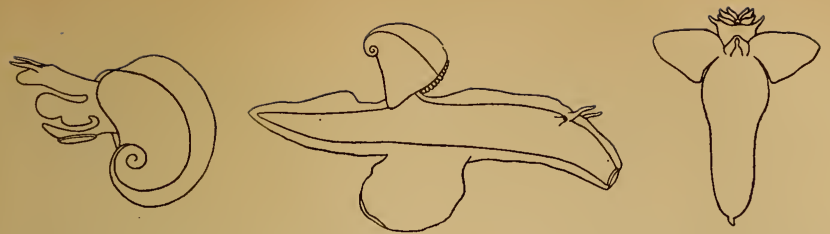

Fig. I31.-Atlanta. Fig. I32.-Carinaria. Fig. I33.-Clione.
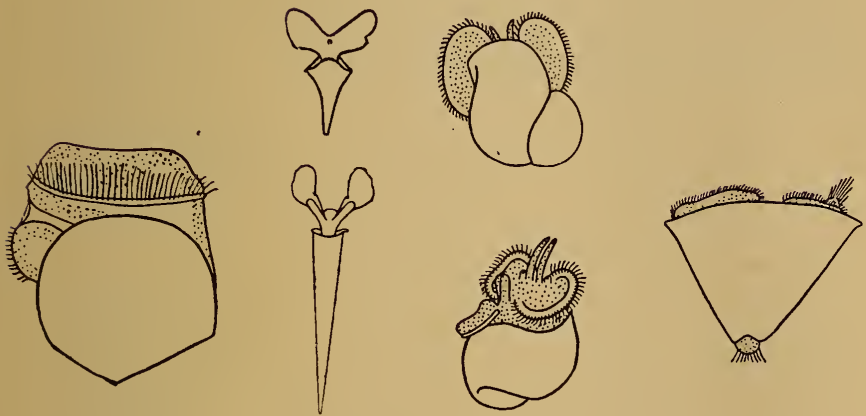

FIG. I34.

FIG. I35.

FIG. I36.

FIG. I37.

Fig. I34.-Oyster Larva. (After Hoek.)

Fig. I35.-Shelled Pteropods: Above, Hyalea; Below, StyLIOLA.

Fig. I36.-Veliger Larva: Above, Dorsal; Below, Ventral. Fig. I37.-LARva OF a PolyzoAN.

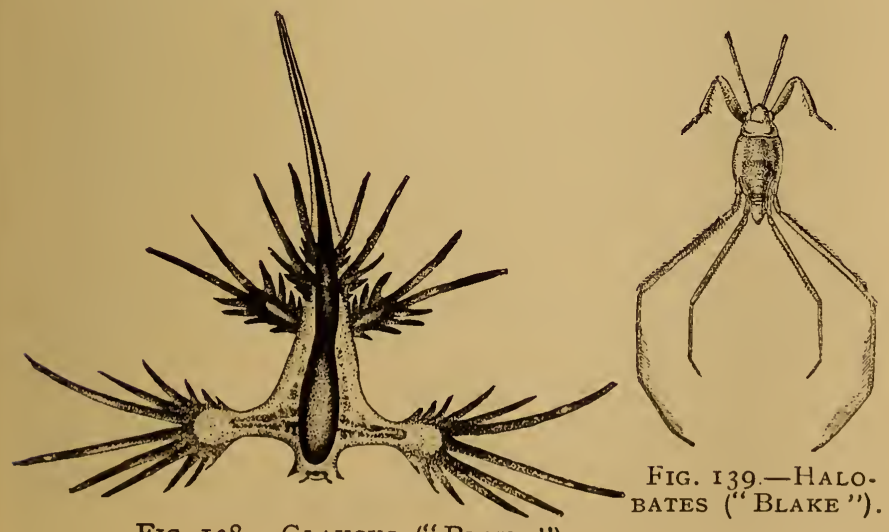

Fig. I38.-Glaucus ("Blake"). 
like material. Others drop the tail and notochord on assuming the adult form; of these Pyrosoma (Fig. I49), brilliantly luminous, as its name "fire-body" implies, is a colony of animals embedded in a common cylinder of jelly, mouths outwards. A solitary form, Doliolum,

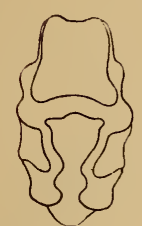

FIG. I40.

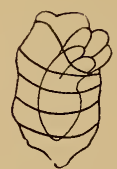

FIG. I4I.

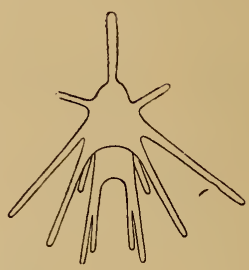

FIG. I42.

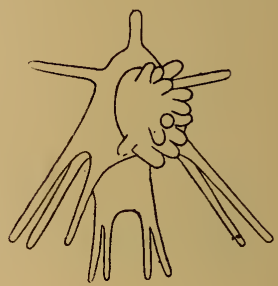

FIG. I43.

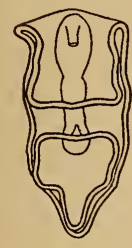

FIG. I44.

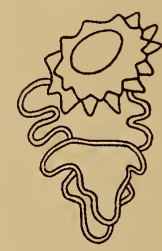

FIG. 145 .

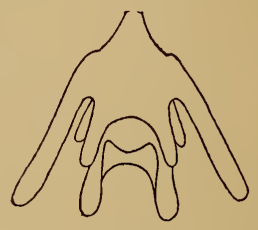

FIG. I46.

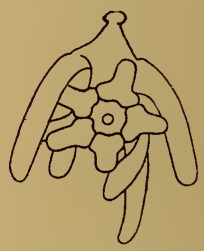

Fig. I47.

Fig. I40.-Auricularia Larva of a Holothurian.

Fig. I4I.-The SAME LATER, THE YOUNG TREPANG SHowing.

Fig. I42.-Pluteus Larva of an Echinoid.

Fig. I43.-The SAME LATER, the Young Sea-Urchin PRomiNENT.

Fig. I44.--BIPINNARIA LARVA OF AN ASTEROID.

FIg. I 45.-THE SAME LATER, CARRYING THE YOUNG STARFISH.

Fig. I46.-Pluteus LaRva of an Ophiuroid.

Fig. I47.-The same later, With the Young Brittle-Star. (Modified from Johannes Müller.)

is remarkable for its complex life-history; the form, A, (Fig. I50) itself developed from a fertilized egg, gives rise to little buds, which wander up on to the projecting horn behind their parent, and arrange themselves in three rows. Those of the side rows, B, grow into a spoon-shape, and act as food and water pumps for the 
rest (Fig. I5I) ; large buds of the middle row, C, presently break off (Fig. I52), carrying on their broken stumps tiny buds, which also belong to the middle row. These

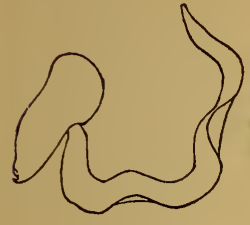

FIG. I48.-APPENDICULARIA. (AFTER LOHMANN.)

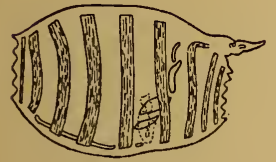

Fig. I 50.-Doliolum. A.-The nurse form which buds B, C, D.

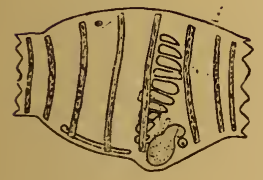

FIG. I 53.-Doliolum. D.-The sexual form.
Fig. I49.-Pyrosoma ("Blake").
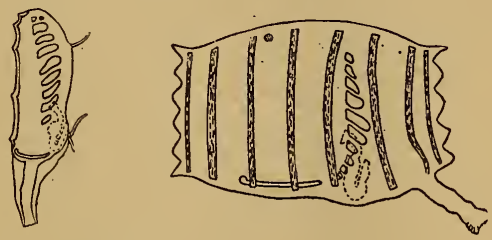

Fig. I 5 I.-DolioLUM.

B.-The spoon form.

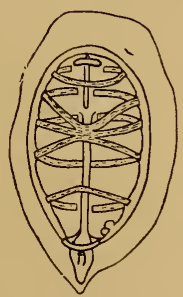

FIG. I 54.-SALPA. The sexual form.
Fig. I 52.-Doliolum. C.-The wandering form carrying buds of $\mathrm{D}$.

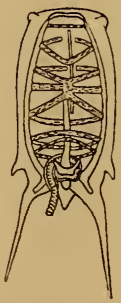

FIG. I 55.-SALPA.

The budding form with a chain of little salps hanging out.

grow up into the sexual form, D (Fig. I53), and break away in their turn; their eggs begin the cycle anew. Even more complex, and not yet fully understood, is 
the life-cycle in two similar forms. Specimens of all such from tropical seas should be carefully preserved for study by competent hands.

Another subdivision is represented by Salpa. In this, an animal which has developed from the egg, buds off a chain of little Salps; first the chain, then the separate individuals are detached, become sexual, and produce eggs, and the life-history begins again (Figs. I54, I55).

A second group is formed by the Hemichordata, in which the notochord is only partly developed; none are planktonic, but one (Balanoglossus) has a planktonic larva, which is not uncommon.

Lastly, in the group Cephalochordata (Amphioxus), in which the notochord extends to the tip of the head, the adult, in shape rather like a fish, lies half buried at the bottom, but the larvæ are planktonic.

Excluding the fish, which are the subject of a separate chapter, the animals above described may be taken to represent fairly completely types of the forms which are likely to be captured at or near the surface.

The next question is, how to catch them. The net in ordinary use, termed a tow net, consists of the frame, the net, and the tin. The frame is best made as follows: From an oil-shop procure a thin I8-foot length of flexible cane, such as is used to poke down stopped drains; a sharp bend in it may be taken out on soaking the bend in boiling water. When straight twist this up into a circle of 5 feet in diameter, and lash the ends in with strong cord or copper wire. The net is best made of Swiss silk (boulting-cloth), such as is used for sifting fine flour; a useful all-round sort has 
fifty or sixty meshes in a linear inch. The material is rather expensive, and if cost has to be seriously considered, a muslin of the same mesh can be used, but is not so lasting. Whichever material be used, the nets should be handsewn with silk, not machined with thread. After use they should be rinsed out with fresh water, and hung in a good current of air. The net is shaped like a cone, 3 feet wide in diameter above, 4 inches in diameter below, and 6 feet long. At the top and bottom it is sewn securely into a stout band of broad tape; to the top band are sewn short pieces of tape to tie it on to the cane frame; through the bottom band should pass a running tape, which will gather it securely over the tin. The "tin" is best made of copper, with a rounded flange round the lip, below which the running tape grips. From the frame run three "bridles" of stout cod line, about 3 feet long, spliced together where they meet; to these is attached the tow rope. For the latter white yacht rope is best ; if too thin it cuts the hands when wet.

The net should be towed very slowly, but both pace and mesh are decided by the sort of animals which it is desired to capture. With a boulting-cloth of sixty meshes per linear inch, about a quarter of a knot is a good speed.

In working from a small boat, 5 to Io fathoms of tow rope should be streamed, but from a ship 20 fathoms should be given, in order to clear the ship's offal. If the ship be hove to, she will generally drift fast enough to take the net out and keep it working; with a small boat, easy rowing, or the minimum speed possible under sail, are enough. From a pier-head in a big estuary or harbour, the strength of the flowing tide is often almost too much; the net should pull 5 to Io pounds against a spring balance. A twenty 
minutes' haul is generally enough; after this the net should be hauled in very gradually, otherwise the pressure of the inside water against the meshes damages the more delicate animals terribly.

Nets of the above pattern can be conveniently worked down to Ioo fathoms when out of soundings; and so far as the present writer's experience goes, far more animals and far more kinds of animals will be captured at 50, 75, or Ioo fathoms than at the actual surface. For this work are required a little handwinch of the simplest kind, and rather more than Ioo fathoms of flexible wire sash-line (such as is used for heavy windows), to the end of which a 20-pound lead is attached (soft copper sash-line, $\frac{3}{8}$ inch circumference, breaking strain about 200 pounds, price about 36 s., but see also the lines given on pp. 277,278 under Yacht Equipment). Put an eye in the free end of the wire to carry the lead, and taking this as Ioo fathoms, mark off backwards $75,50,25$, and o fathoms, as being recognized depths for study. The nets can be then stropped on to the wire at any of the depths required, but not more than two should be used at a time.

If it is impracticable to fix up a winch and work at these depths, still observations should not be confined to the comparatively barren surface. To the ordinary 20 fathoms of tow rope fix a Io-pound lead; attach the nets well above the lead, and tow at 5, IO, or I5 fathoms below the surface if the water allows of it; if not, tow about a half fathom above the bottom.

As soon as it arrives on board, the contents of the tin should be emptied, with plenty of extra water, into a big glass bottle-a wide-mouth pickle-jar or sweetjar is excellent. The larger animals can be picked out with a lifter (an old tablespoon, the bowl bent at right angies to the shank, serves the turn). For those 
of smaller size, take a glass tube, about 8 inches long and $\frac{3}{8}$ inch outside diameter, hold this between thumb and middle finger, stopping the upper end firmly with the first finger ; lower it thus over the animal, remove the first finger, and animal and water will rush up into the tube. Replace the finger, and the tube with its contents can be lifted out if kept vertical. The animals can thus be transferred to glass dishes and examined, or preserved for future study (see Chapter XI.).

In temperate climates most planktonic animals will live for some time in a glass bottle if absolutely clean and kept cool. In the tropics, where the bottle cannot be kept cool, they die very soon, and should be preserved as soon as possible.

For immediate examination on board, as a ship is rarely still enough (except in harbour) to allow of the use of a microscope, a small " dissecting microscope," with simple lenses magnifying about 6 and Io diameters, is absolutely invaluable.

Naturally enough, the animals in Plankton are not always and everywhere the same. In the first place the distance from shore makes a great difference. Plankton from shallow water near land shows numerous larvæ of bottom animals, and such jelly-fish as are budded from hydroids, but over deep water such larvæ are hardly ever present; there are larvæ of planktonic adults, but they are not so numerous in proportion, and these adults are mostly different from those near shore. Hence we distinguish the " neritic," or coast-wise Plankton, from the "oceanic," or bluewater Plankton; the Ioo-fathom line may be roughly taken as the boundary between them, but they pass imperceptibly into one another. Secondly, the temperature of the water makes a great difference in the Plankton; it is fairly obvious that as a rule an animal 
which can stand arctic cold of $30^{\circ}$ to $35^{\circ} \mathrm{F}$. will not be happy in the tropics with a sea temperature of $80^{\circ}$ to $90^{\circ} \mathrm{F}$. (although such cases are said to exist) ; but many marine animals seem to be influenced by quite small differences in temperature. Thirdly, if there be too little salt in the water-for example, in estuaries or the Baltic-many species will not live there. Lastly, the character of the Plankton alters a good deal with the depth; it is not every animal which can thrive in absolute darkness, at a very low temperature, on such casual food as falls from the surface layers towards the bottom.

This last statement opens up a fresh branch of the subject. Plankton is by no means confined to the upper layers of water, but has been captured even at the greatest depth to which suitable nets have been lowered (2,734 to 2,187 fathoms). Such nets, termed " closing nets," are lowered to a known depth, with the mouth closed ; they are then opened by mechanical means, towed either vertically or horizontally for a known distance, closed again, and brought closed to the surface; they therefore only contain animals from the desired depth. This mid-water work has been systematically attempted only of late years, and forms a fascinating branch of study. Very little is known at present about the Plankton of great depths, and any yacht with a steam winch can do most valuable work in this direction. A description of the necessary outfit is rather beyond the scope of these pages, but details can easily be obtained from the Challenger Society. Many of the animals from great depths seem to be confined to deep water, but some are known also from the surface.

Of one branch of Plankton we know almost nothingthat is, of those invertebrates which, although capable 
of swimming a little, are closely dependent on the bottom of the deep sea either for food or for resting. For their capture tow nets are attached to the trawlheads or dredge, streaming a little behind them so as to catch the animals disturbed by raking up the bottom.

The Plankton, then, is not always the same everywhere, but the reasons why it is different in different places are only partly understood ; it seems, however, certain that the temperature has more to do with this than anything else. Some species seem able to stand much greater extremes of temperature than others; but for every species there is a (maximum) temperature above which it cannot live, a (minimum) temperature below which it cannot live, and an (optimum) temperature at which it thrives best. To take a well-known case, characteristic animals of the Gulf Stream and North Atlantic Drift rarely reach as far east as our islands, although the actual water in which they lived travels as far as the North Cape ; they die out as the temperature falls. The slaughter is particularly heavy where hot and cold currents meet.

Supposing that we knew precisely the maximum and minimum temperatures of a species-say $60^{\circ}$ and $45^{\circ} \mathrm{F}$. for a North Atlantic species-then by drawing lines on the map through all the points where $60^{\circ}$ and $45^{\circ} \mathrm{F}$. occurred at the surface, we couid run a surface boundary round the animal, and map its "horizontal distribution." Further, if this species can tolerate so low a temperature as $45^{\circ} \mathrm{F}$. at the surface, there seems to be no reason why it should not live at $45^{\circ} \mathrm{F}$. at any point below the surface; consequently, in addition to the horizontal distribution, we want to be able to map also the distributions at different depths, and thus the space occupied by the species will form an 
irregular figure in three dimensions, with length, breadth, and thickness. Unfortunately, in the present state of knowledge, we are unable to draw this figure with certainty for any single species; hence it will be readily understood how important it is always to record the temperature of the water from which a haul is made, and, if practicable, also the salinity.

One interesting result of the ability of many animals to live below the surface, provided that they keep above their minimum temperature, is that some arctic species are continuously distributed from pole to pole in the deep cold water of mid-ocean; but have never been captured anywhere near the surface in the tropics, where the temperature is above their maximum.

It has been stated (and it appears to be true for great lakes, and to some extent for shallow water such as the English Channel) that the greater part of the Plankton comes to the surface only by night, and sinks to some depth by day as a protection against too bright light. Like many other accepted statements, this stands in need of accurate testing as regards the open ocean. Anyone becalmed in a sailing ship, or hove to in a yacht, could gather valuable information on this point by systematic day and night surface hauls in or near the same position. Still more valuable information would be yielded by similar day and night hauls at different depths. This opens up two new questions-how to get a basis for comparison of different hauls, and how to deal with subsurface hauls which are hardly deep enough to rank as mid-water hauls.

Hauls may be readily compared if standardizedthat is to say, if they are made with nets of similar mouth, length and mesh, for the same time, and at the same speed of towing. In this case all that is necessary is to preserve the whole catch, and to count the 
specimens of any species under study; thus it can be readily shown in accurate terms that a species is rare at the one hour, depth, date, or place, and common at the other. Every haul made for comparative work (and that is pre-eminently the work now required) should be made with standard nets, time, and speed. The only thing difficult of control is the speed, except in a small launch, but this can be read by a current meter (p. 53-57). Standards are suggested on p. I99.

As a rule, the greater number of the species captured at or near the surface at any particular position at sea will be found to extend to about Ioo fathoms at that position (not necessarily elsewhere, where the temperature and other conditions may be different). For a proper study of the alleged up-and-down movements of the Plankton, and for many similar objects, it is desirable to know, not only whether it is rarer or more abundant at the surface under certain circumstances, but also where it goes to when not at the surface. The method of hauls with open nets at various depths (p. I90) will throw a good deal of light on this, but they are not to be trusted absolutely, because they catch specimens from higher levels while being hauled to the surface. For accurate work a closing net should be used horizontally, lighter and smaller than those used for true deep mid-water work, so as to be workable by hand with the small reel and stranded wires already mentioned; they should carry the same standard net, and be used for standard time and at standard speed.

Other points requiring study by similar methods are the supposed movements of Plankton due to rain, breaking seas, wind, fresh water from large rivers, floating ice, and so forth.

A curious feature well worth attention is the way in 
which Plankton becomes concentrated into swarms or streaks; it is by no means universally distributed, even over a small district. Such streaks should be surveyed, if possible for dimensions both horizontally and vertically. Particular attention should be paid to the comparative abundance of plant food inside and outside the area, as well as to their position as regards current and tide, for it has been suggested that they are formed exactly as a river throws raffle on its banks.

All special adaptations of a planktonic organism to its conditions of life should be noted. A striking series of these adaptations is naturally directed towards preventing weak swimmers from sinking. This object is attempted in various ways, of which the chief areeither (a) a diminution of weight by the formation inside the animal of light fluids (in the bubbles of Foraminifera and Radiolaria), fats (Copepoda), jelly (jelly-fish and salps) or gas (Siphonophores) ; or $(b)$ an increase of surface in order to increase the friction in falling through the water, produced either by flattening the body (Phyllosoma, Sapphirina) or the growth of long spines (Foraminifera, Crustacean larvæ).

Coloured sketches from life are always valuable away from home waters. Most of the larger invertebrate Plankton is nearly colourless and transparent, and any exceptions to this should be noted, and, if possible, sketched.

Of late years the Plankton has been used, in connection with the "International Investigation of the North Sea and Adjacent Waters," as a means of tracing out the derivation of the body of water in which it occurs, and as an indication of the amount of available fish-food; for this purpose most attention has been paid to the minuter animals and plants (micro- 
plankton). The methods used in this study are complex, and involve technical training; it may be added that they have not met with universal approval, and the investigation hardly comes within the scope of an elementary handbook.

But even round our own coasts there is much to be learnt of the daily and seasonal movements of the larger Plankton, and of its behaviour under changing conditions of its surroundings. Once clear of European coasts, a traveller may feel certain that his collection of Plankton will be serviceable to science if accompanied by proper observations and full notes.

What the study of Plankton requires nowadays is not the mere collection of specimens, but the collection of facts. Naturalists have described thousands of planktonic animals from all sorts of places, but know very little about how they came there, why they are there and not elsewhere, how they live, what they eat, and what eats them. Without such knowledge the study of Plankton is about as interesting as to read a street directory containing solely names and numbers. Consequently every item of what is called " natural history" should be observed and noted, and every possible detail recorded whenever a haul is made. The routine details are set out in the sample General Log (p. 4I6), subject, of course, to modification for special cases.

Except when an observer is simply collecting Plankton for his own instruction (if even then), no haul should be taken without a definite object; it should have a story to tell of the Plankton of a particular place, hour, depth, or season, of the effect of rain, breaking sea, ebb and flow of tide, and so forth. For the study of all general questions, the hauls should always be standardized as suggested on pp. I 94, I 95, I 99 . 
It will be seen readily from this brief sketch that plenty of interesting work awaits anyone who has opportunity and a tow net. In harbour, from a pier or reef of rocks if the tide serves, from a small boat or a big ship, the tow net can be streamed with the certainty of an interesting result; even if the catch be scanty, the result becomes of value if the reason for its scantiness be found. No observation, however apparently insignificant, is scientifically worthless if it be securely based on fact. On however small a scale, valuable work may be done for science without attacking the more intricate problems. The simple tow-net haul in foreign parts, if accompanied by the necessary observations, will always be worth making, preserving, and submitting to experts for report.

Finally, a word of advice to the beginner who wishes to collect for his own instruction, and to do serious work; he will be at first bewildered with the wealth of life at his disposal, and depressed with the difficulty of finding what is already known, what not. Let him therefore confine himself strictly to the animals of one, or at most two, groups, and hand the rest over to an expert at home ; let him select for his own study a group which has been recently revised, or dealt with in a report from some important expedition, so that he may get the literature of the group under control. The choice of the group will depend to some extent on the waters to be traversed, but in this, as in all such matters, the Society will be glad to advise.

Note.-As it may help the beginner to have standards for open tow nets suggested to him, one of the writers submits his own specification, which does not differ greatly from the nets in use generally on expeditions-(I) Net: circumference of mouth, 5 feet; circumference at tin, I foot; length, 6 feet; meshes per linear inch, 62 ; breadth of top and bottom tapes, I $\frac{1}{2}$ inches. (2) Cane frame, inside diameter, I 8 inches. ?(3) 
Bridles, 2 feet 6 inches long. (4) Length of haul, 20 minutes. (5) Horizons for shallow work, surface, and $25,50,75$, and roo fathoms, with occasional hauls at ${ }_{50}$ fathoms. This writer's new horizontal closing net takes the same silk net as the cane frame, and the results of the two can therefore readily be compared.

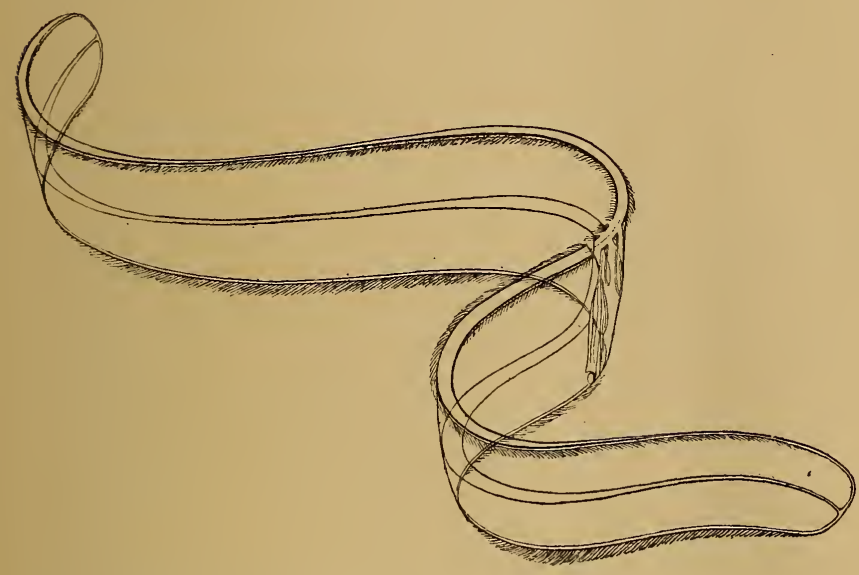

Fig. 156.-Cestus, or Venus's Girdle. (After Chun.) 


\section{CHAPTER VI}

\section{THE SEA F L OOR}

BY SIR JOHN MURRAY

Methods.-The oldest method of sounding was by means of the hand-lead, usually I2 to I4 pounds in weight, " armed" with lard or tallow, to which a sample of the bottom adheres, and with a line marked in fathoms and fractions of a fathom. Practically all the coasts of the world have been surveyed by instruments of this kind used from rowing-boats. When attempts were made to sound in I0O or 200 fathoms, heavier weights and more carefully prepared hempen lines were employed, and the leads were provided with cups, valves, or snappers, to bring up samples of the sands, gravels, and muds. Sir James Clark Ross, during his Antarctic cruise (I839 to I843), made most praiseworthy attempts to sound the greater depths of the ocean with ordinary sounding lines and heavy weights from small boats. $\mathrm{He}$ succeeded in recording depths down to 3,600 fathoms, but, although the time each Ioo fathoms left the reel was noted in the usual way, he was uncertain when the weights reached the bottom, and the results were not altogether trustworthy. About the year I854 Lieutenant Brooke, of the United States Navy, introduced the method of detaching a heavy weight from the sounding-tube on its striking the bottom; henceforth deep soundings were recorded much more fre- 
quently and with greater accuracy, while good samples of the deposit were obtained.

During the "Challenger" Expedition (I872 to I876) sounding with wire had not passed the experimental stage; all that was known for certain was that the same wire could not be used for many soundings without breaking. The "Challenger" made use of a specially made hempen sounding line. It had to carry on each occasion a load of valuable instruments, and in this it was brilliantly successful. Wire rope is suitable for sounding pure and simple; indeed, the systematic investigation of the form of the bottom of the ocean can only be rapidly carried out with wire. For deep sea researches, where many valuable thermometers and other instruments must be sent to the bottom in deep water, hemp rope is much more trustworthy than wire. However, during the recent "Michael Sars" Expedition in the North Atlantic a 6 -strand wire 3 or 4 millimetres in circumference was used, with excellent results, to carry several thermometers and water-bottles down to depths of over I,000 metres.

In the ordinary routine on board the " Challenger " the soundings were made with the Baillie machine (see Fig. I57), the sinker weighing 336 pounds, the tube 25 pounds, and the attached water-bottle 20 pounds. The effective sinking-weight was 333 pounds in water; every roo fathoms of line used in sounding added 6 pounds to this effective sinkingweight. In very shallow water there was acceleration in the rate of descent, but in deep water there was continual and progressive retardation. With wire there is continuous acceleration if allowed to run free like the hemp line.

In recent years soundings have been made by 

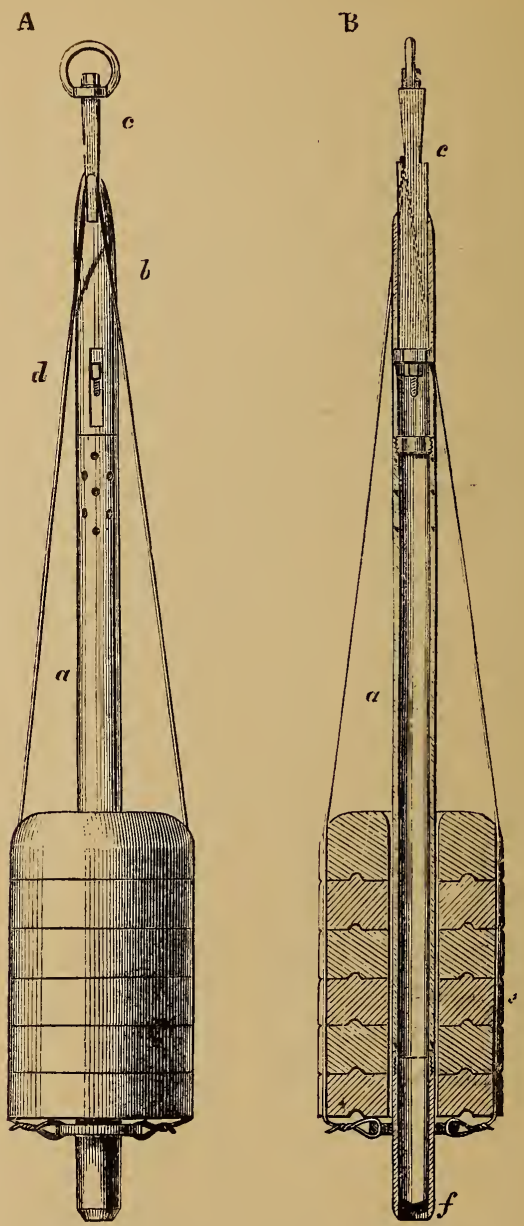

Fig. I 57.-Baillie Sounding Machine as USed on Board H.M.S. "Challenger."

A, In elevation; $\mathrm{B}$, in section. The heavy weights, $e$, drive the central tube, $a$, into the bottom deposit, and the ooze is retained in the tube by the butterfly valve, $f$. As soon as the suspension is relaxed, the shoulder carrying the wire which holds up the heavy weights becomes sheathed, the wire and weights being left on the bottom. 
various types of wire sounding machines, such as the Le Blanc, the Sigsbee, and the Lucas. The Lucas machine (Fig. I98, p. 282) is the one most frequently in use, and is extremely satisfactory. It seems unnecessary to describe these various instruments in detail ; their great advantage is that they indicate at once when the weight strikes the bottom. In well-appointed cable ships soundings in 2,000 fathoms can be made in an hour from start to finish, but in order to do this the wire must be hove in as fast as possible, and breakages of the wire frequently occur. One cannot, therefore, work at this rate with any regard to the safety of instruments attached to the wire. With hempen line the maximum rate of working can be observed, even when the line carries instruments. On cable ships there is usually plenty of old or damaged wire, and where the depth only is required, this old wire is sometimes used and cut adrift when the bottom has been reached in order to save the time of heaving it in.

A great many arrangements have been used with the sounding apparatus to bring up samples of the deposits forming on the bottom in deep water. The " arming " of the hand-lead with lard and tallow has already been mentioned; snappers, cups, and tubes with valves are also used for this purpose. Experience alone can show the best appliance to adopt in special circumstances. On board the "Challenger," when sounding over Red Clay areas, the Baillie sounding tube, $2 \frac{1}{2}$ inches in diameter, without butterfly valves, has been forced from 18 inches to 2 feet into the deposit, and has brought up a section of that depth, the total quantity of clay being more than enough to fill a quart bottle. So far as obtaining a sample of the bottom is concerned when sounding, this is the most successful 
record. Sometimes, however, the whole of the mud would slip out of the tube while being hauled up. To prevent this, valves and balls at the upper end of the tube were used with varying success. In positions where a typical Globigerina Ooze was expected, a butterfly valve was generally inserted in the lower end of the tube, and this arrangement was generally successful in retaining some of the deposit. To place three or four small tubes side by side, without valves, has been found a good arrangement. Gravel and small stones are the most difficult of all samples to recover, and for these the snapper (Fig. I99; p. 282), and the "Rendle tube" are the most successful. During the "Michael Sars" Expedition (IgIO) a heavy contrivance of Nansen's was successfully used to bring up a section of the deposit, but this entailed a stranded wire and a separate sounding operation.

In the dredge and trawl large quantities of the deposits were sometimes brought to the surface, and a careful examination of these threw a great deal of light on the samples procured by the sounding machine. Large samples of mud, ooze, or clay, were carefully passed through wire sieves (Fig. I58) with different sized meshes, and these coarse and fine "washings" were carefully preserved for future examination. It has often been regretted that larger samples procured in the dredge were not preserved and brought home without being passed through sieves.

The samples of deep-sea deposits which are procured are best preserved by being at once placed in wide-mouthed glass-stoppered bottles, and a small quantity of methylated spirit can be with advantage added, although this is not essential. Cork-stoppered bottles and tubes can also be used. Spirit, added to 
the samples which contain sea water, will throw down some of the sulphate of lime, in a gelatinous-like condition (Bathybius), but this is not a very serious objection. When a roll of the deposit is procured from the sounding tube, it should be surrounded with blotting paper, or pushed out on to blotting paper; the whole can then be enveloped by the paper, dried, and retained for future detailed examination. The colour of the sample and any other peculiarities

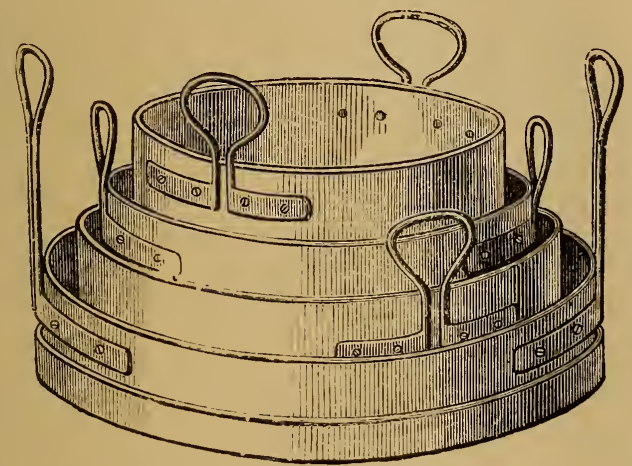

lig. I58. - Set of Sieves for Grading the Contents of DREDGe OR Trawl, OR Material Gathered ON SHore ("Challenger.")

For use the whole set is immersed in a tub of sea water.

should be carefully noted in the wet condition. A label should be put on the outside of the bottle or tube (not on the cork), as well as inside.

The Depth of the Ocean.-The ocean has now been sounded in nearly all directions, and our views as to the relief of the sea floor are slowly becoming more and more definite. It is often asserted that we know very little concerning the depth of the ocean, so few are the soundings compared with its vast extent. It is possible to underrate the extent 
of our knowledge in this respect, for if the extent of the ocean be great, it should be remembered that the uniformity of the conditions is also great over wide areas. Notwithstanding the great number of deepsea soundings recorded since I895, when the depthhemispheres in the final volume of the "Challenger" Reports were published, it is somewhat remarkable that the contours shown on these have been comparatively little altered in their broad general outlines, although many deeps and submarine elevations have been discovered in recent years, and in some regions the contour-lines now present a much more complicated appearance.

These depth-hemispheres have been kept up to date by Sir John Murray and Mr. J. G. Bartholomew. An inspection of the reduced chart given here will show at a glance where deep soundings are most abundant.

The greatest depth yet recorded in the ocean is 5,269 fathoms (9,636 metres), or 66 feet less than six English miles. This was a sounding taken by the U.S.S. "Nero" in the Challenger Deep to the south of the Ladrones, where the "Challenger" recorded a depth of 4,575 fathoms. Depths greater than 5,000 fathoms are also known in the Aldrich Deep in the South Pacific. There are altogether ten deeps in which depths exceeding 4,000 fathoms have been recorded, two of these being in the Atlantic, and the remainder in the Pacific. The term "deep" is limited to those parts of the ocean in which soundings of 3,000 fathoms or deeper have been taken. On the depth-hemispheres above referred to, fifty-seven deeps are now shown-thirty-two in the Pacific, eighteen in the Atlantic, five in the Indian Ocean, and two in the Southern Ocean south of latitude $40^{\circ} \mathrm{S}$. 


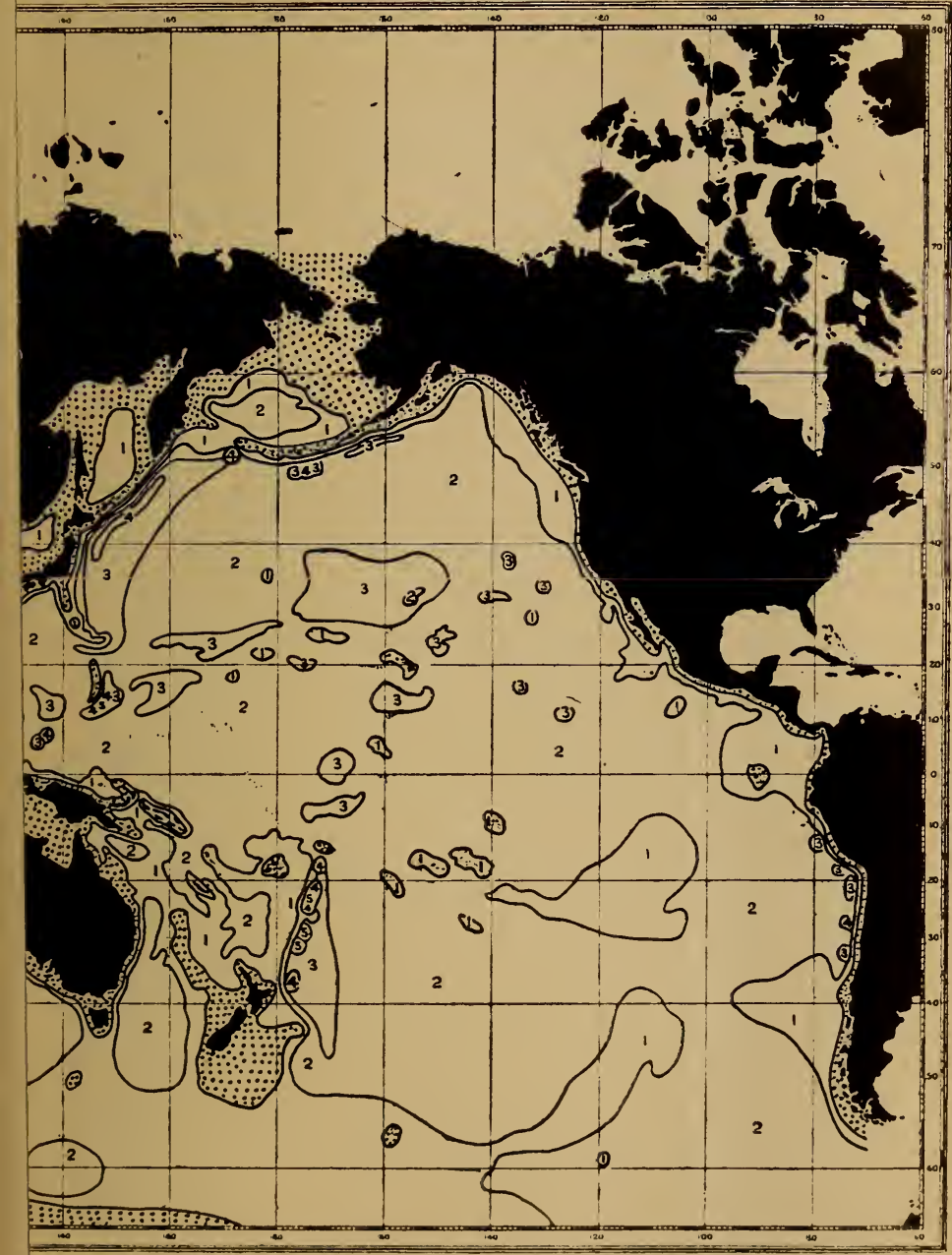

IURRAY.)

busand fathoms, the figure I meaning "over r,ooo fathoms," 2 meaning he Greenland area) for want of detailed observation. 



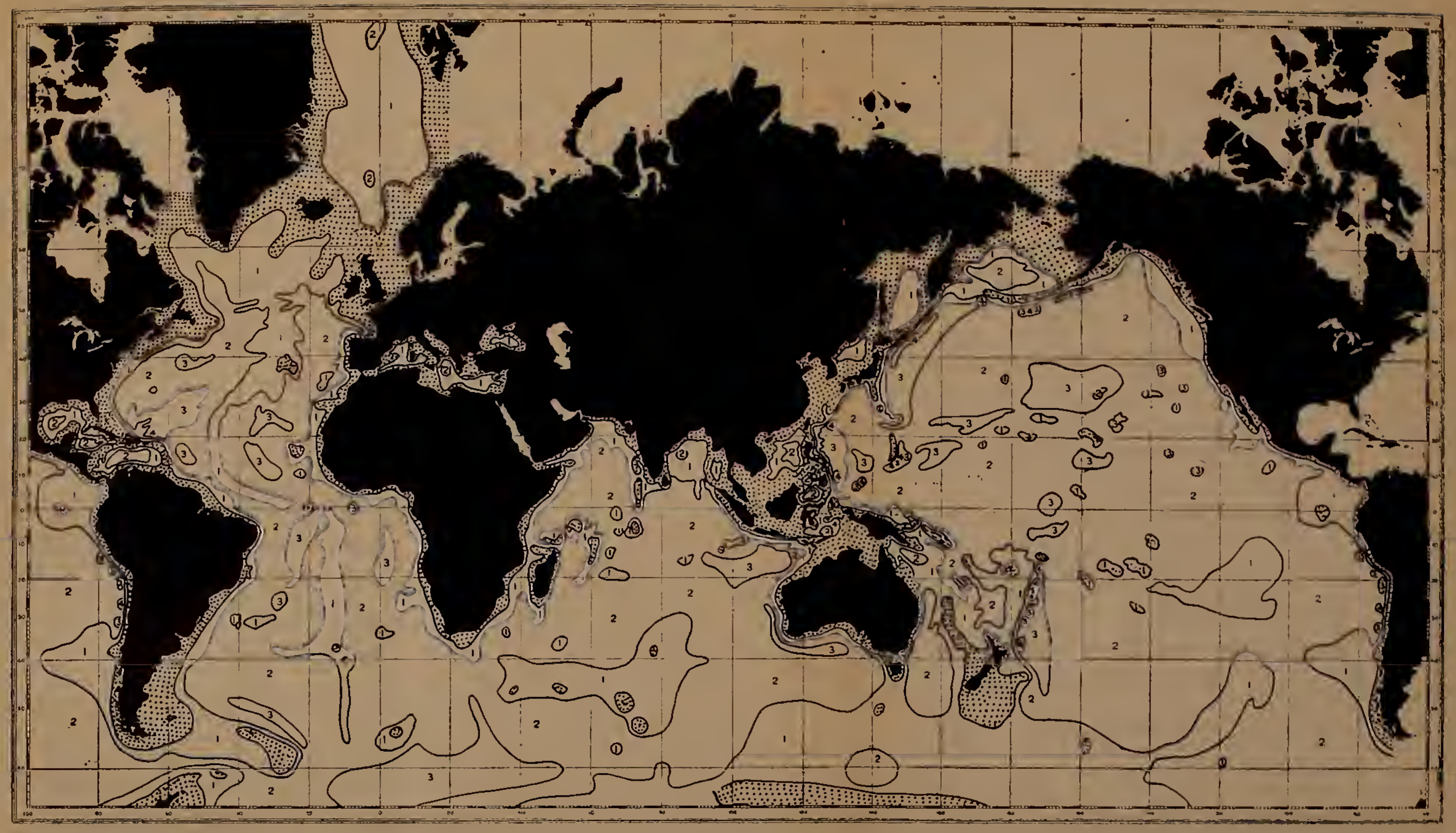

CHART VI.-DEPTHS. (After MURRAY.)

Depths of less than I, ooo fathoms are dotted: beyond these a contour line is drawn at every thousand fathoms, the figure I meaning "over 1,00o fathoms," 2 meaning "over 2,000 fathoms," and so on. The extreme North is left blank (except in the Greenland area) for want of detailed observation. 

From the data at present available the depths over the total floor of the ocean are now estimated as follows :

Between the shore line and the roo-fath.line, 7 per cent.

\begin{tabular}{|c|c|c|c|c|c|}
\hline ", & Ioo-fath. & ", & 1,000 & ," & 9 \\
\hline ", & I,000,", & ," & 2,000 & , & 19 \\
\hline & 2,000 & ", & 3,000 & ", & $5^{8}$ \\
\hline Over & 3,000 fathoms & & & & 7 \\
\hline
\end{tabular}

It will be seen from the above that the extent of the sea-bottom lying between the shore line and a depth of Ioo fathoms (6oo feet) is very nearly equal to the area lying between Ioo fathoms (6oo feet) and $\mathrm{I}, 000$ fathoms $(6,000$ feet). The first area is known as the continental shelf, and is regarded as belonging to the continental areas. Many portions of it were evidently dry land at no very remote geological period. Deep ravines frequently cross the continental shelf, and are believed to be submerged river valleys, which in some cases can be associated with still existing rivers-for instance, the Rhine and the Congo. The materials which cover the continental shelf are to a large extent under the influence of waves, tides, and currents, and are constantly subjected to transport by these agencies. It is believed that waves or currents do not transport other than the very finest particles at depths greater than Ioo to I50 fathoms (600 to 900 feet). In cup-shaped depressions, or sheltered bays within the Ioo-fathoms line, fine nuud may be deposited in relatively shallow depths, but on coasts facing the great ocean basins muddy deposits commence to form at an average depth of Ioo fathoms. Beyond that depth the whole floor of the ocean may be regarded as an area of deposition. We have as yet no evidence of transport by currents at these greater 
depths. ${ }^{*}$ The area between Ioo fathoms and the next 900 fathoms, it will be observed, covers only 9 per cent. of the whole floor of the ocean. This area is called the continental slope. It represents the sides of the ocean basins, and shows a relatively rapid descent into deep water; it is the only area of the ocean's floor which can be regarded as concave upwards.

Beyond I,000 fathoms the floor of the ocean becomes more and more flat and uniform :

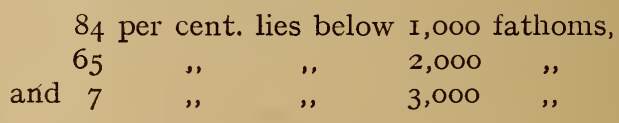

These great submerged plains sink, as we have seen, in some instances to depths of nearly six English miles, and at times they are interrupted by cone-like elevations, some of which do not rise to the surface of the ocean, while others do, and then form groups of volcanic or coral islands. Although a great many soundings have been recorded exceeding 3,000 fathoms, and a great many submarine elevations have been also recorded in recent years, still the general result of recent explorations has been to increase the area of the ocean lying between 2,000 and 3,000 fathoms.

Deposits on the Floor of the Ocean.-We have very few indications of the nature of the solid rocks forming

* On the Wyville Thomson Ridge, between the North of Scotland and the Faeroe Bank, mud is not deposited at depths of 250 and 300 fathoms. The tidal wave, being here confined, apparently sweeps the top of the ridge at these great depths, and we have evidence of the same phenomenon on the saddlebacks between contiguous oceanic islands, and on very deeply submerged ridges. Further observations in this direction are much desired. 
the base on which oceanic deposits have been laid down, and therefore all fragments of rock from a greater depth than Ioo fathoms should be carefully preserved for study. Along some continental coasts fragments have been dredged which indicate an outcrop of tertiary strata. Along some coral atolls solid calcareous rocks have been torn from larger masses, and off both coral atolls and volcanic islands fragments of igneous rocks thickly covered by peroxide of manganese have been broken from steep slopes, indicating an outcrop of volcanic rocks.

In the North Atlantic, from a depth of I, 460 fathoms, the telegraph engineers have brought up, by means of the " Lucas Grapnel," fragments of gneiss which had been broken off larger masses. These may have come from outcrops of bare rock in place, but more probably they were broken from large boulders of gneiss transported to the position by icebergs.

We have likewise very few indications of the thickness of the deposits now covering the floor of the ocean, or of the rate at which these are now forming. In the North Atlantic, telegraph engineers think there are reasons for supposing that about I inch of Globigerina Ooze accumulates in ten years. The rate at which this type of deposit accumulates where cold and warm currents meet at the surface, is probably greater than elsewhere; and the rate at which terrigenous deposits are laid down near the embouchures of large rivers is evidently greater than that of any other type of deposit. The deep Red Clay of the Pacific Ocean far from land appears to accumulate at an exceedingly slow rate.

The materials which make up oceanic deposits are now fairly well known, but are worthy of much more detailed study. They consist of inorganic and organic elements : 
I. Materials of all kinds borne to the ocean by rivers, winds, and floating ice, as well as what is torn from the coasts by waves, currents, and other agencies; these are termed " terrigenous" or " earth born."

2. Materials derived from volcanic eruptions, both submarine and subaerial. Volcanic dust is transported immense distances by the wind. Pumice of various types is worthy of special notice, because its areolar spongy structure, containing cavities filled with gas, admits of very wide distribution, by drifting on the surface of the ocean.

3. Materials of extra-terrestrial origin, which have fallen to the earth from interstellar space, such as cosmic spherules of iron and nickel, and chondrites with lamellar structure.

4. Materials of organic origin may be carried to the ocean by rivers and winds, but the chief source is the hard parts-the shells and skeletons-of organisms which live in the surface, intermediate, or bottom waters of the ocean. These may be composed of lime (calcium carbonate), such as calcareous Algæ, Foraminifera, Corals, Alcyonarian and Tunicate spicules, worm tubes, Ostracod and Cirriped shells, Echinoid spines, shells of Molluscs, Polyzoa, bones of fishes and whales, etc. ; or they may be composed of flinty (siliceous) spicules and frustules, such as Diatoms, Radiolarians, and Sponge spicules. In these organic remains it is important to distinguish between those which belong to floating or Plankton organisms, and those which belong to bottom-living or Benthos organisms. Generally speaking, it has been found that the remains of Plankton organisms predominate in the deposits of deep water far from land, and the remains of bottom organisms predominate in the deposits of shallow waters near shore. 
5. In addition to the foregoing there are many substances which may be termed " chemical" or " secondary" products. Clayey matter, which arises from the decomposition of pumice, felspars, and other minerals on the sea floor, may be regarded as a secondary product ; so also may the manganese nodules so abundant in some Red Clay areas, where the lapilli and bombs of basic rocks thrown out by volcanoes abound ; the palagonite and zeolitic materials found in the Red Clay may be placed in the same category. In addition, "greensand" (glauconite) grains, glauconlric casts of calcareous organisms, phosphatic concretions, sulphate of barium nodules, iron and calcareous concretions, must be classed among the secondary products now forming in the deposits on the sea bed, many of them through the intervention of decaying organic matter and bacteria.

The varied materials just enumerated are distributed very unequally over the floor of the ocean. The terrigenous materials are most abundant along the shores of continents and islands, and in all enclosed and partially enclosed seas. The geological structure of the adjacent land-masses determines the general character of the deposits along the shores and in the shallower waters, especially as regards the inorganic constituents. The deposits off coral-reef shores are, of course, chiefly made up of fragmentary particles derived from the growing reefs. The size of the fragments diminishes, as a rule, as the distance from the shore line and the depth of water increase ; but this is not always the case, for in the very centre of the Pacific and in very deep water rounded fragments of pumice have been obtained of all sizes, up to more than I foot in diameter. Again, in regions now, or in recent geological times, affected bv floating ice, large 
boulders and varied rock-fragments have been frequently dredged up hundreds of miles from land. It is known that seals and penguins may transport rockfragments in their stomachs to great distances. For these, among other reasons, the size of the particles is of little use for the purpose of the classification of marine deposits.

While the detrital matter from continents and islands, and the shells and skeletons of bottom-living organisms, prevail in the deposits near shore and in shallow water, the remains of pelagic or Plankton organisms, and chemical or secondary products, prevail in all the deep water deposits far from land. It is a remarkable fact, however, that in areas where the depth is 3,000 fathoms or deeper, hardly a trace of calcareous pelagic shells, such as those of Foraminifera and Pteropods, is to be found in the deposit, although these may be met with in great abundance in an adjacent area where the depth is only $I, 500$ or $I, 000$ fathoms. In like manner the skeletons of Radiolaria and the frustules of diatoms are not nearly so abundant in some deposits as would be expected from the numbers captured in the surfacewaters of the region. Both calcareous and siliceous remains are dissolved by sea water, and when they are not specially abundant in the surface waters, they may be very rare in, or wholly absent from, the deposits at the bottom. At other times these remains of pelagic organisms appear to be almost entirely masked by the terrigenous materials, or other organic remains, forming the deposit.

From the above considerations it is evident that the materials which go to form marine deposits vary in nature, abundance, and size, according to the structure of the nearest land, the character of the submarine volcanic eruptions, the distance from the shore line, 
the depth of water, and the nature of the organisms living on the bottom and in the surface and subsurface waters. After the detailed study of the marine deposits collected by the "Challenger " and other deepsea expeditions, Murray and Renard proposed the following classification :

\section{MARINe Deposits.*}

I. Deep-sea deposits beyond roo fathoms

\section{Red Clay} Radiolarian ooze

Diatom ooze

Globigerina oozc

Pteropod ooze

Blue mud

Red mud

Green mud

Volcanic mud

Coral mud
2. Shallow - water deposits, between lowwater mark and Ioo fathoms
Sands, gravels, muds, etc.
A. Pelagic deposits formed in deep water removed from land.

B. Terrigenous deposits, formed in deep and shallow water close to landmasses.

3. Littoral deposits between highand low-water marks
Sands, gravels, muds, etc.

It has frequently been pointed out, even by the authors themselves, that this classification is not perfect, but no better has been as yet proposed. It is

* Krümmel has recently introduced the term " hemipelagic" for the deep-sea terrigenous deposits, and "eupelagic" for the pelagic deposits in the above classification ("Handbuch der Ozeanographie," vol. i., p. 205, Stuttgart, 1907). These terms have, however, been employed already to express quite other facts. 
founded on the dominant element or characteristic aspect of each type of deposit, and attempts to bring into prominence their origin and constitution. There is no sharp line of demarcation between the different types; they all shade the one into the other, and it is often difficult to determine what name should be given to a deposit on the border line between two or three types.* For the information of the geologist, physical

* It is essential to be continually on one's guard against sources of error when examining deep-sea deposits. The object in view is to arrive at a true notion of the composition of the deposit as it lies at the bottom of the sea. Sometimes the trawl or dredge may come up filled with fully a ton of manganese nodules, or large and small fragments of pumice ; there may be hundreds of sharks' teeth mixed with dozens of ear-bones of whales. Some of these may have living Lepas or Hydroids, or Serpula, or Foraminifera, attached to them. It has sometimes been supposed that the whole deposit was composed of these remains; it is, however, almost certain that these various objects were embedded in clay, which passed through the meshes of the nets. The same may be observed with reference to the phosphatic and glauconitic nodules found in relatively deep water along continental shores. In using sounding tubes with butterfly valves, a large proportion of the finer parts of the deposit is sometimes washed out while the tube is being hauled in, and the larger calcareous organisms appear to be more abundant than they really are. When a large quantity of deposit is brought up in the dredge or trawl, and passed through sieves, the various constituents are separated, and the different portions have occasionally been described separately; in this way have arisen erroneously the names Orbulina ooze, Biloculina clay, and Coprolitic mud. In like manner the finer parts of a Radiolarian ooze have been described as Diatom ooze, and the coarser parts of a Diatom ooze as Radiolarian ooze. When the deposit is preserved in water or spirit, the sample is sorted into different layers by shaking ; if a portion be taken for description from the upper layers, and another from the lower layers in the bottle, widely different results will be obtained.

The best sample for description is that which is taken 
geographer, and others interested in marine deposits, it is specially important that descriptions should give as nearly as possible the proportions of the various constituents of which the deposit is made up, as well as the size of the mineral fragments. This, it is believed, can best be accomplished by the method adopted in describing the "Challenger" collections, as set forth in the following model :

\section{H.M.S. "Challenger."}

Station, 338. March 2I, 1876 .

Lat. $2 \mathrm{I}^{\circ} \mathrm{I} 5^{\prime} \mathrm{S}$. ; Long., $\mathrm{I} 4^{\circ} 2^{\prime} \mathrm{W}$.

Depth-I,990 fathoms.

Globigerina Ooze.-White, with slight rose tinge, granular, homogeneous, resembling chalk when dry.

Calcium Carbonate (92.54 per cent.).--Globigerinidæ, Pulvinulina (80.00 per cent.) ; Miliolidæ, Textularidæ, Lagenidæ, Rotalidæ, Nummulinidæ ( $\mathrm{r} \cdot 00$ per cent.); otoliths of fish, Gasteropods, Lamellibranchs, Pteropods, Heteropods, Lepas valves, Ostracods, Echinoderm fragments, Polyzoa, Coccoliths, Rhabdoliths (II.54 per cent.).

Residue (7.46 per cent.).-Reddish-brown.

Siliceous Organisms ( $\mathrm{r} \cdot \mathrm{oo}$ per cent.).--Sponge spicules, Radiolaria, imperfect casts of Foraminifera, Astrorhizidæ, Lituolidæ, a few Diatoms.

direct from the sounding tube, and it should be noted whether the sample is taken from the superficial or the deeper layers. With the knowledge we now possess it is possible for an expert to tell approximately the latitude, longitude, and depth from which a deposit has been procured. When, then, a sample bears a label showing a Globigerina ooze, for instance, from a depth or latitude which does not accord with experience, it raises suspicions of mislabelling. This has frequently occurred with samples labelled on the corks, which have becn interchanged. 
Minerals ( $\mathrm{I} \cdot 00$ per cent.).-Mean diameter $0.06 \mathrm{~mm}$., angular; felspar, hornblende, magnetite, magnetic spherules, pumice, a few manganese grains, bronzite spherules.

Fine Washings (5.46 per cent.).-Amorphous matter, with small mineral particles, and fragments of scoriæ and siliceous organisms.

REMARKS.-This is one of the purest Globigerina oozes obtained by the "Challenger," and is almost wholly composed of the dead shells of surface organisms. A few pumice fragments were found in the washings of a large quantity of deposit.

When carbonate of lime is present, the shells and other calcareous organic fragments are determined by microscopic examination. The lime is then removed from the sample by weak hydrochloric acid, and the relative percentages of lime and residue can be approximately estimated by inspection, or determined by a simple analysis. The nature and relative abundance of the clayey matter, mineral particles, and remains of siliceous organisms in the residue can be estimated by microscopic examination. A description of this kind can quite easily be carried out on board ship.

The following is a short description of the principal types of deep-sea deposits :

\section{A.-Pelagic Deposits.}

I. Red Clay.-This deposit is the most characteristic, and probably the most widely distributed, of all deepsea deposits over the ocean's floor, covering a very large portion of the deeper parts of the Pacific. The name is sufficiently expressive of the nature and appearance of this type of deposit, there being always a considerable 
proportion of amorphous clayey matter, usually of a reddish colour, passing in some regions into a dark chocolate colour from the abundance of small grains of peroxide of manganese. Usually the Red Clay contains very few, if any, remains of calcareous organisms, but occasionally there may be an appreciable admixture of the shells of pelagic and bottom-living Foraminifera, teeth and otoliths of fishes, fragments of Echinoderms, Molluscs, Ostracods, Polyzoa, etc., and on approaching shallower water in tropical and temperate regions, the shells of pelagic Foraminifera become more and more numerous until the Red Clay passes into Globigerina Ooze. The remains of siliceous organisms (Radiolaria, Diatoms, Sponge spicules, arenaceous Foraminifera) may generally be detected; and in some regions where the Radiolarian remains become abundant, the Red Clay passes gradually into Radiolarian Ooze, while in other regions towards the far north and far south the Diatom remains increase in number, and the Red Clay may pass into Diatom Ooze. Among the inorganic elements met with in Red Clay, the most constant and widely distributed is pumice, which occurs in larger and smaller fragments down to the most minute particles, and in all stages of disintegration and decomposition; the minerals found in pumice, like sanidine, plagioclase, augite, hornblende, magnetite, etc., are also present, along with basic volcanic glasses frequently transformed into palagonite. The peroxides of iron and manganese are universally distributed throughout the Red Clay, sometimes as minute grains or coatings, sometimes deposited as concretions around organic remains, pumice fragments, and other nuclei, forming manganese nodules of larger or smaller size, especially where the débris, ashes, and lapilli, of basic volcanic rocks are abundant and have undergone 
decomposition. These manganese nodules văry in form and size in different localities ; at one place they

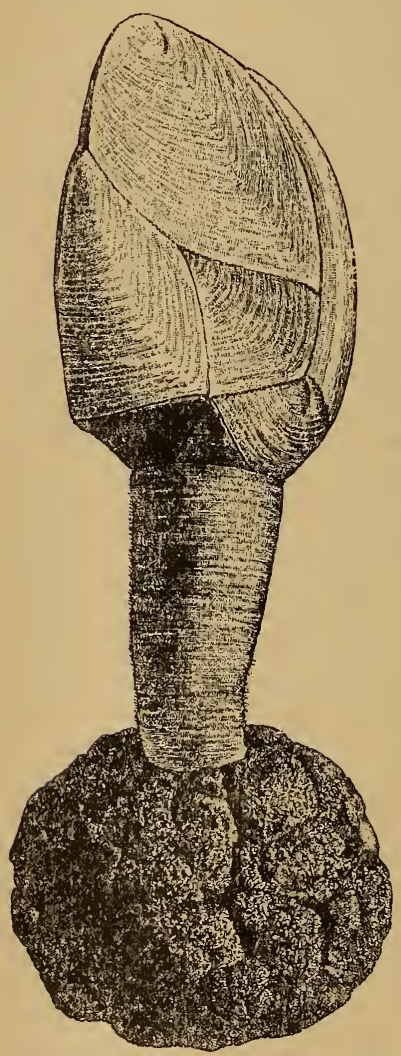

IF IG. I 59.- SCALPELLUM on a Manganese Nodule ("Challenger"). may be large, subspherical, and smooth, resembling a lot of potatoes; at another place smaller, like marbles; at another place large and spherical, but the external surfaces rough to the touch, owing to the numerous mammillations (Fig. I59); at another place flattened with one side rougher than the other; and at yet another place the nodules take the form of huge slabs. With the manganese nodules are usually associated, especially in deep water far from land, numerous

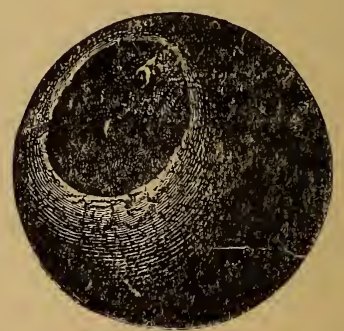

Fig. i6o.-Spherule with Metallic Nucleus COATED WITH Black MAgNeTite, SUPPOSED TO BE OF Cosmic ORIGin ("Challenger").

teeth of sharks and ear-bones of whales, impregnated and coated more or less thickly by the peroxides of iron and manganese. In the Red Clays, also, numerous minute magnetic spherules (Fig. I60), some with 
metalfic nuclei, have been met with, and have also been extracted from the manganese nodules after these have been broken up in a mortar; these spherules are supposed to have fallen from interstellar space, and are hence called " cosmic spherules." In some positions, again, there are small zeolitic crystals (phillipsite), as individuals, twins, stellate groups, and spherulitic aggregations ; these are supposed to be secondary products, formed " in situ," arising from the decomposition of the basic volcanic particles present in the deposits.

Red Clay is estimated to cover an area of about 5I,500,000 square miles (or I33,975,000 square kilometres)-i.e., about 40,800,000 square miles in the Pacific Ocean, about 5,800,000 square miles in the Atlantic Ocean, and about 4,900,000 square miles in the Indian Ocean.

2. Radiolarian Ooze.-This deposit is distinguished by the abundance of the skeletons of Radiolaria, and is found typically in very deep water in the tropical regions of the Pacific and Indian Oceans. It is otherwise similar to the Red Clay just described, and may contain a few shells of pelagic Foraminifera and small angular volcanic mineral particles, fragments of pumice, augite, felspars, hornblende, magnetite, volcanic glass, frequently altered into palagonite, as well as manganese nodules, sharks' teeth, and earbones of cetaceans.

Radiolarian Ooze is estimated to cover an area of about 2,290,000 square miles (or 5,957,000 square kilometres)-i.e., about $I, I 60,000$ square miles in the Pacific Ocean, and about I,I30,00o square miles in the Indian Ocean.

3. Diatom Ooze.-This deposit is distinguished by the prominence of Diatom frustulcs (skeletons), and is therefore characteristic of those regions in which 
these pelagic plants swarm in the surface waters, as in the extreme northern part of the Pacific and far south in the neighbourhood of the Antarctic circle. The skeletons of Radiolaria and the shells of one or two species of pelagic Foraminifera are usually present, as well as continental mineral particles and ice-borne rock fragments, since this deposit occurs generally within the regions affected by floating ice (Fig. I6I).

In some of the Red Clays and Radiolarian Oozes of the Central Pacific the frustules of the large Diatom Coscinodiscus rex are so abundant that the deposit has sometimes been described as a Diatom Ooze.

Diatom Ooze is estimated to cover an area of about I0,880,000 square miles (or $28,300,000$ square kilometres)-principally in the Southern Ocean, with a small area in the North Pacific Ocean.

4. Globigerina Ooze.-This deposit is named from the predominance of the dead shells of Foraminifera, which lived in the surface waters of the ocean, the genus Globigerina (Figs. 78, I62) being the most characteristic, though the representatives of other genera are usually present in the tropics (Fig. I63). Associated with the shells of pelagic Foraminifera are the shells of pelagic Molluscs (Pteropods and Heteropods), pelagic calcareous Algæ (Coccospheres and Rhabdospheres, or their broken fragments-Coccoliths and Rhabdoliths), as well as the remains of calcareous organisms, which habitually live on the bottom of the sea, such as Molluscs, Echinoderms, Annelids, Corals, Polyzoa, and bottom-living Foraminifera. The remains of siliceous organisms (Radiolaria, Diatoms, and Sponge spicules) may generally be detected, and a few small mineral particles, such as felspar, augite, hornblende, magnetite, and volcanic glass, with a small quantity of 


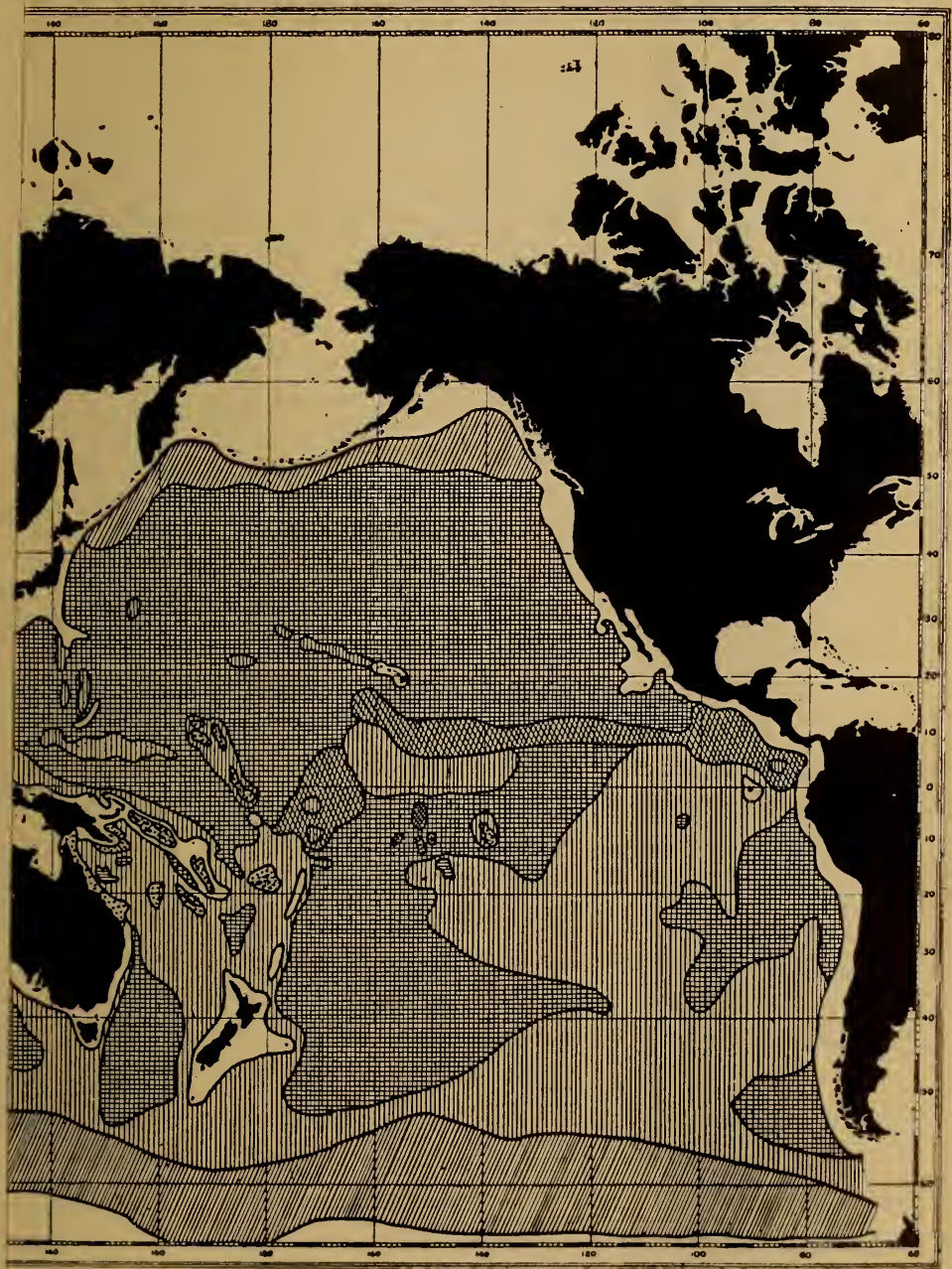

Dolatom ooze radolarian ooze reo cuit

OSITS.

lown.

[Between pp 220, 22x. 



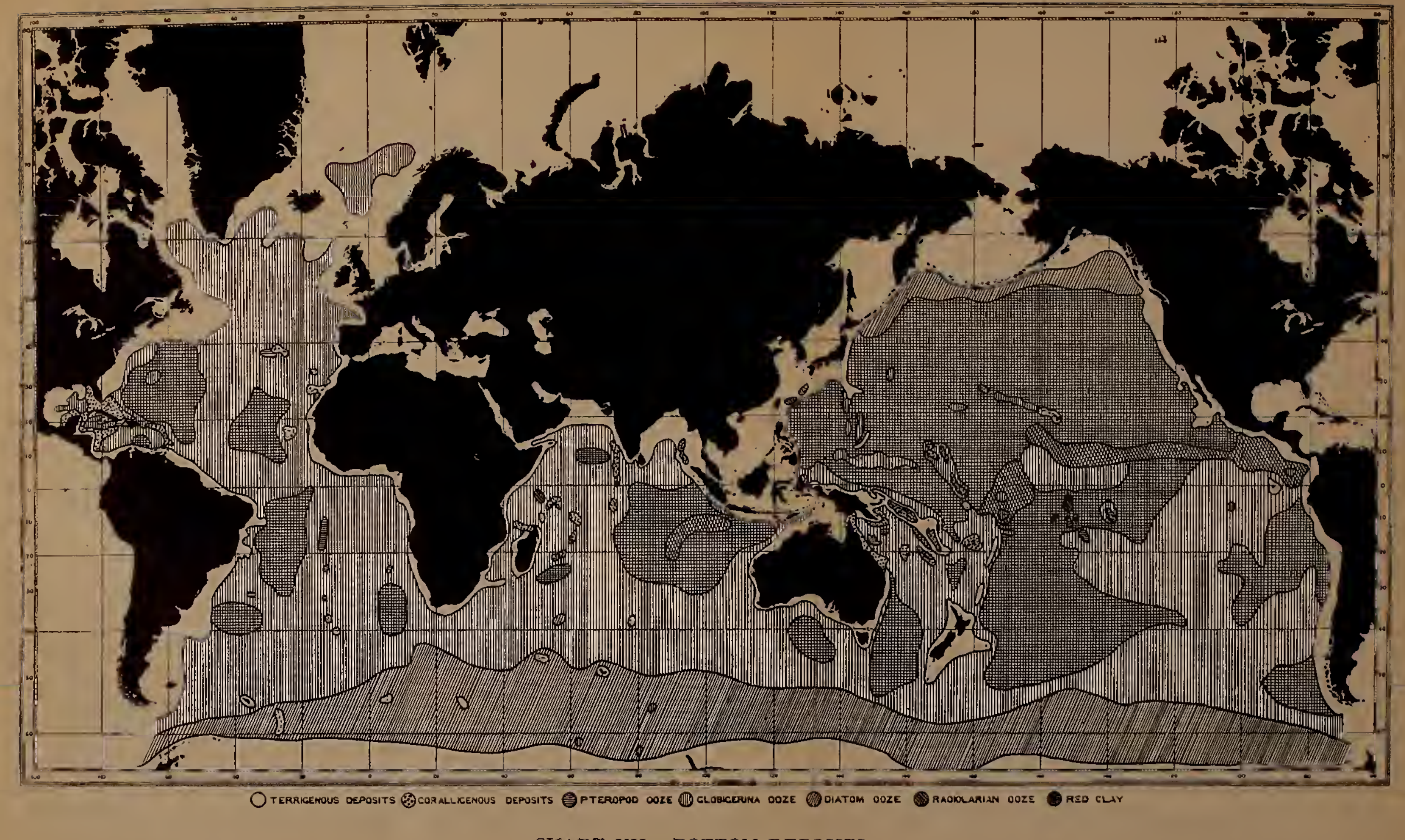

CHART VII.-BOTTOM DEPOSITS

Only the larger areas are here shown. 

clayey matter coloured by the oxides of iron and manganese. This deposit varies greatly in composition both with respect to the species of organisms present and their relative abundance, and also in the abundance and nature of the mineral constituents. In all the great depths of the ocean, exceeding 2,500 or 3,000 fathoms, Globigerina Ooze gives place to Red Clay, even in those regions where pelagic Foraminifera inhabit the surface waters in great profusion; this is ascribed to the longer time during which the shells are exposed to the solvent action of sea water, while falling through the greater depth of water, and while lying uncovered on the bottom.

Globigerina Ooze is estimated to cover an area of about 49,520,000 square miles (or I28,824,000 square kilometres)-i.e., about 22,500,000 square miles in the Atlantic Ocean, about $14,800,000$ square miles in the Pacific Ocean, and about $12,220,000$ square miles in the Indian Ocean.

5. Pteropod Ooze.-This deposit differs from Globigerina Ooze only in the greater abundance of the shells of pelagic Molluscs (Pteropods and Heteropods), and occurs characteristically at lesser depths than the Globigerina Ooze (Fig. I64). Thus Pteropod Ooze may be said to attain its typical development at depths of 800 to I,000 fathoms, while Globigerina Ooze occurs typically at depths of 1,500 to 2,000 fathoms. The reason why the shells of pelagic Molluscs are removed from the deposits at lesser depths than the shells of pelagic Foraminifera is believed to be that these thin and fragile shells present a larger surface to the solvent action of sea water.

Pteropod Ooze is estimated to cover an area of about 400,000 square miles (or I,000,000 square kilometres), principally in the Atlantic Ocean. 


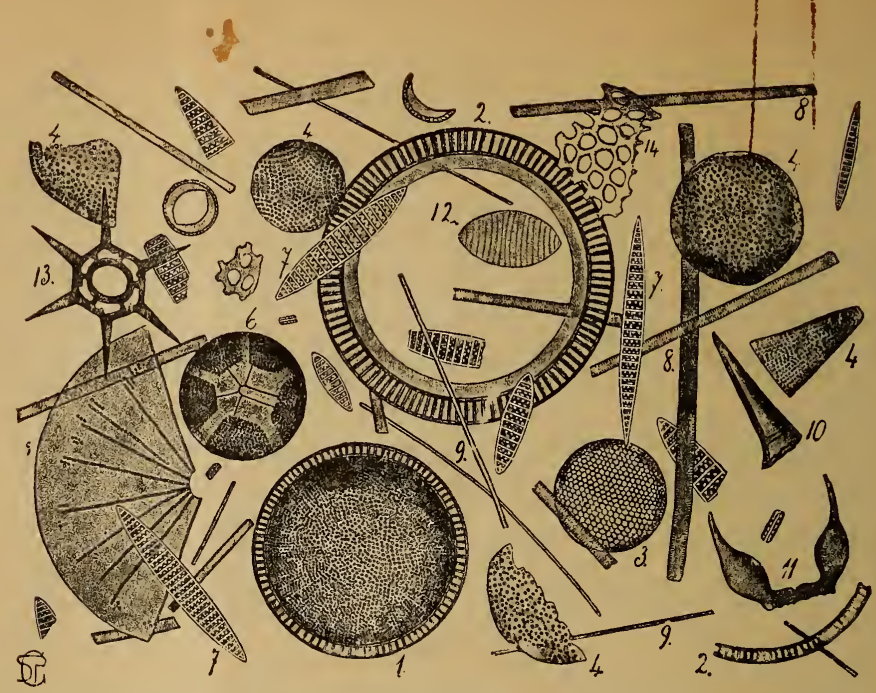

Fig. I6r.-Diatom Ooze. (AFter ChUn, FROM "KrUmMel's OCEANOGRAPHIE," BY PERMISSION OF J. ENGELHORN'S VERLAG IN STUTTGART.)

I-5, Coscinodiscus ; 6, Asteromphalus ; 7, Fragilaria antarctica ; 8, 9, Synedra ; Io, Rhizosolenia ; I I, Chætoceras ; I 2, Navicula (?) ; I 3, Dictyocha ; I4, a broken Radiolarian.

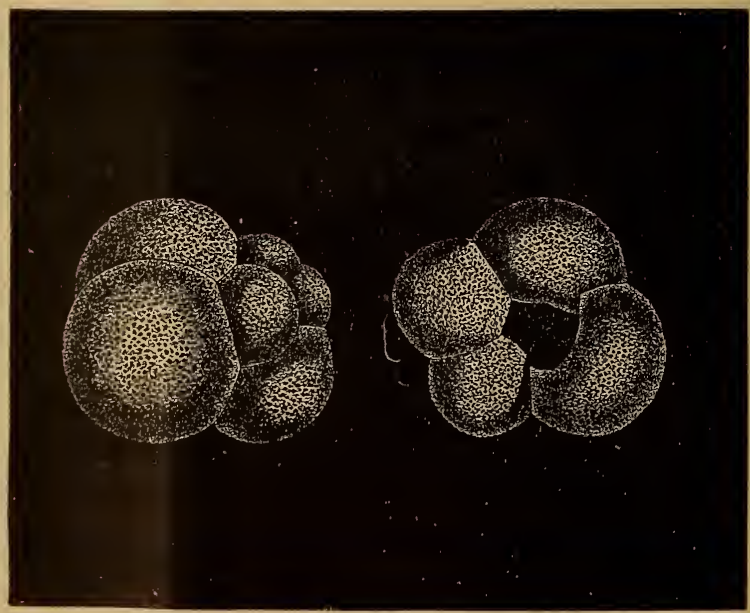

Fig. I62.-Dead Shells of Globigerina, tile Spines of IVhich HAVE BEEN Dissolved IN THEIR FAlL to THE BotToM ("Challenger"). 


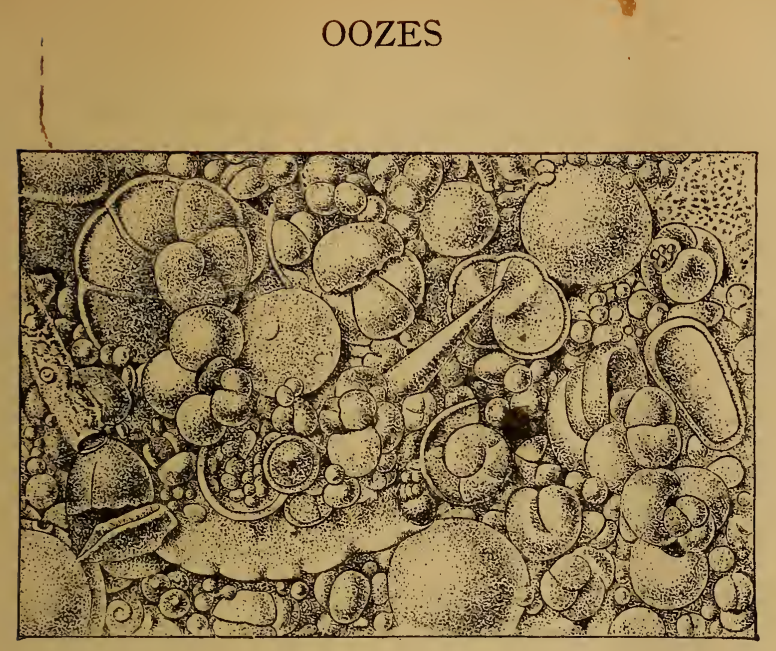

Fig. I63.-GLOBIGERINA OOZE, CONSISTING LARgELY OF Foraminiferan Shells ("Blake").

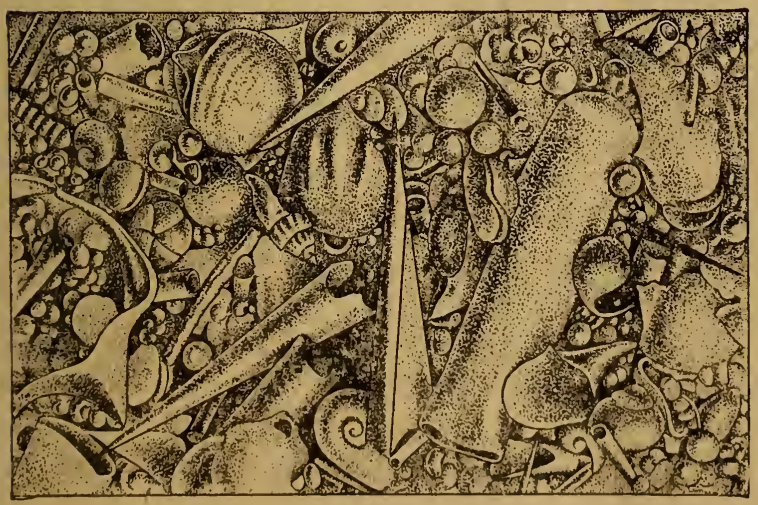

Fig. I64.-Pteropod OOze, Consisting MaINly of Pteropod and Foraminiferan Shells ("Blake").

These figures were originally taken from the "Challenger" Reports. 


\section{B.-Terrigenous Deposits.}

6. Blue Mud.-This deposit is the one most frequently met with in the deeper waters surrounding continental land and in enclosed and partially enclosed seas. It is principally composed of materials derived from the disintegration of continental land, consisting largely of the fragments and minerals of continental rocks (the older crystalline and schistocrystalline rocks, quartzites, sandstones and limestones) of various dimensions, but usually larger near shore and smaller as the deep sea is approached, except in the regions affected by floating ice. Quartz is the characteristic mineral species, associated with orthoclase and plagioclase felspars, green hornblende, mica, etc; glauconite is usually present, but not in such abundance as in the Green Mud. There is usually a considerable proportion of amorphous clayey matter, increasing in amount with increasing distance from land, so that some of the deeper samples have a decidedly clayey aspect, but the deposit, as a rule, may be described as earthy rather than clayey. In some situations the remains of bottom-living organisms may be present in considerable numbers, and in others the remains of pelagic organisms may be so abundant that the deposit resembles a Globigerina Ooze.

Blue Mud is estimated to cover an area of about I4,500,000 square miles (or $37,700,000$ square kilometres).

7. Red Mud.-This is a local variety of Blue Mud, hitherto known only from the Yellow Sea in the Pacific, and off the Brazilian coast in the Atlantic, characterized by the presence of a large quantity of reddish ferruginous matter brought down by the large rivers in the vicinity. 
Red Mud is estimated to cover an area of about I00,000 square miles (or 260,000 square kilometres).

8. Green Mud.-This is a variety of Blue Mud, found along bold exposed coasts where no very large rivers enter the sea, and distinguished by the greater or less abundance of green glauconite grains and glauconitic casts (internal models in green sand), of the shells of calcareous organisms, usually associated with a greenish amorphous (probably organic) matter. In the shallower depths the glauconitic grains and casts are sometimes associated with phosphatic concretions, while the amorphous clayey matter is less abundant, and the deposits, being more granular and more incoherent, are called Green Sands.

Green Mud is estimated to cover an area of about I,000,000 square miles (or 2,600,000 square kilometres).

9. Voleanic Mud.-This deposit occurs around oceanic islands and submarine elevations of volcanic origin, and is made up largely of volcanic rock fragments and volcanic mineral particles, such as lapilli of basaltic and andesitic rocks, especially the vitreous varieties, sanidine, plagioclase, augite, hornblende, rhombic pyroxenes, olivine, and magnetite. In the shallower waters the volcanic particles are larger, associated with less amorphous clayey matter, and the deposits, being less coherent, are called Volcanic Sands. The remains of floating or bottom-living calcareous organisms may become so abundant that it is sometimes difficult to distinguish this deposit from a Globigerina Ooze on the one hand, or from a Coral Mud or Sand on the other.

Volcanic Mud is estimated to cover an area of about 750,000 square miles (or I,950,000 square kilometres). 
Io. Coral Mud.-This deposit occurs off coral islands and coral reefs, and is chiefly made up of fragments of organisms living in the shallow waters and on the reefs, such as calcareous Algæ, Corals, Molluscs, Polyzoa, Annelids, Echinoderms, and Foraminifera. In the shallower waters near the reefs these calcareous fragments are larger, and the more finely divided calcareous matter is less abundant, than in the deeper waters further removed from the reefs; the deposits are then called Coral Sands. These deposits may contain, at times, much volcanic material.

Coral Mud is estimated to cover an area of about $2,700,000$ square miles (or 7,000,000 square kilometres).

\section{General Remarks.}

The Black Sea is far removed from the great oceans, and its deeper water is cut off by submarine barriers at the Bosphorus from the Mediterranean, which in its turn is cut off from the Atlantic by an additional barrier at the Straits of Gibraltar. Vertical circulation is much restricted by this and by the fact that the surface layers are often much less saline than the deeper layers; hence the deeper waters of the Black Sea become more or less saturated with sulphuretted hydrogen; no living organisms (other than bacteria) are met with in depths greater than Ioo fathoms. Amorphous carbonate of lime is precipitated from the water of the Black Sea, and makes up a considerable part of the deposits now in process of formation; this is the only place where this is known to occur in the seas of the present day. In all partially enclosed seas - like the Mediterranean and the Red Sea-circulation is generally cut off by submarine barriers, and this results in thermal and other conditions which are 
less favourable to organisms than the conditions existing in the open ocean. The deposits in those seas which interpenetrate the continental masses are terrigenous in origin, although there may be an approach to pelagic conditions towards the more central parts.

It has already been observed that the continental shelf facing the great oceans is continually swept by waves, tides, and oceanic currents, down to an average depth of roo fathoms. Just beyond this depth all the minute mineral and organic fragments from the continental shelf come to rest on the bottom, and form what I have called the " mud line." This constitutes the great feeding ground of the ocean. Large numbers of Holothurians and other marine creatures here eat the mud to obtain the organic matter associated with it. Indeed, it is more than probable that all marine deposits are in this way passed through the intestines of organisms. Very many Crustaceans frequent this area to pick up the little particles of organic matter which are just settling on the bottom, and some of them-like Nyctiphanes-are provided with phosphorescent organs to enable them to do this more effectively. All these mud-eating creatures are in turn the prey of carnivorous animals, both vertebrate and invertebrate.

The continental slope extends from the mud line (I00 fathoms) down to the mean sphere level (I,450 fathoms).* The continental slope, and similar areas around oceanic islands, present a greater variety of conditions than is found elsewhere on the ocean bed.

* If all the elevated portions of the earth's crust were cut away, and filled into the hollows till the whole surface was uniform, then the whole earth would be covered by an ocean $\mathbf{I}, 450$ fathoms in depth-the mean sphere level. 
At the upper limit the sun's rays may produce twilight, but elsewhere there must be total darkness, except where this is relieved by the phosphorescent light of organisms. The temperature conditions are likewise widely different at the upper and lower limits of the region. At some points the descent from the Ioofathom line is known to be almost perpendicular; at other points outcrops of stratified and volcanic rocks are indicated.

The deposits now being laid down over the continental slope vary greatly according to position. Off large rivers they are chiefly made up of detritus from the land; at other places, especially where cold and warm currents alternately occupy the surface, pelagic conditions are more or less pronounced, and greensand and phosphatic deposits are being laid down; quartz and other continental minerals predominate. Generally it may be said that in enclosed seas, and along the continental shelf and slope, deposits are being formed quite similar to those which have made up the stratified rocks of past ages. Indeed, it seems as if inland seas and the borders of continental masses had again and again been pushed up into dry land, and again and again been torn down and transported to the ocean by the same denuding and disintegrating agents, the final result being that quartz particles accumulate on the continental areas, rendering these rocks specifically lighter than the deposits on the oceanic areas.

In the abysmal regions, beyond the depth of the mean sphere level, covering about one-half of the earth's surface, the physical conditions are uniform and widespread; the temperature everywhere approaches zero Centigrade; the darkness is relieved only by phosphorescent light; motion of all kinds must be extremely slow, and there is little evidence of transport 
or erosion. In these cold and silent depths the deposits vary according to the surface conditions; where organisms which secrete carbonate of lime abound at the surface, we find Globigerina or Pteropod Oozes at the bottom; where silica-secreting organisms abound at the surface, we find Radiolarian or Diatom Oozes at the bottom. In very great depths the calcareous organisms are removed by solution, and in some places the siliceous skeletons are also partly removed. From the deep water of the South Pacific Ocean, at points the farthest removed from continental land on the globe, the trawl brings up over wide areas hundreds of sharks' teeth and dozens of ear-bones of whales, some of them belonging to extinct species, tons of manganese nodules, and, mixed up in the clay, magnetic spherules of metallic iron and nickel, and chondres, which are only found in meteorites. All the indications go to show that the rate of accumulation of the deposit is extremely slow, possibly not more than a foot since Tertiary times. The reason why these teeth and bones and extraterrestrial spherules are found here more abundantly than elsewhere is because few other materials reach these remote and deep areas to cover up or mask them, as in other deposits.

Throughout the abysmal area quartz fragments, when present, are rare, when compared with their abundance in the terrigenous deposits close to shore, and it is very doubtful if any stratified rock has yet been discovered which can be regarded as the equivalent of any deposit now forming in the deep water far from continental land. It is extremely difficult to imagine how a continent, as we understand the term, could ever have existed in the centre of any of the great ocean basins, which appear to be the most stable portions of the earth's crust, while the continental 
areas, especially the border regions, are the most unstable.

From a recent examination of some "Challenger" deposits sent to him from the "Challenger" Office, Professor J. Joly has been able to give the radium contents of deep-sea deposits. He finds that the Red Clays and Radiolarian Oozes contain much more radium than the Globigerina Oozes or terrigenous deposits ; in fact, the radium content is greatest where the rate of deposition is believed to be the least. The idea at once suggests itself that this is connected with the greater amount of cosmic dust in the deep deposits far from land. This is well worthy of the attention of those who in future may dredge up large samples of deposits from the Red Clay areas. 


\title{
CHAPTER VII
}

\section{ANIMALS OF THE SEA FLOOR}

\author{
BY W. T. CALMAN AND G. P. FARRAN
}

IN dealing with the fauna of the sea bottom it is necessary to make use of some convenient and natural classification of the subject. It has long been recognized that, in passing from the shallow water surrounding the shore to the abysses of the ocean, we find many striking changes in the character of the inhabitants associated with the increasing depth; and a classification based on the depth at which the animals live is a more or less natural one. While those areas or zones of depth which are commonly accepted are marked out, rather on account of their physical features than because they possess separate faunas sharply defined from each other, still the assemblage of animals found in each zone, taken as a whole, differs considerably from those of the other zones, and may conveniently be dealt with apart from them.

The zones of depth usually distinguished in European seas are based on those originally defined by Edward Forbes in the middle of the last century. These were the Littoral Zone, the Laminarian Zone, the Coralline Zone, and the region of Deep-Sea Corals. For the last two may be substituted the Continental Shelf and the Continental Slope, and to the list may be added the ocean floor, a region which in Forbes's day was believed to be devoid of living inhabitants, but which more 
recent research has proved to have a varied fauna. These zones must be taken as applying primarily to the shores of the North Atlantic and the Mediterranean, but with some small alteration will be found to hold good for many other seas.

The Littoral Zone, or the space between high and low water mark, is dealt with elsewhere in this volume (Chapter III.). It is necessarily inhabited by a fauna which is able to endure a certain amount of periodic exposure to the air. At its lower limit it passes into what is known in European waters as the Laminarian Zone, taking its name from the oarweed or Tangle (Laminaria), which, with other seaweeds, is its most striking feature. It extends to a variable depth, usually less than I5 fathoms. Though the name Laminarian is somewhat restricted in its application, yet the physical characters of this zone may be recognized almost universally. These may be summed up as the penetration of sunlight, and the consequent presence of abundant vegetable life in the form of brown and red seaweeds ; the exposure to violent wave action which may stir up sediment, and the lowered salinity from the surface drainage of the land even in the absence of any large rivers. It is in this zone that we must look for the majority of the vegetable feeders of the sea, with the exception of those which live upon minute floating diatoms and similar organisms of the Plankton.

Below the region in which the brown seaweeds flourish, or (speaking very roughly) from I5 fathoms downwards, lies the region which we now deal with comprehensively as the Continental Shelf.

As a general rule the land-masses of the globe are surrounded by an area of comparatively shallow water, varying in extent, which has been called the " area of 
the Continental Shelf." This shelf or margin, sloping gradually to a depth of 100 or 200 fathoms, and extending for a distance of from 20 to 200 miles from the shore, is succeeded by a relatively steep declivity, the Continental Slope, descending to the ocean floor; this latter then stretches, at a depth of between I,000 and 3,000 fathoms, over an area measuring about onethird of the whole surface of the globe, and is hollowed out in places into depths of 4,000 or even 5,000 fathoms (compare Chapter VI.). The edge of the Continental Shelf may be taken as a dividing line between two faunal areas, the sloping descent of a continent to the ocean floor being regarded as a sort of neutral ground which, while having a few inhabitants that belong more properly to the Continental Shelf and a few peculiar to itself, is for the most part peopled by species which may be regarded as belonging to the fauna of the deep sea.

It is to be remembered that this dividing line does not mark any sudden change either in the physical conditions or in the animals to be met with, and that any limit which may be chosen must in the nature of things be more or less an arbitrary one, and its position will be different in different regions.

The physical conditions prevailing over the sea bottom are dealt with fully in other parts of this volume (Chapters II. and VI.), and it is only necessary to call attention to some of the chief differences between the areas which we are considering.

\section{The Continental Shelf.}

Throughout the area of the Continental Shelf we find that the variability and liability to sudden alterations in physical conditions, which are so noticeable in the shallow water, are very much reduced. The changes 
in temperature are rather seasonal and gradual than diurnal or rapid, and are not dependent immediately on the alterations of the temperature of the air. The mean temperatures in various regions show, of course, very great differences.

The salinity, like the temperature, is locally fairly constant, the changes being slow, and the range comparatively small, though great differences may be noticed between different seas. The light is very much diminished, passing from a dim twilight in the more shallow parts to complete darkness in the deeper. The actual depth to which light can penetrate depends very much on the clearness and freedom from sediment of the water; but it may be taken that at depths exceeding roo fathoms practically no light can be received from above, while at depths considerably less the amount of light is so small as to have little influence on life.

The absence of light entails the absence of plant life and consequently of vegetable feeders, with the exception of such forms as subsist on microscopic floating vegetable matter. The greater part of the area is too deep to be troubled by wave action, and the force of tides and currents is much diminished. The bottom is fairly uniform over large areas, though the actual types of bottom do not differ materially from those found immediately adjoining, the shore, the materials of the sea floor in both cases being derived from the débris of the adjacent land. It is usually the case that the composition of the bottom becomes finer as the depth and the distance from shore increase, but this is by no means a universal rule, gravel, rocks, and stones being often met with even beyond the edge of the Continental Shelf. The water overlying this zone 
contains in suspension a quantity of organic and mineral matter derived from the shore.

Taken as a whole, the area from low-water mark to the edge of the Continental Shelf possesses a fauna which is perhaps richer and more varied than that of any other area on the surface of the globe. A catalogue of its inhabitants would include all the chief types of invertebrate animals (except the air-breathing Arthropods) and many fishes. It would be impossible within the space at our disposal to attempt even an outline sketch of this fauna and of its variations in different parts of the world, but for the guidance of those unfamiliar with zoology a few of the commoner types represented in the illustrations may be mentioned.

Sponges (Porifera) often form a conspicuous part of the contents of the dredge or trawl in waters of moderate depth, and deserve the attention of the collector, not only for their own sake, but also on account of the numerous Crustacea, worms, and other animals which burrow in them or shelter in the crevices. In passing from shallow to deeper water the shapeless encrusting sponges of the littoral region are replaced, in part at least, by types of definite and often beautiful form (Fig. 165). This is especially the case with the glasssponges (Hexactinellida), of which the well-known Venus's Flower-basket is an example.

Below the depth at which true seaweeds flourish the dredge is often filled with masses of what the fisherman or trawler terms "weed," but which the zoologist recognizes as plant-like animals. Even for the zoologist it is not always easy to distinguish by the unaided eye between the feathery tufts of Hydroids (Figs. 90, 9I, I67) and the much more highly organized Polyzoa. Belonging to the same division of the animal kingdom (Coelenterata) as the Hydroids are the sea-pens, or 


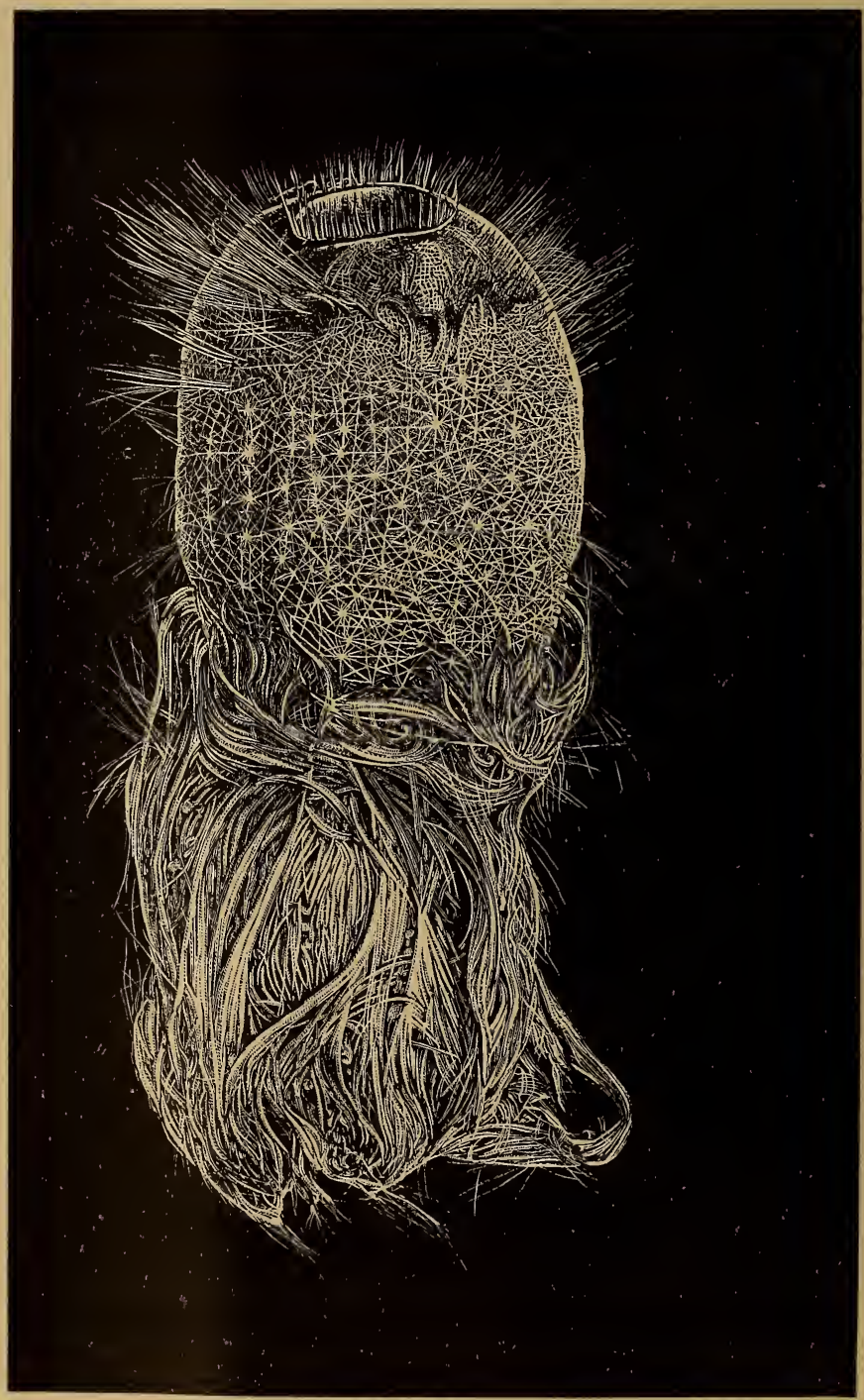

Fig. I65.-Holtenia, a Deep-Sea Glass Sponge ("Challenger"). 
Pennatulida (Fig. I68), the sea-fans, or Gorgoniacea (Figs. I69, I70), the fleshy masses of the " dead-men'sfingers" (Alcyonaria), the sea anemones, the red "or precious coral (Corallium), and the true corals (Madre-

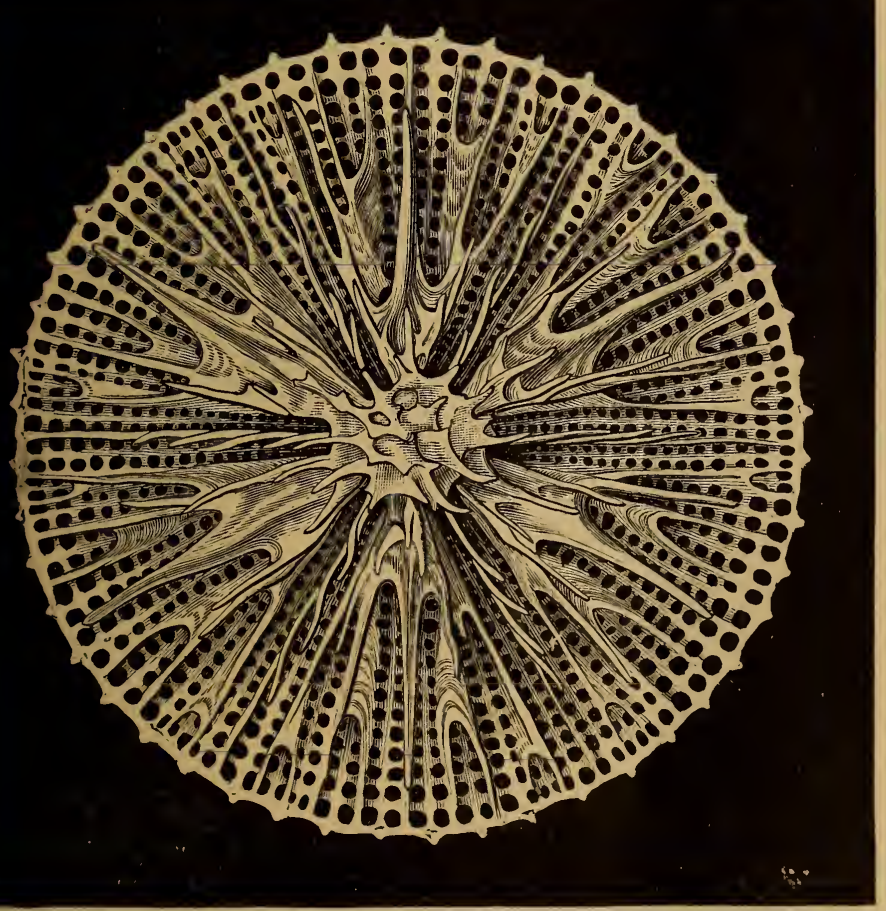

Fig. i66.-Leptopenus, a Deep-Sea Coral (“Challenger").

poraria), both colonial (Fig. 26, p. 90) and solitary (Fig. I66); the true corals are by no means confined to the warmer seas, although it is only there that they display their full luxuriance.

Starfishes (Fig. I74), brittle-stars (Fig. I73), sea- 


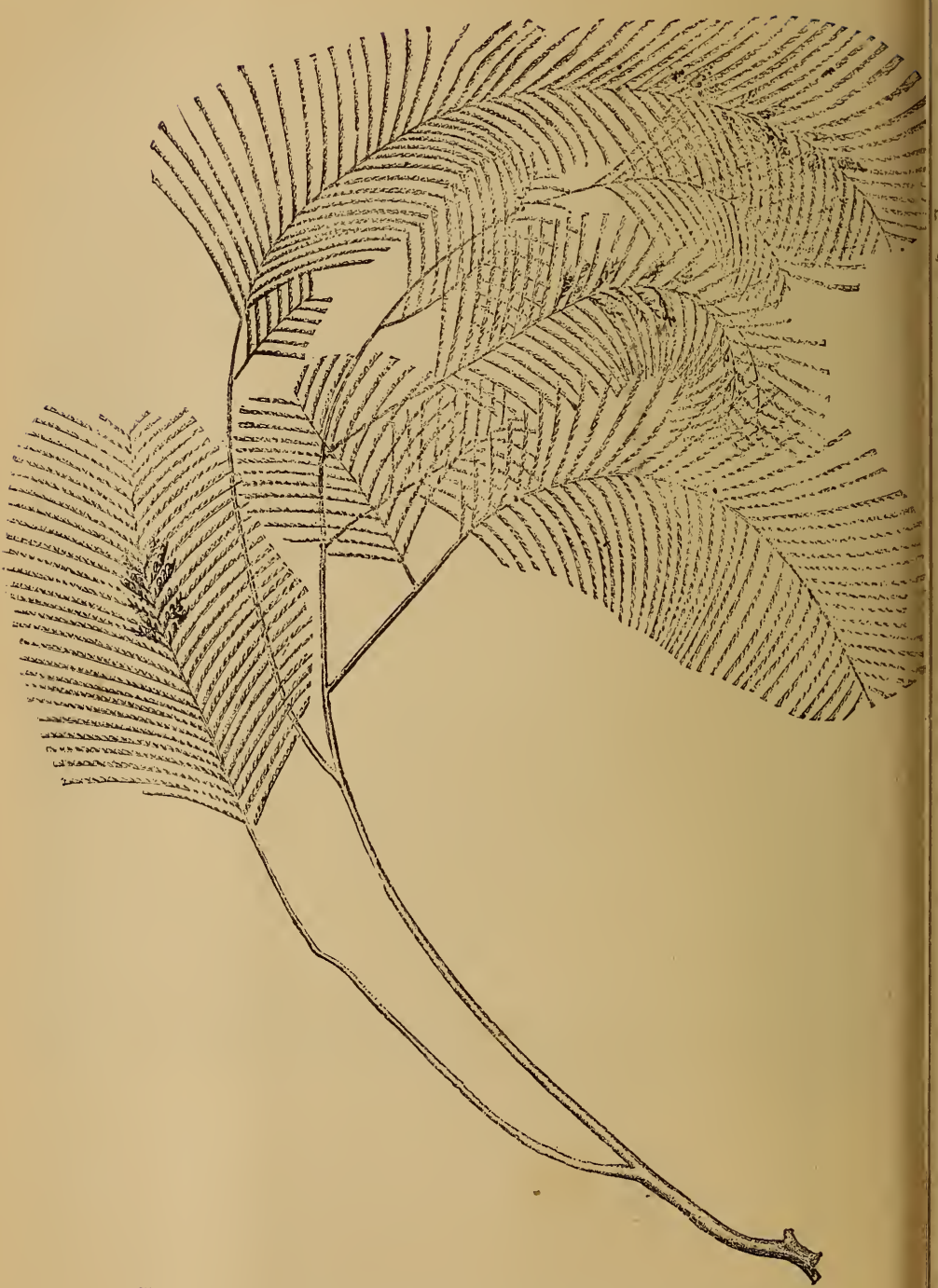

Fig. I67.-Cladocarpus, a Hydroid ("Blake”). 


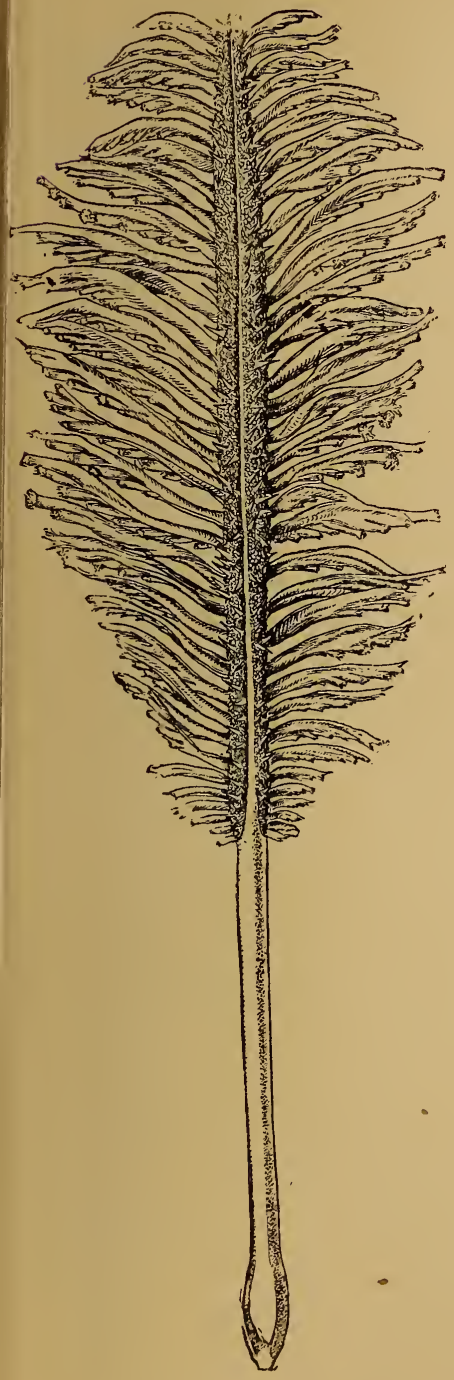

Fig. I68.-Pennatula, A SeaPEN ("BLAKE").

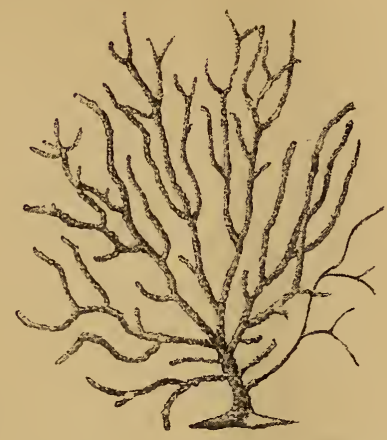

Fig. I69.-Gorgonia, A SEA-FAN

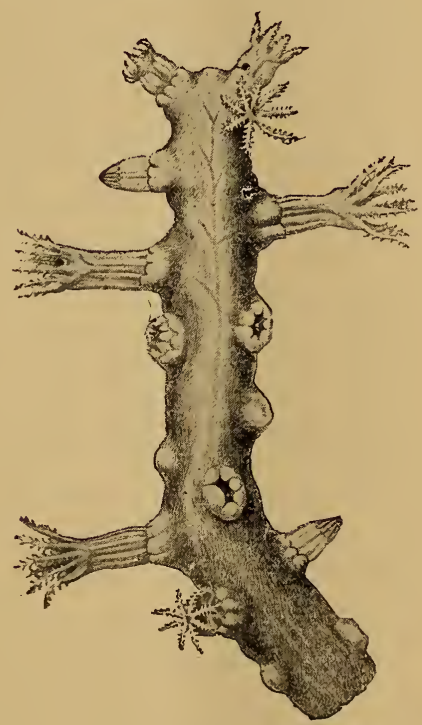

FIG. I7O.-GORGONIA, SHOWING THE POLYPS IN CONTRACTION AND EXPANSION. (FIgS. I69 AND I 70 FROM LANKESTER'S "TREatise ON ZOOLOGY," BY PERMISSION OF MIESSRS. BLACK.) 


\section{ANIMALS OF THE SEA FLOOR}

urchins (Fig. I7I), and their kindred are abundant in all seas. Belonging to the same group (Echinodermata) are the sea-cucumbers, trepangs, or Holothuroidea (Fig. I72), and the feather-stars (Crinoidea), some of the latter free-living like the Antedon of our own seas, some attached by a stalk like the "stone-lilies" of earlier geological epochs (Fig. I75). These stalked crinoids, confined for the most part to fairly deep water, were formerly among the most prized rarities of zoological collections, though the progress of deep-sea exploration has now rendered them tolerably familiar.

Under the name of worms are included very many animals of widely dissimilar appearance. The Planarians are mostly flattened leaf-like forms, often of brilliant colours, which glide smoothly over the surface of stones or shells. The Nemertines may be recognized by their soft, very extensile bodies, and their long threadlike proboscis, which can be completely withdrawn within the animal. They are frequently richly coloured and of very varied form, some slender and of immense length, others short and thick and very fragile, breaking up into small fragments on the least provocation. Burrowing in mud or clay we find the Echiuroids, or spoon-worms, and the Sipunculoids ; the latter with tough leathery bodies, blunt at the tail, and tapering to a small proboscis, which, as in the Nemertines, can be withdrawn into the body like the finger of a glove which is turned inside out.

By far the most important and numerous group of worms is that of the bristle-worms, or Polychætes, which are to be found practically everywhere in salt water (Fig. I78). They carry stumpy, footlike lobes beset with bristles along each side of the body, by means of which they crawl or swim, and breathe by gills which are either situated on the lateral lobes, or 
else (in the tube-dwelling forms) crowded on the head of the animal. These Polychætes may be found in most unexpected places, one species living in the topmost coils of a dead shell inhabited by a hermit-crab, another in the groove on the underside of the common sandstar, and yet another clinging closely to the underside of a species of sea-cucumber. The tube-building forms display an endless variety in their habitations. The tough parchment-like tubes of Chrtopterus and Hyalinoecia (Fig. I76) are buried in sand or mud, others are made of sand or broken shells, some roughly put together, and some built up with exquisite neatness and symmetry. Many species secrete calcareous tubes of various shapes, usually fastened to stones or shells, and closed by a stopper which the inhabitant carries attached to his head. The feathery plumes which many of these tube-dwellers bear as gills are among the most attractive sights of an aquarium, where alone they can be seen to full advantage (Fig. I77). Perhaps the most graceful are those of Sabella and its allies, whose tubes, built largely of mud, have the appearance and texture of india-rubber piping. Though most of the free-living Polychætes are unable to swim, there are a few entirely pelagic species ; and some of the normally creeping forms, when the breeding season arrives, become entirely altered in appearance, developing swimming-lobes along thesides of their bodies, and come to the surface in immense swarms. The "Palolo" of Pacific islands, which, leaving its shelter in the coral reefs, suddenly appears in countless numbers on the shore, is a well-known instance of this change of habit.

The huge group of the Crustacea is one which perhaps attracts more attention than any other. In number of species it far exceeds any other group of marine animals, but most of these are of very minute size 


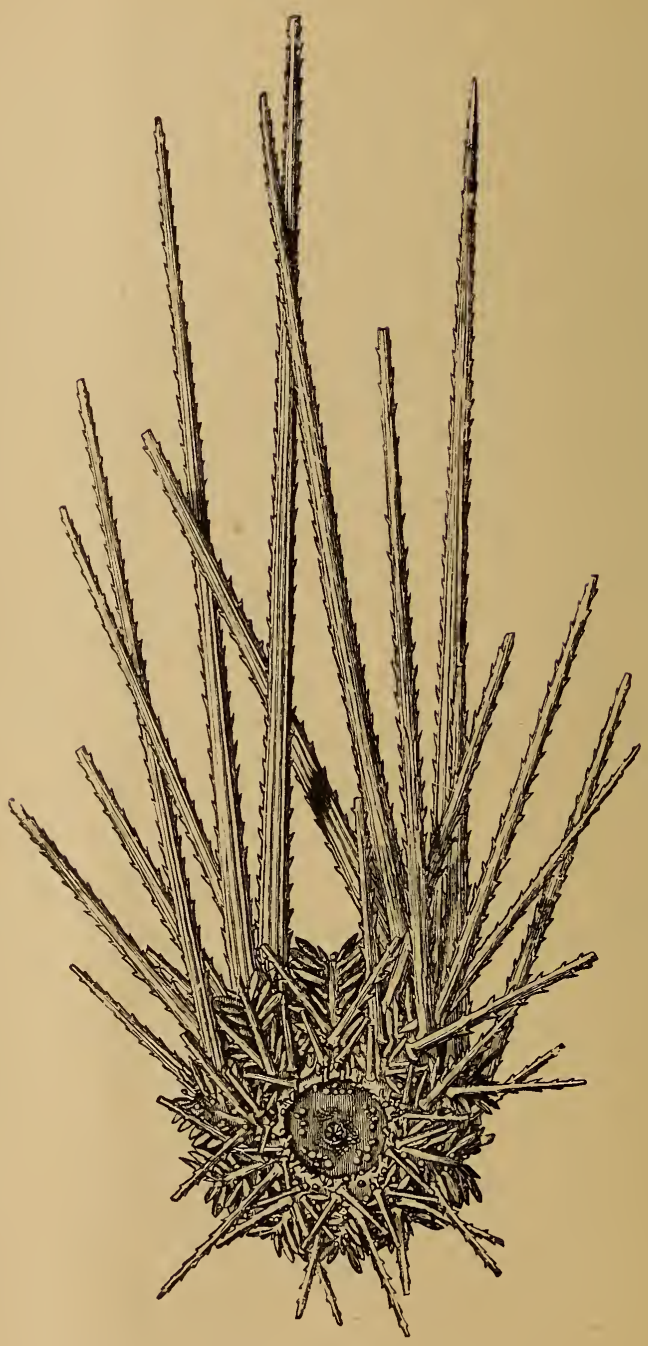

Fig. i71.-Salenia, a Sea-Urchin ("Challenger"). 


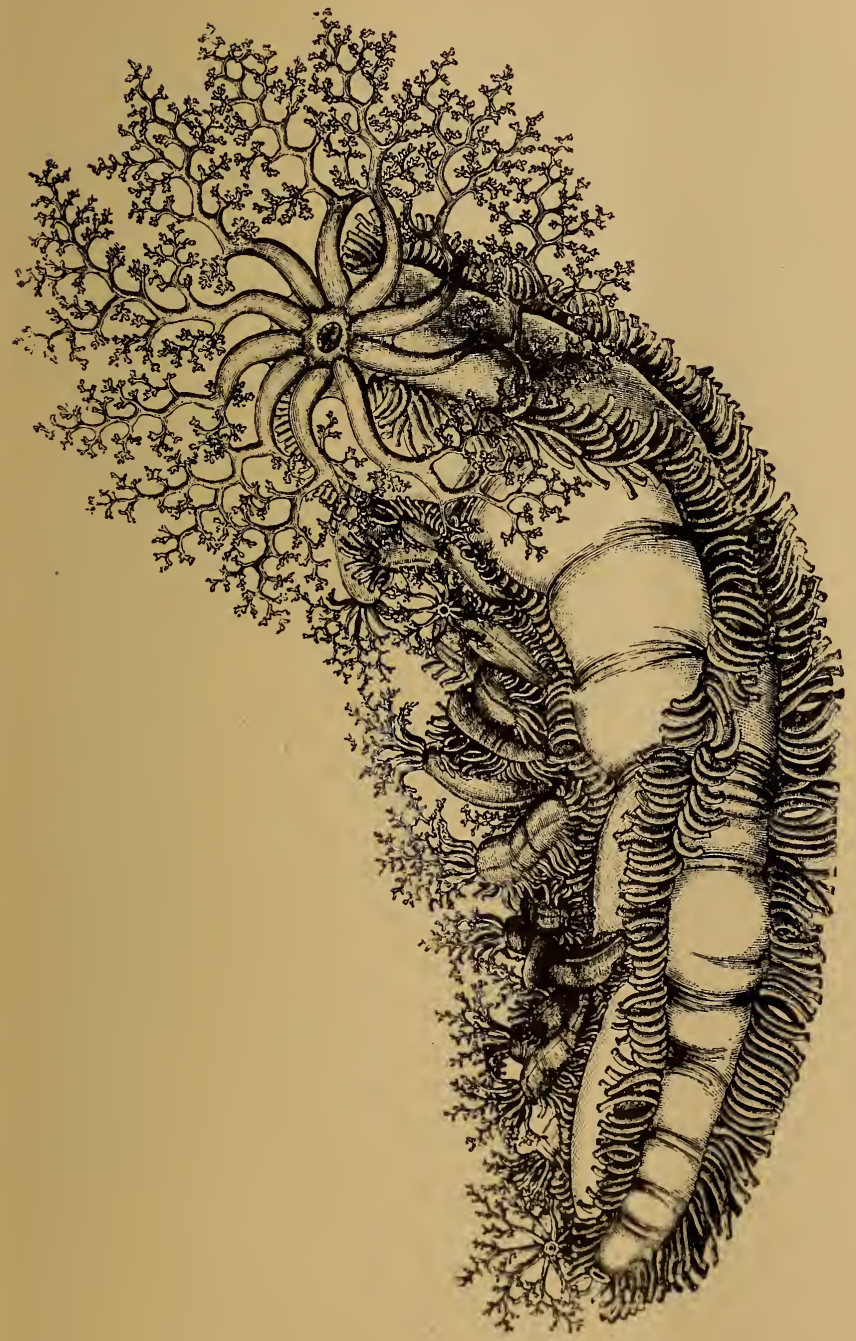

Fig. I72.-A Sea-Cucumber or Trepang ("Challenger"). 
(Entomostraca). It is perhaps not out of place to suggest here that, in order to capture these smaller forms, the water in which dredged material has been put to stand should be strained off through a piece of fine silk. Of these Entomostraca, but very unlike the rest in appearance, are the Cirripedes, including both the stalked barnacles and the sessile acornshells. The stalked forms are for the most part found growing on floating objects, but there is one genus (Scalpellum) with a short stalk, which is often found in deep water attached to Hydroids or other fixed objects (Fig. I59, p. 2I8). The sessile or acornbarnacles are most abundant between tide-marks or in shallow water, but there are a few deep-sea species which reach a very large size. Of the other Entomostraca, the Branchiopods belong to the Plankton (Chapter V.), but the Copepods and Ostracods have many bottom representatives.

There are two very large groups of Crustacea, numbering some thousands of species, which we may conveniently illustrate by the sandhopper and the woodlouse. These are the Amphipods (Fig. I8o) and the Isopods (Fig. I79). They may be found everywhere, and may, for the most part, be recognized by their resemblance to the types above mentioned. One section of the Amphipods, however, the ghost shrimps, or Caprellids, differs very markedly from the rest. The Caprellids may be recognized by their slender skeleton-like bodies, their thin legs, the two front pairs of which are armed with strong claws, and their "looper"-like movements (Fig. IgI, p. 265).

The Cumacea, another group of small Crustacea, living for the most part buried in mud, may be known by their small nut-shaped bodies and their long slender tails ending in a fork. 
Resembling the Prawns in appearance are the so-called "Schizopods," a name including two rather dissimilar groups. Of these, the Euphausiacea (Fig. II8, p. I79), are almost entirely pelagic, the other (Mysidacea) are for the most part bottom-haunting forms, rarely more than an inch in length.

Of the larger Crustacea the most unfamiliar are probably the squills, or mantis shrimps (Squilla) (Fig. II9, p. I79), with small bodies and broad, flattened tails. They carry a powerful pair of claws, which they lift in a manner that recalls the mantis insect. They are rarely found except in the warmer seas.

The most highly organized, and the largest, of the Crustacea, the Decapoda, are usually divided into three groups: (I) The Macrura (or long-tailed), including the lobsters, prawns, and shrimps (Fig. I83); (2) the Anomura (or irregular-tailed) - these comprise, among others, the hermits (Paguridæ), with soft bodies (Fig. I8I), and the Galatheids, in which the tail is broad and flattened, and can either be turned up under the body or else straightened out and used for swimming (Fig. I82); (3) the Brachyura, or crabs proper-these include an immense number of very different forms ; they retain, however, a sufficient family resemblance for recognition as crabs. Some of the more conspicuous types are the swimming crabs, in which the last pair of legs are paddle-shaped and the body flattened, as in the British genera Portunus and Bathynectes; and the spider crabs, which have the legs long and slender, and apparently more designed for concealment than locomotion, the movements of these crabs being deliberate and sluggish, and their bodies often furnished with a crop of seaweeds, Hydroids, or sponges. The Ebalias, with their small round bodies and closely tucked-in claws, might easily 
pass for pebbles, and usually frequent ground where the bottom is of coarse gravel.

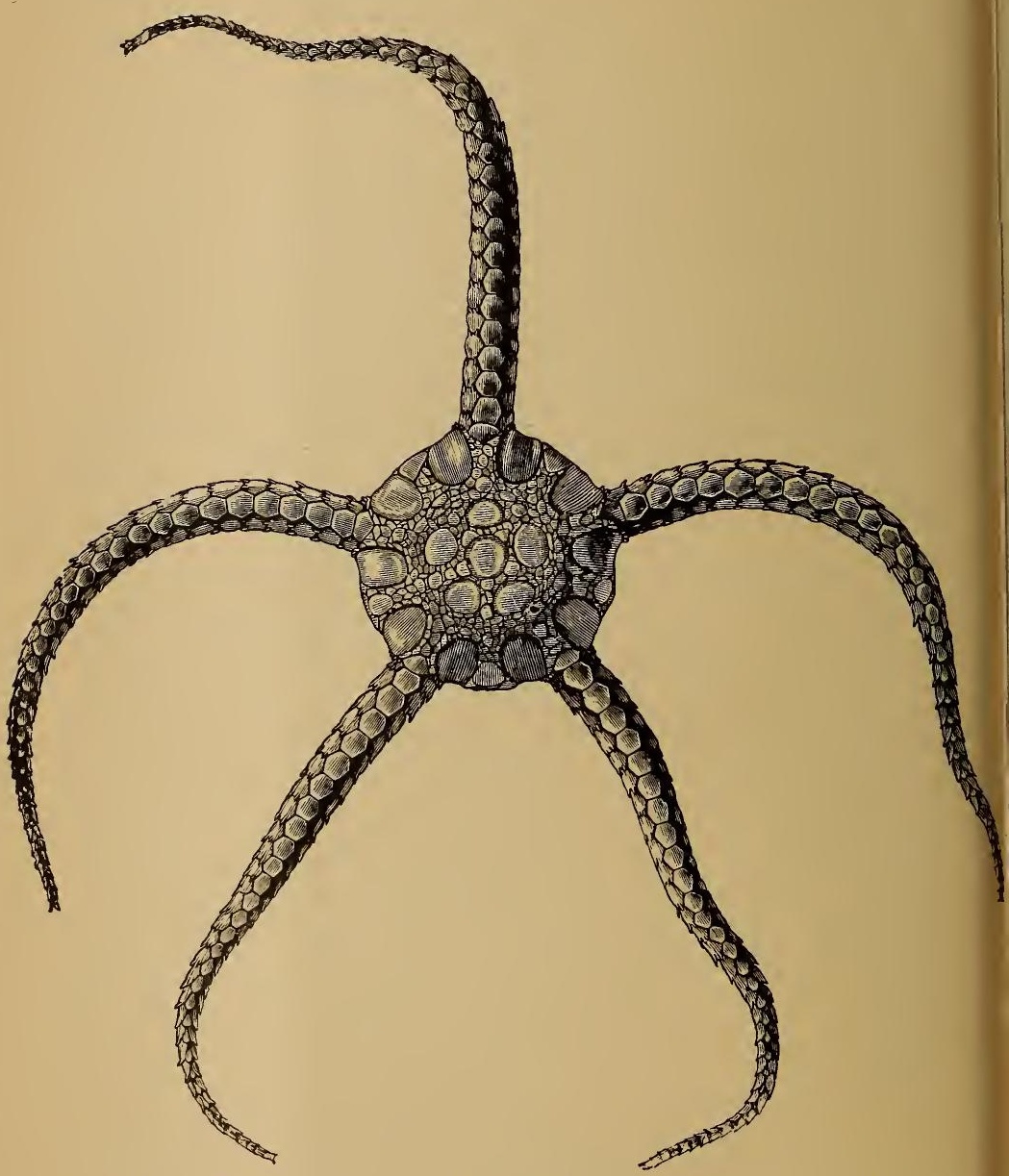

Fig. 173.-Ophiura, a Brittle Star ("Challenger").

The sea spiders, or Pycnogonida, are easily recognized by their resemblance to the animals from which 
they take their English name. In most species the small body scarcely affords room for the attachment of eight (very rarely ten) long slender legs, but in a few cases the legs are short and stout; as, for instance, in the common Pycnogonum littorale, which, in spite of its name, is often found in moderately deep water. Most of the Pycnogons are of small or moderate size, but in some deep-water species the legs may span a length of 2 feet.

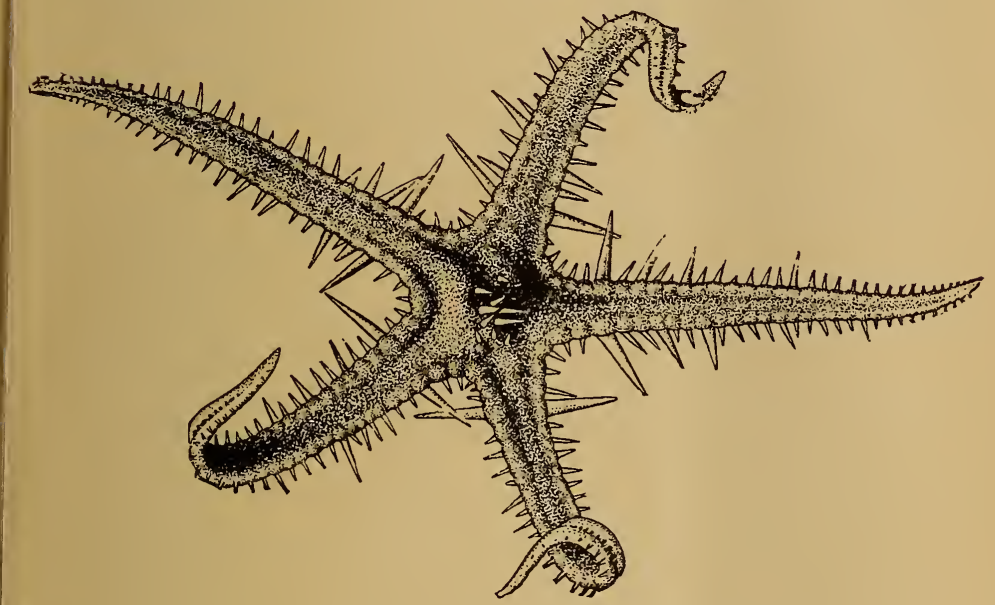

Fig. 174.-ARchaster, A Star-Fish ("Blake").

The commoner forms of the Mollusca, at any rate of the shelled species, are familiar to everyone, but there are some shell-less species, and others with peculiar shells, which call for special note. The usual type of Gastropod, as exemplified by the whelk or periwinkle, bears an asymmetrically coiled shell, but there is reason to believe that the earliest forms of molluscs were symmetrical. This symmetry is still found in the Chitons, in which the shell is made up of eight plates, 
overlapping as in an armadillo or wood-louse (Fig. I84). Allied to the Chitons is a very remarkable group of molluscs, in which the shell is entirely absent. These are for the most part wormlike in form, and are usually found tightly coiled round the branches of Hydroids and Alcyonarians.

The nudibranchs, or sea-slugs, are shell-less gastropods, which externally appear to be symmetrical. They start life, however, in a minute coiled shell. One section of them, the Dorididæ, in which the gills are arranged in a circle on the hinder end of the animal, are found in their greatest development, both in number and size, in tropical seas, where, both along the shore and in shallow water, they attract attention by their large size and brilliant colours. Another section, the Eolididæ, in which the gills are not concentrated on one spot, but scattered as papillæ all over the body, are, on the contrary, very poorly represented in warm seas, but are richly present on our own coasts (Fig. I85).

The Lamellibranchs, comprising such molluscs as the oysters, mussels, cockles, scallops, and so forth, are too well known to need further mention.

Among the Cephalopods, the Octopus and its allies (Fig. I87), with eight equal arms and a rounded body, must be distinguished from the squids and cuttle-fish, which have ten arms, one pair of arms being much longer than the rest. The "paper Nautilus" belongs to the first of these groups. The second includes a great variety of forms-some short and squat, like Sepia, Sepiola, and the cuttle-fish, others elongate like Loligo and the squids (Fig. I86). The pearly Nautilus belongs to a group apart from all the rest. It is the sole representative of a once very abundant Order, to which the Ammonites, so well known as fossils, also belonged. Most of the Cephalopods can swim 
very well, and some are entirely pelagic, but most are to be found at the bottom at moderate depths, and some abysmal forms have been found so deep as 2,000 fathoms.

If we look at the stones brought up by the dredge, we are sure to find many of them covered with a fine lacelike incrustation, which, upon close examination, seems to be made up of minute cells, each perforated by a small pore. These cells are formed by the Polyzoa, each cell having a separate inhabitant, which extrudes a tiny crown of tentacles through the opening. Besides the encrusting forms there are other branching ones (Figs. I88, I89), either soft and finely divided, like Hydroids, as already mentioned, or else thick and hard, like small corals.

Allied to the Polyzoa, but differing from them entirely in appearance, is the group known as the Brachiopods, or lamp shells. The Brachiopods were once classed as Mollusca, on account of their external resemblance to Lamellibranchs, but may generally be distinguished from them by the facts that their valves are unequal in size, and that they are attached by a small stalk, which passes out through a hole in the apex of the larger valve (Fig. I90). They represent a group which was very abundant in early geological times, and of which some forms have persisted almost unchanged to the present day. Many of the species are found at considerable depths.

The Tunicates, or sea squirts, are generally particularly unattractive objects when found among the contents of the dredge. The solitary forms have shapeless sacklike bodies of a gelatinous or leathery texture, often encrusted with mud or sand, and having two openings through which, in the living animal, currents of water enter and leave the body; the colonial 


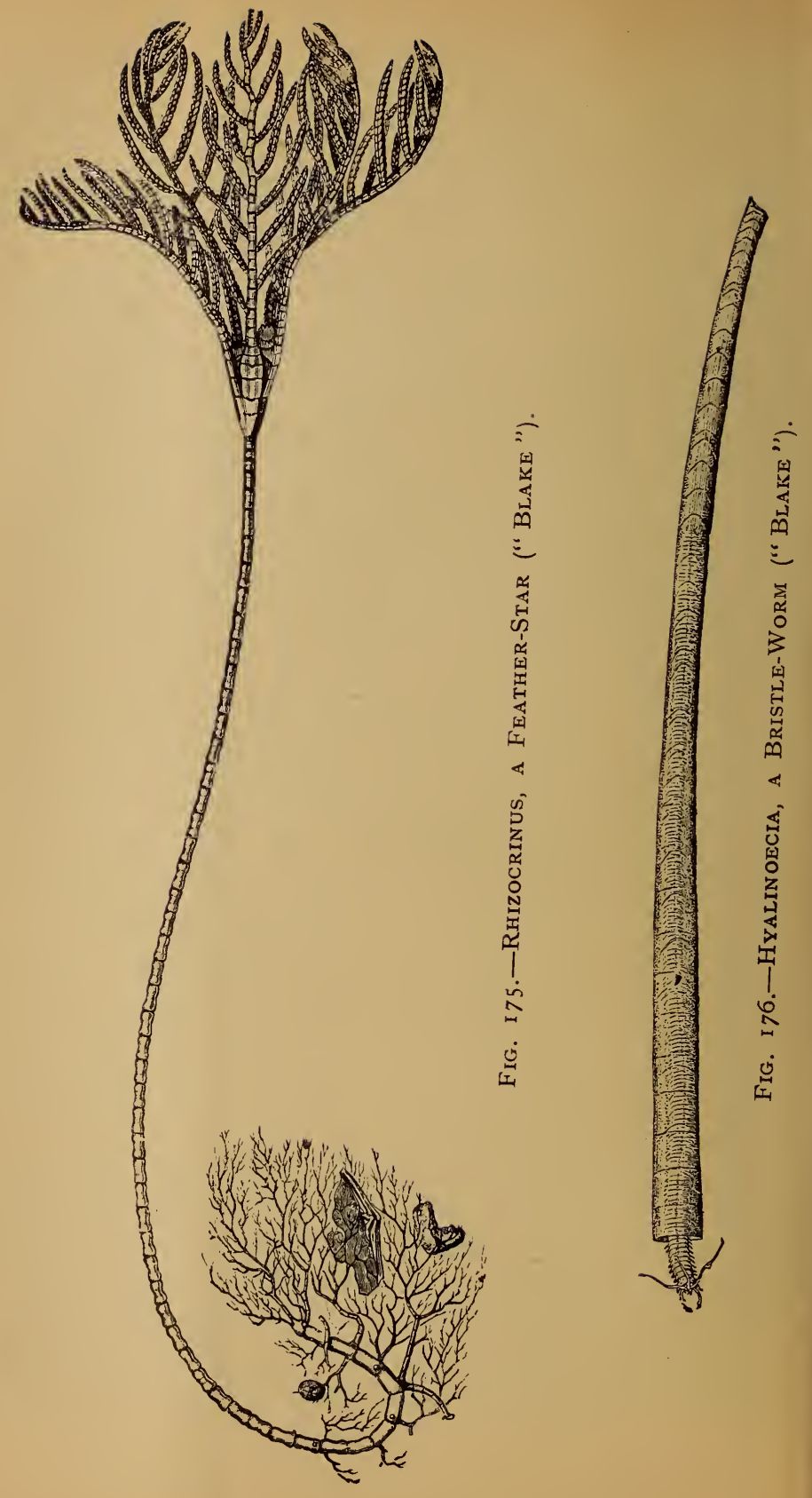





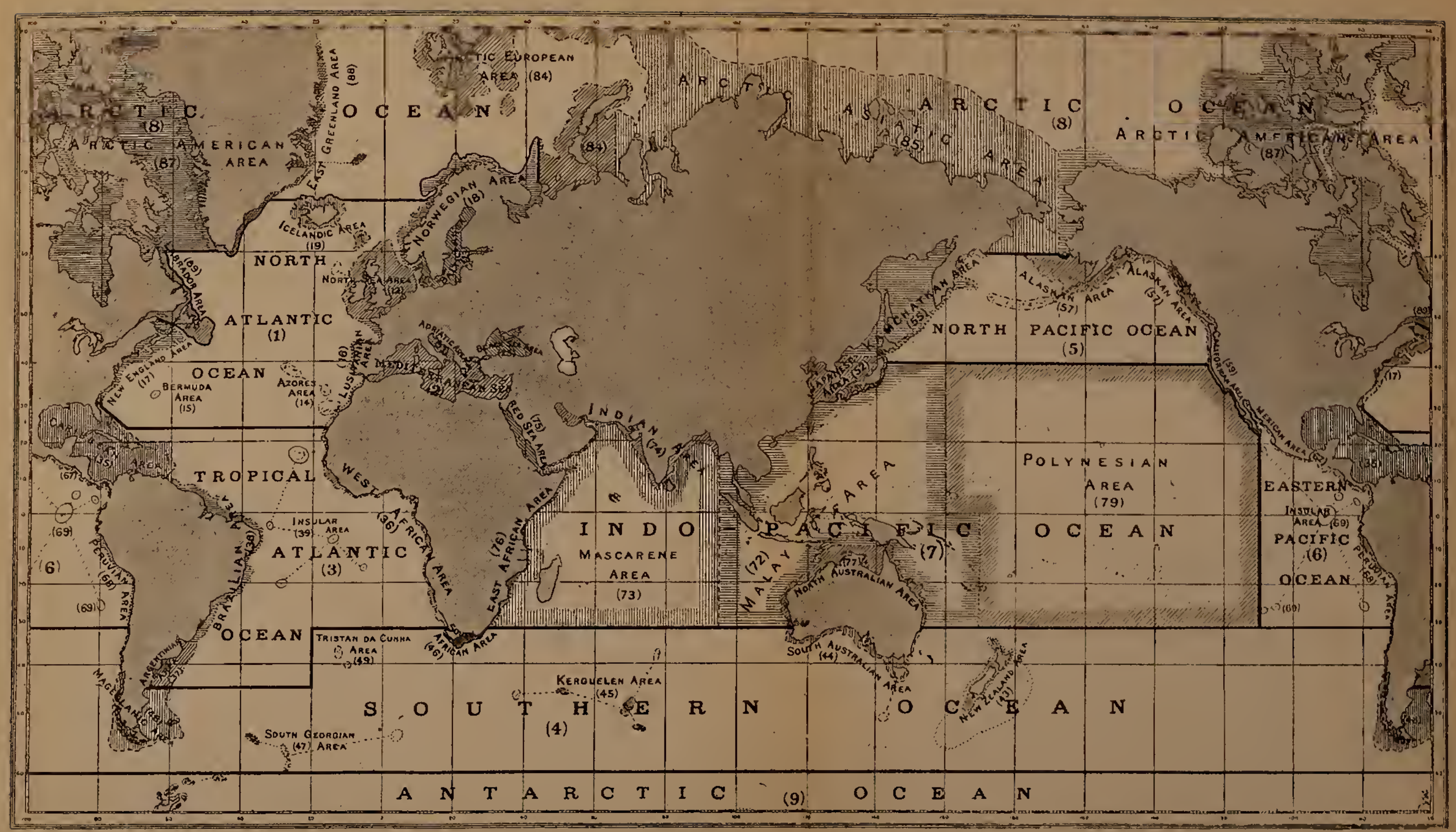

CHART VIII.-AREAS OF MARINE DISTRIBUTION

The areas here adopted for the purposes of the Challenger Society's Bibliography of Marine Faunas are based on what appears to be the natural boundaries of temperature current, depth, etc., which affect the distribution of both floating and bottom animals.

[Between 19, 256, 257. 

forms often encrust stones in large sheets. They are strangely degenerate animals, for they begin life as freeswimming, tadpole-like larvæ, which approach somewhat to the Vertebrates in their structure.
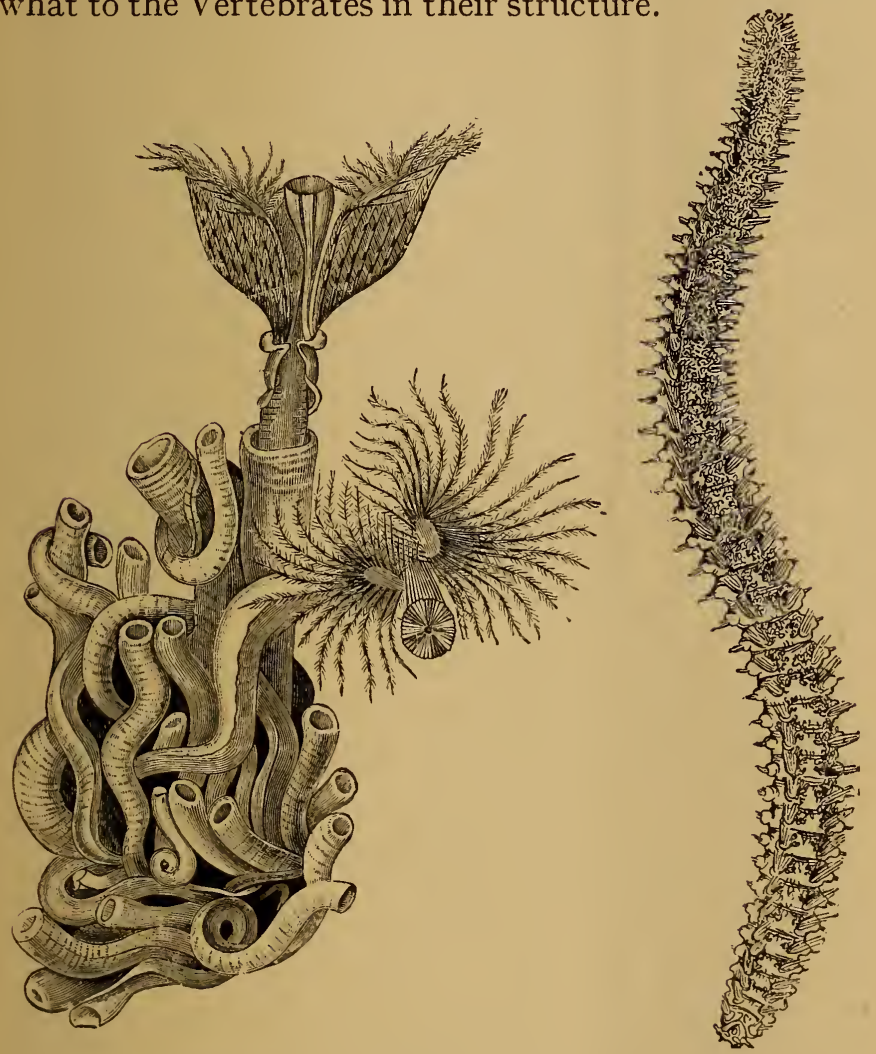

Fig. I 77.-SERPULA, A TUBE-DIVELLING Bristle-Worm. (From the "CAMBRIDGE NATURAL History," By PERMISSION OF MESSRS. MACMILLAN.)

FiG. I 78. - AMPHINOME, A BRISTLEWORM ("BLAKE"). 
As regards the geographical distribution of the animals inhabiting moderate depths, it may be said, speaking very generally, that the character of the fauna is determined rather by temperature than by geographical position. Thus it is found that genera and even species of animals, which may be dredged at a depth of a few fathoms in the Arctic regions, occur at greater depths in the more southern parts of their range, where the shallow water is too warm for them. For example, a certain starfish which is found commonly off the west coast of Ireland between 300 and 400 fathoms, and which stretches as far south as the Bay of Biscay in deep water, occurs at a depth of I5 fathoms within the Arctic circle. Again, the current of relatively cold water which runs northwards along the west coast of South America allows many of the southern types to extend far to the north, and carries the characteristically subantarctic Isopod genus Serolis to the coasts of Southern California.

It is possible to divide up the shallow water of the globe into regions whose faunæ differ from each other, both in the actual species which compose them, and also in the general proportion in which the various groups of the animal kingdom are represented. Thus it is found that the fauna of the shores of East Africa has a much closer resemblance to that of India and of the Pacific than it has to that of South or of West Africa. Similarly, the fauna of the north-east coast of the United States has more species in common with that of the western shores of Europe than with that of the West Indies. In a recent work (Ortmann, "Grundzüge der Marinen Tiergeographie") the coastal waters of the globe, down to Ioo fathoms, have been divided into a number of faunistic regions which may be briefly mentioned here. 
I. The Arctic Region, again subdivided into-

(a) A Circumpolar subregion, which includes Greenland, the north coast of Europe and Asia, and the north and north-east coasts of America ;

(b) An Atlantic Boreal subregion, which includes the west coast of Europe ; and

(c) A Pacific Boreal subregion, which includes the northern shores of the Pacific Ocean from Japan to California.

The tropical parts of the globe are divided into four regions :

2. The Indo-Pacific Region, a very large area stretching from the east coast of Africa to the Islands of Oceania, and including the shores of India, the East Indies, China, and most of Australia.

3. The West American Region, which only includes the small stretch of coast line from California to the south of Ecuador.

4. The East American Region, from Newfoundland to Cape Hatteras in the United States.

5. The West African Region, which is subdivided into-

(a) A Mediterranean subregion; and

(b) A Guinea subregion.

The whole of the Antarctic is included in a single region-

6. The Antarctic Region, which includes the south coast of Australia, the coasts of Cape Colony and German South-West Africa, and the greater part of South America, from the River Plate on the east to Ecuador on the west (this northern extension of the cold region being caused, as has been alluded to above, by the current of cold water running up the west coast of South America). 
The definition of these regions must not be taken as implying that there is any strict demarcation

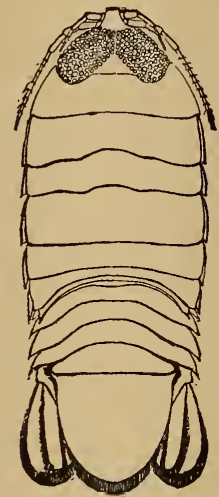

Fig. I 79.-RociNeLA, AN ISOPOD ("BLAKE").

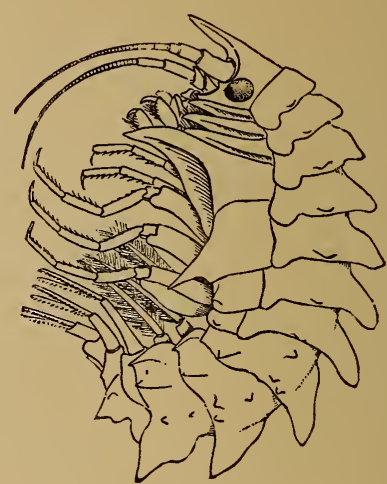

Fig. I80.-EPIMERIA, AN AMPHIPOD ("BLAKE").

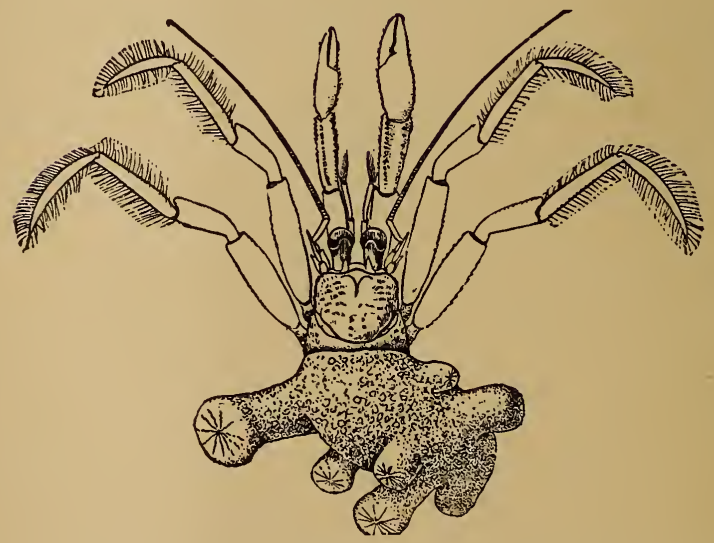

Fig. i8i.-Catapagurus, a Hermit-Crab, its Posterior End in a Shell, on Which lives a Colony of ANemones ("Blake").

between their faunæ. There is naturally a great deal of overlapping, and very many species are common to two 
or more regions; for example, a large number of the common marine animals of the British Isles are to be found in the Mediterranean, often at increased depths.

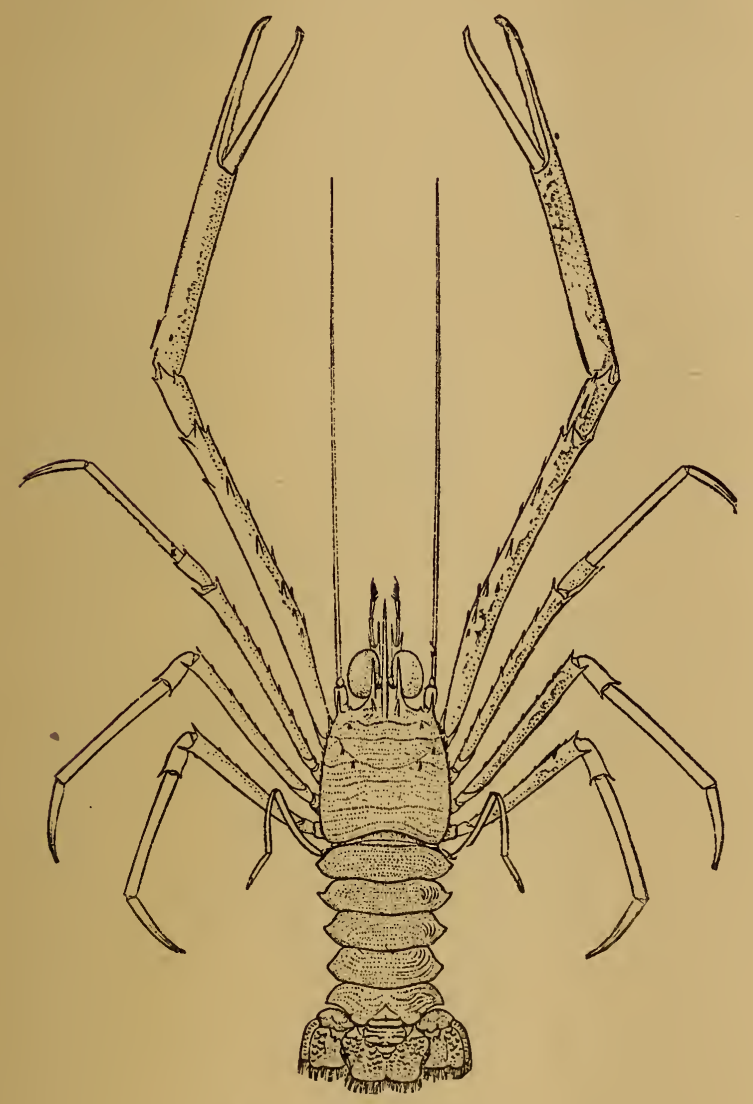

Fig. i 82.-Munida, a Galatheid ("Blake”).

A more detailed subdivision of the seas, on much the same lines as that of Ortmann, but including oceanic bottom areas, and suitable also for planktonic areas, has 


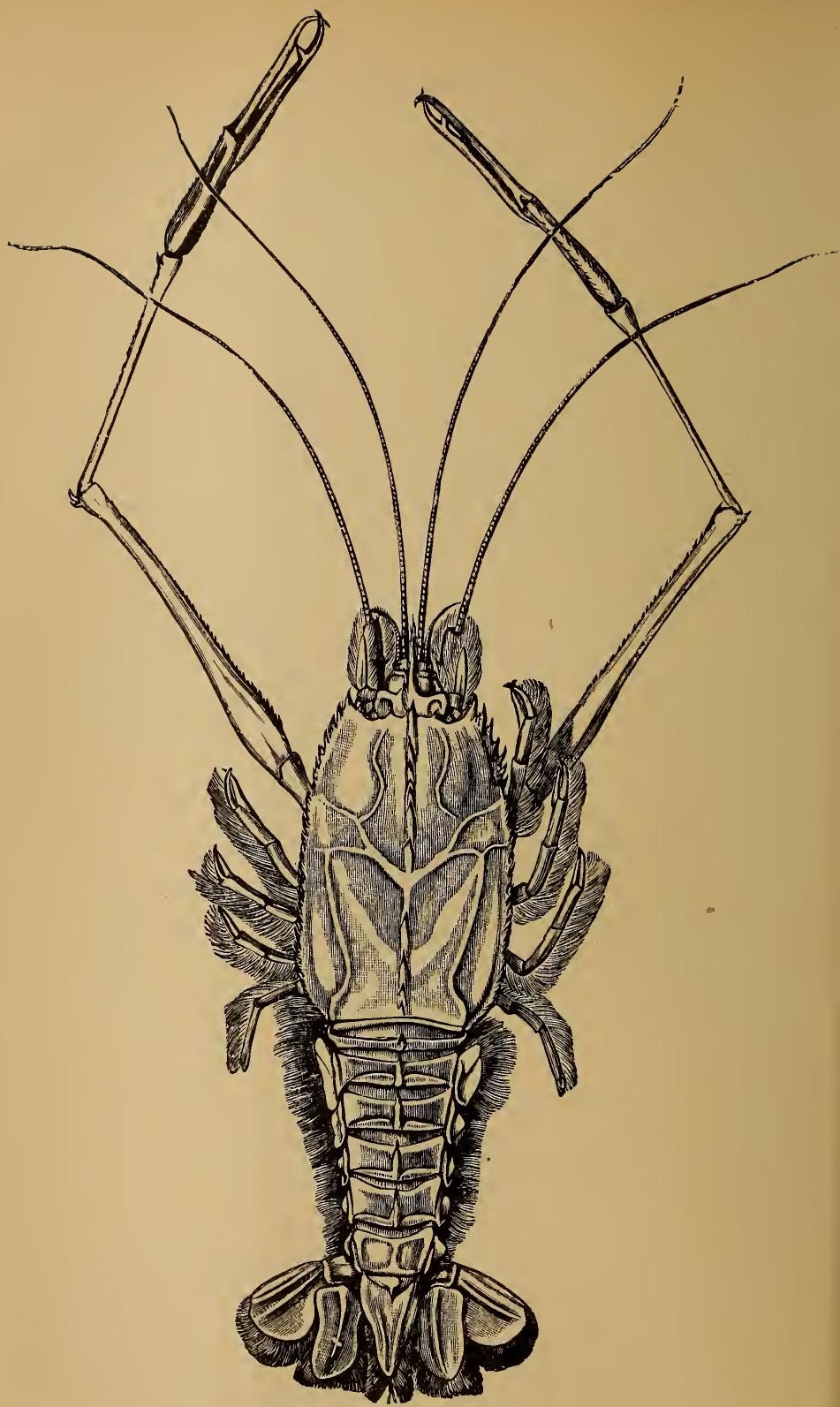

Fig. 183.-Willemcesia, a Deep-Sea Lobster, of the Family ERyonide ("Challenger"). 
been adopted by the Challenger Society for bibliographical work, and is reprinted here as Chart VIII.

The theory, or rather dogma, of bipolarity (that the arctic and antarctic faunæ are more closely allied to each other than they are to the inhabitants of the more equatorial waters) is based on the fact that identical or closely allied forms have been found in both north and south Polar seas, but have not been reported from the intervening waters. The number of undoubted cases of this is not large, and most of them may perhaps be explained as being instances of species which belong to a widespread deep-water fauna, which have been taken at the Poles at moderate depths, but have escaped notice in the abysses of the warmer regions where our knowledge of the deep-sea fauna is very limited.

The local distribution of the fauna within the narrower limits of each region appears to depend largely on the varying character of the sea bottom. Within the limits of the zone which we are considering (from the lower limit of the Laminarian Zone to the edge of the Continental Shelf) it may be said that the differences of fauna due to depth are insignificant as compared with those associated with the different kinds of bottom, and therefore it is impossible to attach importance to the subdivisions of this zone which have been proposed. The types of sea bottom usually met with may be arranged in a descending series beginning with rock and passing through stones, gravel, sand and gravel, pure sand and muddy sand, to mud, varied by the occurrence of beds of dead shells or of the calcareous alga usually known as " coral" (Lithothamnian). In any given district it is usual to find that each of the above-named types of bottom has its own special fauna, and that many species seem to recognize a more minute subdivision than man, whose observations are 


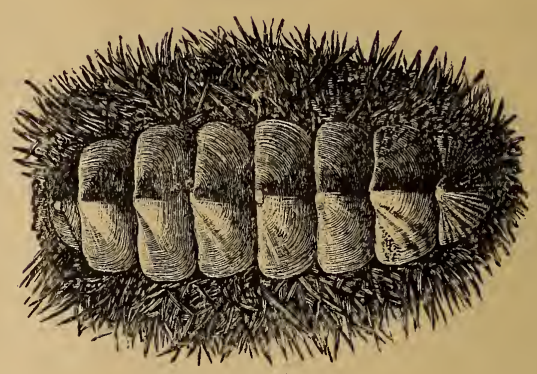

FIG. I84.-CHITON.

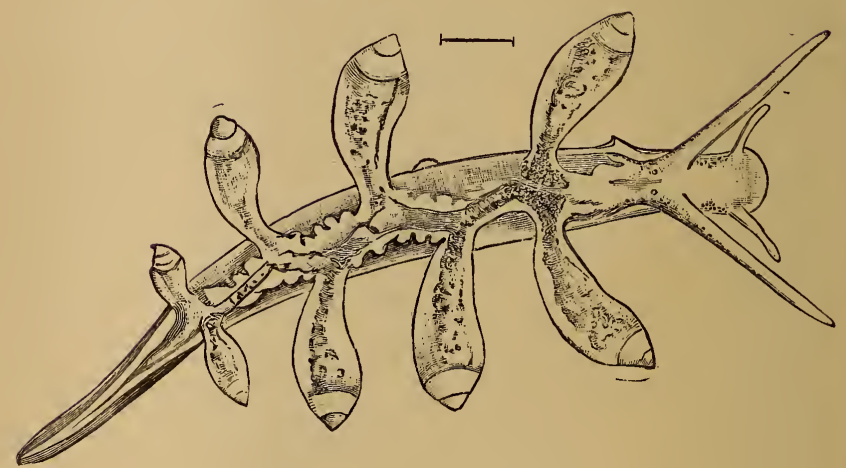

Fig. I85.-Eolis, A SEA-SLUG. (FIgS. I84 AND I85 FROM THE "Cambridge Natural History," By permission of Messrs. Macmilla N.)

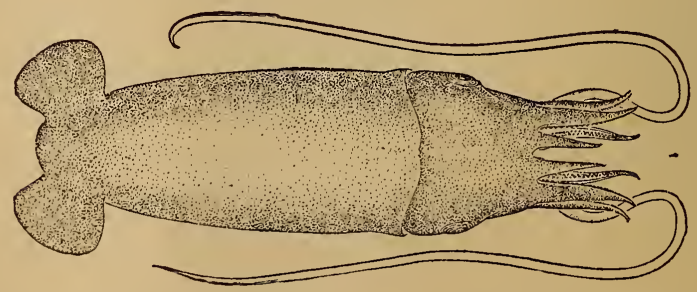

Fig. i86.-Benthoteuthis, a Deep-Sea Souid ("Blake '). 


\section{VARIOUS}

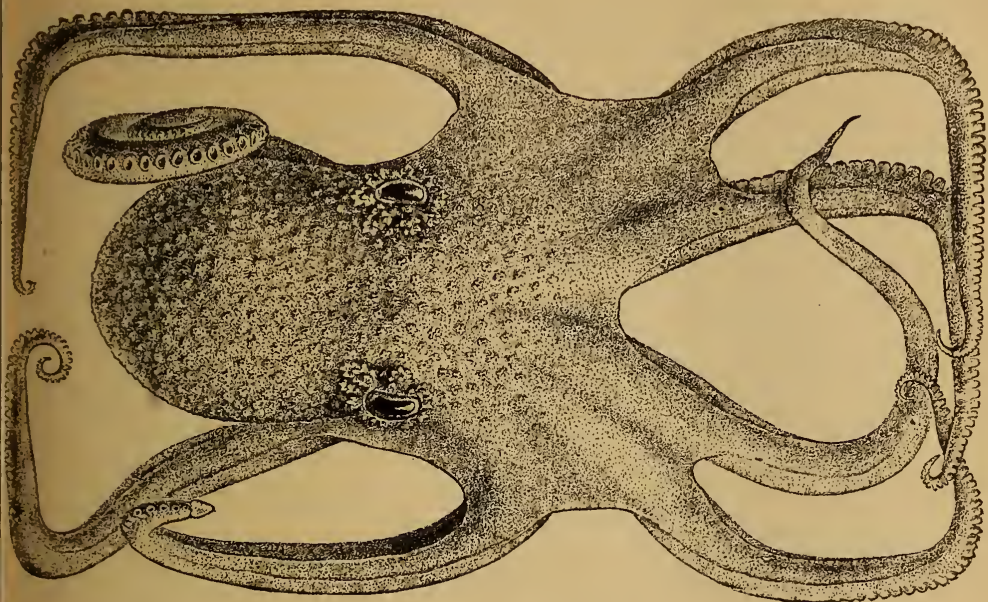

Fig. I87.-Eledone ("Blake”).

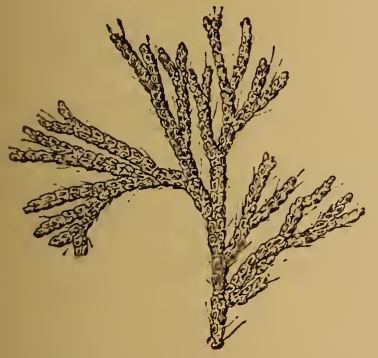

Fig. I88.-Cellularia, oNE OF the Polyzoa ("Blake").

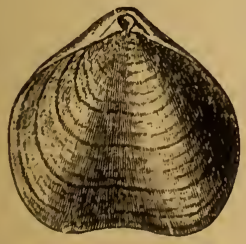

FIG. I90.-TEREBRATULA, A LAMPSHELL ("ChaLLENGER").

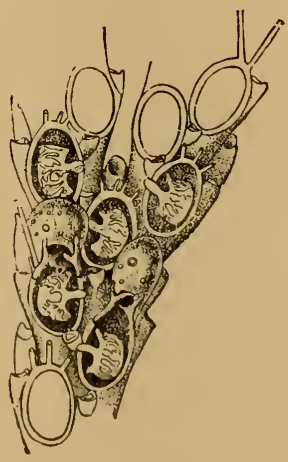

Fig. I89. - Cellularia, MAGNIFIED ("BLAKE"). 
necessarily made from a distance, can appreciate. The reason for the preference for one type of bottom rather than another usually resolves itself into a question of support or of shelter, either for the species itself or for its prey. Of course, there are very many species that may be found indifferently on all sorts of bottom and under all kinds of conditions.

The connection between the nature of the bottom and its inhabitants may be illustrated by an example. In some spots on the west side of the Irish Sea, when a haul of a trawl is made, at least 90 per cent. of the catch consists of the Alcyonarian or "false coral," known as "Dead Men's Fingers" (Alcyonium digitatum), while on the surrounding grounds only a few specimens are to be met with. The reason of this is clear. These spots where Alcyonium flourishes are beds of dead shells, mostly scallops and spiny cockles, which afford a foothold for the swimming larva of the Alcyonarian when seeking a place on which to settle down. Incidentally, the local range of at least three other species is marked out at the same time; two Nudibranchs which feed on Alcyonium are always to be found in the neighbourhood of these shell beds, and also a small Isopod Crustacean which lives on the same species.

In the case of organisms which are free to move about, the reasons for one kind of ground being more suitable than another are not so evident. The Norway lobster, or Dublin Bay prawn (Nephrops norvegicus), which abounds on the mud covering the bottom of a great part of the Irish Sea, rarely ventures on to the adjacent sandy grounds; while the masked crab (Corystes), which frequents a clean sandy bottom, is never found on the mud. The circular crab (Atelecyclus) is not found on either sand or mud, but should be looked for 
in coarse sandy gravel. In these instances the animals find shelter by burrowing beneath the surface (though in the case of the Norway lobster this burrowing habit must be inferred, as it does not seem to have been established by direct observation), and the medium chosen is probably the one best suited to their excavating powers.

The fauna of an area of soft mud affords many instances of animals, either specially modified to meet their peculiar conditions of life, or else adapting themselves to their circumstances without any special structural alteration. Leaving aside those species which are capable of burrowing beneath the surface, we notice that the peculiarities of a mud fauna are due mainly to the absence of any solid points of attachment or support.

\section{The Deep Sea.}

Shortly after the edge of the Continental Shelf is passed, we begin to meet with members of the true deep-sea fauna, which peoples the abysses of the ocean. With the rapidly increasing depth the proportion of shallow-water forms becomes less and less, till at a depth of I,000 fathoms there is hardly a species left of the abundant life of the Continental Shelf. Their place has been taken by a fresh assemblage of animals, which, as a whole, present a very different appearance. If, however, we take into account the very much altered conditions under which they exist, these differences are perhaps not so great as might have been expected. In fact, except amongst the fishes, and, perhaps, some of the sea-cucumbers and Crustaceans, there is hardly an inhabitant of the deep sea which differs so markedly from its nearest allies which live in shallower water, that, were its 
origin unknown, it could be said without hesitation to be an inhabitant of the abyss.

The physical conditions prevailing over the bottom of the deep sea are almost uniform, so far as we can perceive, through long periods of time and throughout all oceans. The darkness is absolute, or broken only by gleams of light from "phosphorescent" animals. The temperature is very low, at most $3^{\circ}$ or $4^{\circ} \mathrm{F}$. above freezing, and constant. The pressure is enormous, upwards of 3 tons per square inch at a depth of 3,000 fathoms. It is hardly necessary to point out that, once the tissues of an organism were adjusted to meet this pressure, it would be felt no more than is the pressure of the atmosphere by the inhabitants of the earth's surface. The effect of this pressure, combined with the low temperature, on the metabolism of the animal (the chemical changes connected with its vital processes) must, however, be very great. The water above the bottom is still or in very slow movement (unless, perhaps, in some narrow straits), and is not rendered turbid by any river sediment or by mud stirred up by currents from the bottom. The bottom itself is covered with a fine ooze, usually without rocks or other solid bodies to afford support to sedentary organisms. In the absence of any vegetable growth the inhabitants of the deep sea must be carnivorous, and as it is not possible for them to sustain life by feeding mutually on each other, we must look for some external source of supply. This is to be found in the constant rain of dead organisms which have lived and perished in the upper layers of the ocean. The existence of this constant supply of organic matter is illustrated by the fact that the oozes which cover the ocean bed over a large part of its extent (Chapter VI.), are formed from the shells 
or skeletons of the microscopic Radiolarians, Foraminifera, or Diatoms, which swarm in the waters above. This does not mean that the whole of the food supply consists of microscopic matter, for in the upper waters representatives of almost every order of marine animals, from whales downwards, may be found.

In the early days of deep-sea exploration it was believed by many naturalists that the unknown depths of the ocean would be found to harbour survivors of an earlier geological epoch which would fill gaps in the known pedigree of the Animal Kingdom. This expectation has not, save in a few instances, been realized, for, although an immense number of deepsea species have been discovered, they are, on the whole, either very like those from shallow water or else have been specially modified to adapt them to the changed conditions of life. On account of this general resemblance of the abysmal fauna to the animals inhabiting shallow water at the present time, rather than to those of a remote geological period, it is generally believed that the inhabitants of the deep sea have migrated thither at some comparatively recent geological age, the migration probably beginning at the close of the Mesozoic Period, and continuing to the present day.

It is hard to point out any features in which, as a whole, the animals of the deep sea differ from those of more shallow waters. Their colours are, as a rule, peculiar. Fishes are usually black, while Crustacea are mostly red or pink. The Echinoderms show a great range of colour, from yellow through orange and red to crimson and purple. Uniform colours are the rule, rather than blotches or stripes, such as are often found in shallow water. These markings may perhaps 
be regarded as protective or warning colouring, which would be no advantage to an animal living in utter darkness. Many of the animals themselves are blind, and probably burrow in the soft ooze, or live a sedentary life, clinging to hydroids, false corals, or sponges. Others have large eyes especially adapted-at least, in some cases-for the perception of faint gleams of light. These are probably more active and predatory types, guided to their prey by its own luminosity, or sometimes having themselves luminous organs, which serve as veritable searchlights.

While the deep-sea fauna, as a whole, is by no means of a primitive type, there are a few cases where it does seem that animals of an antique type have found in the deep sea a refuge from the more strenuous competition of the thickly inhabited shallow waters. This is notably the case with some Crustacea. The Eryonidæ (Fig. I83), a family of flattened lobster-like animals, are the living representatives of a group of which the remains are abundant in the rocks of the Triassic and Jurassic Epochs; the Homolodromiidæ of the deep sea appear to be the most primitive of the existing crabs, and resemble some found fossil in Secondary Rocks; and certain deep-sea prawns (belonging to the families Penæidæ and Acanthephyridæ) are probably of more ancient types than their relatives in shallow water.

Finally, the extreme imperfection of our knowledge of the fauna of the sea bottom in nearly all regions of the world cannot be too strongly emphasized. Even in shallow waters the smaller animals are almost unknown, except in parts of the North Atlantic and Mediterranean; and those who have the opportunity of dredging in depths exceeding Ioo fathoms in any part of the world may be assured that any animals 
which they may find are likely to be of interest and value to specialists. The methods of dredging and trawling are explained in Chapter IX. of this volume, and we need only mention here the importance of carefully sifting the dredged material. The contents of the finest sieves should be preserved in bulk for subsequent examination in the laboratory. It is astonishing what a wealth of living things may often be found by this method in mud which seems at first sight to be barren of life. It need hardly be said that the precise locality of each haul should be carefully noted, and, what is even more important, the exact depth and temperature recorded where possible.

A rare opportunity of obtaining specimens from the greatest depths of the oceans is afforded in the course of repairing deep-sea telegraph cables. These are often encrusted with sponges, corals, barnacles, and other organisms, while Crustacea, Mollusca and Echinoderms are brought up clinging to them. The preservation of such specimens would yield much information regarding the fauna at depths which are otherwise only to be reached by costly and elaborately equipped expeditions.

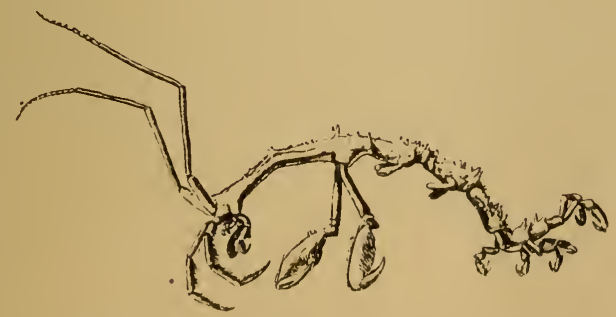

Fig. i91.-Caprella, a Ghost Shrimp.

(After Wyville Tilomson.) 


\section{CHAPTER VIII \\ YACHT EQUIPMENT}

BY S. W. KEMP AND THE EDITOR

Practically all oceanographic work, except heavy dredging and trawling at great depths, can be done from a sailing yacht, if furnished with a little steam capstan, such as is fitted to sailing trawlers, and costs about $£$ IOO.

In a sailing yacht without any steam whatever the collection of water samples, Plankton work down to at least 500 fathoms, and dredging anc trawling in shallow water can be carried on without difficulty.

But in a sailing yacht, whether with or without a capstan, the rig, tonnage, freeboard, and deck space are so important that it would be well to inquire beforehand from experts what branches of the work could be most suitably pursued.

With steam available for propulsion as well as hauling, oceanic work will be done more easily, and more can be got through in the same time. It is not only true that no time is wasted in tacking between stations, but the handling of the ship when at work is much facilitated. In using most deep-sea instruments, especially if driven by messengers (weights which slide down the rope), it is most important that the rope should be kept vertically up and down, and not allowed to stream away as the ship drifts.

With plenty of steam on board, the capstan can be 266 
replaced by a steam winch or windlass, with the result that work can be carried on at far greater depths, and far more rapidly and safely.

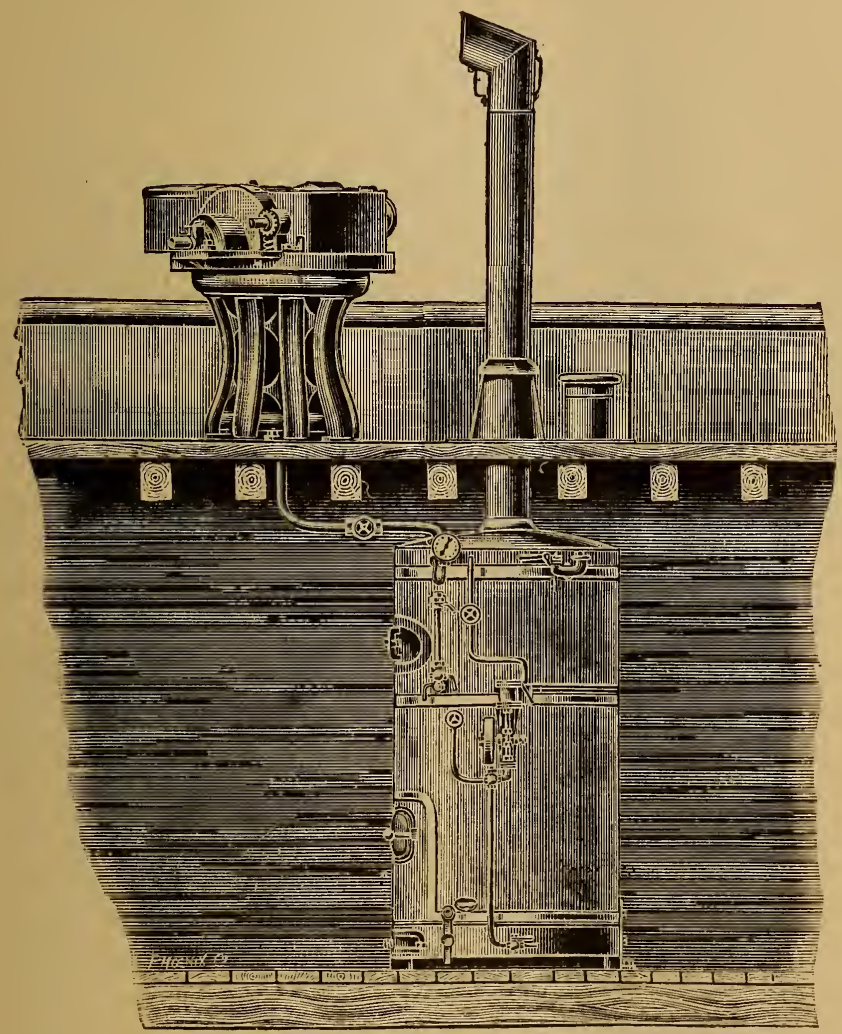

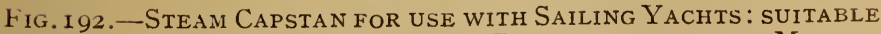
FOR THE LARGEST TRAWLS. (BY PERMISSION OF MESSRS. BROOKE AND Co.)

Supposing that there is no deck engine already on board, the owner will find that a good winch can be utilized for practically every kind of work-ther- 
mometers, water-bottles, soundings, tow nets, dredges, and trawls, as well as for hoisting boats and anchor, cargo and coaling work. With winches (as with much other gear), the owner, master, and engineer must settle the exact specification, according to the work to be done. We can only give the most general indications as a guide.

One may use (I) either a regular trawling winch, on the barrels of which the rope is stored; (2) or a cargo winch, which will haul the rope but not store it. Of these two types, there is no doubt that the regular trawling winch is much to be preferred. It will not only serve for the ordinary work of a cargo winch, but when scientific work is required it will save deck space and hands.

We figure a commercial trawling winch, showing the usual two hauling and storing barrels in the centre of the engine. For really deep-water work this type requires some modification. In the first place, if required for trawling and dredging only, a single large barrel is better than two smaller barrels, the divisions between the latter having been known to burst and cut the rope under pressure. In the second place the brake wheels should be cast solid with the barrel ends, and strengthened by radiating ribs, in order to resist the enormous lateral thrust of a great length of rope wound under tension. But if it is proposed to use closing tow nets and other apparatus with small messengers, which require a slighter rope (p. 279), in addition to trawl and dredge, it might be well to retain the double barrel, using one barrel for each rope, and strengthening the division between them. In this case the barrels should be clutched separately, which is not always the case with commercial trawling winches. 
COMMERCIAL TRAWLING WINCH 269

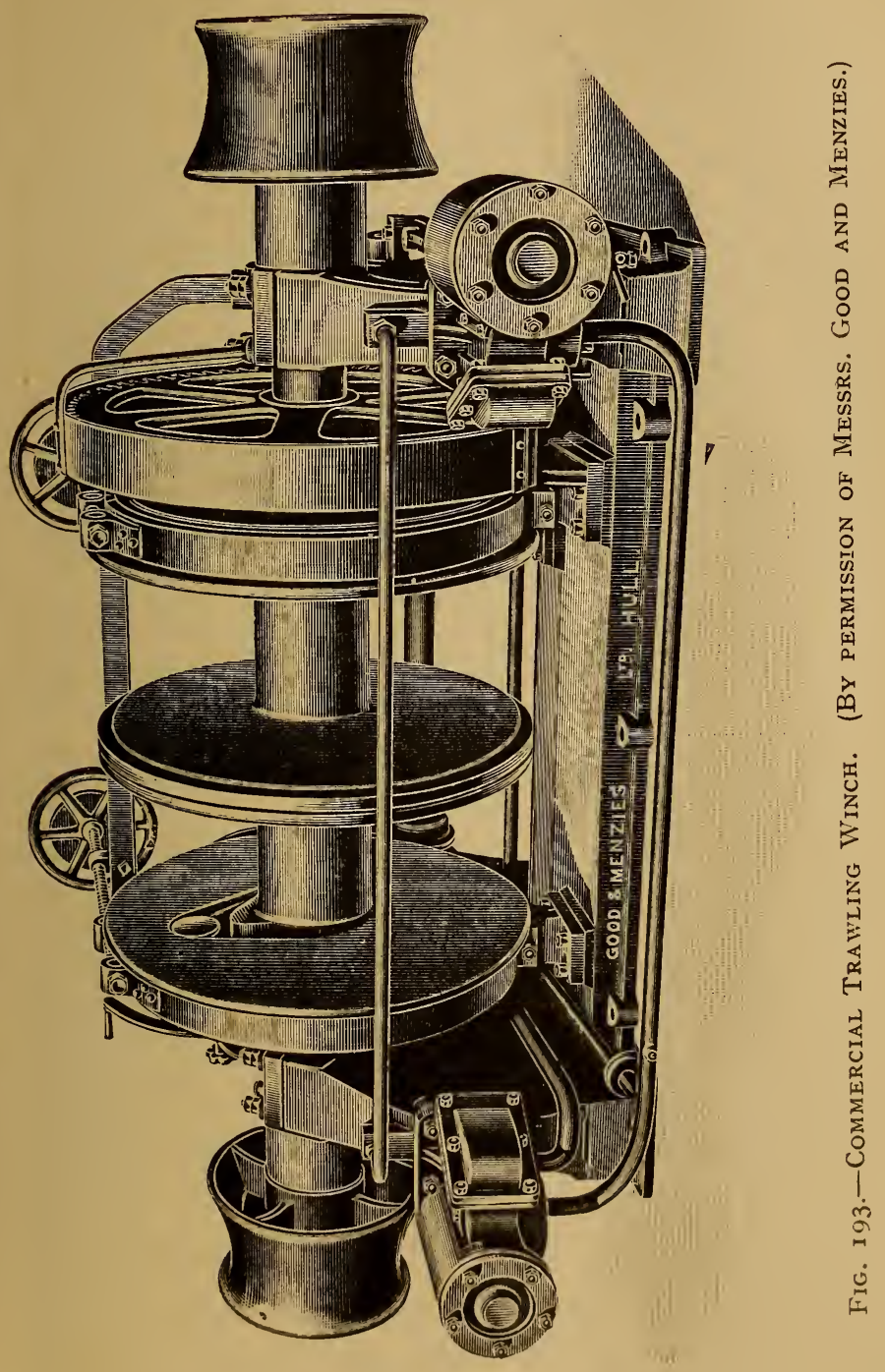


The following specifications of stock commercial winches have been supplied by the courtesy of a wellknown firm :

\begin{tabular}{|c|c|c|c|c|}
\hline & Cylinders. & $\begin{array}{l}\text { Capacity } I_{2} \frac{11}{2} \\
\text { Circ. Rope. }\end{array}$ & $\begin{array}{l}\text { Approximate } \\
\text { Lifting } \\
\text { Power. }\end{array}$ & $\begin{array}{l}\text { Approximate } \\
\text { Price (1.o.r.). }\end{array}$ \\
\hline $\begin{array}{l}\text { Trawling winch } \\
\text { ", } \\
\text { Cargo winch }\end{array}$ & 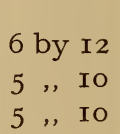 & $\begin{array}{c}\text { fathoms. } \\
\text { I,000 } \\
600 \\
\text { none }\end{array}$ & $\begin{array}{c}\text { tons. } \\
3 \\
2 \\
3\end{array}$ & $\begin{array}{l}£ 95 \\
£^{80} \\
£^{60}\end{array}$ \\
\hline
\end{tabular}

But the capacity can be varied to any workable extent. The largest stock pattern by these particular makers would carry 3,200 fathoms, and the smallest only 200 fathoms of $I \frac{1}{2}$-inch rope.

A cargo winch can be used for all deep-water work if it carries a largish, deeply grooved drum for winding, of (say) I8 or 24 inches diameter, in addition to the ordinary small barrels. This drum will only carry two or three turns, and the wire must be taken up, as it comes off the drum, on to a storage reel of some kind. It is no small labour to reel up I,000 fathoms or so of wire rope by hand power, and as a rule it cannot be taken up as fast as the winch can deliver it ; the method is therefore wasteful of both time and labour, and the storage reel should, if possible, be driven mechanically. If a fairly powerful cargo winch is already on board, which it is not desired to displace, we should recommend that a one or two horse-power steam engine should be fixed behind the winch, so that it could drive, directly or by chain gear, whichever storage reel was required at the moment. A recent expedition used an electric motor for this work. Another plan which has been suggested is to drive the storage reel by an endless rope from the small barrel 
of the winch, the rope being kept taut by passing through a block against which a weight pulls. When the reel tends to run too fast, the rope-drive will slip and so provide the necessary compensation.

It should be remembered that with a cargo winch there is much more wear on the warp than with the trawling winch. In using either of the above methods care should be taken to reduce the slip on the driving drum to a minimum.

Storage reels for the above purposes should be of extra solid construction and provided with a powerful hand brake. Most of the patterns on the market are only intended for occasional use, and are consequently of the very lightest build, with inferior bearings.

\section{A.-Deep Sea.}

\section{Dredging and Trawling.}

As this is the heaviest and in many respects the most difficult part of oceanic work, it should be the first to be considered.

Next in importance to the winch is the wire rope to be employed ; this must be flexible, lest it kink and snap when the strain is taken off, as, for example, when the trawl touches bottom. Flexibility implies several strands, each of numerous wires, and this unfortunately involves weight. Fig. I94 shows a section of a suitable rope, and displays six strands of twenty-four wires each $(6 \times 24)$; each strand has a hemp core, and the whole rope a hemp heart.

Before selecting a rope, it is of great importance to select a manufacturer with care ; it is not every firm which understands the special demands made upon a rope by deep-sea trawling. 
From the catalogues and samples of two reliable makers we take the following specifications as a guide :

(a) 6 by 12

(b) 6,24

(c) 6,24

(d) 6, , 18

(e) 6, , 18

(f) 6, I 8

$$
\text { Circumference. }
$$

Weight per

roo Fathoms.

\begin{tabular}{l} 
inches. \\
\multicolumn{3}{c}{$\frac{3}{4}$} \\
I \\
I $\frac{1}{4}$ \\
I \\
I $\frac{1}{4}$ \\
I $\frac{1}{2}$
\end{tabular}

lb.
32
88
I 31
IOO
I 58
224

\begin{tabular}{|c|c|c|}
\hline \multicolumn{2}{|c|}{$\begin{array}{l}\text { Breaking- } \\
\text { Strain. }\end{array}$} & $\begin{array}{l}\text { Approximate } \\
\text { Price per } \\
\text { roo Fathoms. }\end{array}$ \\
\hline tons. & cwt. & $\begin{array}{ll}E & s,\end{array}$ \\
\hline 3 & o & 33 \\
\hline 4 & IO & - \\
\hline 3 & I I & 44 \\
\hline 4 & $I_{4}$ & 410 \\
\hline 8 & $\mathrm{o}$ & 510 \\
\hline
\end{tabular}

The selection of a rope will, of course, depend largely upon the depth to which it is proposed to work, the probable character of the bottom, and the size of the dredge or trawl. If it is proposed to work down to but not over $\mathrm{I}, 000$ fathoms, a single length of I,500 fathoms of I-inch rope, with breaking-strain about 3 tons, * would probably serve the turn. Taking the second rope specified as an example, a factor of safety of four allows 4 hundredweight for the trawl and its contents.

Work at anything over I,000 fathoms implies an

* It may be mentioned here that H.M.S. " Challenger," used hemp ropes of 2 inches and $2 \frac{1}{2}$ inches circumference, with breaking-strains of I ton I2 hundredweight and 2 tons 6 hundredweight respectively. For shallow-water work was employed a rope of 3 inches circumference, with breaking-strain of 2 tons II hundredweight. But it must be remembered that in water a hemp rope carries much more of its own weight than a steel rope. Sir John Murray informs us that the rope was hauled at the rate of $I, 000$ fathoms per hour, and that during the three and a half years' cruise, when trawlings and dredgings were made at 354 stations, there were only eleven cases of parting of the rope. Wire ropes were first used for such work by Agassiz in 1877 . 
" expedition" rather than a yachting cruise, but for work to 2,500 fathoms the following combination may be suggested: I,500 fathoms of I-inch rope at the trawl end, I,000 fathoms of $1 \frac{1}{4}$-inch, and 500 fathoms of $I_{2} \frac{1}{2}$-inch at the winch end, all shackled together ;*

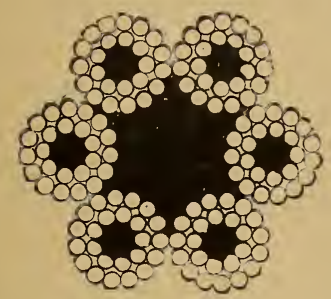

Fig. 194.-Section of Wire Rope. (By Permission of Messrs. Bullivant.)

a special shackle is made for this work. The object of this combination is to strengthen the rope where the heaviest strain comes, and the total result is as follows, taking ropes $d, e, f$ of the list on p. 272 as types:

\begin{tabular}{|c|c|c|c|c|c|}
\hline \multirow[b]{2}{*}{ At sheave } & \multirow[b]{2}{*}{$\cdots$} & \multicolumn{2}{|c|}{ Weight. } & \multicolumn{2}{|c|}{ Breaking-Strain. } \\
\hline & & $\begin{array}{c}\text { ton. } \\
\text { I }\end{array}$ & $\begin{array}{c}\text { cwt. } \\
\text { I7 }\end{array}$ & $\begin{array}{c}\text { tons. } \\
8\end{array}$ & $\begin{array}{r}\text { cwt. } \\
0\end{array}$ \\
\hline Above first shackle & . & $\mathrm{I}$ & 7 & 8 & o \\
\hline Below & . & I & 7 & 4 & $I_{4}$ \\
\hline Above second shackle & . & o & 13 & 4 & $\mathrm{I}_{4}$ \\
\hline Below & .. & 0 & 13 & 3 & II \\
\hline
\end{tabular}

Whether the rope be stored on the winch-barrel or on a separate reel, it should be carefully and evenly spread as it comes in. In hauling heavy gear, especially where the warp is wound directly under consider-

* Owing to the shackles (or splices) such a rope could not be used below I, 500 fathoms for closing-nets or similar apparatus worked by messengers. 
able tension, the spreading is best done by means of a mechanical spreader; this apparatus is sometimes supplied by the manufacturers of trawling-winches. In some patterns the wire is spread by a long steel fork, which moves, either mechanically or by means of a handle fitted to a long pivoted arm, across the face of the barrel. In this type the friction on the warp when hauling heavy weights would be very destructive ; a carrier holding three rollers (two upright and one horizontal) should be substituted. In a simple type, which one of us is able to recommend, the carrier and rollers are made to travel on a slide by the rotation of a long screw-shaft, actuated by a handle from one side. The work can be done with more labour by using a snatchblock on a lanyard or spar; but while this method will be found efficient for light work, or for reeling wire that is not under tension, it is scarcely applicable when hauling heavy gear, for in such cases the strain is so great that the united efforts of two men and a "purchase" will be required.

Greasing is also an essential to the preservation of wire rope. As it comes in, it should pass through welloiled cotton-waste. Castor oil is excellent, but expensive ; boiled oils seem to form a good hard coat ; the ordinary fluid machine oils seem to disappear at once, and should be renewed daily if used at all.

It should be stipulated with the makers that all wire ropes be sent properly coiled on a reel of some kind. As soon as received, if the rope is to go on the trawling-winch, it should be paid on to the winch barrel under a steady strain with the reel revolving; under no circumstances should it be paid on with the reel flat, or from a coil. Before being used for trawling, the whole length should be run out at sea, and carefully reeled up under a fairly high strain. 
Two other pieces of gear are advisable-an accumulator and a recording sheave. The old type of accumulator consisted of a number of stout cylindrical rubber straps between two boards, the whole slung from a derrick or spar, and carrying the block over which the trawl rope runs out-board; the object of this was to lessen any sudden strain on the rope due to the trawl hitching, and to warn the man in charge of such strain. Since the invention of pneumatic tyres, it has been so difficult to get reasonably pure rubber that the less bulky and more reliable steel spring accumulators seem to be advisable. If trawling from a derrick, the topping lift, passing over a block stropped to the mast, is brought down and made fast to the head of a long steel spring, rigged up against the mast.* A sudden strain on the rope pulls down the derrick head, the spring yielding. Such an indication will often enable the gear to be recovered before it is seriously damaged, while with very severe pitches the warp is (probably) saved from snapping.

For really heavy trawling a nipper may be substituted for the accumulator, or used in conjunction with it. This (Fig. I95) is attached by means of a hemp rope to the winch or some other solid deck fixture, and the slack tripping line is also shackled to the same support; the accompanying figure will explain the method employed. Any undue strain causes the hemp rope to break, allowing the wire to pay out from the drum or reel (if the brake is left open), while the nipper is checked by the tripping line, and either falls to the deck or allows the wire to render through it, according to the particular make fitted. A small nipper will also

* This arrangement is figured in Report of the Siboga Expedition, "Description of the Ship," by Lieutenant G. F. Tydeman, Plate I. 
be found useful for holding the warp in the event of anything going wrong ; Figs. I96, I97 illustrate a simple form which may be employed for this purpose.

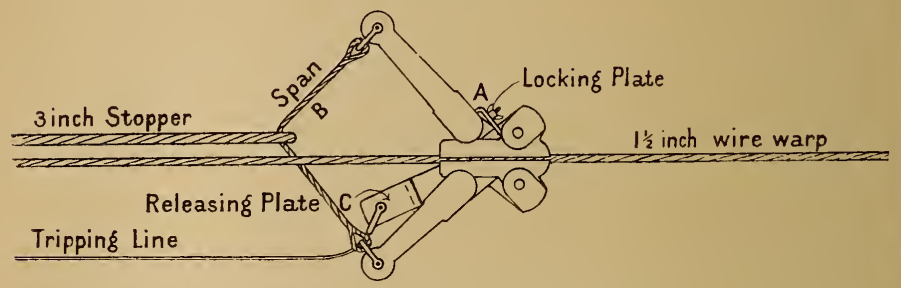

Fig. 195.-NiPPER FOR HeAVy TRAWLING.

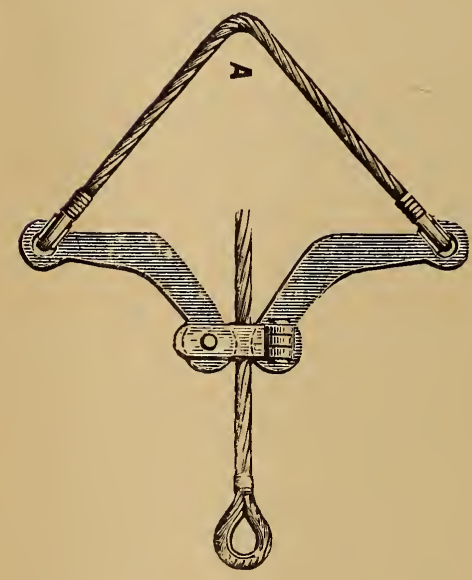

Fig. I96.-SMALl NipPeR RENDERING.

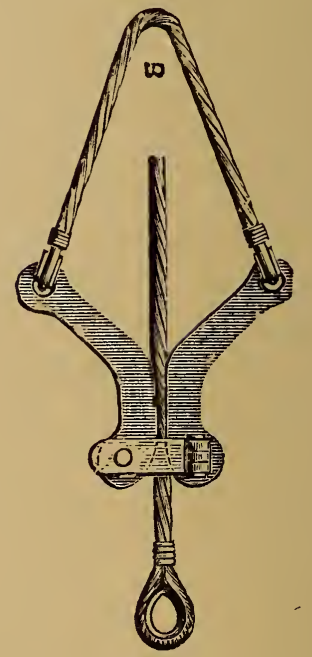

FIG. 197.-SMALl NiPPER GRIPPING.

(Figs. I95 TO I97 BY PERMission OF MESSRS. Bullivant.)

A recording sheave (odometer) of some kind is necessary for work in deep water. This need only consist of a strong sheave of known circumference ( $I$ or $\frac{1}{2}$ 
fathom), to the spindle of which is affixed an ordinary engine-room counter. For working heavy vertical or mid-water nets this sheave may be bolted to the deck, but for work of a lighter character it may be slung from a davit in place of the ordinary snatchblock. If necessary a single turn of the wire may be taken right round the sheave, but this tends to chafe stranded wire. For bottom trawling the recording sheave is scarcely necessary. A sufficiently good estimate of the amount of warp paid out can always be made by eye or by counting the revolutions of the drum, making allowance for the thickness of a heavy wire, if appreciable in comparison with the sheave.

All rollers and sheaves should be brass-bushed if possible, and they should be kept drenched in oil; it is astonishing how soon oil disappears when I,000 fathoms of rope are being paid out, and what disaster attends a block jammed for want of it.

\section{SOUNDING.}

A sounding should always be taken before any gear is shot. In surveying vessels the deep-sea sounding machine is generally rigged in the bows; it can be driven by a swifter from the deck engine. Some forms of deep-sea sounding machines-for example, the Lucas (used by the Hydrographic Office), the Sigsbee, and the Le Blanc-can be driven by their own little engines.

Until recently piano-wire was used for all soundings ; but it is very stiff, and liable to kink and snap if not checked the moment that the lead touches bottom. Instead of this, a stranded wire has come into use in the Navy, of which the following is the specification : Seven strands of 24 S.W.G. galvanized crucible steel 
wire ; diameter, $\frac{1}{16}$ inch ; breaking-strain, 280 pounds ; price 23s. per 300 fathoms.

One of the present writers, after two years' experience, is able to speak highly of the following stranded wire of German manufacture : $3 \times 7$ galvanized steel wires of 0.4 millimetre gauge; diameter, $\frac{3}{32}$ inches; breaking-strain, I,046 pounds; price $£^{6} 7 \mathrm{~s}$. $6 \mathrm{~d}$. per I,000 fathoms.

The high breaking-strain allows this wire to be used for physical operations with water-bottles and capsizing thermometers.

The various types of deep-sea sounding machines have each their own supporters. By the courtesy of the manufacturers we are able to give here the following prices of the Lucas machines as a guide : (I) For depths to 5,000 fathoms, coupled to a Brotherhood threecylinder engine ; the whole fitted to an iron base, EI3I ; (2) the same, with rope-wheel for driving from deckengine, $£ 52$. The capacity is calculated for piano-wire of 22 gauge.

For really deep-sea sounding it is advisable to use a heavy sinker of 50 pounds, which is detached on striking bottom and left there; this method enables the wire to be hauled rapidly, and without danger either of breaking the wire or of bursting the barrel on which it is reeled up. The sinkers are made of cast-iron.

Several types of deep-sea sounding leads are in use, their form being dictated by the fitting employed to bring up a sample of the bottom (cf. Chapter VI., "The Sea Floor"). For the latter purpose have been employed a cup (not now in use) ; a heavy tube, which, when being hauled, is closed below, either by a butterfly valve or a cock; and a snapper, consisting of two tightly fitting buckets which grip a bottom sample. 
The second of these is represented in Fig. I57, p. 202, the third in Fig. I99.

A full account of the Le Blanc sounding machine is furnished in Lieutenant Tydeman's Siboga Report already quoted. The Sigsbee machine is described in the "Bulletin of the United States Fish Commission for I896," p. 3 I2.

The wire should be well greased. A mixture of castor oil and tallow is recommended for stranded wire, applied hot. For single-strand wire boiled oil is good. Very great care should be exercised in spreading the sounding wire evenly on the barrel, and the same precautions taken in paying it on to the barrel from the manufacturer's reel, as in the case of wire rope.

\section{Other Work.}

It is not economical, either of time, labour, or the life of a rope, to use a heavy rope where a lighter one would do the work, and a I-inch rope is not well adapted for other uses than trawling, dredging, and big vertical nets. A lighter and cheaper type of rope can be used for reversing thermometers, current meters, water-bottles, open and closing tow nets-in fact, for everything except bottom work.* A rope of this type was spun to the order of one of the present writers for mid-water work down to 2,500 fathoms; it consisted of seven wires of I6 gauge plough-steel; diameter, $\frac{3}{10}$ inch; breaking-strain, 2 tons; weight (in air) 42 pounds per Ioo fathoms; price about 2Is. per Ioo fathoms. It should be stipulated with the makers that a rope of this type be spun from continuous

* It is not recommended to use Six thermometers with any rope of so large diameter; the vibration tends to jar their indices down, and thus to give defective readings. 
lengths of wire, with no brazed joins; the latter are apt to give way under a severe tension, and to catch and strand when running through a fair lead. It is possible that so stiff a rope would kink if used for bottom work.

\section{B.-Shallow Water.}

The hints already given relate to the most difficult and troublesome part of all oceanographic work, that which involves the most power, time, weight, storagespace, skill, care, and expense. If deep-sea work is the most ambitious, it is also the most interesting; if it is the most difficult, it is also the most needed, and the most productive of striking results.

On the other hand, excellent and valuable work can be done at small depths in almost any part of the world. Even in home waters little has been done systematically outside the Ioo-fathom line; beyond home waters (except in one or two favourite areas) anyone with a rowing-boat and a little apparatus can add materially to knowledge.

\section{Dredging and Trawling.}

In shallow water, down to (say) 200 fathoms near land, it must be remembered that if the net catch on rocky bottom, a breeze acting on the freeboard of a large yacht or steamer will impose a very great strain on the rope; a trawl full of stones or mud is also a menacing possibility. For such work a $I \frac{1}{4}$-inch or $I_{\frac{1}{2}-}$ inch rope, with a breaking-strain of 4 to 8 tons, is desirable ; the lifting power of the deck engine can be somewhat reduced, but an accumulator or some similar protection is certainly required, and a recording sheave indispensable. With this gear a yacht can 
work in as little as 3 or 4 fathoms, if the water is known to be clear of dangers. But in uncharted waters near shore, and particularly in coral seas, the owner will naturally not risk his yacht close in shore. A small sailing boat or steam pinnace, using good tarred I $\frac{1}{2}$-inch hemp rope, hauled and coiled by hand, can easily work an 8 to ro foot beam trawl, or a fairly heavy dredge ; even a yacht's punt can work a small dredge. Very excellent work round foreign ports can be done in this most unambitious way by anyone. One of the most distinguished marine naturalists used a light hand dredge about Io inches long, which he cast like a lead as far as possible, and hauled at once.

\section{Sounding.}

In Fig. 198 is shown a small sounding machine, with capacity of 200 fathoms of piano wire, 22 gauge, price $£^{25}$. A 20-pound sinker, not detaching its weight, carrying a snapper or a valved tube, will suffice.

\section{OTHER WORK.}

A small sounding machine could be utilized with either of the stranded wires mentioned on pp. 277,278 for thermometers, light water-bottles, current meters, etc., down to 200 fathoms (if the barrel will take so much); but valuable instruments should not be trusted to piano wire in a small ship with a short roll. A cheaper form of reel, costing $£ 2$ or $£ 3$ can be knocked up in plain galvanized iron. For some work it is enough to mark the wire by whippings, but if messengers are to be used this marking will not do, and a recording sheave of some kind will be needed ; an excellent little sheave is made for the International Commission for the study of the North Sea. 
The reel or sounder can be fixed close to the ship's - rail, or if fixed amidships the wire can be led over the recording sheave slung from a davit or from a spar,

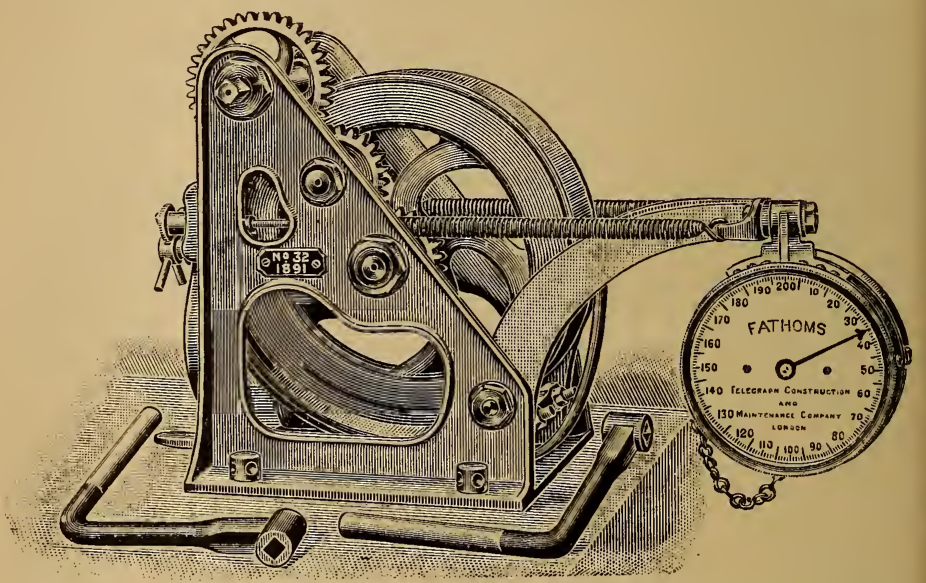

Fig. I98.-Lucas Sounding Machine, Hand-driven. (From KRÜMMEL's “HANDBUCh DER OZeanogRaPhie," BY PERMisSion OF J. ENGELHORN'S VERLAG, STUtTGART.)

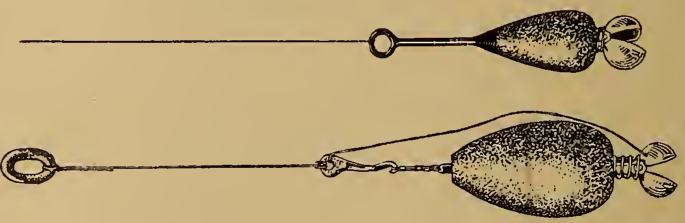

Fig. 199.-Sounding-Leads, With SNapper For Collecting a Bottom Sample. (Lucas SNappers.)

The lower lead has a weight which is detached on striking the bottom.

which can be swung inboard when the gear is up, in order to enable the instruments to be conveniently attached and detached.

Lighting.-If there is a dynamo on board, a " cargo cluster," with enamelled iron shade and flexible con- 
nection, is very useful for working at night. Heavy nets should never be shot at night until the whole, crew is thoroughly well practised in the use of the gear ; a man can easily lose his life by getting a turn of the warp or spans round his leg. A portable "electric torch" is very useful for reading the log, etc., at night.

\section{C.-Laboratory Fitting.}

Some sort of place will have to be used as a laboratory, where the scientific log can be written, collections preserved, labelled, and packed, etc. ; so that a few notes may be here added on fitting it up as a laboratory.

It is perfectly possible, by a little forethought, to do solid work, and yet to keep the yacht as spick and span as any owner can desire.

The position of the laboratory and its fittings will depend entirely on the rig and build of the vessel. It should be amidships and on deck, if possible. It cannot have too much light. A poop deck-house makes an excellent laboratory. Linoleum is the best of floorings.

A very important matter is the work table; this can be either fixed or swinging, and both have their supporters. A stout table, of the kitchen type, with a well oiled top, and a large drawer for charts and flat papers, and firmly bolted down, has this advantage over the swinging pattern - that the space below can be fitted up with pigeonholes of various sizes to take apparatus and accessories of all kinds. As a great deal of the work must be done standing, a height of 3 feet 6 inches* is less back-breaking than the ordinary table height. Half at least of the surface should be divided up permanently, by fiddles about 3 inches high, into

* The taller of the two writers prefers 2 feet ro inches! 
compartments suitable for the bottles or other apparatus required. If this is the only table in the laboratory, the other half should be left clear for writing, charting, drawing, etc., but a separate table, at which one can sit for writing and for a microscope, is a great boon.

If a swinging table be preferred, a stout rail, level with the table and about $\mathrm{I} \frac{1}{2}$ inches clear of its edge, fixed at the corners to stancheons from the floor, will bring up any one lurching against it in a heavy sea.

If there is a dynamo on board, a cluster of lamps should be over the centre of the table; but a hanging oil lamp should not be arranged to throw a shadow over the writing table.

The particular work which it is proposed to attempt will, of course, determine the character of the bottles and apparatus to be kept in the laboratory; but sweetmeat jars, corked store bottles large and small, and corked tubes, are needed in all kinds of zoological and botanical work, and should be racked in quantities round the walls. Bottles of killing and preserving fluids should be racked together. A 2-gallon milkcan, with tap below, and a filter of fine boulting-cloth at the top, is handy for the necessary store of clean water, whether salt or fresh (ship's fresh water not being ideally clean); it should be emptied and refilled every day. An enamelled slop-pail, with a top, should also be racked in a handy position to receive mess and waste fluids of all sorts.

I. Plankton.-Special receptacles in the fiddles of the work table should be made to take two or three sweetmeat jars or large square jars, into which the contents of the tow net tin are emptied for sorting. Other compartments should take those smaller bottles in which the larger organisms are to be pickled. Empty 
the "tin" into the jars with plenty of filtered salt water, pick out the larger specimens with lifter and pipette, and pickle them with as much elaboration as time allows (see Chapter XI., "Preservation "). Add a few drops of undiluted formalin to the jars, and stir the contents gently till they are moribund; they are then allowed to settle. Pour off superfluous water, and transfer them to a wide-mouthed, smaller bottle (say I6 ounces), and fill up with 2 per cent. formalin. Later on, pour this off, and transfer the catch to the storage bottle, and fill up with 7 per cent. formalin.

The use of a compound microscope for live material is almost impossible, except in harbour, but a little " dissecting microscope," with lenses multiplying 6 and IO, or 8 and I8 diameters, is extremely useful ; it can be clamped to a fixed table, or swing in gimbals.

2. Dredging and Trawling.-In this somewhat messier work the contents should be emptied on to an old sail, to save the deck. It is advantageous to lay this over a fish-fiddle (say $4 \times 3$ feet), fixed, when wanted, against a hatch, and to run a coaming 2 inches high round the hatch, which can then be used as a table.

When the material obtained by the trawl or dredge has been deposited on deck an immediate effort must be made to sort the heterogeneous assemblage of animals which is revealed. Scarce or fragile specimens should be transferred at once to glass jars or enamelled dishes. Fish may be placed in baskets, and the commoner invertebrates similarly treated, or stacked in an enamelled fish-kettle or slop-pail in sea water.

Fish should all be measured to the nearest centimetre, and entered in the scrap log-book along with an enumeration of the invertebrates. Unless the identity of the species is established beyond all doubt samples should be preserved. It is evident that 
numbers of indeterminable forms will be found ; these may be entered as Gadoid A, Asteroid A, etc. The same species occurring in subsequent hauls should be referred to in the same way, but unless the identity of the two forms is certain a sample must again be preserved.

When possible the stomachs of fish should be examined, for, apart from the light which is thus thrown on the food-supply of the species, they occasionally contain invertebrates which are seldom or never found in any other way.

Search should be made for hermit crabs and worms resident in the dead shells of molluscs, and for encrusting animals living on stones or other débris. As a rule it is best to avoid attempts at extraction or removal.

The comparatively large animals, obtained in bags of sprat meshing, may be dealt with in the same way, but the sorting of the material collected by the finemeshed nets usually demands so much time that immediate treatment is out of the question. In such cases it is best to transfer the whole to a jar containing 5 per cent. formalin or formol-alcohol, until a more favourable occasion arises. It should be remembered that formalin, even in a 5 per cent. solution, is sufficiently acid to act as a decalcifying agent; all animals which are liable to injury from this cause should be transferred as soon as possible to 70 or 75 per cent. alcohol.

The sand, mud, or ooze, which is sometimes brought up in considerable quantity by the trawl or dredge, generally contains a considerable number of animals. For the treatment of this material sieves must be employed; the process is rather laborious, but the results are as a rule eminently satisfactory. It is best to obtain a set of four sieves (with different sized meshes), which may be employed successively, using the 
coarsest first. The sieves should be made of brass wire gauze, and are more convenient if fitted with handles (Fig. I58). The coarsest should have meshes about $\frac{1}{4}$ inch square, the finer patterns with eight, sixteen, and thirty-two meshes to the inch. It is advisable to preserve a sample of the ooze in alcohol, for many minute organisms will pass through even the smallest of the above meshes. A stream of water from a service pipe may be turned into the sieve, or it may be dipped repeatedly in a bucket of water. Shaking is very destructive and should be avoided.

Samples of stones, sand, mud, or ooze should always be preserved; small canvas bags are useful for this purpose.

3. For chemical and physical work little can be done at sea, beyond the collection of water samples, without extremely elaborate appliances. The fitting up of a laboratory for immediate analysis is a matter too technical for an elementary work such as the present, but the Society is prepared to advise on the point. If such analysis is not contemplated, the chemical and physical work demands little more than proper storage for bottles and apparatus, and a writing-table.

4. Storage of Specimens at Sea.-The larger and rougher specimens obtained by dredge or trawl, after the necessary preservation (Chapter XI.) should have their label tied on to them, and then be wrapped in cheese-cloth and stored in spirit or formalin. It is handy to have on deck for this purpose a wooden tank, lined with lead (zinc tends to pit with formalin). The lid should fit on to a thick rubber flange, and be held down by wedges driven under the cross-stays of the tank. Trays of lath inside serve to distribute the pressure of the upper layers of specimens. A 
useful size of tank is $3 \times I \frac{1}{2} \times I \frac{1}{2}$ feet high. On a long cruise the contents of this can be occasionally transferred to barrels and headed up; to be sent home or stored in the hold.

Large but more delicate specimens can be stored in tobacco jars with very wide mouths; these are made in various sizes, and the lid is screwed down tightly on to a rubber flange by an iron clamp and thumbscrew. Two 4-gallon jars of this type, racked in a padded box, since they are brittle, will hold a very large quantity of material.

Sweetmeat jars, with a cork ring, and the numerous forms of screw-topped jar on the market, are not to be recommended for prolonged storage where they cannot be constantly examined, least of all in the tropics, unless packed in barrels or metal tanks, or tied over with bladder.

Stout "sample-bottles" of various sizes (4, 8, and I2 ounces, are useful) and stout unshouldered tubes of various lengths with carefully picked and fitted corks (not bungs or shives), will carry the smaller stuff. Fill all tubes and bottles with fluid up to the very cork. Put on the galley-range a goodsized glue-pot, containing paraffin wax (melting-point $100^{\circ} \mathrm{F}$., but harder if for use in the tropics) with a little white beeswax, and dip necks and corks twice in this to make all tight. These sample bottles are best stored in trays, partitioned by corrugated strawboards; but, for reasons of great weight, too many trays should not be stored in one case. Long tubes are best in a racked box. Sawdust packing is messy ; it sticks to wet fingers, and is transferred unpleasantly to the specimens. 


\section{CHAPTER IX}

\section{DREDGING AND TRAWLING}

BY E. J. ALLEN AND S. W. KEMP

\section{Dredging.}

DREDGES are suitable for the biological investigation of all grounds that are too rough to admit of trawling ; they are very serviceable for obtaining samples of the bottom, and for testing the nature of unknown localities.

Many different patterns of frame are used for dredging, but these, for the most part, only differ from one another in unimportant structural details. The best type for all ordinary purposes is known as the doublesworded oyster dredge. Fig. 200 shows an example of this type which was used by the "Porcupine" Expedition more than forty years ago, and the pattern has not been modified to any great extent since that date. The essential features of this type of dredge are the obliquely set blades or swords, on both sides of the mouth, the rings by which the net is attached (these prevent the edge of the bag from chafing when working on the bottom), and the loose connection, which allows free lateral movement, between the bridles or arms and the frame. The whole instrument should be strongly made of wrought-iron. Frames about 2 feet long and 6 inches broad are suitable for in-shore work from small boats. For work at depths from io to 
Ioo fathoms patterns from 3 feet to 3 feet 6 inches long and 8 to 9 inches broad are useful, while for very great depths large heavy makes up to 5 feet long and I foot broad are recommended.

The term naturalist's dredge may be restricted to a form of frame which differs from the foregoing only in the absence of swords. The effect of this is that the straight edge of the frame tends to skim the surface of the ground instead of biting into it. This type has been almost entirely superseded by that mentioned above.

The conical dredge is designed to dig into the soil ; of this it brings up a good sample, together with specimens of burrowing animals.

The bag or net which is fastened to the dredge should be quite as long as, if not longer than, the frame, and should not be tapered behind. It may be made of strong manila trawl-twine of 2 -inch mesh, * but a most suitable bag may be constructed from the cod end of an old trawl; this is usually easily procured and fitted. Loose chafing pieces attached to the outside are very useful, and save a great deal of wear and tear. For catching small animals and for use on smooth ground, a lining of sprat netting of I-inch mesh, or even finer, may be fitted inside the bag (some firms stock an extra stout make of sprat netting, which is excellent for this purpose). The lining should be made fully as large as the outer bag, so that the strain is taken up by the latter.

Two small bags may also be fitted in the tail end of the lining ; one of these is made of shrimp netting, and is designed to catch some of the smaller organisms which would pass through the I-inch mesh, while the

* Meshes are measured diagonally when the net is stretched out; thus 2-inch mesh means openings of I square inch. 
other is made of sacking or stout canvas, and preserves a sample of the sand or other fine bottom material.

The two main bags-of trawl-twine and sprat netting-are lashed to rings at the back of the dredge, or they may be fastened directly to the frame by means of seizing wire. Each bag is opened or closed behind by means of a running string through the meshes. The small bags are stitched in position through both the main bags, and their ends are secured by a lashing.

The nets for small frames for use in shallow water are generally of a simple pattern. For these a piece of the cod end of a shrimp-trawl or the extra stout sprat netting mentioned above is suitable, with or without a lining of mosquito netting.

For the conical dredge a strong canvas bag is recommended. Dredges used in deep water should always have a piece of chain fastened to the end of the bag to prevent it getting foul of the frame while being lowered to the bottom, and this device is also useful at all depths when the net is new.

A tow net made of cheese-cloth, with a strong cane ring, is sometimes fastened to the dredge. It is usually attached to the shackle at the end of the warp, with a strop sufficiently long to allow it to lie with its mouth a little behind the frame. By this arrangement the tow net is designed to catch the small animals disturbed by the swords of the dredge. This method has been known to produce the most satisfactory results, but the safe recovery of the tow net is decidedly uncertain.

Tangles (or swabs) consist of lengths of hemp rope teased out, and fastened to the end of the bag or to an iron rod attached by chains to the frame. Starfish and other animals become entangled in the threads of the hemp, and are thus drawn to the surface. Tangles 
were very highly spoken of by the naturalists on the " Challenger," but in recent years they have not been much employed.

The dredge should be attached to the warp in the following way: The eye at the end of one of the bridles is secured to the eye at the end of the warp by means of a screw shackle, and the other eye is made fast merely by a strong strop or lashing of trawl-twine. This arrangement is invaluable in the event of the dredge becoming fast among rocks, for in that case the lashing parts and the frame is drawn along sideways, thus usually clearing the obstruction and preserving the dredge from injury.

In 50 fathoms of water or less it is usually best to pay out warp to the extent of two or three times the depth; in deeper water less is required, and when working in soundings of I,OOO fathoms or more, 400 or 500 fathoms in excess of the depth will be found sufficient. In many localities, however, the nature of the bottom is so extremely rough that, if this amount of warp is given, the strop parts on every occasion. On such grounds it is advisable to pay out only a little warp in excess of the depth, and, after the ship has been stopped, to ascertain if the dredge is biting by holding the warp.* More warp may then be given cautiously if required.

\section{Shooting and Towing.}

Sailing Yachts.-Always tow with the tide if possible. With a moderate amount of way on the boat throw the dredge over on the windward quarter, and pay out a sufficient length of warp. Make the warp fast with a stop of small rope, but be sure to have the end well

* By holding the warp it is often possible to feel a heavy dredge working, even at depths of 500 fathoms. 
secured inboard, so that if the stop parts the whole will not be lost.

Tow slowly, feeling the warp from time to time to make sure that the dredge keeps on the bottom. If the dredge comes fast, lower sail if possible, pass the warp up to the bow of the boat, and haul in until it clears. If it still cannot be got free, try hoisting sail and beating back over it.

In working from small boats it is safer always to lower sail before hauling.

Steam Yachts. - In small vessels it is best as a rule to tow from the warping chock right aft, or from a set of special rollers (consisting of two vertical and one horizontal) placed in the same position. In the absence of a capstan the warp may be eased away from the bollards. For handling the dredge a purchase from the mizzen is useful, and with heavy patterns necessary.

In larger yachts the dredge may be towed direct from the trawling winch, the warp being led through the gallows or trawl-port to a strong davit or snatchblock on the port quarter, but the exact arrangement will vary with different vessels.

For shallow in-shore grounds, especially where very rough, manila warp is better than wire, as it is more easily handled and manœuvred if the dredge becomes fast.

In shooting, the dredge is slung overboard by the derrick or masthead tackle, and slowly lowered away. In very deep water the engines may be put at half speed, and the warp eased away more quickly. When towing from a davit on the port quarter, especially with twinscrew vessels, it is advisable to put the helm hard a-starboard. In this case the dredge should be shot with the ship's head about four points to starboard of the direction in which it is intended to tow, so that 
the ship may at once be brought up on her course when the gear is clear away.

When a sufficient length has been paid out, the warp is made fast by means of a rope-strop and rolling hitch ;* if the dredge fouls, this strop should break. When using manila a few turns of the slack warp should be taken round the bollards, and when towing from the winch barrel the brakes should be left open if plenty of wire remains.

Tow dead slow, preferably with the tide, feeling the warp from time to time to make sure that the dredge is biting properly.

If the dredge hitches and the strop parts, stop the ship at once, and if it does not clear itself immediately haul it up. Should it still remain fast, lead the warp forward and go astern, steaming slowly over the dredge.

The dredge is usually left on the bottom for from ten to thirty minutes; if longer time is given the net may fill right up and the strop on the bridle may part, involving the loss of the greater part of the contents.

The procedure in hauling is obvious. The ship is stopped, the rolling hitch is cast off, and the warp hauled by hand, capstan, or winch. In the latter case it is well to see that the warp is evenly spread across the breadth of the barrel; otherwise loose bights appear which later on will cause considerable annoyance.

With a considerable amount of warp out, it is allowable to go slowly and cautiously astern at the commencement of hauling, a careful watch, of course, being kept that the warp does not come foul of the propeller. If block and tackle are employed for getting

* It is sometimes difficult to make a rolling hitch hold on well-oiled wire-warp, especially when of small diameter; in such cases it will be found that a serving of trawl-twine or a canvas parcelling will materially assist. 
the dredge inboard, it is advisable to keep the frame slung up, and if necessary lashed, until the contents of the bag have been emptied.

\section{Trawling.}

Trawling is the best and easiest way of obtaining extensive samples of the bottom fauna, but the method can only be satisfactorily employed on smooth ground.

Three types of trawl are available for biological investigation-the beam trawl, Agassiz trawl, and otter trawl.

The Beam Trawl.-In this pattern the net is kept open horizontally by a long beam of greenheart or oak, and vertically by a pair of iron runners or heads, Fig. 202 gives a good idea of the appearance of the frame.

Beam trawls may be used at practically any depth, but in very deep water they show a tendency to capsize. the beam dragging along the bottom, and the foot rope completely closing the net. In such cases the haul is naturally a complete failure. With a certain amount of experience in shooting this difficulty may be largely overcome; but the otter and Agassiz trawls will be found more efficient for work in greater depths than 300 fathoms.

The beam trawl collects a larger number of invertebrates than the otter trawl, but does not secure so many fish-active species of the latter are doubtless scared by the beam in its passage along the bottom.

Trawls of this pattern range from 6 to 50 feet in beam-length. Small makes, with a 6 or 8 feet beam, are easily handled from a rowing boat or launch. The commercial beam trawl is usually from 40 to 50 feet in length; these sizes are, however, unwieldy, 
and the procedure in shooting and hauling is very complicated. Yachtsmen will find patterns with a I5 to 30 feet beam -amply large enough. In these sizes the shooting and hauling does not present any considerable difficulty.

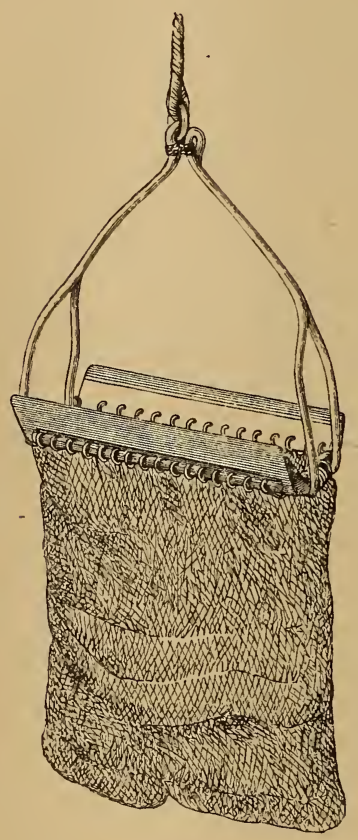

FIG. 200.-BALL DREDGE. (After Wyville Thomson.)

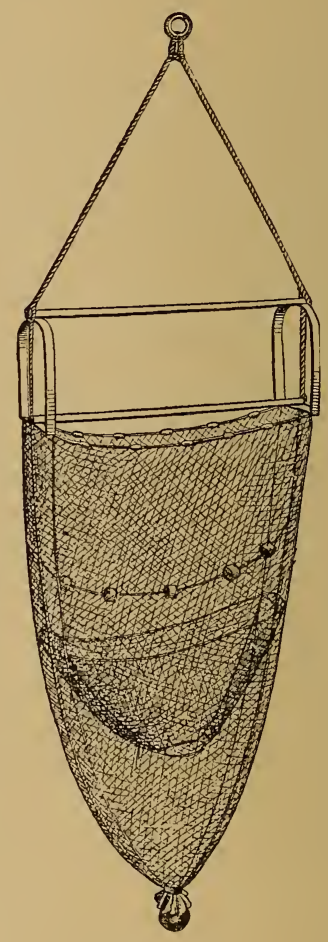

FIG. 20I.-AGASSIZ TRAWL, "Blake" Pattern.

The beam trawl is towed by a pair of spans which are shackled to eyes in the front of the heads. Each span should be three and a half or four times the length of the beam, and as stout as the warp. The head rope of the net is as long as the beam, and is laced to it. 
THE BEAM TRAWL

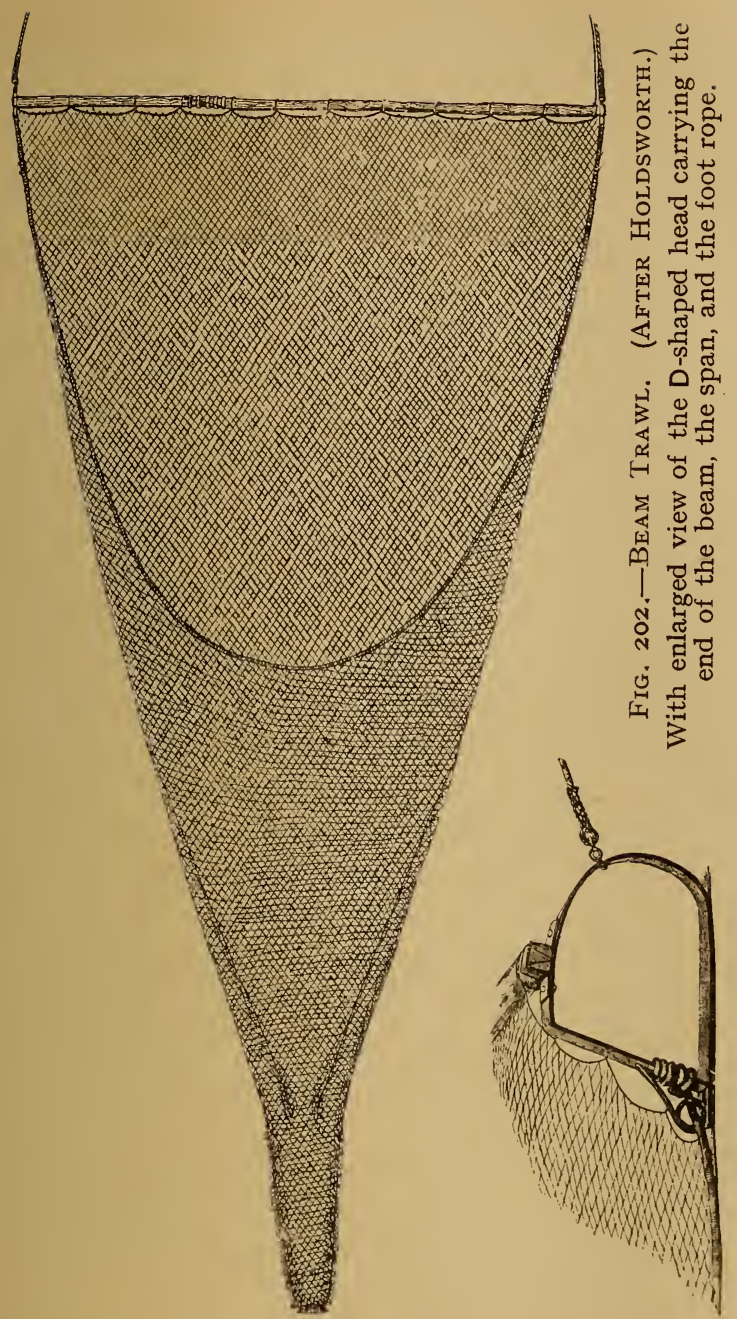

The foot rope, to which the lower edge of the net is attached, is twice the length of the beam. The ends are securely lashed to the eyes at the back of the heads. 
As it is intended to scour the bottom, it is necessary to make the foot rope heavy; for medium-sized trawls 8-inch rope is recommended, weighted by the attachment of lengths of chain.

The net should be about one and a half times the length of the beam. It is made of hemp or manila twine of 2 to $2 \frac{1}{2}$ inch mesh in the back and belly, and I inch double mesh in the cod end. The lower part of the cod end, which comes in contact with the ground, is protected from chafe by an extra piece of stout netting attached on the outside.

The trawl moves comparatively slowly over the sea bottom, and consequently fish which have entered the net frequently manage to swim out again and avoid capture. To obviate this, pockets are formed by stitching together the back and belly of the net at the sides, as indicated in Fig. 202. The net is opened and closed behind by a running string through the meshes.

The 2 or $2 \frac{1}{2}$ inch mesh is much too large to retain any small organisms. The whole net may be lined with sprat netting (I-inch mesh) or bags of the same material and of mosquito netting may be attached to the back, in the path of the swirl caused by the foot rope. The latter system has the advantage that the coarser part of the catch is kept in the trawl, while samples of the smaller animals are separately collected and saved from crushing.

Tow nets with cane or iron rings and a long cheesecloth bag may also be attached to the beam or to the net. If placed too far back, they frequently fill with sand or mud, and burst.

The very small makes of trawl, which are suited for use from rowing boats or launches, are usually known as "shrimp trawls." In these the net is made of stout sprat meshing with a lining of mosquito net. 
The length of warp required varies with the depth. The following table will give some indication of what is required :

In soundings up to 50 fathoms- 3 times the depth.

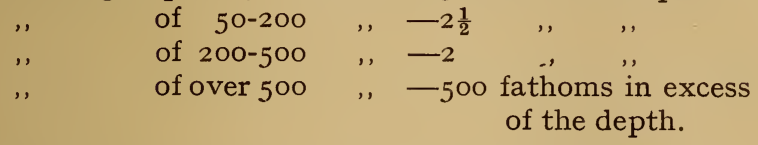

Beam trawls may be towed from the warping chock aft, from a trawl post, or from a wide-mouthed snatchblock* slung from a derrick or davit.

Shooting over the stern is much the most convenient, but the method can only be used with very small patterns. As a general rule, it will be found best to shoot and haul from the port side as far aft as possible. The following is an outline of the procedure :

The trawl is laid on deck with the heels of the irons close to the rail, and with the net brought back over the beam. The spans are coiled down on deck, and the warp, after it has been passed through the trawl port or other fairlead, is shackled to them. It is best to use a separate shackle for each span. When these preparations are complete, way may be got on the ship, and the trawl shot with helm hard a-starboard. The frame is lifted to the rail by hand or by tackle. The cod end is put over the side first, followed by the heads and beam, the trawl drifting away on the port quarter as the spans uncoil. It is best to square the trawl by checking the after span, while the other is let run freely. This should be done while the net is still at the surface and can be seen. When the whole length of the spans has disappeared, the warp may be

* A snatch-block for this purpose must be wide enough to allow the passage of the shackles connecting the warp and spans, and should have a deep V-shaped groove. 
eased slowly away, and the ship brought up on her course. In most cases it will be necessary to trice the warp up to the after hawse pipe, to keep it clear of the propellers. As has already been mentioned under "Dredging," it is advisable to start shooting with the ship's head about four points to starboard of her course, so that she may be straightened up directly the gear has gone away clear. It is necessary to keep a steady strain on the warp, and to check it repeatedly as it is being paid out. Neglect of this precaution is the most frequent cause of a foul shot. When a sufficient length has been given, the warp is made fast (as in dredging) by means of a rope stop or by a nipper (p. 276$)$.

The trawl is generally fished for from one and a half to two and a half hours. By holding the warp it is possible, in moderate depths, to feel the gear working its way along. With a little practice a useful estimate of the nature of the bottom can be formed by this means. If the trawl hitches and the stop parts, the net should be hauled at once. If it still remains fast, lead the warp to the bow, go astern and pull it backwards off the obstruction.

Hauling small beam trawls is not difficult. The warp is reeled in until the spans appear, and each span is separately hauled by hand until the beam and irons are got on board; the net may then be hauled in, foot rope first. This procedure cannot be applied to larger patterns (with beam more than I5 feet in length), for in these makes the weight is too great to admit of the spans being hauled by hand. The addition of a " beam rope" is almost essential in such cases, and it is also advisable to step a stout davit with a snatch-block on the port quarter. The " beam rope" is in reality a third span, used only in hauling. It is 
a few feet longer than the spans, and is made fast by one end to the beam, close to the after head, and by the other to the trawl warp just above the shackle. When the spans appear through the fairlead, the beam rope (which is, of course, slack) is taken off, passed through the snatch-block on the port quarter, and led back to the capstan, or to one of the small drums of the winch. One or two turns are taken on the spans, with the result that the weight of the trawl is borne by the fore span and by the beam rope. A rolling hitch is put round both spans; they are reeled off the drum and the after one unshackled. The trawl is now hauled to the surface by the fore span and beam rope, while the after span is coiled down on deck. When the frame appears at the water's edge, one head after another may be lifted in by the masthead or derrick tackle. The net can then be hauled in over the beam, taking the foot rope first to avoid the loss of any of the contents.

The Agassiz Trawl.-This is a small trawl useful for work in deep water. When a small trawl of the usual pattern is shot in deep water, it is liable to turn over, so that the beam lies on the ground and the net does not fish. In order to obviate this Professor Agassiz devised a trawl with two ground ropes and an iron frame, so arranged that the net would fish whichever way up the trawl fell on the bottom (Fig. 20I). The shape of the frame is shown in the figure. The following dimensions are given by Tanner :

Beam : I I feet.

Runners : length, 4 feet; depth, 3 feet 6 inches; width, 3 inches.

Trawl net: length, 17 feet; mesh, I inch to $\frac{1}{2}$ inch.

For working in water over Ioo fathoms in depth, it has been found advantageous to weight the frame 
considerably, and this may be conveniently done by winding chain around the iron beams. The net should be of "shrimp" or "sprat" mesh. The Agassiz trawl is more useful for catching invertebrates than for fish. The procedure in shooting and hauling does not differ in any essential way from that already detailed under "Dredging" (pp. 292-295).

The Otter Trawl.-For work on small steamboats, especially where a winch or capstan of any kind is available, a small otter trawl is more handy to use than a beam trawl of equal spread. The shape of the net of an otter trawl is practically the same as that of a beam trawl, the difference between the two trawls consisting in the method adopted for keeping the mouth of the net open. In the case of the beam trawl this is effected by the long wooden beam and the two iron heads. In the case of the otter trawl two oblong boards, fitted with iron shoes-the otter boards-are used. The mouth of the net in both beam and otter trawl has a heavy ground rope below, which drags along the sea bottom, and a head line above, which in the beam trawl is attached to the beam, but in the otter trawl is floated up in the water by means of corks or (in deep water) glass floats attached to it. These two ropes, the head line and the ground rope, are made fast at each end to the hinder ends of the oblong otter boards, which, when the net is working, stand on their lower iron-shod edges on the sea bottom.

The two otter boards act after the manner of kites which are "flown" from the stern of the ship by means of two towing warps, one bearing away to starboard, the other to port. Each towing rope is fixed to its otter board by means of iron brackets or of four chains, in such a way that the point of attachment is behind the centre of the board, and the board therefore 
moves forward obliquely to the direction of tow. The two boards in this way keep a strain on the head line and ground rope, which increases with the speed at which the vessel is towing. It is probable that under normal working conditions the distance which the boards actually keep apart is about two-thirds the length of the head line of the trawl. The head line being floated with cork, rises up in an arch between the two boards, and gives a much higher opening to the mouth of the net than is yielded by the beam trawl, in which the height of the opening is fixed by the height of the beam above the ground. This increase in the height of the opening of the mouth of the net constitutes one of the chief advantages of the otter trawl as a fishing instrument, since the take of round fishes, which swim a little above the actual bottom, is thereby much increased.

The size of the otter trawl usually worked on a steam trawler is as follows :

Length of head line, 86 feet. Length of ground rope, I25 feet. Dimensions of otter boards : length, 8 feet ; height, 4 feet 3 inches; thickness, $2 \frac{1}{2}$ inches. Size of mesh, measured diagonally with mesh taut, diminishes from $5 \frac{1}{2}$ inches in the square to $2 \frac{3}{4}$ inches at cod end.

The fine-meshed nets already mentioned in connection with beam trawling may also be fitted to otter trawls.

On a commercial steam trawler two independent towing warps are used, one for each otter board, and special iron gallows are fixed to the vessel's side, fore and aft, for getting in the heavy boards. It is not necessary to give here the details of the method of shooting and hauling these heavy trawls, as this should not be attempted excepting with a specially fitted vessel and under expert direction.

The following instructions may be useful for working 
a small otter trawl from a small vessel, without special fittings. Such a trawl is most conveniently worked with two "bridles" and a single towing warp, as in the case of a beam trawl. Each otter board should not be heavier than can be conveniently handled by one man.

The following dimensions apply to what is perhaps the largest trawl that can be conveniently worked in this way:

Square: Ir.5 feet long; r40 meshes down to I40; mesh, 2 inches.

Top wings, I7 feet long ; 36 meshes down to I2 ; mesh, 2 inches.

Bottom wings : 27 feet long ; 30 meshes down to 28 ; mesh, 2 inches.

Batings: I40 meshes down to 50 ; length, 20 feet (7.75 feet to head of pockets, 8.5 feet of pockets, 8.5 feet $\mathrm{r} 40$ meshes down to 80 ).

Belly : braided same as batings.

Cod end : 50 meshes across ; 1 inch mesh ; 6 feet.

Head rope : 40 feet.

Ground rope : 46 feet.

Length of spans used : 40 feet each span.

Size of otter boards: 3 feet 5 inches $\times 2$ feet $2 \frac{3}{4}$ inches.

A trawl of this pattern may be shot over the stern of the vessel. To prepare the trawl for shooting, attach the head line and ground rope to the two boards, shackle one bridle to each otter board, and then attach the other ends of the bridles to the towing warp by means of a freely working swivel. When the cod end of the net has been tied, steam slowly ahead and pay the net overboard, starting with the cod end. One man should be in charge of each otter board, and should stand on the outside of the bridles. When the net is trailing away 
all clear astern, the two boards are thrown overboard together, and a short length of the bridle is allowed to run out. The bridles are then checked for a moment to give the boards time to open the trawl. When this has happened, and the trawl is squared, the rest of the bridles are run out, being checked at intervals, until the towing warp is reached. The latter should be held for a moment, either by the break of the winch, if one is being used, or round a bollard. The warp is then slowly paid out until the trawl reaches the bottom. The amount of warp required is the same as in the case of the beam trawl. The warp is made fast by a stopper of thin rope, which will part if the trawl comes fast.

When hauling the vessel should be stopped, and the two boards hauled up to the stern together. One of them may then be carried round to the quarter and the net hauled in by hand, the ground rope being brought in first. If there is a heavy catch in the bag, a rope may be passed round it, and the bag hauled in with a tackle from mast or derrick. 


\section{CHAPTER X \\ FISHES AND FISHING*}

BY L. W. BYRNE

THERE are perhaps no living creatures which are more constantly brought to the attention of any person living on or near the sea than fishes, and yet there are not many groups whose habits and life-histories require more elucidation. Our knowledge of the growth and appearance of the young stages of even the commonest fishes of our own coasts has only been acquired within the last quarter of a century, and there are still species of no mean commercial importance of whose breeding habits we are almost completely ignorant.

The persons for whom the present work is primarily intended may well have neither the opportunity nor the leisure to make exhaustive collections of specimens of fish, and our endeavour in the following pages is to direct attention to the class of observation that is likely to prove both interesting to the actual observer and useful either to the student of ichthyology or the practical fisherman.

Whatever the nature of the observation made, it is obviously of the first importance that the species of fish under observation should be correctly identified.

* The author of this chapter desires to make particular acknowledgment of the advice and assistance given him by Mr. E. W. L. Holt, one of the Inspectors of Irish Fisheries. 
To insure this, the safest plan is to preserve at least one specimen of such fish; but as any individual, however carefully preserved, is almost certain to undergo some post-mortem change of shape, and to lose the colours which adorned it in life, it is well, wherever possible, to take careful measurements, and make a sketch or note of the colours of the living or fresh animal. This is important, both in the case of colours, which frequently differ in the two sexes, and are nearly always subject to change at or shortly after death ; and also in the case of delicate scales or fins, which are easily damaged.

Fig. 203 is intended to show the more salient points in the external topography of a fish, and the names by which they are commonly referred to in descriptive literature.

In taking the measurements of a fish the accepted method is, not to follow the contours of the body, but to measure between perpendiculars, as shown in Fig. 204. The measurements ordinarily used in descriptions are those there shown, and, in addition, the distance between the eyes (measured by callipers or compasses between their bony orbits), and sometimes the greatest breadth of the head and body respectively. These measurements should be taken in centimetres and millimetres.

In addition to these measurements it is usual in the case of Teleostean fishes to count the number of rays in the dorsal and anal fins, discriminating between spines and soft rays, and the number of scales (when present) in a longitudinal series along the body above the lateral line and in a transverse series from the back to the belly at the deepest part of the body.

In cases where there is more than one dorsal or anal 


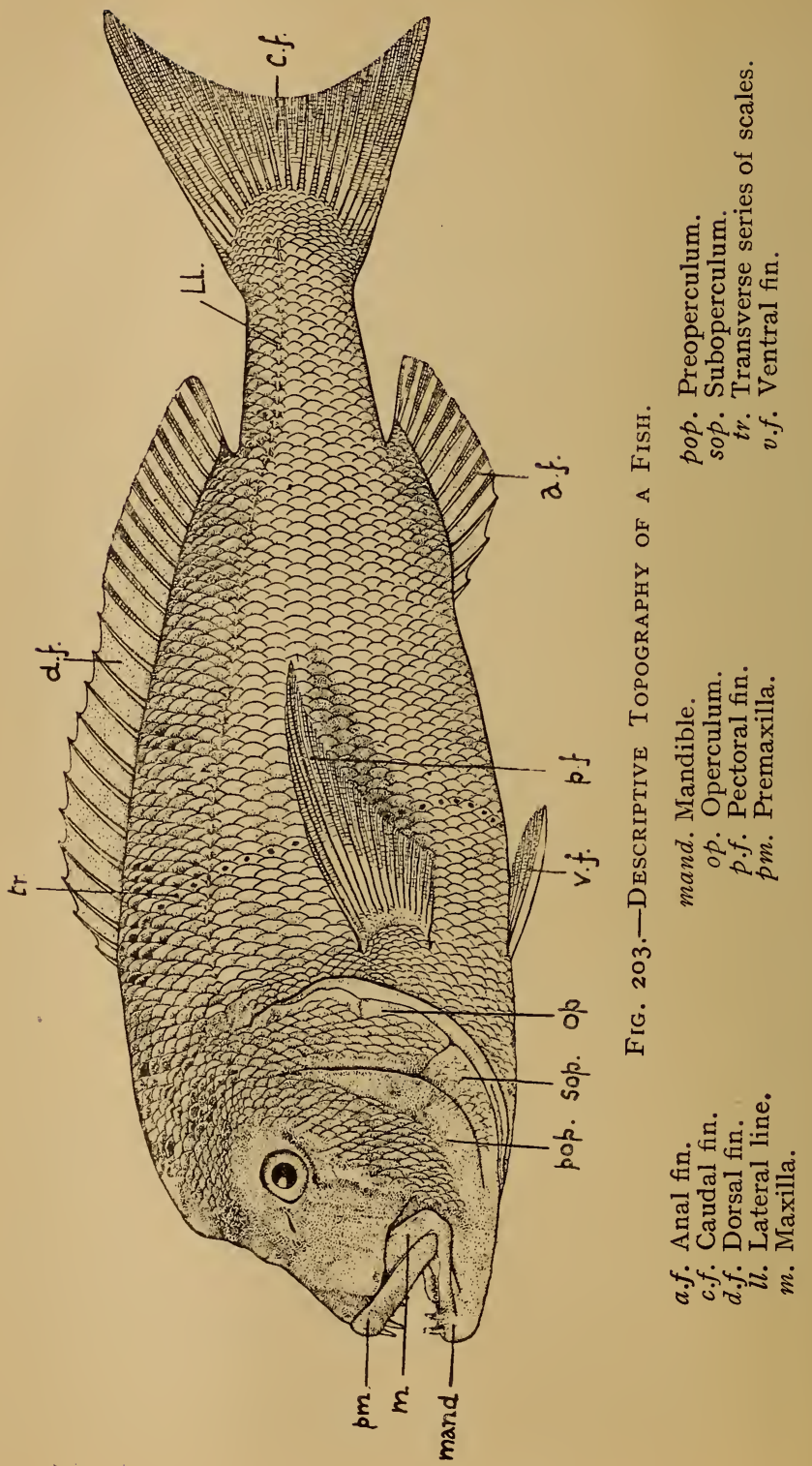




\section{MEASUREMENTS OF A FISH 309}

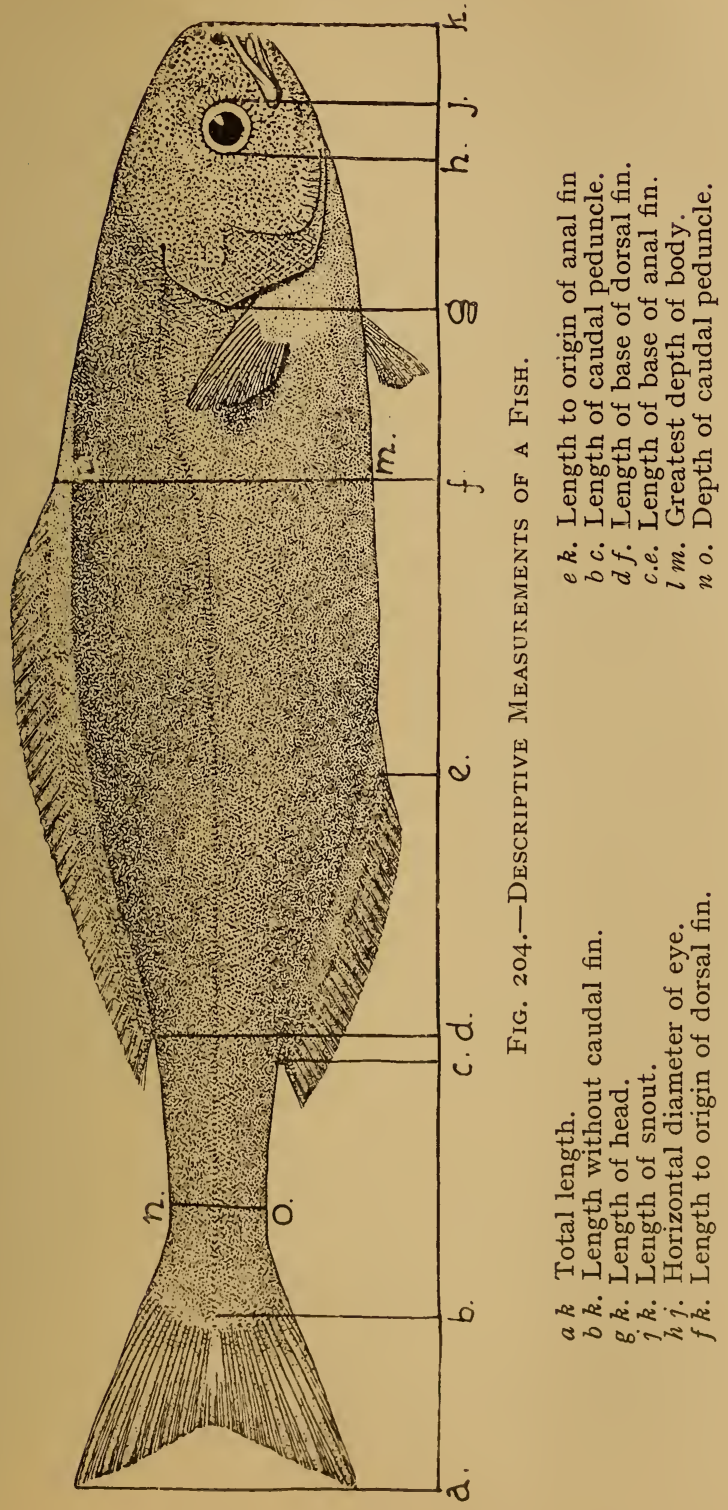


fin, the number of such fins and the number of rays in each should be noted.

When from lack of time it is impossible to take the actual measurements of a series of specimens, their proportions should be noted (for example, eye goes five and a half times into head; head, six times into length without caudal fin, etc.) ; but even where it is only possible to note proportions in this manner, the total length of the specimen examined should always be recorded.

It is well to adopt some regular method of recording measurements in tabular form, any particular notes as to maturity, coloration, shape of fins, or other matters requiring note, being added at the foot of the list of measurements. The general practice is to indicate spinous fin-rays by Roman figures, and soft fin-rays by Arabic numerals, and to insert a comma to mark a break in the continuity of a fin.

The copy on p. 3 II of actual measurements and notes as taken should help to explain this.

Before dealing in detail with the special points to which we think the attention of an observer of fishes should be directed, and with the necessary gear, it seems convenient to commence with a very brief account of the best methods of searching for fishes in localities of different natures, even if the information may have to be repeated hereafter.

To begin at the very margin of the sea, numerous fishes are to be found between tide-marks on rocky shores. In searching a locality of this nature, it is, as a rule, not much use beginning far above half-tide mark, unless large and sheltered rock-pools are to be found at higher levels. The site selected for examination should be as sheltered as possible, and, even on bare and exposed coasts, gullies and crevices among 
the rocks may often be found in which there is a considerable growth of weed, of sponges, and of other encrusting animal growths sufficient to shelter the small animals upon which fishes feed, as well as the fishes themselves.

Species-G. Minutus ; Locality-Inisbofin, August.

\begin{tabular}{|c|c|c|c|c|c|c|}
\hline & I. & 2. & 3. & 4. & 5. & 6. \\
\hline 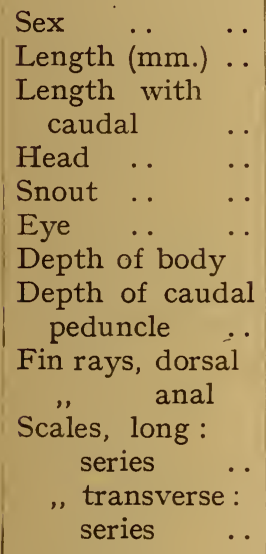 & $\begin{array}{l}q \\
72 \\
82 \\
\text { I6 } \\
4 \cdot 5 \\
4 \cdot 5 \\
\text { I } 2 \\
5 \\
\text { vi, I } 2 \\
\text { I2 } \\
64 \\
\text { I } 7\end{array}$ & $\begin{array}{c}\text { के } \\
65 \\
76 \\
\text { I6 } \\
4 \\
4.5 \\
\text { I0 } \\
5 \\
\text { vi, I2 } \\
\text { 12 } \\
64 \\
\text { I6 }\end{array}$ & 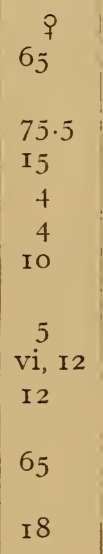 & $\begin{array}{l}\text { } \\
64 \\
73 \\
\text { I } 5 \\
4 \\
4 \\
9 \\
5 \\
\text { vi, I2 } \\
\text { I } 2 \\
62 \\
\text { I6 }\end{array}$ & $\begin{array}{l}\text { ठ } \\
63 \\
73 \\
\text { I5 } \\
4 \\
4 \\
9 \\
5 \\
\text { vi, I } 2 \\
\text { II } \\
62 \\
\text { I6 }\end{array}$ & $\begin{array}{l}{ }^{7} \\
58 \\
69 \\
14 \\
4 \\
4 \\
9 \\
4 \cdot 5 \\
\text { vi, I I } \\
12 \\
66 \\
\\
17\end{array}$ \\
\hline
\end{tabular}

All spent: (5) with some small ripe spermatozoa. Very slight traces of dark pigment on undersides of $\delta \bar{\delta}$, spot on spinous dorsal slightly more intense in $\delta \sigma^{\top}$. Height and shape of soft dorsal similar in both sexes.

It must be remembered that many shore fishes normally spend the period of low water in very small and shallow puddles, or even on a patch of bare sand or fine gravel, provided the spot is sufficiently protected from the sun by sheltering rocks or boulders carrying a growth of weed or encrusting animals. Stones and boulders, of the size of a man's fist, or larger, should be lifted, even 
when loosely packed to the depth of I or 2 feet, and the small pools or wet hollows under them examined, from half-tide mark downwards; hollows or pools under the shelter of growing weed or rocky ledges should also be searched with a hand net (see p. 334).

Larger rock-pools can be similarly searched by dint of wading, or, if too deep for this, by dangling a bait upon a small hook in front of likely looking hollows and crevices, the fisherman being careful to keep himself out of sight.

The roots of such seaweeds as have large tangled and bulbous roots will often repay examination, and are not infrequently selected as nesting sites by some fishes.

On sandy and muddy shores and estuaries the best spots for searching are the pools and runnels left by the receding tide, preferably such as from their situation alter little in depth and position from tide to tide. The hand net already alluded to can be used in such localities, as can any form of shrimp net.

Below tide-marks and in shallow water, sandy and muddy ground can be efficiently searched with almost any form of shrimp net or shrimp trawl (see p. 295), or by a tuck net or hauling seine (see p. 340), according to the depth; especial attention should be paid to beds of sea grass or weed, and to the immediate neighbourhood of ledges or patches of rock.

As the water deepens, recourse must be had to larger and heavier trawls (see pp. 295-305), which can be used on any ground not so uneven or rough as to prevent the ground rope gripping the bottom or to tear the net.

The weed-covered sides of piers and quay-walls will often prove excellent hunting grounds if carefully 
searched with a hand net, or, in deeper water, by fishing close to them with fine tackle.

Rocky ground, ground too rough for trawling, and ground encumbered with wreckage, when below tidemarks, can only really be fished by hook and line. Native fishermen have usually learnt by long experience the best localities for line-fishing, and, in the absence of such guidance as they can afford, experiment alone can discover it. In the absence of local guidance as to baits, almost any large marine worm, mussels, or similar soft-fleshed shellfish, the tails of hermit crabs, cuttle-fish cut into strips, or pieces of almost any fish-preferably such as contain a quantity of fat or oil-may be tried as baits.

Trammels and gill nets (see pp. 335, 337) are most efficiently used when set from the end of a reef of rocks where there is a rapid drop into deeper water.

The surface waters of the sea, whether in-shore or in mid-ocean, should be fished by tow nets of comparatively large mesh at various depths (see p. I88), or by a "young fish net" (see p. 34I), and to such localities the general remarks under the head of " Tow Netting " are applicable. We know of no net really well adapted for taking the larger fishes of the surface waters or middle depths of the ocean.

At the actual surface a line with a spinning or trolling bait can, of course, be used, and fishes are often found accompanying floating weed, wreckage, or large pelagic jelly-fishes.

Sometimes in calm weather a powerful light displayed over the ship's side attracts surface fishes, or, at least, makes them visible, and renders their capture with a dip or hand net possible.

In very deep water, down to abo ut 3,cco fatlem.s fishing may be conducted on the bottom either by 
means of a suitable trawl or dredge (see Chapter IX.), or by long lines. Various forms of fish trap have been tried for fishing under such circumstances, but we are unaware of any such implement suitable for use by any vessel which does not carry a special equipment for deep-sea exploration.

\section{Habits of Fishes.}

From the nature of their haunts it is not always easy to observe the habits of fishes in a wild, state, but such matters as the nature of their food (ascertained by examination of the contents of their bellies), breeding season (tested by the development of roe or milt), and seasonal movements (as shown by their presence or absence in a particular locality at different times of year), should ordinarily be susceptible of ascertainment.

Other matters as to which information may sometimes be obtained are the nature of their haunts, whether at the surface or the bottom, on mud, sand, gravel, or rough ground, or among coral or rocks; the depth at which they are ordinarily found ; and their predilection for salt, brackish, hot, cold, clean, or turbid water. At times such observations may necessitate the use of special gear (closing tow nets), the taking of temperatures, or the testing of the salinity of any particular part of the sea; but the necessary information may often be obtained by the use of simple sounding apparatus or even by ocular observation, while the statements of fishermen on such subjects are often both precise and accurate.

In places where the usual commercial fisheries are confined to in-shore waters, and especially where their main object is to supply a local market, seasonal 
changes of venue and gear in native fishing operations, and of the kinds of fish brought to market, will often afford useful information.

Among shore fishes, the observations of breeding habits, to which allusion will be made later, is often both easy and interesting; and, at whatever depth a fish is captured, sexual differences of form or colour may be observed and noted by comparison of examples of both sexes, especially such as are shown by their roes or milt to be approaching the breeding season.

As an observation of such sexual differences is of the greatest importance to systematists, and can best be made in a living or fresh example, we may briefly point out the details which demand attention :

I. The presence of external copulatory appendages (as in sharks, rays, and chimæroids), or of a prominent genital papilla.

2. Outgrowths of the scales or dermal covering, and differences in the teeth.

3. Differences in the profile of the head and back.

4. Elongated fin rays (especially of the dorsal and anal fins).

5. Thickening of the rays of the pectoral, ventral, or anal fins.

6. Differences in size.

7. Differences in coloration.

8. Differences in the arrangement of the luminous organs of oceanic fishes.

Attention should further be paid to the size at which each sex commences breeding, to the comparative abundance of specimens of the two sexes, and to the permanent or transitory nature of the sexual differences observed.

In many fishes colour changes may occur with startling rapidity, especially under the influences 
of shock or excitement. Such changes are, perhaps, best observed in captive examples, and may often be noticed if a fish is kept in a bucket on deck for a short time after capture.

\section{Eggs.}

Sharks and rays and allied fishes are either viviparous or else lay large eggs enclosed in horny capsules or "purses" (Fig. 205); the dissection of pregnant females will often serve, in viviparous species, to show how many young are born in one litter; or, in oviparous species, to connect an egg capsule with the parent fish.

Teleostean fishes, although sometimes viviparous, usually produce a comparatively large number of small eggs, examples of which are shown in Fig. 207.

These eggs may be either "pelagic" - that is, buoyant and floating in the water at whatever depthor " demersal "- that is, attached to some object, or lying among gravel or débris at the bottom.

The pelagic eggs of different species of fish vary from about 0.5 to 2 millimetres in diameter, while demersal eggs are commonly somewhat larger, and are seldom less than about $\mathrm{I} \cdot 5$ millimetres in diameter. Their diameter is most easily measured by putting them under a microscope of low power, with an eyepiece ruled in squares of about 0.05 millimetre value with the objective employed.

It should be remembered that the eggs of teleostean fishes are very readily fertilized artificially, if ripe examples of both sexes are forthcoming for the purpose. To effect artificial fertilization, all that is necessary is to stroke gently the belly of the fish from in front backwards until eggs or milt are extended, and to 
catch these products on extrusion in a jar containing a little sea water. It is no use trying to fertilize eggs unless naturally extruded by the female; but, in the case of males, milt approaching ripeness and obtained by dissection is sometimes sufficient for the purpose.

If a ripe female is obtainable but no male can be found, the eggs should be allowed to remain in sea water for some hours after extrusion before being

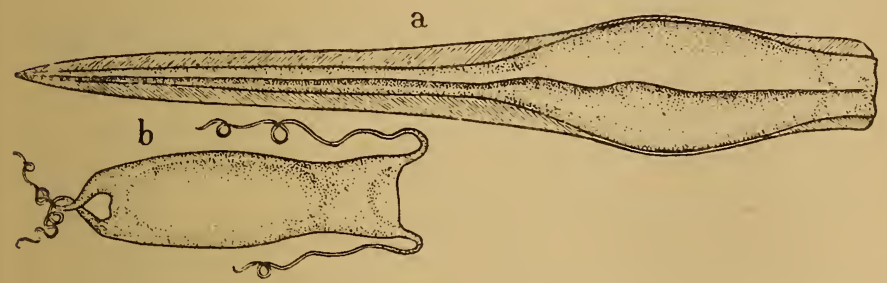

Fig. 205.-Horny Egg Capsule of (a Chimera, (b) Scyllium.

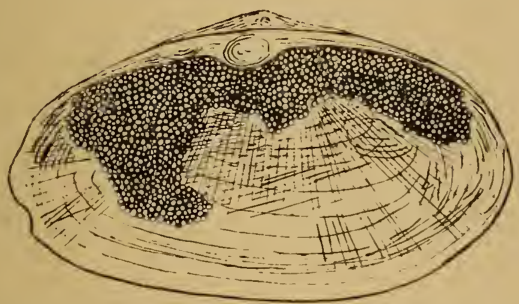

Fig. 206.-Demersal Ova of a Shore Fish (Gobius Minutus) in AN EMPty Shell.

examined, so as to allow them to attain as far as possible their normal size after distension on contact with water.

Pelagic eggs, if not obtained direct from the parent and artificially fertilized, may very often be found among the gatherings of tow nets. When obtained, they may be kept alive for a long period, and their development and hatching watched if they are kept 
in jars of clean sea water of the proper salinity and temperature, occasionally changed. They are, however, very susceptible to sudden changes of salinity or temperature, and care must be taken not suddenly to change them from chilly and saline water of the open sea to the warmer and fresher water of a harbour; such errors and consequent disappointment can generally be guarded against by the use of a little care.

Demersal eggs are occasionally laid either loose or in adhering masses on the sea bottom, and left to hatch (as in the case of the herring); but are more commonly laid either in masses or in an even layer, and cared for by the parent (usually the male) during the process of incubation. Many shore fishes, and some normally living in deeper water, construct nests, or guard or carry about their eggs during development.

Instances of the latter habit may be found in the pipe fishes and sea-horses, in which the male carries the eggs in a pouch or groove in the belly ; and in some catfishes and perciform fishes, in which they are carried in the mouth or throat.

The line between what may be termed nest-building and the mere guarding the eggs is not very easy to draw.

In some cases (e.g., sticklebacks and some wrasses) a more or less elaborate nest of seaweed or other material is formed; in others (Lepadogaster and some blennies and gobies) an empty shell (Fig. 206) or the hollow bulbous root of a seaweed is selected; again, the fish may overturn a shell, so as to form a hollow beneath it, and then conceal the chamber so formed with a covering of sand, or may be contented with a crevice in a rock or overhanging stone. We have known the hollow at the foot of a recording thermometer lifted daily from the harbour where it lay, tenanted by a small 
goby and his brood. From such examples as these the step to those cases in which the eggs are laid in a more or less exposed situation, and merely guarded by the male parent, is a very short one.

When shore collecting, or dredging, or trawling in shallow water, it is, consequently, well carefully to examine crannies in rocks, the undersides of stones and old shells, tins, old bottles, and any other likely sites. Very frequently the secret is disclosed by the discovery of the dutiful parent, and by his reluctance to leave his charge. Often enough the assiduity of the male in defending his charge, and sometimes even his courtship, may be observed in the pool in which he is found ; but matters are facilitated by removing him and his brood into a tank or large shallow dish.

\section{Larvæ.}

The newly hatched larvæ of fishes are, like pelagic eggs, commonly taken in tow nets, and careful observation is required to enable these to be connected with specimens hatched in captivity from the eggs of known parents, or with the older stages which gradually lead to the attainment of the form and characteristics of the adult fish.

Fig. 208 is intended to show the ordinary appearance and main characteristics of the pelagic larvæ of teleostean fishes.

\section{Young.}

The young of fishes are often very different from the adult in form and colour, apparently especially so in the case of pelagic fishes. Series of the young of almost any species of fish are useful, both as a method of ascertaining the probable rate of growth (where the dates 
of capture are known), and as throwing light upon the life-histories of allied but less known species.

Often the young of a fish are found in localities widely different from those ordinarily inhabited by the adult, and, especially in the case of fishes of commercial importance, records of the places in which the young are found at various sizes, their comparative abundance, and their seasonal movements, may have a very great practical value.

Certain differences in form and proportions between the young and adults of fishes are so constant and well known as to deserve mention. For instance, the eye of a young fish is, as a rule (and with the known exception of a few oceanic fishes), proportionately larger than that of the adult, and consequently bears a larger ratio to the length of the head and snout and to the interorbital width. The form of the young is not infrequently slighter, and the serrations of the operculum and preoperculum (if present) may be more strongly marked.

Such characters as an elongated beak, prolonged fin rays, or a characteristic colour pattern, cannot be safely looked for in the young, nor can the elongated fin rays of some larvæ be expected to persist. On the other hand, the number of fin rays and scales is normally very constant throughout life, and, once the larval phase is passed, the positions of the insertions of the paired fins seem to change but little, however subject to modification their shape and the relative lengths of their rays may be.

\section{Oceanic Fishes.}

We advisedly combine under the above heading all the fishes of the open ocean, whether inhabitants of the bottom, the surface, or the intervening waters, 
because it is often difficult to say into which category any particular fish properly falls, and we believe that many fishes have been described as "inhabitants of the greatest depths" upon very insufficient evidence.

It is obvious that a trawl or dredge fished on the bottom at a depth of, say, 2,000 fathoms, and drawn open to the surface may, and probably often does, capture fishes in the course of its ascent. It must therefore be remembered that the presence of a fish in any net hauled open to the surface proves no more than that such fish was not captured at a greater depth than the lowest point touched by the net.

There are, of course, many cases in which sufficient evidence is forthcoming of the nature of the habitat of a particular species, especially in the case of those whose normal habitat is in water of not more than 500 or 600 fathoms depth. Such evidence may be based upon a shape unsuited for pelagic life (as in a flat fish), or for life at the bottom (as in Argyropelecus), as the case may be ; or, again, by constant captures in surface nets or by some instrument such as a long line, which is not well adapted to taking fishes in the course of its descent or ascent. The constant presence in considerable numbers of any fish in trawls fished at about the same depth raises a strong presumption that such fish has been captured in the ordinary course of fishing on the bottom ; and the presence in a fish's belly of bottomliving organisms points also to a normal habitat on the bottom. Thus we may fairly presume that most deep-sea Gadoids, Macrurids, and Scorpænoids are bottom fishes, and that the majority of known Stomiatids and Scopelids do not normally live on the bottom.

Evidence that a fish does not live on the bottom is, however, no evidence whatever of the precise depth at which it does live. Captures in nets fished in the super- 


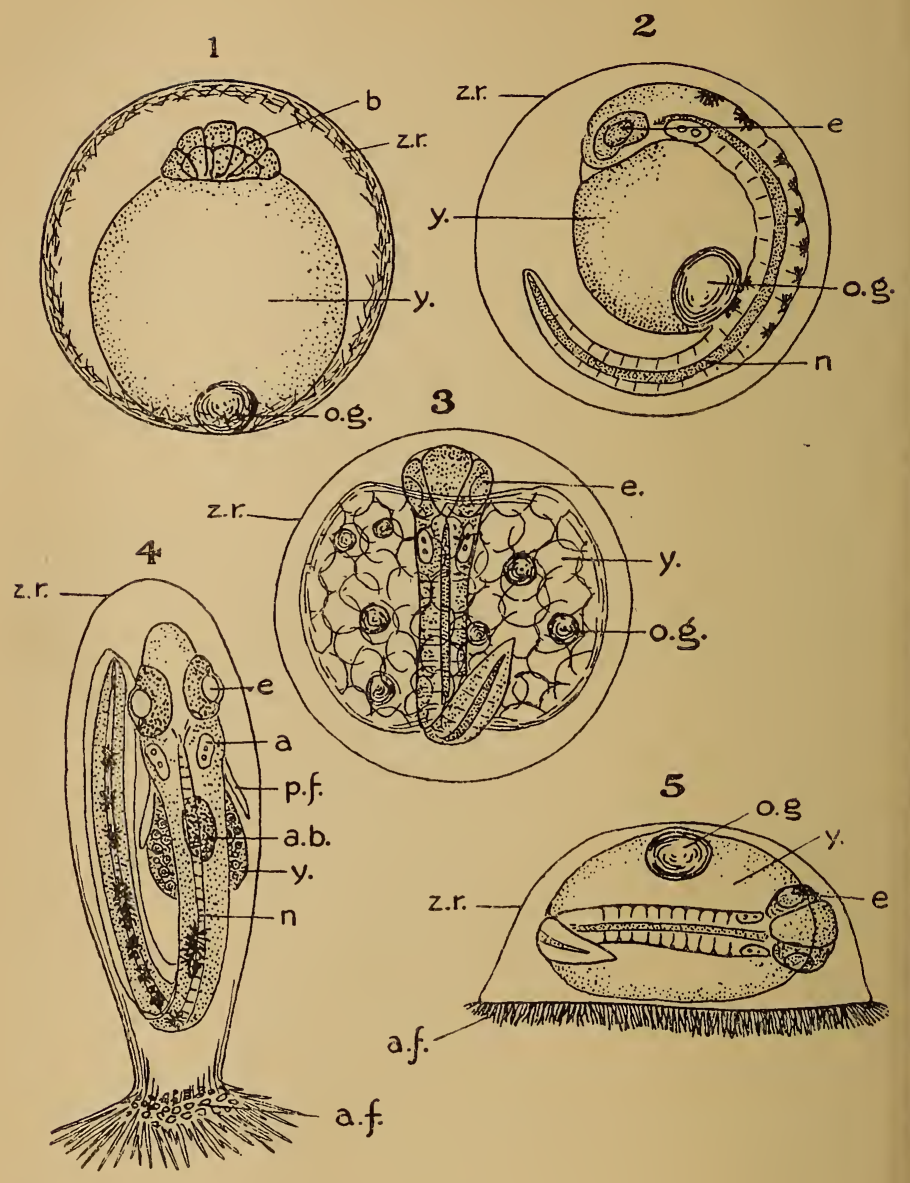

Fig. 207.- $\mathrm{I}, 2,3$, Pelagic Eggs (Diagrammatic) $\times 40$ ca.; 4, Demersal Egg of Goby (after Petersen); 5 , Demersal EgG of Spotted SUCKer (AFter Holt) $\times 30 \mathrm{ca}$.

a. Auditory capsule.

a.b. Air bladder.

a.f. Attachment filaments.

$b$. Blastoderm.

e. Eye. $n$. Notochord.

o.g. Oil globule.

p.f. Pectoral fin.

$y$. Yolk.

$z . v$. Zona radiata. 


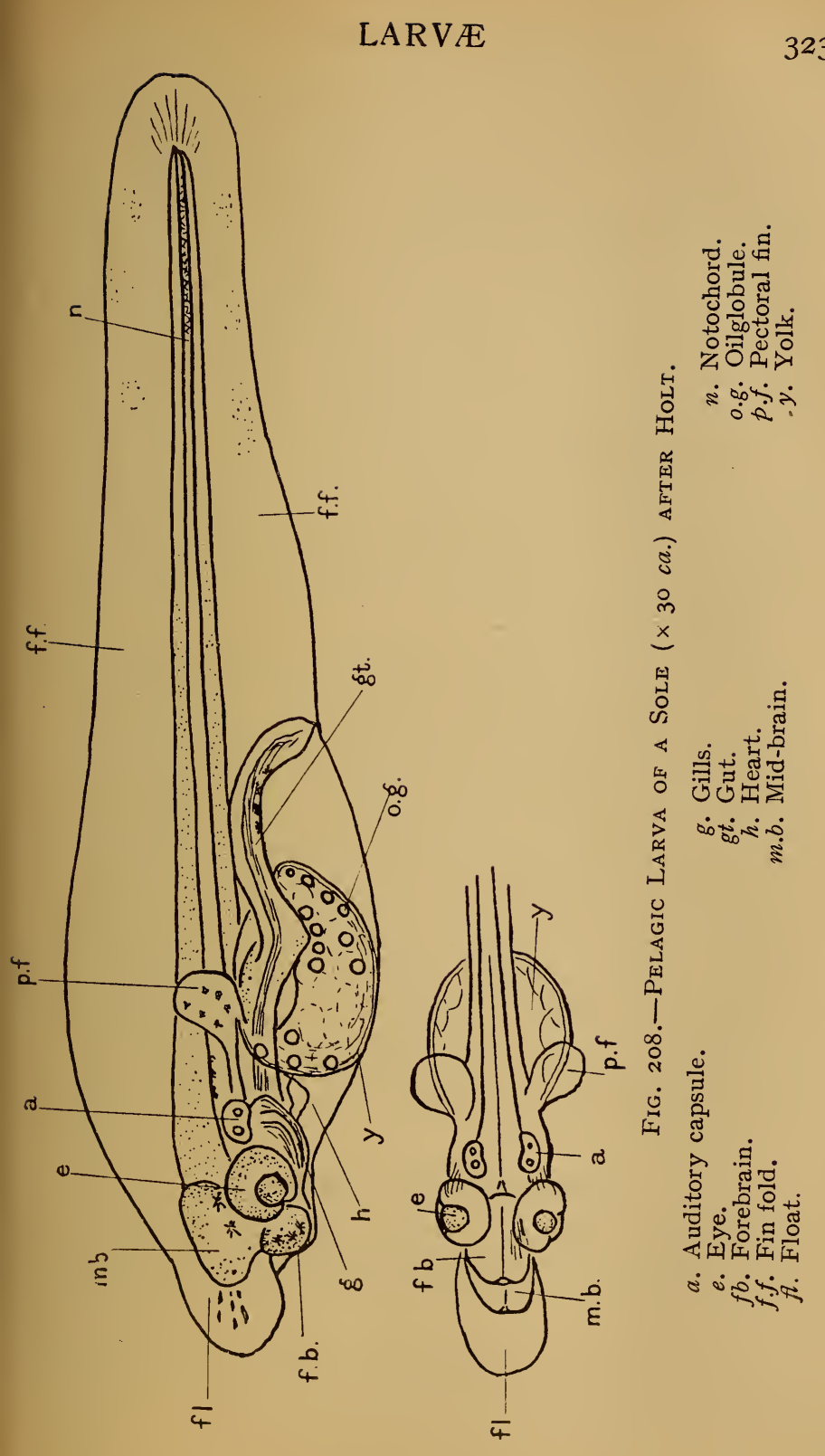


ficial roo or 50 fathoms of the ocean provide valuable records, but the lack of any net at once capable of capturing any but the youngest and smallest fishes, and of being opened and closed at ascertainable depths, leaves us practically in absolute ignorance of the inhabitants of the middle depths of the ocean. Series of hauls taken at the same spot with similar nets fished open from different depths, may afford some evidence of the horizon at which a species is most abundant.

Some slight evidence on this subject has been derived from closing tow nets; but a tow net is ill adapted for the capture of adult fishes, and it is most unsafe to assume that such adults are to be found at the same horizon as the larval and young forms of the species to which they belong.

We believe that for the capture of such larval and young fishes as live in the upper waters of the ocean, a tow net should be allowed to sink to about roo fathoms, since existing records rather point to the region lying between roo and 25 fathoms as the normal habitat of such forms, which are comparatively scarce at the actual surface. Interesting results could probably be obtained by the use of tow nets opening and closing at different depths within this region fished by night.

Wherever possible, a temperature record, taken at the depth at which the gear was supposed to be working, should accompany observations made in the open ocean.

\section{Preservation of Specimens.}

Two preservatives are ordinarily employed in the case of fishes: (I) alcohol, in some form or other; and (2) formalin.

Alcohol has the disadvantage of having to be carried about, of a strength nearly that at which it is used; it 
therefore occupies a great deal more space than formalin, of which a 5 per cent. solution of the ordinary commercial 40 per cent. solution (i.e., a 2 per cent. solution of pure formaldehyde) is sufficiently strong for all ordinary purposes.

Formalin is unsuitable for specimens which are required for osteological work, as, after a time, it softens the bony tissues.

Both preservatives rather rapidly extract the blue and bluish-green colours of many fishes; neither has any great effect on dark pigments, and alcohol dissolves red and yellow pigments more rapidly than formalin. In any case, the colours of fishes-and especially the paler colours-can only be properly studied after preservation if the specimens are kept in light-proof vessels or, at any rate, wrapped in muslin.

Probably the most satisfactory course is to preserve fishes in formalin, and subsequently to transfer to alcohol those which it is desired to retain permanently as museum specimens; in effecting such a transfer, the usual precaution of dehydrating the specimens gradually and successively in 30,50 , and 75 per cent. alcohol, should be observed. In practice, many of the fishes which we handle have been transferred after a few weeks preservation in formalin to a mixture of equal parts of 95 per cent. alcohol and the 2 per cent. solution of pure formaldehyde above mentioned; this seems to make an admirable preservative, but, as it has not yet stood the test of time, we can say nothing as to its permanent value.

For preserving larvæ the methods above suggested. will be found quite satisfactory; preserving solutions containing osmic acid or corrosive sublimate should on no account be used. 


\section{Gear.*}

\section{GENERAL.}

Before dealing in detail with the various kinds of line and net likely to be used by those for whom this work is intended, a few prefatory remarks upon the general subject may prove useful.

I. All lines and nets, of whatever material, should be oil-dressed or barked, not tarred.

2. Hooks, swivels, shackles, and other metal articles, if made of iron or steel, should be galvanized.

3. Many of the lines and nets described take up a lot of room when mounted ready for use ; it is generally better in such cases to carry their component parts, and mount them as and when required.

4. All gear should be well dried after use before being stowed away.

5. Nets in particular constantly need mending, and any vessel carrying nets should also carry at least one person who can mend them.

6. Plenty of spare lines, hooks, snooding, twine, ropes, lead (pipe and wire), corks (or glass floats), and of anything else likely to be required for repairs or renewals, should always be carried.

7. And lastly, never despise native gear, however unpromising in appearance; for one thing, it is always possible to find someone locally who can make it fish efficiently; and, for another, it has probably stood the test of long use in practice. For exploring any waters in which a commercial fishery is carried on, the hiring or subsidising of those who carry it on will probably, in the long-run, prove the best way of securing fish.

* Excluding trawls (as to which see Chapter IX.) and apparatus not primarily intended to catch fishes. 


\section{LINES.}

Hand lines may be used either with or without a rod. Quite apart from its sporting aspects, a rod possesses two advantages : (I) It holds the line clear of the boat, pier, or rock from which it is used ; and (2) it enables lighter tackle to be employed than if a hand line is used.

For fuller information as to sea rods, reels, and lines, reference should be made to such books as the Badminton Library volume on sea-fishing; but the following brief notes may prove useful :

The rod should be stiff and not too long, its metal parts made of phosphor-bronze or some other rustproof metal. It must be remembered that the weight required to keep a line on the bottom in a tideway is considerable, and that a long rod is a nuisance in a boat, and in no way more efficient than a short one.

The reel should be large and of the ordinary Nottingham pattern, with an optional check. We do not know that anything is really better than a strong wooden reel with an easily fitting line drum, preferably with a rust-proof metal flange and back plate; the working parts should be kept well greased and the linedrum fit easily, unless backed with metal; otherwise the wood will swell when saturated with sea water, and the drum jam in the flange. The cost should not exceed Ios. or I2s.

For lines plaited and barked hemp is quite satisfactory and inexpensive, costing from 2s. $6 \mathrm{~d}$. to $4 \mathrm{~s}$. per IOO yards, according to weight; a twisted line is apt to kink, and should be avoided.

Traces and snoods may be of plain or twisted gut, horsehair, wire, hemp, or raw hide, according to the probable weight and biting powers of the prospective fish. 

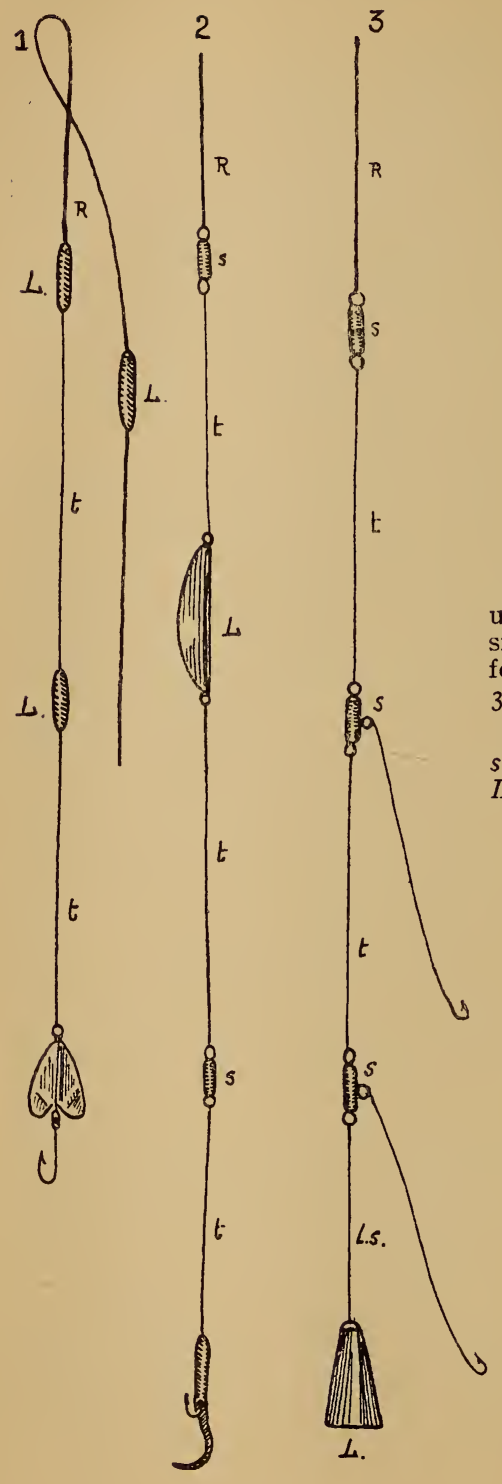

FIG. 209.-TRACES.

I, Spinning trace suitable for use with a hand line with several small leads ; 2 , spinning trace for use with a rod or hand line; 3 , trace for bottom fishing.

$R$, Running line; $t$, trace ; $s$, swivels; l.s., lead-snood ; L. lead. 
Swivels should always be used, whether for bottom fishing or trolling, between the running line and the trace.

Leads for trolling should be boat shaped or drain-pipe shaped-preferably the former if at all heavy. For bottom fishing a conical lead is as good as anything else; this should be attached to the trace by a snood of such strength as to break before the trace, if the lead gets jammed in a crevice among rocks or wreckage. It is advisable in bottom fishing to have a swivel between the trace and the lead-snood. A line rigged as in Fig. 209 permits the lead to be kept on the bottom at whatever depths the hooks are fishing, and render it easy to detect any inability on the lead's part to hold the line straight against tides or currents.

Spinning-baits, both natural and artificial, are numberless; we believe the best natural bait to be a strip of skin and flesh from the tail of some silvery and tough-skinned fish (e.g., a mackerel) or a small silvery fish used whole. Of artificial baits two standard and useful forms are (I) a piece of black, white, or red rubber tubing, and (2) a triangular or fish-tailed piece of bright metal, with its edges turned so as to make it spin. Red worsted, also, has its merits, especially if used in combination with a bright metal spinner.

Fishes which swim and feed in shoals may often be caught by a "jigger"; this is a piece of lead shaped like an ordinary sounding lead, and 6 inches long or less, armed according to fancy with bare hooks. The lead must be scraped bright before use, and is then worked rapidly up and down, so as to hook any fish attracted by curiosity or the prospect of its proving edible.

The above remarks apply generally to hand lines, but such lines must, of course, be considerably heavier 
and stouter than lines used with rods; also the use of plaited lines and swivels is not so necessary. When spinning with a hand-line, it is often more convenient to use several small leads than one large one (see Fig. 209). Hemp lines, 40 fathoms long, should cost from about 20s. to 5os. per dozen, according to weight.

Long lines, spillers, or bolters, are suitable for use in water down to 500 fathoms or more. They possess two great advantages : that they can be used on ground too patchy for trawling, and that they can be left to themselves while the vessel setting them is otherwise occupied; also one very serious disadvantage-that they require a great deal of bait.

The long line as ordinarily used by English fishermen for commercial purposes is 40 fathoms in length, and carries hooks on snoods of from 3 to 5 feet long, fastened on to the line at intervals of $I_{2} \frac{1}{2}$ to 2 fathoms. Any number of such lines up to twenty dozen (which is the full outfit of a modern line-fishing vessel) are fastened together end to end, and fished in one string. The ends of the string are made fast to anchors or weights and their positions marked by buoys ; and, in the case of a long string, further anchors are added at the end of every sixteen lines, and their positions also marked by smaller buoys. Before setting, the lines must be carefully coiled in boxes or shallow baskets (each ordinarily holding eight lines), and the hooks baited and so arranged as to run out smoothly without fouling. Long lines should always be shot across a tide, and, where possible, hauled at slack water. No one who has not had considerable experience of long lines and their ways should ever attempt to set or haul them out of anything but a rowing boat; and it is well to remember that if lines are set at low water or on a rising tide sufficient slack should be allowed on the buoy lines 
to prevent the buoys being drawn under the surface as the tide rises.

By regulating the distance from the buoys at which the lines are fastened to the buoy ropes, a long line may be set so as to fish at any desired distance from the bottom.

By the courtesy of a well-known East Coast firm, we are able to give the following estimates of the cost of long lines and gear. The detailed prices will give the necessary information as to the cost of unmounted lines and anything wanted for renewals. Mounted lines are not very easy to stow, and it might be advisable only to mount at least a part of the lines as and when wanted.

The prices given are for baskets of eight lines (320 fathoms in all); for ordinary use by yachtsmen or others fishing for scientific purposes, one or two baskets would probably be ample, and such a string would only require to be anchored and buoyed at the ends. The weights given are per line of 40 fathoms.

Halibut Fishing Gear.

8 5-pound Russian hemp long lines, 40 fathoms

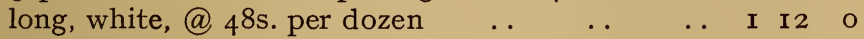
I6o No.3 hooks and loops @ 22s.6d.per I,00o .. 39 I6o 6o-inch cotton snoods, tanned, @ 35s. per I,000 59

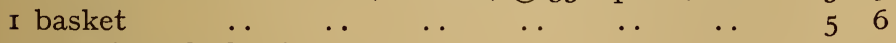

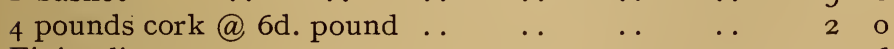

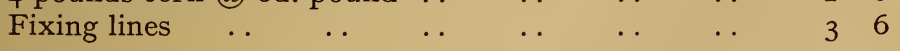
Extra for swivel hooks per basket $\begin{array}{rrrrrrr}\text { Per } & \text { basket } & & \ldots & £ 2 & \text { I2 } & 6 \\ & \ldots & . & \ldots & 6 & 6\end{array}$

Cod Fishing Gear.

8 3-pound lines, as above, @ 30s.per dozen I6o No. 6 hooks and loops, @ 2os. per 1,00o I60 6o-inch cotton snoods, as above
Basket, cork, and fixing, as above . .

$$
\begin{aligned}
& \text { £ s. d. } \\
& \text {.. I } 0 \text { o } \\
& \text {.. } 33 \\
& \text {.. } 59 \\
& \text { Per basket .. } \quad \ldots £ \overline{20} 0
\end{aligned}
$$


HAdDock or Whiting Fishing Gear. $£$ s. d. 8 2-pound lines, as above, @ 2Is. per dozen $\ldots . \quad I_{4} 0$ I6o No. I5 hooks and loops, @ 20s. per 1,000 .. 33 Snoods, basket, cork, and fixing, as above .. $\quad \ldots \quad r 6 \quad 9$

Per basket .. £I I4 O

The following are required for a full outfit of 20 dozen lines :

5 s. d.

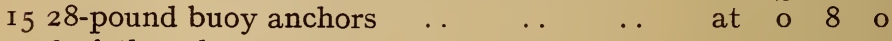

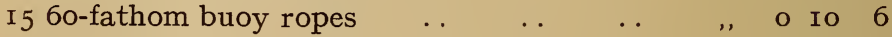

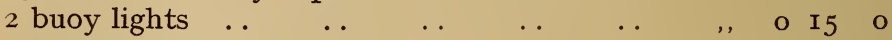

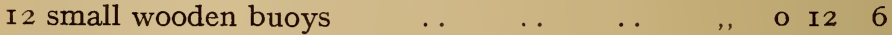

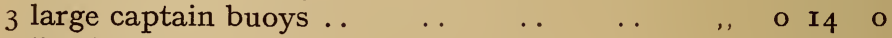

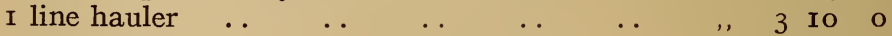

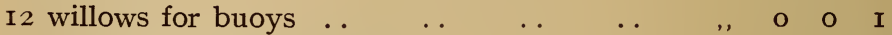

I2 yards bunting for buoys $\ldots$.

Plain hooks, unmounted, should cost from $5 \mathrm{~s} .6 \mathrm{~d}$. to 7s. $6 \mathrm{~d}$. per I,000 ; and conger swivel hooks, unmounted, about $£ I$ I8s. per I,000.

As will be seen, the only item which varies much in price in lines of various strength is the actual lines themselves, which increase in price according to their weight.

We believe that Scotch fishermen often use 6ofathom lines, five lines to a basket; these cost about $£$ I I2s. 6d. per basket. We do not know the weight of such lines, which is, however, probably 3 to 4 pounds per line.

A commercial line fishery is carried on off the Portuguese coast in very deep water, and as the method employed may be found useful elsewhere, a brief description of the gear examined and described by Vaillant follows.

The line used consists of a hauling line, 650 to 700 fathoms long, and about $\frac{1}{4}$ inch in diameter, to which are fastened twenty to forty hook lines of the 
same material. Each hook line is about 16 fathoms long, and carries twenty cod-hooks on snoods 5 feet in length. The only weight used is made fast at the end of the last hook line (the first to be shot), and no buoy is used, the end of the hauling line being made

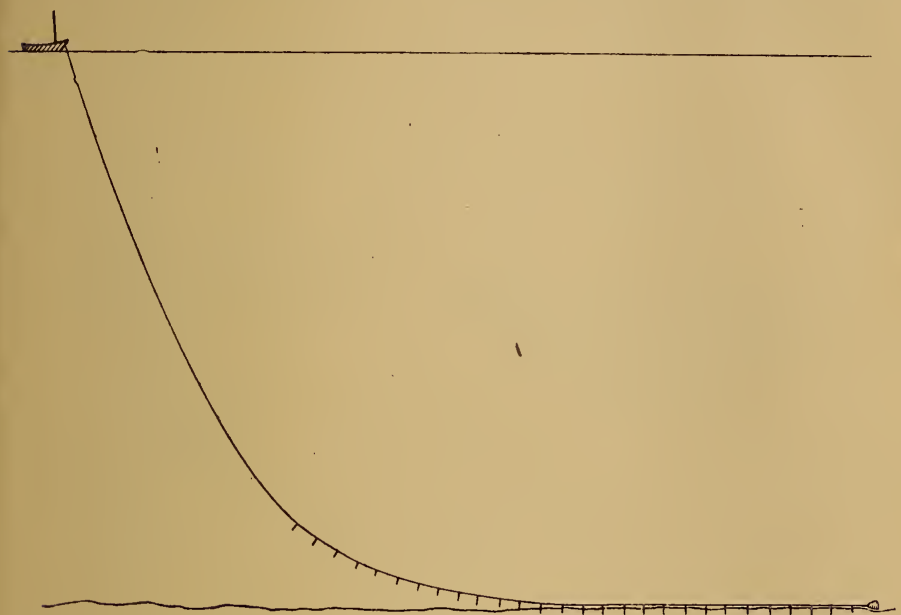

Fig. 2io.-Long Line, as Used by Portuguese Fishermen.

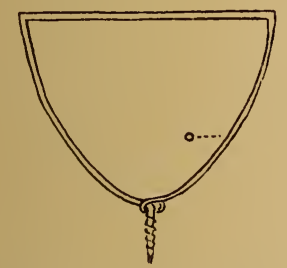

FIG. 2II.-HAND NeT FRAME.

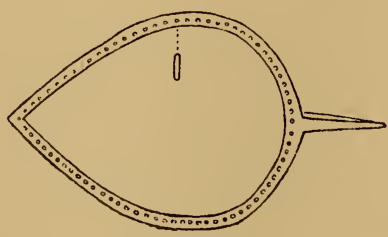

Fig. 212.-Frame of Hand Net FOR USE AMONG ROCKS.

fast to the boat. As fished, at least the last ten or fifteen hook lines actually lie on the bottom.

If it is desired to buoy a long line of the type above described in deep water, it would probably be prudent to use an empty Io-gallon water-breaker at least. 


\section{NeTs.}

I. HAND NETS.

Hand nets for use among rocks should have frames of one of the forms shown in Figs. 2II, 2I2. The form of ring shown in Fig. 2II is best adapted for light nets for general use, or heavier nets for use on sand or mud; while that shown in Fig. 2 I2 is more suited for heavy nets for use among rocks. The first of these could be used with a net of either strong netting or stout mosquito net. Nets of either type, complete with handle, should cost from $4 \mathrm{~s}$. to Ios., according to size and make.

On sandy or muddy ground much larger nets can be used, and many forms of such nets are locally used in different parts of the country for shrimping ; the large shore nets used for this purpose on the Lincolnshire coast, which are about Io feet in the beam and have

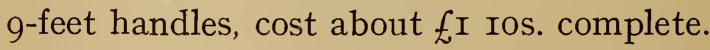

\section{DIP NETS.}

Dip nets are nets mounted on circular rings lowered into the water by means of a pole, and baited. They are left stationary until a fish enters, and are then rapidly lifted above the surface. Small nets of this type, mounted on galvanized iron rings 24 to 36 inches in diameter, and costing with the necessary lines about IOs. to I5s. each, are commonly used for catching prawns, and are suitable for taking small fishes in the neighbourhood of rocks (see Fig. 2I3). A net of this pattern would probably be improved by the addition of a second ring, which would enable it to collapse on the bottom without fouling. Much larger nets 
mounted on wooden or wire rings, and, where necessary, baited, are commonly used abroad for taking small

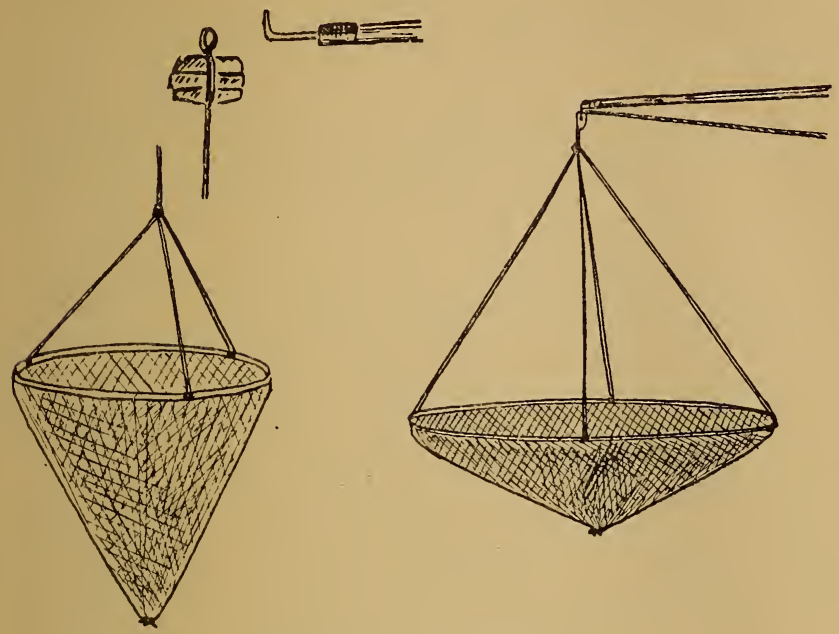

Fig. 213.-Dip Nets.

fishes in shallow water; such a net, a fathom in diameter, ought not to cost more than $\mathrm{I}_{5} \mathrm{~s}$. or so, and larger nets in proportion.

\section{FIXED NETS.}

Gill Nets.-The simplest form of fixed net is the gill net, or splash net, which is simply a net of suitable mesh for the capture of the fish, mounted very slack on the head and ground ropes. The ends of the net are made fast to some fixed object or anchored, their positions, where necessary, being marked by buoys. The head rope carries sufficient corks or glass floats to keep it at the surface, and the bottom rope must be sufficiently weighted to hold the bottom. A gill net will, of course, only catch such fish as are of a size to 
mesh themselves, and, to prove efficient, should be set so as to fish by night.

A well-known firm has kindly supplied the following quotation, which will serve as a guide to cost :

"Splash-net, 70 meshes deep-i.e., 8 to 9 feet deep-2 $\frac{1}{2}$ inch mesh, 36/9 ply-cotton, barked and mounted on two lines on top and bottom, corked and leaded ready for fishing, 7d. per yard."

A train of drift nets, such as that next mentioned, could be moored so as to fish as a gill net, if a properly leaded ground line were fastened along its foot; but a drift net is ordinarily rather deep for use as a gill net, and is not always mounted along the foot.

The pollen fishers of Lough Neagh use gill nets (locally termed "trammels") made of exceedingly light but strong linen thread; these nets are made at Lisburne, and possess the advantage over either hemp or cotton nets of stowing into much smaller space and wearing better. In cases where economy of room is important, it might be well worth while to have nets made of linen thread.

Drift Nets (Fig. 2I4) are similar in their operations to gill nets, but are constructed to fish at or near the surface; they are not moored, but drift on the tide. For commercial purposes a train of drift nets, often far over a mile in length, is used; these nets are fastened end to end, and carry sufficient cork on the head ropes to keep them upright in the water, but not necessarily to keep the head rope at the surface. At frequent intervals buoys of wood or canvas are fastened to the head rope, and the length of the buoy lines regulates the depth at which the nets fish. Drift nets may or may not be mounted on a foot rope; in shallow water, where the ground is rough, the absence of such a mounting may 
prevent damage to the nets from hitching in rocks. A train of nets is, however, made fast at fairly frequent intervals to a stout hauling warp, which serves the double purpose of preventing nets being lost if the head rope is cut by a passing steamship, and of taking a part of the strain during the process of hauling.

We are informed by well-known makers that a short train of drift nets-say, 400 yards long, hanging about 7 yards deep-mounted on two lines on top and bottom, and corked on top, should cost about £I6 I6s. In the case of such a short train a separate hauling rope could probably be safely dispensed with, but the above estimate does not include buoys or buoy lines.

To prove effective, drift nets must be fished by night, or, if by day, only in thick or discoloured water ; fishermen, as the result of long experience, generally believe that the greatest number of fish enter the nets just about dusk and dawn. Drift nets should be shot from a vessel moving with the wind; when the nets are all overboard, a greater or less length of hauling warp (according to wind, size of vessel, and length of train of nets) is paid out, and the vessel brought up head to wind ; masts are unstepped, and all gear likely to offer resistance to the wind stowed, and both vessel and nets drift on the tide, the weight of the vessel tending to keep the hauling rope taut, and so to prevent the nets fouling.

The trammel * is set in the same way as a gill net, but its action is different; it is peculiar in being made up of three distinct nets or sets of meshes fastened together at the head, foot, and ends. The two outer nets are of large mesh, mounted taut on the head and ground ropes, and set so that the meshes exactly corre-

* The term "trammel" is commonly applied to gill nets in Ireland. 
spond. The middle net is twice as long and twice as deep as the two outer ones, has a very much smaller mesh, and is mounted very slack on the head rope. The result of this is that a fish, coming in either direction, on striking the net, carries a portion of the middle net through the large mesh of the outer wall, and is thus trapped and held. For commercial purposes, the walls of a trammel are ordinarily some 40 to 50 fathoms long, with a 9 or Io-inch mesh between knots, and a depth of twelve to twenty meshes; the middle net is 80 or Ioo fathoms long, but set on a head rope of the same length as the walls, and has a mesh of about 2 inches, and a depth of some fifty or sixty meshes. The length and depth of the net and size of meshes must be varied according to the probable size of the prospective fish.

A Scotch firm of net manufacturers has kindly supplied the following estimate:

"Trammel, 9 feet deep, barked and mounted on I5-thread rope on bottom, and 9-thread rope on top, corked and leaded ready for fishing, Is. 5d. per yard. Dimensions : two outside pieces, 20 meshes deep, 9-inch mesh, 2I-ply cotton. Inside piece, I20 meshes deep, $2 \frac{1}{4}$-inch mesh, $36 / 9$ ply cotton."

Like other fixed nets, trammels should be used by night; they are not easy to dry properly, and consequently liable to rot if not very carefully treated. Moreover, cleaning a trammel after use on weedy or crab-frequented ground is a task calculated to try the patience of Job himself.

In ordering any fixed net, the maker should be told the purpose for which it is intended, as a clue to the size of mesh required; probably. the mesh could be best described by giving the size of fish anticipatede.g., "East Coast herring," "spring mackerel," or "pollack." 


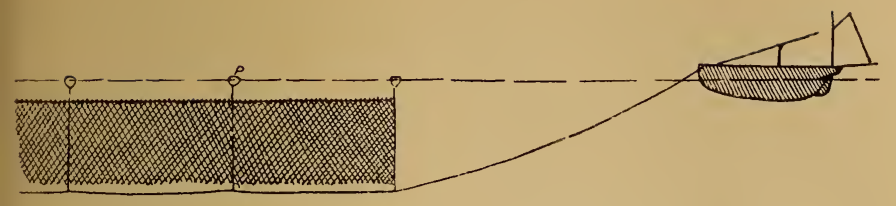

Fig. 2i 4.-Part of a Train of Drift Nets (Diagrammatic).

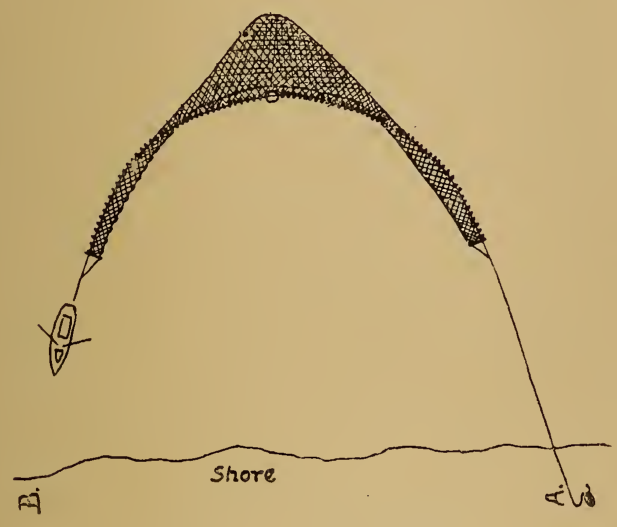

Fig. 2I 5.-SEINE NET.

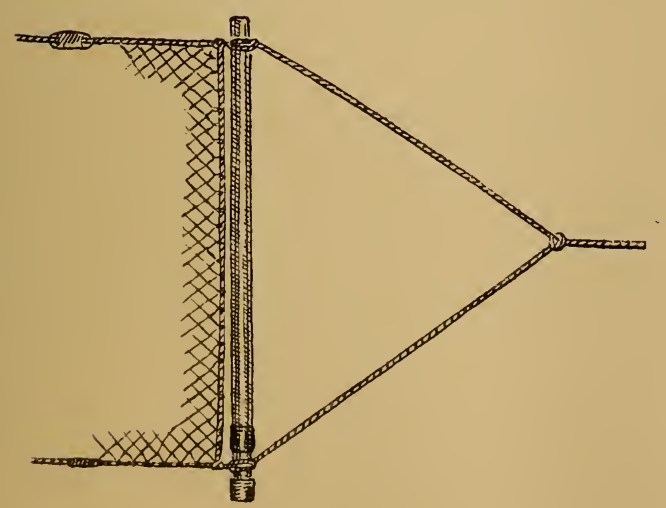

Fig. 216.-End of a Seine Net. 
Seines.-A seine, or sean, is a long, comparatively shallow net, which is so shot that it can be drawn over a certain area of ground or water in such manner as to capture anything within that area. For the purposes of this chapter, all seines other than those fished from the shore may be disregarded. The head rope of such nets must carry sufficient cork to float buoyantly, and the ground rope be so weighted as to hold the bottom. The head and ground ropes are generally kept in their relative positions, and held apart while the net is being hauled by poles at the ends of the net round which they are hitched (see Fig. 2I6). Such nets are commonly shot from a boat which is rowed out from the shore and back again, the end of one hauling rope being left on the shore during the shot (A in Fig. 2I5), and the end of the other landed some distance away (B in Fig. 2I5). The net is then hauled ashore, the two ends being brought closer to one another during the process, until the central part of the net is finally brought ashore about midway between the points at which the hauling ropes were originally left and landed. A tuck seine only differs from a seine in having a bunt, or bag (analogous to the cod end of a trawl), in its centre, which collects the fish and prevents their escape.

Seines and tuck seines are principally of use for catching fish on a smooth strand, particularly on a gradually shelving beach or in an estuary. They are most efficient if fished by night or at low-water springs, and if there is any appreciable tide or current, the boat must be rowed against such tide or current while shooting the net.

For commercial purposes seine nets which have no bunt are frequently used, but such nets require very careful handling, and are not suitable for the inexperienced. On the other hand, a tuck seine of moderate 
size is not at all a difficult net to work; the best net of this description known to us is that used by the Saltash fishermen in the Tamar, briefly described below. Such a net can be easily worked by two men with a small rowing boat, and may be procured locally for about $£ 6$, including poles and hauling warps.

A tuck seine should be set somewhat slack on the head and ground ropes, which are each about 48 yards long ; each wing is 20 yards long and about $2 \frac{1}{2}$ yards deep, and the mesh decreases from the pole to the bunt, the depth of the net remaining the same, or increasing very slightly (e.g., the wings may be set up at $2 \frac{1}{2}$-inch

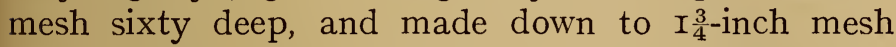
ninety deep). The bunt is about 6 yards long, about 300 meshes round where it joins the wings, and of the same mesh as their inner ends, tapering nearly to a point without any great reduction in the mesh. The head and ground ropes are hitched round the poles (which are each 6 feet long) a short distance beyond the ends of the wings, and are then carried out and joined round an eye to which the hauling warp is shackled. The mesh must, of course, depend upon the size of fish which it is desired to capture.

\section{The Mid-Water OtTer Net.}

Although the "Young-Fish Net," or mid-water otter net,* originally designed by Professor Petersen of Copenhagen, is in reality little more than a very large and special tow net, it may be conveniently included here as being the only net hitherto designed which is suitable for the capture of small fishes at the surface or in mid water. The net itself is made of some coarse-meshed material such as "screw cloth,"

* The writer is indebted to Mr. G. P. Farran for much information with regard to this net. 
which is sufficiently fine to retain small fishes and sufficiently strong to stand the strain of fishing. As ordinarily constructed, it has a rectangular mouth about 7 feet wide by 5 feet deep, a length of about 2I feet, and tapers to an opening of about 2 feet in diameter at the cod end. The sides of the mouth are laced on to stout wooden poles, and the net is kept open while fishing by otter-boards (see p. 302), which are joined by ropes to the head and foot of the poles.

A net of the size above described can be obtained in Denmark at a cost of about I40 kroner ( $£ 7$ IOs.), and the poles, weights, and boards for about 65 kroner (£3 ros.). The material of which the Danish nets are made is apparently woven of coarse linen thread and

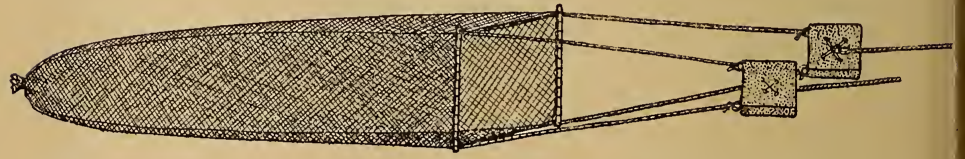

Fig. 217.-Petersen's Yngel-Trawl or Young-Fish Net.

has about I25 meshes to the metre, costing 2 kroner per metre. Similar nets made of Manchester "screw cloth" have proved quite satisfactory and are much cheaper, as about 50 yards of material at about 7 d. per yard are required and the cost of making up by a sail-maker should not exceed $£ \mathrm{I}$, thus reducing the total cost of the net to about $£_{2}$ Ios.

In fishing the net in deep water a heavy lead weight (ordinarily about 40 pounds) should be attached to the shackle fastening the spans to the hauling warp, and the otter-boards must always be well weighted. The net may be shot from a single block with a little way on the vessel, and the otter-boards lowered together, as, if properly weighted, they spread as soon as they are in the water. 
Surface hauls should only be of short duration (e.g., fifteen minutes), as the net soon becomes choked with jelly-fish, salps, and the like, but in deep water hauls of less than an hour's duration cannot be expected to give much result. The net may be fished actually on or just clear of the bottom with good effect, but is very liable to injury if so fished.

\section{Miscellaneous Gear.}

Some fishes may be taken in crab or lobster pots suitably baited; probably the pots made of netting stretched over a metal or wood frame are better than those made entirely of osier.

Narrow and shallow creeks and channels may be fished by stretching a short gill net across them, and beating the water up towards it by wading in line with poles and splashing, or by dragging another net towards the fixed one. 


\title{
CHAPTER XI
}

\section{PRESERVATION OF MARINE ORGANISMS}

\author{
BY E. J. ALIEN AND EDWARD T. BROWNE
}

\section{Introduction.}

IT is impossible within the space allotted to this section to describe in any detail all the numerous methods for the preservation of marine organisms. We have selected the simplest methods, which, if carefully carried out, should yield good results. Those who require their specimens preserved by refined methods for minute microscopical investigations are strongly advised to consult that indispensable book, "The Microtomist's Vade-Mecum," by Dr. A. Bolles Lee. This book should be in the hands of every marine naturalist, and we have frequently consulted its pages for this chapter. We are also indebted for methods to Dr. S. F. Harmer and Mr. R. L. Leiper, and especially to Mr. A. J. Smith, who has charge of the Preservation Department in the Marine Laboratory at Plymouth.

The subject matter of this chapter is really in two parts. General information and simple methods such as are within every traveller's power are printed in large type ; but the more technical and delicate methods of preservation, for detailed microscopic study rather than faunistic collection, are printed in a smaller type ; 
such methods are suitable only for those who have at their disposal a regular laboratory, on shore or on board a yacht; it is even to be hoped that these latter instructions may prove of value to the smaller fixed marine laboratories in far-away seas.

The successful preservation of marine organisms depends not only upon selecting the right method, but frequently upon a certain amount of practice. A naturalist going on a foreign cruise, who is not experienced in preservation, is advised to take a course of instruction at a marine laboratory, where he would soon learn the right way of setting to work.

It is quite easy to kill animals by simply placing them in formalin or alcohol, but the results are not always satisfactory. Some may have a lifelike appearance, whilst others may contract into a lump, or even break up into pieces ; hence it may be necessary to anæsthetize the contractile animals with cocaine, menthol, or some other narcotic before killing them. There are two methods of killing animals, the results of which are quite different. The one is simply to destroy the life of the animal by anæsthetics, without at the same time destroying the life of the tissues, which may survive for some time after the death of the animal. This method is quite suitable for specimens intended for museums and for identification. The other method is to kill the tissues first by certain chemicals, and the death of the tissues causes the death of the animal. When animals are wanted for minute microscopical investigations this latter method is always used, and its success depends upon killing the cells of the tissues before they have time to undergo any change, by chemicals which do not produce a visible change within the cell. The process of " fixing" the contents of the cell and the shape of the cell is called "fixation." An 


\section{PRESERVATION OF MARINE ORGANISMS}

important factor in the success of fixation is the quick penetration of the chemicals through the tissues. Slow penetration gives time for the innermost cells or tissues to undergo post-mortem changes before they are properly fixed.

The preservation of an animal after death, or of its tissues after fixation, is the final stage in the prevention of decay. The preserving fluids commonly used are either formalin or alcohol, and their preserving action should be understood. We take as an example a big jelly-fish, the jelly of which is more than 90 per cent. water. When alcohol is used as the preserving fluid, all the water in the jelly has to be turned out, and alcohol of a different strength substituted. The first bath of alcohol is considerably reduced in strength by the water from the jelly. Fresh alcohol is then substituted, and this second bath becomes less diluted. The changing of the alcohol must go on until one is sure that the specimen is thoroughly saturated with alcohol of at least 70 per cent. strength. Weak solutions of alcohol have no preserving qualities, and are not proof against bacteria.

Formalin, on the contrary, is a watery fluid, and it has simply to mix with the watery fluids inside the jelly. During the process of mixing its original strength is lessened by dilution, as in the case of alcohol, and a certain quantity is used up in chemical action on the tissues. But so long as there is a small percentage of formalin present the jelly is safe against decay, owing to the powerful antiseptic properties of formalin. 


\section{CHEMICALS USED IN PRESERVATION.}

A. Preserving Fluids : Formalin, alcohol, formolalcohol.

B. FIXING FLUIDS: Corrosive sublimate, picric acid, picro-formol, chromic acid, Flemming's solution, Hermann's solution, osmic acid.

C. Anesthetics : Cocaine, menthol, alcohol.

\section{A. Preserving Fluids.}

Formalin (Formaldehyde, Formol).-Formalin and formol are commercial names given to a solution of formaldehyde, which is a gaseous compound, $\mathrm{HCOH}$, in water. This solution, when first placed on the market, contained 40 per cent. of formaldehyde, but it was found that at this strength the solution was liable to undergo chemical changes and to throw down a precipitate, whereas a weaker solution remained unchanged. The solutions of formaldehyde now vary from 30 per cent. to about 40 per cent. Formalin is a powerful antiseptic, and is manufactured on a large scale for disinfecting purposes; even a very weak solution has a deadly effect upon bacteria. It can be obtained from retail chemists and photographic dealers, but when large quantities are required it is advisable to purchase it directly from a manufacturing chemist, and at the same time to ascertain the strength of the solution. Formalin requires careful handling; its vapour has an irritating effect upon the nose and eyes, but, fortunately, the irritation soon passes away without doing any harm. The action of the solution upon the hands is to harden the skin and to make it slightly rough. Weak solutions, as a rule, are not injurious, 


\section{PRESERVATION OF MARINE ORGANISMS}

but it is advisable to wash one's hands directly after an immersion in formalin, and never to allow the 30 per cent. solution to dry into the skin. There are, however, people whose skin is seriously affected ; the skin breaks, after the manner of chilblains, with deep, open cracks, which are painful, and take some time to heal ; and the fingers feel numb. None of these effects, however, are permanent, or in the slightest degree dangerous.

The hardening and preserving properties of formalin for animal tissues were discovered independently by Blum and Hermann in I893, and probably no one has been more benefited by this important discovery than the marine naturalist. Previous to I 893 alcohol was practically the only fluid used for the preservation of marine animals. It must not be supposed that formalin has completely supplanted alcohol, though the qualities of the former have been loudly praised and the existence of alcohol almost forgotten by some naturalists.

Formalin has two great advantages over alcohol: (I) It does not usually produce a shrinkage of the tissues; therefore it is a splendid fluid for the preservation of delicate, soft-bodied animals, such as jellyfishes. (2) It is a great time-saving fluid, as specimens can be placed straight into formalin without requiring any further attention; whereas with alcohol it is usually necessary to pass specimens through a series of different grades of strength, each grade requiring a certain length of time, or to change a strong grade several times so as to get rid of the watery fluids within the specimens.

To marine naturalists formalin has two special advantages: (I) It can be diluted with sea water, as well as with fresh water. When alcohol is mixed with sea 
water, certain salts in the latter are precipitated, and the solution becomes turbid. (2) It is sold as a concentrated solution, and for our purposes it has to be considerably diluted with water; it is therefore a convenient fluid to take on board a ship, where storage space is frequently limited, and on expeditions, when weights have to be carefully considered.

As a rule most marine animals can be satisfactorily preserved in formalin, but there are exceptions, where formalin is inferior to alcohol, or even quite useless. It destroys completely certain kinds of calcareous structures, such as the spicules in calcareous sponges and the calcareous skeleton of some larvæ. The dissolving away of calcareous substances is due to formic acid, which is nearly always present in formalin. On the other hand, shells of molluscs may be left for years in formalin without showing any apparent destruction. The action of formalin upon animal tissues is variable, depending upon the chemical composition of the tissue ; it may harden, soften, or destroy.

There is one group of animals for which formalin is not suitable-namely, the Ctenophora. Its effect upon the Ctenophores is interesting and worth mentioning here. Pleurobrachia looks splendid after it has been killed in formalin 5 per cent. in sea water, and remains all right for a few months. Later on its jelly shows visible signs of shrinkage. The shrinkage continues until the specimen becomes quite shrivelled up, and eventually disintegrates. Beroe frequently shrivels up in the course of a few days, or the process of shrinkage may be extended over a few months. Bolina, one of the most delicate Ctenophores, dissolves at once in formalin.

Strength of Solution.-Before dealing with the strengths of the solutions suitable for the preservation 
of marine animals, it is necessary to make quite clear the difference between formaldehyde ro per cent. and formalin Io per cent. Formalin, as purchased, contains a definite quantity of the gaseous formaldehyde dissolved in water, and the percentage of formaldehyde present should be stated on the manufacturer's label thus: "Formaldehyde 40 per cent." To make up a solution so as to contain ro per cent. of formaldehyde we must add three parts of water to the quantity taken out of the 40 per cent. stock bottle (IOO c.c. of formaldehyde 40 per cent. +300 c.c. of water). But if we make up a solution to contain Io per cent. of formalin, then to the quantity taken out of the bottle labelled "Formaldehyde 40 per cent." we add nine parts of water (I0O C.c. of formaldehyde 40 per cent. + 900 c.c. of water). This ro per cent. solution of formalin is equivalent to formaldehyde 4 per cent., and formaldehyde ro per cent. is two and a half times stronger than formalin Io per cent.

Both methods of making up working solutions are in use; and as authors frequently use the terms "formaldehyde" and "formalin" indiscriminately, without giving a clue as to whether the percentages refer to formaldehyde or formalin, there is consequently much confusion.

There can be no doubt that the scientific method is to reckon the percentage in the quantity of formaldehyde present, especially as the commercial solutions of formaldehyde now vary from 30 to 40 per cent.

Formaldehyde Io per cent. is a constant strength, whereas formalin Io per cent. is liable to vary in the amount of formaldehyde present, according to the strength of stock solution.

The unscientific method of making solutions prevails, partly because all commercial solutions were sold 
for many years as 40 per cent. strength, and partly because it is very easy to read percentages in a centimetre measure.

Successful preservation with formalin depends upon using sufficient formaldehyde to fix every cell in the specimen, and a surplus sufficient to prevent subsequent maceration. A specimen which is properly fixed and preserved in 50 c.c. of formaldehyde 4 per cent. can also be fixed and preserved in 50 c.c. of formaldehyde 2 per cent., providing that the latter solution be changed once. It is much the safest plan to allow the specimen to soak for two or three days in formaldehyde 2 per cent., and then to change it into formaldehyde 4 per cent. It is a great mistake to be stingy over the formalin; use it freely, and change the solution at least once, or, if this cannot be done, make up the strength by adding a very small quantity of the strongest formalin.

There can be no doubt that collectors, as a rule, do not use sufficient formalin, and forget that their specimens are very liable to remain untouched for two or three years. Specimens which are worth a place in a permanent collection are worth a little extra trouble and a little extra formalin.

Concerning the strength of the solutions of formalin for preservation there is a difference of opinion. Some workers use weak and others fairly strong solutions. A good, useful solution for general work is formaldehyde 4 per cent., which is made up thus: Formaldehyde 40 per cent. (or about 40 per cent.), I part; water, 9 parts. The bottle may be labelled either "Formalin Io per cent.," or "Formaldehyde 4 per cent."

If the commercial solution is purchased at 30 per cent. strength, then the following proportions should 
be taken: Formaldehyde 30 per cent., I part; water, $6 \frac{1}{2}$ parts. This solution contains formalin 13.3 per cent., and is equivalent to formaldehyde 4 per cent.

Some animals can be killed at once by dropping them into formalin Io per cent., or by pouring the solution into the sea water containing the animals; but others are not killed quickly enough, and have sufficient time to contract or to cast off appendages. For the latter class of animals either an anæsthetic, like cocaine, may be used before adding the formalin, or another chemical, like picric acid, added to the formalin, to quicken the killing action.

The value of formalin in fixation is to prevent shrinkage, and for this purpose it has been added with success to several well-known fixative formulæ.

Alcohol.-The alcohol used for preserving purposes is pure methylated spirit, known as Industrial methylated spirit, upon which excise duty must be paid within the limits of the British Excise, or an exemption permit obtained from the Custom House, London. The ordinary methylated spirit obtained from a dealer is quite useless for preserving marine animals, as it contains certain chemicals, put in to prevent people from drinking it. Directly water is added to this liquid it takes on the appearance of milk, and a very fine precipitate is thrown down. All attempts to get rid of this precipitate are only waste of labour, as an additional drop of water starts a fresh precipitate in a filtered solution.

Pure methylated spirit when purchased is commonly called " 90 per cent. alcohol," though its strength may be slightly greater than 90 per cent. This may be diluted with water so as to make up solutions containing 30 per cent., 50 per cent., and 70 per cent. of alcohol. These solutions can either be made up by 
the use of an alcoholometer, or by adding definite volumes of water, according to the table given below.

Table for Diluting Alcohol.

(From Bolles Lee.)

Grade

Required.

Per cent.

$9 \circ$ per cent.

8o per cent.

Original Grade.

\begin{tabular}{r|rr|r|r|r}
80 & $\mathrm{I} 3 \cdot 8$ & - & - & - & - \\
75 & $2 \mathrm{I} \cdot 9$ & $7 \cdot 2$ & - & - & - \\
70 & $3 \mathrm{I} \cdot 0$ & $\mathrm{I} 5 \cdot 3$ & $7 \cdot 6$ & - & - \\
60 & $53 \cdot 6$ & $35 \cdot 4$ & $26 \cdot 4$ & $\mathrm{I} 7 \cdot 5$ & - \\
50 & $84 \cdot 7$ & $63 \cdot 0$ & $52 \cdot 4$ & $4 \mathrm{I} \cdot 7$ & - \\
40 & $\mathrm{I} 30 \cdot 8$ & $104 \cdot 0$ & $90 \cdot 7$ & $77 \cdot 5$ & $25 \cdot 5$ \\
30 & $206 \cdot 2$ & I $7 \mathrm{I} \cdot 0$ & $\mathrm{I} 53 \cdot 6$ & $\mathrm{I} 36 \cdot 0$ & $67 \cdot 4$ \\
\hline
\end{tabular}

To use this table find in the upper horizontal row of figures the percentage of the alcohol that it is desired to dilute, and in the vertical row to the left the percentage of the alcohol it is desired to arrive at. Then follow out the vertical and horizontal rows headed respectively by these figures, and the figure printed at the point of intersection of the two rows will show how many volumes of water must be taken in order to reduce Ioo volumes of the original alcohol to the required grade. Thus, if it be required to manufacture some 70 per cent. alcohol, starting with 90 per cent., we find the figure 70 in the vertical column, and at the point of intersection we read 3I, showing that $3 \mathrm{I}$ volumes of water must be added to Ioo volumes of 90 per cent. alcohol.

A rougher method of diluting 90 per cent. alcohol is as follows: Take a number of volumes of 90 per cent. equal to the percentage desired, and add a number of 
volumes of water equal to the difference between the percentage desired and 90. Thus, to make 70 per cent., take 70 volumes of 90 per cent., and add 20 of water ; to make 50 per cent., take 50 volumes of 90 per cent., and add 40 of water ; and so on.

All solutions of alcohol should be made with pure fresh water (ordinary ship's water should be filtered first, even if distilled). Water loaded with mineral salts gives a precipitate when mixed with alcohol, and unless the precipitate is removed by filtration or decantation the specimens generally become coated with a very fine dirty sediment.

Alcohol by itself is not good for fixing purposes, but is generally used in combination with other chemicals, as it increases their penetrating power. It is a good hardening agent, but unfortunately it produces a considerable amount of shrinkage in the tissues.

As a preservative it is excellent, and the safest of all preservatives for specimens intended for permanent collections. Though formalin is its strong rival, still formalin is a newly discovered fluid and a rather unstable one, and we have yet to find out how long its preserving qualities are going to last. Hydroids and Medusæ which have been in formalin Io per cent. for twelve years show no visible signs of deterioration.

The strength of the alcohol commonly used for the preservation of animals lies between 70 and 80 per cent. The minimum strength should be rigidly fixed at 70 per cent. A slight increase over 70 per cent.- say 75 per cent.-is an advantage, because it provides a margin against evaporation.

Delicate, soft-bodied animals should not be placed straight into 70 per cent., but first into 30 per cent. alcohol for a few hours, and then in 50 per cent. for several hours, and each solution should be changed at 
least once. Transfer from 50 per cent. to 70 per cent. The passage through these different grades of alcohol reduces the amount of shrinkage, and gradually removes the watery fluids from the body of the animal. It is very important for all the tissues of the body to be thoroughly permeated with 70 per cent. alcohol, hence the necessity of changing at least once the 70 per cent. solutions. As weak solutions of alcohol quickly produce maceration of the tissues, it is advisable not to leave specimens too long in the weak grades.

Alcohol which has become weakened by water from the animals soaked in it (so long as it does not contain chemicals) should be kept, and coarse animalsCrustacea, fish, starfish, etc.-can have their first brief soaking in this before being transferred to stronger alcohol. An alcoholometer is useful here. This spirit should be thrown away when of a less strength than 30 per cent. But if it is not necessary to economize alcohol, then animals with hard coats, such as crabs, or with firm bodies, such as fishes, can be placed at once in 70 per cent.; after a preliminary soaking the alcohol must be changed. The number of changes required depends upon the size of the animal and the quantity of alcohol used for each bath. The most important thing is to keep up the strength of the final solution, and not to store away the specimens until they have become thoroughly permeated with at least 70 per cent. alcohol.

It is well to remember that the weakest grade of alcohol is the heaviest, and remains at the bottom of the vessel. When passing specimens through different strengths of alcohol, an occasional stir up should be given, just to help on the process of mixing, and to bring the stronger alcohol into contact with the specimens. 
Formol-Alcohol (Formalin Spirit).-This is made by adding 5 per cent. of commercial formol (40 per cent. formaldehyde) to alcohol of 70 per cent., thus : Alcohol 70 per cent., 95 c.c. ; formaldehyde 40 per cent., 5 c.c.

Formol-alcohol is one of the best preserving fluids for general collections which are not required for histological work. The specimens are put directly into the fluid, which should be changed after about twenty-four hours. In the case of animals which contract readily; they should be anæsthetized with cocaine, menthol, or weak spirit, before being put into the formol-spirit.

In cases where it is important to preserve delicate calcareous structures (e.g., Holothurians) this mixture is not recommended, as it may develop an acid reaction.

\section{B. Fixing Fluids.}

Corrosive sublimate (bichloride of mercury, $\mathrm{Hg} \cdot \mathrm{Cl}_{2}$ ) is probably the most generally useful fixing fluid, when specimens are required for minute study of their cellstructure.

It is used either as a simple saturated solution in water, or can be mixed with glacial acetic acid if it is not desired to preserve calcareous structures. For marine animals the following proportions are recommended : Bichloride of mercury, saturated solution in distilled water,* 95 c.c.; glacial acetic acid, 5 c.c. Both the simple saturated solution of sublimate and

* One hundred cubic centimetres of distilled water will dissolve 6 or 7 grammes of bichloride of mercury at ordinary temperatures. It is best to add an excess of the bichloride and dissolve in hot water. On board ship it is easiest to have a big bottle, with an inch or two of powdered corrosive sublimate at the bottom, and fill it up with water every night ; it will be saturated by morning if shaken occasionally. 
the sublimate-acetic mixture kill and penetrate more rapidly if used hot, at a temperature of $70^{\circ}$ or $80^{\circ} \mathrm{C}$. Many forms can be killed and fixed in an extended condition by plunging them rapidly from a dish of sea water in which they are well expanded into a vessel containing hot corrosive sublimate solution.

The time during which objects must remain in corrosive sublimate solutions varies very much, especially with their size. Small delicate organisms will be sufficiently fixed in ten to fifteen minutes. Larger organisms and pieces of compact tissue may remain from one to twenty-four hours with advantage.

After removal from the sublimate solution or sublimate-acetic mixture, the objects are rinsed in fresh water, and then transferred to 70 per cent. alcohol, to which a few drops of tincture of iodine* are added. A considerable volume of the alcohol should be used, and enough iodine to make it of " a good port wine colour." The colour is gradually destroyed by the corrosive sublimate. When the alcohol has lost all the colour it should be changed, and fresh tincture of iodine added. This process should be repeated until the iodine colour remains for twelve or twenty-four hours, when the object is removed to fresh 70 per cent. alcohol, without the addition of iodine, in which it may be left.

Corrosive sublimate is more soluble in alcohol than in water, and a saturated solution in 70 per cent. alcohol is sometimes used for fixing with good results. It is also more soluble in sea water (or common salt solution) than in distilled water, and the sea water solution is sometimes recommended. In both these cases the subsequent treatment of the specimens is

* Tincture of iodine is made by dissolving iodine in strong alcohol. 
similar to that described above, excepting that after using the sea water solution the washing in fresh water should be more thorough.

This is a most deadly poison if taken internally, and a saturated solution looks exactly like plain water.

Picric acid is a bright yellowish flaky powder, which is scheduled under the Explosives Act. In a glass bottle by itself there is good evidence that it is a harmless substance, especially when kept under water, but on the discharge near it of a detonator it becomes a violent explosive. It is used in the manufacture of bombs and shells, under the names of melinite, lyddite, etc. The Board of Trade Regulations forbid its conveyance on board a ship (see p. III, note).

Picric acid is often used for rapidly killing marine animals, and is a good fixative, with a great penetrating power. It may be either used alone or in combination with other chemicals. As a saturated solution in water is always used, there is no trouble about making up the stock solution. Simply place some picric acid in a bottle and fill up with water. If clean fresh water should not be available, then sea water may be used instead. A little picric goes a long way, for one part of picric dissolves in about eighty-six parts of water ; but it is more soluble in hot water.

There is one disadvantage with picric acid-namely, the trouble of removing the yellow stain. After the specimen has been properly fixed in picric, transfer it to alcohol, and change the alcohol several times, until the fluid is no longer yellow. It does not matter very much about the specimen remaining yellow. To remove all traces of the stain from the specimen generally takes several days and many changes of alcohol. 
Specimens, after they have been fixed with picric, should not be soaked in water; but if they are not wanted for histological work, then formalin may be used instead of alcohol.

Picro-formol Solution.-This solution is a splendid fixative, with a great power of penetration, and kills very quickly. Bouin's formula :

Picric acid, saturated aqueous solution, 75 parts ; formalin, 30 or 40 per cent., 25 parts ; acetic acid, 5 parts.

When fixation is completed wash out the stain with alcohol, and preserve in 70 per cent. alcohol. If the specimens should not be wanted for histological work, then formalin may be used instead of alcohol.

Chromic Acid. - Weak solutions of chromic acid in water are often useful ; 2 per cent., I per cent., and 0.5 per cent. solutions are generally employed, the specimens remaining in the solution for some hours. After chromic acid the specimens should be very thoroughly washed in fresh water, being allowed to remain in running water for even twenty-four hours. After washing they are transferred to 30 per cent. alcohol, then to 50 per cent. alcohol, and finally to 70 per cent. alcohol, in which they may be kept. Chromic acid specimens are best kept in the dark.

The disadvantage of chromic acid is that objects preserved in it are often difficult to stain.

Chromo-acetic Acid. - Chromic acid, 0.2 to 0.25 per cent.; acetic acid, $\mathrm{O} \cdot \mathrm{I}$ per cent., in water. Proceed as in the case of chromic acid.

Flemming's Fluid (Strong). - One per cent. chromic acid, I5 parts ; 2 per cent. osmic acid, 4 parts ; glacial acetic acid, I part.

This is one of the best fixing agents for preserving the minute structure of cells. Only small pieces of tissue should be put into this fluid, as it does not penetrate well. The specimens should remain in the fluid for several hours, or if they are large for several days. Wash well in running water, as in the case of chromic acid specimens, and bring gradually to 70 per cent. alcohol.

The specimens are generally very much blackened by the osmic acid in the solution, and are often difficult to stain, especially if the washing has not been sufficiently thorough. 
Hermann's Solution.-This is similar to Flemming's solution, excepting that I per cent. platinum chloride is used instead of I per cent. chromic acid. The solution is used in the same way as Flemming's solution. It is said to preserve the protoplasmic structures better than Flemming's fluid.

Osmic Acid. - A very powerful killing agent for small organisms, such as Protozoa or small Crustacea. It is generally used in $\frac{1}{2}$ per cent. solution. The vapour of the acid is also used, a drop of water containing minute organisms being put in a closed dish in which a few drops of osmic acid solution have been placed. A great disadvantage of osmic acid is that it blackens the specimen very much, especially if the tissue is of a fatty nature; the blackening can be removed with a weak solution of chlorine, which does not improve the tissues for microscopic work.

\section{Anæsthetics.}

If put immediately into a fixing fluid many marine animals contract and shrink up. It is therefore necessary, in order to get well-expanded specimens, to anæsthetize before killing. The substances generally used for this purpose are cocaine, menthol, and very weak alcohol. Chloral hydrate is also sometimes used, as well as other anæsthetics. It is to be noted, however, that the methods of anæsthetization are not to be recommended for use in the tropics; the animals die and rot too quickly in small bodies of water (see p. III).

Cocaine (hydrochloride of cocaine) is a useful and powerful anæsthetic. A I per cent. solution in distilled water should be made up and a few drops added to the sea water containing the living specimen in a fully expanded condition. It is best to increase the dose at intervals, and not to add the full quantity at once or suddenly. A sudden overdose frequently makes the animal contract; if it does not show signs of expanding within about three minutes, then remove it into a vessel of clean sea water and let it revive. Try next time with less cocaine.

Solutions of cocaine do not keep very long, and are usually spoilt by fungoid growths. It is advisable not to make up more than IOO c.c.

Directly the animal becomes anæsthetized pour in the killing or fixing solution. After adding corrosive sublimate or picric acid a precipitate, is frequently produced. The pre- 
cipitate consists of cocaine, and is soluble in alcohol or in an excess of picric acid. The safest plan to insure good fixation and at the same time to get rid of the precipitate is to remove the specimen to another vessel and add more fixative.

Menthol.-This substance is now much used, and with great success, for anæsthetizing the larger marine animals.

The animals are put into a clean vessel, with sufficient sea water to cover them well, and the surface of the water is strewn with crystals of menthol. As the menthol dissolves the animals expand, and eventually become quite anæsthetized. In from twelve to twenty-four hours they may be transferred to a suitable fixing fluid in which they will be preserved with little, if any, contraction. Anemones, Holothurians, Asscidians, and many Molluscs have been successfully treated in this way.

Alcohol.-Seventy per cent. alcohol, added drop by drop to sea water in which marine animals are living, will often cause them to die in an expanded condition. The rate at which the drops are added varies in different cases, and no definite rules can be given.

Chloretone is recommended by Bigelow as a most satisfactory anæsthetic for medusæ and siphonophores. A I per cent. solution is used, and a small quantity is added to the sea water containing the specimens.

\section{NOTES ON STORING SPECIMENS.}

Bottles with Cork Stoppers.-Bottles and tubes are generally sold with inferior corks, which are often perforated with small holes. It is advisable to order corks of a good quality, such as are used in chemical laboratories; bungs and shives should be avoided. A good cork makes an excellent stopper, provided that it fits nicely and is well driven in. For a cork to grip firmly, a bottle with a slightly tapering neck is required, a little wider at the bottom than at the top, so when the cork swells it cannot slip out. The ordinary straight glass tube requires a cork with straight sides, and the cork should be well squeezed before being 


\section{PRESERVATION OF MARINE ORGANISMS}

put in. Even then it is liable to slip up, especially if the tube contains alcohol. There is always an uncertainty with corked bottles. They are safe for short periods up to about twelve months, and after that they should be examined at least once a year. The risk of leakage and evaporation can be considerably reduced by coating the cork with paraffin wax, and this should always be done before finally storing away the bottles. The method is quick and simple, and the gain in security is well worth the trouble. It is as follows :

After corking, wipe the top of the cork and the rim of the bottle, and then place the bottle aside for a day, or longer, to dry. It is very important that the cork should be perfectly dry, and no fluid in the crevice between the rim and the cork. When the bottles are ready for coating, melt some hard paraffin wax (paraffin wax candles or any kind of hard wax may be used) in a small metal pot. A gluepot is a great comfort for this purpose on board ship ; it can be stood on the galley-range. Then dip the cork deep enough to cover about a quarter of an inch of the glass. After the first coat has solidified and cooled, give a second dip, quickly in and out, or else the first coat will have time to melt off. A bottle or tube properly sealed with paraffin wax will stand against evaporation for several years. Some bottles and tubes recently examined after being stored away for eight years were quite sound; but a few showed a slight loss of fluid, though the paraffin coating was externally flawless and perfect. On further examination it was found that the paraffin was no longer adhering to the glass.

Miniature bottles, with a capacity of about $\frac{1}{2}$ ounce (I5 c.c.), made of thin glass and fitted with a good 
cork, are very useful and convenient for small specimens. All bottles should have wide mouths, and the I ounce (30 c.c.), 2 ounce, 3 ounce, and 4 ounce sizes are recommended.

Some wide-mouthed bottles are sold with a cork fastened on to a wooden cap. They look very neat and nice, but have proved to be an utter failure for fluids.

Alcohol dissolves out the brown tannin in cork, and the specimens usually absorb the tannin, and turn to a brownish colour. If the specimens are wanted for histological „work, corks should be avoided and glass stoppers used.

Bottles with Glass Stoppers.-For the permanent storage of specimens a glass-stoppered bottle is not to be surpassed. The small sizes $-\frac{1}{2}$ ounce (I5 c.c.) to 4 ounces (I20 C.c.) - are most suitable for general use, and when larger sizes are required it is much cheaper to select a good glass-capped fruit-jar.

Glass-stoppered bottles vary considerably in quality and in price. The cheap ones have rather coarsely ground stoppers, not always fitting accurately in the neck of the bottle. The best quality have very smooth-ground stoppers, each ground to its bottle; they fit accurately, and are usually numbered.

Everyone who has had any experience with glassstoppered bottles sooner or later finds out that even the best quality bottle is not absolutely proof against the evaporation of alcohol. To prevent evaporation the stopper is often coated with vaseline or lard. The disadvantage of vaseline is that it becomes too liquid in warm weather, and it gradually works its way down the stopper and drops into the fluid, forming a harmless oil globule in alcohol, and an oily scum over formalin. Lard, on the contrary, slowly loses its 


\section{PRESERVATION OF MARINE ORGANISMS}

greasy nature and dries up. A mixture of vaseline and beeswax is perhaps the best substance for glass stoppers. It is made by first melting in a pot a few small lumps of beeswax, adding some vaseline, and well stirring up. The consistence of the mixture, when cold, should be like soft butter on a warm day. The beeswax raises the liquefying-point of vaseline. The whole of the ground glass of the stopper should not be coated with the mixture, but only the uppermost part. Just put on a narrow band with the aid of a penknife or a flat stick.

When glass-stoppered bottles containing specimens are sent by post or by train, the stoppers should be tied down with string or held by a rubber band.

Glass Jars with Metal Caps. - These jars are commonly sold for the storage of jam, honey, and other substances. Their sizes are denoted by their capacity for weight, and not by fluid capacity. The most useful sizes are the $\frac{1}{2}$ pound (holding 5 fluid ounces, or I5O c.c.) and the I pound ( 350 c.c.). The metal cap screws on to the rim of the jar, and inside the cap there is a thin sheet of common cork, which is quite satisfactory for jam, etc., but not for fluids. The cap is sometimes made of iron coated with tin or some other white metal, or it may be made of a soft or hard alloy of some kind or other. These jars, as purchased, are very useful just for temporary purposes, but not suitable for a long storage of specimens. As the jars are very cheap and very convenient, several attempts have been made to render them watertight and to keep the fluid away from the metal. Alcohol, and especially formalin, attacks the metal cap, and if left long enough the metal corrodes away and the cap becomes perforated. The most successful method for making these jars serviceable is the one used in the laboratory 
at Plymouth. The cork disc inside the cap is removed, and a disc of rubber, punched to the exact size of the cap, is fastened in the place of the cork.

Glass Jars with Glass Caps.-These jars are used for preserved fruits in syrup, and are the best jars to take on collecting expeditions. The cap is a glass disc with a projecting rim, which rests upon a rubber ring fitted on the neck of the bottle. There are several devices for holding down the glass cap, and it would be difficult to say which is the best. The jars are more costly than those with metal caps, and run in larger sizes, from I to 4 pounds ( $I, 800$ c.c.). An excellent $j a r$ in the series is known as the "Apricot" jar, which is a squat 2-pound jar (I,000 c.c. capacity), with an extra large mouth.

The common " sweetstuff" jar, with a glass stopper, to which is fitted a cork rim, is not recommended for travelling purposes. These jars are not intended for fluids, and usually leak. The cork strip cracks easily, and the stoppers are difficult to raise.

For large specimens stoneware tobacco-jars, with extra wide mouth, which have a top that can be screwed down on a rubber ring, are very convenient. They can be obtained in several sizes.

For collecting expeditions jars fitted with rubber discs can be recommended, and for storage special wooden boxes should be made, fitted with partitions for the isolation of each bottle, and the bottom and partitions and the inside of the lid lined with thick felt. With these boxes the jars are always ready for use ; there is no unpacking or packing up.

Glass Tubes with Cotton-Wool Plugs.-This method is often used for the isolation of specimens in small tubes, and it can be thoroughly recommended. The tubes are tightly plugged with absorbent cotton-wool, in- 
stead of a cork, and they are at once placed into a wide-mouthed glass jar, filled with the same fluid as in the tubes. It is an excellent system for collecting expeditions, as the small tubes are safe inside the large jars, and are quickly packed. It is advisable to place a layer of wool at the bottom of the jar, a little between the tubes, and some on the top. This will prevent the tubes from rattling about inside the jar, and reduce the risk of breakage. The large jar must be filled to the brim with fluid, so that all the tubes are properly immersed.

Damage done by Air Bubbles in Tubes and Bottles.Although great care is sometimes taken in preserving specimens, yet no care is taken in properly storing them for travelling. There is nothing more disastrous to delicate animals than an air bubble rolling up and down a narrow tube, or a large air-space in a bottle which is subject to the rolling of a ship or the shaking of a railway train. There is not the slightest difficulty in filling a bottle with fluid up to the bottom of the stopper, but narrow glass tubes require special treatment. Fill the tube to the brim with the preserving fluid, and insert a tight-fitting plug of absorbent cotton-wool, which should have been previously soaked in the same fluid. After a little practice it is quite easy to insert the plug without introducing an air bubble. The tubes can either be stored in a large glass jar, filled with the preserving fluid, or corked and sealed with paraffin wax.

Labels.-Those who are contemplating an extensive collecting expedition should provide themselves with proper labels, made of good paper, upon which, at least, should be printed: "Date," "Number," " Locality," "Preservation." The best and safest place for a label is no doubt inside the bottle, and as the label will be in 
the fluid, it is necessary to select a tough, unglazed paper (see p. 4I5). A record which is frequently omitted on labels is the method of preservation. It is by no means an unimportant detail, especially when the specimens are handed over to a specialist for examination.

\section{PRESERVATION.}

Plankton. - The preservation of the whole catch of a tow net, just as it comes on board, without any sorting of the specimens, is a simple operation. Animals with hard coats, such as Crustacea, stand the treatment very well, but soft-bodied animals, such as jelly-fishes, usually contract and become very much distorted.

The best method is to pour the Plankton from the can (at the bottom of the tow net) into a glass jar. Stir the Plankton round with a rod, and at the same time pour in a little formalin 5 per cent. or Io per cent. Take out the larger animals with lifter and pipette. Keep on stirring for about a minute, so as to mix thoroughly the formalin with the sea water; then allow the Plankton to settle to the bottom. Soon after the Plankton has settled, pour off as much of the fluid as possible, and transfer the Plankton to a bottle. Allow the Plankton to settle, and reduce the quantity of fluid to a minimum. The next step is to fill up the bottle with formalin 5 per cent. or Io per cent., and occasionally give the contents of the bottle a stir up. A bottle should not be more than half full of Plankton. It is advisable after a few days either to pour off the formalin and add a fresh supply, or to pour in a very small quantity of strong formalin. Opalescence of the fluid is a sign that it needs changing. 
Another method is to first kill the Plankton by pouring some picric acid solution into the glass jar, and then add a little formalin 5 per cent. or Io per cent. Leave the Plankton in this very dilute picroformol solution for an hour or two, occasionally stirring up. Finally transfer the Plankton to a bottle, and fill it up with formalin 5 per cent. or Io per cent. The fluid will remain yellow, but the small quantity of picric present may be neglected. It is important to use plenty of formalin, for an extra strong dose does no harm, and to remember occasionally to stir up the contents of the bottle.

Corrosive sublimate must never be used instead of picric acid for this wholesale method of quickly preserving Plankton. The presence of corrosive sublimate in formalin leads to the formation of a precipitate, which adheres firmly to all the specimens.

Protozoa may be preserved in weak osmic acid. If they are numerous, the osmic acid may be added to the water containing them ( 2 or 3 drops of $\frac{1}{2}$ per cent. osmic to Io c.c. of water) ; the Protozoa are allowed to settle, or, better, separated by means of a centrifuge. They should be stained with dilute picro-carmine, and brought gradually into 70 per cent. alcohol.

If one is dealing with a few specimens only in a drop of water on a slide, the drop may either be exposed to osmic acid vapour, or some solution may be run in under a cover-glass.

Radiolaria should be preserved with dilute osmic acid, or with corrosive sublimate.' Acanthometra killed with corrosive sublimate (about one minute in saturated solution) keep better than those preserved in osmic acid.

Porifera.-One simple and ready method of preserving sponges satisfactorily is to hang them up in strong alcohol (the strongest obtainable, absolute 
alcohol giving the best result). By hanging them in the fluid the strength of the alcohol surrounding them is kept as high as possible. They should be transferred to fresh alcohol after a few hours, and again in the course of a day or two.

They may also be well preserved by plunging them into osmic acid (I per cent. solution), in which they should remain for from three to five minutes. Small specimens taken from a rock-pool and put immediately into tubes containing osmic acid give excellent preparations. Larger sponges will need to be cut into small pieces before being placed in the preserving fluid, and the sooner this is done after the sponge is taken from the sea, the better the result will be.

Hydroids may be easily killed and preserved by simply placing them in formalin Io per cent., but one must not expect to see the hydranths nicely expanded by this method.

Most gymnoblastic hydranths can be killed in a fairly good state of expansion by quickly plunging the expanded colony into warm corrosive sublimate, and, moving it slowly up and down for about a minute. Wash afterwards in water to remove the corrosive, and transfer to formalin or alcohol. A safer method for catching the hydranths nicely expanded is to anæsthetize with menthol, which takes many hours, and then to kill with corrosive. Many calyptoblastic forms can be killed in a fair state of expansion by simply plunging the colony into warm corrosive, and giving it a gentle shaking. They are more sensitive to the presence of anæsthetics than the gymnoblastic forms, and to kill the hydranths well expanded requires a considerable amount of practice.

Hydromedusæ.-The successful preservation of medusæ, or any other delicatc, soft-bodied animals, 
depends to a great extent upon the healthy condition of the specimens. Directly the tow net comes on board, the Plankton must be poured into a glass jar, and the jelly-fishes at once picked out by means of a pipette or some other handy instrument, and placed in a glass vessel containing sea water. This glass vessel must be absolutely clean, and free from the slightest trace of chemicals.

The medusæ should be given about half an hour to expand and to recover from the shock. If the medusæ after the first half-hour look in a sickly condition, the sooner they are preserved the better ; but if in a healthy condition there is no need to hurry over their preservation. They may be left in the vessel for several hours, provided that it is kept in a cool place out of the heat of a summer's sun.

The simplest and quickest method for preserving either a few specimens or several dozen is by pouring diluted formalin into the sea water. The secret of success depends upon keeping the medusæ in motion whilst the formalin is being poured in. First stir the medusæ very slowly and very gently round and round with a clean glass rod. When all are in motion, begin pouring in the formalin slowly and gently down the side of the vessel. About Io c.c. of formalin Io per cent. may be taken as about the mean quantity to add to I0o c.c. of sea water. An exact quantity is of little importance, and it is better to add too much than too little. Keep the medusæ in motion whilst the formalin is being added, and for at least two minutes after. The stirring is very important, as it produces an even distribution of the formalin in the sea water, and the motion keeps the medusæ off the bottom, and allows them to die in a fairly well-expanded condition. Some species are more liable to contract than 
others, and much depends upon the condition of the specimens.

The medusæ may be left at the bottom of the vessel for a few hours, and then they should be transferred to a stronger solution of formalin-about 5 per cent.and finally stored away in formalin Io per cent.

To obtain medusæ in a nice state of expansion, and with tentacles stretched out, it is necessary to use an anæsthetic. This gives a little extra trouble, but the results are well worth the trouble when really nice specimens are wanted. One of the best anæsthetics is hydrochloride of cocaine, in either a I per cent. or a 2 per cent. solution.

Place the medusæ in a small glass vessel with just sufficient sea water for them to swim in. After they have expanded, add a little cocaine (about 3 c.c. of I per cent. for every Ioo c.c. of sea water), and stir gently with a glass rod to mix the cocaine with the sea water. If the medusæ at the end of about ten to fifteen minutes have their tentacles expanded, and do not contract when touched with a glass rod, no more cocaine need be added; but if still active, add a little more cocaine, and repeat the stirring process. It is better to add about half the cocaine at first, and gradually to increase the quantity, than to give the whole dose at once. An overdose generally causes a prolonged contraction. As soon as the medusæ are anæsthetized, stir them gently round and pour in the formalin solution. Keep on stirring whilst the formalin is being added, and for a minute or longer after. Specimens must not be left long in any solutions containing cocaine, as it has a softening action upon the jelly. A medusa anæsthetized with cocaine may also be killed with picric acid, corrosive sublimate, or any other good fixing solution. 
Siphonophores.-The belled forms (Calyconectæ) are about the easiest siphonophores to preserve, and for them formalin is recommended. The stolon bearing the cormidia usually becomes contracted, but occasionally one is killed in an expanded condition. A sudden dose of picric acid is a good killing agent, as it acts very quickly. Leave the specimens in the picric for about twenty minutes, and then gradually transfer to formalin or alcohol.

The forms with a small float (Physonectæ) require a considerable amount of skill, patience, and experience for their successful preservation in an expanded condition. Unless one is prepared to devote the necessary time and attention to the operation, it is far better to place the colonies of these and the other groups in formalin 5 per cent. or ro per cent., and chance the result. When dismemberment of the colony takes place, collect the fragments and put them all into a small bottle.

For killing colonies in an expanded condition a mixture of corrosive sublimate and copper sulphate is frequently used. After the death of the colony, a few drops of nitric acid are added to prevent the formation of precipitates. Then Flemming's solution is poured in for the purpose of hardening the tissues. After about twenty-four hours in the above mixture alcohol is introduced, just a few drops at a time, and the strength very slowly and gradually increased to 70 per cent. Nearly all the methods for the preservation of Siphonophora were published before the advent of formalin, and alcohol is always recommended. Formalin, however, has several advantages over alcohol for these delicate organisms, and should always be given a good trial.

Menthol has been used as an anæsthetic with some 
success. At the right moment formalin is poured in to kill. The success depends upon adding the formalin just at that moment.

The Cystonectæ (Physalia, etc.) are quickly killed with a mixture of corrosive sublimate and acetic acid. Transfer to chromic acid $\frac{1}{2}$ per cent. for about an hour, and then remove to dilute alcohol, and gradually increase the strength to 70 per cent. Care must be taken not to touch a living. Physalia, as its stinging power is tremendous, and the pain is excruciating.

The Disconectæ (Velella, Porpita, etc.) are fairly easy to preserve. Velella may be killed with picric acid or corrosive sublimate. Add, after death, a little chromic acid for hardening the tissues. Leave the specimen for about half an hour in the mixture, and then transfer to dilute alcohol after picric, but after corrosive wash well in water and then put into alcohol. Velella frequently dies fairly well expanded in formalin. Porpita is best killed with picric acid ; transfer to alcohol or formalin.

Scyphomedusæ are quickly killed with formalin. Make up a solution of about 5 per cent. formalin by pouring some strong formalin into sea water. Select a vessel a little larger than the specimen, pour in the formalin solution, and place the specimen in, mouth upwards. Leave it alone for about an hour, and then add a little strong formalin and give a gentle stir up. It must not be forgotten that Scyphomedusæ contain an enormous amount of watery fluid, hence the necessity for adding strong formalin to keep up the strength of the solution, which should be at least ro per cent., before storing away the specimen. In the case of large Scyphomedusæ it is best to give small doses of strong formalin at intervals of about two or three days, and to give a thorough stir up, moving the specimens about. 


\section{PRESERVATION OF MARINE ORGANISMS}

It is a distinct advantage, soon after killing the medusa in formalin, to pour in some chromic acidabout a 5 per cent. solution-just enough to colour the formalin. The chromic acid makes the jelly tough and more pliable, so that there is less risk of breakage when the specimens are handled for examination. The yellowish-brown colour of the chromic acid may be disregarded, because in the course of a few months the colour changes to a pale bluish-green, owing to the oxidation of the chromic acid.

The successful preservation of Scyphomedusæ, especially the large ones, greatly depends upon using plenty of strong formalin.

Ctenophores are troublesome animals to preserve, because nearly every genus requires special treatment. There is, however, one general rule to be rememberednamely, that Ctenophores must not be stored away in formalin, but always in alcohol 70 per cent.

Pleurobrachia may be killed in formalin 5 per cent. in sea water. The simplest method is to fill a large test-tube or a tall cylindrical measuring-glass with the formalin solution, and to drop the specimens in. Leave them alone until they sink to the bottom, and then remove to formalin 5 per cent. in fresh water. They may be left in formalin for a few weeks, but it is best not to delay their transference into alcohol too long. Begin with very dilute alcohol, and gradually work up to 70 per cent. strength.

Beroe may occasionally be killed in a fairly good, expanded condition by allowing it to swim in a small glass pot, with just sufficient sea water to cover it, and then, when fully expanded, pouring in very quickly a large quantity of corrosive sublimate (saturated solution in sea water). As soon as the specimen has become white, pour off the corrosive and add fresh 
water. Wash it well in several changes of water to remove the corrosive, and then transfer gradually from very weak alcohol to 70 per cent. alcohol.

Bolina dissolves up at once in formalin. The best results are obtained by killing quickly with Flemming's solution, and selecting quite small specimens. Leave them in the solution for about half an hour, wash slightly in water, and transfer very gradually from very weak alcohol to 70 per cent. alcohol.

Flemming's solution is about the best killing and fixing solution for Ctenophores.

Anemones and Corals are amongst the most difficult of marine animals to preserve in an expanded state. For ordinary sea anemones, formalin, followed by formalin-spirit, is preferred. The method which is most often successful is to anæsthetize with menthol (p. 36I); the process usually takes from twelve to twenty-four hours. When the creatures no longer react when touched, plunge them suddenly into formalin or formalin-spirit (see p. 356), or into hot corrosive sublimate, any one of which preserving fluids gives good results.

For "corals," such as Caryophyllia, Alcyonium, and Gorgonia, use hot corrosive sublimate after the menthol, or 5 per cent. formalin followed by cold saturated corrosive sublimate. But a plunge into 90 per cent. spirit, not allowed to get weaker than 70 per cent., has given fair results for anatomical work.

Starfishes.-Specimens required to show only external features may be preserved in 70 per cent. alcohol or in formalin. They retain their natural shape better if they are put for two or three minutes into fresh water before being piaced in the preserving fluid. If the internal anatomy is to be studied, an incision should be made along the length of each arm, so as to allow 
the preserving fluid to enter, and the specimen be preserved in 2 per cent. chromic acid, washed in running water, and transferred to 70 per cent. alcohol; or the specimen may be placed at once in formalinspirit, or 5 per cent. formalin, without the use of chromic acid.

Antedon.--Specimens thrown flat into a shallow dish of strong spirit give good results. There should be just enough spirit to cover the specimens.

Echinoids.-Echinus and similar forms may be preserved with the tube feet expanded by transferring a healthy specimen suddenly to strong acetic acid or to warm 70 per cent. alcohol. If only the internal parts are required, a hole should be made in the shell, and the specimen put at once into 70 per cent. spirit, or into formalin-spirit.

Holothurians.- Specimens merely killed in spirit, and with spirit also injected by the anus, are sufficient for the purposes of the ordinary collector.

Formalin and all acids should be avoided, as it is important not to injure the calcareous plates in the skin.

But if nicely expanded specimens are desired, they should be anæsthetized in the ordinary way with menthol (about twelve hours). They will then generally remain expanded. As soon as they cease to react when the tentacles are touched, they may be transferred to 70 per cent. spirit, and at the same time injected with 90 per cent. spirit through the anus.

Polychæta.-To preserve these worms the following has proved to be the most useful general method: The worms are first placed in a vessel of clean sea water, and 70 per cent. alcohol is added drop by drop, and mixed by gentle stirring with the sea water. The operation is repeated every few minutes, the dose of 
alcohol being increased on each occasion. In the course of ten or fifteen minutes the worms will become motionless and limp, and will show no movement on being touched. They are then taken one at a time from the sea water, and laid upon a dry glass plate, on which they are stretched out with the help of two camel-hair brushes. In this position they are killed with formalin-spirit (70 per cent. alcohol, I00 volumes; formalin 40 per cent., 5 volumes), placed on them by means of one of the camel-hair brushes, only enough being used just to surround the worm, without running over the glass plate. If the worms contract or become slightly contorted when the formalinspirit is first added, as they generally do, they should be straightened out with the brushes, and held in a suitable position until they begin to get hard. After a few minutes on the glass plate they will become sufficiently hard to be removed to a flat-bottomed dish containing formalin-spirit, in which the fixing process should be completed. In practice one may have a considerable number of the worms on the glass plate at the same time, continually moving some to the dish of formalin-spirit, and taking fresh ones from the sea water.

After being in the flat-bottomed dish for some hours, the worms may be transferred to tubes, and stored permanently in formalin-spirit.

Aphrodite and Hermione are killed well extended if placed in fresh water for ten or fifteen minutes.

For histological work, Hermann's fluid, Flemming's fluid, and corrosive sublimate-acetic acid mixture, give good results. The worms should be killed by adding alcohol to the sea water, and the first stage of hardening should be carried out on a dry glass plate in the way above described, Hermann's fluid, etc., being used 
instead of formalin-spirit. For their further treatment, see p. 359 .

We are indebted to Mr. R. T. Leiper for the following notes on the preservation of parasitic worms.

\section{(a) Preservation.}

Nematoda.-The worms are washed by shaking in I per cent. saline solution, killed by plunging each separately into a quantity of 70 per cent. alcohol that has been heated to its boiling-point, and stored in fresh 70 per cent. alcohol for examination. If this method is properly applied the worms should die in an extended and straightened position.

Trematoda. - Clean by shaking in a test-tube half full of I per cent. saline solution; the dirty liquid having been decanted off, one-third of the tube is filled again with I per cent. saline, in which the worms are shaken vigorously, and an equal quantity of saturated $\mathrm{HgCl}_{2}$ quickly added-the vigorous shaking being continued for several minutes thereafter. This treatment should kill and fix the flukes in an extended position. The parasites may be left in the fixing fluid several days, or they may be transferred immediately to water, washed for twelve hours, and finally stored in 70 per cent. alcohol.

Large trematodes, sections of which are required for diagnosis, may be treated in the same way, or formalin ro per cent. may be substituted for the corrosive sublimate as fixing reagent, and a weaker strength, say 3 per cent., used as a storing medium.

Cestoda. - The strobila are washed gently in I per cent. saline, fixed in a solution containing equal parts of saturated corrosive sublimate and 70 per cent. alcohol, to which a few drops of glacial acetic acid have been added-the whole heated to about $50^{\circ} \mathrm{C}$. The tapeworms remain in the fixing fluid until it is cold ; they are then washed in running water for twelve hours, and transferred to 70 per cent. alcohol.

\section{(b) Examination.}

Nematoda.-The worms, preserved in 70 per cent. alcohol, are transferred to a solution made up of 70 per cent. alcohol containing 5 per cent. glycerine. This solution is then placed on a warm plate or incubator at about $60^{\circ} \mathrm{C}$, , and allowed to evaporate slowly. The process takes about twenty-four 
hours, or even two days, to complete, by which time the alcohol and water will have passed off as vapour, leaving the worms in viscid-almost pure-glycerine. They may then be examined in pure glycerine, or mounted in glycerine jelly as permanent slide-preparations.

For rapid examination the specimens after fixation in boiling 70 per cent. may be transferred to absolute alcohol for thirty minutes, and then cleaned in " white " creosote.

By this method the details of all small nematodes may be seen perfectly. In the case of large forms, like some of the Ascaridæ, the details of internal anatomy can be made out by transference from 70 per cent. alcohol to spirit, and thence to creosote. The worms should be examined in creosote, and then returned, for keeping, to 70 per cent. alcohol.

Trematoda.-Small forms are examined whole, after clearing in creosote, being transferred thereto from spirit.

For examination of large opaque forms sections are necessary; for this rapid transference from formalin through acetone direct to paraffin is suitable.

When dehydration is complete, which may be tested by transference to aniline oil (if this is done the specimen must be returned to acetone), transfer to a warm mixture of acetone and paraffin, when infiltration is rapidly effected under an exhaust pump.

If it is desired to stain whole flukes they should be left several days in very weak hæmatoxylin, and then differentiated with weak acid.

Cestoda. - Stain by immersion in weak hæmatoxylin after fixing, or by direct immersion whilst alive in weak hæmatoxylin and weak glycerine. Differentiate with acid after several days, and mount according to general methods.

Copepoda, Ostracoda, etc.-Preserve in 5 per cent. formalin in sea water. They may either be kept permanently in this fluid, or be subsequently transferred to 70 per cent. alcohol, the latter being perhaps the better plan.

For histological work, Hermann's fluid or corrosive sublimate give good results.

Amphipoda and Isopoda, Cirrhipedia, ete.-For general purposes these may all be put directly into 


\section{PRESERVATION OF MARINE ORGANISMS}

70 per cent. alcohol. Formalin 5 per cent. may also be used, but it does not give such good results, as it attacks the carapace.

Decapoda.-Crabs, shrimps, prawns, etc., should be killed in fresh water, and then put into 70 per cent. alcohol. If put directly into alcohol, most of the crabs are liable to throw off some of their legs. In the case of crabs and lobsters larger than (say) half a crown, it is advisable to slit up the membrane at the back of the carapace with a sharp knife, so as to let the alcohol get into the interior.

For histological work on all Crustacea any of the ordinary preserving fluids may be used, but they do not easily penetrate the chitinous coat. Hot corrosive sublimate probably gives the best result. Excellent results may, however, be obtained with Flemming's, Hermann's, and other fluids, if a specimen can be obtained which has only just moulted and is in the "soft" condition. The great secret of obtaining good histological preparations of Crustacea is to use only specimens in this condition, as not only is the preservation very much improved, but the making of sections becomes easy, instead of wellnigh impossible.

Polyzoa.-For general purposes Polyzoa are best put directly into 70 per cent. alcohol. This enables the soft parts to be examined, or admits of the specimens being easily dried for examination of the calcareous skeleton. If it is wished to preserve the colour of a colony, it should be washed with fresh water to remove the salt, and then dried in the air, without the use of spirit.

Bowerbankia-like forms and Ctenostomes in general may be preserved in formalin.

If it is desired to preserve material with the polypites expanded, first anæsthetize with cocaine, and 
then kill rapidly with formalin. In the case of calcareous material, transfer at once from the formalin to 70 per cent. alcohol. Other reagents may be used instead of formalin, but are best employed hot.

Nudibranchiata.-Kill by plunging suddenly into glacial acetic acid. Transfer at once to weak and then to 70 per cent. alcohol, or transfer at once to 5 per cent. formalin. The larger forms, such as Archidoris tuberculata, are best killed with menthol or anæsthetized by the alcohol method, and preserved in formalin-spirit.

Gastropoda and Lamellibranchiata.-These may often be killed expanded by putting crystals of menthol on the surface of the sea water containing them. Alcohol, added very slowly to the sea water, will sometimes produce the same result, but is very uncertain. After killing, any of the ordinary preserving fluids may be used, formalin-spirit being good for general purposes. In the case of lamellibranchs, it is a good plan to slip a wedge of wood or cork between the open valves, to prevent them closing again.

Simple and Compound Ascidians.-Anæsthetize with menthol, and preserve in 2 per cent. chromic acid solution, or in any of the ordinary preserving fluids.

The free-swimming Tunicates (Salpa, Doliolum, Pyrosoma, etc.) are easily preserved by simply placing them in formalin Io per cent. Allow them to soak for a day or two, and then increase the strength of the formalin. The addition of a very small quantity of chromic acid I per cent. solution to the formalin is an advantage, as it helps to harden the gelatinous test.

Salpæ arranged in chains frequently become isolated when only formalin is used. A mixture of corrosive sublimate and acetic (ro c.c. glacial acetic and 90 c.c. corrosive sublimate) is very good for their retention 
in chains. Pour a large quantity of the mixture into the vessel containing the Salps. Wash well in water before transferring to alcohol or formalin.

Doliolum and other very small Salps may be killed by dropping them into picric acid, but simple formalin acts very well.

Fishes.-The best preservatives for fishes are(I) Five per cent. formalin (say 2 per cent. formaldehyde) ; (2) 70 per cent. alcohol ; and (3) 70 per cent. alcohol to which 5 per cent. formalin has been added.

For preserving for a short time only there is little doubt that 5 per cent. formalin is the best, as both the form and colour are better retained. After a considerable time, however, the specimens deteriorate.

Holt and Byrne recommend preserving first in 5 per cent. formalin (40 per cent. strength), and then transferring to alcohol, or after a few weeks to equal parts 95 per cent. alcohol and formalin 5 per cent.

Fish intended specially for dissection are best preserved in formol-alcohol.

The best way of preserving the colours of fish is to preserve in 5 per cent. formalin, and keep the specimens in the dark. But even under these conditions the colours last a few months only.

Fish Eggs and Larvæ.-These are best preserved in 5 per cent. formalin. They retain both form and size well in this fluid, whereas in alcohol they shrink considerably. 


\section{CHAPTER XII}

\section{WHALES, SEALS, AND SEA-SERPENTS}

BY D'ARCY WENTWOR'TH THOMPSON

\section{Whales.}

THERE is a deal of interest in whales. The seafarer rejoices to meet them in the monotony of his ocean voyage; the fisherman welcomes them in the narrow waters as harbingers of the herring-shoals; the merchant sees in them the object of a rich and still widening commerce; the naturalist considers their manifold variety in form and habit, the marvellous adaptation of their bodies within and without to their strange existence, their orderly migrations, and the unsolved problems of their remote ancestral origin.

Whales and dolphins of all kinds form, in our modern classification, the group Cetacea ; for so we have learnt to use an ancient word which the Greek mariners used of all manner of great sea-monsters, shark or tunny or whale. And the Cetacea form, for us, one order of the mammals-that is to say, of those warmblooded vertebrate animals that suckle their young at the breast. Behind these simple facts we hide a deal of ignorance; for as to what the mammalia are, how their several orders are related to one another and in what way or ways they have been evolved from Reptiles or other lower vertebrates, of all these things we have neither definite knowledge nor plausible 


\section{WHALES, SEALS, AND SEA-SERPENTS}

and accepted hypothesis. But whether or no, the Cetacea are mammals and not fish. The hairy coat of the ordinary mammal has disappeared; for, wet and matted, without its entanglement of air, the hairy covering would wholly cease to act as an efficient non-conductor of heat. Its part is played by the thick layer of blubber under the smooth skin, and just a few hairs remain about the lips, especially in the young, to remind us of the former presence of a hairy coat. The blood is copious and hot, and in various parts of the creature's body complex networks of small bloodvessels, the "retia mirabilia," are formed to hold the plentiful supply. The hind-legs have disappeared to outer view; but, within the body, remnants of the pelvis, thigh-bones, and sometimes even of the leg-bones, are still to be found. The fore-limbs are in many ways peculiar : the arm-bone is extremely short, sometimes almost as broad as it is long; its great round head moves freely on the shoulder-blade, but elsewhere the limb has little or no freedom, the fingers being bound together by sinew and skin, and the flipper moving all of a piece. The flippers are usually small, but sometimes of great length, as in the Caaing Whale (Globiocephalus) and the Humpback (Megaptera); and it is not by their means that the creature swims, but by the sculling action of the flukes of the mighty tail, the flippers being in all probability mainly for the purpose of maintaining equilibrium in the water, for keeping the animal on an even keel. While all other mammals soever have in the fingers and toes the same number of joints that we have, in the whales these numbers are always exceeded; and sometimes (Globiocephalus) the finger has twenty joints or more, so that the limb has a great resemblance (however that may have been brought about) to the 
many-jointed paddle of Ichthyosaurus and the other allied marine extinct sea-dragons. In every curve of the whale's body we seem to see an adaptation of form to motion in water; even where we have, as in the Sperm and Greenland Whales, a great blunt head behind which the body tapers away, it can be shown that, as in the not very differently shaped hull of an old Dutch schooner, such a conformation is on lines directly suited to speedy progrếss.

While all the Cetacea are so far alike as to be very easily distinguished from all other animals, yet there are great differences between one whale and another ; and not the least of these differences are in respect of size. For some of the smaller dolphins are only about a yard long, while many species of whales attain a length of 50,6o, or 70 feet ; and the largest of all, the Blue Whale, or Sibbald's Rorqual, is said to reach Ioo feet in length, and examples of 85 feet are well authenticated. We may make a rough estimate of the weight of one of these gigantic creatures by remembering the simple rule that in bodies of similar shape the bulk or weight will vary as the cubes of the linear dimensions. I find that a fœtal Rorqual, just a foot long, weighs I pound 6 ounces. It follows that a whale of 40 feet long should weigh $40^{3}$, or 64,000 times as much as the said fœtus, or somewhere about 38 tons ; a whale 85 feet long would, on the same proportion, weigh close upon ten times as much, or somewhere about 370 tons; and a whale roo feet long would weigh about 600 tons.

The Cetacea at present existing are divided by naturalists into two great groups-the Whalebone Whales and the Toothed Whales, with which latter the dolphins and porpoises are included.

The Whalebone Whales are technically known as 
the Mystacoceti, which literally means the "Moustache Whales," but which name, more than two thousand years ago, was already corrupted and punned upon into $\mu \hat{v}$ sò $\kappa \eta$ tos, the "Mouse Whale" or "Whale Mouse." There are two families of Whalebone Whales, the Balænidæ and the Balænopteridæ; the former including the so-called " Right Whales," and the latter the "Rorquals" or Finners and the "Humpbacked Whale." The chief difference between the two families is one of degree, the whalebone in the former being very long, and in the latter comparatively short. Naturally the mouth in the former is enormous, and the head also huge in proportion; so that a very different appearance is given to the animal, and its body looks short and small behind its gigantic head. The Right Whales are by no means so large as the largest of the Rorquals, and 45 to 50 feet is a large size for a Greenland Whale. Such a whale has whalebone of II to I2 feet in length, and whalebone of I3 feet in length is about the largest known, at least nowadays. Owing doubtless to the comparatively short body, the Right Whales have no dorsal fin, while such a fin is always present (though sometimes small) in the longer bodied Rorquals. Lastly, and this is a useful character for the recognition of the diverse kinds at sea, the Rorquals disappear gradually from view, seldom or never diving tail up, while the Right Whales dive more suddenly, the great head plunging down while the flukes of the tail are tossed upwards.

Among the Balænidæ many different species of Balæna, or Right Whale, have been described, and naturalists are not yet agreed as to their number or distinctive characters. In the North Atlantic region we have certainly two, Balæna mysticetus, the Greenland W'hale, and B. glacialis or biscayensis, the Bis- 
cayan Whale, or Nordkaper, to which latter our whaling captains sometimes restrict the name Right Whale.

The Greenland Whale is the true Polar Whale, and is never found very far from the edge of the ice (Fig. 2I8); it is, unfortunately, on the high road to extinction. In the seventeenth century it was the object of an immense fishery, shared by Holland, England, and France, and the great Dutch settlement of Smeerenberg, in Spitzbergen, employed at one time (about the year I680) 260 ships and over I4,000 men. Those were the great days of the Arctic whale fishery. Oil was the great object of the trade, for whalebone was as yet of little value; the cities of Europe were lighted with whale-oil, and the slaughter was prodigious. Before long the whales became very scarce in the neighbourhood of Spitzbergen, where the Greenland Whale appears to be now totally extinct; it appears also to be nowadays absent from the east side of Greenland, and it is not known from the north coast of Asia, eastward of Spitzbergen, until we get very near to Behring Straits. The British whale fishers have at all times chiefly resorted to Davis Straits. Up to the beginning of the last century almost every East Coast port sent out its whalers, but at present about four vessels from Dundee are all that is left of the dwindling fleet. Between I788 and I879, 8,4I5 whales were brought into Scottish harbours; the present yearly average is something like half a dozen. Another fleet of whalers still sails from San Francisco to the Sea of Ochotsk and the Behring Sea, and in summer-time through Behring Straits to Point Barrow and Herschel Island. In 1893 the fleet captured 293 whales. Some naturalists are inclined to think that we have, or had, three great tribes or races of the Greenland Whale, appertaining respectively to Spitzbergen, to Davis 
Straits and Baffin's Bay, and to the neighbourhood of Behring Straits. It is in the last of these regions that the species seems still to exist in the greatest plenty. Much has been written about the annual migrations of the whale, southward in autumn and northward with the retreating ice. In the Davis Straits Fishery the old males come southward in early winter along the west coast of Greenland, the females and young animals taking a different course in the direction of Hudson Straits. In spring the males go westward from the neighbourhood of Disco, and meet the females somewhere about Baffin's Bay. When the ice in Lancaster Sound breaks up, the whales pass northward, and their chief haunt in summer is in the neighbourhood of Prince Regent's Inlet.

The Greenland Whale is deep bluish-black in colour over the back, and grey upon the belly; the neck and throat are white.

Long before the Arctic whale fishery began, a very ancient and important fishery was carried on from the Basque cities. Of this fishery records are said to exist as far back as the ninth century, and when other nations began the pursuit of the whale it was Basque sailors who taught them the trade and accompanied them as harpooners. "Harpoon" itself is said to be a Basque word. This Basque fishery was very flourishing in the sixteenth century, and only became extinct in the beginning of the eighteenth. We owe to the great surgeon, Ambrose Paré, an account of the fishery at its chief seat, Biarritz.

The Biscayan Whale differs from the Polar or Greenland Whale in several minor characters, but the chief difference is in the smaller head, and the correspondingly shorter whalebone; this does not exceed 7 feet in length, and is of a coarser quality than that of the 


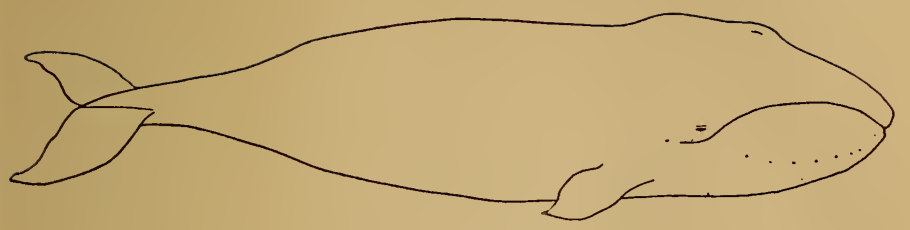

Fig. 2I8.-Balæna mysticetus. (From “Fauna Arctica.")

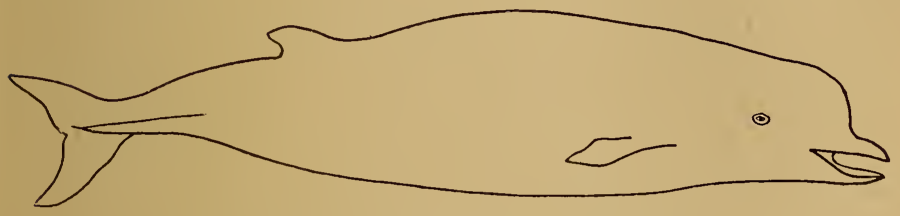

FIG. 2I9.-HYPEROÖDON ROSTRATUS.

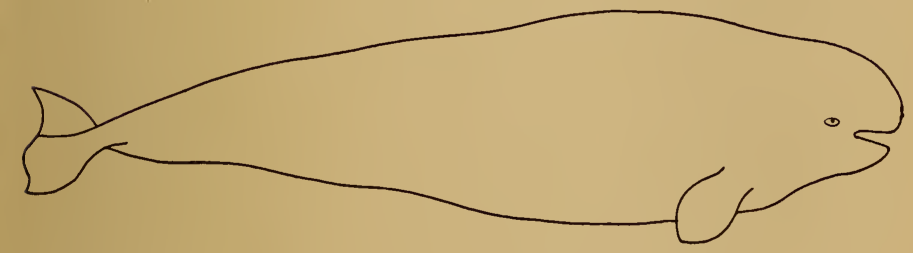

Fig. 220.-Delphinapterus leucas.

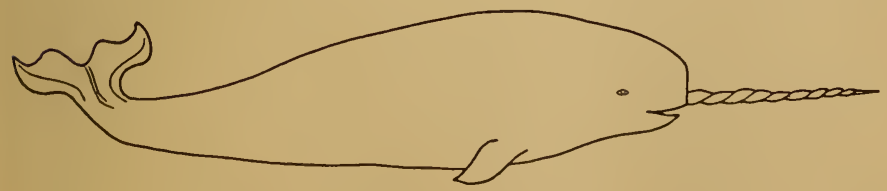

Fig. 22I.-MONODON MONOCEROS. 
Greenland Whale. For a long time naturalists supposed that this species was entirely extinct. In recent years, however, it has been captured in considerable numbers at several of the many whaling stations that have been established on our own coasts and elsewhere around the North Atlantic. It appears to be not infrequent in Iceland, and lately many examples have been got at the whaling station of Bunavenader in the Hebrides. This whale has also been got in the Mediterranean, and it is known from as far off as the Azores, Bermuda, and Bear Island in the neighbourhood of Spitzbergen. It is accordingly a great wanderer, and it may be that its wanderings are greater still, for some naturalists are inclined to doubt whether there be any real distinction between this species of the North Atlantic and the so-called B. australis of the Southern Ocean. This latter whale was the object of an immense American fishery in the beginning of the nineteenth century, and from I804 to I8I7 no less than I93,522 " southern Right Whales" are said to have been taken by their fleet. As in the North Atlantic, this great slaughter was supposed to have led to its extermination, and several Antarctic expeditions, including a small fleet of Dundee whalers sent out in I892, have failed to rediscover it. But it has been suggested that the reason for this failure is that the search has been conducted in the neighbourhood of the ice, in places where the Greenland Whale would be likely to occur ; while, on the other hand, this southern whale was, if not identical with, at least very closely akin to, the Biscayan Whale, and lived remote from the ice in the temperate regions of the ocean. In the northern half of the Pacific Ocean there is another Right Whale, the so-called B. japonica, hunted from time immemorial by the Japanese, and in late years also by the 
Americans and the Russians. Its wanderings appear to be both wide and regular, from the Sea of Ochotsk through the "Kadiak Ground," off the Alaskan coast southward to Oregon. Scammon gives a vivid account of the whale fishery in these seas. Here again the specific distinctness of this whale is by no means certain, and we may take it that it is at least very closely akin to our Biscayan Whale. It is at all times a difficult matter to identify with certainty the whales caught by the whale fishers, save in those cases where the whales are "flensed" ashore, under circumstances where bones and other specimens are likely to be collected and preserved. Thus some of the Dundee whaling captains are of opinion that any Right Whales which they occasionally get to the eastward of Greenland belong, not to the true Greenland Whale or Bowhead, but to what they call the Right Whale, and we call the Biscayan Whale. Indeed, it is an open question what species was the chief object of the great Spitzbergen fishery, and I am inclined to think it is not at all unlikely that the Atlantic or Biscayan Whale formed a great part of the catch.

The family Mystacoceti contains one other species very distinct from the rest ; this is the Pigmy Whale (Neobalæna marginata), a rare animal known only from the South Australian and New Zealand seas. It is but little known, and appears to be a link between the present family and the next ; it is only about I6 feet long.

The Balænopteridæ, including the Rorquals or Finner Whales and a few others, are Whalebone Whales of large size, resembling the former family in general structure and habits, but with shorter whalebone and smaller heads; there is a dorsal fin, and the skin of the throat is curiously pleated or furrowed in long 


\section{WHALES, SEALS, AND SEA-SERPENTS}

regular grooves. All the great whales that come ashore from time to time upon our coasts belong to this family. A curious study of their occurrences on the continental coasts of the North Sea might be made in the seaport towns of Germany, Holland, and Denmark, where it was for centuries the custom to record the stranding of a whale by a commemorative picture hung in the Rathhaus or Council Chamber. Till recent years the whales of this family were immune from persecution, but it is very different nowadays. About forty years ago a Norwegian sea-captain, Svend Foyn, began a fishery for these whales off the north coast of Finmark. The short baleen is of little value, but the whales yield an abundance of oil, their bones make excellent manure, and even the flesh is utilized, being dried, ground to powder, and used in part for manure and in part for mixing with cattle-foods. Svend Foyn made a fortune, and laid the foundations of a great industry. Political reasons led towards the end of the nineteenth century to the closure of the Norwegian fishery, the local fishermen asserting that the slaughter of the whales diminished their catch of fish; but the Norwegian whale fishers carried their trade elsewhere to Færoe, Iceland, Scotland, Newfoundland, and more recently to a number of stations in the Southern Ocean, the Falklands, South Georgia, South Orkney, and elsewhere. In Shetland there are now four stations, and there is another at Bunavenader, in Harris ; there are also one or two in Ireland. The method of fishing is everywhere the same, by means of small steamers armed with a powerful harpoon gun. The whales are towed ashore, and their carcasses are rapidly disposed of with the aid of elaborate machinery.

The following table shows the catch in Scotland in recent years : 


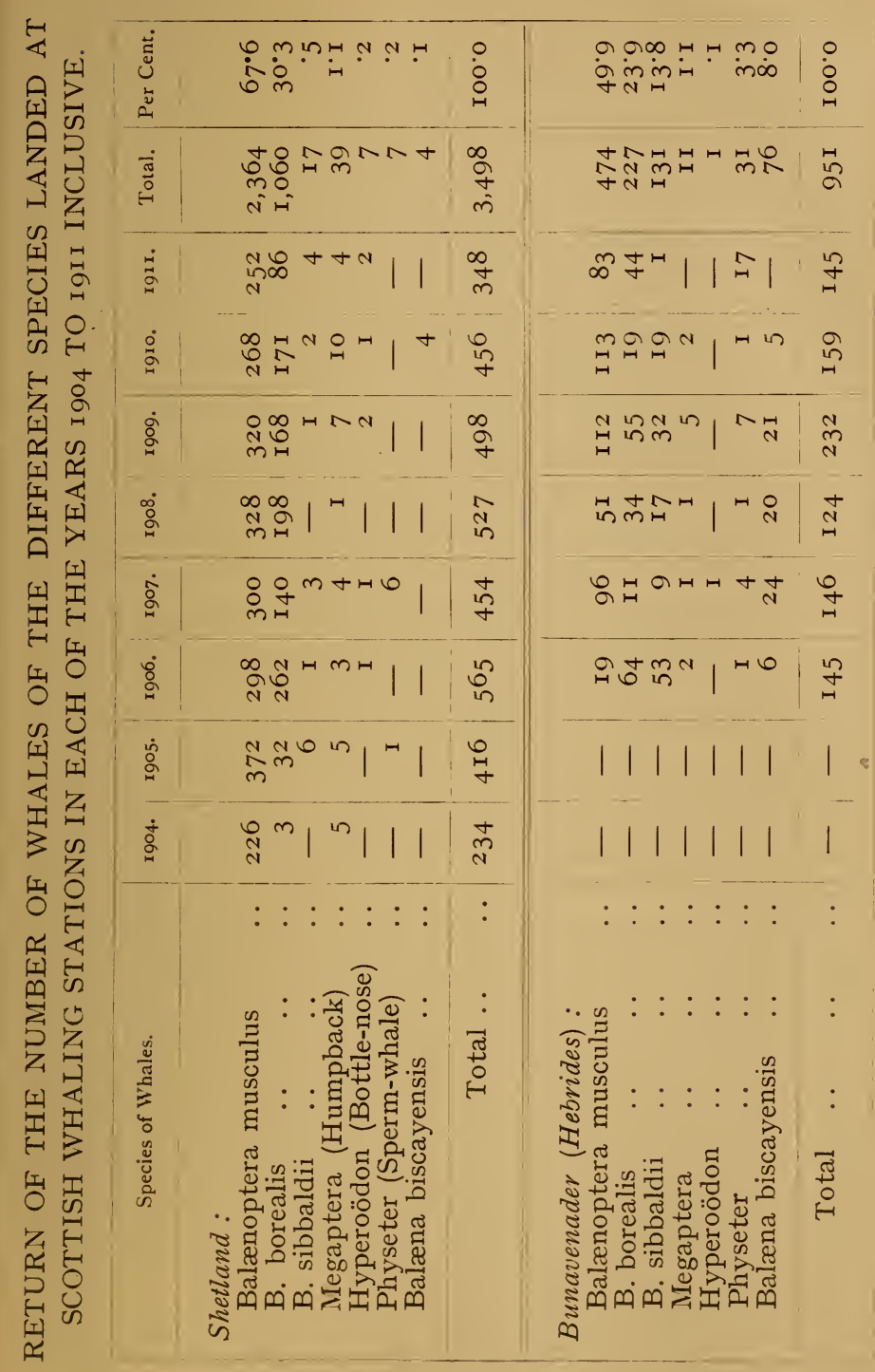


The industry is prosperous, and the demands for its products appear to increase continually. It is certain that it cannot long continue without making an impression on the numbers of the various species.

B. musculus, the Finner Whale, forms the bulk (68 per cent.) of the Shetland catch. This is nearly, but not quite, the largest of the Rorquals, reaching a length of over 70 feet. It feeds chiefly upon small Crustacea, especially Calanus finmarchicus. It is the commonest of the Rorquals to be stranded upon our shores. Closely allied to it is B. borealis, or Rudolphi's Whale. This whale, which, till the establishment of these whaling stations, was supposed to be exceedingly rare, is now found to be abundant, but it is curiously irregular in its appearance. In some years-for instance, in I906-it nearly equalled B. musculus in the Shetland catch, while in the previous year the latter species was ten times the more numerous. The average length of this whale is a little over 40 feet. Its whalebone, though short, approaches that of the Greenland Whale in fineness of texture, and is worth about $f^{\mathrm{I}} \mathrm{mo}$ a ton, or four times as much as that of the common Finner.

The greatest of all the Rorquals is B. sibbaldi-the Blue Whale-whose average length is about 80 feet. This whale is rare at Shetland, but more abundant at Bunavenader, where, on the other hand, the common Finner is less common than is the Shetland one. The Blue Whale is also plentiful at Færoe and off the coast of Finmark ; it is likewise common at Iceland and at Newfoundland ; and in the whalingstations of this latter island about 300 were caught in the season of I904-I905.

Allied to the Rorquals is the so-called Humpback Whale (Megaptera boops), distinguished by its shorter 
and bulkier form, and especially by its immense flippers, which are white in colour, and curiously scolloped on the edge. This whale grows to a length of about 50 feet, and appears to be very widely distributed, though it is not yet certain whether the Humpbacks of the North and South Atlantic and of the North and South Pacific are distinguishable from one another as species or races or not. As a matter of fact, they are probably inseparable, but these whales are particularly variable, and Captain Scammon declares that he never saw two alike. This is a true surface-feeding whale, feeding in the North chiefly on Boreophausia, and in the Antarctic on the large southern species of Euphausia ; but it does not disdain fish, especially the Arctic Lodde (Osmerus arcticus). In the north it appears chiefly in summer-time, but also sometimes in February and March. It is said to swim quietly in summer-time, but to be very restless in winter, when it approaches the coast for the purpose, so the fishermen say, of freeing itself from parasites. It is certainly the case that this whale is especially infested with barnacles, and great clusters of the large whale barnacle (Coronula balænarum), generally clustered over in their turn with Conchoderma aurita, are always to be found upon its skin. It is said to be common about the Bermudas in February, and in the Southern Hemisphere its chief abundance is in the winter season; so it may well be that this whale crosses the line in its annual migrations. It is also one of the whales of which specimens caught on the European coasts have been found with American harpoons embedded in them. This whale was reckoned a very rare wanderer to our coasts in former times, the great Tay whale of 1883 being one of three or four known examples. But it is now caught regularly in 


\section{WHALES, SEALS, AND SEA-SERPENTS}

moderate numbers both at Shetland and the Hebrides, where together twelve individuals were killed in Igog. In March, I88I, it is recorded that the Varanger Fjord, in the North of Norway, was "boiling" with these Humpback Whales.

On the Pacific Coast of America there is yet another large whalebone whale, the Californian Grey Whale (Rachianectes glaucus). This whale is, or has been, extremely abundant, chiefly off the coast of California and Oregon, where it is hunted from the shore. It has, however, a reputation for ferocity. In September, I908, off the west coast of Vancouver Island, I had the good fortune to see a marvellous shoal of whales, in all probability of this species. The old "Amphion," under Captain (now Admiral) Frank Finnis, steamed slowly through them in a dead calm one Sunday morning, while service was being held upon the poop, and in every direction as far as one could see the great beasts were lolling and grunting and puffing and blowing on the smooth water.

So much for the family of Whalebone Whales, from which we now pass to the Odontoceti, or toothed whales. These entirely lack the whalebone fringes, and are provided with teeth, that vaiy greatly in number, disposition, and size. Typically (that is to say, in the ordinary dolphins), they are very numerous, small and conical-all alike, without distinction of molars, canines, etc., set in imperfectly formed sockets, or practically open grooves, along the edge of the jaw. There is but a single set, no milk-teeth being displaced by the permanent dentition. In short, in a variety of ways the teeth of the dolphins are more like those of the reptiles than of the ordinary mammals.

The greatest of the toothed whales is the Sperm Whale, or Cachalot (Physeter macrocephalus), which 
attains a length of over 60 feet, or, according to some statements, as much as 80 feet. The gigantic head and straight blunt forehead gives this whale a characteristic appearance, the head being swollen out by a huge mass of the peculiar fatty substance known as "spermaceti." The teeth are large, and limited to the lower jaw. The blow-hole stands a little to one side at the very front of the head. This whale is absolutely cosmopolitan, its chief haunts being in the warmer seas. The jaw is so overhung by the great head that, like a shark, it has to turn over on its back to bite. Its food, like several of the other toothed whales, consists mainly of cuttle-fishes, and several gigantic species of the latter are only known from their half-digested remains found within the stomach of the whale. The Prince of Monaco has taken great interest in this curious method of studying these rare oceanic cuttle-fish. The Sperm Whale on its wanderings comes now and then to our own coasts. It is seldom caught at Shetland, but the Hebridean whaling-station got no less than seven individuals in I909; and it is a very curious circumstance that all the sperm whales captured on our Scottish whalingstations are found to be males, and males of moderate size. The old bulls fight for possession of the cows on the breeding-grounds in southern latitudes, and the young males, defeated and driven from their haunts, wander over the ocean. They get into the great warm ocean currents, such as the Gulf Stream, and so, in no inconsiderable numbers, reach our coasts and perish there. Towards the end of the eighteenth century London sent out a considerable fleet to the sperm-whale fishing, numbering at one time as many as seventy-five vessels, and it was British whalers who opened up the remote whaling-grounds of the Pacific 


\section{WHALES, SEALS, AND SEA-SERPENTS}

and Indian Oceans. But still earlier the Nantucket whalers had pursued the Sperm Whale, and the fishery is at present entirely in American hands; the reader is doubtless familiar with Mr. Frank Bullen's graphic descriptions in "The Cruise of the "Cachalot." ' Besides the oil (which is much more valuable than that of any other whales) and spermaceti, the Sperm Whale yields the very curious product known as " ambergris." This is a concretion of the intestines, is usually intermixed with cuttle-fish beaks, and is probably a product of the digested cuttle-fish. It is one of the most costly articles in commerce. While having but little perfume of its own, it is a constituent of all the finer scents, and seems to have some curious property of blending and improving the perfumes with which it is mixed. Now and then large masses of it have been found cast ashore or floating in the ocean.

There is a curious and rare species in the Southern Ocean, called the Pigmy Sperm Whale (Kogia), a miniature-some $I_{5}$ feet long - of its great ally.

There comes next a subfamily, known as the Ziphioid or Beaked Whales. These are whales of moderate size, and, like the Sperm Whale, make their diet of cuttlefish. One species, the Bottle-nosed Whale (Fig. 2I9) or Hyperoödon, is the object of a fishery, chiefly in Norwegian hands, and prosecuted by small vessels from Labrador to Nova Zembla. The Bottle-nosed whales go about in small herds, and, like the other Ziphioids, the male and female are recognizably different, the male having greatly enlarged crests upon its skull. The oil contains a considerable percentage of spermaceti, and the skin makes an excellent leather, supplying a great deal of what are known as porpoise leather boots. This whale can leap right out of the water, and is said to turn its head from side to side 
while in the air. The other Ziphioids (Mesoplodon, Berardius, and Ziphius) are all more or less rare forms which have been found in various parts of the world, but in such small numbers that the number and character of the species are still in dispute. Mesoplodon and Ziphius have both occurred on our own coasts, and it appears to be a common or general rule that when an individual comes ashore, its mate will before very long be found stranded in the near neighbourhood.

There remains the family of the Delphinidæ, or Dolphins, which includes a number of very diverse forms. The largest is the Great Killer Whale, or Grampus (Orca gladiator), an animal reaching some 30 feet long. This whale is easily recognized by its high curved dorsal fin. It has in each jaw ten or twelve powerful teeth. Its body is conspicuously marked with white or yellowish bands. It is a fierce, predaceous creature, attacking seals, porpoises, and the like, and even sometimes the larger whales. Eschricht says that thirteen porpoises and fourteen seals were taken from the stomach of a single individual. Three species of the dolphin family are hunted by man. The first of these is the so-called "Ca'ing Whale" (Globiocephalus melas); this whale is not large or valuable enough for an extended commerce, but is of great value to the inhabitants of Orkney and the Færoe Islands, where herds coming inshore in the summer months are surrounded by all the boats of the neighbourhood, and driven with shouts and splashings to the beach. This whale, like the Sperm Whale, is a feeder upon cuttlefish.

Next we have the White Whale, or Beluga (Delphinapterus leucas). This is a northern species, especially abundant off the coasts of Labrador and Canada; it 
is a small whale, about Io or I2 feet long, and is an eater of fish, especially, it is said, of salmon (Fig. 220). Its skin, like that of Hyperoödon, is used for leather. The Dundee whalers still bring a considerable number of White Whales, chiefly from the neighbourhood of Cumberland Gulf.

Closely akin to the Beluga is that very curious creature, the Narwhal. The teeth of this whale are all absent save one, and this one, which is present only in the males, is magnified into the long, twisted tusk (Fig. 22I). In the embryo, besides rudiments of the other teeth, two small tusks may always be detected, and, as a rare abnormality, both of these occasionally grow to a full size. One such two-horned Narwhal, in the museum at Hamburg, is one of the oldest natural history specimens in the museums of the world. The Narwhal is exclusively Arctic, but has now and then wandered as far as our own coasts. It is valuable only for its ivory, which brings a fair price. Some five-andtwenty years ago the price was extremely high, and I used to be told that the commodity had been " cornered" by a petty Indian rajah, who stockaded his palace all round with a fence of the tusks, confident in their exceptional virtue against the Evil Eye.

There is but little difference between the porpoises and the true dolphins, the chief being that the teeth of the latter are pointed, while those of the former have flattened, spade-shaped crowns. The porpoise is the commonest of all our native Cetacea, and is very frequently caught in the fishermen's nets. It comes far up our rivers, and has been seen in the Seine at Paris. Its flesh was an old-time dainty, and, by the way, it is in this respect not exceptional, for the flesh of the larger whales is said to be extremely good eating. I 
once saw a very young porpoise taken out of the stomach of a very large cod.

The dolphins include several genera and many species, of which it is impossible to treat within the short limits of this article. Neither, with any amount of description, would it be often possible for the traveller to identify the many dolphins that he sees tumbling and leaping alongside his ship, with whose course it gives them no trouble to keep pace. The Common Dolphin (Delphinus delphis) is particularly abundant in the Mediterranean, and its representations on Greek coins and in medieval heraldry, though sometimes fanciful enough, are by no means unlike the glimpse we catch of it as it flings itself out of the sea. The White-beaked Dolphins (Lagenorhynchus) are also not very uncommon visitors to our coasts. One which I once found in Galway Bay was streaked and scored all over with what seemed to be traces of an encounter with some great cuttle-fish; and similar markings, ascribed to the same cause, have been seen by others both on these dolphins and on some of the Ziphioid Whales.

There are a few rare and curious Cetaceans which inhabit rivers. There is a genus of dolphins called Sotalia, of which one species inhabits the Cameroon River (where it is said to feed, alone of all whales, upon a vegetable diet) ; another lives in China, in the River Amoy; and a third in the rivers and bays of the Atlantic Coast of South America. The last is very common at Rio de Janeiro, where it is protected by superstition, having a reputation of being friendly to man, and of bringing home for burial the bodies of the drowned.

Then, lastly, there are three other river-dwelling dolphins, long-snouted, many-toothed, and possessing 


\section{WHALES, SEALS, AND SEA-SERPENTS}

several curious characters-among others, a separation of the cervical vertebræ, and consequent flexibility of neck, which is found in no other Cetaceans. These three genera constitute a separate family, the Platanistidæ. The first of these is Platanista gangetica, the "Susu " of the Ganges ; it inhabits the Ganges and the Indus, going far up both rivers, and grubbing in the mud for food with its long snout. The next genus, Inia, inhabits the Amazons; its colour is in the main pink, with many curious variations. It is said to be dangerous to man, and the Sotalia, already alluded to, is said to defend the swimmer against its attacks. The last genus, Pontoporia, lives also in the rivers of South America, especially the Amazons and the La Plate. All of these fluviatile dolphins are rare in museums, and the traveller should not neglect to take note of their habits, and, when possible, to preserve their remains. I am told that there is one, for instance, in the rivers of Sarawak, which does not appear to be known to naturalists.

\section{Seals.}

The seals, or Pinnipedia, constitute a suborder of the great group Carnivora, and agree with the land carnivores in the main characters of their dentition and in many other anatomical points. Awkward upon land, the seal's movements in the water are singularly graceful. Swimming by means of its broad, webbed feet (for, unlike the Cetacea, the tail is short and degenerate), aided by sinuous movements of the whole body, the creature glides rapidly along, with nothing but the head exposed; and every now and then it stops to raise its little head and stare about with its big eyes. 
There are three families of seals: the Otariidæ, or Eared Seals; the Trichechidæ, or Walruses; and the Phocidæ, or True Seals. Of the Phocidæ we have in the North Atlantic region six species, all of which are common to both sides of the ocean, and of which all but one have been found upon the British coasts. The common Grey or Harbour Seal (P. vitulina), grey with darker spots, and with a black ring round the eye, is very common on our coasts, and has a bad reputation as a poacher of salmon. It is accordingly killed in large numbers at the mouth of the Tay and other salmon rivers. It swims far up into fresh water; it never resorts to the ice, but breeds in rocky places on the shore. It grows to about 5 feet long, or rather more. A similar and probably identical species, the so-called Leopard Seal, is found in California, and in the North Pacific. It has a close ally, Phoca pallasii. Smaller than the Grey Seal, and smallest, indeed, of the family, is the little Ringed Seal ( $P$. fotida), the back of which is marked with large whitish spots. This seal is common in the Baltic, and is found now and then on our own coasts, but its proper home is in the Arctic. It is of importance to the Esquimaux for food and clothing ; and it has curious habits, making for itself roofed habitations in the ice, like the " igloos " of the Esquimaux. This is the seal whose bones are often found in our Scotch brick-clays, which are of glacial origin, and it must have been abundant on our coasts in that Arctic period. It is closely allied to the Caspian Seal and to the seal which inhabits Lake Baikal ; and the presence of seals in these great inland seas may perhaps be looked upon as a survival from that same epoch. The Harp Seal, or Greenland Seal, inhabits the edges of the drifting ice, and forms the chief part of the great Newfoundland seal fishery. 


\section{WHALES, SEALS, AND SEA-SERPENTS}

The adult male is whitish in colour, with a great black belt across the shoulders and down each side, which saddle-shaped mark only becomes fully formed about the fifth year. The female is much smaller ; the young are pale grey, with dark spots. Still larger than the Greenland Seal is the Bearded Seal (Erignathus barbatus), the Ogdook of the Esquimaux, which grows to a length of 9 or Io feet. It is sometimes called the Square-Flipper Seal. It is not uncommon in Norway. On the other side of the Atlantic it goes as far south as Labrador, and is also found both in the Greenland and the Siberian seas. The Grey Seal (Halichœrus gryphus) is nowhere very abundant, but comes occasionally to our own coasts. It is confined to the Atlantic region. It is light grey in colour, and the male grows to 8 or 9 feet long. There is-or used in recent years to be-a breeding-place of this seal on the Fro Islands, off the Trondhjem Fjord, where about Ioo young were reared annually, and there are larger breeding-places near Hammerfest ; but its numbers are of late years greatly diminished. Indeed, the habit of resorting, as this seal and the Greenland Seal do, to a common breeding-place, instead of going in solitary pairs, as the Common Seal does, would seem to be a sad disadvantage for the species in its struggle for existence with mankind. The last of the northern seals is the Hooded Seal (Cystophora cristata). This is a moderately large seal, the male being about 8 feet long, and the female 7 feet. In colour it is bluishblack, with whitish spots; but the young, as in the Harp or Greenland Seal, are born white. The head is small, and bears in the male a very curious muscular sac, which is capable of inflation, and when fully stretched measures about I2 inches long by 9 inches high. This seal seems to be most abundant in the 
seas between Iceland and Greenland, where large numbers are killed by Norwegian sealers. It is fairly plentiful in the Spitzbergen region, but becomes scarce on the northern coasts of Europe and Asia.

In the Mediterranean one seal only occurs, the Monk Seal (Monachus albiventer), and this is therefore the seal referred to by ancient authors, from Homer downwards. It occurs also in Madeira and the Canary Islands. Very little seems to be known of the habits of this animal, and of its breeding-places, and any traveller who may have an opportunity of studying it-for instance, in the Archipelago or the Levantwould do well to take careful notes, and, if possible, photographs. A very similar and closely allied species, M. tropicalis, is found in the West Indies, where it haunts the " Kays " or reefs of rocks round many of the islands. This seal was first mentioned by Dampier, who made a sealing voyage to the Alacrana reefs, off Yucatan, in 1675 . In his time the seals were very abundant, and much hunted, but they are now so scarce all through the West Indian region as to seem on the verge of extinction.

The true seals of the North Pacific are, as has been said, more or less closely allied to, if not identical with, those of the North Atlantic. One characteristic species, which does not occur in the Atlantic, is the Ribbon Seal (Histriophoca fasciata). This seal inhabits the Kuriles, the Sea of Ochotsk, and Behring Sea, but is everywhere scarce. It is a very beautiful seal, the male being of a dark brown with a tinge of olive green, with a broad yellow band running across the neck and sides, and forming a "saddle" similar to that of the Harp Seal. This seal is much prized by the Alieuts and Esquimaux for ornamental purposes. Little or nothing is known of its habits, and it has very 


\section{WHALES, SEALS, AND SEA-SERPENTS}

seldom come under the observation of European travellers.

In the Antarctic we have other species of seals, quite distinct from the northern genera. These are Stenorhynchus, the Leopard Seal, a very large species ; Lobodon, the Crab-eating Seal ; Leptonyx, or Weddell's Seal ; and Ommatophoca, or Ross's Seal, a small and rare species, with enormous eyes. Recent Antarctic expeditions have added much to our knowledge of these seals, and have brought specimens in abundance to our museums.

The last genus of the true seals is the Sea Elephant (Macrorhinus), of which one species (M. leoninus) has long been known from the Antarctic seas, and another (M. angustirostris) occurs in small and dwindling numbers off the coast of California. The sea elephants are the largest of all the seals, old bulls measuring about 20 feet long; but the females are very much smaller. The southern sea elephants (which, by the way, may or may not be all referable to a single species) were in former times slaughtered in great numbers at Kerguelen, the Crozets, and Heard Island ; and in California the northern species was still plentiful and vigorously pursued at the time of the rush to the gold-diggings in I849 and following years.

The walruses form a family by themselves, the Trichechidæ, containing one or perhaps two species, for naturalists are not agreed as to whether the Atlantic and Pacific races of this animal should be looked upon as specifically distinct or not. However this may be, it is always, so far as I know, easy to distinguish between one and the other, for the tusks of Pacific specimens are notably longer, thinner, and more convergent than are those from the Atlantic region. Unlike the seals, which are fish-eaters, the walrus lives upon " clams" - 
that is to say, cockles, Myas, Mactras, and other burrowing shellfish, the digging out of which from the sand and gravel seems to be the chief use of the great tusks. The walrus is now verging rapidly towards extinction. In Spitzbergen, where thirty or forty years ago it was in prodigious numbers, it is now scarce, and, in fact, the once great herds which existed in that region, at Nova Zembla, and in Greenland, are already a thing of the past. The Pacific walrus is confined to a narrow stretch of coast in North-Eastern Asia, and a still smaller part of the opposite American coast. Here in the early part of the nineteenth century Middendorff described them as existing in hundreds of thousands, and even between 1870 and 1880 the tusks of about 12,000 walruses were brought annually to San Francisco by the American whalers. In the Pribylov Islands, where they were still numerous in 1874 , I only saw in I897 a single dead carcass. The walrus has several times been known to wander to the northern and western coasts of Scotland, the last time about 1857 ; but we may take it as certain that such an event will not happen again.

The Eared Seals, or Otariidæ, form the third and last family of the Pinnipedes. These include, in the first place, the genus Otaria, the Fur Seals, so well known for the international complications to which they have given rise. The genus does not occur in the Northern Atlantic ; its distribution would seem to be in the main Antarctic, from which ocean the range of one species to the Behring Sea appears to be a great but exceptional extension. Everywhere we have here a record of exterminations, and even in the Pribylov Islands the herds are now but a shadow of their former greatness. The chief breeding-places of Fur Seals are, or were, in the Antarctic region, at the Auckland 


\section{WHALES, SEALS, AND SEA-SERPENTS}

Islands, St. Paul, and Amsterdam Islands, etc. (O. forsteri); on Robben Island and some other South African islands and coasts (O. antarctica) ; on various parts of the South American coast, where their haunts often give rise to the name Lobitos Islands-i.e., the islands of the sea-wolves-from Uruguay round Cape Horn to Chili and the Galapages (O. australis) ; and, chief of all, in Behring Sea and the Pribylovs, the Commander Islands, and the Kuriles (O. ursina). The several breeding-grounds in the Kuriles have been exterminated for about twenty years, and it is said that in the times of relaxed supervision during the Japanese War the Russian breeding-grounds of the Commander Islands were all but depleted. A Fur Seal " rookery" is one of the great sights of natural history. The bulls come ashore in spring; each gathers together a harem of as many females as he can attract to himself, and can defend by ceaseless combat from his neighbours. The bulls remain at their posts all through the season, never entering the water to feed, and by late summer are gaunt and lean. At the height of the season the long beach is a densely crowded mass of bulls, females, and pups, in noise and stench and ceaseless movement.

The genus Zalophus is allied, but differs in the want of the fine fur of the Otarias. To this belongs the black "sea lion" of the Californian coast. This animal is very graceful and docile, and is often trained for menagerie purposes. Another species of the same genus occurs on the northern coasts of Australia, and northwards to Japan. One other genus is Eumetopias, to which a single species, Steller's Sea Lion, belongs. In contrast to the Fur Seals, which congregate in great "rookeries" in a few well-known spots, these sea lions disperse in small colonies, and may be seen 
on rocks and islands all round the North Pacific from California to the Kuriles. A protected colony on the "seal rocks" forms one of the sights of San Francisco. They are huge, sluggish animals, sprawling with difficulty on the ground, and are generally seen basking in shallow water, or lying motionless on the sand. I once saw very large numbers of them on the sandy beaches of Boguslov, the remarkable volcanic island near Unalaska which appeared within the memory of man, and which so continually changes its shape and outline that no two successive visits bring away identical views. While all these many species are well known to naturalists and well represented in museums, the traveller may still do good service by taking notes of their habits, and by photographing them under natural conditions.

\section{Sea-Serpents.}

No epitome, however short, of the creatures that the mariner may hope to witness would be complete without mention of the most famous and mysterious of them all, the great " sea-serpent "; but he is not the only " sea-serpent."*

Sea-serpents, or sea-snakes, are common enough, and constitute the family Hydrophidæ. These snakes live a purely aquatic life (with one exception), and frequent the tropical parts of the Indian and Pacific Oceans. A single species lives in a fresh-water lake in the Philippines. When removed from the water they appear to be blind, and soon die. They are all

* See, in particular, Henry Lee, "Sea Monsters Unmasked," in the "International Fisheries Exhibition Handbooks," vol. iii., pp. 321-440, London, I884 ; and A. C. Oudemans, "The Great Sea Serpent," Leiden and London, 1892. 


\section{Io WHALES, SEALS, AND SEA-SERPENTS}

virulently poisonous, and fierce in their attack ; and my old master, Sir Wyville Thomson, used to tell comical tales of the panic they sometimes caused among the naturalists of the "Challenger," when he and his colleagues were wading among the coral reefs. They are adapted in various ways for their aquatic life. The head is small and pointed; the belly is not flattened like that of an ordinary snake, but sharp or keeled like that of a herring; the tail is flattened like that of a fish, but is at the same time prehensile, and the snake clings by means of it, like a little sea-horse, to weed or coral. The lungs are of great size, and the nostrils have valves which can be tightly closed, so that, on the one hand, the creature can dive with safety, and on the other hand it may float motionless on the surface, buoyed up by its store of air. They are all viviparous. They feed on fishes, and it is said that the instant effect of their poison is to relax the whole body of the fish, so that it may be safely swallowed head foremost, its spiny fins offering no obstacle in their relaxed condition. There are many kinds of sea-snakes, belonging to several different genera. They are in most cases brilliantly coloured, often in alternate rings of black and white, sometimes adorned with green and yellow. In Indian and other eastern harbours the passenger may at times recognize their slender and gaudy shapes, swimming in the clear water. The widely distributed Hydrus platurus (or Pelamys bicolor), a rather small species, conspicuous with its yellow belly, and the much larger Distira cyanocincta, more or less annulated with black, are perhaps the oftenest seen. Many species are over a yard long, and the largest, D. grandis (from Malay and North Australia), is about 8 feet long. Specimens 12 feet long are said to have occurred.

The sea-serpents of Aristotle and of Pliny seem to 
have been no more than immense eels, a family of fishes which contains many diverse, and in some cases gigantic, kinds. A famous sea-serpent that came ashore on Stronsa, in Orkney, in I808, measured 56 feet long, and was carefully chronicled and described in the Transactions of the Wernerian Society, was almost certainly a huge oar-fish of the genus Regalecus. Sir Everard Home, it is true, identified the two vertebræ which alone were preserved as those of the great Basking Shark; but I have examined vertebræ of both fish, and believe that, in a more or less mutilated condition, they might well be mistaken for one another, even by an anatomist.

But the great sea-serpent is something other than these, and, whatever it may be, the many accounts of its appearance deserve a patient hearing and judicial investigation. More things than one seem to have been included under its name. It is now " that sea-beast Leviathan, which God of all His works Created hugest that swim the ocean stream "; in Milton's account of which is mixed up the Eastern tale of Sindbad the Sailor, and the great whale on which he and his comrades landed and built their fire. Again as the Kraken of Pontoppidan (who himself, however, distinguishes between the Kraken and the true sea-serpent) it is clearly recognizable as some sort of gigantic cuttlefish or octopus; and of the same kind was also in all probability the "very long and frightful sea-monster " seen by the Rev. Hans Egede off Greenland in I734. Now, though these latter denizens of the great deeps come but seldom into the hands of competent observers, yet we do know, for certain, that cuttle-fishes of enormous size exist in the various oceans. Professor Owen described one which came ashore on the Island of Achill, whose arms were 30 feet long, and whose eyes 


\section{I2 WHALES, SEALS, AND SEA-SERPENTS}

were great globes $5_{5}$ inches in diameter; and Professor Verrill has collected notes of a considerable number observed from time to time, chiefly on Newfoundland, whose arms ranged from 30 to 42 feet in length, and whose entire length, body and arms and all, were in some cases over 50 feet. We have every reason to suppose that these few stragglers that have been stranded and measured give us but a very imperfect idea of the dimensions that may actually be attained. Again, in Japanese pictures and carvings we have portrayed, with evident good faith and accuracy, precisely similar monsters of the cuttle-fish kind. As has been already mentioned in these pages, the Prince of Monaco has on several occasions discovered in the stomach of the Sperm Whale the halfdigested remains of cuttle-fish, great, if not so great, as these ; and it may be remembered that many stories of the sea-serpent describe it as in combat with the whale, and wrapping its long coils about the Cetacean's body. Dr. Andrew Wilson and (afterwards, and in greater detail) Mr. Henry Lee have shown that many stories of the sea-serpent might be so interpreted as to correspond to just such gigantic cuttle-fish as Owen, Verrill, and the other naturalists have proved the existence of. Thus in Hans Egede's drawing and description of his monster, with its spouting head and writhing tail, both elevated high above the surface of the sea, we seem to see the tail and one of the sinuous tentacles of a great cuttle, whose head and remaining tentacles were still submerged.

Then, again, there are many other accounts, which describe a more serpent-like animal, floating in huge coils upon the sea, such as that reported from the Indian Ocean by the Captain of H.M.S. "Dædalus " in I 848 , by the officers of the barque "Pauline" in I877, 
or by the Commander of the Royal Yacht " Osborne" off Sicily in the same year. Even in such accounts of the long serpent, with pointed head, swimming rapidly on a calm sea, coil after coil, Mr. Lee thinks that we have all that could well be seen from the deck of the body of a gigantic cuttle-fish, propelling itself, as its habit is, backwards by the rush of water expelled from its " funnel," with its tail-fin simulating the serpent's head, and the wavy outline of its trunk, head, and tentacles giving the appearance of the long serpentine body.

There is a big and interesting book by Dr. Oudemans of the Hague, published in I892, in which practically all the recorded appearances of the sea-serpent are chronicled and discussed; and Dr. Oudemans is fully convinced that underlying many of them we have a fragmentary account of something for which the cuttlefish theory does not suffice. Since the publication of this book one of the most remarkable of all accounts of the sea-serpent has been published in the Proceedings of the Zoological Society by two eye-witnesses, Mr. E. G. B. Meade-Waldo and Mr. M. G. Nicoll, who had seen the creature from the Earl of Crawford's yacht "Valhalla," off the coast of Brazil, on December 7, I 905. They saw a great fin about 6 feet long standing up out of the water, and then suddenly in front of the fin a turtle-like head shot up on a long eel-like neck, of which about 6 or 8 feet were visible. Neither the shape nor the size of the creature's body could be made out.

It is impossible to epitomize here the many other accounts of the serpent, for which the reader must be referred to Dr. Oudemans' book, and to the same source the reader must go for Dr. Oudemans' own elaborate deductions and conclusions as to what the sea-serpent really is. Suffice it here to say that he believes it to be a mammal, and to belong to the Order 


\section{I4 WHALES, SEALS, AND SEA-SERPENTS}

of the Pinnipedia, in near alliance to the eared or fur seals. We know that closely allied to these same Pinnipeds was a certain gigantic creature of the Tertiary Period-viz., Zeuglodon, or Basilosaurus as it was first called. This great mammal, with small head, serrate teeth, long neck, and huge, more or less whalelike body, would, if we could believe it still to linger on in existing oceans, be a sea-serpent indeed.

But whether the great sea-serpent be a giant cuttlefish or Zeuglodont mammal, or whatever else it may be, to meet it on the high seas, with opportunity to observe, sketch, and photograph it, is something for which the seafaring traveller may reasonably keep a sharp lookout, that he may see this marvel of all marvels of the great waters, and may so help further to transmute this old tradition into the language of prosaic science. 


\title{
CHAPTER XIII
}

\section{LOGS, NOTES, AND LABELS ; ODDS AND ENDS}

\author{
BY THE EDITOR
}

LOGGING, note-taking, and labelling with cold, wet fingers form at best an unpleasant task even on a fine day; they should therefore be simplified as far as possible.

All note and log books should be bound in a glazed waterproof cloth, paged, if possible, with a white rag paper rather than with a pulp paper; on no account with paper of a highly sized surface. The notebooks should be of a size to slip easily into a pocket ; the size of logbooks will depend to some extent on the handwriting, but I2 inches long by 8 inches high is a good size ; if they are to be used on deck, a thin sheet of lead (about I6 metal gauge) tacked on to one cover, will prevent their being blown overboard. At night a fair copy should be made of each day's log, and the day's notebook glanced through; this often enables errors and omissions to be detected while the facts are fresh in the memory.

All labels should be placed inside the bottle, except with water samples. The paper should be selected with some care; soft wood-pulp paper should on no account be used. A "vegetable parchment" paper is good, but any good stout rag paper will serve the turn, if it does not rub away after soaking in water for some days. Write with a B or BB pencil, or with Wolff's 


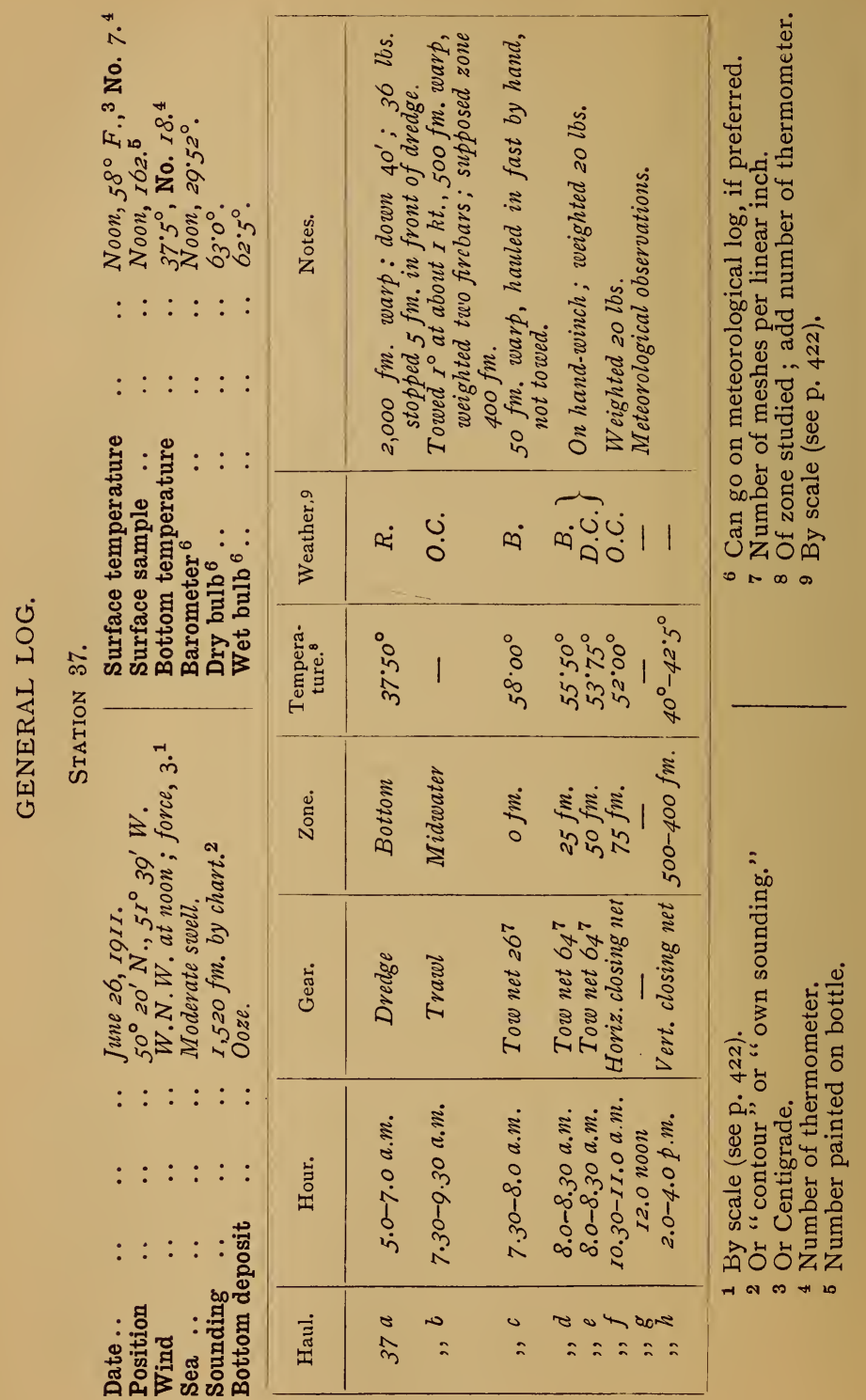



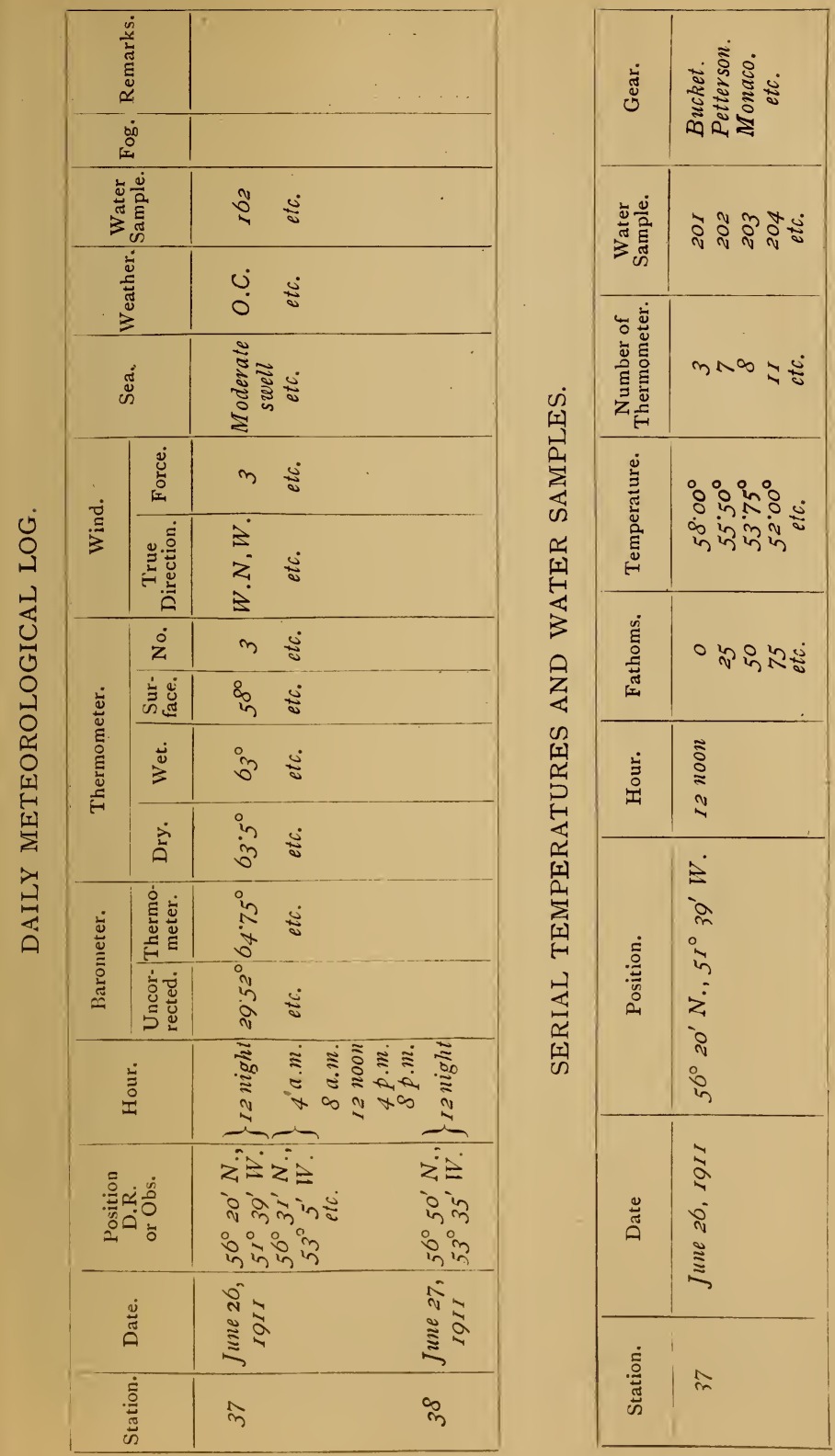
Chinese ink; both of these stand years of immersion in formalin or alcohol.

Paper labels are unsatisfactory in the case of fish preserved in tanks, for the friction caused by the motion of the ship rapidly obliterates the writing. A folded label, with the writing inside, will, however, be found to stand fairly well if inserted in the mouth or under the gill cover of the fish ; better still are the soft copper labels supplied for use in gardening.

Three sample logs form pp. 4I6, 4I7, to be varied according to the character of the work proposed; the italics represent examples, not real observations. If the traveller does not intend to take detailed temperatures and water observations, everything at sea can be got on to the first pattern. The writer strongly recommends the principle of a number for each day (I2.0 midnight till II.59 p.m.), and a letter for each operation; this method simplifies labelling, and enormously facilitates reference. Anyone who has worked over the Reports of some recent expeditions, in which each kind of gear and observation had its special series of numbers, will appreciate the advantages of a single series, and of a single printed table to which to refer.

The log and note books cannot contain too many details. Their value may not be apparent at once, but someone, perhaps in twenty years' time, will find in them just the clue that he is seeking.

It is hardly possible to get out a log for the shorecollector; he must rely chiefly on his notebook. In this case also it is a good plan to take a number for each day's work, subdividing it by letters according to his fancy. The following points should always be noted.

Date ; locality (from W. side of Smith's Point for two miles westerly); time (12.0 noon to 6.0 p.m.); tide (half-ebb to L.W., springs) ; weather (cloudy and blowy, 
bar. 29, falling); temperature (of rock pools); ground (rocks with Fucus on the point, some pools, the rest fine sand with isolated rocks). For animals and plants note the following kind of thing : Dry or submerged; in sand, or mud, or on rock; under rocks or stones; adhering or washed out from weed or rock; sifted out of sand; relation to H.W. and L.W. marks, etc. A specimen by itself has very little value; a specimen with full notes of its habits and habitat is a discovery.

Conversion of Fathoms and Metres.

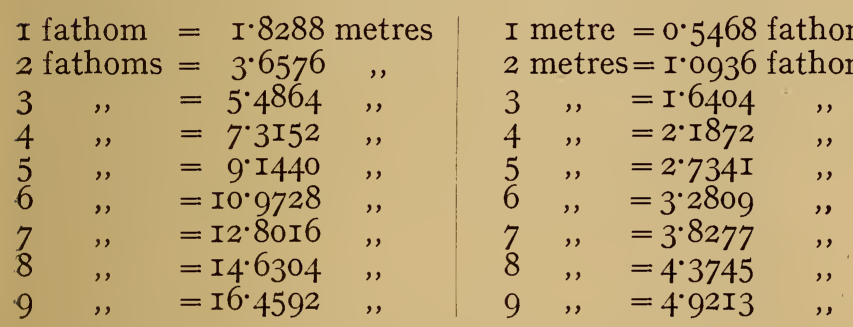

A little use of the decimal point will enable any conversion of fathoms into metres, or the converse. Thus, suppose that it is desired to find how many metres are equal to I,537 fathoms :-

$\begin{aligned} \mathrm{I}, 000 \text { fathoms } & =\mathrm{I}, 828 \cdot 80 \text { metres } \\ 500 \quad, \quad & =9 \mathrm{I} 4.40 \quad, \\ 30 \quad, & =54.86 \quad, \\ 7 \quad, & =\mathrm{I} 2.80 \quad,\end{aligned}$

$\mathrm{I}, 537$ fathoms $=2,810 \cdot 86$ metres

THERMOMETRIC CONVERSION.

The following tables can be used for air temperatures and -ordinary work ; but, as having only one place of decimals, they are not accurate enough to satisfy the modern hydrographer. 
Conversion of Centigrade into Fahrenheit.

\begin{tabular}{|c|c|c|c|c|}
\hline${ }^{\circ} \mathrm{C} .={ }^{\circ} \mathrm{F}$. & ${ }^{\circ} \mathrm{C} .={ }^{\circ} \mathrm{F}$. & ${ }^{\circ} \mathrm{C} .=^{\circ} \mathrm{F}$. & ${ }^{\circ} \mathrm{C} .={ }^{\circ} \mathrm{F}$. & ${ }^{\circ} \mathrm{C} .={ }^{\circ} \mathrm{F}$. \\
\hline $55=\mathrm{I} 3 \mathrm{I} \cdot \mathrm{O}$ & $37=98 \cdot 6$ & $19=66 \cdot 2$ & $I=33.8$ & I $3=8 \cdot 6$ \\
\hline $54=I 29^{\circ} 2$ & $36=96 \cdot 8$ & $I 8=64 \cdot 4$ & & $I_{4}=6 \cdot 8$ \\
\hline $53=127 \cdot 4$ & $35=95^{\circ} \mathrm{O}$ & $I 7=62 \cdot 6$ & Plus. & I $5=5 \cdot 0$ \\
\hline $5^{2}=125^{\circ} 6$ & $34=93 \cdot 2$ & $16=60 \cdot 8$ & $0=32 \cdot 0$ & I $6=3 \cdot 2$ \\
\hline $5 \mathrm{I}=\mathrm{I} 23.8$ & $33=9 \mathrm{I} \cdot 4$ & I $5=59^{\circ} \mathrm{O}$ & & $\mathrm{I} 7=\mathrm{I} \cdot 4$ \\
\hline $5 \mathrm{O}=\mathrm{I} 22 \cdot \mathrm{O}$ & $3^{2}=89 \cdot 6$ & $I 4=57 \cdot 2$ & Minus. & \\
\hline $49=\mathrm{I} 20 \cdot 2$ & $3 I=87 \cdot 8$ & I $3=55^{\circ} 4$ & $I=30 \cdot 2$ & \\
\hline $48=\operatorname{II~} 8 \cdot 4$ & $30=86^{\circ} 0$ & $12=53.6$ & $2=28 \cdot 4$ & \\
\hline $47=\mathrm{II} 6 \cdot 6$ & $29=84 \cdot 2$ & $\mathrm{II}=5 \mathrm{I} \cdot 8$ & $3=26 \cdot 6$ & Decimals. \\
\hline $46=$ I I $4 \cdot 8$ & $28=82 \cdot 4$ & $\mathrm{IO}=5 \mathrm{O}^{\circ} \mathrm{O}$ & $4=24 \cdot 8$ & $O \cdot I=O \cdot I 8$ \\
\hline $45=\operatorname{II} 3.0$ & $27=80 \cdot 6$ & $9=48 \cdot 2$ & $5=23^{\circ} \mathrm{O}$ & $0 \cdot 2=0 \cdot 36$ \\
\hline $44=$ I I I 2 & $26=78 \cdot 8$ & $8=46 \cdot 4$ & $6=2 I \cdot 2$ & $0 \cdot 3=0.54$ \\
\hline $43=109^{\circ} 4$ & $25=77 \cdot 0$ & $7=44 \cdot 6$ & $7=19 \cdot 4$ & $0 \cdot 4=0.72$ \\
\hline $42=107 \cdot 6$ & $24=75^{\circ} 2$ & $6=42 \cdot 8$ & $8=17 \cdot 6$ & $0.5=0.90$ \\
\hline $4 I=105^{\circ} 8$ & $23=73.4$ & $5=4 \mathrm{I} \cdot \mathrm{O}$ & $9=15 \cdot 8$ & $0 \cdot 6=I \cdot 08$ \\
\hline $40=104^{\circ} \mathrm{O}$ & $22=71 \cdot 6$ & $4=39 \cdot 2$ & $\mathrm{IO}=\mathrm{I} 4^{\circ} \mathrm{O}$ & $0 \cdot 7=\mathrm{I} \cdot 26$ \\
\hline $39=102 \cdot 2$ & $2 I=69 \cdot 8$ & $3=37 \cdot 4$ & $\mathrm{II}=\mathrm{I} 2 \cdot 2$ & $0 \cdot 8=I \cdot 44$ \\
\hline $38=100 \cdot 4$ & $20=68 \cdot 0$ & $2=35 \cdot 6$ & $\mathrm{I} 2=\mathrm{IO} \cdot 4$ & $0 \cdot 9=1 \cdot 62$ \\
\hline
\end{tabular}

Example-to convert $17 \cdot 6^{\circ} \mathrm{C}$. into Fahrenheit :

$$
\begin{aligned}
\text { I } 7 \cdot 0^{\circ} \mathrm{C} . & =62 \cdot 6^{\circ} \mathrm{F} . \\
0.6^{\circ} \mathrm{C} . & =1 \cdot 08^{\circ} \mathrm{F} . \\
\hline \text { I } 7 \cdot 6^{\circ} \mathrm{C} . & =63.68^{\circ} \mathrm{F} .
\end{aligned}
$$

General formulæ :

\begin{tabular}{|c|c|c|c|c|c|}
\hline$\circ \mathrm{F} .={ }^{\circ} \mathrm{C}$. & ${ }^{\circ} \mathrm{F} .={ }^{\circ} \mathrm{C}$. & ${ }^{\circ} \mathrm{F},=\circ \mathrm{C}$ & ${ }^{\circ} \mathrm{F} .={ }^{\circ} \mathrm{C}$. & ${ }^{\circ} \mathrm{F} .={ }^{\circ} \mathrm{C}$. & ${ }^{\circ} \mathrm{F} .={ }^{\circ} \mathrm{C}$. \\
\hline I $30=54^{\circ} 4$ & IO $8=42 \cdot 2$ & $86=30^{\circ} 0$ & $64=17 \cdot 7$ & $42=5 \cdot 5$ & $22=5 \cdot 5$ \\
\hline I $29=53.8$ & IO $7=4 \mathrm{I} \cdot 6$ & $85=29^{\circ} 4$ & $63=17 \cdot 2$ & $4^{\mathrm{I}}=5^{\circ} \mathrm{O}$ & $2 I=\sigma \cdot I$ \\
\hline I $28=53 \cdot 3$ & $106=4 \mathrm{I} \cdot \mathrm{I}$ & $84=28 \cdot 8$ & $62=16 \cdot 6$ & $40=4 \cdot 4$ & $20=6 \cdot 6$ \\
\hline I $27=5^{2} \cdot 7$ & $105=40 \cdot 5$ & $83=28 \cdot 3$ & $6 \mathrm{I}=\mathrm{I} 6 \cdot \mathrm{I}$ & $39=3 \cdot 8$ & $19=7 \cdot 2$ \\
\hline I $26=52 \cdot 2$ & $\mathrm{IO} 4=40^{\circ} \mathrm{O}$ & $82=27 \cdot 7$ & $60=15 \cdot 5$ & $38=3 \cdot 3$ & $18=7 \cdot 7$ \\
\hline I $25=5 \mathrm{I} \cdot 6$ & IO $3=39.4$ & $8 \mathrm{I}=27^{\circ} 2$ & $59=\mathrm{I} 5^{\circ} \mathrm{O}$ & $37=2 \cdot 7$ & $I 7=8 \cdot 3$ \\
\hline $\mathrm{I} 24=5 \mathrm{I} \cdot \mathrm{I}$ & IO $2=38.8$ & $80=26 \cdot 6$ & $5^{8}=14 \cdot 4$ & $36=2 \cdot 2$ & $16=8.8$ \\
\hline I $23=50 \cdot 5$ & IOI $=38 \cdot 3$ & $79=26 \cdot I$ & $57=13 \cdot 8$ & $35=\mathrm{I} \cdot 6$ & I $5=9 \cdot 4$ \\
\hline $\mathrm{I} 22=5 \mathrm{O}^{\circ} \mathrm{O}$ & $\mathrm{IOO}=37^{\circ} \cdot$ & $78=25 \cdot 5$ & $56=13 \cdot 3$ & $34=I \cdot I$ & $\mathrm{I} 4=\mathrm{IO} \cdot \mathrm{O}$ \\
\hline I 2 I $=49^{\circ} 4$ & $99=37^{\circ} \cdot 2$ & $77=25^{\circ} \mathrm{O}$ & $55=12 \cdot 7$ & $33=0.5$ & $13=10 \cdot 5$ \\
\hline I $20=48 \cdot 8$ & $98=36 \cdot 6$ & $76=24 \cdot 4$ & $54=12 \cdot 2$ & Plus & $\mathrm{I} 2=\mathrm{II} \cdot \mathrm{I}$ \\
\hline I I $9=48 \cdot 3$ & $97=36 \cdot I$ & $75=23 \cdot 8$ & $53=\mathrm{II} \cdot 6$ & $32=0^{\circ} 0$ & $\mathrm{II}=\mathrm{II} \cdot 6$ \\
\hline I I $8=47 \cdot 7$ & $96=35 \cdot 5$ & $74=23 \cdot 3$ & $52=I I \cdot I$ & Minus & $\mathrm{IO}=\mathrm{I} 2 \cdot 2$ \\
\hline I I $7=47^{\circ} 2$ & $95^{\circ}=35^{\circ} \mathrm{O}$ & $73=22 \cdot 7$ & $5 \mathrm{I}=10 \cdot 5$ & $3 I=0 \cdot 5$ & $9=12 \cdot 7$ \\
\hline I I $6=46 \cdot 6$ & $94=34^{\circ} 4$ & $72=22 \cdot 2$ & $50=10^{\circ} \mathrm{O}$ & $3 \mathrm{O}=\mathrm{I} \cdot \mathrm{I}$ & $8=13 \cdot 3$ \\
\hline I I $5=46 \cdot$ I & $93=33 \cdot 8$ & $7 \mathrm{I}=2 \mathrm{I} \cdot 6$ & $49=9 \cdot 4$ & $29=I \cdot 6$ & $7=\mathrm{I} 3 \cdot 8$ \\
\hline I I $4=45^{\circ} 5$ & $92=33 \cdot 3$ & $7 \mathrm{O}=2 \mathrm{I} \cdot \mathrm{I}$ & $48=8 \cdot 8$ & $28=2 \cdot 2$ & $6=14 \cdot 4$ \\
\hline I I $3=45^{\circ} \mathrm{O}$ & $9 \mathrm{I}=32 \cdot 7$ & $69=20 \cdot 5$ & $47=8 \cdot 3$ & $27=2 \cdot 7$ & $5=\mathrm{I} 5^{\circ} \mathrm{O}$ \\
\hline I I $2=44^{\circ} 4$ & $90=3^{2 \cdot 2}$ & $68=20^{\circ} 0$ & $46=7 \cdot 7$ & $26=3 \cdot 3$ & $4=15 \cdot 5$ \\
\hline I I I $=43 \cdot 8$ & $89=3 I \cdot 6$ & $67=19 \cdot 4$ & $45=7 \cdot 2$ & $25=3 \cdot 8$ & $3=\mathrm{I} 6 \cdot \mathrm{I}$ \\
\hline I IO $=43 \cdot 3$ & $88=3 I \cdot I$ & $66=18 \cdot 8$ & $44=6 \cdot 6$ & $24=4 \cdot 4$ & $2=16 \cdot 6$ \\
\hline \multirow[t]{2}{*}{$109=42 \cdot 7$} & $87=30 \cdot 5$ & $65=18 \cdot 3$ & $43=6 \cdot I$ & $23=5^{\circ} \mathrm{O}$ & $\mathrm{I}=\mathrm{I} 7 \cdot 2$ \\
\hline & & & & & $0=17 \cdot 7$ \\
\hline
\end{tabular}

$$
\begin{aligned}
& { }^{\circ} \mathrm{F} .=\frac{9}{5}{ }^{\circ} \mathrm{C} .+32 \\
& \circ \mathrm{C} .=\frac{5\left({ }^{\circ} \mathrm{F} .-32\right)}{9} .
\end{aligned}
$$

Conversion of Fahrenheit into Centigrade. 


\section{Meridians used in some Foreign Charts in Terms of Longitude From GreENWICH.}

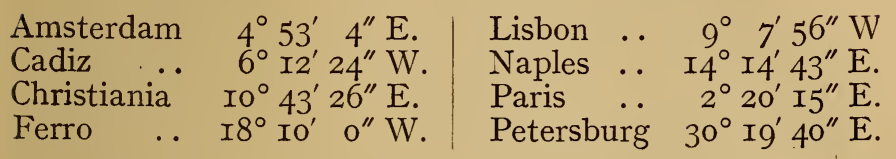

\section{Nautical and Geographic Miles.}

Nautical mile $=6,08$ o feet. Geographical mile $=6,086$ feet.

The nautical mile is one minute of latitude. Since the earth is not truly spherical, the length of a minute of latitude increases from 6,046 feet at the equator to 6,108 feet at the poles. For navigational purposes and chart work an average value (6o8o feet) is always used. On plans (charts of small area, such as harbours), the "minute of latitude in " the place-that is to say, its true value in the place-is used instead of the nautical mile.

The geographical mile is one minute of longitude on the equator.

Abbreviations for Bottom Deposits used in AdMiralty Charts (Admiralty Chart, X. II).

b. blue.

blk. black.

br. brown.

brk. broken.

c. coarse.

cl. clay.

crl. coral.

d. dark.

f. fine.

g. gravel.

gn. green.

grd. ground.

gy. grey.

h. hard.

m. mud.

oys. oysters.

oz. ooze. peb. pebbles.

r. rock.

rot. rotten.

s. sand.

sft. soft.

sh. shell.

spk. speckled.

st. stones.

stf. stiff.

w. white.

wd. weed.

y. yellow.

for. Foraminifera.

gl. Globigerina.

pt. Pteropod.

rad. Radiolaria. 
WIND, WEATHER, AND FOG SCALES.*

WIND.

\begin{tabular}{|c|c|c|c|c|c|}
\hline No. & Description. & $\begin{array}{l}\text { Miles per } \\
\text { Hour. }\end{array}$ & No. & Description. & $\begin{array}{l}\text { Miles per } \\
\text { Hour. }\end{array}$ \\
\hline $\begin{array}{l}0 \\
I \\
2 \\
3 \\
4 \\
5 \\
6\end{array}$ & $\begin{array}{l}\text { Calm .. } \\
\text { Light breeze .. } \\
\text { ", },, \quad \ldots \\
\text { Moderate breeze } \\
\text { ", } \\
\text { Strong wind }\end{array}$ & $\begin{array}{rr}\text { Under I } \\
\text { I to } & 3 \\
4,, & 7 \\
8, & \text { I } \\
\text { I3 ,, } & \text { I } 8 \\
\text { I9 },, & 24 \\
25,, & 3 \text { I }\end{array}$ & $\begin{array}{r}7 \\
8 \\
9 \\
\text { I0 } \\
\text { II } \\
\text { I2 }\end{array}$ & $\begin{array}{l}\text { Strong wind } \\
\text { Gale force } \\
\text { ", " } \\
\text { Storm force } \\
\text { ", ", } \\
\text { Hurricane }\end{array}$ & $\begin{array}{l}32 \text { to } 38 \\
39,, 46 \\
47,, 54 \\
55,, 63 \\
64,, 75 \\
y\end{array}$ \\
\hline
\end{tabular}

WEATHER.

b. blue sky.

c. clouds, detached.

d. drizzling rain.

e. wet without rain.

f. fog.

g. gloomy.

h. hail.

1. lightning.

m. misty.

o. overcast. p. passing showers.

q. squally.

r. rain.

s. snow.

t. thunder.

u. ugly appearance of weather.

v. objects unusually visible. w. dew.

z. haze.

Intensity can be indicated by underlining. Duration of rain, hail, snow, and sleet should always be recorded, and can be indicated by a numeral preceding the letter; thus $5 \mathrm{r}=$ five hours of rain.

* Abbreviated from those issued by the Meteorological Office ; revised form of Beaufort's scales. 
FOG.

No.

Description.

- No fog or mist, horizon clear.

I Light fog or mist, horizon invisible ; objects visible at working distances.

2 (Moderate fog; lights, passing vessels, and landmarks

3 generally indistinct under a mile. Fog signals sounded.

4 fThick fog; ships' lights and vessels invisible at $5\{$ quarter-mile or less.

\section{MARINE STATIONS}

IT is hoped that this section may prove useful to travellers in need of local information. Even those State or Official stations marked $t$, which are not open to researchers from outside, may be relied upon in most cases for advice and assistance.

This list has been revised by means of Professor C. A. Kofoid's "Biological Stations of Europe" (U.S. Bureau of Education), Washington, I9Io, which contains full descriptions and photographs of the stations, boats, etc. Assistant Directors are marked A.D. 


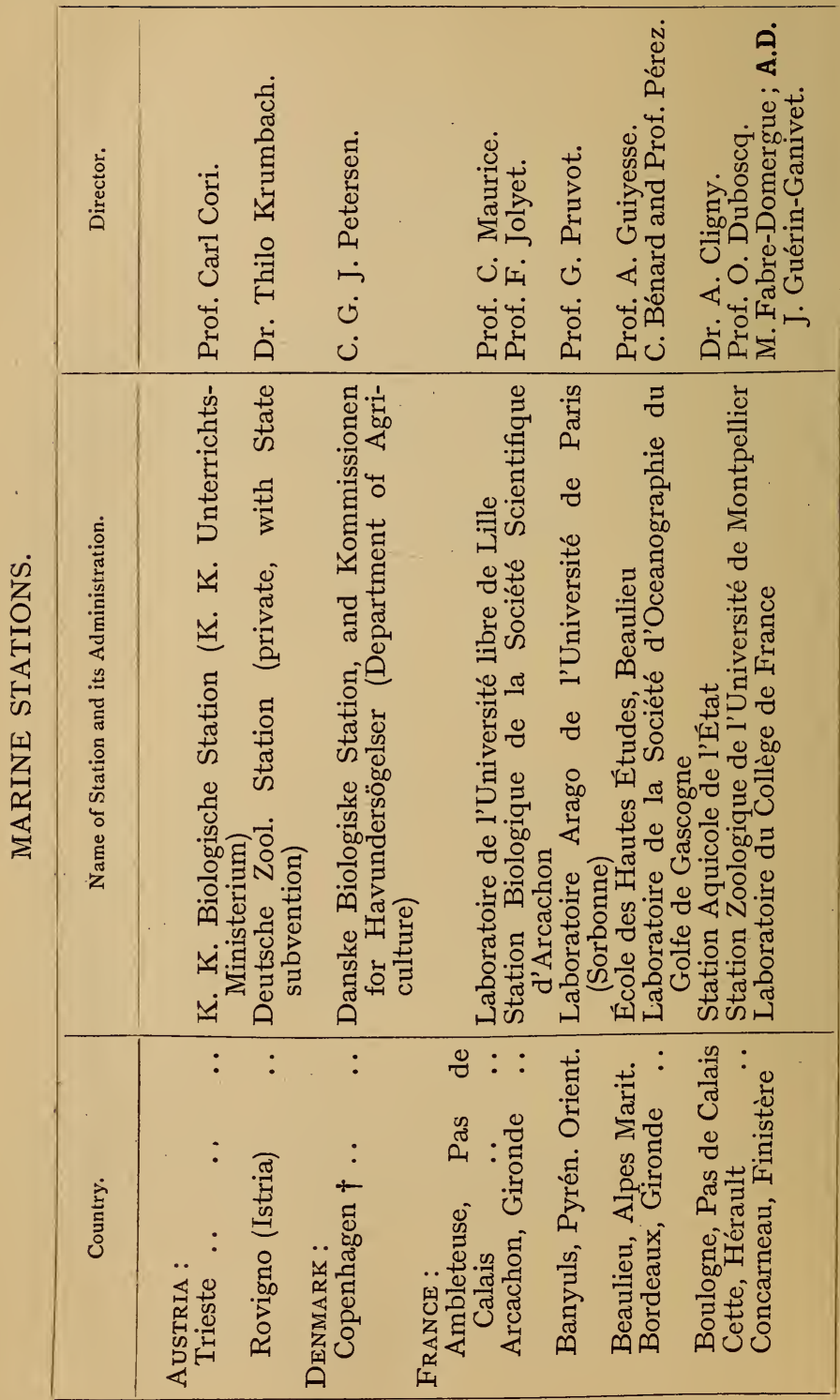




\begin{tabular}{|c|c|c|c|c|c|}
\hline & 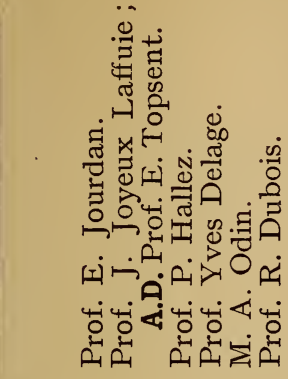 & 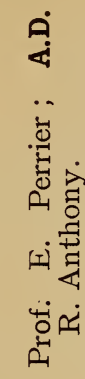 & 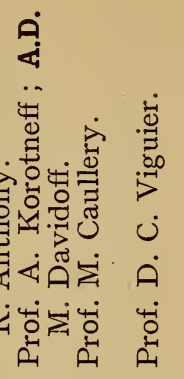 & 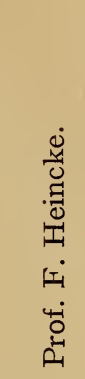 & 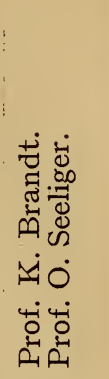 \\
\hline & 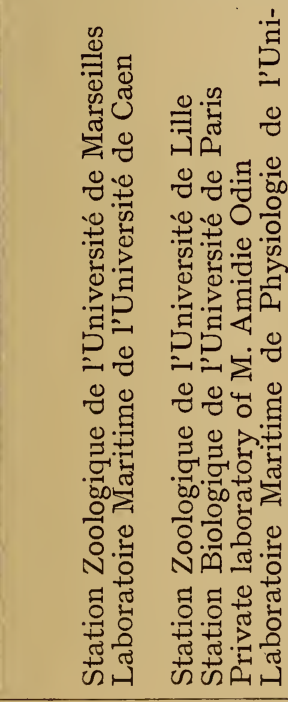 & 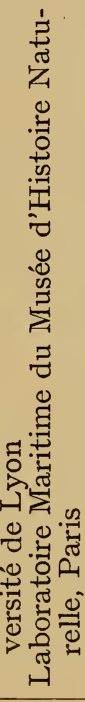 & 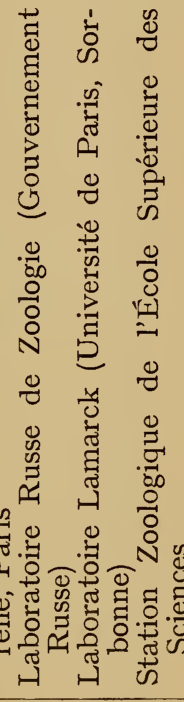 & 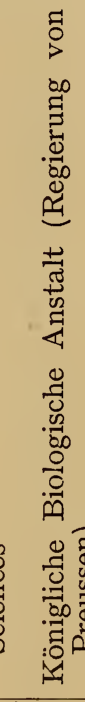 & 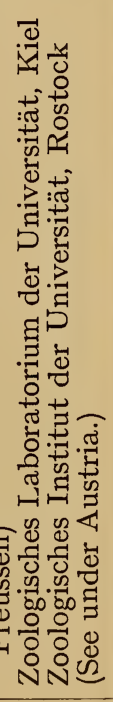 \\
\hline & 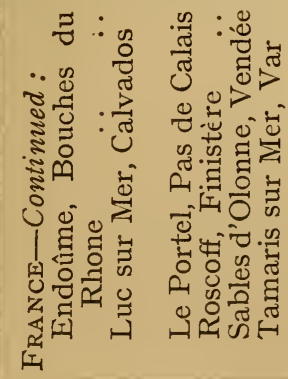 & 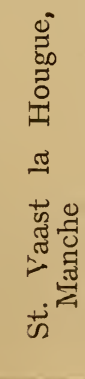 & 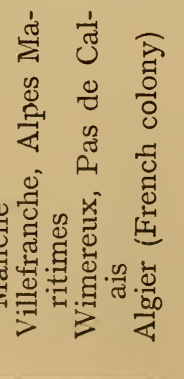 & 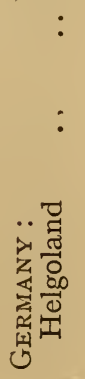 & 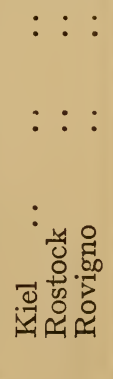 \\
\hline
\end{tabular}




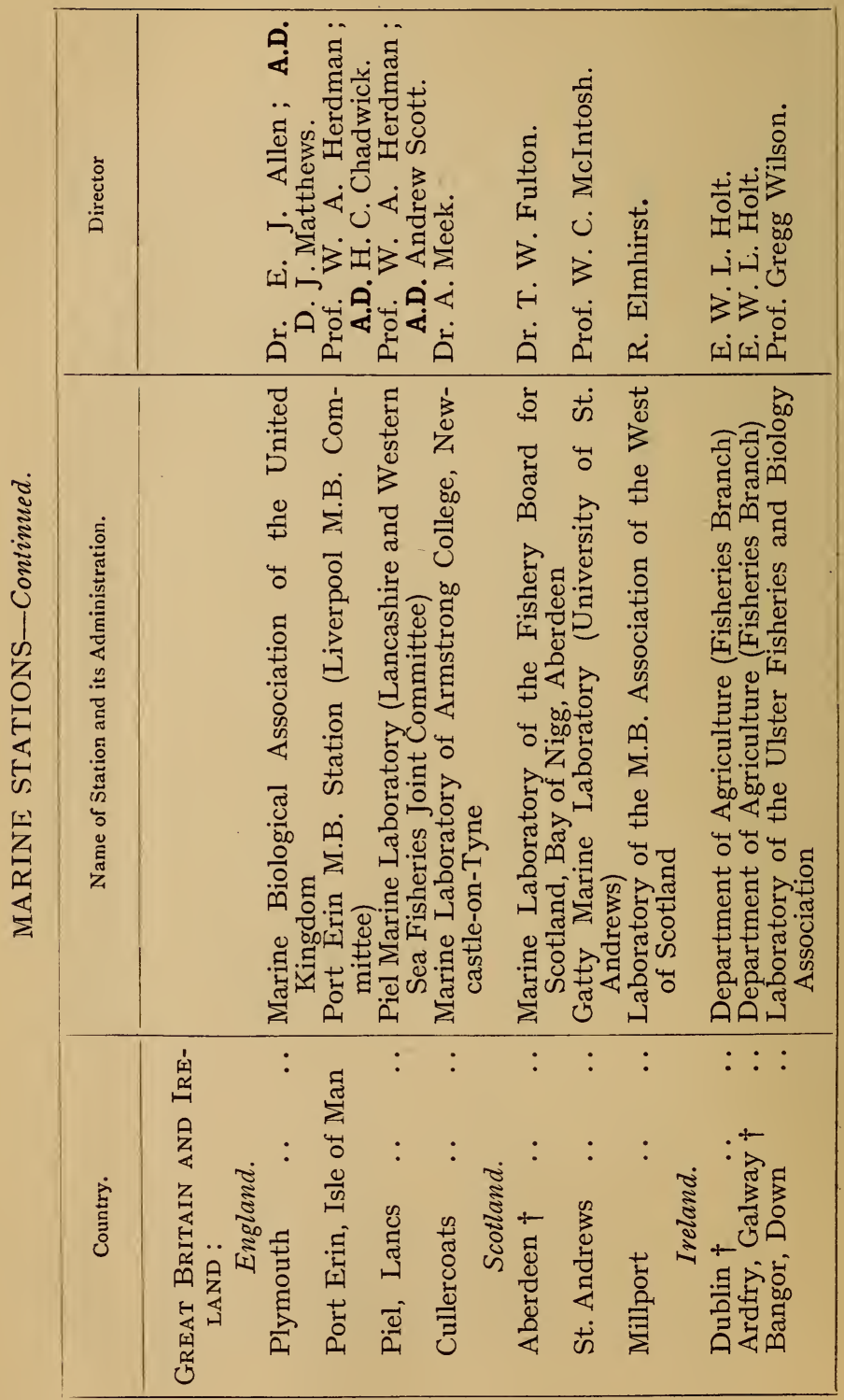




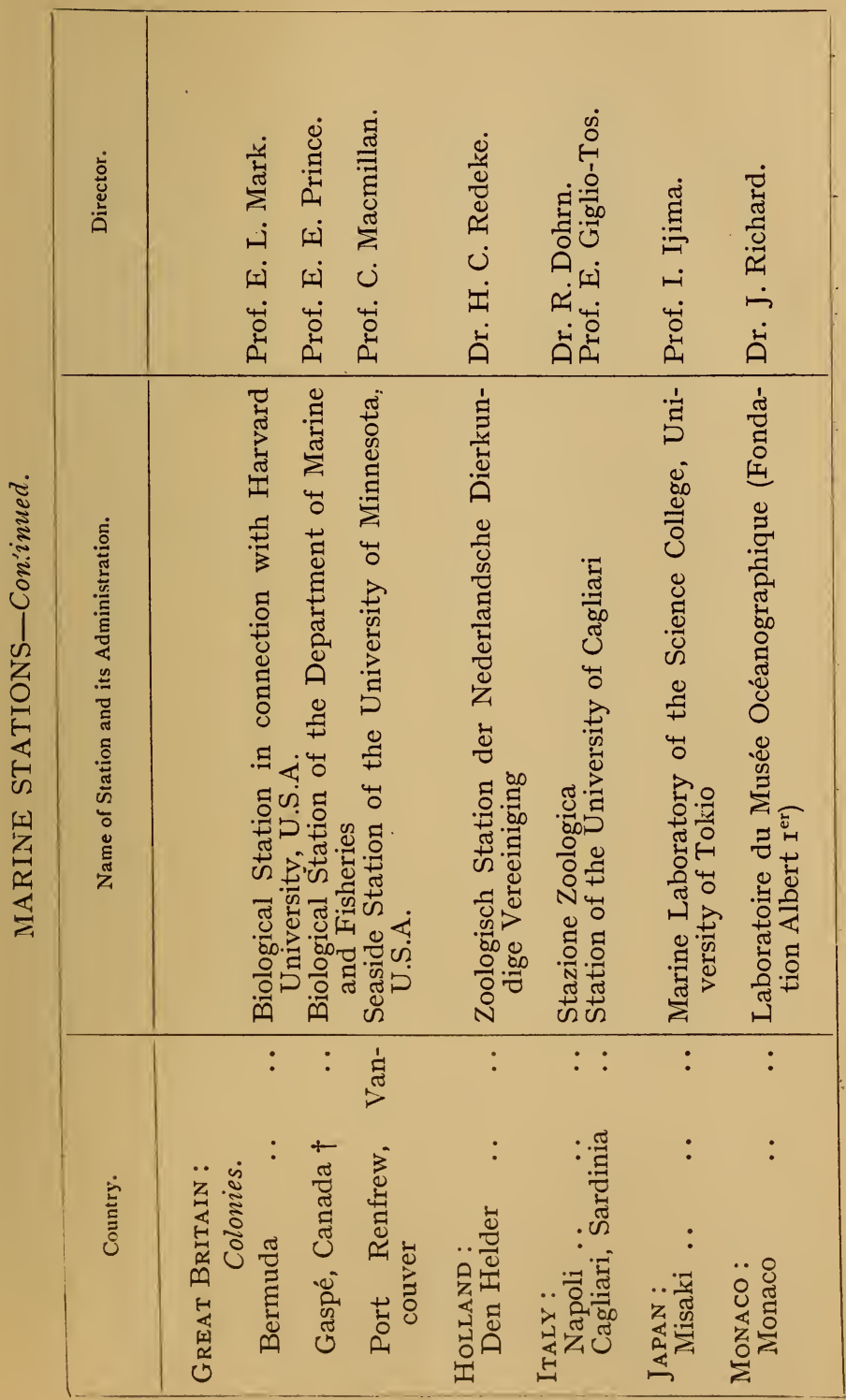




\begin{tabular}{|c|c|c|c|c|c|c|c|}
\hline 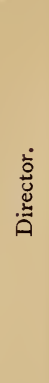 & 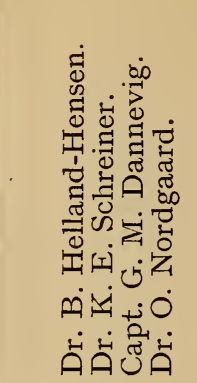 & 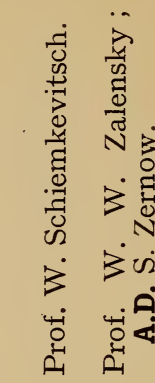 & & 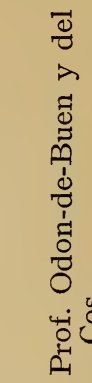 & 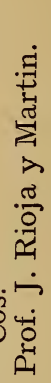 & 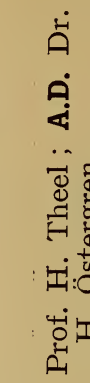 & 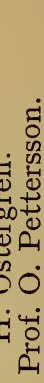 \\
\hline 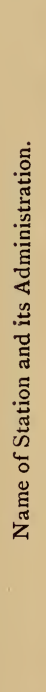 & 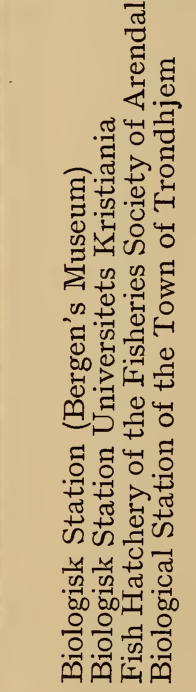 & 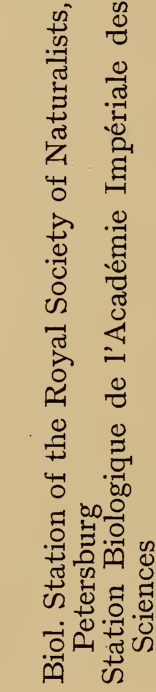 & 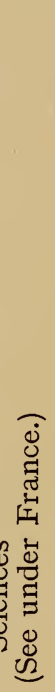 & 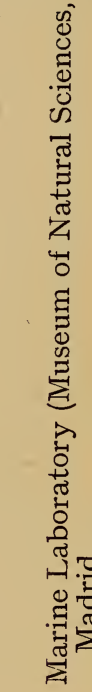 & 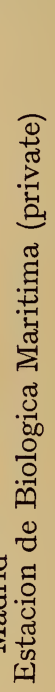 & 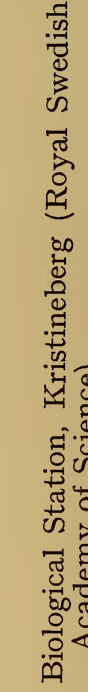 & 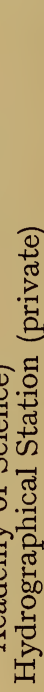 \\
\hline 苞 & 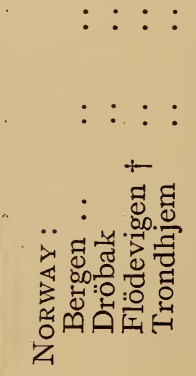 & 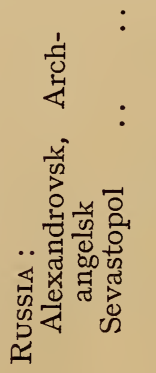 & 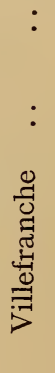 & 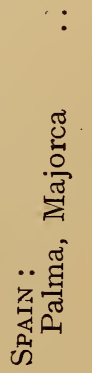 & 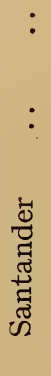 & 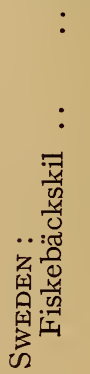 & 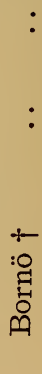 \\
\hline
\end{tabular}




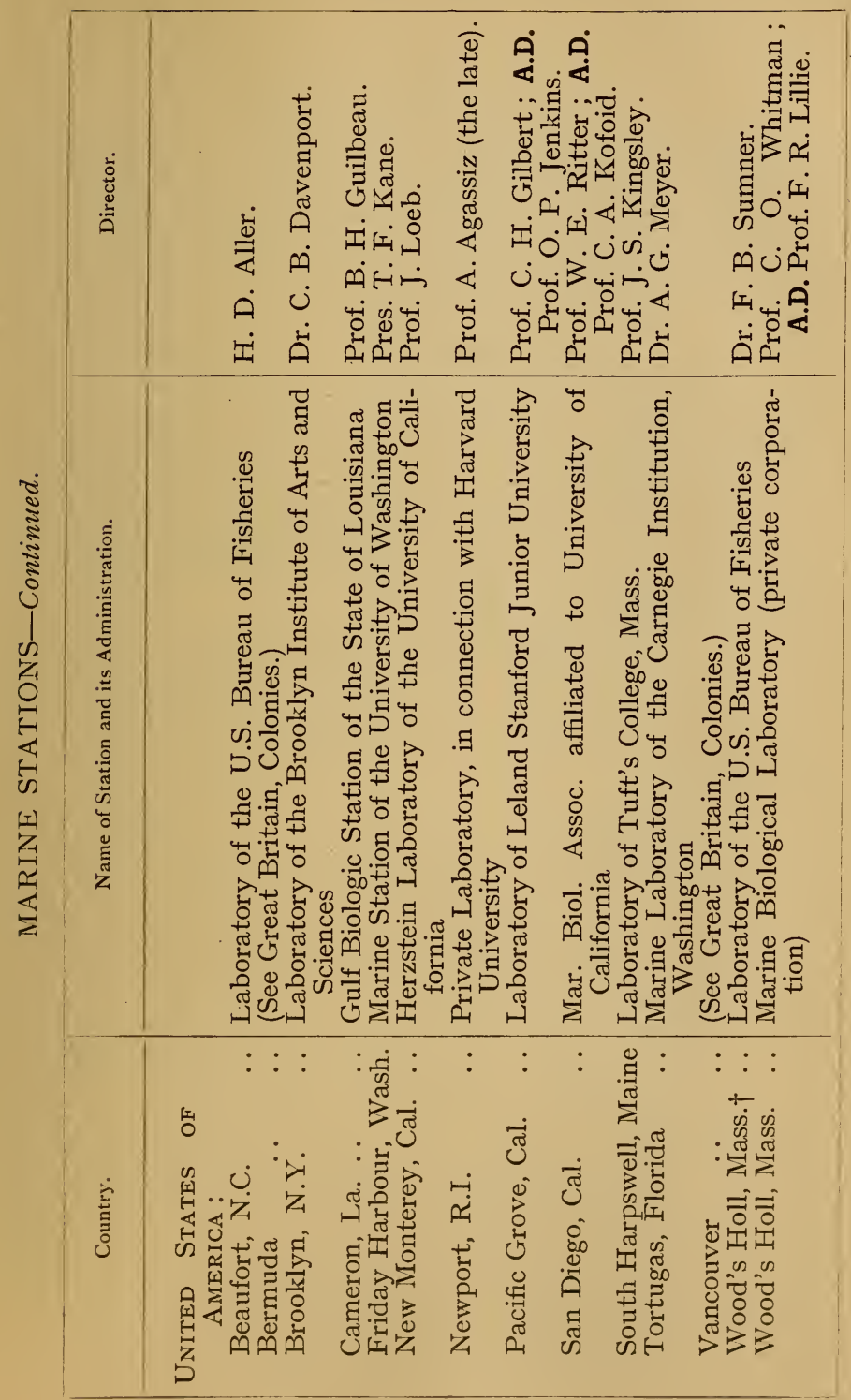




\section{CLASSIFICATION TABLES}

THESE classifications are intended simply as a ready means for the untrained observers to pigeon-hole the forms mentioned in the book. Their aim is practical ; accordingly they do not contain all the latest recondite polysyllables which are to be found in the specialistic memoirs.

\section{ANIMALS.}

Protozoa (One-Celled Animals).

I. Gymnomyxa :

I. Foraminifera :

(I) Imperforata.

(2) Perforata.

2. Radiolaria :

(I) Peripylaria.

(2) Monopylaria.

(3) Tripylaria.

(4) Acantharia.

Astrorhiza, Biloculina, Cornuspira, Lituola, Miliola.

Globigerina, Nodosaria, Nummulina. Orbulina, Pulvinulina, Rotalia, Textularia.

Collozoum, Heliosphæra, Thalassicolla, Eucyrtidium, Stylospira.

Challengeron, Coelodendrum, Conchidium, Euphysetta, Tuscarora. Acanthometra.

II. Corticata :
I. Ciliata.
2. Euflagellata.
3. Cystoflagellata.
4. Dinoflagellata.

\section{Noctiluca.}

Ceratium, Peridinium.

\section{Metazoa (Many-Celled Animals).}

\section{Porifera, or Parazoa (Sponges) :}

I. Calcarea.

2. Myxospongiæ.

3. Hexactinellida.

4. Demospongiæ.

Euplectella (Venus's flower-basket). Hyalonema.

II. Cœlenterata :

I. Hydromedusæ (jellyfish and their fixed hydroids).

2. Siphonophora (jellyfish):

(I) Calyconectæ.

(2) Physonectæ.

(3) Cystonectæ.

(4) Disconectæ.
Diphyes.

Physophora.

Physalia.

Porpita, Velella. 
3. Scyphomedusæ (jelly- Aurelia, Pelagia, Rhizostoma. fish).

4. Anthozoa :

(I) Actiniaria (an- Arachnactis, Minyas. emones).

(2) Alcyonaria (false Alcyonium, Corallium, Gorgonia, Helicorals). opora, Pennatula.

(3) Madreporaria Caryophyllia, Leptopenus, Madrepora. true corals).

5. Ctenophora (jelly-fish). "Beroe, Bolina, Cestus, Pleurobrachia.

III. Turbellaria, or Planaria (flatworms).

IV. Nemertina, or Nemertea.

V. Trematoda (flukes).

VI. Cestoda (tapeworms).

VII. Nematoda (roundworms).

VIII. Sipunculoidea.

IX. Chætopoda (bristle-worms) :

I. Archiannelida.

Polygordius.

2. Polychæta :

(I) Phanerocephala. Amphinome, Autolytus, Aphrodite, Chætopterus, Hermione, Hyalinoecia, Nerine, Palolo, Tomopteris,

(2) Cryptocephala. Sabella, Serpula.

2. Oligochæta (earth: worms).

3. Hirudinea (leeches).

4. Echiuroidea (spoonworms).

5. Rotifera.

X. Crustacea :

I. Cladocera (Branchio- Evadne. poda.

2. Ostracoda.

Conchœcia.

3. Copepoda.

Calanus, Caligus, Sapphirina, Temora.

4. Cirrhipedia (barnacles).

5. Cumacea.

6. Amphipoda.

Cuma.

Caprella, Epimeria, Euthemisto, Phronima.

7. Isopoda.

8. Stomatopoda.

Cirolana, Rocinela, Serolis.

Squilla.

9. Schizopoda.

Io. Decapoda.

Euphausia, Mysis, Nyctiphanes.

(I) Macrura (lob. Acanthephyra, Eryon, Lucifer, Nester group). phrops, Palinurus, Penæus, Sergestes, Willemœsia.

(2) Anomura (her- Callianassa, Catapagurus, Galathea, mit group). Munida, Pagurus.

(3) Brachyura Atelecyclus, Bathynectes, Corystes. (crab group). Cryptochirus, Ebalia, Hapalocarcinus, Homolodromia, Maja, Portunus, Thia. 
XI. Insecta.

XII. Arachnida (spiders, etc.).

XIII. Pycnogonida.

XIV. Mollusca (shellfish) :

I. Gastropoda.

2. Lamellibranchiata.

3. Cephalopoda.

XV. Polyzoa or Bryozoa.

XVI. Brachiopoda (lamp-shells). Terebratula.

XVII. Echinodermata :

I. Holothuroide pangs).

2. Crinoidea (feather- Antedon, Rhizocrinus. stars).

3. Echinoidea (sea- Echinus, Salenia. urchins).

4. Ophiuroidea (brittle- Ophioglypha. stars).

5. Asteroidea (starfish).

XVIII. Chaetognatha.

XIX. Chordata :

I. Urochordata, or Tunicata.

2. Hemichordata.

3. Cephalochordata (lancelets).

4. Cyclostomata (lampreys).

5. Pisces (true fish).

(I) Chondropterygii Raja, Chimæra, Scyllium. (sharks and rays).

(2) Teleostomi (bony fish).

6. Ophidia (snakes).

7. Cetacea (whales) :

(I) Mystacocœti.

(2) Odontocœti.

8. Pinnipedia (seals).
Halobates.

Desis.

Pycnogonun.

Atlanta, Archidoris, Carinaria, Chiton, Clione, Doris, Eolis, Glaucus, Hyalea, Janthina, Styliola.

Lithodomus.

rgonauta, Benthoteuthis, Eledone, Loligo, Nautilus, Octopus, Sepia, Sepiola, Spirula.

Bowerbankia, Cellularia.

Archaster.

Sagitta, Spadella.

Appendicularia, Doliolum, Pyrosoma, Salpa.

Balanoglossus (Enteropneusta).

Amphioxus.

Argyropelecus, Gadus, Gobius, Lepadogaster, Macrura, Regalecus, Scopelus, Scorpæna, Solea, Stomias.

Hydrus, Distira.

Balæna, Balænoptera, Megaptera.

Delphinus, Monodon, Orca, Phocæna, Physeter.

Otaria, Phoca, Trichecus. 


\section{PLANTS \\ Thallophyta.}

I. Myxophyceæ (Cyanophyceæ) :
I. Chroococcaceæ.
2. Nostocaceæ.

II. Chrys monadinæ :

I. Coccolithophoridæ.

III. Dinoflagellata :

I. Peridiniæ.

2. Pyrocystidæ.

IV. Acontæ :
I. Diatomaceæ.

V. Chlorophyceæ :

I. Halosphæraceæ.

2. Ulvaceæ.

3. Cladophoraceæ.

4. Dasycladaceæ.

5. Codiaceæ.

6. Caulerpaceæ.

VI. Phæophyceæ :

I. Ectocarpacex.

2. Encoeliaceæ.

3. Desmarestiaceæ.

4. Ralfsiæ.

5. Laminariaceæ.

6. Cutleriaceæ.

7. Fucaceæ.

8. Dictyotaceaæ.

VII. Rhodophyceæ :

r. Helminthocladiaceæ.

2. Gigartinaceæ.

3. Rhodymeniaceæ.

4. Delesseriaceæ.

5. Rhodomelaceæ.

6. Ceramiaceæ.

7. Grateloupiaceæ.

8. Corallinaceæ.
Calothrix, Lyngbya, Rivularia, Scytonema, Trichodesmium.

Coccosphera, Rhabdosphera.

Ceratium, Peridinium, Ornithocercus. Pyrocystis.

Bacteriastrum, Chætoceras, Coscinodiscus, Pinnularia, Planktoniella, Sceletonema.

Halosphæra.

Enteromorpha, Monostroma, Ulva.

Chætomorpha, Cladospora, Urospora.

Acetabularia, Bornetella, Cymopolia, Neomeris.

Halimeda, Penicillus, Udothea.

Caulerpa.

Ectocarpus.

Asperococcus.

Desmarestia.

Ralfsia.

Ecklonia, Egregia, Eisenia, Laminaria, Lessonia, Macrocystis, Nereocystis, Saccorhiza.

Cutleria.

Ascophyllum, Cystophyllum, Cystoseira, Durvillæa, Fucus, Halidrys, Himanthalia, Hormoseira, Notheia, Pelvetia, Sargassum, Scytothalia, Turbinaria.

Dictyota, Halyseris, Lobospira, Padina, Taonia.

Nemalion.

Gigartin?.

Rhodymenia.

Claudea, Delesseria, Martensia, Van. voo:stia.

Laurencia, Polysiphonia.

Ceramium, Ptilota.

Halymenia.

Amphiroa, Arthrocardia, Corallina, Lithophyllum, Lithothamnion, Melo. besia.

Phanerogamia.

Potamogetonaceæ.

Cymodocea.

Hydrocharidaceæ. Halophila. 


\section{LITERATURE}

ONLY the merest outline of a guide to the literature of the subject can be given here. A general view of terrestrial phenomena, "popularly" written but scientifically sound, is furnished by Dr. H. R. Mill's "Realm of Nature." Further, Wyville Thomson's "Depths of the Sea," Alcock's " Naturalist in Indian Seas," Moseley's " Notes by a Naturalist on H.M.S. Challenger," and "Three Cruises of the Blake," by Agassiz, supply accounts of typical expeditions which are excellent and valuable reading. In Krümmel's "Handbuch der Ozeanographie" we have a textbook of pure oceanography (excluding zoology and botany), written with a thoroughness and wealth of detail truly Teutonic, but suitable only for somewhat advanced students.

From these we have to plunge almost at once into the more technical monographs. As a rule the most valuable are those of the more recent expeditions-the "National" or Plankton Expedition (North Atlantic Ocean), the "Valdivia" (Atlantic and Indian Oceans), the "Siboga" (East Indies), and the "Belgica". (Antarctic) - but many of the "Challenger" Reports are still indispensable. The majority of these are zoological and botanical reports, but there are also volumes dealing with chemistry, physics, meteorology, and equipment. The monographs of the Naples Station are the best guide in some groups. Once the observer has selected 
his subject or his group, he will make a selection from these sources.

Beyond them lies the nebulous myriad of papers scattered in technical journals. For zoologists the best path is the card-catalogue prepared by the "Challenger" Society ; by this means it is possible to find all that has been published on the marine fauna of a region, or even of a lonely island. But many Reports of Expeditions contain very full lists of special papers.

General zoological and botanical textbooks of all grades are only too numerous. For the purposes of the reader whom we have in mind, the volumes of the "Cambridge Natural History" are to be recommended, and on the botanical side Murray's "Introduction to the Study of Seaweeds" will be found helpful. Anatomical and systematic textbooks are beyond the scope of this work.

\section{The Air.}

I. "Instructions for Keeping the Meteorological Log," "Barometric Manual for the Use of Seamen," and other publications of the Meteorological Office.

2. "Atmospheric Circulation": Challenger Report by Dr. A. Buchan.

3. Bartholomew's "Physical Atlas," vol. iii.

4. "Ozeanographie and Maritime Meteorologie": Valdivia Report by Dr. A. Schott.

5. "Hints to Meteorological Observers " : W. Marriott.

6. "Seas and Skies in Many Latitudes": Hon. R. Abercrombie.

7. For special seas, the Pilot, Wind, and Current Charts of the Meteorological Office; also the Admiralty "Pilots," "Sailing Directions," and Charts.

\section{The Water.}

I. "Oceanic Circulation": Challenger Report by Dr. A. Buchan.

2. Numerous "Publications de Circonstance" issued by the Conseil Permanent International pour l'Exploration de la Mer. 
3. "The Norwegian Sea" : B. Helland Hensen and F. Nansen.

4. "Hydrographical Tables" : M. Knudsen.

5. "The Tides and Kindred Phenomena of the United Kingdom " : Sir G. H. Darwin.

See also I., Nos. 3, 4, 7 .

\section{THE SHORE.}

I. "Coral Reefs" : Charles Darwin.

2. "Corals and Coral Islands" : J. D. Dana.

3. "Animal Life" : Carl Semper.

4. "Physical Geography " : F. M. Davis.

5. "Les Dépôts Marins" : L. W. Collet.

6. "Maldive and Laccadive Archipelagoes": Cambridge Univ. Press.

See also I., No. 7 .

IV. The Plants.

I. "Pflanzenleben der Hochsee" : G. Schütt.

2. "Meeresalgen Deutschlands und Oesterreichs": F. Hauck.

3. "Phycologia Britannica" : W. H. Harvey.

4. "Nereis Borealis-americana" : W. H. Harvey.

5. "Nereis Australis" : W. H. Harvey.

6. "Phycologia Australica " : W. H. Harvey.

7. "Marine Algæ of New England" : W. G. Farlow.

8. " Some Aqueous Media for Preserving Algæ " : Setchell and Osterhout, Bot. Gaz., xxi., I 40.

\section{The Floating Animals.}

I. "Planktonkunde": A. Steuer (an admirable book, and the only one which deals with the whole subject).

2. "Nordisches Plankton" : by various authors, for work in the North Atlantic and dependent waters.

3. For special groups the Reports of the Expeditions cited above should be used, and contain references to the previous literature.

\section{The SeA Floor.}

I. "Deep Sea Deposits": Challenger Report, by Murray and Renard.

2. "Grund Proben ": Valdivia Report, by Murray and Philippi.

3. "Report of the Albatross Expedition, I904-1905": A. Agassiz, in Mem. Mus. Comp. Zool., xxxiii.

VII. Animals of the Sea Floor.

I. "Grundzüge der Marinen Tiergeographie" : A. Ortmann.

See also remarks under V., No. 3 . 
X. Fishes.

In addition to the Reports of Expeditions above :

I. "Introduction to the Study of Fishes" : A. Günther (I880).

2. "Cambridge Natural History: Fishes" (I904).

3. "Oceanic Ichthyology": Goode and Bean. This is a compilation dealing with the oceanic fishes of the Atlantic, with numerous figures and full references. In spite of an apparent want of revision, it is probably the most generally useful book because the most comprehensive. The descriptions given must, however, be carefully checked by reference to the earlier authors cited.

4. "British Marine Food Fishes": McIntosh and Masterman.

5. "Marketable Marine Fishes" : J. T. Cunningham.

Of books dealing with the fishes of particular areas we may mention :

I. Great Britain and Ireland : Yarrell (I 859-I860); Couch (I862-I865); and Day (I880-I884).

2. France : Moreau (I882).

3. Scandinavia : Smitt (I893-I895).

4. India : "Fauna of British India : Fishes": Day.

5. North and Central America: "Fishes of North and Middle America" : Jordan and Evermann.

6. Australia: Stead.

For books dealing with the fishes of particular areas, reference should be made to the article "Ichthyology," in " Encyclopædia Britannica," eleventh edition. 


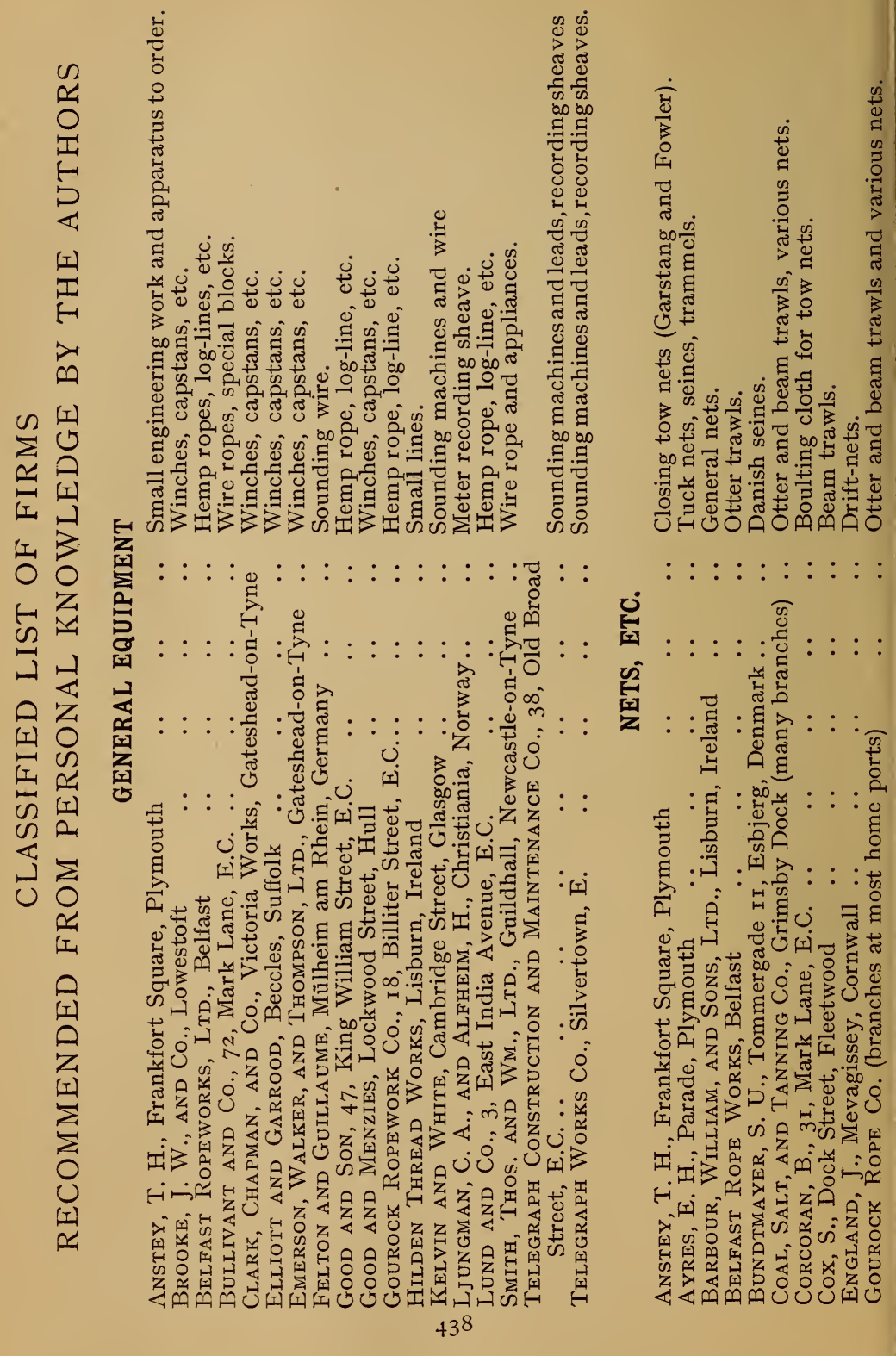




\section{LIST OF FIRMS RECOMMENDED}

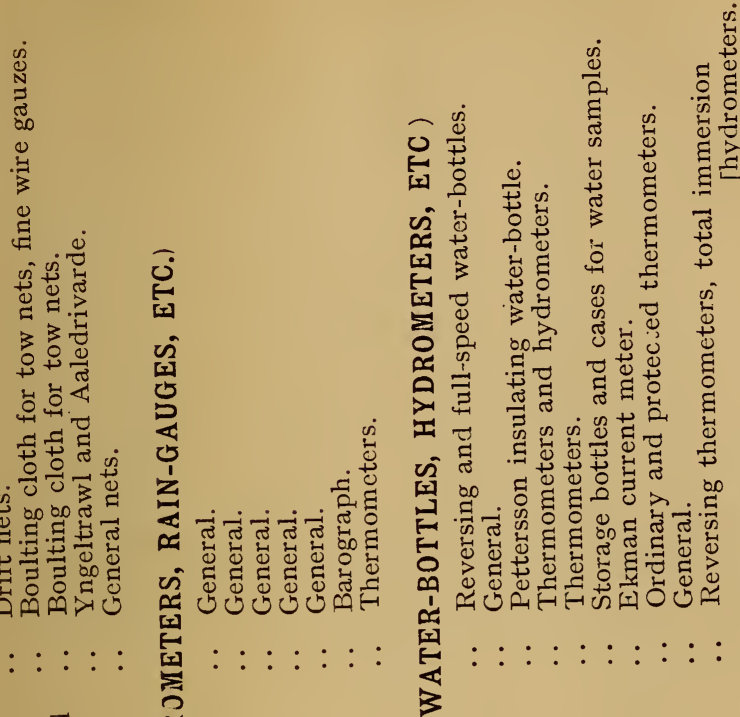

$:$ : $:$ : 蛋 $:::::::$

च ช 華苍范焉 गुण्य द. 氙 री

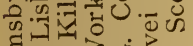

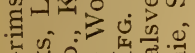

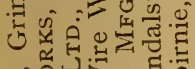

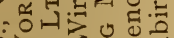

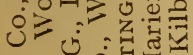
सी

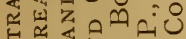

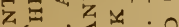

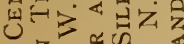
$z$ a $2<$

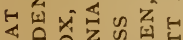

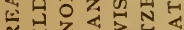

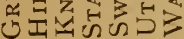

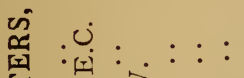

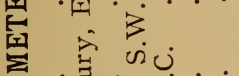

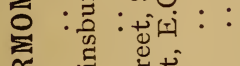

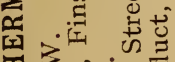

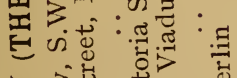

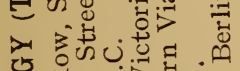

of

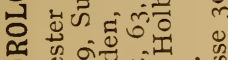

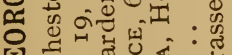

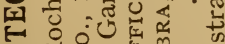

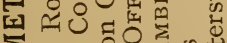

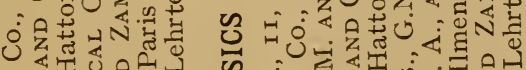

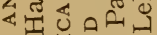
合落:

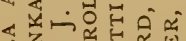

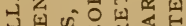

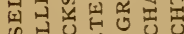
क

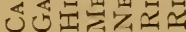
< द

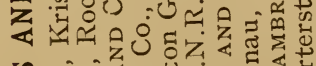

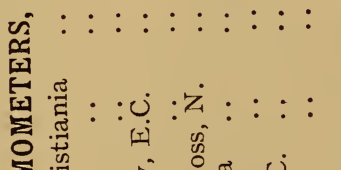

造

跑

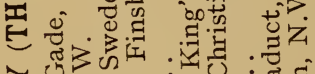
व थ

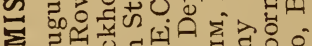
ज्ञ I 0 तु की 0 च 完 a $z<z$. $z z^{2}$

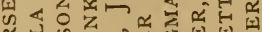
क्य की मी

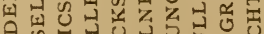

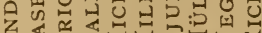

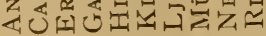
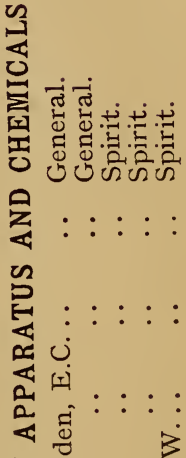

¿

응 ¿ 舟

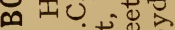

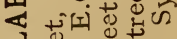
0.

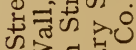
级 등 댕 की

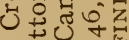

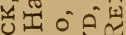
0 붕ํ요 «ن 0 ن

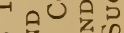
0 药范

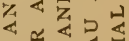

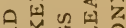

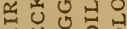
ヘ口ตAO 


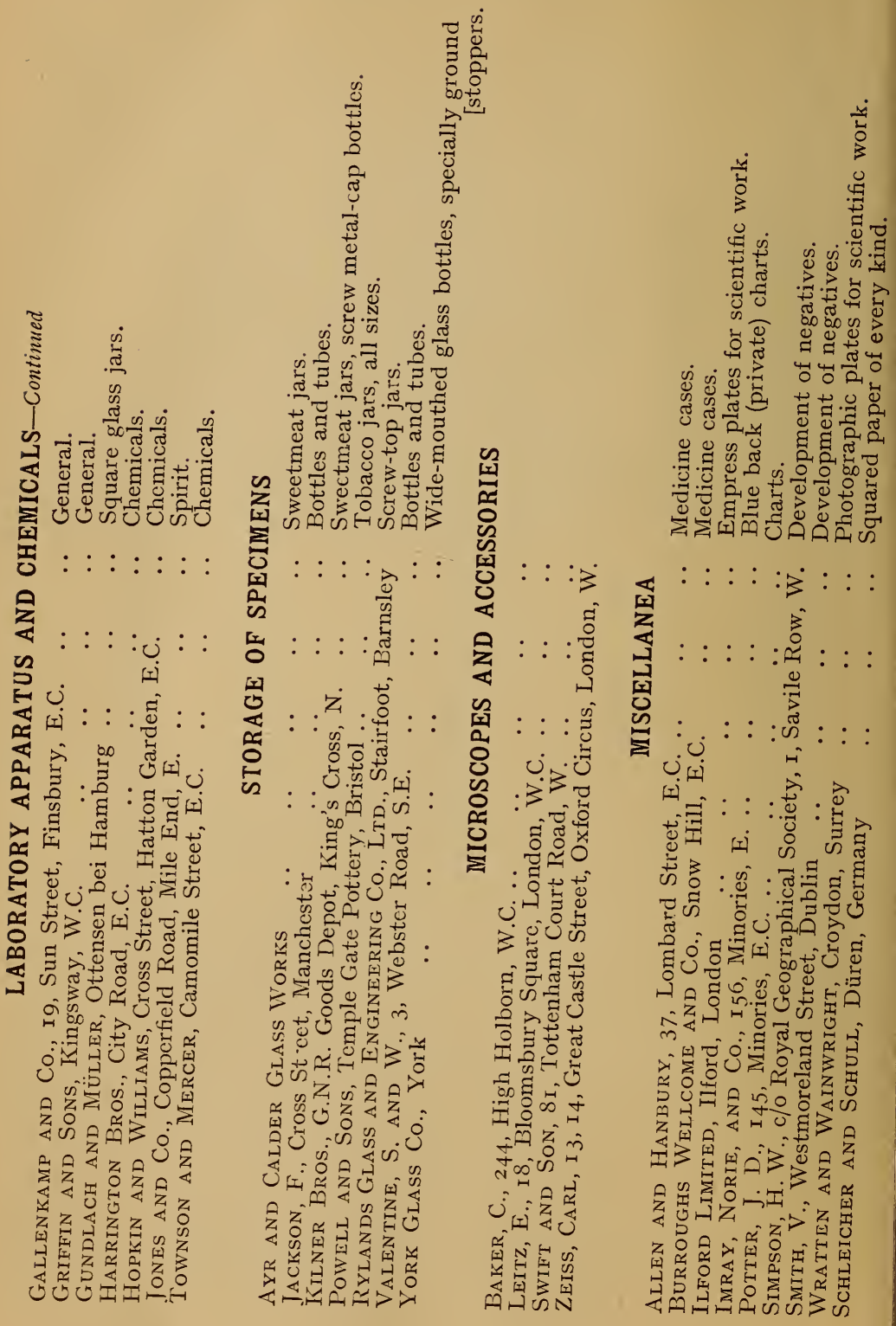




\section{INDEX}

Numerals in thick type refer to the page where a figure is given.

Abyss $=$ the greater depths of the ocean

Abyssal animals, 26I-265

conditions, 228,229

Acanthephyridæ, 264

Acanthometra, I64, 166, 368

Accumulator, 275

Acetabularia, I 35, 140

Achyla, roo

Acorn-shells. See Cirrhipedia

Actiniaria. See Anemones

Agar-agar, I6I

Agarum, I 42

Agassiz trawl. See Trawl

Aglaozonia, I39

Air, Chapter I., I-25

circulation and temperature, 4-I 2

cloud and fog, I 8

instruments, I 2 -I 7

rainfall, I9, 20

special problems, 22-25

upper, 20-22

wind observations, I7

Alaria, I 42

Alcohol as anæsthetic, 36I general use, 352-355 purchase abroad, I Io

Alcyonaria (false corals), 79, 94, 237

Alcyonium, 260, 375

Aldrich Deep, 206

Ambergris, 398

Ammonites, 248

Amphinome, 25 I

Amphioxus, 76,188

Amphipoda bottom, 244

plankton, 178

preservation, 379
Amphirhoa, I 5I

Anæsthetics, I I I, 360, 36I

Anchor, work at, 7I, I98

Anemometer, I7

Anemones of corals, 89-94

of plankton, I 74

preservation, 375

Aneroid, I4

Animals, classification, 430-432

floating, Chapter V., I 62-1 99 collection, I 88-I90, I97I99

description, I63-I 88

distribution, I9I-I96

preservation, $367-382$

sorting and pickling, 284-285

special adaptations, 196

swarms, I96

temperature, I93-I94

vertical movement, I94

of Sea Floor, Chapter VII., $23 I-265$

continental shelf, 233$25 \mathrm{I}$

distribution, 252-26I

deep sea, 26I-265

zones, 23 I-233

Anomura, 245

Antedon, 240,376

Aphrodite, 377

Appendicularia, I 84, 187

Arachnactis, 173, I 75

Archæolithothamnion, I6o

Archaster, 247

Argonauta, I 83, 248

Argyropelecus, 32 I

Arthrocardia, I 5 I

Ascidians. See Urochordata 
Ascophyllum, I 43

Asperococcus, I39

Aspiration psychrometer, 16

Asteroidea. See Starfish

Astrorhiza, 80

Atelecyclus, 260

Atlanta, I 82, 185

Atmosphere, circulation, 4-II daily variation, 22

description, I, 2

pressure, I-I I

temperature, II, I2

upper, $7,20,22$

Atoll, 88, 98, 99

Auricularia of trepangs, 186

Autolytus, I 75

Azores, 84

Bacteriastrum, 118

Baillie sounder, 201, 202

Bait, 74, 75, 329

Balænidæ, 386-39r

Balænopteridæ, 39I-396

Balanoglossus, 76, 100, 188

Balloons for upper currents, 2 I

Barnacles. See Cirrhipedia

Barograph, $\mathrm{I}_{4}$

Barometer, aneroid, I4 mercurial, I3, I4

Barrier reef, 87,89

Bathybius, 205

Bathynectes, 245

Beam trawl. See Trawl

Beaufort's scales, 422, 423

Beluga, 399

Benthoteuthis, 258

Berardius, 399

Bermuda, 85 (bis).

Beroe, I72, I 75, 349, 374

Biloculina clay, 2 I 4

Biological stations, 423-429

Bipinnaria of star-fish, 186

Bipolarity, 257

Black Sea, 226

Blue algæ. See Cyanophyceæ

Bolina, 349, 375

Boreophausia, 395

Bornetella, I 35, 140

Bottle-nose whale, $398, \mathbf{3 8 9}$

Bottles, storage, for animals, $36 I-364$

for water samples, 33 , 34
Bottom deposits. See Deposits

Bougainvillea, 1\%0, $1 \% 1$

Boulder zone, 87

Brachiopoda (lamp - shells), 249

Brachyura, bottom, 245

of plankton, $\mathrm{x} 80$

preservation, 380

Branchiopoda, 244

Brittle-stars larvæ, x 84, 186 of bottom, 237, 246

Brook, Lieutenant, U.S. Navy, 200

Brown algæ. See Phæophyceæ

Bucket for water samples, 34

Ca'aing whale, 384,399

Cables as collectors, 265

Cachalot. See Sperm whale

Calanus, 19\%, 394

Caligus, 17y

Callianassa larva, 181

Calothrix, 134, 136

Calyconectæ, preservation, 372

Canaries, 84

Cape Verde Islands, 84

Caprella, 244, 265

Capstan, steam, 267

Carinaria, I82, 185

Caryophyllia, 375

Catapagurus, 254

Caulerpa, $\mathrm{x}_{35}, \mathrm{x}_{3} 8,140$

Cellularia, 259

Centigrade into Fahrenheit, 420

Cephalochordata. See Amphioxus

Cephalopoda. See Cuttle-fish

Ceratium, I20, I2I, 122, I64

Cetacea. See Whales

Cestoda, preservation, 378,379

Cestus, I 75, 199

Chætoceras, I I 7, 119

Chætognatha, I 75, 176

Chætomorpha, I 26, I 35, 136

Chætopoda (bristle-worms), I 75 , 240, 24I, 250, 251 larvæ, 176 preservation, 376,377

Chætopterus, $176,24 \mathrm{I}$

Challenger, H.M.S., v dredge rope, $272 \mathrm{n}$. sample deposit, $2 \mathrm{I}_{5}$ 


\section{INDEX}

Challenger,H.M.S., soundings, 20I Coral, depth, 94

Challenger Society's "regions," 255, Chart VIII.

Challengeron, 167

Chemicals for preservation, $347^{-}$ $36 \mathrm{I}$

Chimæra egg capsule, 317

Chiton, 247, 258

Chloretone, 36I

Chlorophyceæ (green algæ), I 6 , I 2 I, I27, I 35

Chondrites, 2 ro

Christmas Island, 85

Chromatophores, II 7

Chromic acid, 359

Chromo-acetic acid, 359

Ciliata, I64

Cirolana, $19 y$

Cirrhipedia, I78, 244

Nauplius, 181

preservation, 379

Cladocarpus, 238

Cladocera, 178

Cladophora, I26, I35, 136

Claudea, I 26, I 52, 155

Clay, red. See Red clay

Clione, 185

Closed seas, $63,226,227$

Cloud observations, I9

Cocaine, 360

Coccolithophoridæ, 124

Coccosphæra, II4, I24, 125, 220

Coelodendrum, 167

Cœlenterata of bottom, 235239.

See also Hydroids, Jellyfish

Collozoum, $\mathrm{I}_{4}$

Conchidium, I67

Conchœcia, 17y, I 78

Constantinea, I 52

Continental shelf, $207,227,23$ I 233

animals of, $234^{-261}$

slope, 208, 227, 23I, 233

Continents, former connections, 83

instability, 228-230

Copepoda, I 78, 244

preservation, 379

Coprolitic mud, 2 I 4

Coral anemones, 89-94, 375

mud, I00, 226

oolite and breccia, 86

rate of growth, 92

reefs and islands, 82-IO5

composition, 94

disintegration, roo, IO2

Corallina, I 27 , I $5 \mathrm{I}$

theories, 96 et seq.

Corallinaceæ, I 5 O-I 52

Coralline Zone, 231

Corallium, 237

Coronæ, 23

Coronula, 395

Corrosive sublimate, III, 356$35^{8}, 368$

Corystes, 260

Coscinodiscus, 220

Cosmic dust, 2 ro, 218, 230

Cretaceous period, land of, 83

Crinoidea. See Sea-lilies

Crustacea, collection, 74

moults, I 80-I 82

of bottom, 24 I-246

of deep sea, $26_{3}, 26_{4}$

of plankton, I78-I 82

preservation. 379,380

Cryptochirus, 78

Ctenophora, I 75, 349, 374

Cumacea, 244

Currents, effect on animals, 252

on plants, I3 I

general account, 57-64

meters, 53-57, 63-64

midwater, 63

Cutleria, I39

Cuttle-fish, I 83, 248, 249 as "sea-serpents," 4II-4I3, in rocks, 78

Cyanophyceæ (blue algæ, or Myxophyceæ), I 6, I24, I27, I 34

Cyclonic storms, 9-I I

Cymodocea, 73

Cymopolia, 140

Cystonectæ, preservation, 373

Cystophora, 404

Cystophyllum, I43

Cystoseira, I 43

Darkness. See Light

Darwin, theory of coral reefs, 96 
Decapoda preservation, 380

Deeps, 206

Deep-sea animals, 26I-265 conditions, 228, 229 dredging and trawling, 27I277

fish, 32I, 324 sounding, 277-279

Delesseria, I 26, I 52

Delphinapterus, 389, 399

Delphinidæ, 399-402

Delphinus, 4 OI

Demersal fish eggs, 3 I $6,31 \%$, 3 I 8 , 322

Deposition, rate of, 209, 229

Deposits, animals in, 286,287 chart symbols, $42 \mathrm{I}$ classification, 2 I 3 collection, 203-205

description, 208-226 errors of examination, 2I 4 form for description, 2 I 5 on continental border, 227 , 228

radium in, 230

samples of, 287 .

thickness, 209

Depth, animal plankton, I92 ocean, 205-208

Desis, 79 plants, I 29

Desmarestia, I26

Deviation of winds, 5

Diatoms, I I6-II 9 in deposits, $2 \mathrm{I} 2$ ooze, 2I3, 2I 4, 2I7, 2I9, $220,222,229$

Dictyoneuron, I 42

Dictyota, I 43,145

Dictyotaceæ, I 38, I 42, I 43

Doldrums, 6

Dines' anemometer, I7

Diphyes, 172

Disconectæ, preservation, 373

Distira, 4 Io

Distribution of bottom animals, $252-264$
of floating animals, I9I-
I 96 of plants, I32, I33

Diurnal variation, 22, 32

Doliolum, life-history, $186, \mathbf{1 8 \%}$, I 88
Doliolum, Phromina in, 180 preservation, $38 \mathrm{I}$

Dorididæ, 248

Dredges, 289-292, 296 for plants, I 53 shooting and towing, 292295

Dredging, Chapter IX., 289295 deep-sea, 27I-277 shallow, $280-28 \mathrm{I}$ sorting catch, 285,286

Drift currents, 57 net, $336,337,339$

Durvillea, I 43, 149

Eared seals, 407-409

Ebalia, 245

Echinodermata, bottom, 237, 240 deep-sea, 263 larvæ, 186 plankton, I 84

Echinoidea. See Sea-urchins

Echiuroidea, 240

Ecklonia, I 26, I32, 140, I 42

Ectocarpus, I 38

Egregia, I 42, 144

Eisenia, I 42

Ekman's correction table for thermometers, 43

current meter, 53-56, 55, I 02

Eledone, 259

Elevation of land, 67-69

Enteromorpha, I3I, I35

Enteropneusta. See Balanoglossus

Entomostraca, 244

Eolididæ, 248

Eolis, 258

Ephyra, I69, 1\%1

Epimeria, 254

Erignathus, 404

Eryonidæ, 264

Eucheuma, I6I

Eucyrtidium, 166

Eumetopias, 408

Euphausiacea, 245, 395

Euphysa, $1 \% 0$

Euphysetta, 16y

Euthemisto, $19 y$

Evadne, 1\%\%, I7s 
Faeroe Channel, 63

Fahrenheit into Centigrade, 420 Falcon Island, Tonga, ro3

Fathoms into metres, 4 r 9

Feather-stars. See Sea-lilies

Fcrtilization of fish eggs, 316 , 317

Fiji, 83, 85, 88, 98

Finner whale. See Rorqual

Fish, artificial fertilization, 3I6, 317

eggs and young, 316-320, 322,323

external characters, 308

habits, etc., 3I4-3I6

measurement, 307-3 I I

nests, 3 I 8

oceanic, 320-324

preservation, $324,325,382$

sea collection, 3I 3, 3I 4

sexual characters, 3 I 5

shore collection, etc., 74 et seq., 3ro-3r 2

Fishes and Fishing, Chapter X., 306-343

Fishing gear, 326-343

hand lines, 327-330

long lines, 330-333

nets, $334-343$

Fixation of cells, 345

Fixed plants. See Plants, fixed

Flagellata, r 64

Flemming's fluid, 359

Floating plants. See Plants, floating

Florideæ. See Rhodophyceæ

Fog observations, I 8 scale, 423

Foraminifera, $79, \mathbf{8 0}, \mathbf{8 1}, 95, \mathrm{r} 63$ in deposits, 2 I 2

Forbes' zones of depth, 23 I

Formaldehyde, 347

Formalin for animals, I I I, 285 , $347-35^{2}$

for plants, II6, I 57

spirit, 356

Formic aldehyde. See Formaldehyde

Formol. See Formalin alcohol, 356

Fringing reef, 87

Fucaceæ, r 38, I 43, r 58, r6 r

Fucus, I 33, I 43, 148
Gadoids (cod tribe), 321

Galatheidæ, 245

Gases of sea water, analysis, 32

Gastropoda, bottom, 247,248

plankton, r $82, \mathrm{I} 85$

preservation, $38 \mathrm{I}$

Geographic mile, 42 I

Gigartina, 147

Gill net, 335

Glauconite, 2 I I

Glaucus, 185

Globigerina, 165, 222

ooze, 2I3, 2I7, 220, 22 [,

223, 229

analysis of, 2 I 5,2 I 6

Globiocephalus, 384, 399

Gnathophausia, 179

Goby eggs, 31\%, 318, 322

Gondwanaland, 83

Gorgonia, 239, 375

Gradient, isobaric, 6

Grampus, 399

Grease, sheaves, 277 wire ropes, 274,279

Green Algæ. See Chlorophyceæ ray, 24

Greenland whale, $385,387,388$, 389,390

Greensand, 2I I, 225, 228

Halichœrus, 404

Halidrys, I 43

Halimeda, 94, r 35, 136, 138

Halo, 23, 24

Halobates, 79, 185

Halophila, 73

Halosphæra, I 2 r, 123

Halymenia, r 47 , I 50

Halyseris, I 43

Hand lines, 327-330

Hapalocarcinus, 78

Hapteres, I 27

Harpoon, 388

Hawaii, 84

Heliopora, roo

Hemichordata, I 88

Herbarium, preservation for, I 57 -I $6 \mathrm{I}$

Hermann's solution, 360

Hermione, 377

Heteropoda in deposits, 220, 22 I

Hildenbrandtia, I26, I33

Himanthalia, r 43,149 
Histriophoca, 405

Holothuroidea. See Trepangs

Holtenia, 236

Homolodromiidæ, 264

Homothermic layer of air, 20

Hornogonia, I 34

Hormosira, I 43, 149

Horse latitudes, 7

Humpback whale, $384,394.396$

Hurricane, Io

Hyalea, 185

Hyalinœcia, 24I, 250

Hydroids, I68-I 7 I, 235 preservation, 369

Hydromedusæ, I68, I69 preservation, 369-37I

Hydrometer, 52, 53

Hydrophidæ, 409, 4IO

Hydrus, 79, 4 IO

Hyperoodon, 398, 389

Ianthina, I 82

Ice-borne material, 209, 2I I, 2 I 2

Inia, 402

Insects, I 84

Insulating water-bottle, $37-42$

Iridæa, I 47

Islands, classification, 82

Isobar, a line drawn through points of similar atmospheric pressure

Isobaric charts, 5 gradients, 6 , Io, I I

Isohaline, a line drawn through points of similar saltness

Isohalines, 30

Isopoda of bottom, 244 of plankton, I 80 preservation, 379

Isotherm, a line drawn through points of similar temperature

Isothermal layer of air, 20

Jars for storage, 364,365

Jelly-fish, I68-I 74 preservation, 369-375

Kelp. See Laminariæ

Kelvin's sounder, 28

Killer whale, 399

Killing animals, methods, 345

Kites, meteorological, 20, 2 I

Kofoid's water-bottle, I I6
Kogia, 398

Krakatoa, dust from, 2 I

Krümmel on Sargassum, I 46 , I 47

Labels, 366, 367, 4I 5, 4I 8

Laboratory, yacht's, 283-288

Lagena, 8I

Lagenorhynchus, 4 OI

Lagoon, 87 et seq., I оo et seq.

Lamellibranchia, bottom, 248 plankton, I 82

preservation, $38 \mathrm{I}$

Laminariæ, I3I, I39, I42, I58, I6I

Laminarian zone, 23I, 232

Land breeze, 8 study of, 66-69

Laurencia, I 52

Le Blanc sounder, 277, 279

Lepadogaster, 31 8

Leptonyx, 406

Leptopenus, $23 \%$

Lessonia, I 42, 144

Light, effect on plants, I28, I29, 234 penetration of, I 29, 228, 234

Lines. See Fishing

Line squall, 9

Lithodomus, 78

Lithophyllum, I 5 I, 160

Lithothamnium, 73, 94, 95, 127, I 5 I, I $52,160,257$

Littoral deposits, $2 \mathrm{I} 3$ region, I 28,129 zone, 23I, 232. See also Shore

Lobodon, 406

Lobospira, I 43

Lobsters, 245

Logs, 4I 5-4I 9

Lohmann's pumping method, I I 5

Loligo, 248

Long lines, 33o-333

Lucas sounding machine, 203, $277,278,281,282$

Lucifer, 183

Luminosity of animals, 262, 264

Lyngbya, I 34

Macrocystis, 140, I 42

Macrorhinus, 406 
Macrura (Crustacea) of bottom, 245 of plankton, I 80

Macruridæ (fish), 32 I

Madrepora, 90

Madreporaria, 237. See Coral

Manganese nodules, 2II, 2 I4, 218

Marine stations, 423-429

Martensia, I 52

Mauritius, 8.4

Maury, Admiral, 3

Mean sphere level, $227 \mathrm{n}$.

Medicine, I07

Mediterranean, a closed sea, 63

Medusæ, I 68-I 72

Megalopa larva, 181, I 82

Megaptera, 384, 394-396

Melobesia, I 5 I

Menthol, 36I

Mercury bichloride, 356-358

Meridians, foreign, 42 I

Mesoplodon, 399

Metazoa, I63

Meteorological Office, British, 3 German and American, 4 instruments, I2-I 7, I9, 21

Meteorology, Chapter I. See also Atmosphere, Wind, etc.

Methylated spirit. See Alcohol

Metres into fathoms, 4I9

Metric conversions, 4I9, 240

Microscope, 285

Midwater currents, 63 study, 192

trawl, 34I, 342

Miles, nautic and geographic, $42 \mathrm{I}$

Miliolina, 80

Millepora, 91, I оo, 93

Mitraria, 176

Mollusca, bottom, 247-249 plankton, 182,183 preservation, $38 \mathrm{I}$ shore collection, 74 et seq

Monachus, 405

Monodon, 389,400

Monostroma, I26, I35

Monsoon, 8

Monthly Pilot Charts, 4

Mud line, 227

Muds, $213,224-226$

Mysidacea, 245
Mystacceti (whalebone whales),

$386-396$
Myxophyceæ. See Cyanophyceæ

Nansen-Pettersson water-bottle, $37-42,38$

Nansen's sounder, 204

Narwhal. See Monodon

Nauplius, I 80,181, I $S_{2}$

Nautical mile, 42 I

Nautilus, I 83 paper. See Argonauta pearly, I83, 248

Nemalion, I 50

Nematoda, preservation, 378 , 379

Nemertina, $24^{\circ}$

Neobalæna, 39 I

Neomeris, I 35

Nephrops, 260

Nereidæ, I 75

Nereocystis, I 42, 145

Nerine, 176

Neritic plankton, I9I

Nero Deep, 206

Nets. See Tow net, Trawl, Dredge

fishing, dip, 334, 335

drift, $336,337,339$

gill, 335

hand, 333, 334

seine, 339-34 I

trammel, 336-338

young fish, 34I, 342, 343

Nipper, 275, 276

Noctiluca, I64, 167

Nodosaria, 80

Notheia, I 43

Notochord, I84

Nudibranchia, bottom, $24^{8}$

preservation, 38I

Nyctiphanes, 179, 227

Obelia, 171

Oceanic circulation, 57-64

fishes, 320-324

plankton, I9I

Oceans, depth of, 205-208

permanence of, 229

Octopus. See Cuttle-fish

Odometer, 276, 28I 
Odontoceti, 396-402

Oiling sheaves, 277 wire ropes, 274, 279

Ommatophora, 406

Ophiura, 246

Ophiuroidea. See Brittle-stars

Orbulina ooze, $2 \mathrm{I}_{4}$

Orca, 399

Ornithocercus, 122

Ortmann's coastal regions, 253

Osmerus, 395

Osmic acid, 360

Ostracoda of bottom, 244 of plankton, 178 preservation, 379

Otariidæ, 407-409

Otter trawl. See Trawl midwater, 34I, 342

Oudemans on the sea-serpent, 4 I 3

Outfit, tropical, I05-II2, I 56

Oyster. larva, 185

Padina, I 43

Paguridæ, 245

Palinurus larva, I 82

Palolo, 24 I

Pelagia, 172

Pelagic (high-sea or oceanic) deposits, 2I 3, 2I6-223

fish eggs, $316-3$ I 8,322

Pelamys, 4IO

Pelvetia, I 43

Penæus larvæ, 181

Peneidæ, 264

Peneroplis, 80

Penicillus, 135

Pennatula, 239

Perforating algæ, I 35

Peridiniales, I I6, I 20, I 2 I

Peridinium, 123, I64

Petersen's young-fish net, 34I343

Phæophyceæ, I 27, I3S

Phæosporæ, I 38

Phialidium, $1 \% 0$

Phocidæ, 403-406

Phosphorescence. See Luminosity

Photographic apparatus, Io8

Phronima, 19\%, I 78

Phyllophora, I 33

Phyllosoma, I82, 183
Physalia, 172, I 74, 373

Physeter. See Sperm whale

Physonectæ, preservation, 372

Phytoplankton. See Plants, floating

Piano-wire, 277

Picric acid, I I I , 358, 359

Picroformol, 359

Pillsbury meter, 64

Pilot charts, meteorological, 4

Pinnipedia, 402-409

Pinnularia, I I9

Planaria, 240

Plankton, animal. See Animals, floating

plant. See Plants, floating as food, 163

Planktoniella, 118

Plants, Chapter IV., II3-I6I

classification, 433

fixed, I 26-I 6I collection, I $52, \quad$ I $_{53}$, I 56, I 57 distribution, I 32 economic utility, I6I environment, I 28-I 32 orders of, 127 preservation, I 57-I6I shore regions, 128

floating, I I $3-\mathbf{I} 25$ collection, I I 4-I I 6 preservation, I I 6

Platanista, 402

Pleurobrachia, 173, I 75, 349, 374

Pluteus larvæ, $\mathbf{1 8 6}$

Pollicipes, 78

Polychæta. See Chætopoda

Polygordius, $\mathbf{1}^{176}$

Polysiphonia, I 26, I 50, I 52, 154

Polystomella, 8I

Polyzoa, 94

bottom, 249

plankton, I 84,185

preservation, 380

Pontoporeia, 402

Porcupine, H.M.S., dredge, 289 ,

296

Porifera. See Sponges

Porphyra, I 26

Porpita, 173, 373

Porpoises, 400

Portunus, 245

Postelsia, I 42 
Prawns, 245

Preservation, Chapter XI., 344382

at sea, $284-287$

chemicals, $347-36 \mathrm{I}$

deposits, 204, 205

fish, 324,325

fixed plants, I 57-I6I

floating plants, I I 6, I 24, I 25

methods, 367-382

shore animals, I IO-II 2

Press for plants, $\mathbf{1 6 0}$

Pressure of air. See Atmospheric pressure

Protozoa, I63 preservation, 368

Psychrometer, I 6

Pteropods, I82, 185

in deposits, 212

ooze, 2 I3, 22I, 223, 229

Ptilota, I 52

Pumice, 2IO, $2 \mathrm{I}_{4}$

Pumping of barometer, I3, I4

Pumps for plankton, II 5

Pycnogonida, 78, 246, 247

Pyknometer, 53

Pyrocystales, I I6, I 2 I

Pyrocystis, I2 I, 125

Pyrosoma, I86, 18\%, 38 I

Quartz, 224, 228, 229

Rachianectes, 396

Radiolaria, 164 in deposits, 212

ooze, 2I3, 2I 4, 2I 7, 2I9, 229

Rain, effect on animals, 65, 195

Rainbow, 23

Rainfall, I9

Ralfsia, I 26, I39

Ray eggs, 316

Recording sheave, $276,277,28 \mathrm{I}$

Red algæ. See Rhodophyceæ

Red clay, 2II, 2I3, 2I6-2I9, 230

Regalecus, 4I I

Regions of distribution, 253, 255. Chart VIII.

Réunion, 84

Rhabdosphæra, II 4, I24, 125, 220

Rhizocrinus, 250

Rhizostoma, $\mathbf{1 7 1}$

Rhodomelaceæ, I $_{50}$
Rhodophyceæ, I 27, I 47, I50

Rhodymenia, I 52, 155, I6I

Right whales. See Balænidæ

Rivularia, I 34

Rocinela, 254

Rock collection, 66 pool, 72

Rodriguez, 84

Rope. See Wire rope hemp, $272 \mathrm{n}$.

Rorqual, 385, 39I-394

Ross, Sir James, 200

Rotifera, I 75

Sabella, 24I

Saccorhiza, I 42, 145

Sagitta, 176

St. Elmo's fire, 25

Salenia, 242

Salinity, 29-3I, 52, 234 effect on plankton, 192 on plants, 130

Salps, I 84 , I $86, \mathbf{1 8 7}, \mathbf{1} 88,38$ I

Samoa, 84

Sapphirina, 197, I 78

Sargassum, I 43, I46, I47, 148, 149

Scalpellum, 218, 244

Sceletonema, 118

Schizopoda, 180, 245

Scopelidæ, 32I

Scorpænidæ, 32 I

Scyllium, egg capsule, 317

Scyphomedusæ, I 68- 772 preservation, 373,374

Scytonema, I34

Scytothalia, I 43

Seals, 402-409

Sea anemones. See Anemones breeze, 8

cucumbers. See Trepangs

Floor, Chapter VI., 200-230 deposits, 208-230 depth, 205-208 sounding, 200-205 See also Deposits

level, why meteorological data reduced to, 2

lilies, $240,250,376$ larvæ, $\mathbf{I} 84$

lions, 408

snakes, 79, 409, 410

urchins larvæ, I 84, 186 
Sea Urchins, bottom, 237, 240, 242 preservation, 376

Sea water. See Water weeds. See Plants

Sean. See Seine

"Sea-serpents," 409-4I4

Seine net, 339-34 I

Sepia, 248

Sepiola, 248

Sergestidæ, I8o, 183

Serolis, 252

Serpula, 251

Setchell on preserving plants, I 52, I 53

Seychelles, 83

Shark eggs, 3 I 6 teeth in deposits, 2I 4,2 I 8

Shore, Chapter III., 65-II 2 collecting, 65-82, 310-3 I 2 gear, IO9-I I 2

fishes, 3 IO-3I3

Shrimps, 245

Shrimp trawl. See Trawl

Siboga, H.Neth.M.S., accumulator, 275

sounder, 279

Sieves, 204, 205, 286, 287

Sigsbee sounder, 277, 279

Siphoneæ, I35

Siphonophora, I 74

preservation, 372,373

Sipunculoidea, 240

Snappers for deposits, $2 \mathrm{O}_{4}, 282$

Sole larva, 323

Sotalia, 4OI, 402

Sounding, 20I-203, 277-279, 28I, 282

machines, 277, 28I, 282

Spadella, ${ }^{\nabla} \mathbf{1 7} 6$

Specific gravity, 30, 52

Spermaceti, 397

Sperm whale, $385,396-398$

Sphærococcus, I6I

Spirit. See Alcohol

Spirula, I83

Splachnidium, I 26

Sponges, 235

Squalls, 9

preservation, 368,369

Squamariaceæ, 73

Squid. See Cuttle-fish

Squilla, 179, 181, 245

Starfish, bottom, $237,240,247$
Starfish, larvæ, I 84, 186

preservation, 375

Steam hauling gear, 266-27I

Stenorhynchus (seal), 406

Stomatopoda of plankton, I80I 82

Stomiatidæ, $32 \mathrm{I}$

Storage bottles for water samples, 33

of specimens, $287,288,36 \mathrm{I}$ 367

Storms, 9-I I

Stream currents, 57

Styliola, 185

Stylospira, 166

Sublittoral region, I28, I 29

Subsidence, 67-69, 96, 97

Sunlight, penetration of water, 32

Sun pillar, 24

Surface samples of water, $34,5 \mathrm{I}$

Surging of barometer, I3, I 4

Swabs or tangles, 70, $7 \mathrm{I}$, 29I

Syllidæ, I75

Tahiti, 84

Tangles or swabs, $70,7 \mathrm{I}, 29 \mathrm{I}$

Tanks for storage, I II, 287, 288

Taonia, I43

Telegraph cables, animals on, 265

Teleostei (bony fishes),

Temora, $17 y$ eggs, 316,317

Temperature, air, II, I2, 22 deep-sea, 262 effect on plants, I3I, I32

on animals, I9I-I93, 252

water, 31, 32, 62

Terebratula, 259

Terrigenous deposits, 2Io, 2I 3 , 224-226

Textularia, 8I

Thalassicolla, I64

Thallus, 127

Thermograph, I6

Thermometer, air, I 5-I 7

water, $35-37$

corrections for, 42,43 , 46

errors, $35,36,44,46,49$

insulating, 50 
Thermometer, water, maximum and minimum, 45, 49, $297 \mathrm{n}$.

reversing, 42-48, 45

Thermometric scale conversion, 4I 9,420

Thermostat, 53

Thia larva, 181

Tide, effect on shore animals, 66 gauges, 64

Tomopteris, I 75, 176

Tornado, 9

Tow net, closing, I 92, I95

on dredge, 29I

on trawl, 298

open, I88-I90, I93

standard, I94, I95, I99 treatment, I 55, I 89

Traces for fishing lines, 327,328

Trade winds, 7

Trammel net, $336-338$

Trawl, Agassiz, 296, 301-302 beam, 295-30I, 2)y midwater, 34I, 342 otter, 302-305

Trawling, 295-305 deep-sea, 27 I-277 shallow, $28 \mathrm{O}-28 \mathrm{I}$ sorting catch, 285,286

Trematoda, preservation, 378 , 379

Trepangs, 227, 240, 243

collection, 74 , 100

larvæ, I84, 186

preservation, 376

Trichechidæ, 406, 407

Trichodesmium, 123, I24

Trichogyne, I 50

Trochammina, 8I

Tropical outfit, I05-I I2, I 56

Tuck seine. See Seine

Tunicata. See Urochordata

Turbinaria, I 43

Tuscarora, 16\%

Typhoon, Io

Udothea, I 35, 139

Ulva, I 26, I 35,136

Upwelling, a movement of deeper water to or towards the surface

cause of, 62
Upwelling, effect on atmospheric temperature, 12

Urochordata, I 84, 249, 25I

preservation, $3^{81}$

Urospora, I35

Vanvoorstia, I26

Velella, 173, I 74, 373

Veliger larva, I 82, 185

Vertebralina, 8I

Volcanic deposits, 2 Io, 2 I I islands, 83,208

mud, 2I 3,225

Volcanoes, submarine, IO3

Walrus, 406, 407

Water, Chapter II., 26-64

bottle, how to work, 50, 5I insulating, $37-42$

Kofoid's, for wateri and plankton, I 6

reversing, $42 \mathrm{n} ., 4^{8}$

bucket for samples, 34

chemical and physical work, $5^{2}$

composition, 29

general circulation, 57-64

observations needed, 28

source of bottom, 62

storage bottles for samples, 33,34

temperature, 3I, 32

uniform conditions at great depths, 27

Waterspout, 9, 23

Waves, angle of wind impact, 22 height measurable by barometer, I 5

Waxing corks and stoppers, 288 Weather, effect on floating animals, 195 on shore animals, 65,66 scale, 422

Whales, 383-402 ear-bones in deposits, 214

Whaling stations and returns, 392, 393

White whale, $\mathbf{3 8 9}, 399$

Wilemœsia, 256

Winch, steam, 269

Wind, 5-9 angle of impact, 22 deviation of, 5 
Wind observations, $\mathbf{I}_{7}$

scale, 422

Wire rope, dredging and trawling, $271-274$

greasing, 277,279 sounding, 277,278 tow nets, I9o, 279 water bottles, 50,201

Worms, of plankton, 175 shore collection, 77 See also Chætopoda, etc.

Wyville Thomson Ridge, $208 \mathrm{n}$.

Yacht deep-sea work, 27I-28o Equipment, Chapter VIII. 266-288
Yacht handling, 292-295, 300, 304,305

laboratory, etc., $283-288$ shallow work, $280-283$ steam haulage, 266-27I

Young fish net, 34I, 342

Yngel-trawl, 34I, 342

\section{Zalophus, 408}

Zeuglodon, 4I 4

Ziphioid whales, 398, 399

Zoëa larva, 181, I 82

Zoological stations, 423-429

Zooplankton. See Animals, floating

Zostera, I 26 


\section{PHOTOGRAPHIC MATERIALS FOR SCIENTIFIC WORK}

WRATTEN \& WAINRIGHT, LTD., manufacture photographic Dry Plates and Colour Filters for all purposes.

Ordinary Plates, renowned for the past 35 years;

Colour Sensitive Plates, including the famous

"Wratten Panchromatic," the most colour sensitive plate in the world; Lantern Plates, on which it is easy to obtain a variety of tones; Process Plates, X-Ray Plates, Special Plates for Microscopy, Spectroscopy, and other scientific purposes ; Colour Filters for use as Orthocromatic Screens, Contrast and Compensating Screens; Tricolour Filters; Filters for Safelights, and every purpose for which filters are required.

Send for our Latest Descriptive Price List for explanatory account of our manufactures

\section{WRATTEN AND WAINWRIGHT, LTD. CROYDON, ENGLAND \\ OLDEST ESTABLISHED DRY PLATE MAKERS IN THE WORLD}

\section{MARINE}

\section{BIOLOGICAL ASSOCIATION OF THE UNITED KINGDOM}

Dredges, trawls, plankton-nets, and other collecting apparatus supplied ; also living and preserved specimens of marine animals and plants for research, museum, and teaching work.

For Prices and other particulars, as well as for Terms of Membership of the Association, apply to

THE DIRECTOR, The Laboratory, GITADEL HILL PL YMOUTH 


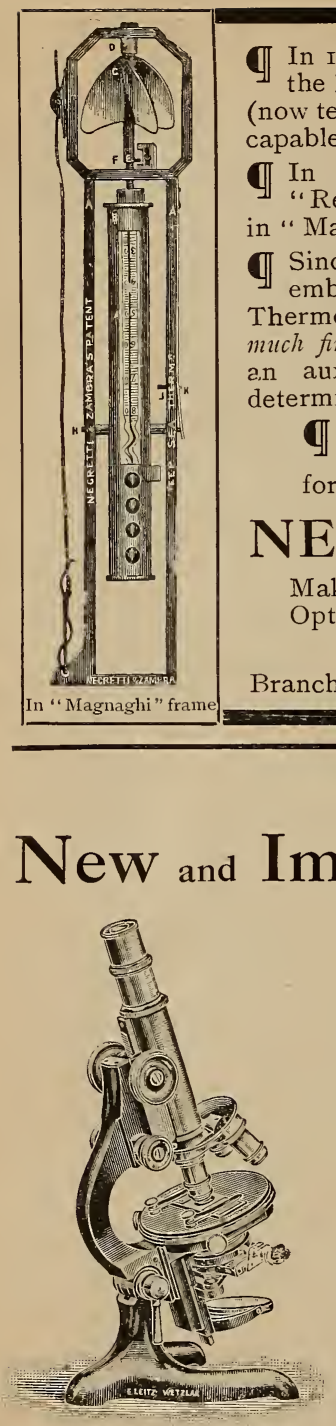

\section{LEITZ}

\section{New and Improved Microscopes}

\section{SUITABLE FOR EVERY REQUIREMENT}

in a variety of models, possessing many advantages over the older type, and embodying several important features not to be found in any others.

\section{LEITZ ENGLISH MODEL MICRO-} SCOPES, combining the most important features of the English and Continental Stands.

Portable Microscopes, Binocular and Monocular Dissecting Microscopes, Aplanatic Pocket Lenses.

Microtomes, Photo-micrographic Apparatus, Projection Lanterns, Prism Field and Opera Glasses, etc.

Descriptive Price Lists of any or all of above post free.

E. LEITZ, 18 Bloomsbury Sq., London, W.C. 


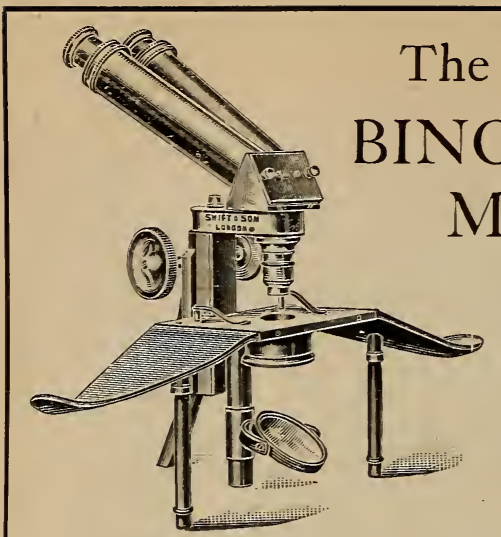

"Stephenson" CULAR MICROSCOPE

This is the ideal instrument for Biological IVork, as it yields a perfect

ERECT STEREOSCOPIC IMAGE

Extremely low powers can be used on this stand

Price, with pair of Oculars, $£ 10$

Complete Catalogue of Biological, Bacteriological, and Petrological Microscopes and Apparatus on application

\section{JAMES SWIFT AND SON}

Contractors to all Scientific Departments of H.M. Government

Grands Prix, Diplomas of Honour, and Gold Medals at London, Paris, Brussels, etc.

University Optical Works, 8i Tottenham Court Rd., London

\section{JAMES J. HICKS}

(INCORPORATED WiTH W. F. STANLEY \& Co., LTD.)

Maker to the Admiralty and all Departments of the Government

The Actual Manufacturer of Scientific Instruments

for Marine and General Use

8, 9, \& 10, HATTON GARDEN, LONDON, E.C.

ILLUSTRATED CATALOGUES POST FREE

Inclusive of

Aneroid Barometers

Thermometers for

Deep-Sea Temperatures

Sextants

Marine Clinometers

Compasses

Artificial Horizons

etc.

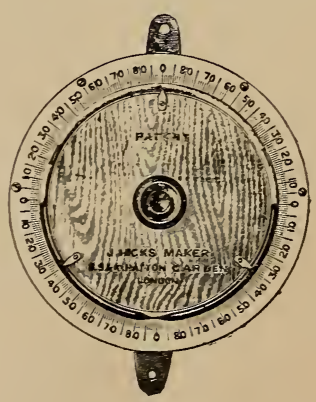

Inclusive of

Marine Mercurial Barometers

Hydrometers of all kinds

Salt - Water Hydrometers

Electrical Alarm Thermometers

Sunshine Recorders etc. 


\section{ILFORD}

\section{PLATES and PAPERS}

specially produced for Scientific Photography.

Of Dealers throughout the World.

\section{ILFORD, Limited,}

\section{Ilford, London, E.}

33 Years' Unrivalled Repute. 


\section{AKTIEBOLAGET \\ L. M. ERICSSON \& CO. STOCKHOLM, SWEDEN}

Manufacturers of Hydrographic Instruments

Speciality: Petterson-Nansen Insulating Water-Bottles

Representatives :

THE BRITISH L. M. ERICSSON

MANUFACTURING CO., LTD.

Byron House, 82-85 Fleet Street, London, E.C.

\section{WM. BARBOUR \& SONS, LTD.}
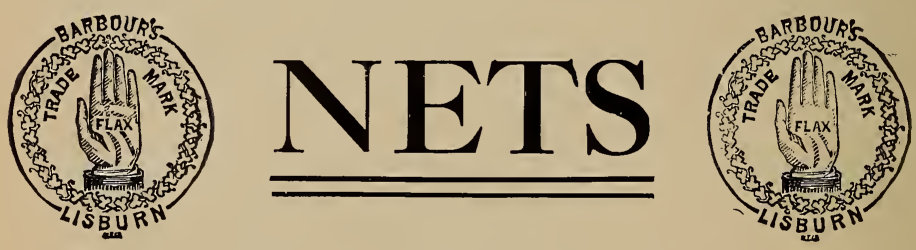

All kinds of Nets \& Netting Twines for Home \& Export

WRITE FOR PRICES

WORKS : LISBURN, IRELAND 


\section{Thos. \& W M. SMith, Ltd.}

Wire Rope Manufacturers

\section{NEWCASTLE-ON-TYNE \\ ENGLAND}

Makers of Wire Ropes of the highest breaking stress and greatest reliability for Deep Sea Dredging; also special Shackles, Reels, and other appliances for use with same, as supplied to the Valdivia, Siboga, Ermak, and Discovery

On the Valdivia expedition dredging operations were successfully carried out with our special Wire Ropes to a depth of 5,248 metres, or over $3 \frac{1}{4}$ miles.

000000000000000

Telegraphic \& Cable Address: "SMITHS, NeWCASTLE-ON-TYNE." 

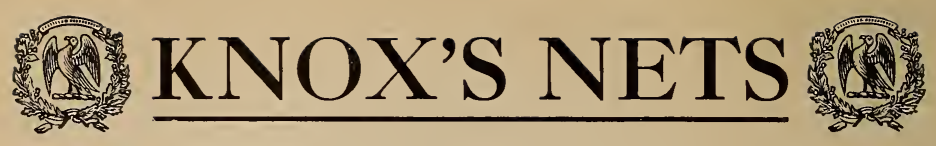

$$
\begin{gathered}
\text { LINEN } \\
\text { HEMP, AND COTTON } \\
\text { Only very best materials used }
\end{gathered}
$$

NETS OF EVERY KIND SUPPLIED. MADE ON THE MOST IMPROVED MACHINERY

WRITE TO

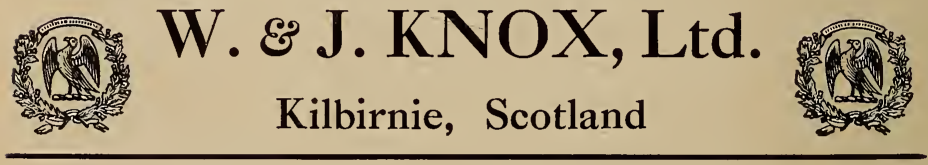

\section{"HOW TO GO TO SEA" (IN THE MERCHANT SERVICE)}

A complete, practical, up-to-date, and reliable illustrated Guide for Parents and Guardians, giving full particulars of all the Training Establishments both for officers and lower ratings, with a complete list of owners who take apprentices and their terms, and other information.

Compiled by FREDERICK, H. STAFFORD

Secretary, Incorporated Thames Nautical Training College, H.M.S. "Worcester"

\section{PRICE - - $2 / 6$ net}

SYLLABUS OF CONTENTS

Part I.-TRAINing FOR OfFICERs: Introduction - "The Sea and its Prospects"Stationary Training Ships-Sea-Going Training Ships-Apprentices-Sail or Steam Training -Victualling-Midshipmen's Outfit-Qualifications for Masters' and Mates' CertificatesRates of Pay-Royal Naval Reserve-Hooghly Pilot Service, Royal Indian Marine-Marine Engineers, with Apprenticeship Particulars-Trinity Pilot Service, etc.

PART II.: Voluntary Training Ships-Industrial School Ships-Reformatory ShipsShipping Federation Scheme of Apprenticeships-Wages of Seamen-Apprentices' OutfitComplete List of Sailing Ship and Steam Ship Owners taking Apprentices, with Terms.

\section{THE BEST BOOK ON THE SUBJECT ISSUED}

JAMES BROWN \& SON, 52 Darnley Street, Glasgow 


\section{Bullivant \& Co., LTd.}

MANUFACTURERS OF

\section{Flexible Steel Wire Ropes}

FOR

SHIPS' HAWSERS, CRANES, LIFTS, DERRICKS, Etc.

FLEXIBLE. DURABLE. RELIABLE Only one Uniform Quality supplied

Running and Standing Rigging Fitted Complete Specially Flexible Steel Wire Trawl Warps

MAKERS OF

BLOCKS, PULLEYS, AND ALL APPLIANCES FOR WORKING WIRE ROPES

WIRE ROPE GUTTING MACHINES (SELBY'S PATENT)

For Cutting WIRE ROPES up to 9 in. circumference

\section{BULLIVANT \& CO., LTD.}

Registered Offices

72, MARK LANE, LONDON, E.C.

Works : Millwall, E. 
DUFOUR \& CO.'S Celebrated Swiss

\section{SILK BOLTING CLOTHS}

Especially adapted for tow nets and sieves used in connection with oceanic research

Apply to

SWISS SILK BOLTING CLOTH MFG. CO. LTD., THAL (Switzerland)

\section{THE YACHTING WORLD}

GOES EVERYWHERE

IS READ EVERYWHERE

IS APPRECIATED EVERYWHERE

The real test of the value and influence of a Newspaper lies in its advertisements. The number and character of our advertisements speak for themselves

\section{THE YACHTING WORLD}

is to be found on board the Steamships of all the leading lines sailing from and to British ports, including

Hamburg-Amerika Line

White Star Line

Cunard Steamship Co.

Royal Mail Steam Packet Co.

P. \& O. Steam Navigation Co.

Shaw, Saville, \& Albion Co., Ltd.

Mersey Steam Ship Co.

Bibby Bros. \& Co.
Booth Steam Ship Co.

Houlder Bros. \& Co., Ltd.

British India Co.

Elder, Dempster \& Co.

Atlantic Transport Co., Ltd. Hall Line, Ltd.

Shire Line

Aberdeen Line

Price 3d. WeEkLY

Subscriptions: Abroad, $£ 1$ 0s. 6d.; United Kingdom, 17s. 6d.

Telephone No: 13241 Central.

Telegrams: "Yotnews, London."

Head Office: $\left\{\begin{array}{l}37, \text { WALBROOK } \\ \text { LONDON, E. C. }\end{array}\right.$ 


\section{Admiralty Charts}

The LATEST Editions of Charts, Plans and Sailing Directions, published by the Admiralty, can be obtained from

\section{J. D. POTTER}

Admiralty Agent (by Appointment) and Publisher of

Nautical Books

\section{MINORIES, LONDON, E.C.}

The Official Catalogue of Charts, Plans and Sailing Directions, published by the Admiralty (issued Annually in March) can be obtained Free of Charge on application to the Chart Agency, I45 Minories, London, E.C., or from any of the sub-agencies at the Home or Foreign Ports.

\section{THE YACHTING MONTHLY and Marine Motor Magazine.}

Published on the ist of every month. An illustrated magazine of interest and value to all who are interested in ships and the sea. One Shilling, of all Booksellers and Newsagents. Subscription, I 2/- a year at home, $15 /$ - abroad, post free. Specimen copy, $1 / 3$ post free, from the Publisher, 43, Leicester Square, London, W.C. 


\title{
THE TIDES AND KINDRED PHENOMENA OF THE SOLAR SYSTEM. By Sir George Howard Darwin, K.C.B.
}

\begin{abstract}
"Combining accuracy of statement with extreme lucidity and conciseness of style, and the careful avoidance of unnecessarily technical language, the book forms a valuable contribution to the literature of the subject, containing the most up-to-date information in a readily assimilable-form."-Oxford Chronicle.

"No scientific library can be efficient without possessing a copy as a textbook or book of reference. The book has now become indispensable to the astronomer and the observatories, to the geodesist and geographer; in short, to all who wish to know up-to-date facts of the cosmos."-Knowledge.
\end{abstract}

A New Edition of this book, thoroughly revised and brought up to date, is in preparation, and will be ready very shortly

\section{THE REALM OF NATURE: A Manual of Phy- siography. By Dr. Hugh Robert Mill, Director of British Rainfall Organization. With many Coloured Maps and Illus- trations. Crown 8vo. 5s.}

Recent geographical discovery has added a good deal to our knowledge, and it has been thought advisable to collect the latest information into this volume so that the principles which it enunciates may be based upon the latest available evidence.

This revision has entailed a vast amount of labour; but it is confidently anticipated that the book in its new form will contain more accurate and valuable statistics than can be found in anything but the most advanced treatises on physiography.

MICROSCOPY. The Construction, Theory, and Use of the Microscope. By Edmund J. Spitta, F.R.A.S., F.R.M.S., etc. With numerous Diagrams and Illustrations. Second Edition. 12s. 6d. net.

"Let us hasten to urge every student of the microscope who wishes to gain a thorough understanding of its principles and possibilities and its defects, and every user of the instrument who desires a work of reference to which he may turn for an explanation of some unexplained optical phenomenon, or for particulars of up-to-date apparatus, to procure a copy of Mr. Spitta's book without delay."-Nature.

\section{SMALL BOAT SAILING; or, Practical Hints for} Practical Yachtsmen. By E. F. Knight, Author of "Where Three Empires Meet," "The Cruise of the Falcon," etc. With numerous Diagrams. Large Crown 8vo. 5s. net.

". . a most valuable work for young yachtsmen who wish to become proficient in handling their boats."-Yachtsman.

"Yachtsmen of all classes should learn much from this skilled and interesting handbook.

.. It will at once take rank as a first authority on its subject." - Scotsman.

LONDON : JOHN MURRAY, ALBEMARLE STREET, W. 


